\title{
16977361
}

\section{EXPERIMENTAL TESTING ON THE COMPRESSIVE STRENGTH OF SOLID STEEL ROUND BARS}

BY

Marwan Saliba, B. Eng

Ryerson University, Toronto, 2002

\author{
A Thesis \\ Presented to Ryerson University \\ In partial fulfillment of the \\ Requirement for the degree of \\ Master of Applied Science \\ In the program of \\ Civil Engineering \\ Toronto, Ontario, Canada, 2005 \\ Marwan Saliba 2005@
}


UMI Number: EC53762

\section{INFORMATION TO USERS}

The quality of this reproduction is dependent upon the quality of the copy submitted. Broken or indistinct print, colored or poor quality illustrations and photographs, print bleed-through, substandard margins, and improper alignment can adversely affect reproduction.

In the unlikely event that the author did not send a complete manuscript and there are missing pages, these will be noted. Also, if unauthorized copyright material had to be removed, a note will indicate the deletion.

\section{$\mathrm{UMI}^{\circ}$}

UMI Microform EC53762

Copyright 2009 by ProQuest LLC

All rights reserved. This microform edition is protected against unauthorized copying under Title 17, United States Code.

ProQuest LLC

789 East Eisenhower Parkway

P.O. Box 1346

Ann Arbor, MI 48106-1346 


\section{Author's Declaration}

I hereby declare that I am the sole author of this thesis.

I authorize Ryerson to lend this document to other institutions or individuals for the purpose of scholarly research.

Marwan Saliba

I further authorize Ryerson University to reproduce the document by photocopying or by other means, in total or part, at the request of other institutions or individuals for the purpose of scholarly research.

Marwan Saliba 
Ryerson University requires the signatures of all persons using or photocopying this thesis.

Please sign below, and give address and date.

\begin{tabular}{|c|c|c|c|}
\hline Name & Address & Signature & Date \\
\hline & & & \\
\hline & & & \\
\hline & & & \\
\hline & & & \\
\hline & & & \\
\hline & & & \\
\hline & & & \\
\hline & & & \\
\hline & & & \\
\hline & & & \\
\hline & & & \\
\hline & & & \\
\hline & & & \\
\hline & & & \\
\hline & & & \\
\hline & & & \\
\hline & & & \\
\hline & & & \\
\hline & & & \\
\hline & & & \\
\hline & & & \\
\hline & & & \\
\hline & & & \\
\hline & & & \\
\hline & & & \\
\hline & & & \\
\hline & & & \\
\hline & & & \\
\hline & & & \\
\hline & & & \\
\hline & & & \\
\hline & & & \\
\hline & & & \\
\hline & & & \\
\hline
\end{tabular}




\section{ABSTRACT}

\section{EXPERIMENTAL TESTING ON THE COMPRESSIVE STRENGTH OF SOLID STEEL ROUND BARS \\ MARWAN SALIBA, M.A.SC. THESIS, CIVIL ENGINEERING DEPARTMENT, RYERSON UNIVERSITY, TORONTO, 2005}

Solid steel round bars are used as legs, diagonals and horizontal members of a communication tower. The Canadian Standards, CAN/CSA-S16.1-94, AISC-LRFD Specifications of 1993, and the European Standard, Eurocode 3, provide the factored compressive resistance of structural steel members other than solid rounds. While, the Current Canadian Standard, CAN/CSA-S37-01 of 2001, for Antenna towers and Antenna Supporting Structures specifies empirical expressions for the compressive strength of solid rounds based on the SSRC column curves for non-solid-round bars and the results from experimental investigation on the compressive resistance of solid rounds carried out back to 1965 . This thesis provides a summary of the available literature on the compressive strength of solid rounds as well as the results of recently tested large solid round bars. Correlation between the results from these tests and the current practice for the design of solid rounds is investigated. Recommendations to update the available code equations are drawn. 


\section{ACKNOWLEDGEMENTS}

I wish to express my deep appreciation to my advisor Dr. K. Sennah at Ryerson University, for his constant support and valuable supervision during the development of this research. Dr. Sennah devoted his time and effort to make this study a success. His most helpful guidance is greatly appreciated.

The author wishes to acknowledge the companies that donated the steel material and provided financial support to this research work. These companies are Radian Communication Systems Corp. of Oakville, Ontario, Sabre Communications Corp. of Sioux City, IA, U.S.A., and ERI, Electronics Research Inc. of Chandler, Indiana, U.S.A. The author also acknowledges the financial support of the Structural Steel Education Foundation of the Canadian Institute of Steel Construction.

The author wishes to thank N. Jaalouk for his assistance in the experimental work. The author is also very grateful to his parents and brothers for their great support and encouragement during the course of this study. 
TO MY FAMILY 


\section{TABLE OF CONTENTS}

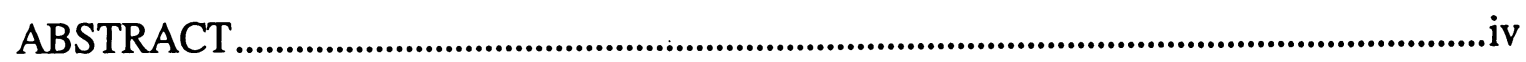

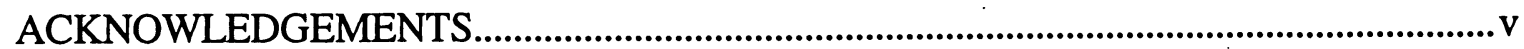

TABLE OF CONTENTS .............................................................................................

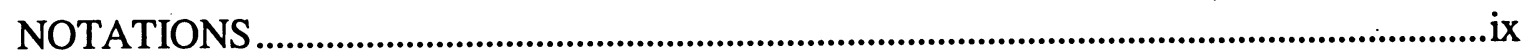

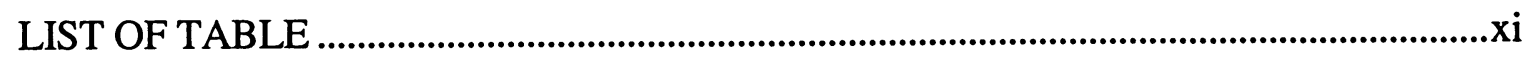

LIST OF FIGURES …….......................................................................................................

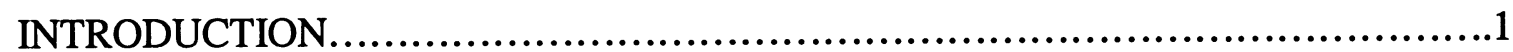

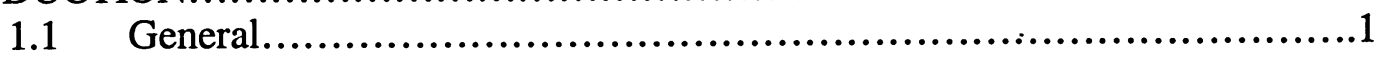

$1.2 \quad$ Need for Investigation.................................................

1.3 Objectives of the Thesis................................................4

1.4 Outline of the Thesis.................................................4

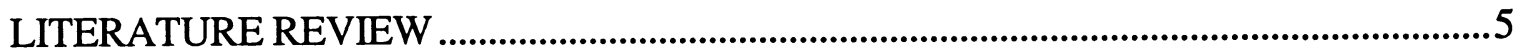

$2.1 \quad$ General.......................................................................

2.2 Critical-load Theory....................................................

2.3 Inelastic Buckling of Column.......................................6

2.4 Imperfect Column................................................. 8

2.5 Compressive Resistance of Steel Columns..............................8

2.5.1 Influence of Residual Stresses.......................................10

2.5.2 Influence of Out-of-Straightness....................................12

2.5.3 Effect of Cold-Straightening ........................................13

2.6 Structural Stability Research Council (SSRC) Column Strength Curves..15

2.7 Canadian Standards...................................................17

$2.8 \quad$ AISC (LRFD) Specifications.......................................18

2.9 European Standard................................................19 


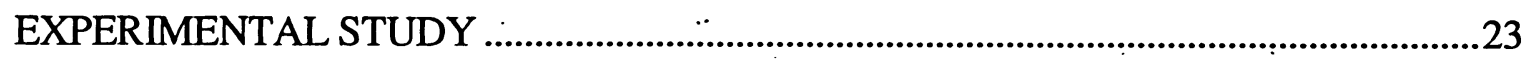

$3.1 \quad$ General................................................................23

3.2 Description of the Test Specimens.....................................23

3.2.1 Testing Centrally Loaded Columns made of Stress-Relieved Steel........23

3.2.2 Testing Centrally Loaded Columns made of Non-Stress-Relieved Steel..23

3.2.3 Stub Column Test.....................................................24

3.3 Test Set-Up....................................................25

3.4 Instrumentations......................................................26

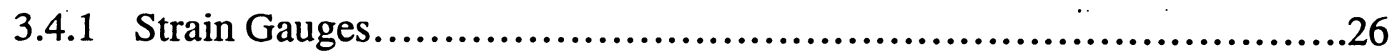

3.4.2 Mechanical Dial Gauges............................................27

3.4.3 Automatic Strain Indicator............................................27

3.5 Test Procedure......................................................27

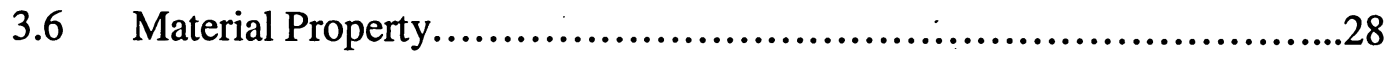

3.7 Determination of Yield Strength from Tension Coupons.................28

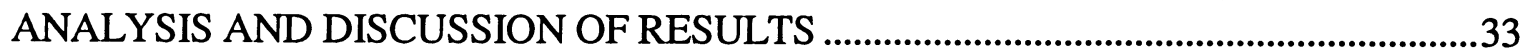

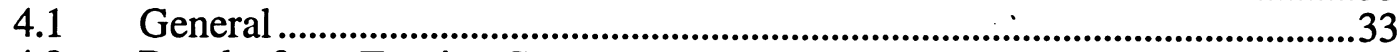

$4.2 \quad$ Results from Tension Coupon .....................................................................34

4.3 Results from Testing Centrally Loaded Columns Made of StressRelieved Steel ......................................................................................................35

4.4 Correlation between the Experimental Failure Load of StressRelieved Steel Bars and the Compressive Resistance as Obtained from Design Standards

4.5 Results from Testing Centrally Loaded Columns Made of Non-StressRelieved Steel.............................................................39

4.6 Correlation between the Experimental Failure Load of Non-StressRelieved Steel Bars and the Compressive Resistance as Obtained from Design Standards..........................................................44

4.7 Results from Testing Stub Columns.................................43

CONCLUSIONS AND RECOMMENDATIONS ...........................................................4.45

$5.1 \quad$ General ................................................................45

5.2 Conclusions.......................................................46

5.3 Recommendations for Future Research.............................47

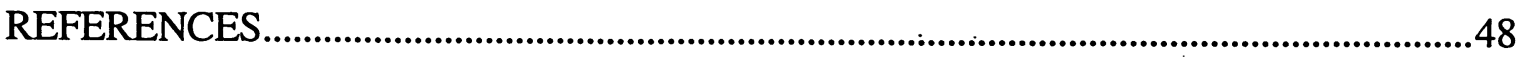




\section{NOTATIONS}
A
Cross-sectional area of member
$\mathrm{C}_{\mathrm{r}}$
Compressive resistance of a member
$\mathrm{E}$
Modulus of elasticity
$E_{\text {eff }}$
Effective modulus
EI
Elastic stiffness
$\mathrm{E}_{\mathrm{r}}$
Reduced modulus
$\mathrm{E}_{\mathrm{t}}$
Tangent modulus
$F_{y}$
Yield stress
$\bar{F} y$
Average value of equivalent yield strengths
Moment of inertia of a section
Effective buckling length factor, or Characteristic value of a parameter
$\mathrm{K}_{\mathrm{s}}$
Coefficient of variation modification factor for steel
Unbraced length of the solid round bar
$\mathrm{N}$
Design value of axial compressive force
Column axial load
$\mathrm{P}_{\mathrm{E}}$
Euler buckling load
$\mathrm{P}_{\mathrm{r}}$
Reduced modulus load
$P_{t}$
Tangent modulus load
$\mathbf{r}$
Governing radius of gyration about the plane of buckling
Column displacement
$\mathrm{V}_{\mathrm{s}}$
Coefficient of variation of equivalent yield strengths
$w$
Column displacement 
Initial out-of-straightness

$\sigma$

Compressive strength, or Standard deviation

$\lambda$

Non-dimensional slenderness parameter

$\bar{\lambda}_{M}$

Non-dimensional slenderness in bending

$\phi$

Resistance factor for compression

$\delta$

Total deflection at mid height of solid round bar

$\vartheta$

Rotation

$\varepsilon$

Strain

$\Delta$

Displacement

$\alpha$

Imperfection factor

$\chi$

Reduction factor according to the standard and buckling curves as used in Europe 


\section{LIST OF TABLE}

Table

Table 2.1 Ultimate limit state analysis.

Table 2.2 Parameters $\alpha$ for calculation of reduction factor $x$...........................52

Table 3.1 Details of Test Specimens: 20 Stress Relieved Specimens.....................52

Table 3.2 Details of Test Specimens: 25 Non-Stress Relieved Specimens................53

Table 3.3 Details of Test Specimens: 8 Non-Stress Relieved Specimens................53

Table 3.4 Details of Test Specimens: 7 Stub Columns for Non-Stress Relieved

Specimens...............................................................54

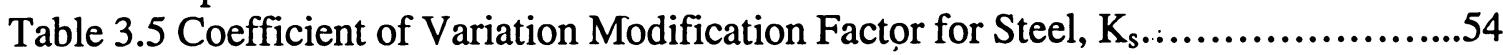

Table 4.1 Results of coupon testing for stress-relieved bars...........................55

Table 4.2 Results of coupon testing for non-stress-relieved bars........................55

Table 4.3 Results of testing to-collapse 20 stress-relieved steel solid rounds..............56

Table 4.4 Comparison between the experimental finding and available Code equations

For 20 stress-relieved steel bars using theoretical buckling length..............57

Table 4.5 Comparison between the experimental finding and available Code equations

For 20 stress-relieved steel bars using the practical buckling length.............58

Table 4.6 Results of testing to-collapse 25 non-stress-relieved steel solid rounds.........59

Table 4.7 Comparison between the experimental finding and available Code equations

For 25 non-stress-relieved steel bars using theoretical buckling length........60

Table 4.8 Comparison between the experimental finding and available Code equations

For 25 non-stress-relieved steel bars using practical buckling length...........61

Table 4.9 Results of testing to-collapse 8 non-stress-relieved steel solid rounds.........62

Table 4.10 Comparison between the experimental finding and available Code

Equations for 8 non-stress-relieved steel bars using the theoretical buckling

length...................................................................63

Table 4.11 Comparison between the experimental finding and available Code

Equations for 8 non-stress-relieved steel bars using practical buckling

Length................................................................64

Table 4.12 Stub column test results for non-stress-relieved steel solid rounds...........64 


\section{LIST OF FIGURES}

Figure

Figure 1.1 Views of communication towers

Figure 1.2 Close-up view of tower segment.

Figure 2.1 Behavior of perfect and imperfect columns (Galambos, 1998).

Figure 2.2 General stress-strain relationship (Galambos, 1998).

Figure 2.3 Column curve.

Figure 2.4 Initially bent column

Figure 2.5 Effective length factor (CAN/CSA S16-01, 2003).

Figure 2.6 SSRC column strength curve 1 for structural steel (Bjordhovde, 1972), (Based on maximum strength and initial out-of-straightness of $L / 1000$ ).

Figure 2.7 SSRC column strength curve 2 for structural steel (Bjordhovde, 1972), (Based on maximum strength and initial out-of-straightness of L/1000)...

Figure 2.8 SSRC column strength curve 3 for structural steel (Bjordhovde, 1972), (Based on maximum strength and initial out-of-straightness of $\mathrm{L} / 500)$.......................71

Figure 2.9 Buckling curves (Eurocode 3, 2003)........................................71

Figure 3.1 View of the MTS machine..................................................72

Figure 3.2 Schematic diagram of the specimen setup and strain gauge locations..........73

Figure 3.3 Test set-ups for axial resistance of solid rounds.................................74

Figure 3.4 Test set up for tension coupon before and after failure.......................74

Figure 4.1 Views of coupon sample preparation procedure............................75

Figure 4.2 Stress-strain curve for the coupon sample of SR 38-mm bar.................76

Figure 4.3 Initial part of the stress-strain curve for the coupon sample of SR 51-mm bar76 Figure 4.4 Stress-strain curve for the coupon sample of SR 64-mm bar..................77

Figure 4.5 Stress-strain curve for the coupon sample of SR 76-mm bar....................77

Figure 4.6 Stress-strain curve for the coupon sample of SR 89-mm bar..................78

Figure 4.7 Stress-strain curve for the coupon sample of SR 102-mm bar...............78

Figure 4.8 Stress-strain curve for the coupon sample of SR 128-mm bar................79

Figure 4.9 Views of the coupon sample for 38-mm bar before and after testing...........79

Figure 4.10 Initial portion of the stress-strain curve for the coupon sample of NSR 38$\mathrm{mm}$ bar.

Figure 4.11 Views of the coupon sample for $51-\mathrm{mm}$ bar before and after testing........80 Figure 4.12 Initial part of the stress-strain curve for the coupon sample of NSR 51-mm bar.

Figure 4.13 Views of the coupon sample for $64-\mathrm{mm}$ bar before and after testing.........81 Figure 4.14 Initial part of the stress-strain curve for the coupon sample of NSR 64-mm bar.

Figure 4.15 Views of the coupon sample for $76-\mathrm{mm}$ bar before and after testing........88 Figure 4.16 Initial portion of the stress-strain curve for the coupon sample of NSR 76mm bar.

Figure 4.17 Views of the coupon sample for $89-\mathrm{mm}$ bar before and after testing..........83 Figure 4.18 Initial part of the stress-strain curve for the coupon sample of NSR $89-\mathrm{mm}$ bar. 
Figure 4.19 Views of the coupon sample for $102-\mathrm{mm}$ bar before and after testing.........84 Figure 4.20 Initial portion of the stress-strain curve for the coupon sample of NSR 102mm bar.............................................................................85

Figure 4.21 Views of the coupon sample for 114-mm bar before and after testing........85 Figure 4.22 Initial part of the stress-strain curve for the coupon sample of NSR 114-mm bar...................................................................................86

Figure 4.23 Views of specimen SR-1 before and after testing.........................87

Figure 4.24 Axial load-strain relationships for specimen SR-1 .......................87

Figure 4.25 Load-lateral deflection curves for specimen SR-1 .........................88

Figure 4.26 Views of specimen SR-2 before and after testing.........................88

Figure 4.27 Axial load-strain relationships for specimen SR-2 ........................89

Figure 4.28 Load-lateral deflection curves for specimen SR-2 ........................89

Figure 4.29 Load versus overall shortening curve for specimen SR-2 ..................90

Figure 4.30 Views of specimen SR-3 before and after testing........................90

Figure 4.31 Axial load-strain relationships for specimen SR-3 ......................91

Figure 4.32 Load-lateral deflection curves for specimen SR-3 .........................91

Figure 4.33 Load versus overall shortening curve for specimen SR-3 ...................92

Figure 4.34 Views of specimen SR-4 before and after testing.........................92

Figure 4.35 Axial load-strain relationships for specimen SR-4.........................93

Figure 4.36 Load-lateral deflection curves for specimen SR-4........................93

Figure 4.37 Load versus overall shortening curve for specimen SR-4..................94

Figure 4.38 Views of specimen SR-5 before and after testing.........................94

Figure 4.39 Axial load-strain relationships for specimen SR-5.......................95

Figure 4.40 Load-lateral deflection curves for specimen SR-5.......................95

Figure 4.41 Load versus overall shortening curve for specimen SR-5 ..................96

Figure 4.42 Views of specimen SR-6 before and after testing.........................96

Figure 4.43 Axial load-strain relationships for specimen SR-6......................97

Figure 4.44 Load-lateral deflection curves for specimen SR-6........................97

Figure 4.45 Load versus overall shortening curve for specimen SR-6.................98

Figure 4.46 Views of specimen SR-7 before and after testing.........................98

Figure 4.47 Axial load-strain relationships for specimen SR-7 ........................99

Figure 4.48 Load-lateral deflection curves for specimen SR-7 ........................99

Figure 4.48 Load versus overall shortening curve for specimen SR-7 .................100

Figure 4.49 Views of specimen SR-8 before and after testing.........................100

Figure 4.50 Axial load-strain relationships for specimen SR-8.......................101

Figure 4.51 Load-lateral deflection curves for specimen SR-8 .......................101

Figure 4.52 Load versus overall shortening curve for specimen SR-8 ................102

Figure 4.53 Views of specimen SR-9 before and after testing. ......................102

Figure 4.54 Axial load-strain relationships for specimen SR-9.......................103

Figure 4.55 Load versus overall shortening curve for specimen SR-9................103

Figure 4.56 Views of specimen SR-10 before and after testing.......................104

Figure 4.57 Axial load-strain relationships for specimen SR-10......................104

Figure 5.58 Load-lateral deflection curves for specimen SR-10.....................105

Figure 4.59 Load versus overall shortening curve for specimen SR-10 ...............105

Figure 4.60 Views of specimen SR-11 before and after testing........................106

Figure 4.61 Axial load-strain relationships for specimen SR-11.....................106 
Figure 4.62 Load-lateral deflection curves for specimen SR-11 ......................107

Figure 4.63 Load versus overall shortening curve for specimen SR-11 ...............107

Figure 4.64 Views of specimen SR-12 before and after testing........................108

Figure 4.65 Axial load-strain relationships for specimen SR-12 .....................108

Figure 4.66 Load-lateral deflection curves for specimen SR-12.....................109

Figure 4.67 Load versus overall shortening curve for specimen SR-12 ................109

Figure 4.68 Views of specimen SR-13 before and after testing........................110

Figure 4.69 Axial load-strain relationships for specimen SR-13 .......................110

Figure 4.70 Load-lateral deflection curves for specimen SR-13.....................111

Figure 4.71 Load versus overall shortening curve for specimen SR-13 .................111

Figure 4.72 Views of specimen SR-14 before and after testing.......................112

Figure 4.73 Axial load-strain relationships for specimen SR-14.....................112

Figure 4.74 Load-lateral deflection curves for specimen SR-14.....................113

Figure 4.75 Load versus overall shortening curve for specimen SR-14 ...............113

Figure 4.76 Views of specimen SR-15 before and after testing.......................114

Figure 4.77 Axial load-strain relationships for specimen SR-15....................114

Figure 4.78 Load-lateral deflection curves for specimen SR-15......................115

Figure 4.79 Load versus overall shortening curve for specimen NSR-15..............115

Figure 4.80 Views of specimen SR-16 before and after testing........................116

Figure 4.81 Axial load-strain relationships for specimen SR-16......................116

Figure 4.82 Load-lateral deflection curves for specimen SR-16......................117

Figure 4.83 Load versus overall shortening curve for specimen SR-16.................117

Figure 4.84 Views of specimen SR-17 before and after testing........................118

Figure 4.85 Axial load-strain relationships for specimen SR-17 ....................118

Figure 4.86 Load-lateral deflection curves for specimen SR-17 ......................119

Figure 4.87 Load versus overall shortening curve for specimen SR-17.................119

Figure 4.88 Views of specimen SR-18 before and after testing.......................120

Figure 4.89 Axial load-strain relationships for specimen SR-18 .....................120

Figure 4.90 Load-lateral deflection curves for specimen SR-18 ...................121

Figure 4.91 Load versus overall shortening curve for specimen SR-18...............121

Figure 4.92 Views of specimen SR-19 before and after testing......................122

Figure 4.93 Axial load-strain relationship for specimen SR-19.....................122

Figure 4.94 Load-lateral deflection curves for specimen SR-19....................123

Figure 4.95 Load versus overall shortening curve for specimen SR-19................123

Figure 4.96 Views of specimen SR-20 before and after testing.......................124

Figure 4.97 Axial load-strain relationships for specimen SR-20....................124

Figure 4.98 Load versus overall shortening curve for specimen SR-20...............125

Figure 4.99 Load versus overall shortening curve for specimen SR-20...............125

Figure 4.100 Views of specimen NSR-1 before and after testing......................126

Figure 4.101 Views of specimen NSR-2 before and after testing.......................126

Figure 4.102 Axial load-strain relationships for specimen NSR-2 ....................127

Figure 4.103 Load-lateral deflection curves for specimen NSR-2 ...................127

Figure 4.104 Load versus overall shortening curve for specimen NSR-2 ..............128

Figure 4.105 Views of specimen NSR-3 before and after testing......................128

Figure 4.106 Axial load-strain relationships for specimen NSR-3 ....................129

Figure 4.107 Load-lateral deflection curves for specimen NSR-3....................129 
Figure 4.108 Load versus overall shortening curve for specimen NSR-3 ...............130

Figure 4.109 Views of specimen NSR-4 before and after testing.....................130

Figure 4.110 Axial load-strain relationships for specimen NSR-4 ....................131

Figure 4.111 Load-lateral deflection curves for specimen NSR-4 ....................131

Figure 4.112 Load versus overall shortening curve for specimen NSR-4.............132

Figure 4.113 Views of specimen NSR-5 before and after testing......................132

Figure 4.114 Axial load-strain relationships for specimen NSR-5 ....................133

Figure 4.115 Load-lateral deflection curves for specimen NSR-5 ...................133

Figure 4.116 Load versus overall shortening curve for specimen NSR -5...............134

Figure 4.117 Views of specimen NSR-6 before and after testing......................134

Figure 4.118 Axial load-strain relationships for specimen NSR-6....................135

Figure 4.119 Load-lateral deflection curves for specimen NSR-6.....................135

Figure 4.120 Load versus overall shortening curve for specimen NSR-6................136

Figure 4.121 Views of specimen NSR-7 before and after testing.....................136

Figure 4.122 Axial load-strain relationships for specimen NSR-7 .....................137

Figure 4.123 Load-lateral deflection curves for specimen NSR-7 ....................137

Figure 4.124 Load versus overall shortening curve for specimen NSR-7 ..............138

Figure 4.125 Views of specimen NSR-8 before and after testing......................138

Figure 4.126 Axial load-strain relationships for specimen NSR-8 ....................139.

Figure 4.127 Load-lateral deflection curves for specimen NSR-8 ....................139

Figure 4.128 Load versus overall shortening curve for specimen NSR-8 ..............140

Figure 4.129 Views of specimen NSR-9 before and after testing......................140

Figure 4.130 Axial load-strain relationships for specimen NSR-9....................141

Figure 4.131 Load-lateral deflection curves for specimen NSR-9...................141

Figure 4.132 Load versus overall shortening curve for specimen NSR-9...............142

Figure 4.133 Views of specimen NSR-10 before and after testing......................142

Figure 4.134 Axial load-strain relationships for specimen NSR-10 ..................143

Figure 4.135 Load-lateral deflection curves for specimen NSR-10..................143

Figure 4.136 Load versus overall shortening curve for specimen NSR-10.............144

Figure 4.137 Views of specimen NSR-11 before and after testing.....................144

Figure 4.138 Axial load-strain relationships for specimen NSR-11 ..................145

Figure 4.139 Load versus overall shortening curve for specimen NSR-11............145

Figure 4.140 Views of specimen NSR-12 before and after testing.....................146

Figure 4.141 Axial load-strain relationships for specimen NSR-12 ..................146

Figure 4.142 Load-lateral deflection curves for specimen NSR-12 ...................147

Figure 4.143 Load versus overall shortening curve for specimen NSR-12 .............147

Figure 4.144 Views of specimen NSR-13 before and after testing.....................148

Figure 4.145 Axial load-strain relationships for specimen NSR-13..................148

Figure 4.146 Load-lateral deflection curves for specimen NSR-13....................149

Figure 4.147 Load versus overall shortening curve for specimen NSR-13 .............149

Figure 4.148 Views of specimen NSR-14 before and after testing......................150

Figure 4.149 Axial load-strain relationships for specimen NSR-14 .................150

Figure 4.150 Load-lateral deflection curves for specimen NSR-14..................151

Figure 4.151 Load versus overall shortening curve for specimen NSR-14.............151

Figure 4.152 Views of specimen NSR-15 before and after testing.....................152

Figure 4.153 Axial load-strain relationships for specimen NSR-15:...................152 
Figure 4.154 Load-lateral deflection curves for specimen NSR-15 ..................153

Figure 4.155 Load versus overall shortening curve for specimen NSR-15.............153

Figure 4.156 Views of specimen NSR-16 before and after testing.....................154

Figure 4.157 Axial load-strain relationships for specimen NSR-16...................154

Figure 4.158 Load-lateral deflection curves for specimen NSR-16....................155

Figure 4.159 Load versus overall shortening curve for specimen NSR-16..............155

Figure 4.160 Views of specimen NSR-17 before and after testing.....................156

Figure 4.161 Axial load-strain relationships for specimen NSR-17 ...................156

Figure 4.162. Load-lateral deflection curves for specimen NSR-17 ....................157

Figure 4.163 Load versus overall shortening curve for specimen NSR-17..............157

Figure 4.164 Views of specimen NSR-18 before and after testing......................158

Figure 4.165 Axial load-strain relationships for specimen NSR-18..................158

Figure 4.166 Load-lateral deflection curves for specimen NSR-18...................159

Figure 4.167 Load versus overall shortening curve for specimen NSR-18..............159

Figure 4.168 Views of specimen NSR-19 before and after testing.....................160

Figure 4.169 Axial load-strain relationships for specimen NSR-19...................160

Figure 4.170 Load-lateral deflection curves for specimen NSR-19...................161

Figure 4.171 Load versus overall shortening curve for specimen NSR-19...............161

Figure 4.172 Views of specimen NSR-20 before and after testing......................162

Figure 4.173 Axial load-strain relationships for specimen NSR-20...................162

Figure 4.174 Load versus overall shortening curve for specimẹn NSR-20..............163

Figure 4.175 Load versus overall shortening curve for specimen NSR-20..............163

Figure 4.176 Views of specimen NSR-21 before and after testing.....................164

Figure 4.177 Axial load-strain relationships for specimen NSR-21...................164

Figure 4.178 Load-lateral deflection curves for specimen NSR-21 ......................165

Figure 4.179 Load versus overall shortening curve for specimen NSR-21 .............165

Figure 4.180 Views of specimen NSR-22 before and after testing......................166

Figure 4.181 Axial load-strain relationships for specimen NSR-22 ....................166

Figure 4.182 Load-lateral deflection curves for specimen NSR-22 ....................167

Figure 4.183 Load versus overall shortening curve for specimen NSR-22 ..............167

Figure 4.184 Views of specimen NSR-23 before and after testing......................168

Figure 4.185 Axial load-strain relationships for specimen NSR-23..................168

Figure 4.186 Load-lateral deflection curves for specimen NSR-23..................169

Figure 4.187 Load versus overall shortening curve for specimen NSR-23 ...............169

Figure 4.188 Views of specimen NSR-24 before and after testing.....................170

Figure 4.189 Axial load-strain relationships for specimen NSR-24 ....................170

Figure 4.190 Load-lateral deflection curves for specimen.NSR-24 ...................171

Figure 4:191 Load versus overall shortening curve for specimen NSR-24 .............171

Figure 4.192 Views of specimen NSR-25 before and after testing......................172

Figure 4.193 Axial load-strain relationships for specimen NSR-25...................172

Figure 4.194 Load-lateral deflection curves for specimen NSR-25...................173

Figure 4.195 Load versus overall shortening curve for specimen NSR-25..............173

Figure 4.196 Views of the NSR tested specimens

Figure 4.197 Views of specimen NSR-26 before and after testing.......................174

Figure 4.198 Axial load-strain relationships for specimen NSR-26....................175

Figure 4.199 Views of specimen NSR-27 before and after testing......................175 
Figure 4.200 Axial load-strain relationships for specimen NSR-27.....................176

Figure 4.201 Load versus overall shortening curve for specimen NSR-27..............176

Figure 4.202 Views of specimen NSR-28 before and after testing......................177

Figure 4.203 Axial load-strain relationships for specimen NSR-28...................177

Figure 4.204 Load versus overall shortening curve for specimen NSR-28..............178

Figure 4.205 Views of specimen NSR-29 before and after testing.....................178

Figure 4.206 Axial load-strain relationships for specimen NSR-29....................179

Figure 4.207 Load versus overall shortening curve for specimen NSR-29..............179

Figure 4.208 Views of specimen NSR-30before and after testing.......................180

Figure 4.209 Axial load-strain relationships for specimen NSR-30 ...................180

Figure 4.210 Load versus overall shortening curve for specimen NSR-30.............181

Figure 4.211 Views of specimen NSR-31 before and after testing.....................181

Figure 4.212 Axial load-strain relationships for specimen NSR-31 ..................182

Figure 4.213 Load versus overall shortening curve for specimen NSR-31 .............182

Figure 4.214 Views of specimen NSR-32 before and after testing.....................183

Figure 4.215 Axial load-strain relationships for specimen NSR-32 .................183

Figure 4.216 Load versus overall shortening curve for NSR-32 . .....................184

Figure 4.217 Views of specimen NSR-33 before and after testing.....................184

Figure 4.218 Axial load-strain relationships for specimen NSR-33...................185

Figure 4.219 Load versus overall shortening for specimen NSR-33...................185

Figure 4.220 Views of specimen SC-1 before and after testing ......................186

Figure 4.221 Axial load-strain relationships for specimen SC-1 .....................186

Figure 4.222 Load versus overall shortening curve for specimen SC-1 ...............187

Figure 4.223 Views of specimen SC-2 before and after testing......................187

Figure 4.224 Axial load-strain relationships for specimen SC-2 ....................188

Figure 4.225 Load versus overall shortening curve for specimen SC-2 ................188

Figure 4.226 Views of specimen SC-3 before and after testing........................189

Figure 4.227 Axial load-strain relationships for specimen SC-3 .....................189

Figure 4.228 Load versus overall shortening curve for specimen SC-3.................190

Figure 4.229 Views of specimen SC-4 before and after testing........................190

Figure 4.230 Axial load-strain relationships for specimen SC-4.....................191

Figure 4.231 Load versus overall shortening curve for specimen SC-4................191

Figure 4.232 Views of specimen SC-5 before and after testing.......................192

Figure 4.233 Axial load-strain relationships for specimen SC-5.....................192

Figure 4.234 Load versus overall shortening curve for specimen SC-5.................193

Figure 4.235 Views of specimen SC-6 before and after testing.......................193

Figure 4.236 Axial load-strain relationships for specimen SC-6.......................194

Figure 4.237 Load versus overall shortening curve for specimen SC-6................194

Figure 4.238 Views of specimen SC-7 before and after testing........................195

Figure 4.239 Axial load-strain relationships for specimen SC-7 ......................195

Figure 4.240 Load versus overall shortening curve for specimen SC-7................196 


\section{CHAPTER I \\ INTRODUCTION ·}

\subsection{General}

In the information industry, satellites, antenna towers and cables are used to transmit the signal from communication tools. Some of these communication tools are mobile phones and pagers. Antenna towers are the best choice because they are relatively economical and effective for remote transmission, especially in North America where land area is large and distances among the cities and towns are great. Antenna tower transmission of signals is the best medium, which is widely used not only in Canada but also in USA and Europe. These kinds of steel towers have their own characteristic. They are tall and slender. They can be classified into three types as shown in Figure 1.1, namely: (a) monopoles with heights up to $70 \mathrm{~m}$; (b) self-supporting towers with heights up to $120 \mathrm{~m}$; and (c) guyed towers with heights up to $620 \mathrm{~m}$. The environmental factors like the land-use classification of the property and whether the surrounding area is residential, industrial or agricultural play an essential part in determining the height of the tower. The telecommunication towers used in Canada are either square based self-supporting towers or triangular towers supported by guy cables, depending upon various factors, such as the space available at the site for its installation and the height of the tower. The most popular cross-section of the tower is the triangular shape. Legs, diagonals and horizontals are made of solid round steel bars with varying diameters and with all the joints welded or bolted. View of tower segment is shown in Figure 1.2. Solid round steel bars are widely used in the industry as compression members. For example, with increasing needs in information industry for transmitting communication signals, antenna towers made of solid round steel bars are frequently used 
around the world for their economy and effectiveness. It should be noted, however, that the residual stresses in the material, which may occur during rolling, heat treatment, rotary straightening or other processes, may have significant influence on the behaviour of the these members.

The towers are subjected to self-weight, snow, wind loads and also earthquake loads in seismic areas. Although the behaviour of the entire tower is rather complicated when subjected to these loads, the resultant forces in the members are mainly axial tension or compression. Hence, the behaviour of the tower members under axial forces is the most important consideration in the tower design. For this reason, the properties of the members with the residual stresses must be studied in order to obtain an optimized design while satisfying the safety requirements. Design loads during fabrication, erection and service can be classified as two categories, vertical loads and transverse loads. Leg members (chords) bear vertical loads and bending moments caused by transverse loads. But most of the shear force is borne by cross-brace diagonals, one in compression and the other in tension. In designing these members, not only the strength and stiffness but also the stability problems should be considered. The advancement of knowledge and technology has always resulted in an improvement in the specifications and the underlying philosophy through which various structures are designed. Since antenna towers are made of steel, the progress in the specifications concerning the design of steel structures generally, and the antenna towers specially, should be studied. 


\subsection{Need for Investigation}

The behavior of members in tension is very simple compared with that of those in compression. The mostly used philosophy for steel tower design at the present time is based on the ultimate strength of the members. There are many factors affecting the behavior of compression members, for example, the properties of steel, the slenderness of the member, the end constraints, cross-section of the member, initial out-of-straightness of the column, etc. The effect of end restraints, an important consideration in column stability analysis, is generally represented by the effective length factor. Residual stress is another factor influencing the compression behavior of the steel members and a lot of work on this topic has been done. But unfortunately, most of the work was on wideflange shapes. Few research results are available on solid round steel. For members in compression, because of the existence of residual stresses, early localized yielding occurs at some part of the cross section when the loading increases and the ultimate strength is appreciably reduced. Also, the fatigue life will be shortened due to the residual stresses when the tower is subjected to dynamic loads such as wind load. The superseded Canadian Standards of 1994, CAN/CSA-S16.1-94, AISC-LRFD Specifications of 1993, and the European Standard, Eurocode 3, provide the factored compressive resistance of structural steel members other than solid rounds. While, the Current Canadian Standard, CAN/CSA-S37-01 of 2001, for Antenna towers and Antenna Supporting Structures specifies empirical expressions for the compressive strength of solid rounds based on the well-known Structural Stability Research Council (SSRC) column curves for non-solidround members as well as the results from experimental investigation on the compressive resistance of solid rounds carried out back to 1965. As a result, there is an urgent need for 
experimental data on the load carrying capacity of solid rounds made of stress-relieved or non-stress-relieved steel so that the code equation can be easily updated. This will reflect on considerable savings to owners of communication towers and other structures that use solid rounds as primary members.

\subsection{Objectives of the study}

The objectives of the study are:

i) To experimentally determine the compressive resistance of solid round steel members made of stress-relieved or non-stress-relieved steel.

ii) To compare the experimental failure loads with the compressive resistance of solid rounds obtained from the available codes and specifications.

iii) To recommend modification factors to the available code equations for the compressive resistance of solid rounds based on the experimental results obtained in this thesis.

\subsection{Outline of the Thesis}

The thesis begins with an introduction to communication towers, followed by the need and objectives of the present investigation. The relevant literature is reviewed in Chapter 2. In chapter 3, details of experimental test set-up, geometric properties of the tested solid round steel members, support assembly and loading conditions are presented. Experimental results are presented and analyzed in Chapter 4. Finally, the conclusions and recommendations for further study are presented in Chapter 5. 


\section{CHAPTER II \\ LITERATURE REVIEW}

\subsection{General}

This chapter summarizes the literature pertained to the compressive strength of axially loaded steel members with emphasis on solid steel rounds. The literature review includes the critical-load theory, inelastic buckling of columns, imperfect column, compressive resistance of columns, influence of resídual stresses, influence of out-of-straightness, effect of cold-straightening, American specification, Canadian Standard, and European Code pertained to compressive resistance of columns

\subsection{Critical-Load Theory}

The strength of a perfectly straight prismatic column with perfect central loading and well-defined end restraints is the Euler load, $P_{E}$, as long as the material is still elastic when buckling occurs (Galambos, 1998):

$$
P E=\frac{\pi^{2} E I}{(K L)^{2}}
$$

where,

EI is the elastic stiffness,

$\mathrm{L}$ is the length of the column 
$\mathrm{K}$ is the effective length factor ( 1.0 for perfectly frictionless pins).

When the axial load attains $P_{E}$, a stable equilibrium configuration is possible even in the presence of lateral deflection (Figure 2.1a), while the load remains essentially constant (Figure 2.1b, path $\mathrm{OAB}$ ). Even if an initial deflection, and/or an initial load eccentricity is present, the maximum load will approach the Euler load asymptotically as long as the material remains elastic (curve $C$ in Figure 2.1b)

\subsection{Inelastic Buckling of Column}

Many practical columns are in a range of slenderness where at buckling portions of the columns are no longer elastic. The stiffness of the column is reduced by yielding, which may be a result of the nonlinearity in the material itself or it may be due to partial yielding of the cross section at points of compressive residual stress. The post-buckling behaviour of such a column is radically different from the elastic column. Bifurcation buckling occurs at the tangent modulus load, point D in Figure 2.1 (c) (Galambos 1998):

$$
P_{t}=\frac{\pi^{2} E_{t} I}{(K L)^{2}}
$$

where, $E_{t}$ is the tangent modulus. The tangent modulus $E_{t}$ is the slope of the stress-strain curve at a load level (Figure 2-2) when the material is non-linear.

Further lateral deflection is possible only if the load increases. If there were no further changes in stiffness due to yielding, the load would asymptotically approach the reduced modulus load as the deflection becomes large, (Point E in Figure 2-1c)(Galambos 1998):

$$
\operatorname{Pr}=\frac{\pi^{2} E_{r} I}{(K L)^{2}}
$$


where, $E_{r}$ is the reduced modulus.

In presence of residual stress, $E_{r}$ and $E_{t}$ depend on the shape of the cross-section. Since increased loading beyond the tangent modulus load results in further yielding, stiffness continues to be reduced and the load-deflection curve achieves a peak, $\left(\mathrm{P}_{\max }\right)$ point $\mathrm{F}$ in Figure 2-1(c) beyond which it falls off. Thus, a perfect inelastic column will begin to deflect laterally when $P=P_{t}$ and $P_{t}<P_{\max }<P_{r}$ (Galambos 1998).

In linear analysis of columns, it is assumed that the material behaves according to Hooke's law and the stresses in the member must remain below the proportional limit of the material for this postulation to be valid. From Figure 2-3 it can be seen that for slender columns, the applied load reaches Euler's load before the axial stress exceeds the proportional limit. The Euler load represents the correct buckling load of such members and the linear elastic analysis is therefore valid for slender columns. For stocky columns, the axial stress will exceed the proportional limit of the material before the applied load reaches the Euler load. Therefore, the results of the elastic analysis are not valid for stocky columns, and the buckling load of stocky columns must be determined by taking inelastic behaviour into account. This type of buckling is known as inelastic buckling. For columns that buckle inelastically, some of the fibres in the cross-section have been yielded before buckling occurs. Consequently, only the fibres that remain elastic are effective in resisting the additional applied force. Since only a small portion of the cross-section is effective in resisting the axial force at buckling, the elastic modulus $E$ is replaced by an effective modulus, $\mathrm{E}_{\mathrm{eff}}$, to describe the behaviour of the inelastic column. 


\subsection{Imperfect Column}

In Euler theory, the member is assumed to be perfectly straight and the loading is assumed to be concentric at every cross-section of the member. However, in actual structures, perfect members do not exist; minor imperfections of shape and small eccentricities of loading are present. For studying the behavior of an imperfect column, consider a member whose centroidal axis is initially bent and assume that the material obeys Hooke's law and that the deformations are small.

The initial deflection is assumed to be of the form (Figure 2.4):

$$
y_{o}=a \sin \left(\frac{\pi x}{L}\right)
$$

Due to the axially applied load $P$, the resulting bending moment in the column is given by

$$
\mathrm{M}=\mathrm{P}\left(y_{0}+y\right)
$$

And the total deflection at mid-height is given by

$$
\delta=\frac{a}{1-(P / P E)}
$$

Where, $y_{0}$ is the initial out-of-straightness of the column, $\mathrm{L}$ is the column length, $\mathrm{y}$ is the lateral deflection at distance $\mathrm{x}$ from the column end.

\subsection{Compressive Resistance of Steel Columns}

Steel columns are conventionally classified as short, intermediate, or long members, and each category has an associated characteristic type of behavior. A short column is one, which can resist a load equal to the yield load. A long column fails by elastic buckling on which the maximum load depends only on the bending stiffness (EI) 
and length of the member. Columns in the intermediate range are most common in steel structures (Figure 2.3). Failure is characterized by inelastic buckling and is greatly influenced by the magnitude and pattern of residual stresses that are present and the magnitude, shape of the initial imperfections or out-of-straightness and the end restraint. These effects lessen for both shorter and longer columns. To take into account these effects, a computerized maximum strength analysis was performed (Bjorhovde 1972) first on basic data available from carefully constructed column tests performed at Lehigh University on W-shaped and hollow column sections. Next, a set of 112 column curves was generated for members from whom measured residual-stress distributions were available, assuming an initial crookedness of $1 / 1000$ of the column length and zero end restraint. Bjorhovde grouped the whole spectrum of column behavior to three column curves known as Structural Stability Research Council (SSRC) Column Strength Curves 1, 2 and 3 (Galambos 1998).

In a pilot investigation conducted from 1954 to 1956, the behavior of $70-\mathrm{mm}$ diameter stress-relieved bars was studied experimentally (Fujita and Driscoll 1962). Three stub-column tests, nine axially loaded column tests (eight "T-1" steel bars and one structural carbon-steel bar), and two eccentrically loaded column tests were performed. The slenderness ratios of these bars ranged from 30 to 73 . Comparison with the tangent modulus concept for axially loaded columns, and with an inelastic strength theory for the eccentrically loaded columns, showed that the ultimate strength of solid round columns might be predicted adequately by theory. 
Latter, (Galambos and Yoda, 1962) reported testing four axially loaded solid round bars of $190.5 \mathrm{~mm}$ diameter and slenderness .ratios of 52,61, 66 and 67, respectively. Then, Galambos (1965) added the results of the experimental ultimate axial compressive strength of fourteen bars with diameter $70 \mathrm{~mm}$ slenderness rations ranging from 30 to 62 . The effects of residual stress and initial crookedness on column strength were also considered. The initial out-of-straightness (also refereed as initial crookedness or initial curvature) also affects the primary column strength. The analysis of the strength of inelastic, initially curved columns has either made use of assumed values and shapes of the initial out-of-straightness, or can use actually measured data. The former is the most common, mostly because the measurements that are available for columns are rare. This applies in particular to the magnitude of the maximum out-of-straightness, normally assumed to occur at the mid-height of the member. The latter is usually thought to be that of a half -sine wave (Bjorhovde 1972).

\subsubsection{Influence Of Residual Stresses}

Residual stresses in structural steel shapes and plates result primarily from uneven cooling after rolling of hot-rolled steel columns. The quick cooling parts of sections when solidified resist further shortening, while those parts that are still hot tend to shorten further as they cool. The net result is that the area that cooled more quickly has residual compressive stresses, while the slower cooling areas have residual tensile stresses. In the elastic region, residual stresses and initial crookedness have a significant influence on the strength of solid round bars. These stresses are of particular importance for columns with slenderness ratio varying from approximately 40 to 120 , a range that includes a very large 
percentage of real-world columns. The influence of the initial crookedness is predominant if only small residual stresses are present. For materials, which are quenched without stress relieving, the effect of residual stresses and initial crookedness is significant (Galambos 1965). Few researchers (among them: Hetenyi, 1957; Watanabe et al., 1955; Bühler, 1954) measured experimentally the residual stresses in cylindrical steel bars by the boring-out technique. According to the study by Nitta and Thürlimann (1962b) on the effect of thermal residual stresses and initial deflections on solid round steel bars, members containing high residual stress caused by water quenching, for example, carry approximately a 10 to $20 \%$ lower load than air-cooled or stress-relieved steel columns, provided that the generalized slenderness ratio and initial deflections are the same. Few authors utilized analytical and numerical simulation techniques, such as the finite-element method, to predict residual stresses produced by the manufacturing process (Jahanian, 1995; Toparli and Aksoy, 1991; Kamamato et al., 1985; Weiner and Huddleston, 1959). Recently, Weiner and Huddleston showed a solution of the phase-transformation stresses from the standpoint of the flow theory of plasticity. Since the process for obtaining a general solution is very involved it seems almost inevitable to introduce simplifying assumptions when performing numerical calculations. Hence certain constant values of the material properties are used as a common value for the whole cooling instead of taking the true values corresponding to the variable temperatures. By including the effect of the residual stresses in steel columns a reasonable approach to the solution of the buckling load was suggested by Osgood, Yang and others.

Fujita and Driscoll (1962) solved graphically the ultimate strength of H-shape and built-up columns including the effect of residual stresses due to welding. Since these 
particular solutions are not applicable to any other cross sectional shapes in which the magnitude and the distribution pattern of residual stresses are different, further studies are necessary in order to visualize the true column behavior until failure occurs. Most recently, Ding (2000) used the classical boring-out method to determine the residual stresses on fourteen samples of hot-rolled solid round steel bars. The diameter of the specimens ranged from 38.1 to $152.4 \mathrm{~mm}$, with yield strength of $456 \mathrm{MPa}$. It should be noted that the residual stresses are an unavoidable consequence of the manufacturing process. Hence, the measurement of them is needed in order to assess the performance of columns under combined effect.

The results obtained by the studies of Batterman and Johnston (1967) showed that the separate effects of residual stresses and initial curvature cannot be added to give a good approximation of the combined effects on the maximum column strength. Residual stresses have little effect on the maximum strength of very slender columns, either straight or initially crooked, which have strengths approaching the Euler load. However, such columns made of higher-strength steels can tolerate much greater lateral deflection before yield or before becoming unstable. The differences in column strength, caused by variations in the shape of the residual stress pattern, are smaller for initially curved columns than for initially straight columns.

\subsubsection{Influence Of Out-of-Straightness}

The initial out-of-straightness (also referred to as initial crookedness or initial curvature) also affects the primary column strength. The analysis of the strength of inelastic, 
initially curved columns has either made use of assumed values and shapes of the initial outof-straightness, or can use actually measured data. The former is the most common, mostly because the measurements that are available for columns are rare. This applies in particular to the magnitude of the maximum out-of-straightness, normally assumed to occur at midheight of the member. The latter is usually thought to be that of half-sine wave (Batterman and Johnston, 1967; Bjorhovde and Tall, 1971).

\subsubsection{Effect of Cold-Straightening}

The strength of cold-straightened columns is, in general, greater than that of the corresponding as-rolled members because of the improved straightness and redistribution of residual stress (Alpsten 1970). According to the study by Nitta and Thürlimann (1962a) on the effect of cold straightening on the ultimate strength of circular columns, the tangent modulus concept cannot be used for predication of cold-straightening columns, as there exists no bifurcation point in the load-deflection curve of coldstraightened column, which contains ant-symmetric residual stress. The strength depends upon the magnitude of the cold-straightening residual stresses and the out-of-straightness remaining after cold-straightening operation. The load carrying capacity of such column can be determined by ultimate load analysis.

Fujita and Deiscoll (1962) tested nine axially loaded bars and two eccentrically loaded bars (eight USS "T-1" constructional alloy steel bars and one structural carbon steel bar). The bars were of $70 \mathrm{~mm}$ in diameter, with slenderness ratio $(\mathrm{KL} / \mathrm{r})$ ranging from 30 to 73 . The bars were cold straightened and subsequently stress-relieved, followed 
by air-cooling. Comparison with the theory based on the 'tangent modulus" concept for axially loaded columns, and with an inelastic-strength theory for the eccentrically loaded columns shows that the ultimate strength of solid round columns may be predicated adequately by the tangent modulus concept.

Recently, Mull (1999) experimentally determined the compressive resistance of forty steel solid round specimens for five different diameters of specimens ranging from $31.75 \mathrm{~mm}$ to $57.15 \mathrm{~mm}$. The effective slenderness ratios of the specimens varied from 59 to 117. The specimens were tested as pinned-end columns loaded concentrically. From the measured strain data, it was determined that only sixteen of the forty specimens had load eccentricities less than or equal to $1 / 500^{\text {th }}$ of the effective length of the specimen. For these sixteen specimens, the ratio of the resistance computed from the Canadian Standard "Limit States Design of Steel Structures", CAN/CSA-S16.1-94, to the experimental failure loads ranged from 0.98 to 0.79 , and, for resistances computed from AISC-LRFD Specification (1993), the ratios ranged from 1.10 to 0.89 . So, more tests need to be carried out of wide range of solid rounds, especially of large diameters, to reach recommendations that may provide considerable savings in the design and evaluation of solid round bars. Previous studies on the effective length factors of solid round bars used as bracing diagonals (Jaboo, 1998; Sun, 1999, Chen, 2000; Lim, 2000) and as chord members (Qureshi, 1999). General effective length factors for structural steel members are specified in CAN/CSA-S16-01, Figure 2.5. 


\subsection{Structural Stability Research Council (SSRC) Column Strength}

\section{Curves}

In a major study, Bjorhovde (1972) examined the deterministic and probabilistic characteristics of column strength in general and developed an extensive database for the maximum strengths of centrally loaded compression members, covering the full practical range of shapes, steel grades, and manufacturing methods. This study resulted in a collection of 112 maximum-strength column curved. Then, these curves were subdivided into groups of curves with a mean or similar curve for each group. The latter defines the multiple column curve concept (Bjorhovde and Tall, 1971; Bjorhovde, 1972; Bjorhovde and Birkemoe, 1979). This results in three curves known as SSRC column strength curves 1, 2 and 3, and they are reproduced as shown in Figures 2.6, 2.7 and 2.8, respectively. Algebraic representations of the three column strength curves were obtained by curve fitting, and the resulting equations are as follows:

SSRC curve 1:

1. For $0 \leq \lambda \leq 0.15$

2. For $0.15 \leq \lambda \leq 1.2$

3. For $1.2 \leq \lambda \leq 1.8$

4. For $1.8 \leq \lambda \leq 2.8$

5. For $\lambda \geq 2.8$

$$
\begin{aligned}
& \sigma_{\mu}=\sigma_{\mathrm{y}} \\
& \sigma_{\mu}=\sigma_{\mathrm{y}}\left(0.990+0.122 \lambda-0.367 \lambda^{2}\right) \\
& \sigma_{\mu}=\sigma_{\mathrm{y}}\left(0.051+0.801 \lambda^{-2}\right) \\
& \sigma_{\mu}=\sigma_{\mathrm{y}}\left(0.008+0.942 \lambda^{-2}\right) \\
& \sigma_{\mu}=\sigma_{\mathrm{y}} \lambda^{-2} \text { (Euler Load) }
\end{aligned}
$$

SSRC curve 2:
1. For $0 \leq \lambda \leq 0.15$
2. For $0.15 \leq \lambda \leq 1.0$
3. For $1.0 \leq \lambda \leq 2.0$
4. For $2.0 \leq \lambda \leq 3.6$
5. For $\lambda \geq 3.6$

$\sigma_{\mu}=\sigma_{\mathrm{y}}$

$\sigma_{\mu}=\sigma_{\mathrm{y}}\left(1.035-0.202 \lambda-0.222 \lambda^{2}\right)$

$\sigma_{\mu}=\sigma_{\mathrm{y}}\left(-0.111+0.636 \lambda^{-1}+0.087 \lambda^{-2}\right)$

$\sigma_{\mu}=\sigma_{\mathrm{y}}\left(0.009+0.877 \lambda^{-2}\right)$

$\sigma_{\mu}=\sigma_{\mathrm{y}} \lambda^{-2}$ (Euler Load) 
SSRC curve 3:

1. For $0 \leq \lambda \leq 0.15$

2. For $0.15 \leq \lambda \leq 0.8$

$\sigma_{\mu}=\sigma_{\mathrm{y}}$

3. For $0.8 \leq \lambda \leq 2.2$

$\sigma_{\mu}=\sigma_{\mathrm{y}}(1.093-0.622 \lambda)$

4. For $2.2 \leq \lambda \leq 5.0$

$\sigma_{\mu}=\sigma_{\mathrm{y}}\left(-0.128+0.707 \lambda^{-1}-0.102 \lambda^{-2}\right)$

5. For $\lambda \geq 5.0$

$\sigma_{\mu}=\sigma_{\mathrm{y}}\left(0.008+0.792 \lambda^{-2}\right)$

$\sigma_{\mu}=\sigma_{\mathrm{y}} \lambda^{-2}$ (Euler Load)

\subsection{Canadian Standards}

The experimental investigation on the compressive resistance of solid rounds carried out was as far back as to 1965 on structural carbon and construction alloy steel (Galambos and Ueda, 1962; Galambos, 1965). Since there is no other literature on the compressive resistance of solid rounds, the superseded version of the Canadian Standard for Antennas, Towers, and Antenna-Supporting Structures, CAN/CSA-S37-94, assumed the applicability of Column Strength Curve 2 of the Structural Stability Research Council (Galambos, 1998) to hot rolled solid round bars $51 \mathrm{~mm}$ in diameter and less and to hotrolled solid round bars greater than $51 \mathrm{~mm}$ in diameter that are stress-relieved to manufacturer's recommendations after initial cold-straightening at the mill. It should be noted that the resulting equations of the SSRC Column Strength curve 2, equations 1 to 5 listed below, were obtained for W-shapes and hollow structural sections.
$0 \leq \lambda \leq 0.15$
$C_{r}=\phi \cdot A \cdot F_{y}$
$0.15<\lambda \leq 1.0$
$C_{r}=\phi \cdot A \cdot F_{y}\left[1.035-0.202 \lambda-0.222 \lambda^{2}\right]$
$1.0<\lambda \leq 2.0$
$C_{r}=\phi . A . F_{y}\left[-0.111+0.636 \lambda^{-1}+0.087 \lambda^{-2}.\right]$
$2.0<\lambda \leq 3.6$
$C_{r}=\phi \cdot A \cdot F_{y}\left[0.009+0.877 \lambda^{-2}\right]$
$3.6<\lambda \leq 5.0$
$C_{r}=\phi \cdot A \cdot F_{y}\left[\lambda^{-2}\right]$ 
where:

$\lambda=\frac{K L}{r} \sqrt{\frac{F_{y}}{\pi^{2} E}} ; F_{\mathrm{y}}=$ yield stress; $\phi=$ resistance factor; $\mathrm{A}=$ cross-sectional area; $\lambda=$ slenderness function; $\mathrm{L}=$ length of member; $\mathrm{r}=$ radius of gyration; $\mathrm{K}=$ effective length factor; $\mathrm{E}=$ modulus of elasticity.

Also, the CAN/CSA-S37-94 presented expressions of the compressive resistance of solid round bars greater than $51 \mathrm{~mm}$ in diameter and not stress-relieved after cold straightening, based on Column Strength Curve 3 of the Structural Stability Research Council (Galambos 1998).

$0<\lambda \leq 0.8$

$$
C_{r}=\phi \cdot A \cdot F_{y}[1.093-0.622 \lambda]
$$

$0.8<\lambda \leq 2.3$

$$
C_{r}=\phi \cdot A \cdot F_{y}\left[-0.128+0.707 \lambda^{-1}-0.102 \lambda^{-2}\right]
$$

$2.3<\lambda \leq 5.0$

$$
C_{r}=\phi \cdot A \cdot F_{y}\left[0.008+0.792 \lambda^{-2}\right]
$$

Most recently, the Canadian Standard for Antenna towers and Antenna Supporting Structures, CAN/CSA-S37-01, was released to the public, with some modifications to the expressions found in the superseded version of 1994 for compressive strength of solid rounds. These modifications were based on results of testing a limited number of solid rounds back to 1965 . The factored axial compressive resistance, $C_{r}$, of a member is determined by the following formula:

$$
C_{r}=\phi \frac{A F_{y}}{\left[1+\lambda^{2 n}\right]^{1 / n}}
$$


where:

$\mathrm{n}=1.34$ for hot rolled round bars $51 \mathrm{~mm}$ in diameter and less; hot rolled solid round bars greater than $51 \mathrm{~mm}$ in diameter and stress relieved to manufacturer's recommendations after initial cold straightening at the mill.

$=0.93$ for hot-rolled solid round bars greater than $51 \mathrm{~mm}$ in diameter and not stress relieved after cold straightening.

It should be noted that earlier versions of the Canadian Standard "Limit States Design of Steel Structures" adopted Equations 2.7 to 2.14 for solid round bars till 1994 version of the standard. However, the current standard "CAN/CSA-S16-01" (2003) omitted these equations for the insufficient data in the literature that supports them. It adopts equation 2:15 for shapes other than solid rounds.

In summary, there is a lack of available literature that would assist code writers to specify more economical and safe expressions for the compressive strength of stressrelieved and non-stress-relieved solid round steel bars. Also, as manufacturing methods have advanced considerably since the current equations were formulated, there is a need to revisit this issue.

\subsection{AISC (LRFD) Specifications}

According to the AISC-LRFD, "Load and Resistance Factor Design Specifications for Structural Steel Buildings", [American Institute of Steel Construction Inc. 1993], the compressive resistance of structural steel members of different shapes is given by: 


$$
C_{r}=\phi \cdot A \cdot F_{c r}
$$

Where,

$$
\begin{array}{ll}
F_{c r}=\left[0.658^{\lambda^{2}}\right] F_{y} & \text { for } \lambda \leq 1.5, \text { and } \\
F_{c r}=\left[\frac{0.877}{\lambda^{2}}\right] F_{y} & \text { for } \lambda>1.5
\end{array}
$$

It should be noted that equations 2.17 and 2.18 represent SSRC column strength curve 2 and apply for structural steel shapes other than solid rounds.

\subsection{European Standard}

This European Standard for the design of steel structures, Eurocode 3, (CEN, 2003) specifies rules relating to ultimate limit state analysis of the buckling resistance of steel linear members and frames susceptible to loss of stability. Buckling is a phenomenon in which displacement, $v$ or $w$, of a member occurs, or rotation, $v$, occurs about its major axis, or both occur in combination. A distinction is conventionally made between lateral buckling and lateral torsional buckling. Lateral buckling is a phenomenon in which displacements, $v$ or $w$, of a member occurs, or both occur in conjunction, any rotation, $\vartheta$, about its major axis being neglected. Lateral torsional buckling is a phenomenon in which displacements, $v$ and $w$, of a member occur in combination with rotation, $\vartheta$, about its major axis, consideration of the latter being obligatory.

Eurocode 3 specifies that the analysis shall take the form of one of the methods given in Table 2.1 shown below, taking into account the following factors:

- Plastic capacity of materials 
- Imperfections

- Internal forces and moments

- The effects of deformations

- Slip

- The structural contribution of cross sections

- Deductions in cross-sectional area for holes

As a simplification, lateral buckling and lateral torsional buckling may be checked separately, first carrying out the analysis for lateral buckling and then that for lateral torsional buckling whereby, in the latter case, members shall be notionally singled out of the structural system and subjected to the internal forces and moments acting at the member ends (when considering the system as a whole) and to those acting on the member considered in isolation. Details on whether first or second order theory is to be applied are given together with the relevant method of analysis

The materials used shall be of sufficient plastic capacity. Calculations may be based on assumptions of linear elastic-perfectly plastic stress-strain behavior instead of actual behavior. Reasonable assumptions shall be made in order to take into account the effects of geometrical and structural imperfections. Typical geometrical imperfections are accidental load eccentricity and deviations from design geometry. Typical structural imperfections would be residual stresses. The internal forces and moments occurring at significant points in the members shall be calculated on the basis of the design actions. Calculations of internal forces and moments usually make allowance for deformation effects on equilibrium, using as the design stiffness values the characteristic stiffness 
obtained by dividing the nominal characteristics of cross section and the elastic characteristic and shear moduli by a partial safety factor $\gamma_{M}$ equal to 1.1 . The effect of deformations resulting from stresses due to shear forces may normally be ignored.

Members notionally singled out of the system and considered in isolation shall be analyzed for lateral torsional buckling. Their end moments may require to be determined by second order theory. The moments in the span may then be calculated by first order theory using these end moments.

An analysis of lateral torsional buckling is not required for the following:

- Hollow sections

- Members with sufficient lateral or torsional restraint

- Members designed to be in bending, provided that their non-dimensional slenderness in bending, $\bar{\lambda}_{\mathrm{M}}$, is not more than 0.4

The ultimate limit state analysis shall be made for the direction in which buckling will take place, using equation 2-19

$$
\frac{N}{x . N_{p l, d}} \leq 1
$$

Where $\mathrm{N}$ is design value of the compressive force, $\mathrm{N}_{\mathrm{pl}, \mathrm{d}}$ is the design buckling resistance of the compression member, $\mathrm{x}$ is a reduction factor according to the standard and buckling curved as used in Europe.

$$
\begin{aligned}
& \text { If } \quad \bar{\lambda}_{K} \leq 0.2 ; \chi=1 \\
& \text { If } \quad \bar{\lambda}_{K}>0.2 ; x=\frac{1}{k+\sqrt{k^{2}-\bar{\lambda}_{K}^{2}}}
\end{aligned}
$$




$$
\text { where } k=0.5\left[1+\alpha\left(\bar{\lambda}_{k}-0.2\right)+\bar{\lambda}_{k}^{2} j\right.
$$

As a simplification, in cases where $\bar{\lambda}_{K}>3.0$ :

$$
x=\frac{1}{\bar{\lambda}_{k}\left(\bar{\lambda}_{k}+\alpha\right)}
$$

Where $\alpha$ is the imperfection factor being taken from Table 2.2 for curve $\mathrm{c}$.

In lieu of the above equations, $\chi$ can be obtained from curve $c$ in Figure 2.9. 



\section{Chapter III}

\section{EXPERIMENTAL STUDY}

\subsection{General}

Axially loaded column strength tests were conducted at the structural laboratory of Ryerson University on 20 stress-relived steel solid rounds and 35 non-stress-relieved steel solid rounds on different diameter and length. Also, a set of 7 stub columns was tested to collapse. This chapter reports the sizes of the tested specimens as well as the test set-up used to conduct each type of testing.

\subsection{Description of the test specimens}

\subsubsection{Testing Centrally Loaded Columns made of Stress-Relieved Steel}

To minimize initial geometric imperfections of the specimen, the column specimen is cut from a straight portion of the stock. Both ends of the specimen are milled. 20 solid rounds made of stress-relieved steel were cut to size per the dimensions shown in Table 3.1. This type of specimens was supplied by Radian Communications Systems Inc. of Oakville, Ontario, Canada. The diameter of the columns ranged from 38 to $128 \mathrm{~mm}$, with slenderness ratios ranging from 10 to 70 . It should be noted that the common slenderness ratios for existing tower members range from 40 to 70 . However, the inclusion of smaller slenderness ratios was considered as a result of the considerable high compressive forces in the tower legs in high seismic regions. Table 3.1 summarizes the details of these specimens. The results of these tests would be in the form of 
lateral deflection of the column at mid-height; axial strains, column shortening and mode of failure.

\subsubsection{Testing Centrally Loaded Columns made of Non-Stress-Relieved Steel}

Two sets of solid rounds made of non-stress-relieved steel were supplied by ERI, Electronics Research Inc. of Chandler, Indiana, U.S.A. The first set included 25 solid rounds with diameter ranging from $38 \mathrm{~mm}$ to $114 \mathrm{~mm}$ and slenderness ratios ranging from 20 to 75 , as shown in Table 3.2. The other set has longer length, with slenderness ratios ranging from 25 to 91. Table 3.3 summarizes the details of these specimens. These tests were intended to stand on the level of the effect of residual stresses arising from the manufacturing process on the column compressive resistance.

\subsubsection{Stub Column Tests:}

Stub column tests were made of short bars to determine the average compressive stressstrain characteristics of the solid round when instability effects are excluded. This information will be used in a subsequent study for the determination of the tangent-modulus curved needed for the theoretical predication of the critical load of the axially loaded columns and to stand on the percentage reduction in strength when using longer length of columns. SSRC Guidelines (Galambos, 1998) recommend the length of the hot-rolled stub columns to be $2 \mathrm{~d}+250 \mathrm{~mm}$ or $3 \mathrm{~d}$, whichever is the smaller, where $d$ is the diameter of the bar.

Seven stub columns were supplied by ERI, Electronics Research Inc. of Chandler, Indiana, U.S.A. Table 3.4 summarizes the details of the tested stub columns. The length-todiameter ratio of the stub was maintained at 4 . The diameter of the stubs ranged from $38 \mathrm{~mm}$ to 
$114 \mathrm{~mm}$, maintaining a slenderness ratio of 16. These specimens were cold-sawed from the stock and the ends of the columns were milled plane and perpendicular to the longitudinal axis of the column. Stub column tests are expected to provide Young's modulus of elasticity, proportional limit stress, yield strength, elastic range, elastic-plastic range, onset of strain hardening, strain-hardening range, and strain-hardening modulus.

\subsection{Test Set-Up}

The specimens were tested in the Structural Laboratory of Ryerson University. Two test set-ups were used to conduct the columns strength tests as well as stud column tests. The first test set-up utilized the available 4500-kN compression testing (MTS) machine, shown in Figure 3.1. The clear head of between the upper and lower end plates can accommodate specimens of maximum length of $1118 \mathrm{~mm}$. As a result, all specimens shown in Tables 3.1 to 3.4 were tested using the MTS machine except specimen NSR-26 shown in Table 3.3. This specimen was tested in a set-up prepared to accommodate specimen height of $1219 \mathrm{~mm}$.

The second set up was installed between the upper and lower steel beams of the available self-contained 3D structural steel testing facility in the structural laboratory. A hydraulic jack having a capacity of $900 \mathrm{kN}$ was used for the application of the load. The jack was mounted on a W-shape monorail beam supported by a rigid portal frame as shown in Figure 3.3-b. A universal flat load cell, of $900 \mathrm{kN}$ capacity, was used to measure the applied loads on bridge models. While Figure 3.3 shows the two test setups mentioned herein. 
Three types of end conditions were applied to the columns tested in the MTS machine, namely, hinged-hinged (H-H), hinged-fixed (H-F) and fixed-fixed (F-F). A hemispherical bearing block at the upper and/or lower end of the machine provided a uniform distribution of applied stress in the test specimen and ensured the pinned-end restraints of the specimen while flat-ended conditions were considered at the lower end and/or upper end of the specimen ensuring fixed-end constrains. Figure 3.2 shows schematic diagram of the specimens in a test setup with hinged-fixed conditions.

\subsection{Instrumentations}

\subsubsection{Strain Gauges}

Electric resistance strain gauges, manufactures by Kyowa, Japan, type KFG-5-120-C111, with a gauge length of $5 \mathrm{~mm}$ and a gauge factor of 2.12 were used to measure the axial strain in the test specimen. Four strain gauges were attached in North, East, South and West directions, as shown in Figure 3.2 to measure the axial strain in the specimen at its. mid-height. For the application of strain gauges, the surface was properly polished with a $50 \mathrm{~mm}$ air grinder using a brush, grit size-50, for roughening and grit size-180 for finishing; and then cleaned with acetone,

followed by application of M-Prep conditioner-A and M-prep Neutralizer-5A: Conditioner-A (non-flammable phosphoric acid) was water based acidic surface cleaner, and M-prep Neutralizer-5A (non-flammable ammonia water) was a water based alkaline surface cleaner. After polishing and cleaning the surfaces, Fastac accelerator-H, Sicomet-7000 (for use with cyanacrylate adhesives), was applied on the polished and cleaned surface, followed by the application of the strain gauge adhesive (alkyl cyanoacrylate ester), along with the strain gauge. 


\subsubsection{Mechanical Dial Gauges}

Mechanical dial having travel sensitivity $0.01 \mathrm{~mm}$ were used to measure the lateral deflection in the north and east directions at the mid-height of the column. The dial gauge readings were manually taken at specific increments of the loading throughout the test. In some specimens, Linear Variable Displacement Transducers, LVDT's, were used to measure lateral deflection in two perpendicular directions.

\subsubsection{Automatic Strain Indicator}

Daytronics system 10 data acquisition unit was used to capture the strain reading from rebar strain gauges. This unit consists of balancing unit having quarter, half and full bridge connections of the circuit and data acquisition system which was connected to the computer. Data from the acquisition system was captured using Visual Designer software from Intelligent Instrumentation.

\subsection{Test Procedure}

Initial dimensions (length, diameter and out-of-straightness) of each specimen were recorded. Then, each specimen was aligned centrally within the testing machine. Dial gauges were installed at the north and east sides of the column at its mid-height. Strain gauge wires were connected to the automatic strain indicator. When using the MTS machine, the load was applied at a rate of $6.9 \mathrm{MPa} / \mathrm{min}$ (Galambos, 1998). The converted load rate for each specimen is listed in the last column of Tables 3.1 to 3.4. The MTS machine software recorded the applied load per second as well as the overall shortening of the column with the applied load till failure. At a specified load increment, the readings from the strain gauges and the dial gauges were recorded. 


\subsection{Material Property}

The tensile yield strength is the key mechanical property required by codes and design practice. Because of its standard usage, it is the most accepted value for analyzing and comparing test data. Since the tensile testing is sensitive to the rate of straining, stability test data can easily be shifted by more than $20 \%$ if care is not exercised in conducting the tension test and in reporting the test method employed and its results.

Seven tensile coupons for stress relieved steel columns as well as seven tensile coupons taken from non-stress-relieved steel specimens were tested, corresponding to each bar size. The tensile coupons were prepared in accordance with ASTM Standards. The total length of the specimens was $200 \mathrm{~mm}$, with a gauge length of $50 \mathrm{~mm}$ and diameter of $12.5 \mathrm{~mm}$. Figure 3.5 shows the test set-up for tension coupon test before and after failure, respectively. Typical loadelongation curve for the tensile coupons are given in the following chapter. The values of yield stress, tensile strength and percent elongation for each specimen are presented in the following chapter.

\subsection{Determination of Yield Strength from Tension Coupons}

Kennedy and Gad (1980; CSA, 2000) provided guidance to determine representative material strength for use in the evaluation of existing bridges from the test of material samples taken from the bridge. The analysis and interpretation of test data may often be made difficult by presence of spurious high or low observations in the data set. A test observation can be ignored if reasons for its extreme value can be identified and its exclusion from the analysis can be justified. However, such justification may be difficult if there are less than 6 samples in total. 
The yield strength for evaluation, $F_{y}$, is determined from Eq. (3-1) (CSA, 2000). In this equation, it is assumed that the difference between yield strength observed during a coupon test and static yield strength is $28 \mathrm{MPa}$.

$$
F y=(\overline{F y}-28) e^{-1.3 K s V s}
$$

where,

$\overline{F y} \quad=$ Average value of equivalent yield strengths from the tests $=\frac{1}{n} \sum_{i=1}^{n} F_{y i}$

$K_{s}=$ coefficient of variation modification factor for steel from Table 3.5. Coefficient $K_{s}$ is a measure of confidence in strength data and reflects effect of sample size on the uncertainty of the mean value; higher value of $\mathrm{K}_{\mathrm{s}}$ means a greater uncertainty and hence a lower degree of confidence. This confidence in data improves as the number of sample increases. The equivalent yield strength of each coupon is its reported yield strength from the test, except of a coupon is obtained from the flange of a rolled member, the equivalent yield strength of that coupon may be taken as 1.05 times the reported yield strength from the test.

$n \quad=$ number of strength tests

$V_{s} \quad=$ coefficient of variation of equivalent yield strengths from the tests. It is dimensionless and is defined as the standard deviation divided by the mean $r=\frac{\sigma}{\overline{F y}}$.

As a general case, the mean value of $\mathrm{x}$ is denoted by $\mu \mathrm{x}$. For a continuous random variable, the mean value is defined as 


$$
\mu x=\int_{-\infty}^{+\infty} x f_{x}(x) d x
$$

For a discrete random variable, the mean value is defined as

$$
\mu x=\sum_{\text {allx }} x_{i} p_{x}\left(x_{i}\right)
$$

The expected value of $\mathrm{X}$ is commonly denoted by $\mathrm{E}(\mathrm{X})$ and is equal to the mean value of the variable as defined above:

$$
E(X)=\mu x
$$

It is also possible to determine the expected value of $\mathrm{X}^{\mathrm{n}}$. This expected value is called the nth moment of $\mathrm{X}$ and is defined for continuous variables as

$$
\begin{aligned}
& E\left(X^{n}\right)=\int_{-\infty}^{+\infty} x^{n} f_{x}(x) d x \\
& E\left(X^{n}\right)=\sum_{\text {allxi }} x_{i}^{n} p_{x}\left(x_{i}\right)
\end{aligned}
$$

The variance of $X$, commonly denoted as $\sigma_{x}^{2}$, is defined as the expected value of $(X-\mu x)^{2}$ and is equal to

$$
\begin{aligned}
& \sigma_{x}^{2}=\int_{-\infty}^{+\infty}(x-\mu x)^{2} f x(x) d x \quad \text { (Continuous random variable) } \\
& \sigma_{x}^{2}=\sum_{\text {allxi }}\left(x_{i}-\mu x\right)^{2} p_{x}\left(x_{i}\right) \quad \text { (Discrete random variable) }
\end{aligned}
$$

An important relationship exits among the mean, variance, and second moment of a random variable $X$ :

$$
\sigma_{x}^{2}=E\left(X^{2}\right)-\mu_{x}^{2}
$$


The standard deviation of $\mathrm{X}$ is defined as the positive square root of the variance:

$$
\sigma_{x}=\sqrt{\sigma_{x}^{2}}
$$

The nondimensional coefficient of variation, $\mathrm{Vx}$, is defined as the standard deviation divided by the mean:

$$
V_{x}=\frac{\sigma_{x}}{\mu_{x}}
$$

This parameter is always taken to be positive by convention even though the mean may be negative. In many practical applications, the true distribution is not known, and one needs to estimate parameters using test data. If a set of $n$ observations $\left\{x_{1}, x_{2}, \ldots, x_{n}\right\}$ are obtained for a particular random variable $X$, then the true mean $\mu \mathrm{x}$ can be approximated by the sample mean $\bar{x}$ and the true standard deviation $\sigma_{x}$ can be approximated by the sample standard deviation $S_{x}$

The sample mean is calculated as

$$
\bar{x}=\frac{1}{n} \sum_{i=1}^{n} x_{i}
$$

$\sigma \quad=$ standard deviation is calculated as follows $=S_{x}$

$$
=\sqrt{\frac{\sum_{i=1}^{n}(X i-\bar{X})^{2}}{n-1}}
$$

This method provides the specified yield strength in the structural drawings that can be used in calculating the ultimate load carrying capacity of the column. This value is usually less that the 
average yield strength obtained from tests. In this study, it was decided to use the actual yield strength as obtained experimentally for each coupon to obtain the ultimate strength of the respective specimen. This approach will make the comparison more realistic than using a lower value of yield strength or the commercial yield strength of Grade 50 steel. 


\section{CHAPTER IV}

\section{ANALYSIS AND DISCUSSION OF RESULTS}

\subsection{General}

The results from testing to-collapse 20 solid round bars made of stress-relieved steel and 33 solid round bars made of non-stress-relieved steel, under increasing monotonic axial compressive load, are reported in this chapter. Also, the results from testing 7 stub columns are reported in this chapter. Moreover, results from tensile testing of 7 coupons made of stress-relieved steel and other 7 coupons made of non-stressrelieved steel are reported for different bar diameters. The applied load, the measured axial strain at the mid-height of the column specimen, the lateral deflection at the midheight and the machine crosshead movement were recorded using a data acquisition system.

The compressive resistance obtained from testing were then compared with the compressive resistances computed based on the Canadian Standard (CAN/CSA-S37-01), the American Specifications (AISC-LRFD) and the European Standard (Euro code 3). The comparison between the experimental findings and the available Code equations for the steel bars was performed using the theoretical buckling length as well as the recommended practical buckling length specified in the Canadian Standard CAN/CSAS16-01. 


\subsection{Results from Tension Coupons}

Seven tensile coupons for stress relieved steel columns as well as seven tensile coupons taken from non-stress-relieved steel specimens were tested. Columns 1 and 2 of Tables 4.1 and 4.2 summarize the column diameters from which the coupon was machined towards their centroids. The tensile coupons were prepared in accordance with ASTM Standards. The total length of the specimens was $200 \mathrm{~mm}$, with a gauge length of $50 \mathrm{~mm}$ and diameter of $12.5 \mathrm{~mm}$. Figure 4.1 shows views of coupon samples during and after the fabrication process. While Figure 3.5 shows the test set-up for tension coupon test before and after failure, respectively.

Results from tensile testing the coupons made of stress-relieved steel and nonstress-relieved steel are presented in Table 4.1 and 4.2, respectively. Each table provides the average of three measurements for the diameter of each tension coupon, area of the tension coupon, peak load and stress, modulus of elasticity, the yield stress, percentage elongation at break and reduction of cross-sectional area after failure. It should be noted that the yield stress was calculated based on the $0.2 \%$-offset method when recorded stress-strain curve did not show the flat-yield plateaux at the end of the elastic stage and before entering the plastic stage.

Figures 4.2 to 4.8 show the recorded axial stress-strain relationship for each tested bar diameter shown in Table 4.1. Some of these curves show distinct upper yield point and flat-yield plateaux before entering the non-linear stage. While others show no yield point before at the end of the elastic stage. Each of the tensile coupons failed in a ductile 
manner as indicated in the calculated percentage elongations at break and reduction in cross-sectional area. Each coupon failed in a form of cup and cone. Figures 4.9 and 4.10 show the failure mode and the initial portion of the stress-strain curve of a coupon taken from a 38-mm diameter bar made of non-stress-relieved steel (NSR). Figures 4.11 and 4.12 show similar graphs for 51-mm diameter bar. Also, Figures 4.13 to 4.22 show similar graphs for coupons taken from NSR bars of diameters 64, 76, 89, 102 and 114 $\mathrm{mm}$.

\subsection{Results from Testing Centrally Loaded Columns Made of Stress- Relieved Steel}

Tests to-collapse on 20 solid round bars made of stress-relieved steel were performed to check the accuracy of the compressive resistance equations specified in steel Standards, Specifications and Codes, when applied to solid rounds. The experimental failure load, as well as other pertinent information, such as diameter, length, end conditions, load rate and slenderness ratio, are given in Table 4.3. Three end conditions were considered while testing, namely: hinged-hinged $(\mathrm{H}-\mathrm{H})$, hinged-fixed (H-F), and fixed-fixed (F-F) conditions as listed in Table 4.3 for each tested column. Increasing axial load was applied to each column and readings from strains gauges for axial strains, and from LVDT's for column lateral deflection at its height, were recorded. The MTS machine recorded the crosshead movement with time as during the test. It should be noted that crosshead movement gives an indication of the average shortening over the column length. It should be noted that columns SR-18, SR-19 and SR-20 of 128 
mm diameter did not fail because the applied axial load reached the specified capacity of the MTS machine of $4500 \mathrm{KN}$.

Figures 4.23 to 4.99 show the results from testing the 20 solid rounds made of stress-relieved steel. They include views of each specimen before and after failure. As an example, Figure 4.23 shows views of specimens SR-1 of $38 \mathrm{~mm}$ diameter and $660 \mathrm{~mm}$ length before and after failure. It can be observed that buckling is the dominant mode of failure for all specimens. Also, these figures include the measured axial strain at each load level. For example, Figure 4.65 shows the relationship between the applied axial load and the axial strains recorded at four points at the mid-height of the column. Two of these points represent the axial strains at the column surface along a line parallel to the machine head (north-south direction), while the other two points represent the axial strains at the column surface along a line perpendicular to the machine head (east-west direction). It can be observed that the strain readings at the four points are very close to each other which prove that there was almost no eccentricity on the application of the load. However, some columns show uneven distribution of axial strains along the perimeter of the columns at its mid-height. It should be noted that care was given at the first few increments of load at the start of each test to locate the column centrally as much as possible. Then, the test was continued till failure. It should be noted that the plane of buckling failure differ from one column to the other. This is why in some figures, such as Figure 4.65, it can be observed that buckling occurred about the east-west axis. While in Figure 4.31, failure occurred at the axis located between the south and west directions. 
Some of Figures 4.23 to 4.99 provide the lateral deflection of tested column at its mid-height with increase in axial load. For example, Figure 4.25 shows LVDT readings in the east and north direction of the specimen. It should be noted that the two readings are not interrelated. However, they may give an indication of load level at which buckling started (usually when deflection deviates from the straight line relationship with load). One may observe that in ideal column (the one that has no initial out-of-straightness), the lateral deflection is almost zero till the column buckles laterally. However, this situation did not exist in many of the tested column since there is a small initial imperfection (crookedness) before applying the axial load. Some of Figures 4.23 to 4.99 provide the movement of the sensitive crosshead relative to the fixed crosshead using a built in LVDT, as automatically recorded by the MTS machine, with increase in applied axial load. For example, Figure 4.37 shows the change in the average shortening of column SR-4 of $51 \mathrm{~m}$ diameter and $661 \mathrm{~mm}$ length, along its length.

\subsection{Correlation between the Experimental Failure Load of Stress- Relieved Steel Bars and the Compressive Resistance as Obtained from}

\section{Design Standards.}

The compressive resistances of the tested columns made of stress-relived steel were computed based on the available empirical expressions specified in the Canadian Standard (CAN/CSA-S37-01), the American Specifications (AISC-LRFD) and the European Standard (Euro code 3). A resistance factor, $\varphi$, of 1.0 was considered to take into account the actual failure load obtained experimentally. Then, the obtained compressive resistance for each column was correlated with the results from tests. 
It should be noted that three end conditions were considered while testing, namely: hinged-hinged $(\mathrm{H}-\mathrm{H})$, hinged-fixed $(\mathrm{H}-\mathrm{F})$, and fixed-fixed $(\mathrm{F}-\mathrm{F})$ conditions. For theoretical calculations of the slenderness factor, $\lambda$, the effective buckling length, $\mathrm{k}$, was taken as 1 in case of H-H condition, 0.707 in case of H-F condition and 0.5 in case of F-F condition, as specified in CSA-S16-01 (see Figure 2.5). In testing columns under full fixed-end condition, the full restraint may not exist throughout the test. Therefore, the effective length factor of the tested column may not be constant with increase in the applied load. This may be partly attributed to the indeterminate nature of the stress distribution at the column end, particularly in the load range in which the material yields. As a result, an increase in the effective length factor, $\mathrm{K}$, is expected in case of fixed end condition tested experimentally. In case of $\mathrm{H}-\mathrm{H}$ condition, this problem does not exist because the critical condition exists at the mid-height of the column. In actual structures, the condition of full-fixity is approached only when the column is anchored securely to a foundation for which rotation is negligible, or when the column is framed integrally to a girder many times more rigid than itself. As a result, CAN/CSA-S16-01 recommends a design value for $\mathrm{k}$ as a modification to the ideal value, taking into account the fact that neither perfect fixity nor perfect flexibility is attained in practice. Figure 2.5 summarizes these values as 0.8 for H-F columns and 0.65 for F-F columns.

Table 4.4 shows the comparison between the experimental ultimate load and the compressive resistance of solid rounds made of stress-relieved steel as obtained from CSA-S37-01, AISC-LRFD and Euro code 3, based on the theoretical buckling length factors. While, Table 4.5 presents similar comparison but based on the recommended 
practical buckling length factor shown in Figure 2.5. As it can be observed that the experimental failure load is always more or equal to the theoretical ultimate resistance. The following table summarizes the minimum, maximum and average value of the ratio between the experimental failure load the theoretical compressive resistance as obtained from the code equations. The standard deviation and the coefficient of variation are also presented in the table.

\begin{tabular}{|l|l|l|l|l|l|l|}
\hline $\begin{array}{l}\text { Effective } \\
\text { length factor, } \mathrm{k}\end{array}$ & & Mini & Max. & Average & $\begin{array}{l}\text { Standard } \\
\text { deviation }\end{array}$ & $\begin{array}{l}\text { Coefficient } \\
\text { of } \\
\text { variation }\end{array}$ \\
\hline \multirow{3}{*}{ Theoretical } & AISC-LRFD & 1.00 & 1.52 & 1.24 & 0.161 & $12.9 \%$ \\
\cline { 2 - 7 } & CSA-S37-01 & 1.00 & 1.68 & 1.27 & 0.189 & $14.9 \%$ \\
\cline { 2 - 7 } & EURO Code & 1.02 & 1.85 & 1.34 & 0.222 & $16.5 \%$ \\
\hline \multirow{3}{*}{ Practical } & AISC-LRFD & 1.00 & 1.62 & 1.29 & 0.161 & $12.4 \%$ \\
\cline { 2 - 7 } & CSA-S37-01 & 1.00 & 1.78 & 1.33 & 0.201 & $15.1 \%$ \\
\cline { 2 - 7 } & EURO Code & 1.02 & 1.96 & 1.42 & 0.243 & $17.0 \%$ \\
\hline
\end{tabular}

One may notice that the average ratios of the experimental failure load to that obtained from available code equations are always more than 1. As an example, CSA-3701 underestimates the compressive resistance by about $27 \%$ and $33 \%$ when using the theoretical or practical effective buckling length factor, respectively. Considering the variation in results, the ratio between the experimental failure load and the compressive resistance as obtained from S37-01 equations is 1.08 in case of stress-relieved steel bars.

\subsection{Results from Testing Centrally Loaded Columns Made of Non-}

\section{Stress-Relieved Steel}

Tests to-collapse on 33 solid round bars made of non-stress-relieved steel were performed to check the accuracy of the compressive resistance equations specified in 
steel Standards, Specifications and Codes, when applied to solid rounds. The experimental failure load, as well as other pertinent information, such as diameter, length, end conditions, load rate and slenderness ratio, are given in Table 4.6 and 4.9. In this case, two end conditions were considered while testing, namely: hinged-hinged $(\mathrm{H}-\mathrm{H})$, and hinged-fixed (H-F). Increasing axial load was applied to each column and readings from strains gauges for axial strains, and from LVDT's for column lateral deflection at its height, were recorded. The MTS machine recorded the crosshead movement with time as during the test. It should be noted that columns NSR-22, NSR-23 and NSR-24, NSR-25 and NSR-33 of $114 \mathrm{~mm}$ diameter did not fail because the applied axial load reached the specified capacity of the MTS machine of $4500 \mathrm{KN}$.

Figures 4.100 to 4.219 show the results from testing the 33 solid rounds made of non-stress-relieved steel. They include views of each specimen before and after failure. As an example, Figure 4.100 shows views of specimens NSR-1 of $38 \mathrm{~mm}$ diameter and $508 \mathrm{~mm}$ length before and after failure. It can be observed that buckling is the dominant mode of failure for all specimens. Also, these figures include the measured axial strain at each load level. For example, Figure 4.106 shows the relationship between the applied axial load and the axial strains recorded at four points at the mid-height of the column. It can be observed that the strain readings at the four points are very close to each other which prove that there was almost no eccentricity on the application of the load. However, some columns show uneven distribution of axial strains along the perimeter of the columns at its mid-height. It should be noted that care was given at the first few 
increments of load at the start of each test to locate the column centrally as much as possible. Then, the test was continued till failure.

Some of Figures 4.100 to 4.219 provide the lateral deflection of tested column at its mid-height with increase in axial load: For example, Figure 4.107 shows LVDT readings in the east and north direction of column NSR-3 OF $38 \mathrm{~mm}$ diameter and 914 mm length. Some of Figures 4.100 to 4.219 provide the movement of the sensitive crosshead relative to the fixed crosshead using a built-in LVDT, as automatically recorded by the MTS machine, with increase in applied axial load. For example, Figure 4.128 shows the change in the average shortening of column NSR-8 of $64 \mathrm{~m}$ diameter and $771 \mathrm{~mm}$ length, along its length.

\subsection{Correlation between the Experimental Failure Load of Non-Stress- Relieved Steel Bars and the Compressive Resistance as Obtained from Design Standards.}

The compressive resistances of the tested columns made of non-stress-relived steel were computed based on the based on the available empirical expressions specified in the Canadian Standard (CAN/CSA-S37-01), the American Specifications (AISCLRFD) and the European Standard (Euro code 3). A resistance factor, $\varphi$, of 1.0 was considered to take into account the actual failure load obtained experimentally. Then, the obtained compressive resistance for each column was correlated with the results from tests.

It should be noted that two end conditions were considered while testing, namely: hinged-hinged $(\mathrm{H}-\mathrm{H})$ and hinged-fixed $(\mathrm{H}-\mathrm{F})$ conditions. For theoretical calculations of 
the slenderness factor, $\lambda$, the effective buckling length, $\mathrm{k}$, was taken as 1 in case of $\mathrm{H}-\mathrm{H}$ condition and 0.707 in case of H-F condition, as specified in CSA-S16-01 (see Figure 2.5). However, the compressive resistance of the tested columns was also calculated using the recommended practical effective buckling length factor per Figure 2.5, that is 0.8 for H-F columns.

Tables 4.7 and 4.10 show the comparison between the experimental ultimate load and the compressive resistance of solid rounds made of non-stress-relieved steel as obtained from CSA-S37-01, AISC-LRFD and Euro code 3, based on the theoretical buckling length factors. While, Tables 4.8 and 4.11 present similar comparison but based on the recommended practical buckling length factor shown in Figure 2:5. As it can be observed that the experimental failure load is always more or equal to the theoretical ultimate resistance. The following table summarizes the minimum, maximum and average value of the ration between the experimental failure load the theoretical compressive resistance as obtained from the code equations. The standard deviation and the coefficient of variation are also presented in the table.

\begin{tabular}{|l|l|l|l|l|l|l|}
\hline $\begin{array}{l}\text { Effective } \\
\text { length factor, } \mathrm{k}\end{array}$ & & Mini & Max. & Average & $\begin{array}{l}\text { Standard } \\
\text { deviation }\end{array}$ & $\begin{array}{l}\text { Coefficient } \\
\text { of } \\
\text { variation }\end{array}$ \\
\hline \multirow{3}{*}{ Theoretical } & AISC-LRFD & 1.00 & 1.41 & 1.19 & 0.095 & $8.0 \%$ \\
\cline { 2 - 8 } & CSA-S37-01 & 1.07 & 1.54 & 1.33 & 0.118 & $8.9 \%$ \\
\cline { 2 - 7 } & EURO Code & 1.09 & 1.69 & 1.31 & 0.121 & $9.0 \%$ \\
\hline \multirow{3}{*}{ Practical } & AISC-LRFD & 1.03 & 1.41 & 1.22 & 0.080 & $6.5 \%$ \\
\cline { 2 - 8 } & CSA-S37-01 & 1.12 & 1.65 & 1.37 & 0.120 & $8.8 \%$ \\
\cline { 2 - 7 } & EURO Code & 1.09 & 1.69 & 1.35 & 0.128 & $9.5 \%$ \\
\hline
\end{tabular}


One may notice that the average ratios of the experimental failure load to that obtained from available code equations are always more than 1. As an example, CSA-3701 underestimates the compressive resistance by about $33 \%$ and $37 \%$ when using the theoretical or practical effective buckling length factor, respectively. Considering the variation in results, the ratio between the experimental failure load and the compressive resistance as obtained from S37-01 equations is 1.22 in case of non-stress-relieved steel bars. It can be observed that the inclusion of the practical effective buckling length factor in compressive resistance calculations provides conservative results when designing a compression member. However, for the sake of revising the available code expressions, it is advisable to use the theoretical effective buckling length factor in compressive resistance calculations so that it can be very close to the experimental failure load.

\subsection{Results from Testing Stub Columns}

Stub column tests were made of short bars to determine the average compressive stressstrain characteristics of the solid round when instability effects are excluded. One stub column test was performed for each bar size listed in Table 3.4. Axially symmetric residual stresses are introduced in the bars by non-uniform cooling of the member after rolling or heat treatment. In case of stud column (SC-1) listed in Table 3.4, the specimen was carefully centered in the MTS machine. Then, two LVDT's were placed at the midheight of the specimen to measure the lateral deflection which was observed to be insignificant. Also four strain gauges are used to measure axial strains around the stub cross-section at its mid-height. Figure 4.222 show the stub column SC-1 before and after testing. Figure 4.221 show the relationship between the axial load and the corresponding 
axial strain at the mid-height of the stub. While, Figure 4.222 show the relationship between the applied axial load and the corresponding cross-head movement. A linear relation was observed with increase in applied axial load up to a certain load increment when residual stress effect started to force the stub cross-section to behave non-linearly. At failure, the stub buckled laterally as shown in Figure 4.222.

The yield stress of the stub column can simply be obtained at $0.2 \%$ offset of strain. Also, modulus of elasticity of the stub column can be obtained as the slope of the straight line portion of the stress-strain curve. However, the maximum compressive residual stress can be obtained by subtracting the stress at which deviation from linearity was first observed in the stub column test from the yield stress. Figures 4.223 to 4.240 show views of the stub column before and after testing, the axial load-strain relationship and the axial load-crosshead movement relationship for stub columns SC-2 to SC-7. Also, Table 4.12 lists the size, end conditions, load rate and experimental failure load for each stub column tested at the structural laboratory. These results will be used in a further. research to verify the finite element modelling to be used to obtain the compressive resistance of non-stress-relieved solid round bars. 


\section{CHAPTER V \\ CONCLUSIONS AND RECOMMENDATIONS}

\subsection{General}

The need for information on the compressive resistance of solid round bars made of stress-relieved or non-stress-relieved steel arose from the increased use of these bars in communication towers. Solid steel round bars are used as leg members, diagonal members and horizontal members of a communication tower. The superseded Canadian Standards of 1994, CAN/CSA-S16.1-94, AISC-LRFD Specifications of 1993, and the European Standard, Euro code 3, provide the factored compressive resistance of structural steel members other than solid rounds. While, the Current Canadian Standard, CAN/CSA-S37-01 of 2001, for Antenna towers and Antenna Supporting Structures specifies empirical expressions for the compressive strength of solid rounds based on the well-known Structural Stability Research Council (SSRC) column curves for non-solid-round members as well as the results from experimental investigation on the compressive resistance of solid rounds carried out back to 1965 . This thesis provides a summary of the results of tests on 20 stress-relived steel solid rounds, 33 non-stress-relieved steel solid rounds on different diameter and length and 
7 stub columns. Correlation between the results from these tests and the current practice for the design of solid rounds is investigated. The following section summarizes the conclusions deduced from this research.

\subsection{Conclusions}

Based on the findings of this research, the following conclusions are drawn:

1- For slenderness ratios ranging from 18 to 70, CAN/CSA-S37-01 provides an ultimate compressive resistance of solid round bars made of stress-relieved steel that is about an average of $27 \%$ less that that obtained experimentally. While AISC-LRFD provides a conservative compressive resistance of an average of $24 \%$. Euro Code 3 provides the highest conservative value of an average of $34 \%$.

2- For slenderness ratios ranging from 20 to 91 , CAN/CSA-S37-01 provides an ultimate compressive resistance of solid round bars made of non-stress-relieved steel that is $33 \%$ less that that obtained experimentally. While AISC-LRFD and Euro Code 3 provide conservative compressive resistance of $19 \%$ and $31 \%$, respectively, more than that obtained experimentally.

3- Based on the results from the current study, code writers may update the available expression in CSA-S37-01 by multiplying the available code expressions for the compressive strength of solid round bars by a magnification factor of 1.08 in case of stress-relieved steel bars and 1.22 in case of non-stress-relieved steel bars for economical design, considering the practical effective buckling length factor. Also, this increase in compressive resistance of solid rounds would assist the practicing engineers in the evaluation of the load-carrying capacity of existing antenna towers since even a small 
increase in strength for live load can make the difference between demolishing a tower or leaving it in service.

4- Results from experimental testing shows that the compressive resistance bars made of stress-relieved steel is greater than that for bars made of non-stress-relieved steel.

\subsection{Recommendations for Future Research}

Based on the findings from the current research, the following points of search need further investigations:

1- Finite Element modelling, including geometric and material nonlinearity, for buckling behaviour of axially loaded solid steel round bars made of stressrelieved steel or non-stress-relieved steel. In the latter, the actual distribution of residual stresses in bar cross-section should be incorporated in the modelling.

2- More experiments to-collapse on bars of slenderness ratios between 100 and 140 to widen the scope of application of the proposed expressions of the compressive resistance of solid rounds.

3- Conduct testing on short bars to determine the state of residual stresses in nonstress-relieved steel due to the manufacturing process as well as cold straightening. 
. 


\section{REFERENCES}

Alpsten, G. (1970). Residual Stresses and Strength of Cold-Straightened Wide-Flange

Shapes. Jernkontorets Ann., Vol. 154.

American Institute of Steel Construction, Inc. (1993). Load and Resistance Factor Design

Specification for Structural Steel Buildings, AISC-LRFD. Chicago, Illinois, USA.

Batterman, R., and Johanston, B. (1967). Behaviour and Maximum Strength of Metal

Columns. Journal of the Structural Division, ASCE, Vol. 93, No. ST2, pp. 205-230.

Bjorhovde, R. (1972). Deterministic and Probabilistic Approaches to the Strength of

Steel Columns. Ph.D. Dissertation, Lehigh University, Bethlehem, Pa.

Bjorhovde, R. and Birkemoe, P. C. (1979). Limit States Design of HSS Columns.

Canadian Journal of Civil Engineering, 6(2): ??-??.

Bjorhovde, R., and Tall, L. (1971). Maximum Column Strength and the Multiple

Column Curve Concept. Report No. 337.29, Lehigh University, Fritz Eng. Lab, Bethlehem, PA.

Bühler, H. (1954). Complete Determination of the State of Residual Stress in Solid and

Hollow Metal Cylinders, Residual Stresses, Residual Stresses in Metals and Metal

Construction. Edited by W. R. Osgood, Reinhold Publishing Corporation, New York, N. Y., PP. 305-329.

Canadian Standards Association. (1994). Antennas, Towers, and Antenna-Supporting Structures. CAN/CSA-S37-94, Rexdale, Ontario, Canada.

Canadian Standards Association. (2003). Limit States Design of Steel Structures. CAN/CSA-S16-01, Rexdale, Ontario, Canada. 
Canadian Standards Association. (2001). Antennas, Towers, and Antenna-Supporting Structures. CAN/CSA-S37-01, Rexdale,.Ontario, Canada.

CEN. (2003). Eurocode 3 part 1.1: General Rules and Rules for Steel Buildings. CEN, European Committee for Standardization, Brussels, Belgium.

Chen, Z. (2000). Theoretical Effective Length Factors for Cross-Braced Solid Round Diagonals. M.Sc. Thesis, Civil and Environmental Engineering; University of Windsor, Windsor, Ontario, Canada.

Ding, Y. (2000). Residual Stresses in Hot-Rolled Solid Round Steel Bars and their Effect on the Compressive Resistance of Members. M.A.Sc. Thesis, Civil and Environmental Engineering, University of Windsor, Windsor, Ontario, Canada.

Fujita, Y, and Driscoll, G. (1962). Strength of Round Columns. Journal of the Structural Division, ASCE, Vol. 88, No. ST2, pp. 43-59.

Galambos, T. V. (1998). Guide to Stability Design Criteria for Metal Structures, $5^{\text {th }}$ Edition. Structural Stability Research Council, John Wiley \& Sons Inc., New York, N.Y.

Galambos, T. V. (1965). Strength of Round Steel Columns. ASCE Journal of the Structural Division, 91(ST1): 121-140.

Galambos, T. V., and Ueda, Yukio. (1962). Column tests on 7 1/2 in. Round Solid Bars. ASCE, Journal of the Structural Division, 88(ST4):1-17.

Hetenyi, M. (1957). Handbook of Experimental Stress Analysis. Third Edition, John Wiley \& Sons Inc., New York, N.Y. 
Jaboo, K. S. (1998). Effective Length Factors for Solid Round Diagonal Bracing Members in Latticed Towers. M.Sc. Thesis, Civil and Environmental Engineering, University of Windsor, Windsor, Ontario, Canada.

Jahanian, S. (1995). Residual and Thermo-elasto-plastic Stress Distributions in a Heat Treated Solid Cylinder. Materials at High Temperatures, 13(2):103-110.

Kamamato, S., Nihimori T., and Kinoshita, S. (1985). Analysis of Residual Stress and

Distortion Resulting from Quenching in Large Low-Alloy Steel Shafts. Journal of Material Science and Technology, 1:798-804.

Kennedy, D.J.L., and Gad, A.M. (1980). Limit States Design of Steel Structures Performance Factors. Canadian Journal of Civil Engineering 7(1): 45-47.

Lim, H. L. (2000). Effective Length Factors for Solid Round Members in K-Braced and Z-Braced Antenna Towers. M.Sc. Thesis, Civil and Environmental Engineering, University of Windsor, Windsor, Ontario, Canada.

Mull, N. C. (1999). Compressive Resistance of Solid Rounds. M.Sc. Thesis, Civil \& Environmental Engineering, University of Windsor, Windsor, Ontario, Canada.

Nitta, A. and Thülimann, B. (1962a). Ultimate Strength of High Yield Strength Constructional-Alloy Circular Columns - Effect of Cold-Straightening. Publication, IABSE, 22: 265-288.

Nitta, A. and Thürlimann, B. (1962b). Ultimate Strength of High Yield Strength Constructional-Alloy Circular Columns - Effect of Thermal Residual Stresses. Publication, IABSE, 22: 231-264. 
Qureshi, A. K. (1999). Effective Length Factors for Solid Round Chord Members of Guyed Towers. M.Sc. Thesis, Civil and Environmental Engineering, University of Windsor, Windsor, Ontario, Canada.

Sun, Y. (1999). Effective Length Factors for Solid Round Diagonal Members in Guyed Communication Towers. M.Sc. Thesis, Civil and Environmental Engineering, University of Windsor, Windsor, Ontario, Canada.

Toparli, M. and Aksoy, T. (1991). Calculation of Residual Stresses in Cylindrical Steel Bars Quenched in Water from $600^{\circ} \mathrm{C}$. Proceedings of AMSE Conference, New Delhi, India, 4:93- 104.

Watanabe, M., Sato, K., and Goda, S. (1955). Thermal and Residual Stresses of Circular Cylinders Suddenly Cooled From the Uniformly Heated Conditions. Journal of the Society of Naval Architects of Japan, 88: 155-164.

Weiner, J. H. and Huddleston, J. V. 1959. Transient and Residual Stresses in HeatTreated Cylinders. Journal of Applied Mechanics, 26E(1): 31-39. 
Table 2.1 Ultimate limit state analysis

\begin{tabular}{|l|l|l|l|}
\hline \multirow{2}{*}{} & \multirow{2}{*}{ Method } & \multicolumn{2}{|c|}{\begin{tabular}{c} 
Calculation of \\
\cline { 3 - 4 }
\end{tabular}} \\
\cline { 3 - 4 } & & \multicolumn{2}{c|}{ Resistances } \\
\cline { 3 - 4 } & & \multicolumn{2}{c|}{ According to } \\
\hline 1 & Elastic-elastic & Elastic theory & Elastic theory \\
\hline 2 & Elastic-plastic & Elastic theory & Plastic theory \\
\hline 3 & Plastic-plastic & Plastic hinge theory & Plastic theory \\
\hline
\end{tabular}

Table 2.2 Parameters $\alpha$ for calculation of reduction factor $x$

\begin{tabular}{|c|c|c|c|c|}
\hline Buckling Curve & a & b & c & d \\
\hline$\alpha$ & 0.21 & 0.34 & 0.49 & 0.76 \\
\hline
\end{tabular}

Table 3.1 Details of Test Specimens: 20 Stress Relieved Specimens

\begin{tabular}{|l|l|l|l|l|l|}
\hline $\begin{array}{c}\text { Specimen } \\
\text { number }\end{array}$ & $\begin{array}{c}\text { Diameter } \\
(\mathrm{mm})\end{array}$ & $\begin{array}{c}\text { Length } \\
(\mathrm{mm})\end{array}$ & $\begin{array}{l}\text { End } \\
\text { condition }\end{array}$ & \multicolumn{1}{|c|}{ KL/r } & $\begin{array}{c}\text { Load rate } \\
(\mathrm{KN} / \mathrm{sec} .)\end{array}$ \\
\hline SR-1 & 38 & 660 & H-H & 70.0 & 0.13 \\
\hline SR-2 & 38 & 813 & H-F & 60.4 & 0.13 \\
\hline SR-3 & 38 & 1143 & F-F & 60.0 & 0.13 \\
\hline SR-4 & 51 & 661 & H-H & 52.0 & 0.23 \\
\hline SR-5 & 51 & 812 & H-F & 45.2 & 0.23 \\
\hline SR-6 & 51 & 1143 & F-F & 44.8 & 0.23 \\
\hline SR-7 & 64 & 660 & H-H & 41.2 & 0.37 \\
\hline SR-8 & 64 & 813 & H-F & 50.8 & 0.37 \\
\hline SR-9 & 64 & 1143 & F-F & 35.6 & 0.37 \\
\hline SR-10 & 76 & 660 & H-H & 34.8 & 0.52 \\
\hline SR-11 & 76 & 1140 & F-F & 30.0 & 0.52 \\
\hline SR-12 & 89 & 661 & H-H & 29.6 & 0.73 \\
\hline SR-13 & 89 & 813 & H-F & 26.0 & 0.73 \\
\hline SR-14 & 89 & 1142 & F-F & 25.6 & 0.73 \\
\hline SR-15 & 102 & 661 & H-H & 26.0 & 0.94 \\
\hline SR-16 & 102 & 813 & H-F & 22.4 & 0.94 \\
\hline SR-17 & 102 & 1143 & F-F & 22.4 & 0.94 \\
\hline SR-18 & 128 & 660 & H-H & 20.6 & 1.5 \\
\hline SR-19 & 128 & 813 & H-F & 18.0 & 1.5 \\
\hline SR-20 & 128 & 1143 & F-F & 18.0 & 1.5 \\
\hline
\end{tabular}


Table 3.2 Details of Test Specimens: 25 Non-Stress Relieved Specimens

\begin{tabular}{|l|l|l|l|l|l|}
\hline $\begin{array}{c}\text { Specimen } \\
\text { number }\end{array}$ & $\begin{array}{c}\text { Diameter } \\
(\mathrm{mm})\end{array}$ & $\begin{array}{c}\text { Length } \\
(\mathrm{mm})\end{array}$ & $\begin{array}{c}\text { End } \\
\text { condition }\end{array}$ & $\mathrm{KL} / \mathrm{r}$ & $\begin{array}{c}\text { Load rate } \\
(\mathrm{KN} / \mathrm{sec} .)\end{array}$ \\
\hline NSR-1 & 38 & 508 & $\mathrm{H}-\mathrm{H}$ & 53.5 & 0.13 \\
\hline NSR-2 & 38 & 711 & $\mathrm{H}-\mathrm{H}$ & 74.8 & 0.10 \\
\hline NSR-3 & 38 & 914 & $\mathrm{H}-\mathrm{F}$ & 68.0 & 0.11 \\
\hline NSR-4 & 51 & 508 & $\mathrm{H}-\mathrm{H}$ & 39.8 & 0.23 \\
\hline NSR-5 & 51 & 711 & $\mathrm{H}-\mathrm{H}$ & 55.8 & 0.20 \\
\hline NSR-6 & 51 & 914 & H-F & 47.0 & 0.21 \\
\hline NSR-7 & 64 & 508 & H-H & 31.8 & 0.32 \\
\hline NSR-8 & 64 & 711 & H-H & 44.4 & 0.28 \\
\hline NSR-9 & 64 & 914 & H-F & 40.0 & 0.29 \\
\hline NSR-10 & 76 & 610 & H-H & 32.1 & 0.45 \\
\hline NSR-11 & 76 & 711 & H-H & 37.4 & 0.43 \\
\hline NSR-12 & 76 & 813 & H-F & 30.3 & 0.46 \\
\hline NSR-13 & 76 & 914 & H-F & 34.0 & 0.44 \\
\hline NSR-14 & 89 & 610 & H-H & 27.4 & 0.64 \\
\hline NSR-15 & 89 & 711 & H-H & 32.0 & 0.61 \\
\hline NSR-16 & 89 & 813 & H-F & 25.8 & 0.65 \\
\hline NSR-17 & 89 & 914 & H-F & 29.0 & 0.63 \\
\hline NSR-18 & 100 & 610 & H-H & 24.4 & 0.82 \\
\hline NSR-19 & 100 & 711 & H-H & 28.4 & 0.78 \\
\hline NSR-20 & 100 & 813 & H-F & 23.0 & 0.82 \\
\hline NSR-21 & 100 & 914 & H-F & 25.8 & 0.80 \\
\hline NSR-22 & 114 & 610 & H-H & 21.4 & 1.10 \\
\hline NSR-23 & 114 & 711 & H-H & 24.9 & 1.06 \\
\hline NSR-24 & 114 & 813 & H-F & 20.1 & 1.10 \\
\hline NSR-25 & 114 & 914 & H-F & 22.33 & 1.08 \\
\hline & & & & & \\
\hline
\end{tabular}


Table 3.3 Details of Test Specimens: 8 Non-Stress Relieved Specimens

\begin{tabular}{|l|l|l|l|l|l|}
\hline $\begin{array}{c}\text { Specimen } \\
\text { number }\end{array}$ & $\begin{array}{c}\text { Diameter } \\
(\mathrm{mm})\end{array}$ & $\begin{array}{c}\text { Length } \\
(\mathrm{mm})\end{array}$ & $\begin{array}{c}\text { End } \\
\text { condition }\end{array}$ & KUr & $\begin{array}{c}\text { Load rate } \\
(\mathrm{KN} / \mathrm{sec} .)\end{array}$ \\
\hline NSR-26 & 38 & 1219 & H-F & 91 & 0.13 \\
\hline NSR-27 & 38 & 1118 & H-F & 83 & 0.13 \\
\hline NSR-28 & 51 & 1118 & H-F & 62 & 0.24 \\
\hline NSR-29 & 64 & 1118 & H-F & 49 & 0.38 \\
\hline NSR-30 & 76 & 1016 & H-F & 38 & 0.53 \\
\hline NSR-31 & 89 & 1016 & H-F & 32 & 0.73 \\
\hline NSR-32 & 102 & 1016 & H-F & 28 & 0.95 \\
\hline NSR-33 & 114 & 1016 & H-F & 25 & 1.19 \\
\hline
\end{tabular}

Table 3.4 Details of Test Specimens: 7 Stub Columns for Non-Stress Relieved Specimens

\begin{tabular}{|l|l|l|l|l|l|}
\hline $\begin{array}{c}\text { Specimen } \\
\text { number }\end{array}$ & $\begin{array}{c}\text { Diameter } \\
(\mathrm{mm})\end{array}$ & $\begin{array}{c}\text { Length } \\
(\mathrm{mm})\end{array}$ & $\begin{array}{l}\text { End } \\
\text { condition }\end{array}$ & KU/r & $\begin{array}{c}\text { Load rate } \\
(\mathrm{KN} / \mathrm{sec} .)\end{array}$ \\
\hline SC-1 & 38 & 152 & H-H & 16 & 0.13 \\
\hline SC-2 & 51 & 203 & H-H & 16 & 0.24 \\
\hline SC-3 & 64 & 254 & H-H & 16 & 0.38 \\
\hline SC-4 & 76 & 305 & H-H & 16 & 0.53 \\
\hline SC-5 & 89 & 356 & H-H & 16 & 0.73 \\
\hline SC-6 & 102 & 406 & H-H & 16 & 0.95 \\
\hline SC-7 & 114 & 457 & H-H & 16 & 1.19 \\
\hline
\end{tabular}

Table 3.5 Coefficient of Variation Modification Factor for Steel, $\mathrm{K}_{\mathrm{s}}$

\begin{tabular}{|l|l|l|l|l|l|l|l|l|l|l|l|}
\hline $\mathrm{n}$ & 3 & 4 & 5 & 6 & 8 & 10 & 12 & 16 & 20 & 25 & 30 or more \\
\hline $\mathrm{K}_{\mathrm{s}}$ & 3.46 & 2.34 & 1.92 & 1.69 & 1.45 & 1.32 & 1.24 & 1.14 & 1.08 & 1.03 & 1.00 \\
\hline
\end{tabular}




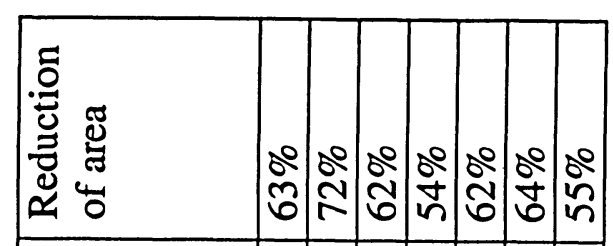

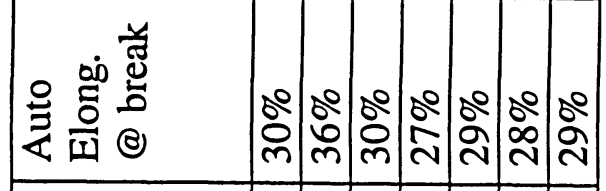

()

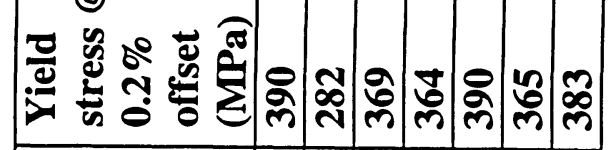

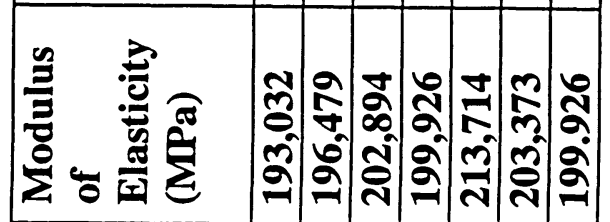

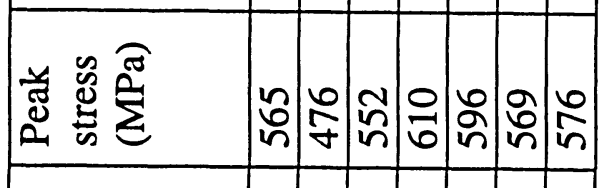

善急全

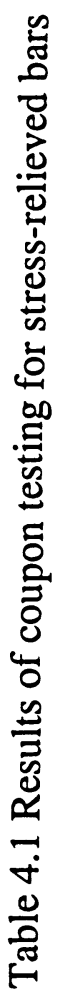

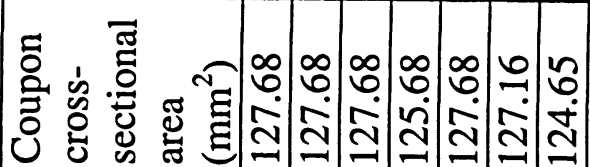

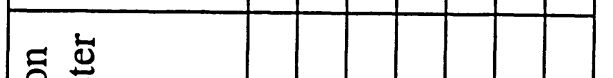

ธี ํㅓㅇ

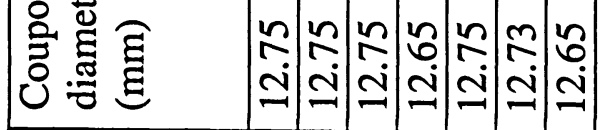

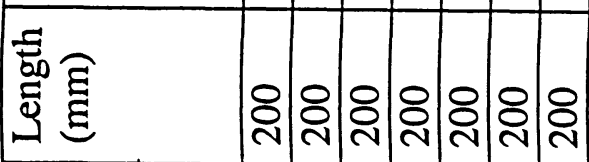

营

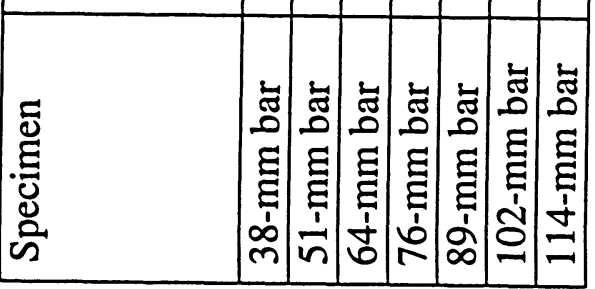

\begin{tabular}{|c|c|c|c|c|c|c|c|}
\hline 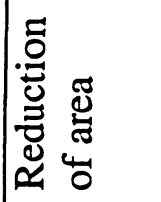 & $\mid \begin{array}{l}0^{2} \\
\frac{1}{2} \\
6\end{array}$ & స̊ำ & 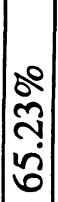 & $\begin{array}{l}0 \\
+ \\
\infty \\
\text { ஸे }\end{array}$ & $\begin{array}{l}\frac{0}{2} \\
n \\
n \\
n\end{array}$ & $\frac{\infty}{\infty}$ & \\
\hline 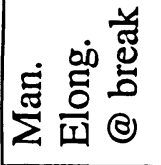 & $\begin{array}{l}0 \\
n \\
0 \\
\dot{0} \\
m\end{array}$ & $\mid \begin{array}{l}0 \\
\text { à } \\
\text { ฺे }\end{array}$ & $\left|\begin{array}{l}0 \\
0 \\
0 \\
0 \\
\end{array}\right|$ & 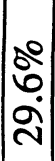 & $\frac{\pi}{n}$ & $\begin{array}{l}0 \\
\infty \\
N \\
\infty \\
N\end{array}$ & \\
\hline
\end{tabular}

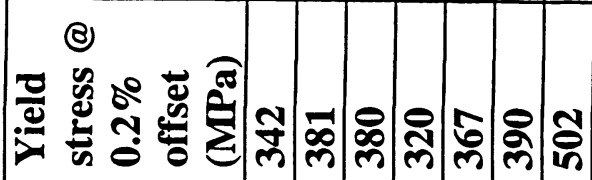

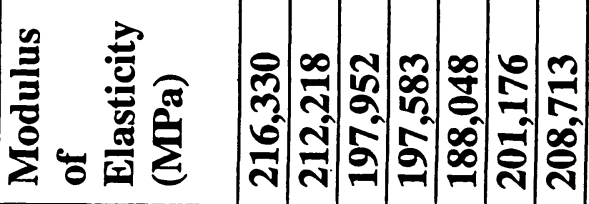

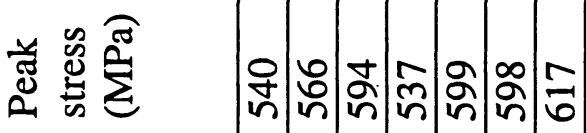

\begin{tabular}{|c|c|c|c|c|c|c|}
\hline 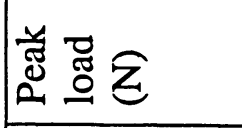 & $\mid \begin{array}{c}9 \\
7 \\
\infty \\
0\end{array}$ & $\frac{0}{\infty}$ & 守 & 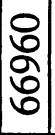 & 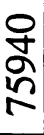 & 옴 \\
\hline 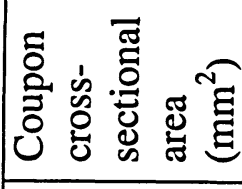 & $\begin{array}{l}\infty \\
0 \\
\\
\end{array}$ & $\mid \begin{array}{l}\infty \\
0 \\
\grave{1} \\
\end{array}$ & $\begin{array}{l}\infty \\
0 \\
\\
-\end{array}$ & 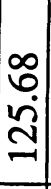 & $\begin{array}{l}\infty \\
0 \\
\\
\end{array}$ & $\begin{array}{l}0 \\
\\
\\
-1\end{array}$ \\
\hline 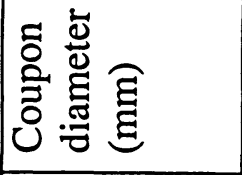 & $\begin{array}{c}n \\
\sim \\
\sim\end{array}$ & $\left|\begin{array}{c}n \\
\sim \\
\sim \\
c\end{array}\right|$ & $\begin{array}{l}n \\
\sim \\
\end{array}$ & $\begin{array}{l}n \\
6 \\
\\
-\end{array}$ & $\stackrel{n}{\sim}$ & $\stackrel{m}{\sim}$ \\
\hline 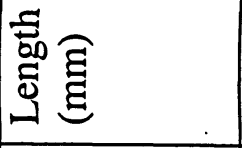 & ন্নি & স্ণ & ઠ્స్ & ઠ્సి & ర్ల & ঠి \\
\hline 氖 & $\mid$ & (6) & $\nabla$ & $\div$ & ळ) & 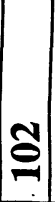 \\
\hline 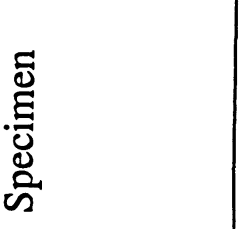 & 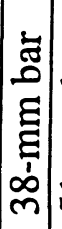 & $\begin{array}{c}\text { : } \\
\vdots \\
\vdots \\
\vdots \\
\frac{1}{n}\end{array}$ & 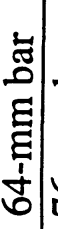 & 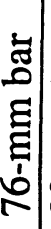 & 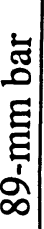 & 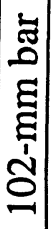 \\
\hline
\end{tabular}




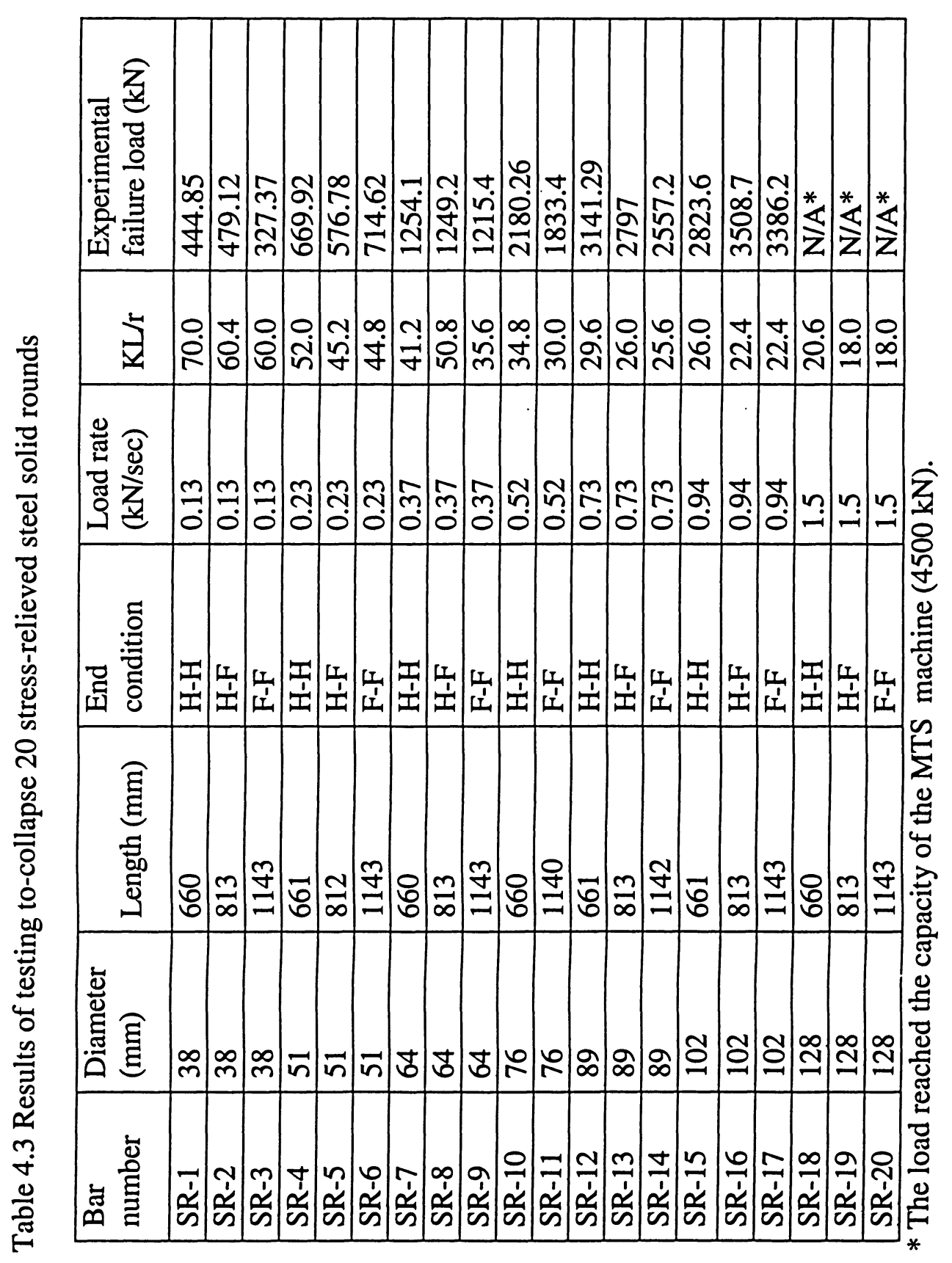




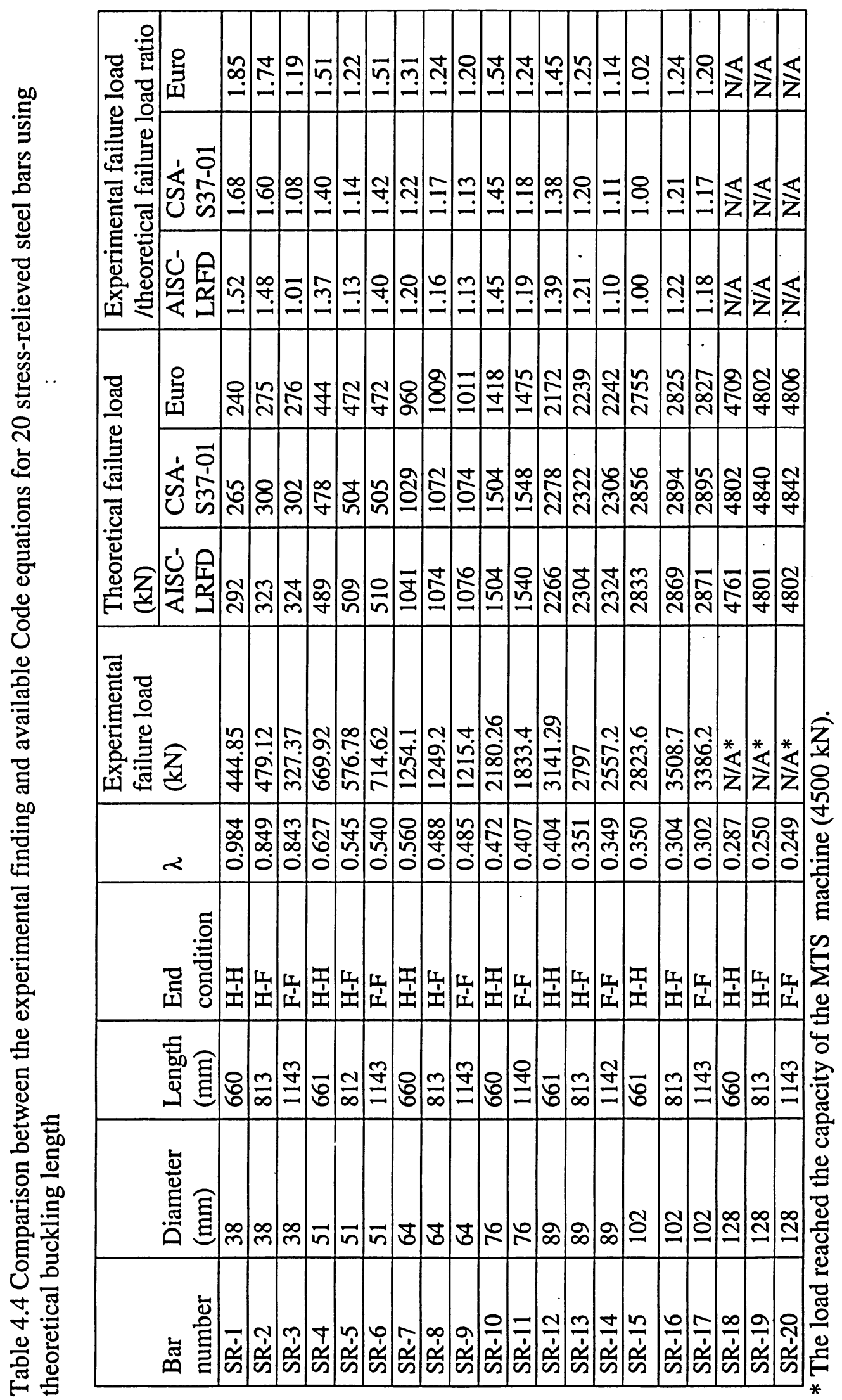




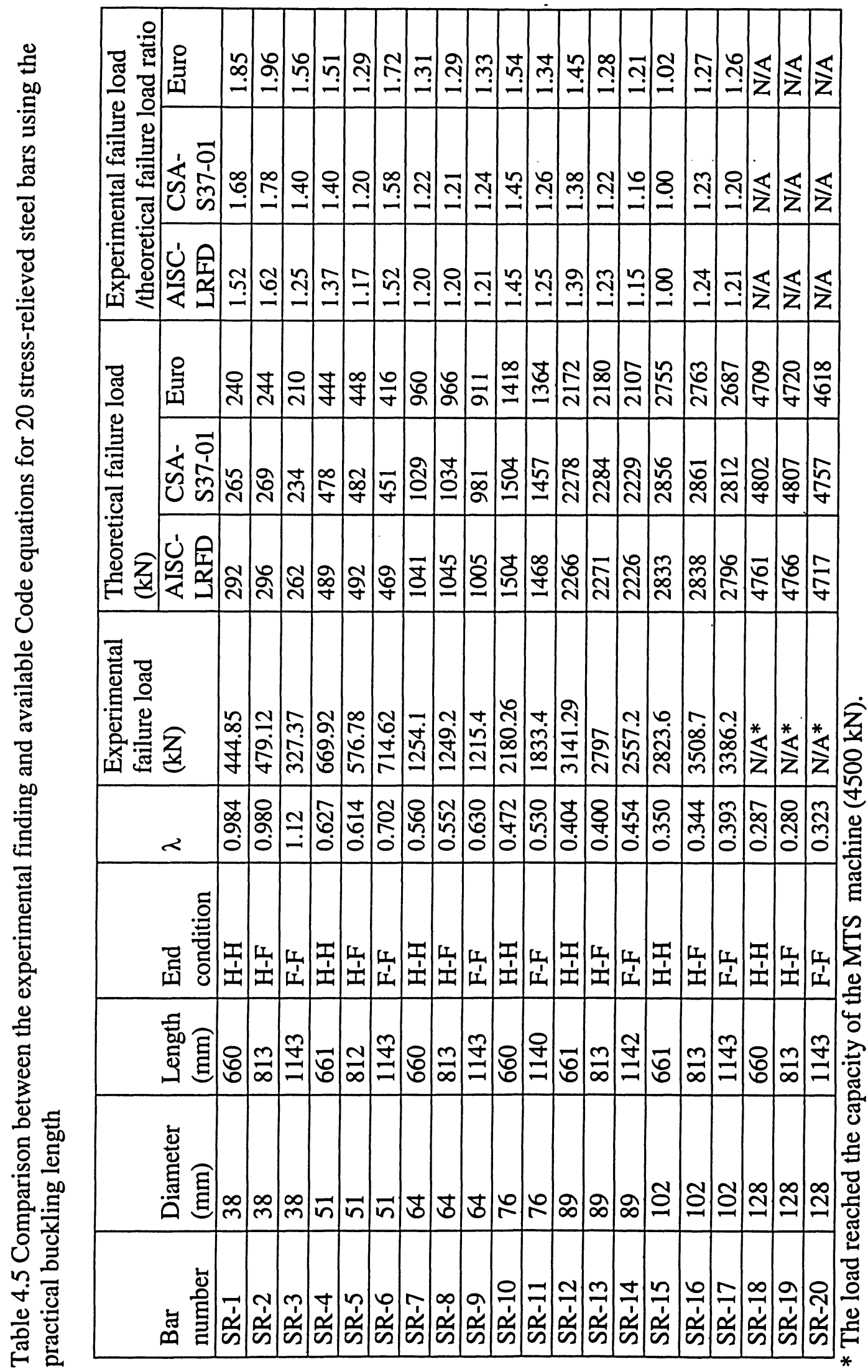




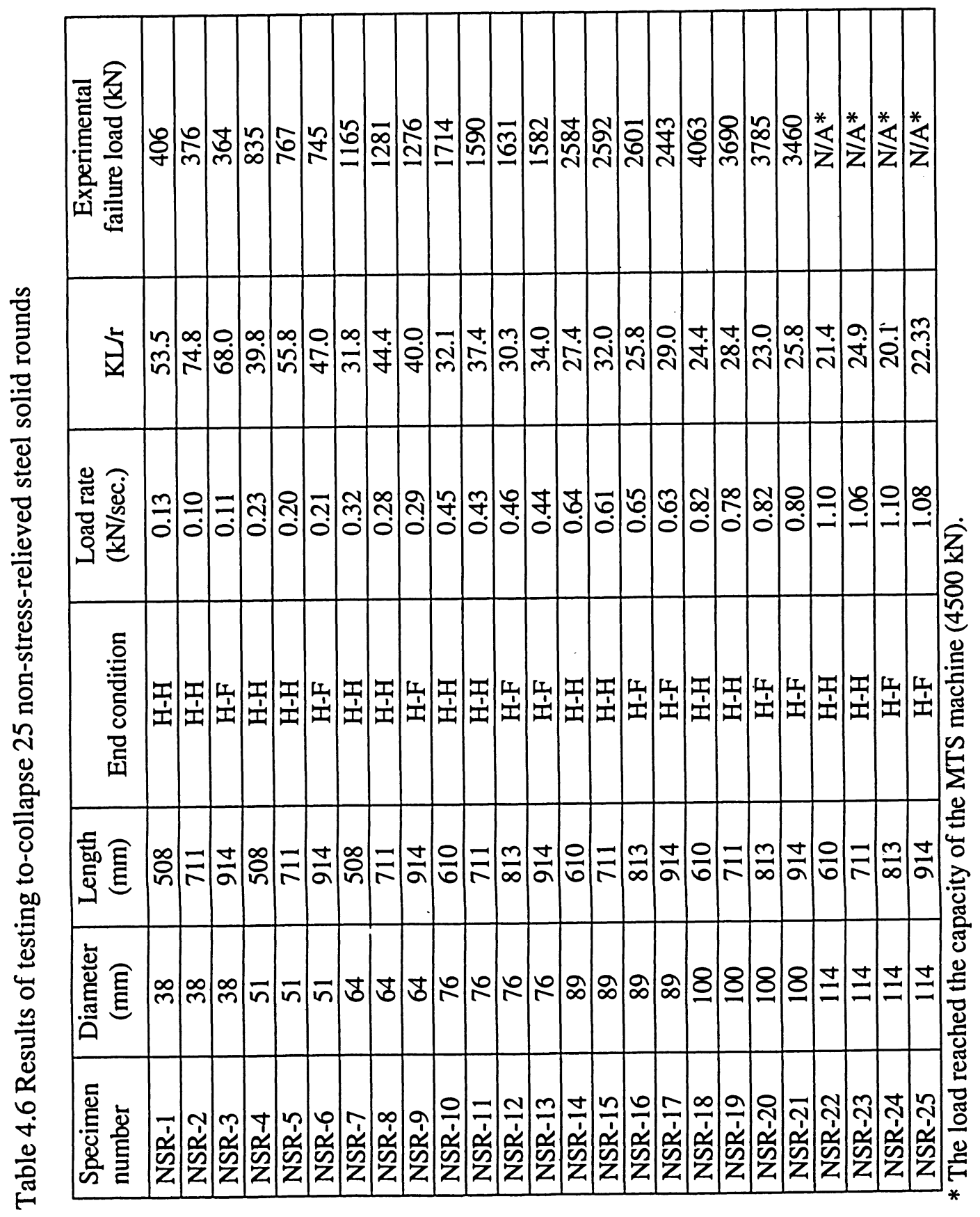




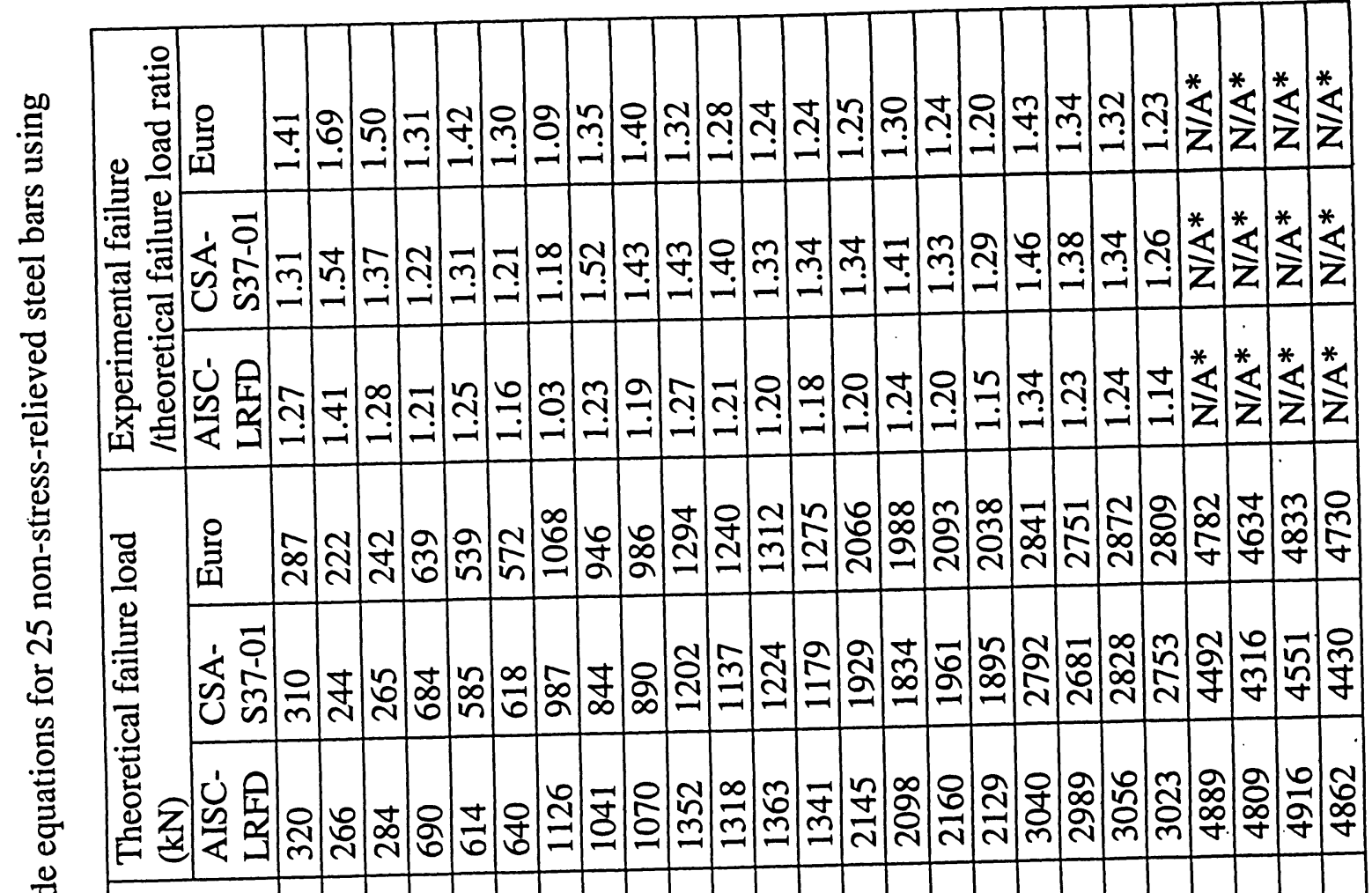

莡

○事

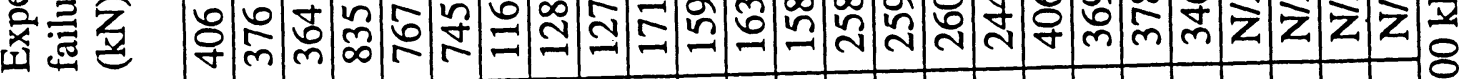

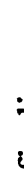

$\stackrel{\infty}{\Xi}$

$\alpha$

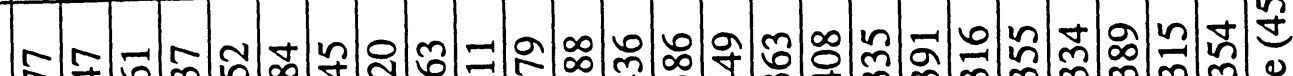

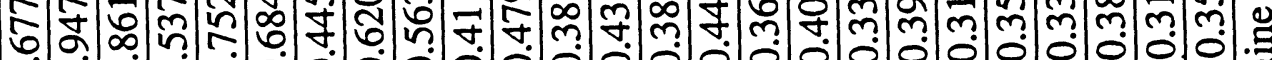

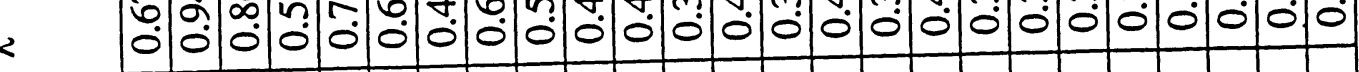

छ

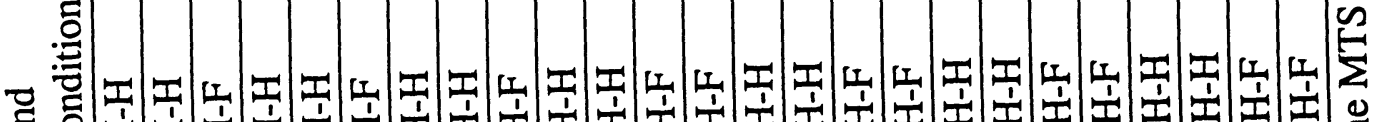

晋

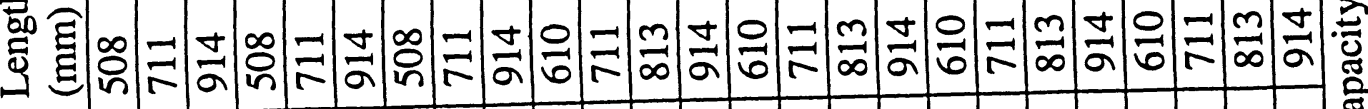

$\int \mid \frac{1}{ \pm}$

.

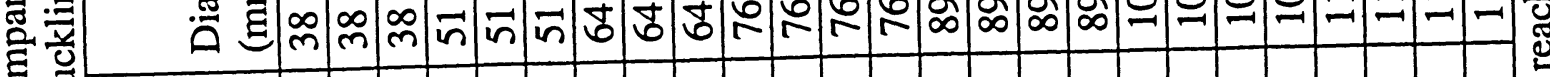

نㄹำ

T.

$\frac{0}{0}$ 


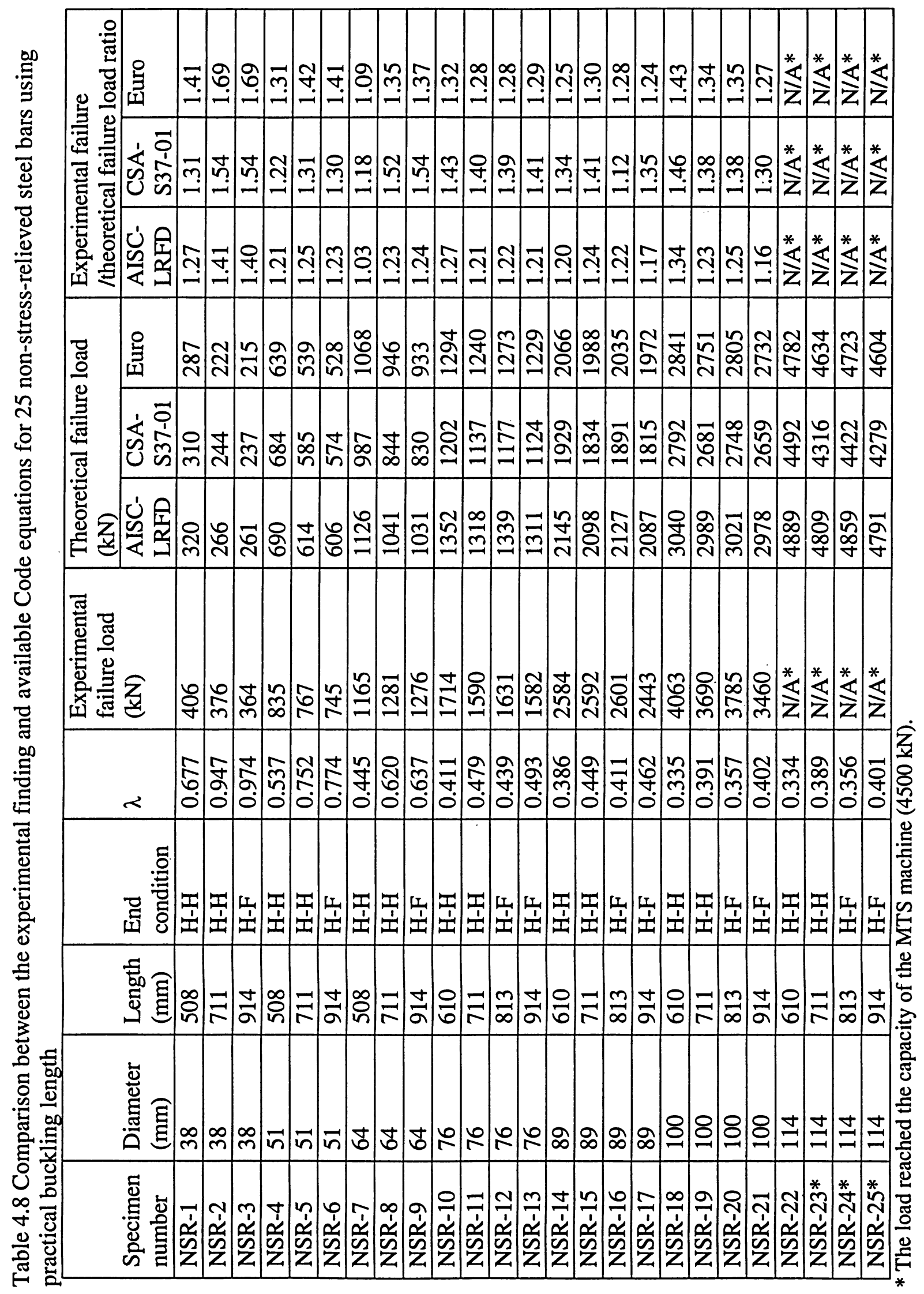




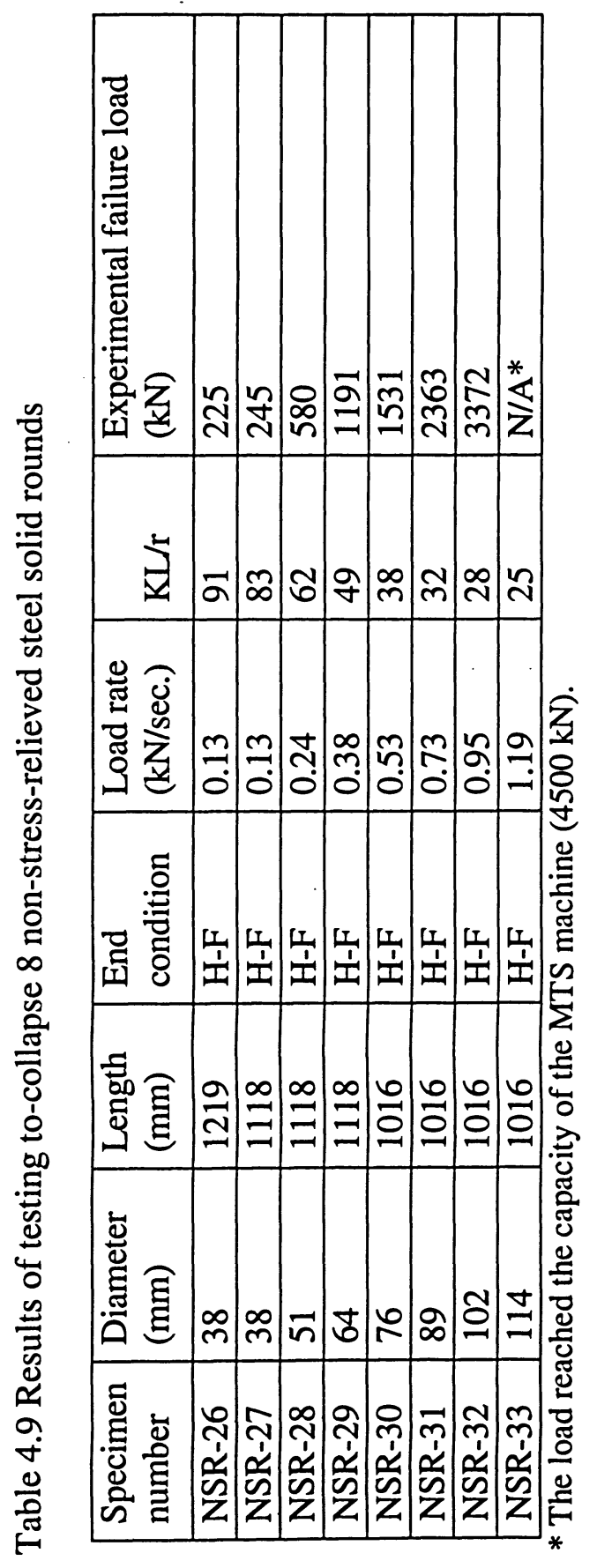




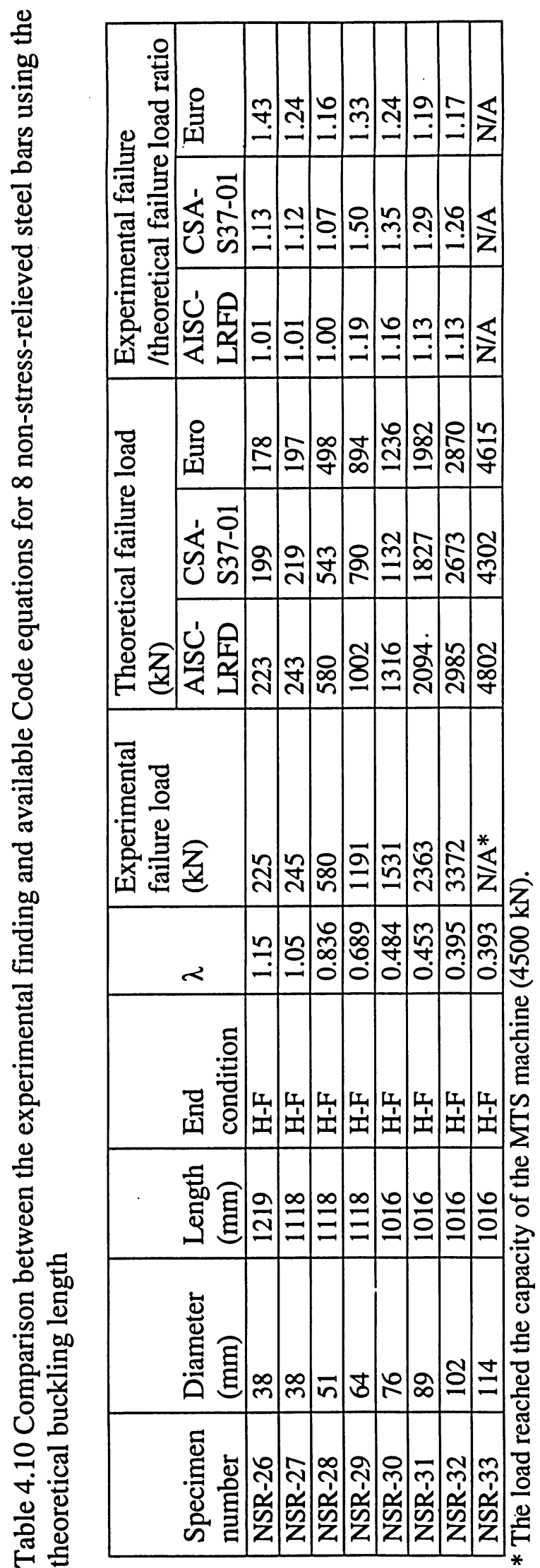



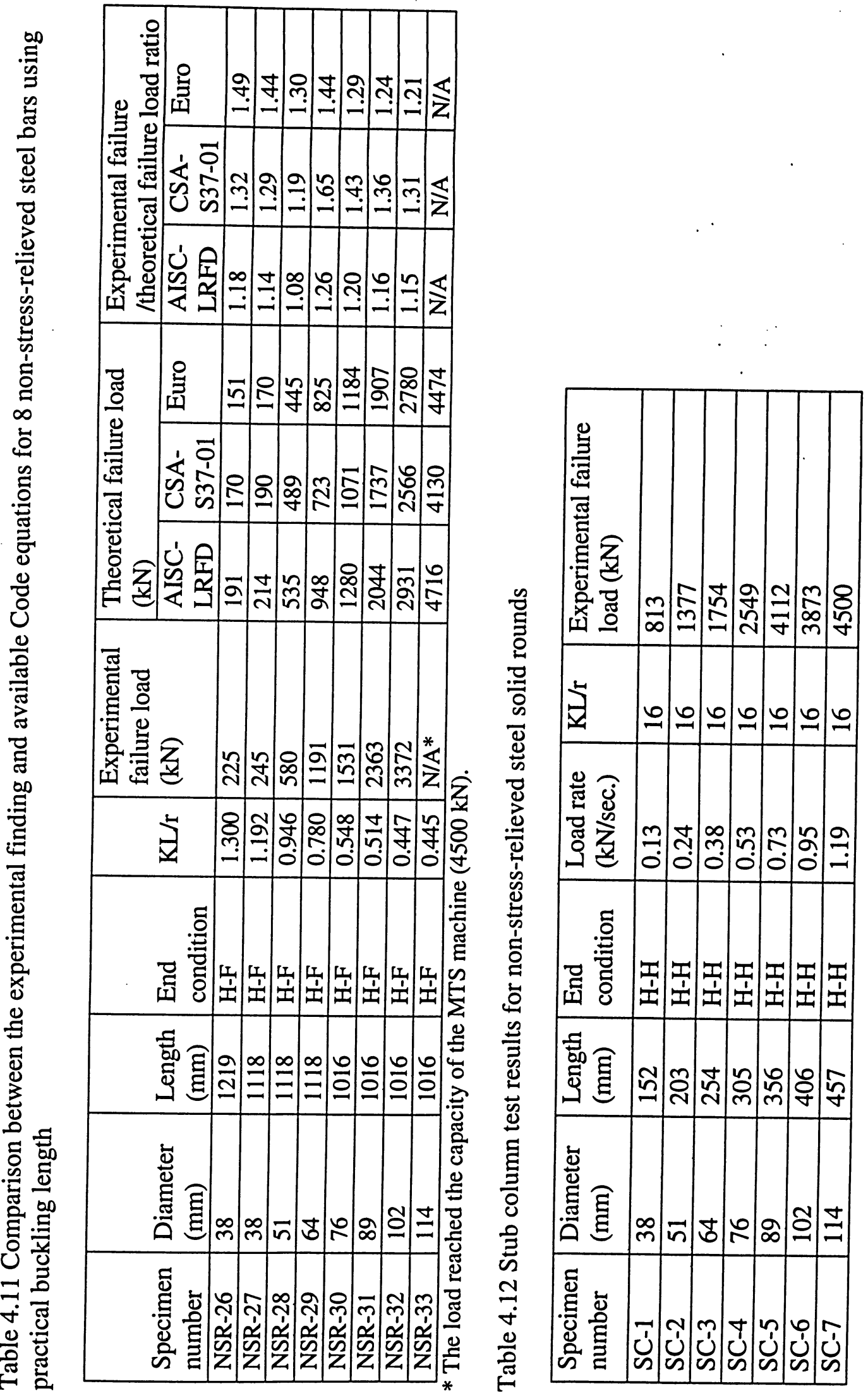

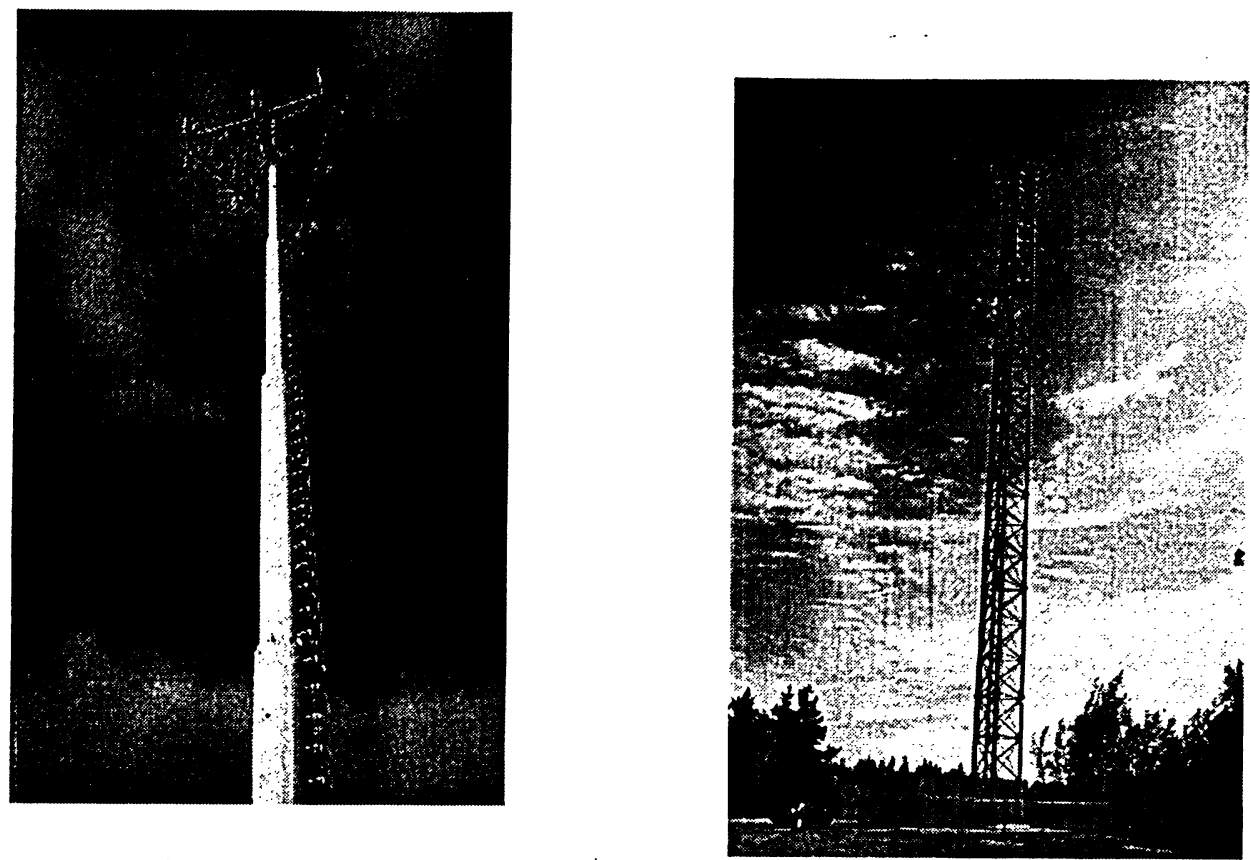

a- Monopoles (up to $70 \mathrm{~m}$ ) b- Self-supporting towers (up to $120 \mathrm{~m}$ )

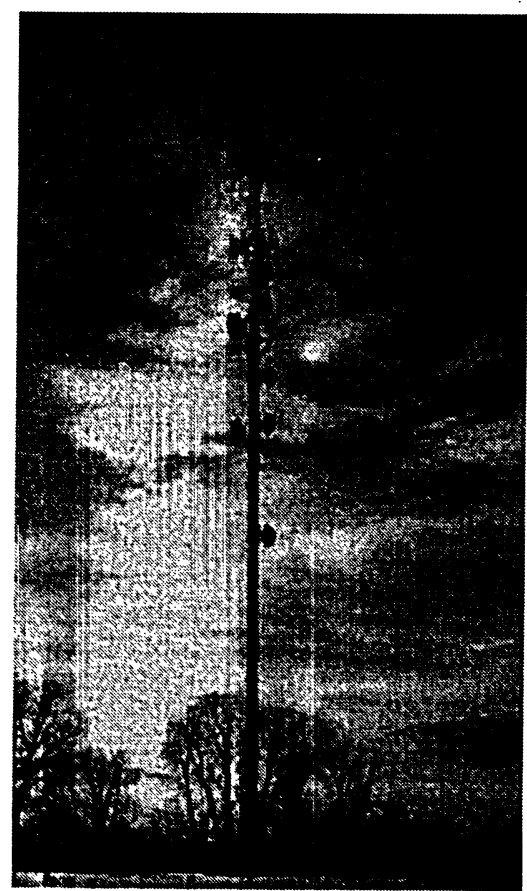

c- Guyed towers (up to $620 \mathrm{~m}$ )

Figure 1.1 Views of communication towers 


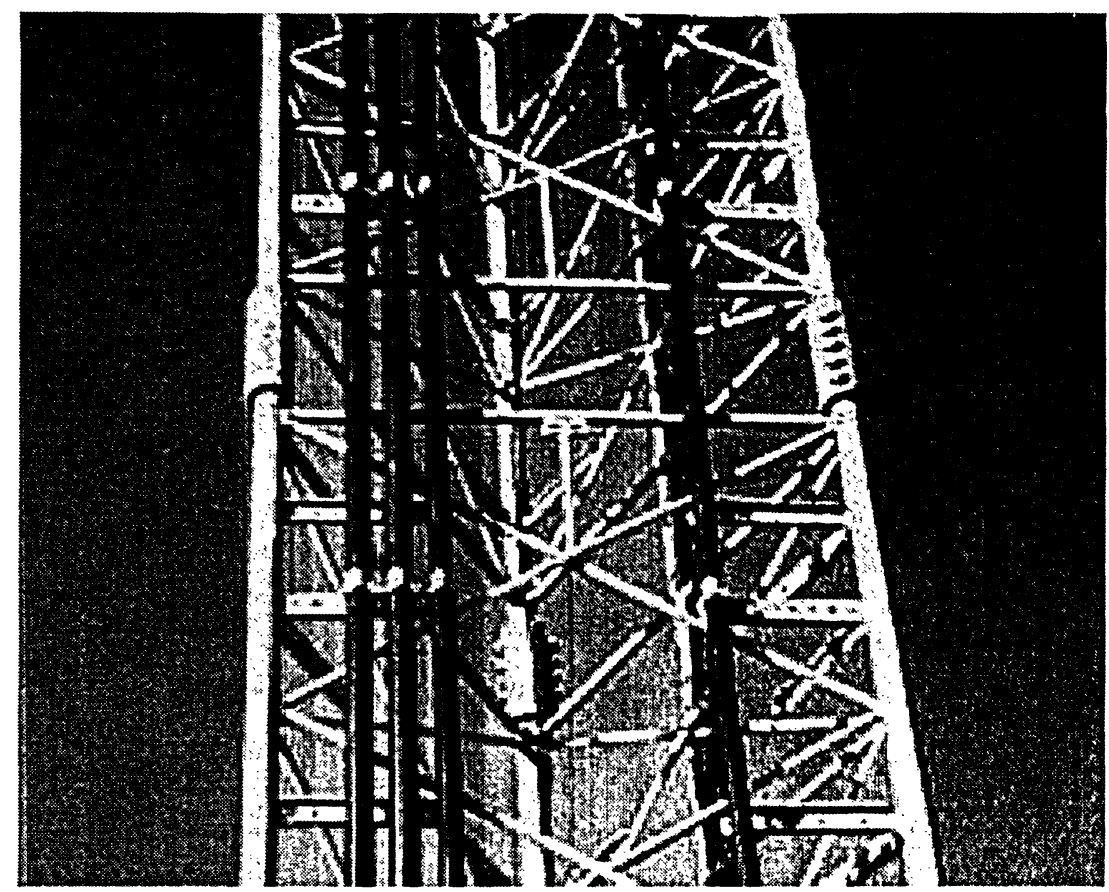

Figure 1.2 Close-up view of tower segment

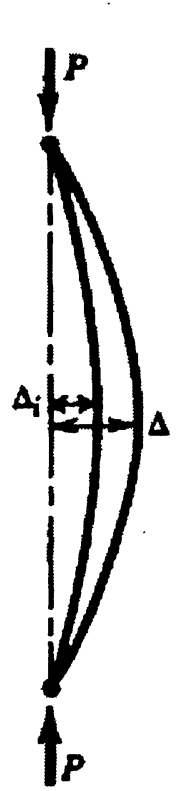

(a)

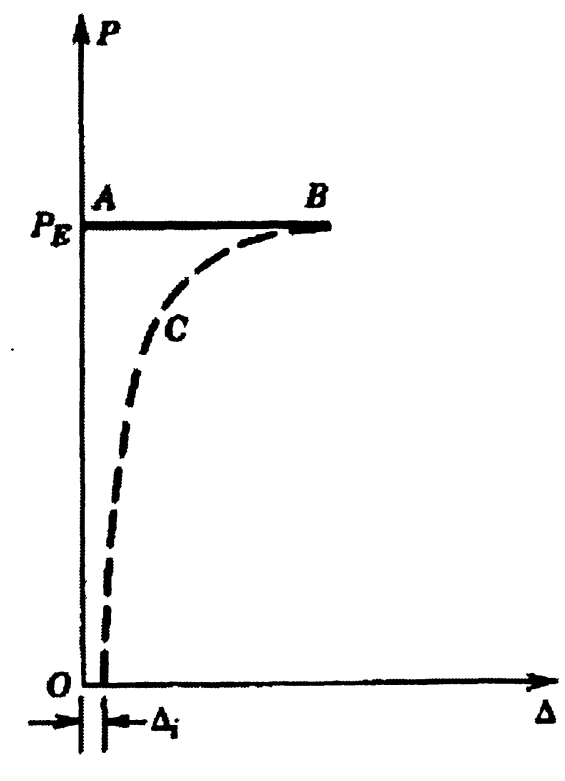

(b)

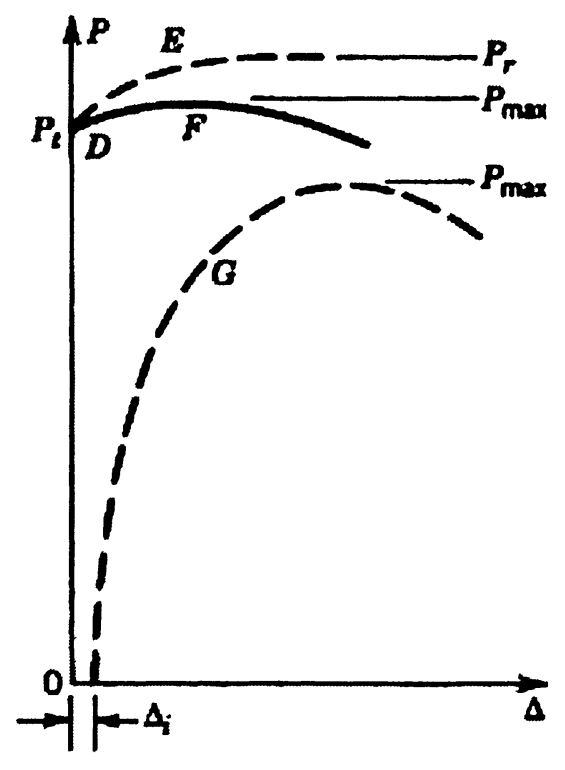

(c)

Figure 2.1 Behavior of perfect and imperfect columns (Galambos, 1998) 


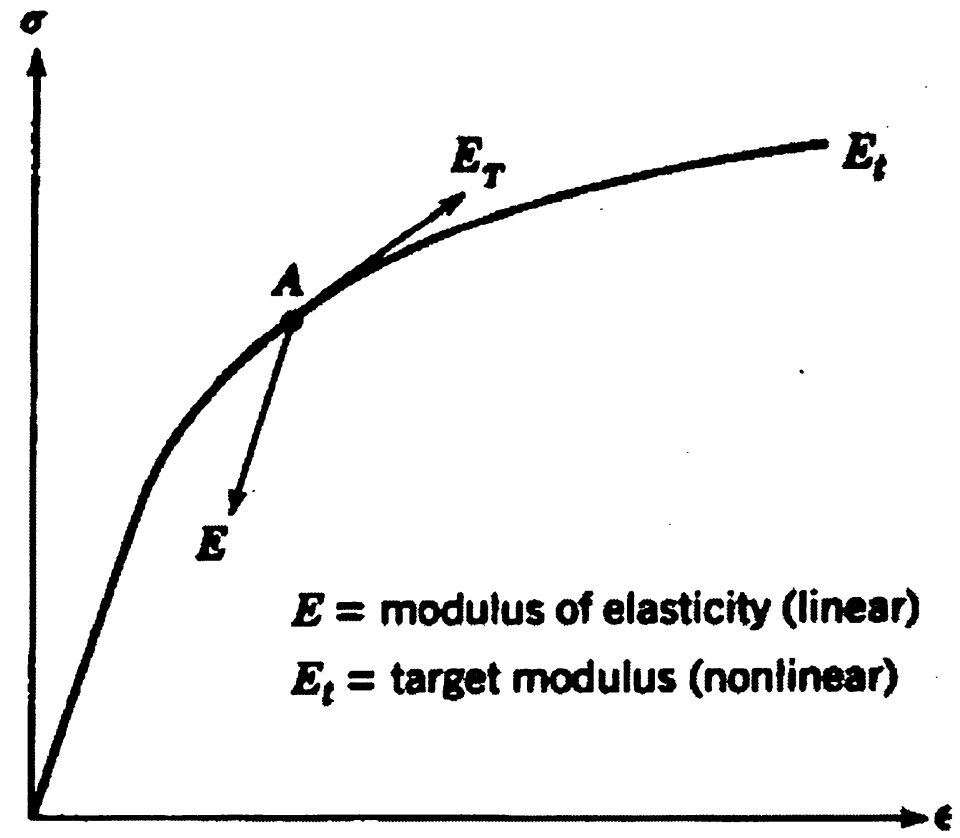

Figure 2.2 General stress-strain relationship (Galambos, 1998)

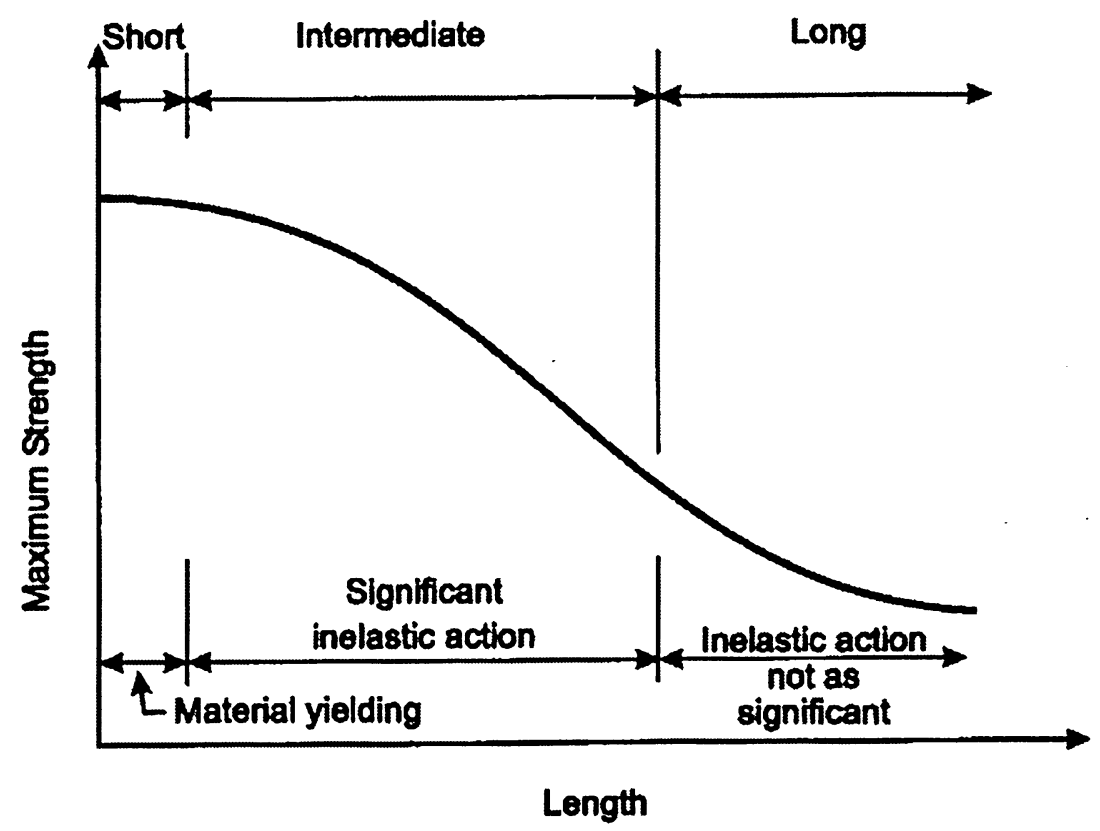

Figure 2.3 Column curve 


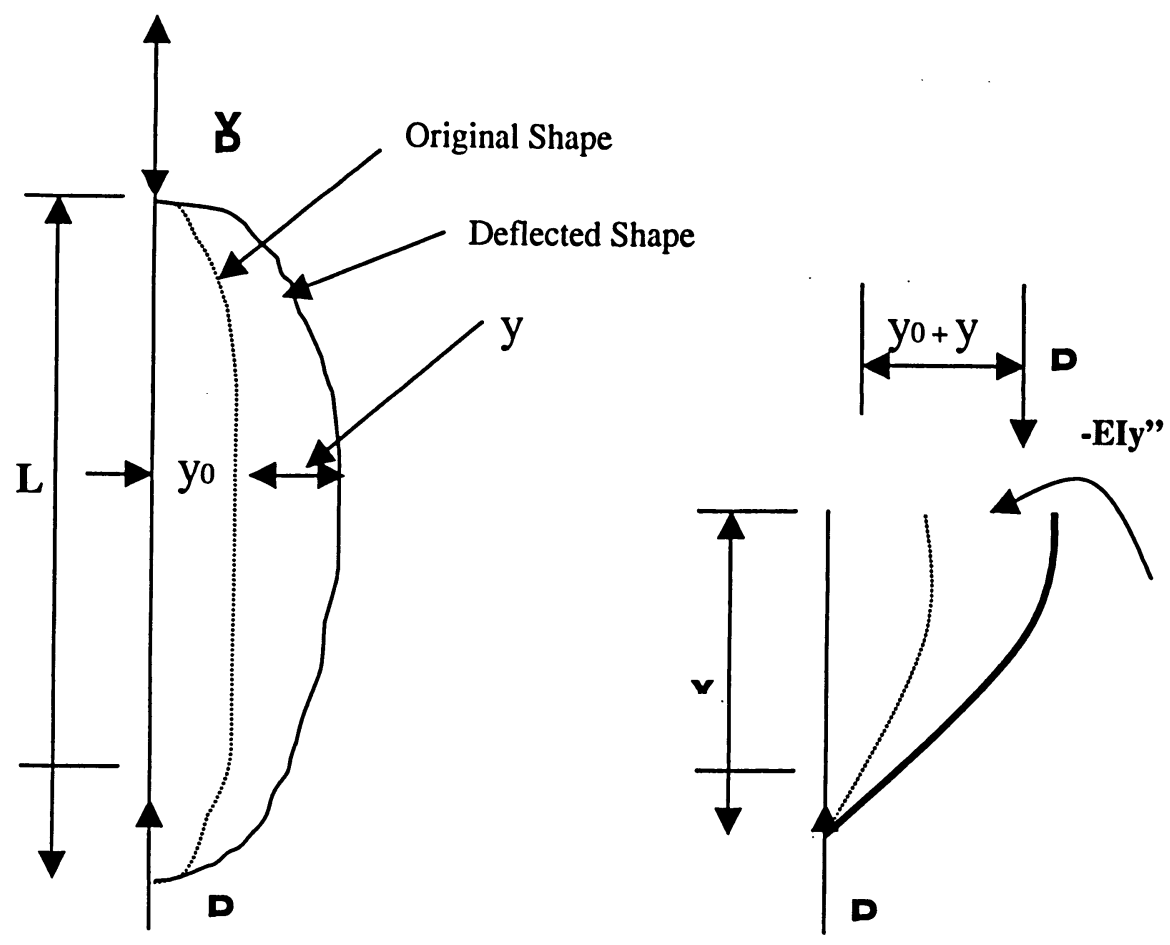

Figure 2.4 Initially bent column 


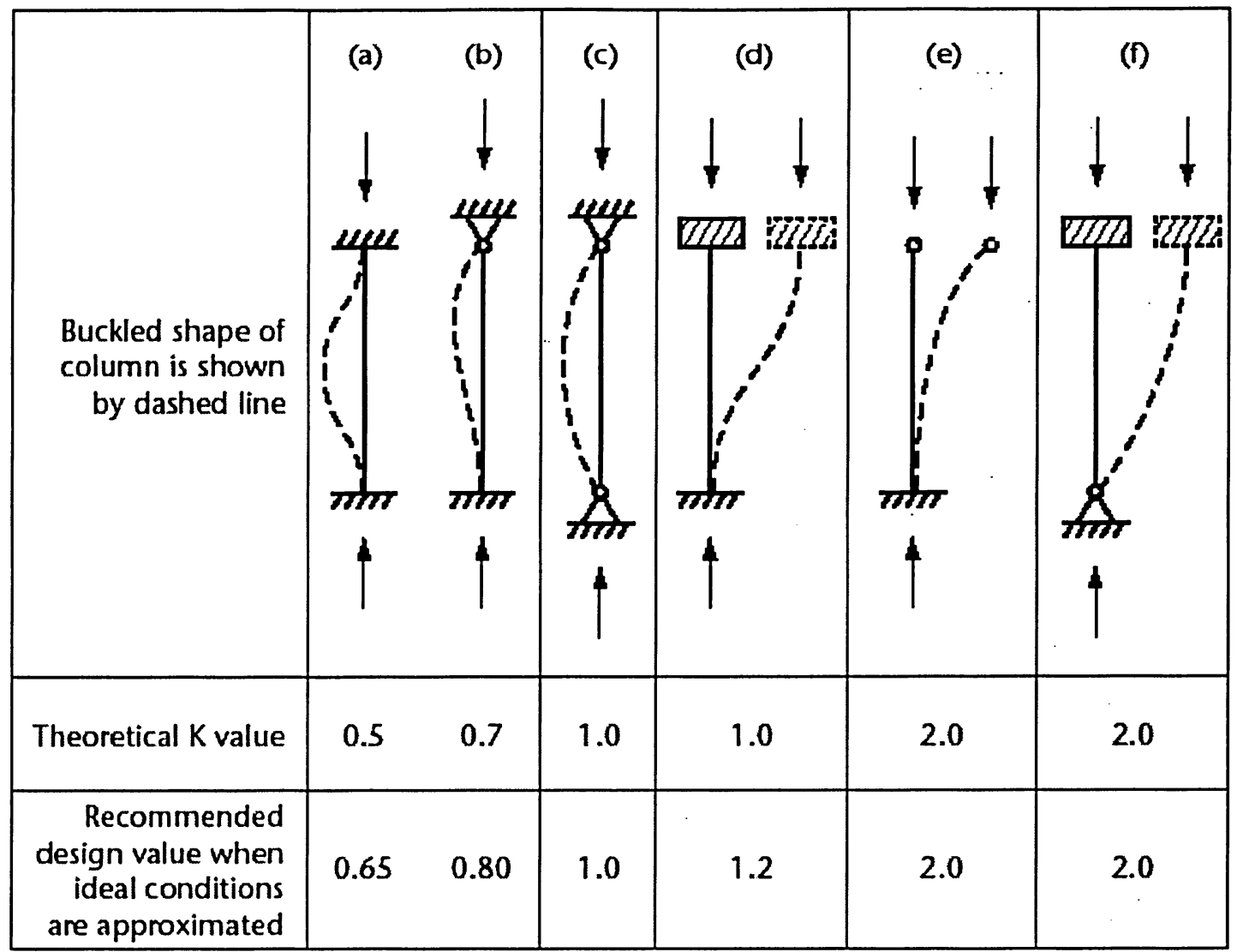

\begin{tabular}{|l|c|c|}
\hline \multirow{2}{*}{ End condition code } & \multicolumn{1}{|c|}{ Rotation fixed, translation fixed } \\
\cline { 2 - 3 } & \multicolumn{1}{|c|}{ Rotation free, translation fixed } \\
\cline { 2 - 3 } & 9 & Rotation fixed, translation free \\
\hline & 9 & Rotation free, translation free \\
\hline
\end{tabular}

Figure 2.5 Effective length factor (CAN/CSA S16-01, 2003) 


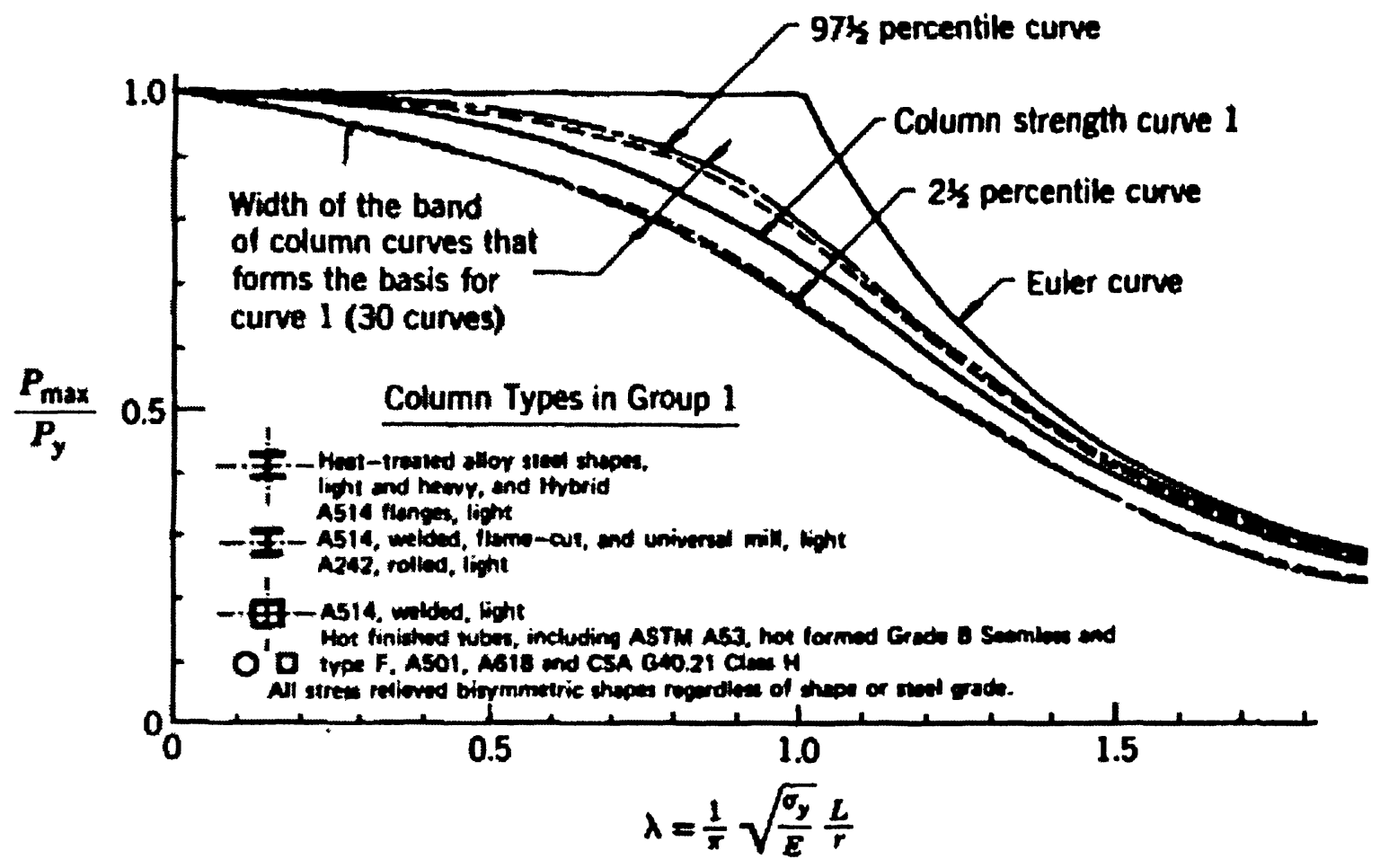

Figure 2.6 SSRC column strength curve 1 for structural steel (Bjordhovde, 1972), (Based on maximum strength and initial out-of-straightness of $\mathrm{L} / 1000$ )

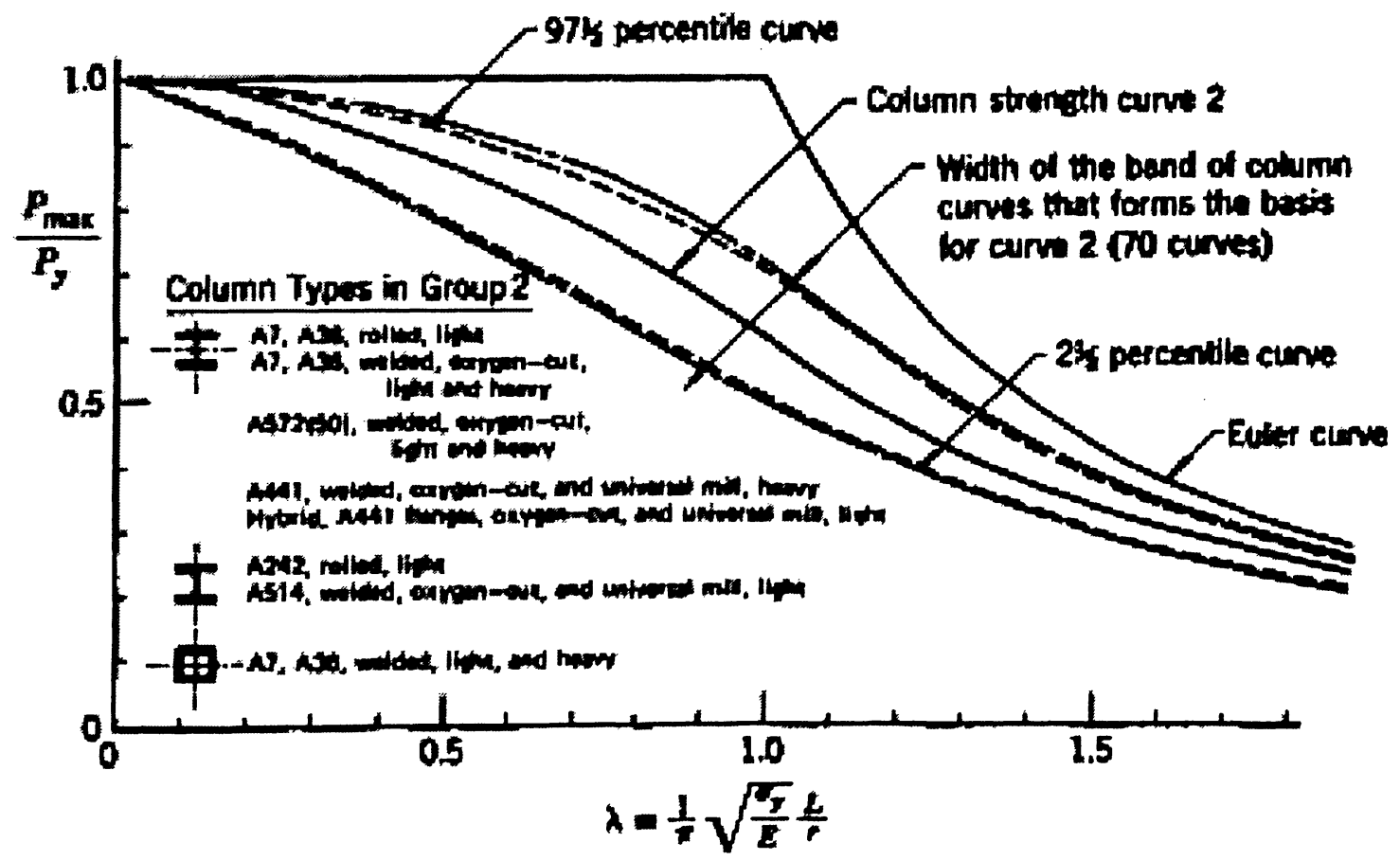

Figure 2.7 SSRC column strength curve 2 for structural steel (Bjordhovde, 1972), (Based on maximum strength and initial out-of-straightness of L/1000) 


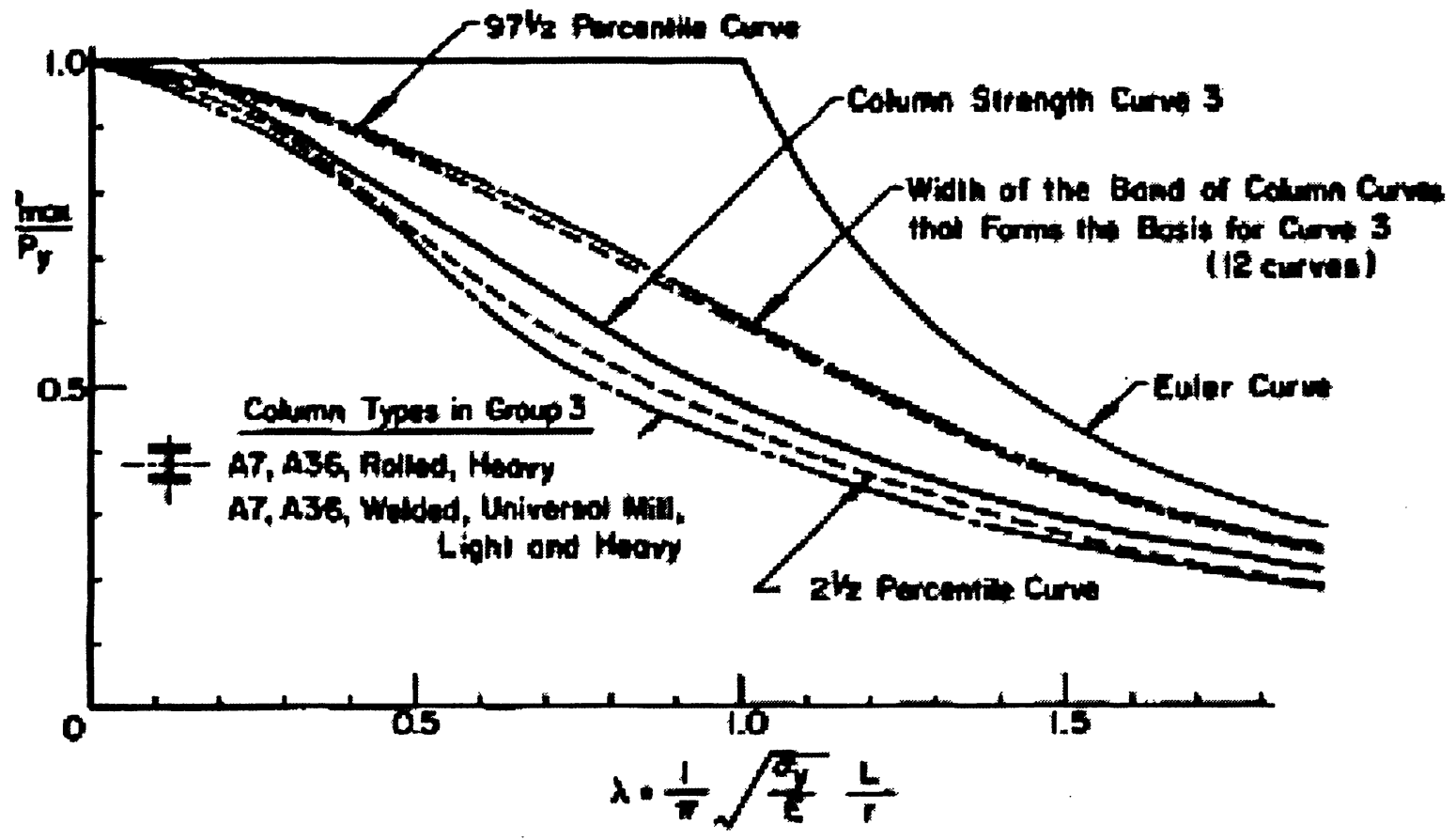

Figure 2.8 SSRC column strength curve 3 for structural steel (Bjordhovde, 1972), (Based on maximum strength and initial out-of-straightness of L/500)

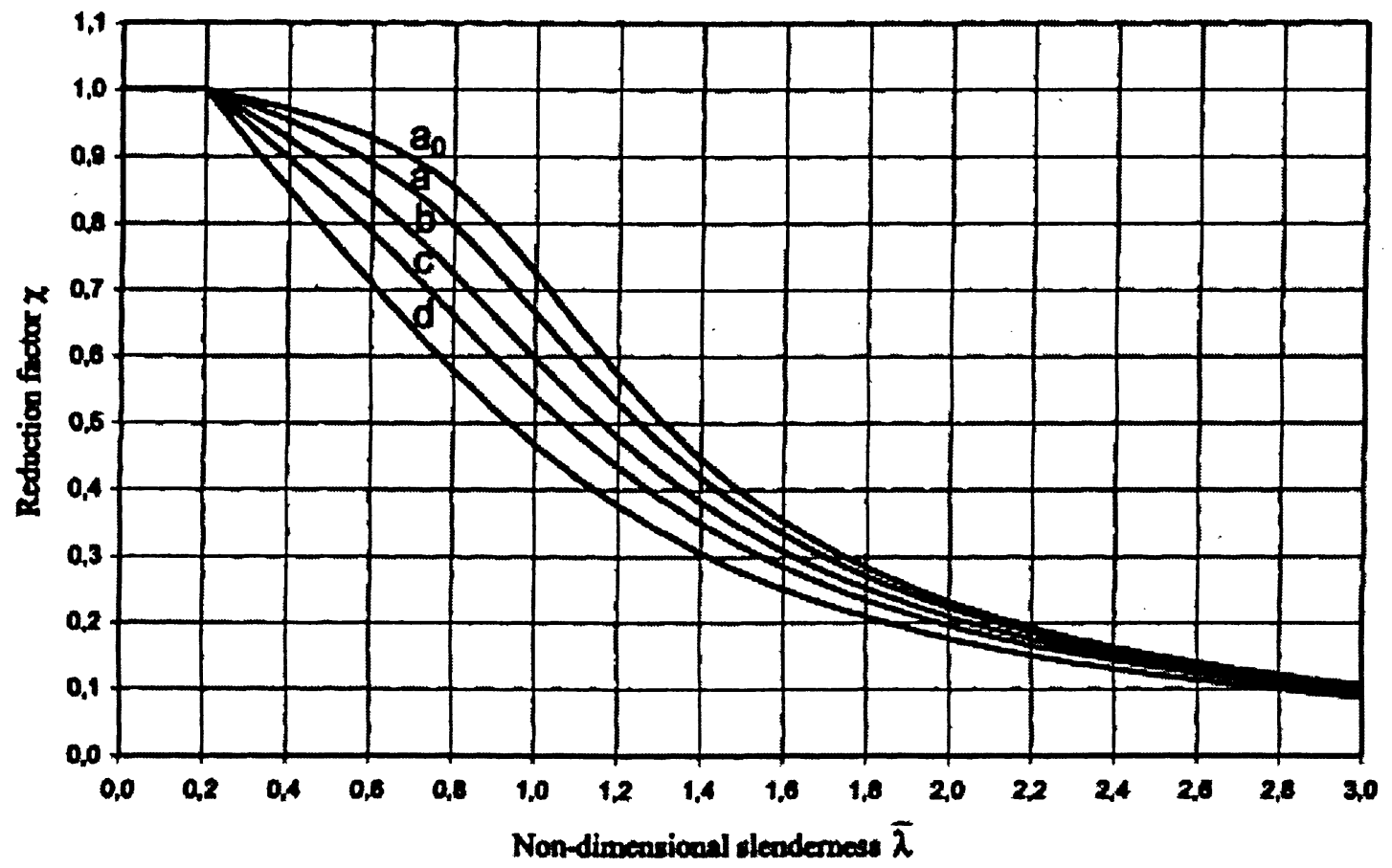

Figure 2.9 Buckling curves (Eurocode 3, 2003) 


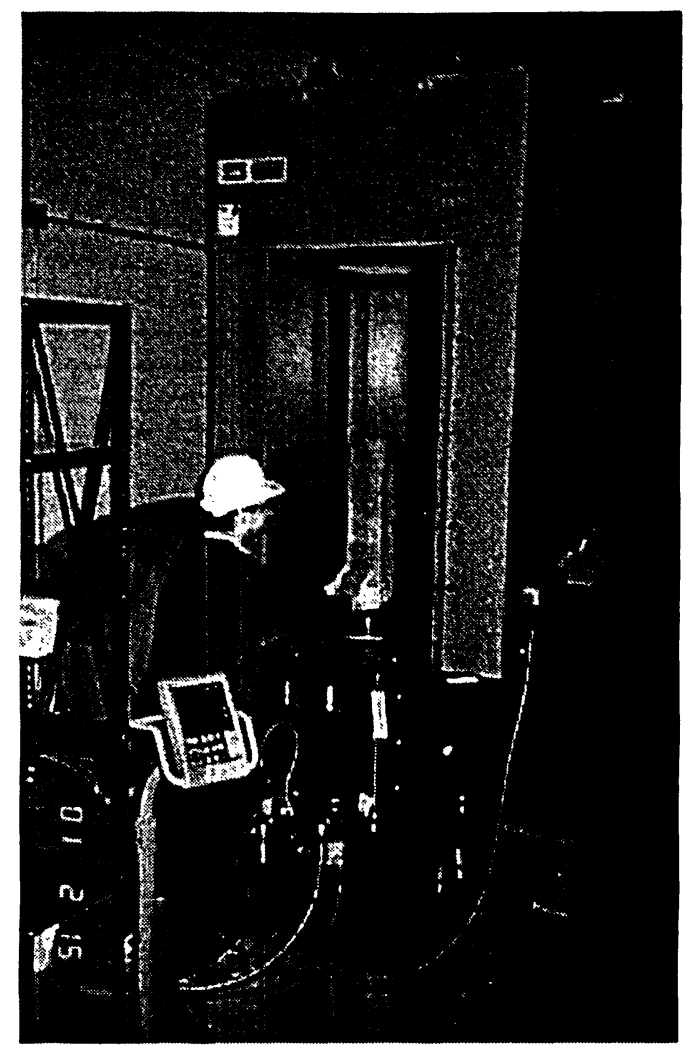

Figure 3.1 View of the MTS machine 


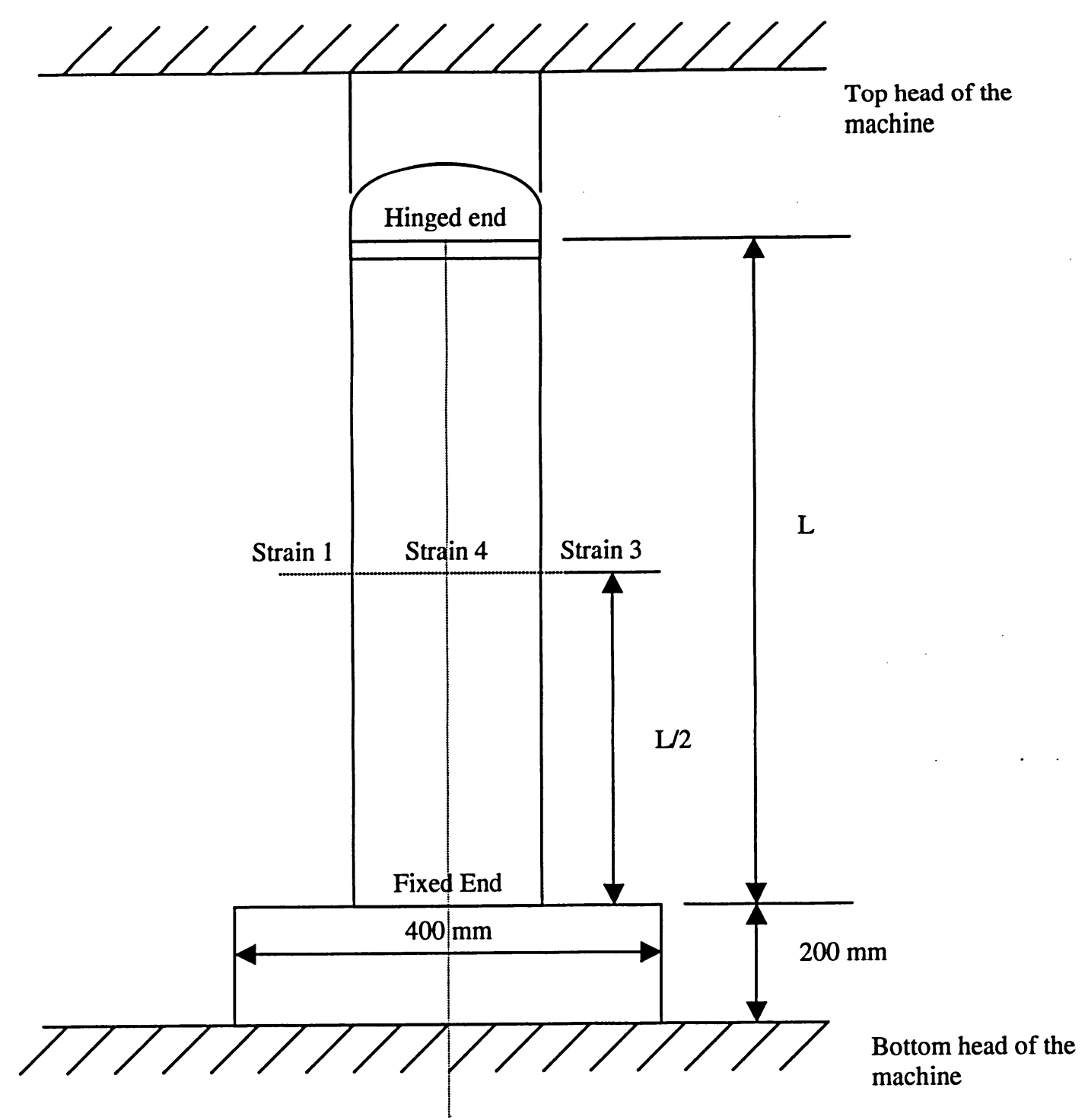

Strain 2

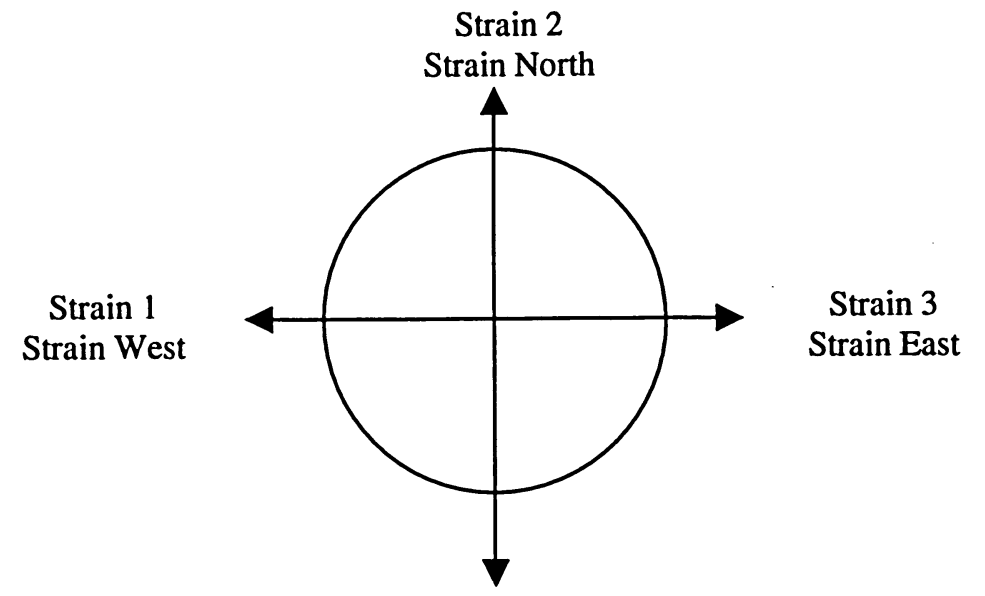

Strain 4

Strain South

Figure 3.2 Schematic diagram of the specimen setup and strain gauge locations 


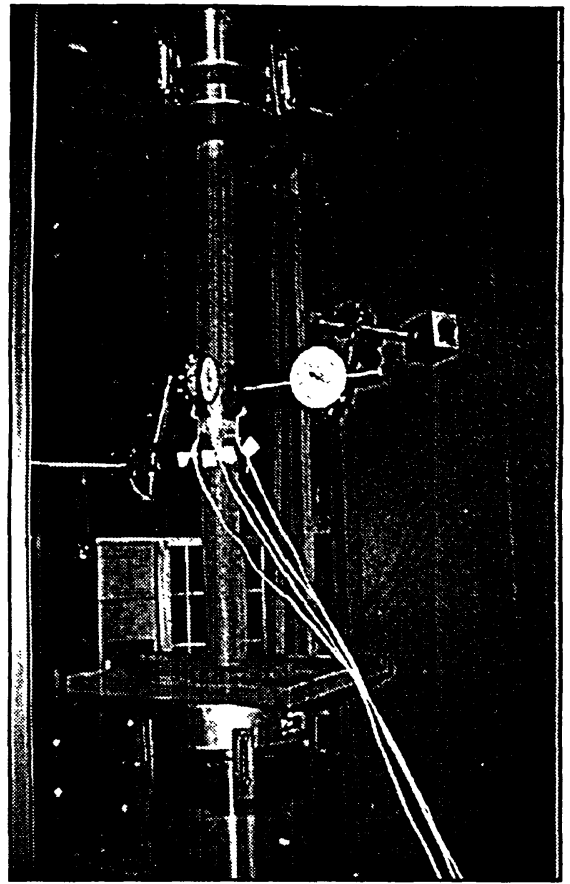

(a)

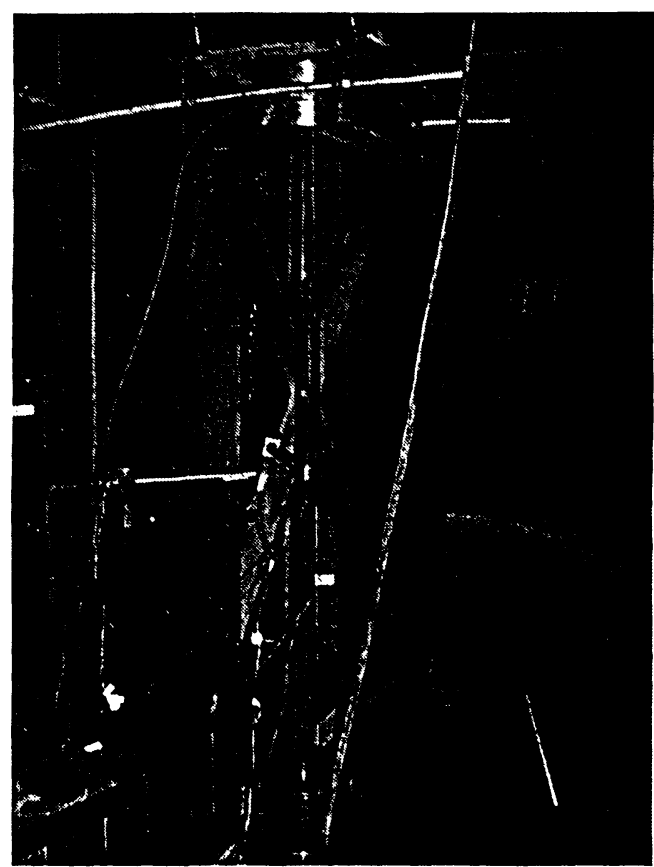

(b)

Figure 3.3 Test set-ups for axial resistance of solid rounds
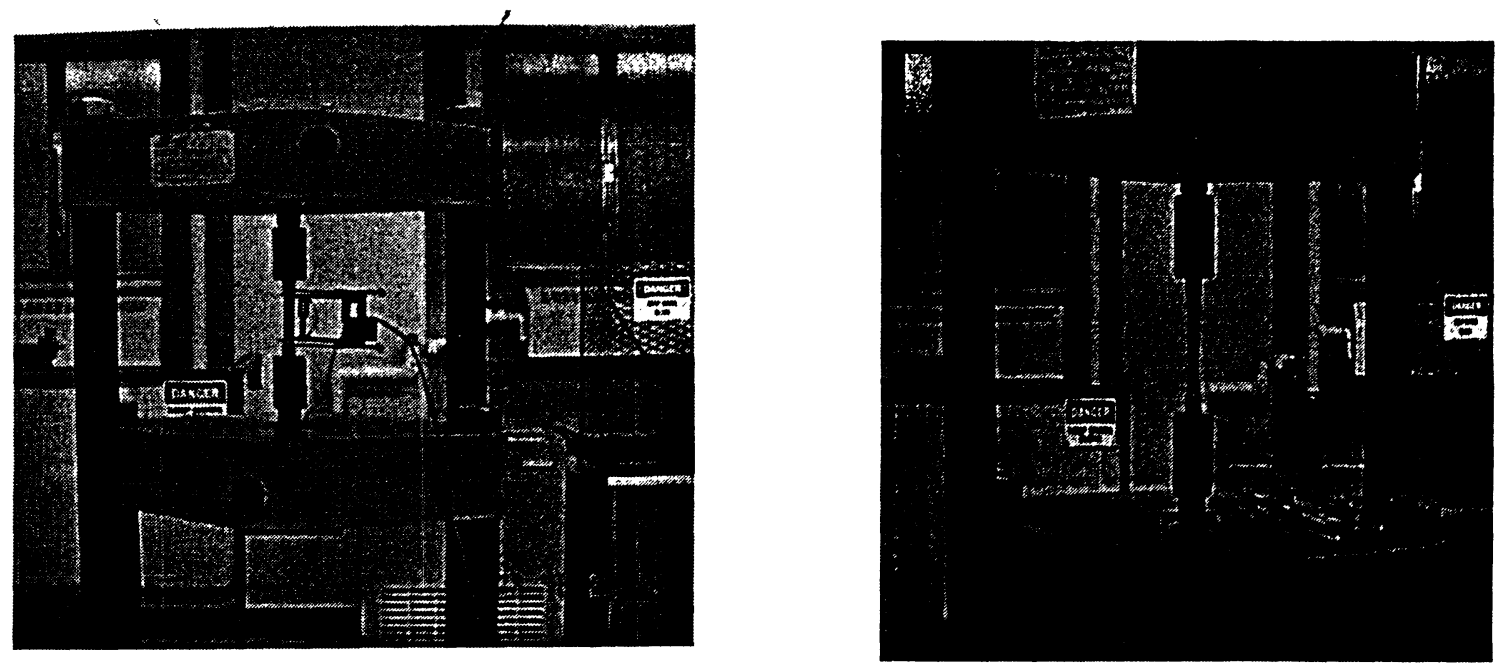

Figure 3.4 Test set up for tension coupon before and after failure 

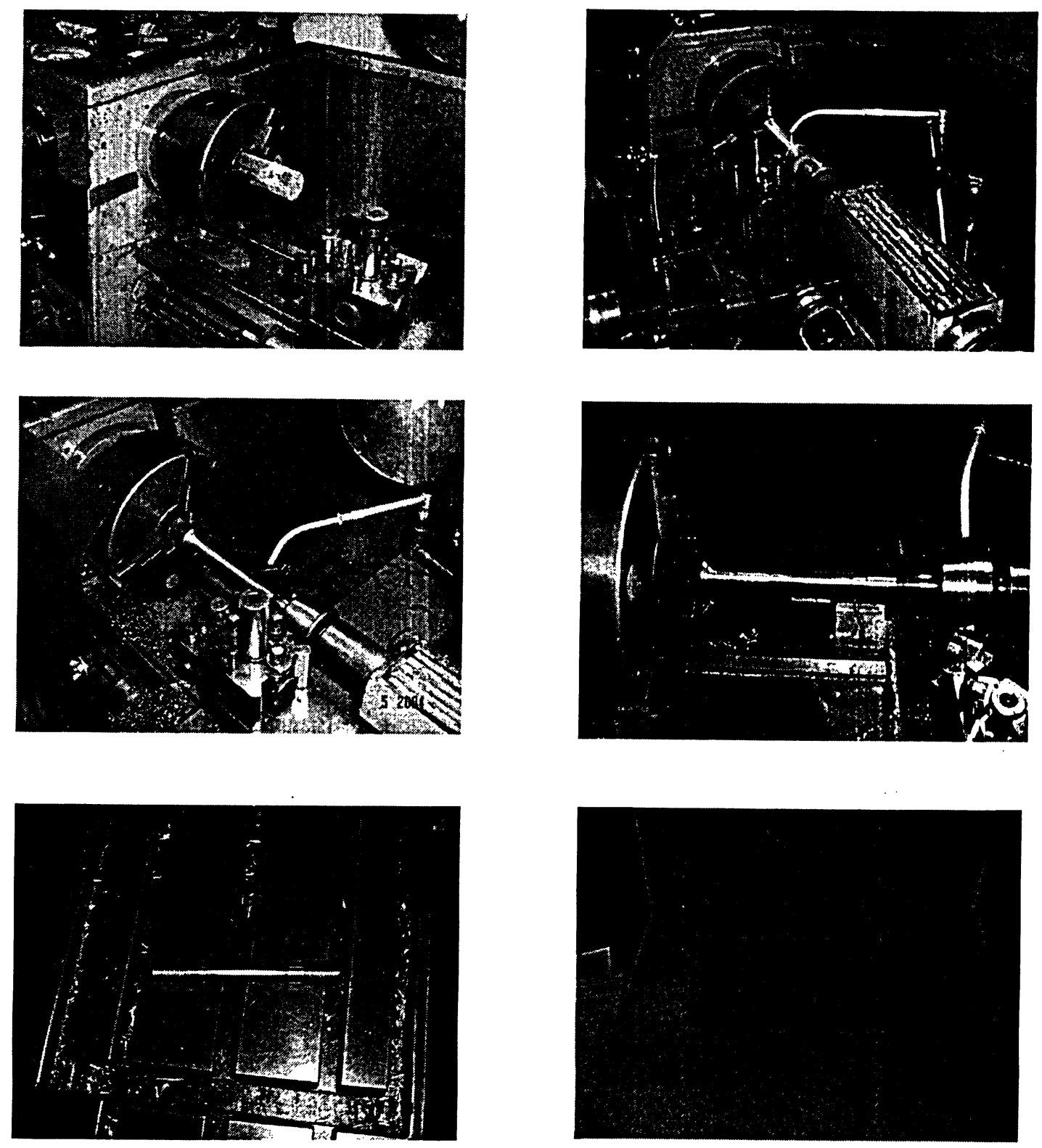

Figure 4.1 Views of coupon sample preparation procedure 


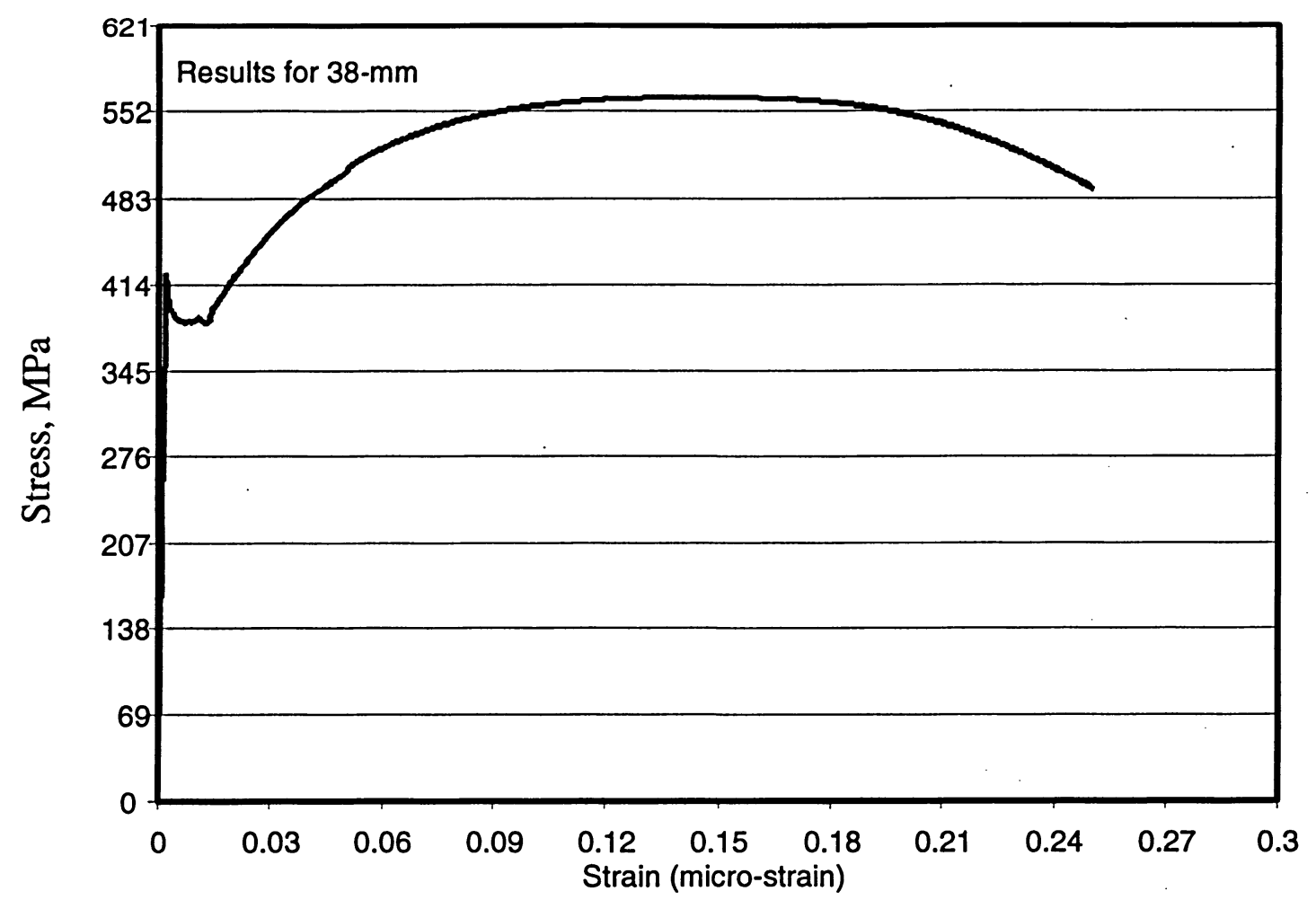

Figure 4.2 Stress-strain curve for the coupon sample of SR 38-mm bar

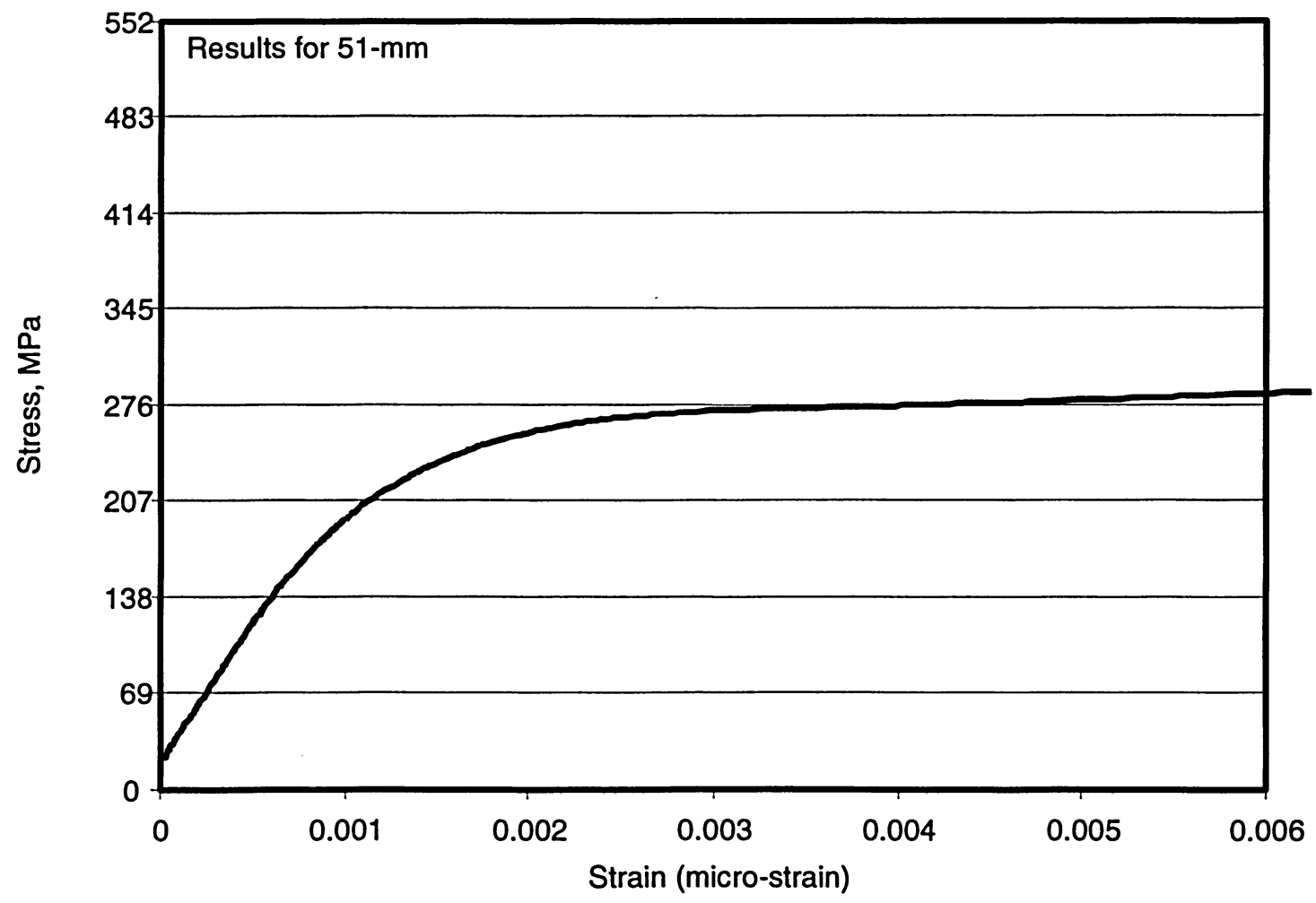

Figure 4.3 Initial part of the stress-strain curve for the coupon sample of SR 51-mm bar 


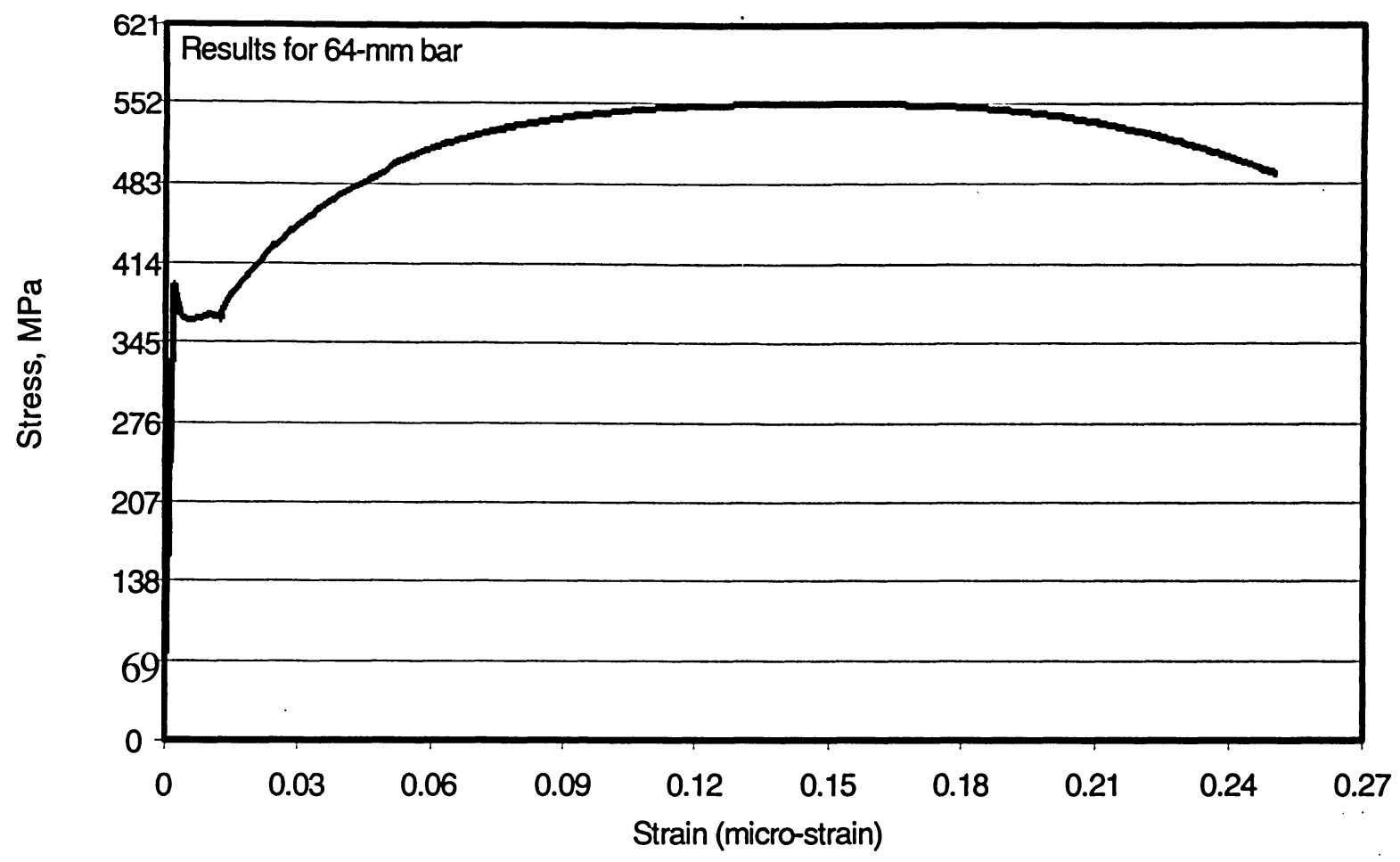

Figure 4.4 Stress-strain curve for the coupon sample of SR 64-mm bar

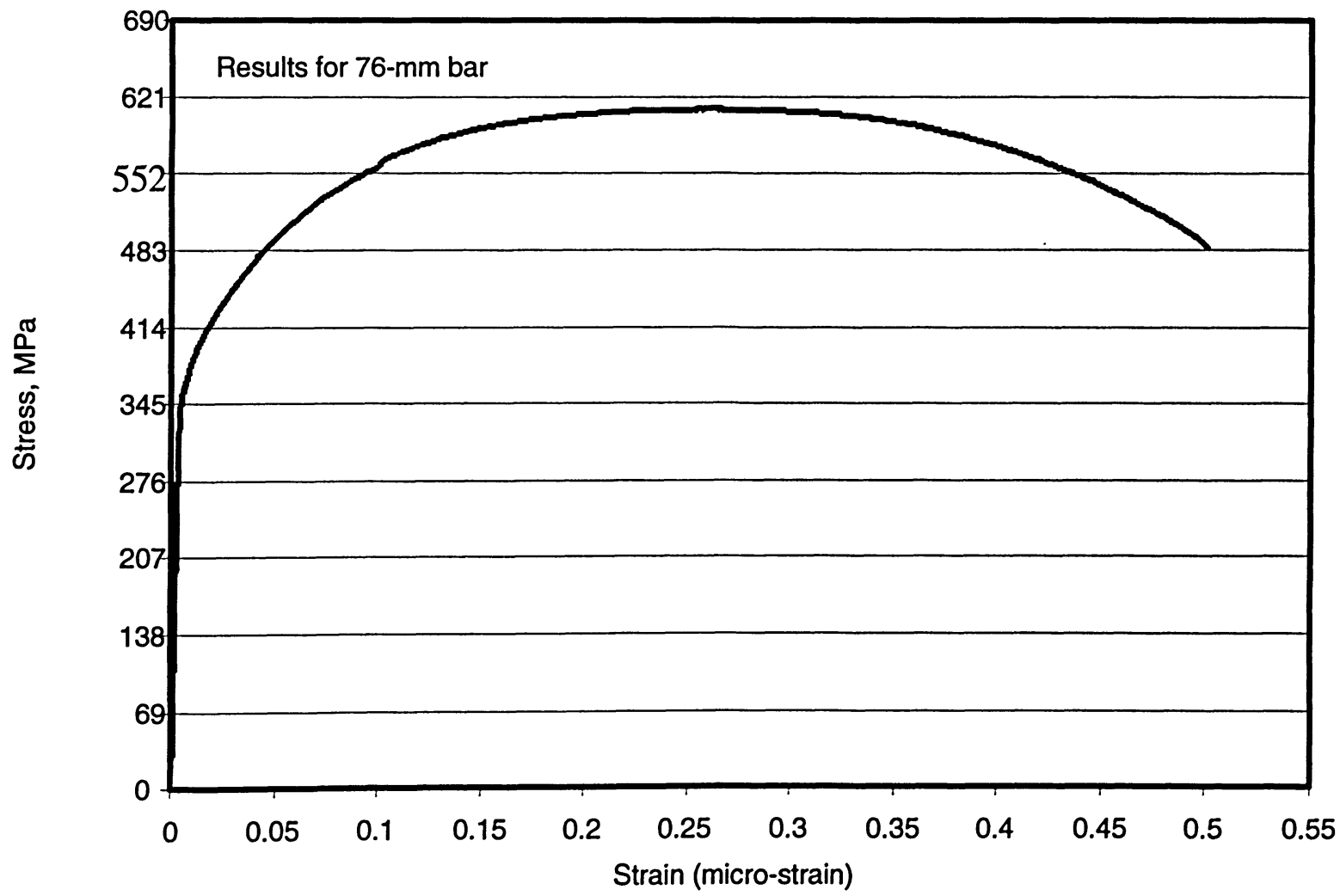

Figure 4.5 Stress-strain curve for the coupon sample of SR 76-mm bar 


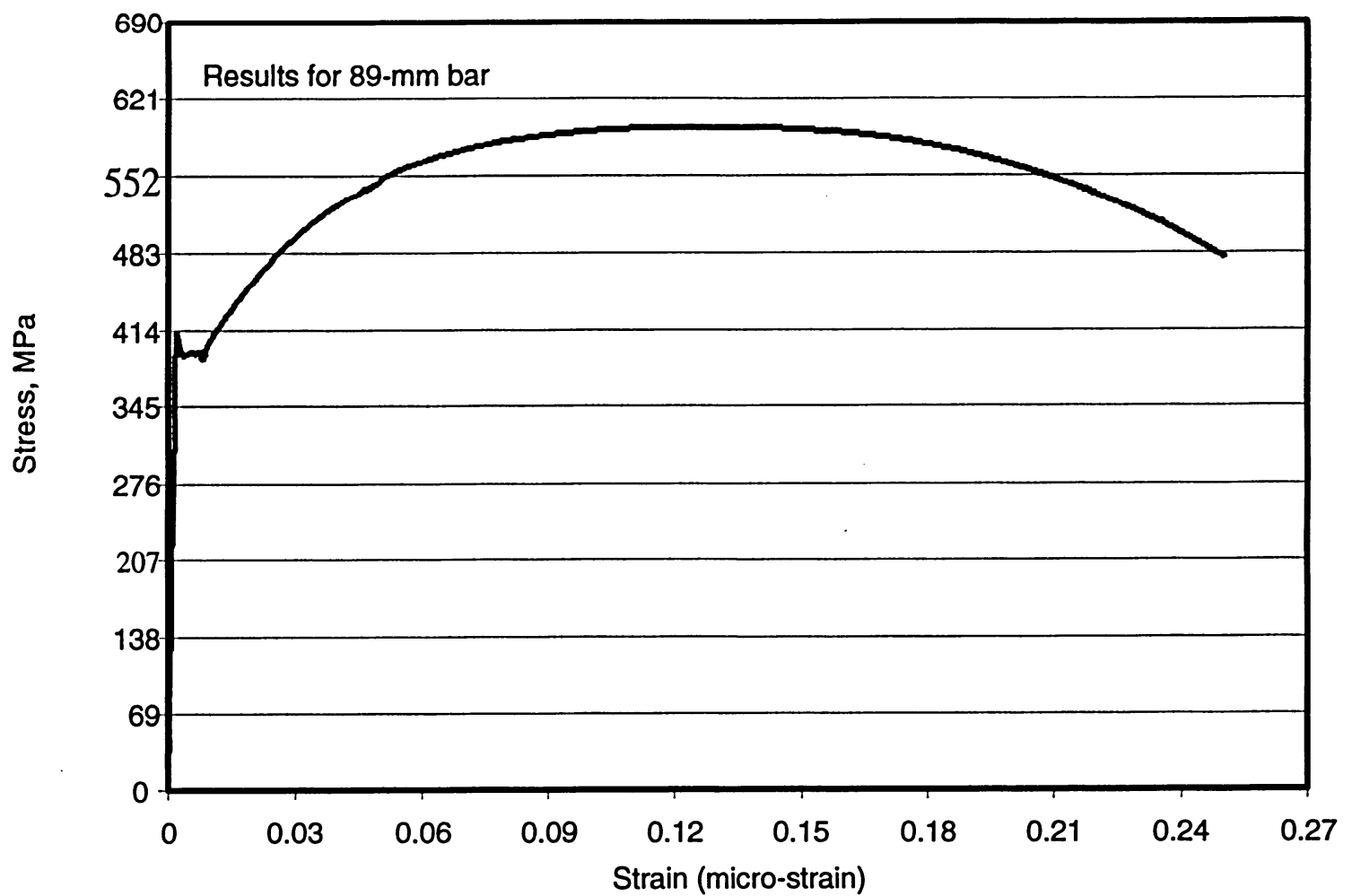

Figure 4.6 Stress-strain curve for the coupon sample of SR 89-mm bar

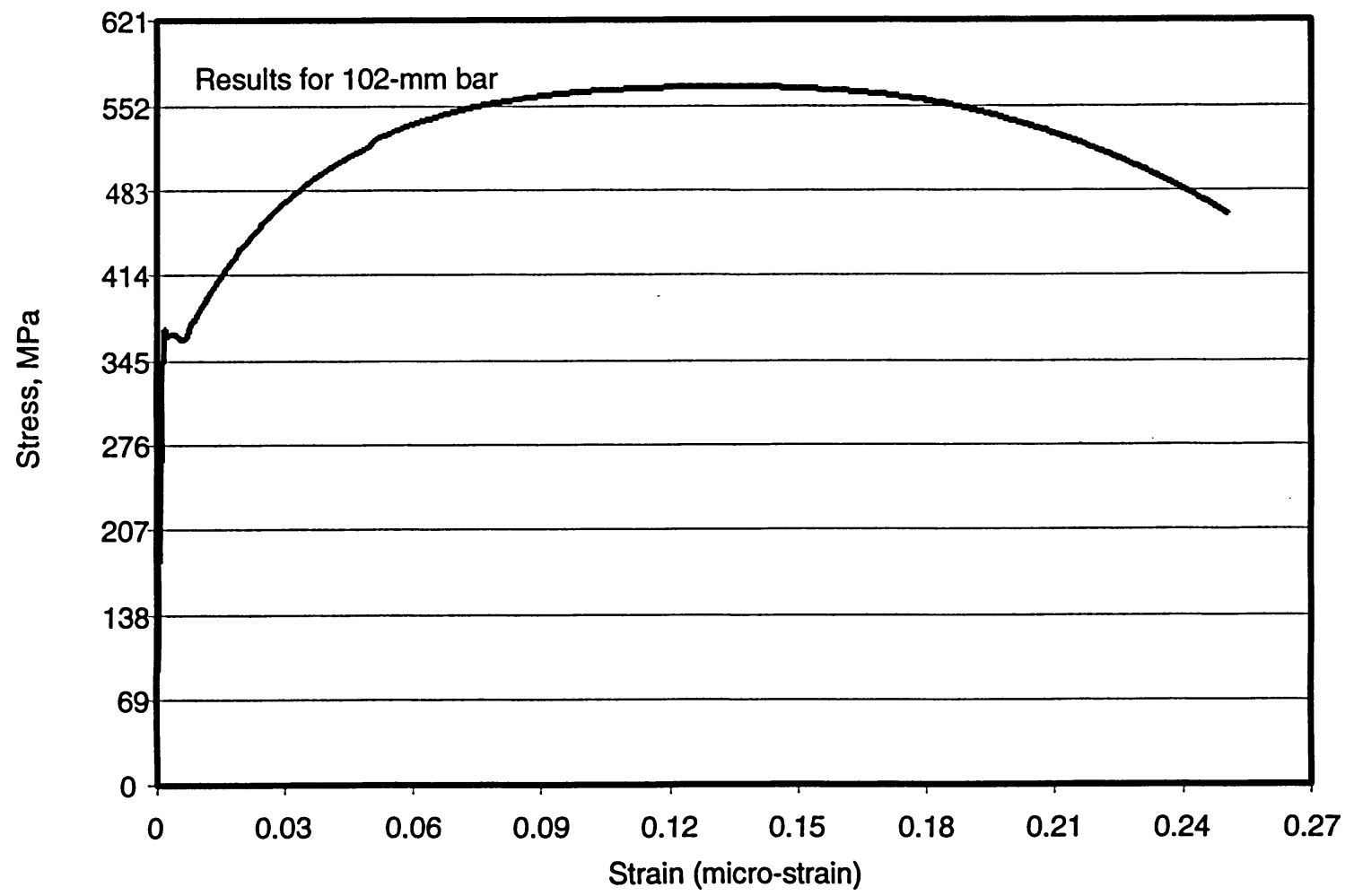

Figure 4.7 Stress-strain curve for the coupon sample of SR 102-mm bar 


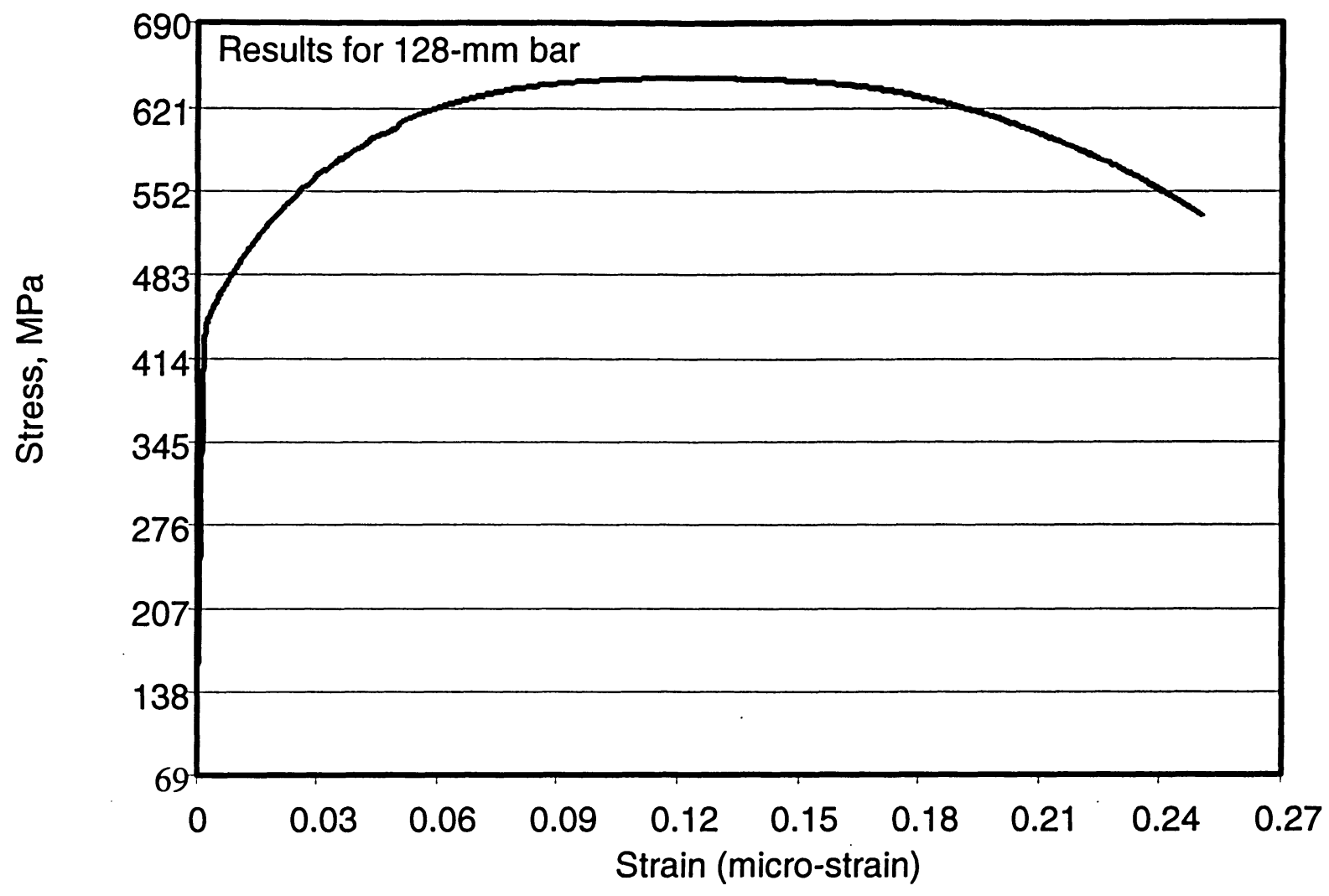

Figure 4.8 Stress-strain curve for the coupon sample of SR 128-mm bar
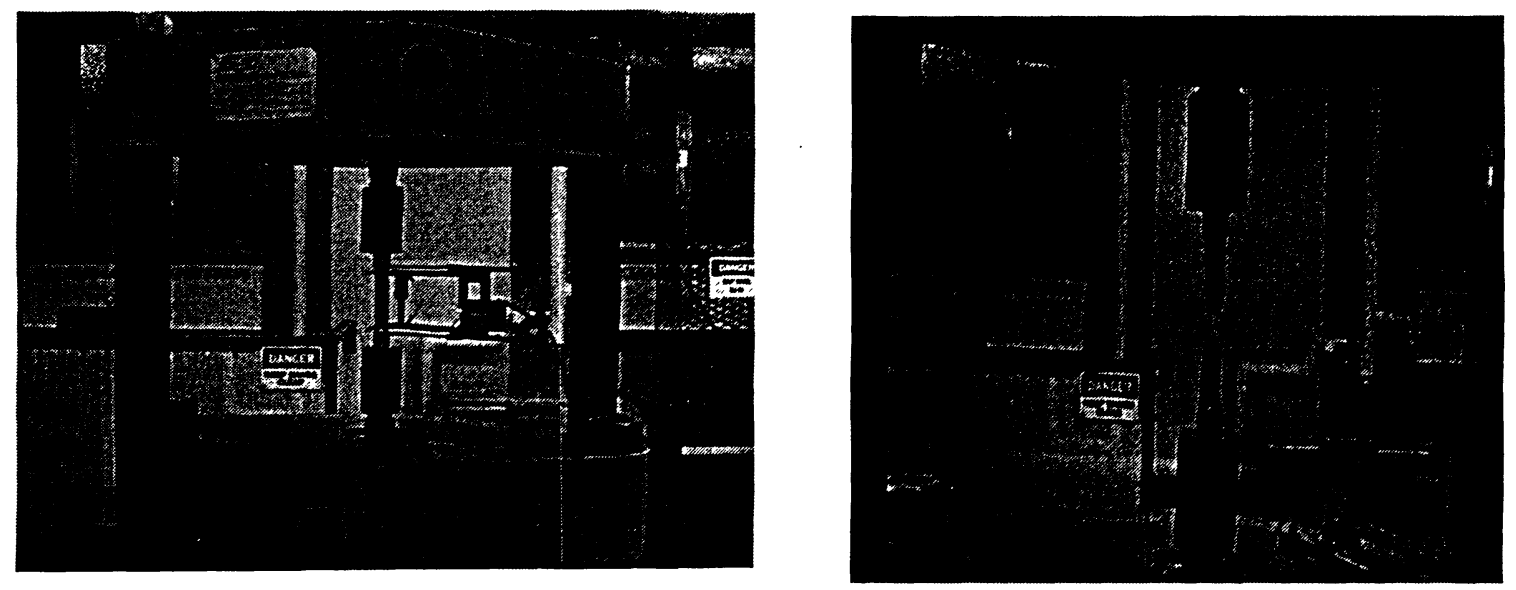

Figure 4.9 Views of the coupon sample for $38-\mathrm{mm}$ bar before and after testing 


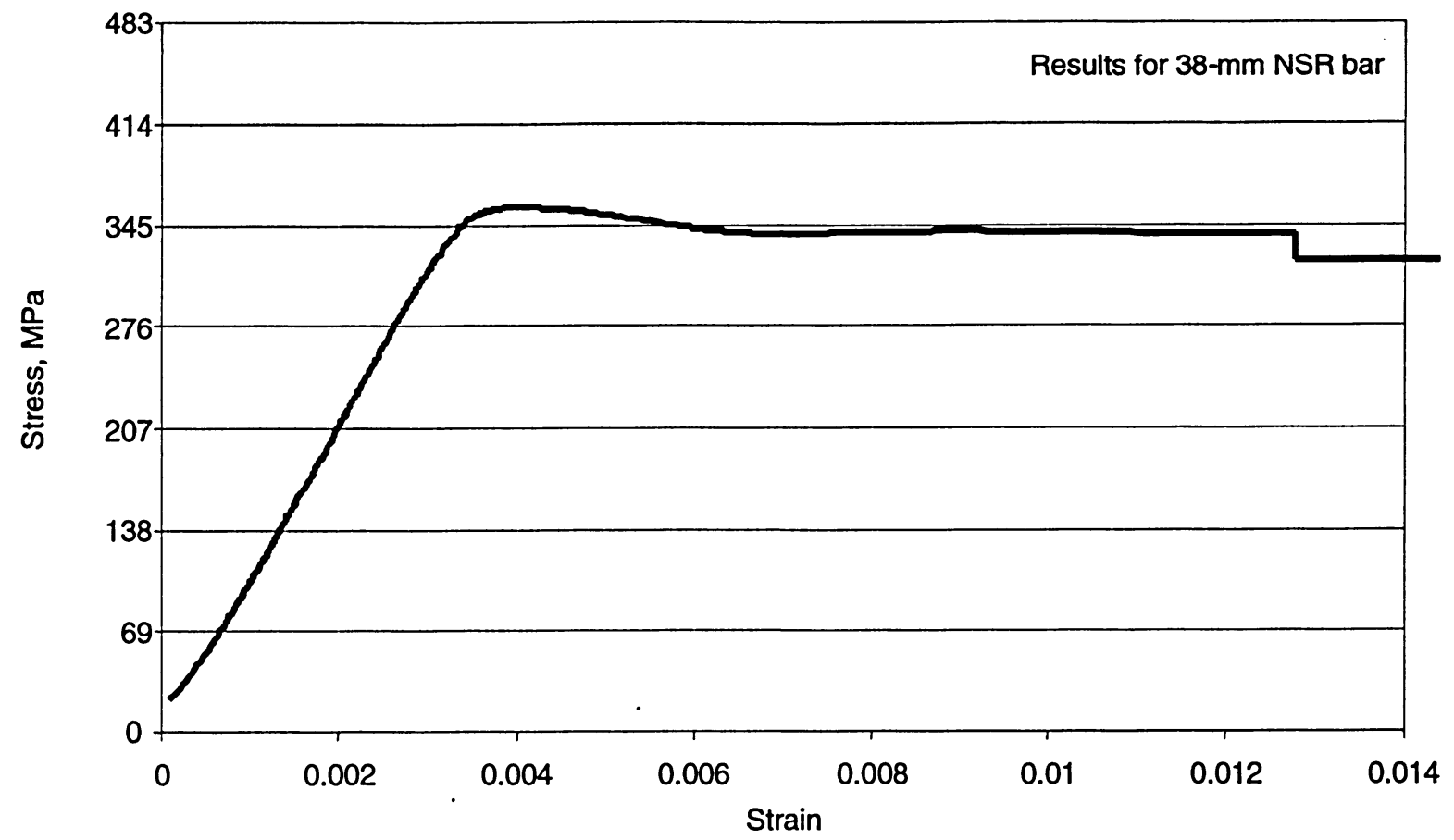

Figure 4.10 Initial portion of the stress-strain curve for the coupon sample of NSR 38-mm bar
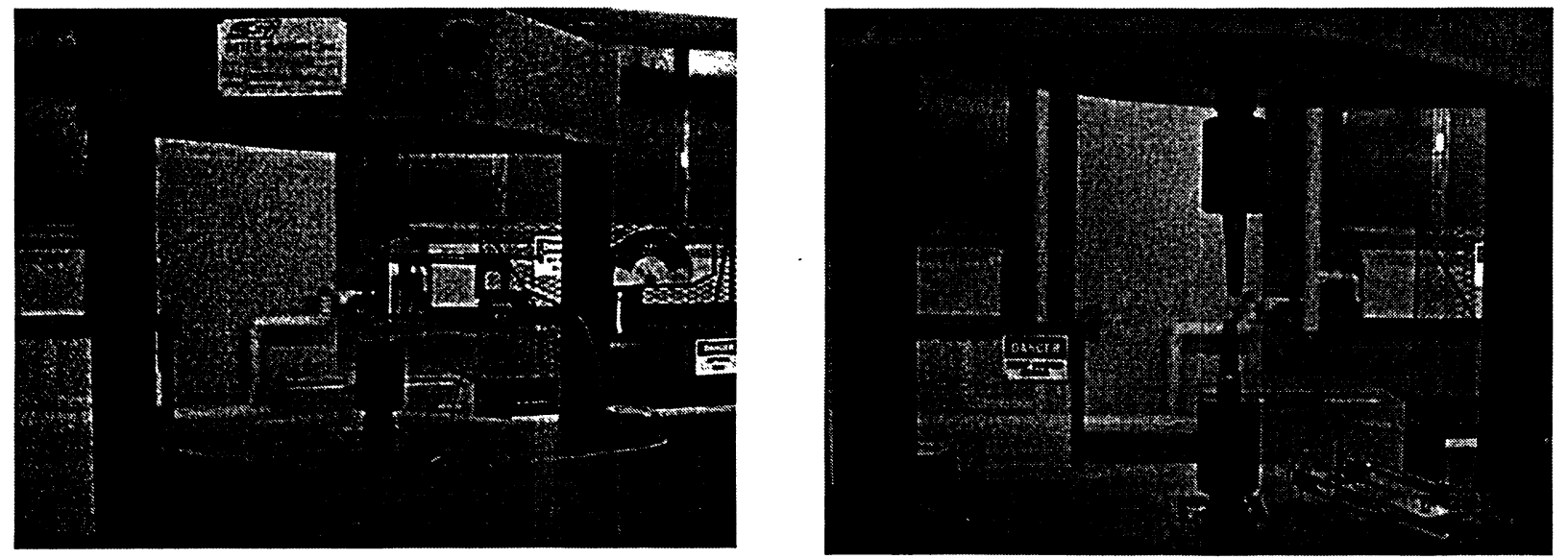

Figure 4.11 Views of the coupon sample for $51-\mathrm{mm}$ bar before and after testing 


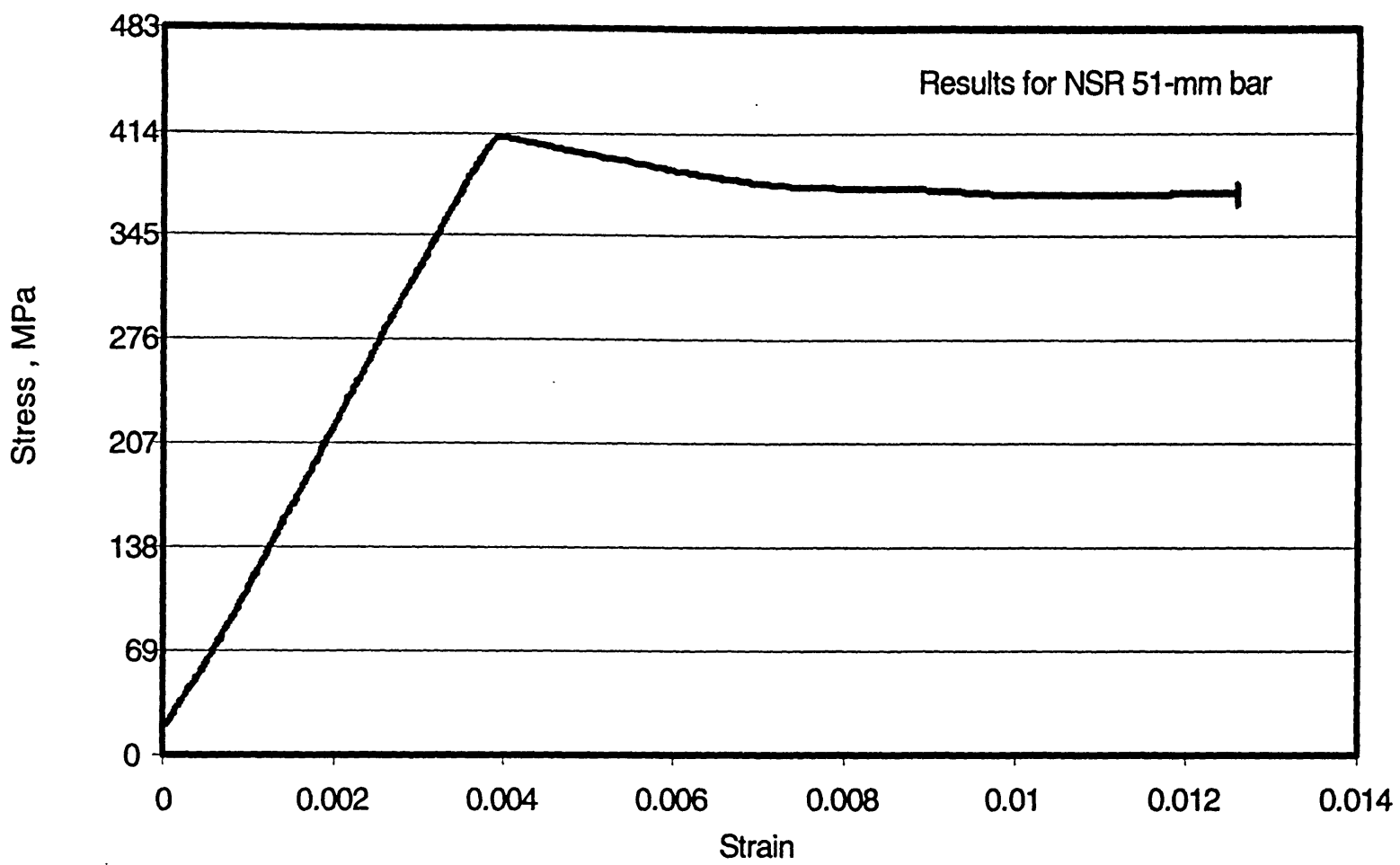

Figure 4.12 Initial part of the stress-strain curve for the coupon sample of NSR 51-mm bar
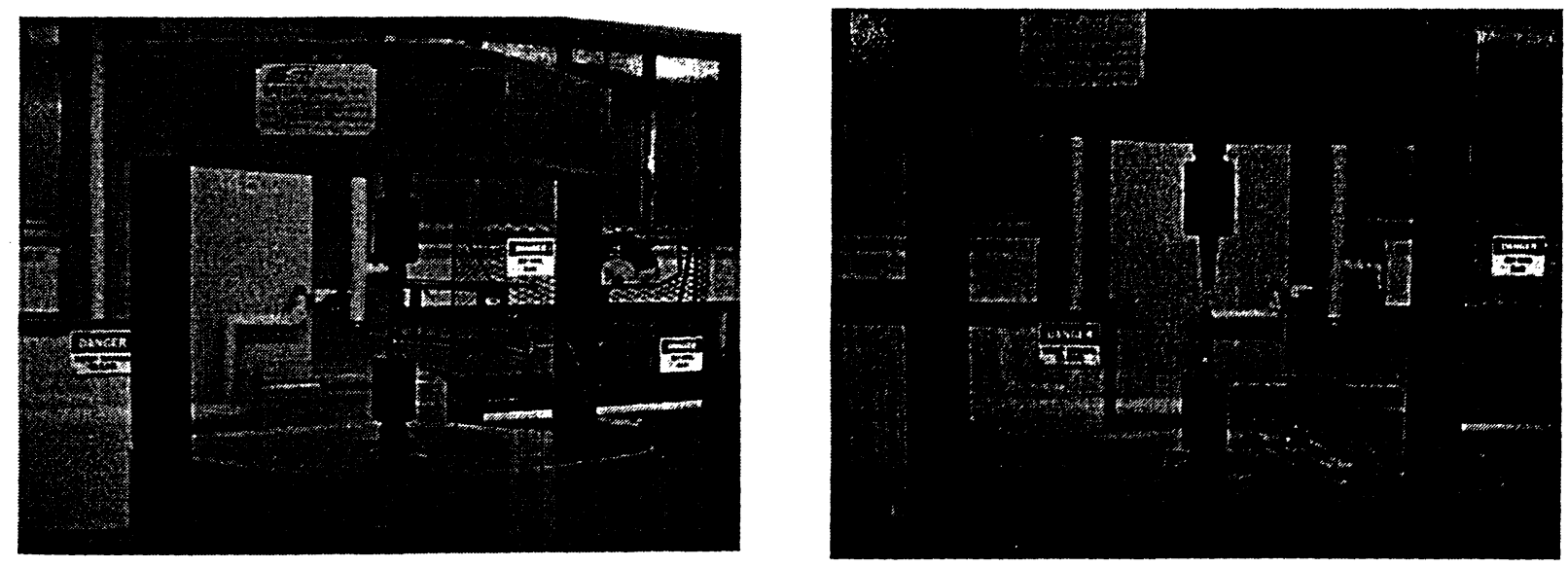

Figure 4.13 Views of the coupon sample for $64-\mathrm{mm}$ bar before and after testing 


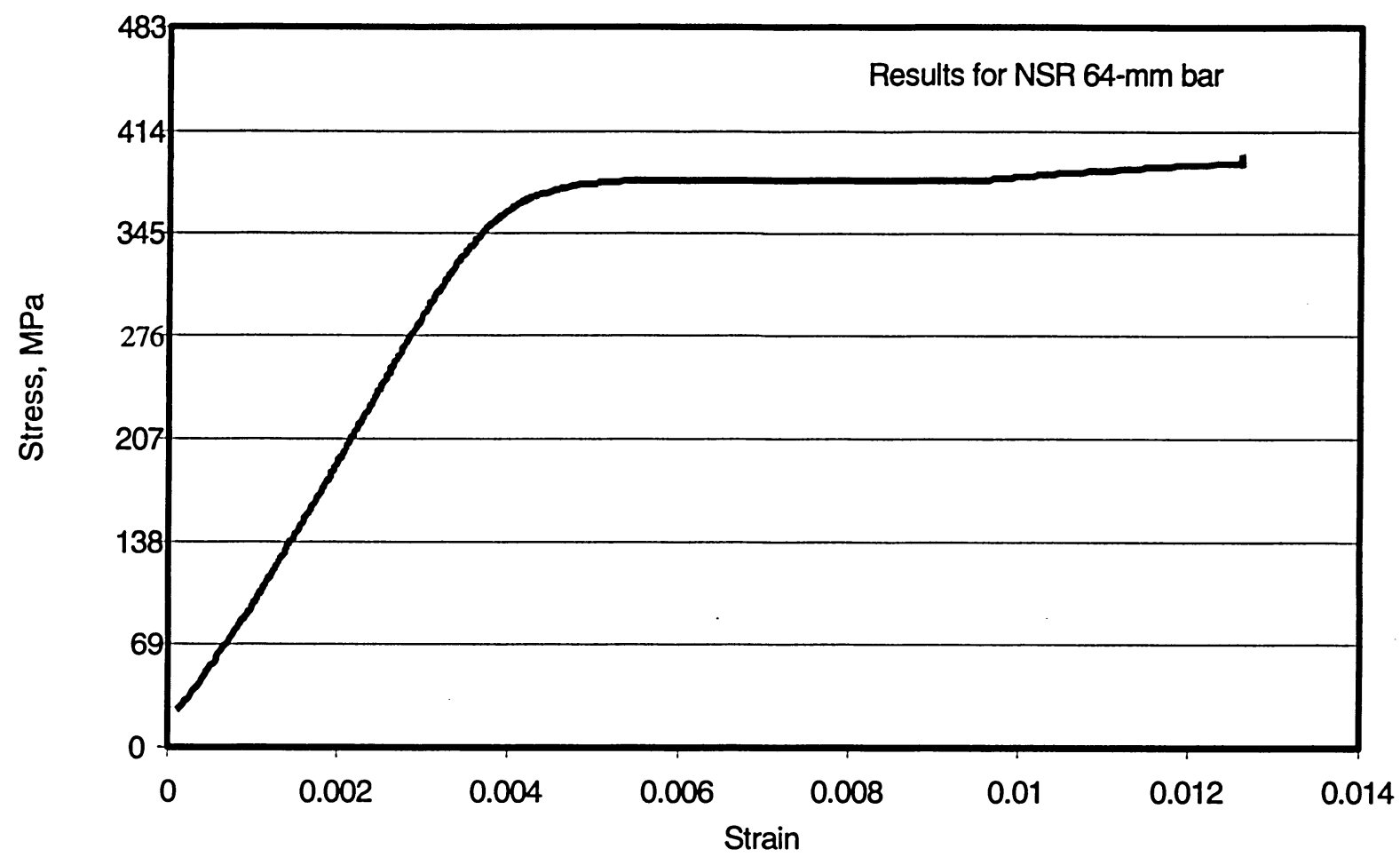

Figure 4.14 Initial part of the stress-strain curve for the coupon sample of NSR 64-mm bar
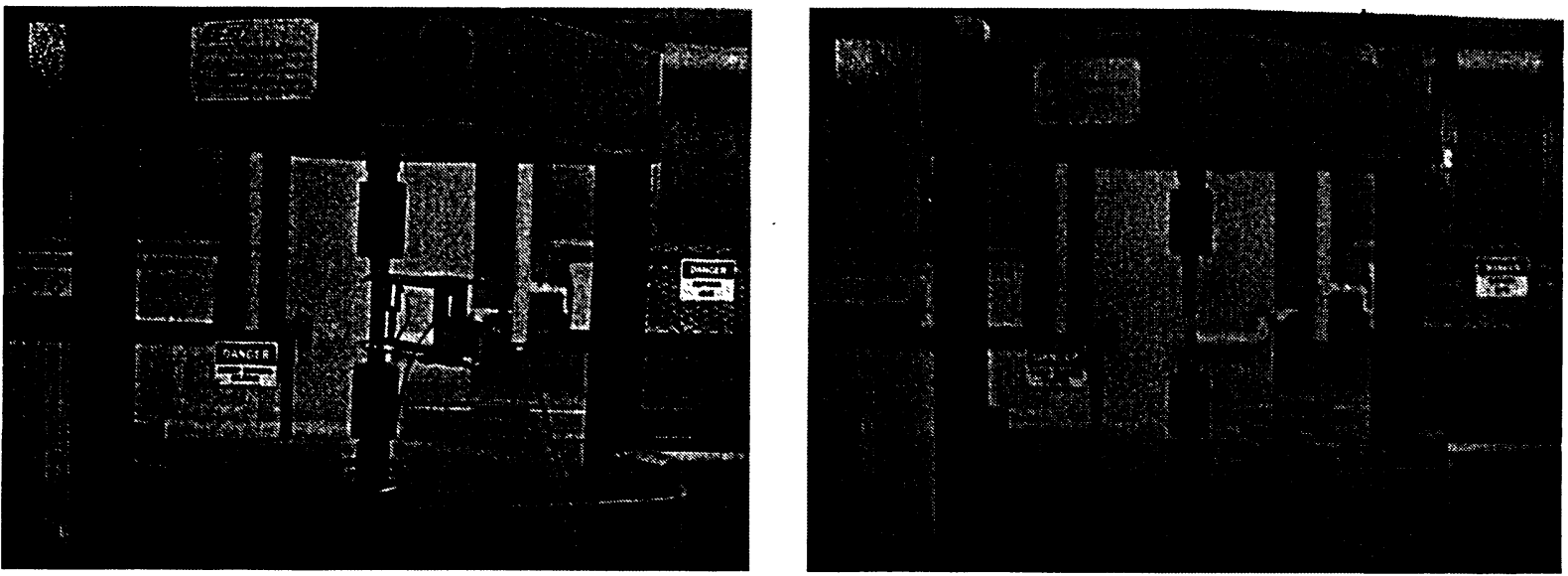

Figure 4.15 Views of the coupon sample for 76-mm bar before and after testing 


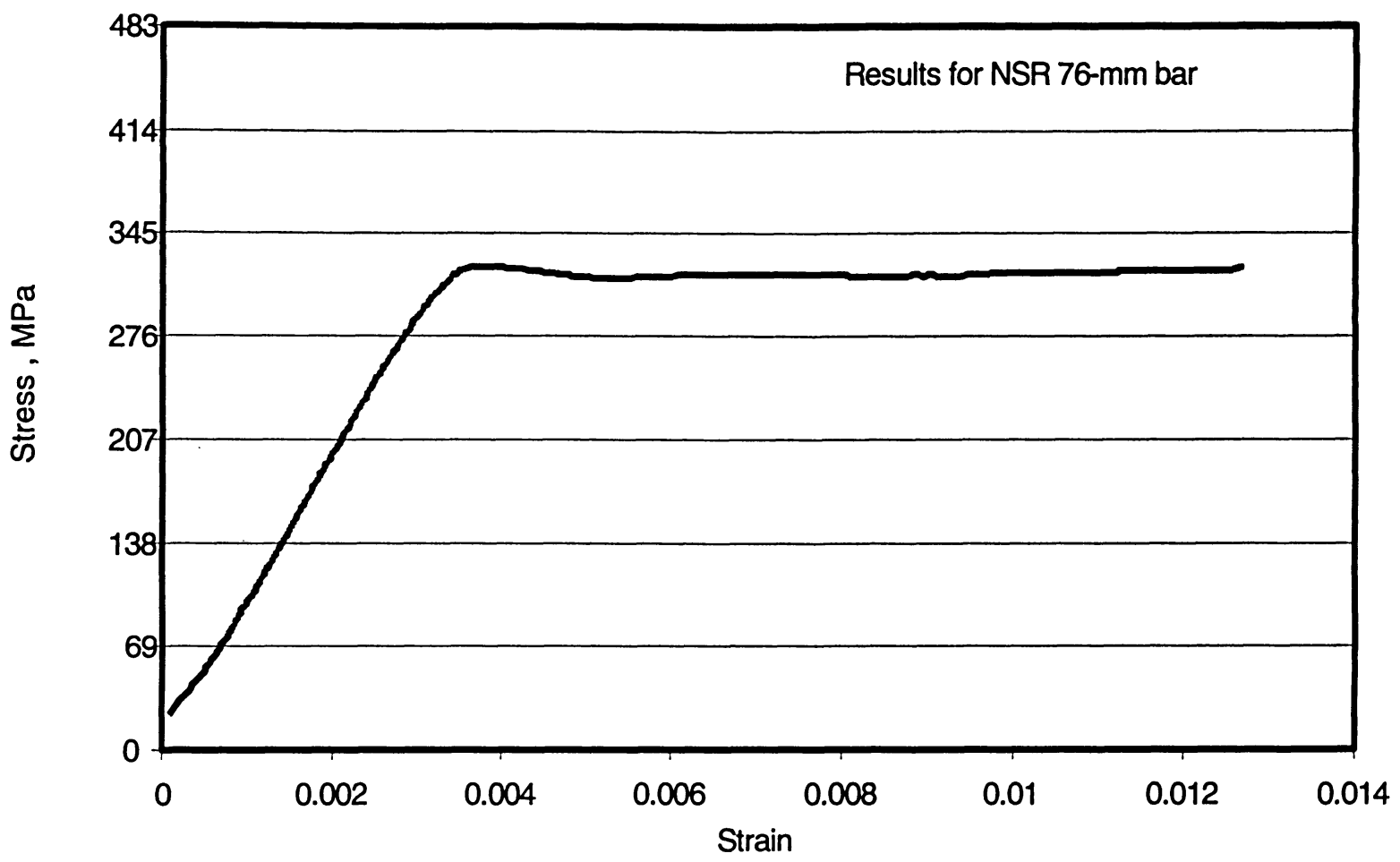

Figure 4.16 Initial portion of the stress-strain curve for the coupon sample of NSR 76-mm bar
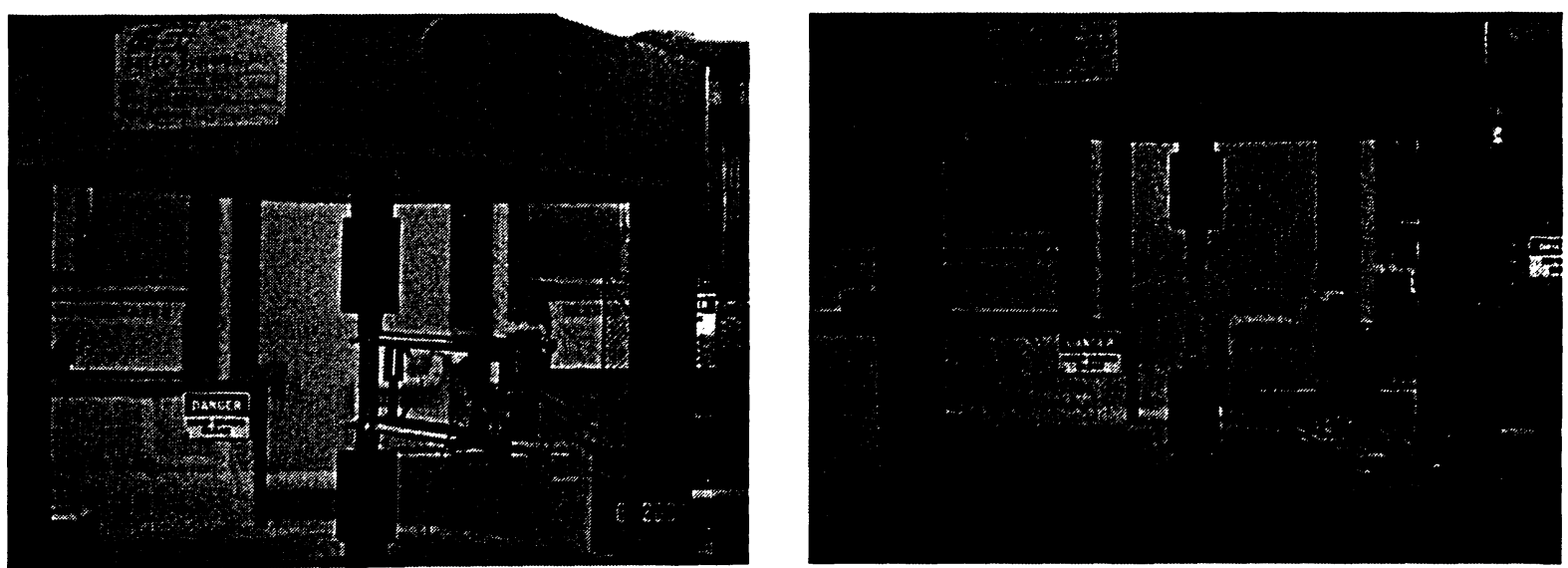

Figure 4.17 Views of the coupon sample for $89-\mathrm{mm}$ bar before and after testing 


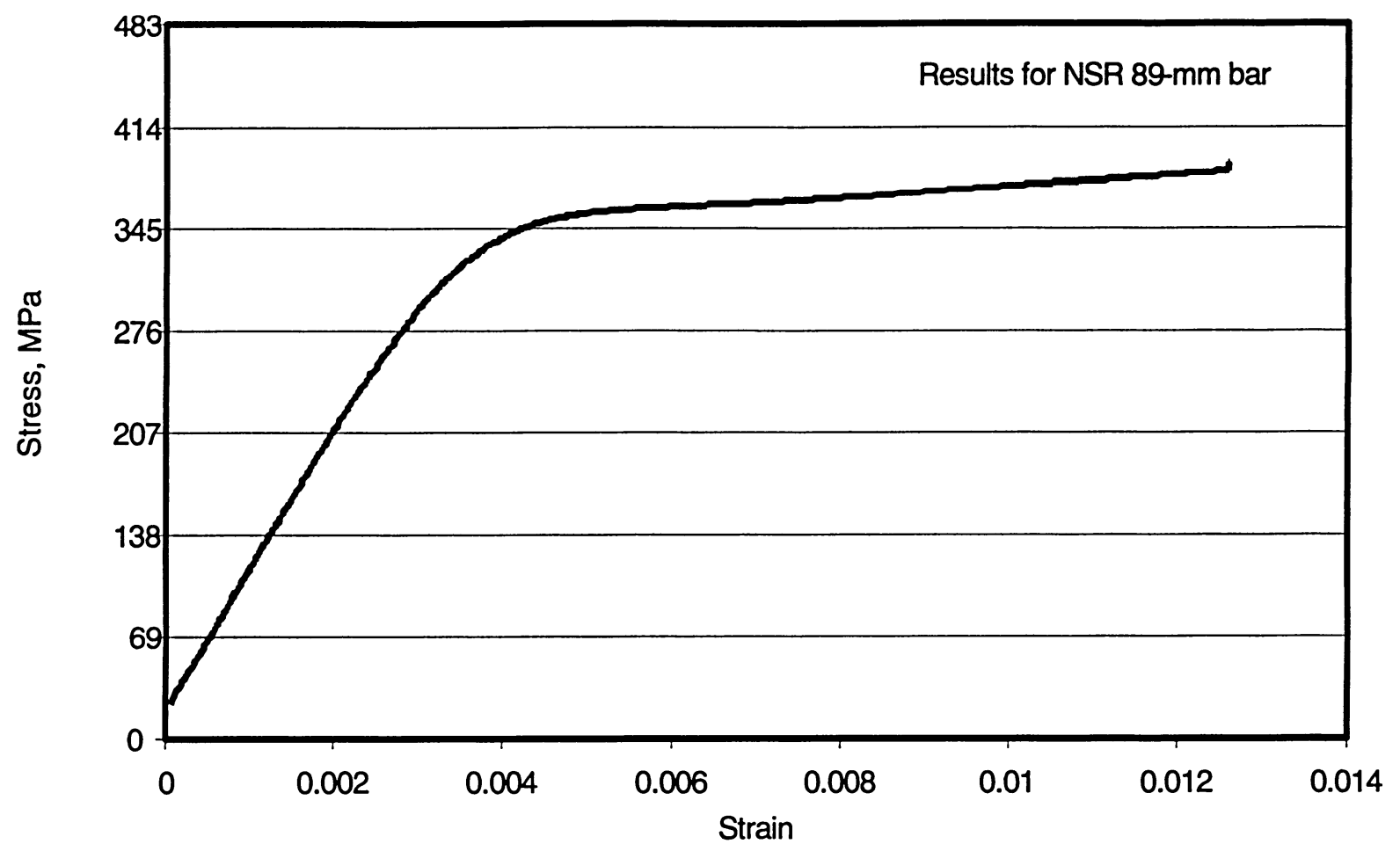

Figure 4.18 Initial part of the stress-strain curve for the coupon sample of NSR 89-mm bar
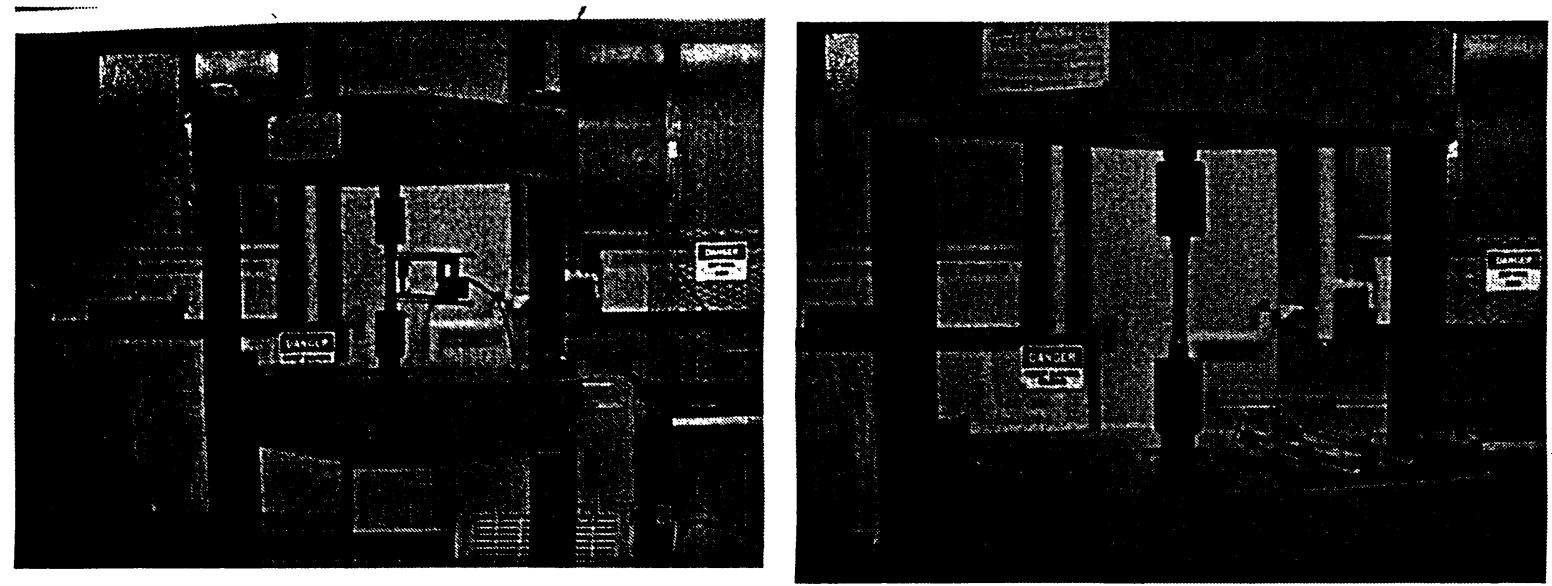

Figure 4.19 Views of the coupon sample for $102-\mathrm{mm}$ bar before and after testing 


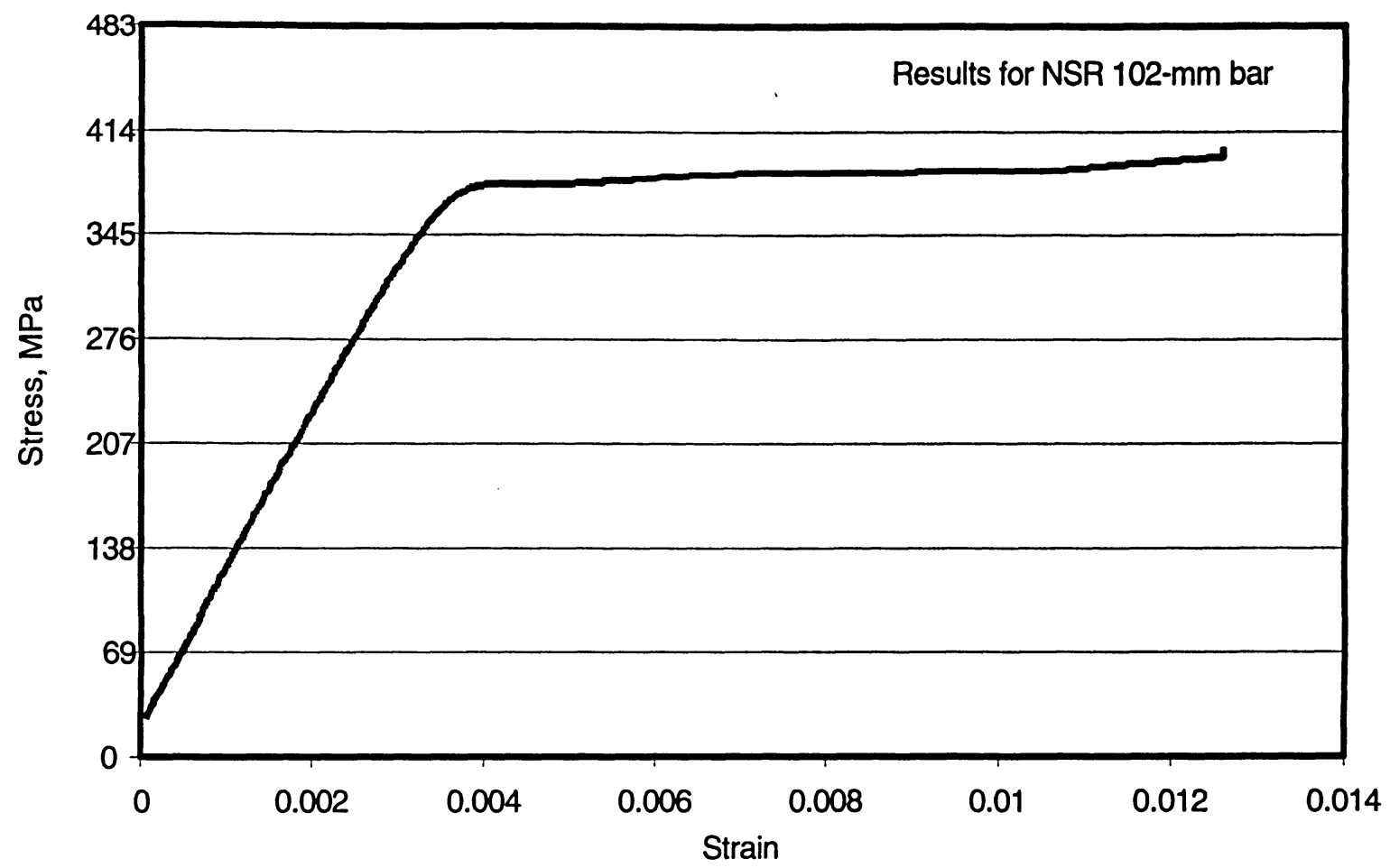

Figure 4.20 Initial portion of the stress-strain curve for the coupon sample of NSR 102-mm bar

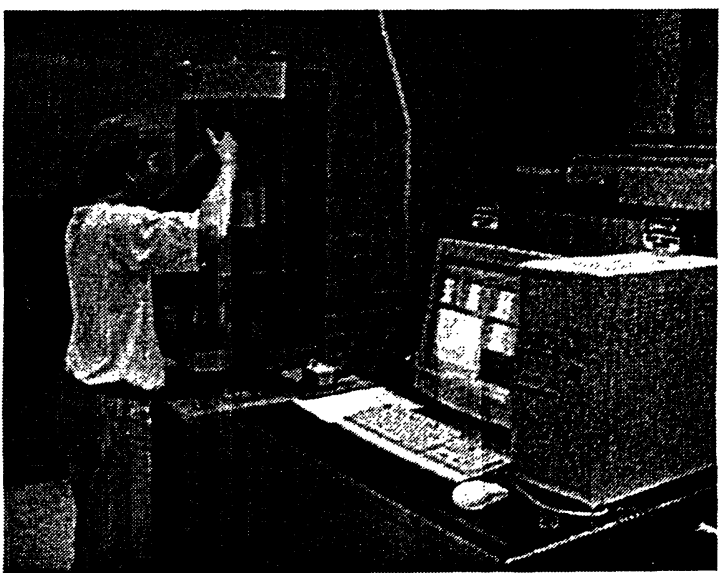

114-mm bar before and after testing

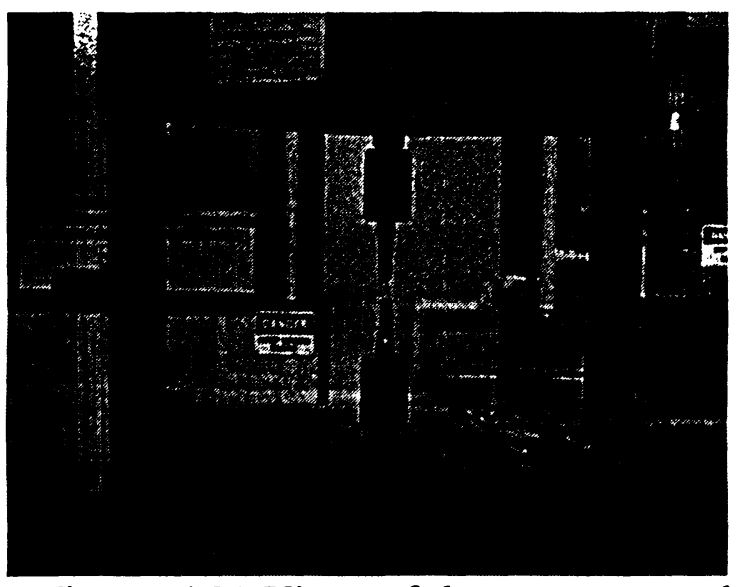

Figure 4.21 Views of the coupon sample for 


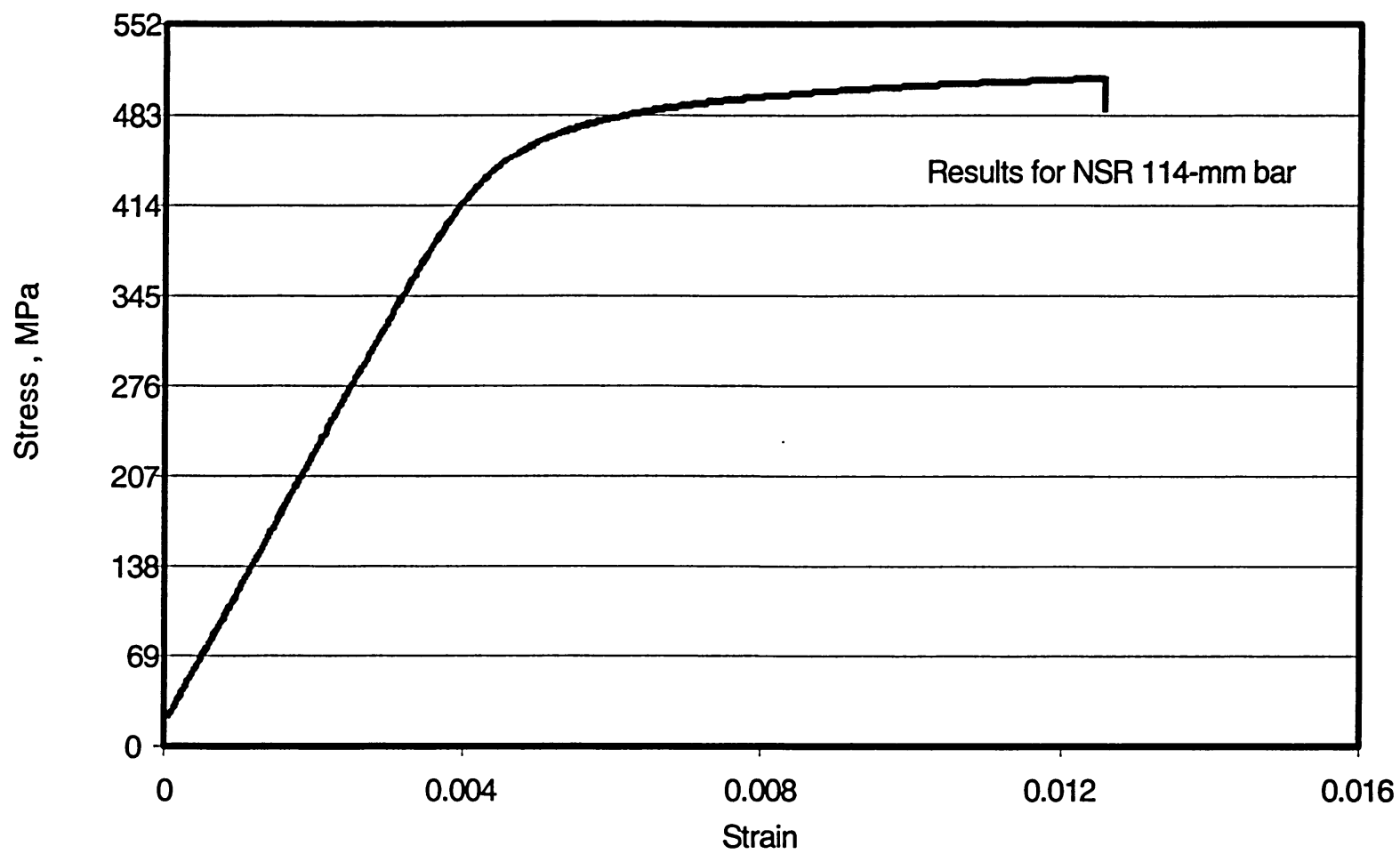

Figure 4.22 Initial part of the stress-strain curve for the coupon sample of NSR 114-mm bar 

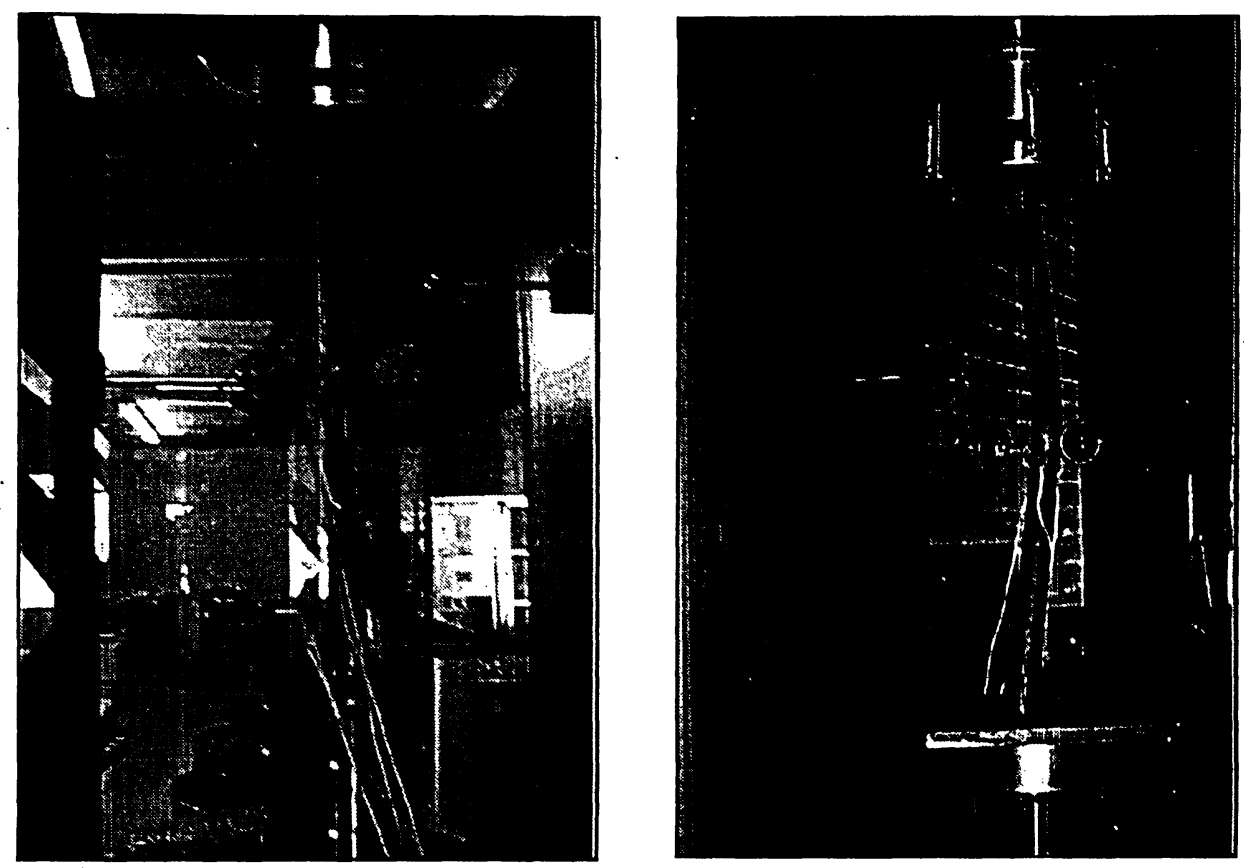

Figure 4.23 Views of specimen SR-1 before and after testing

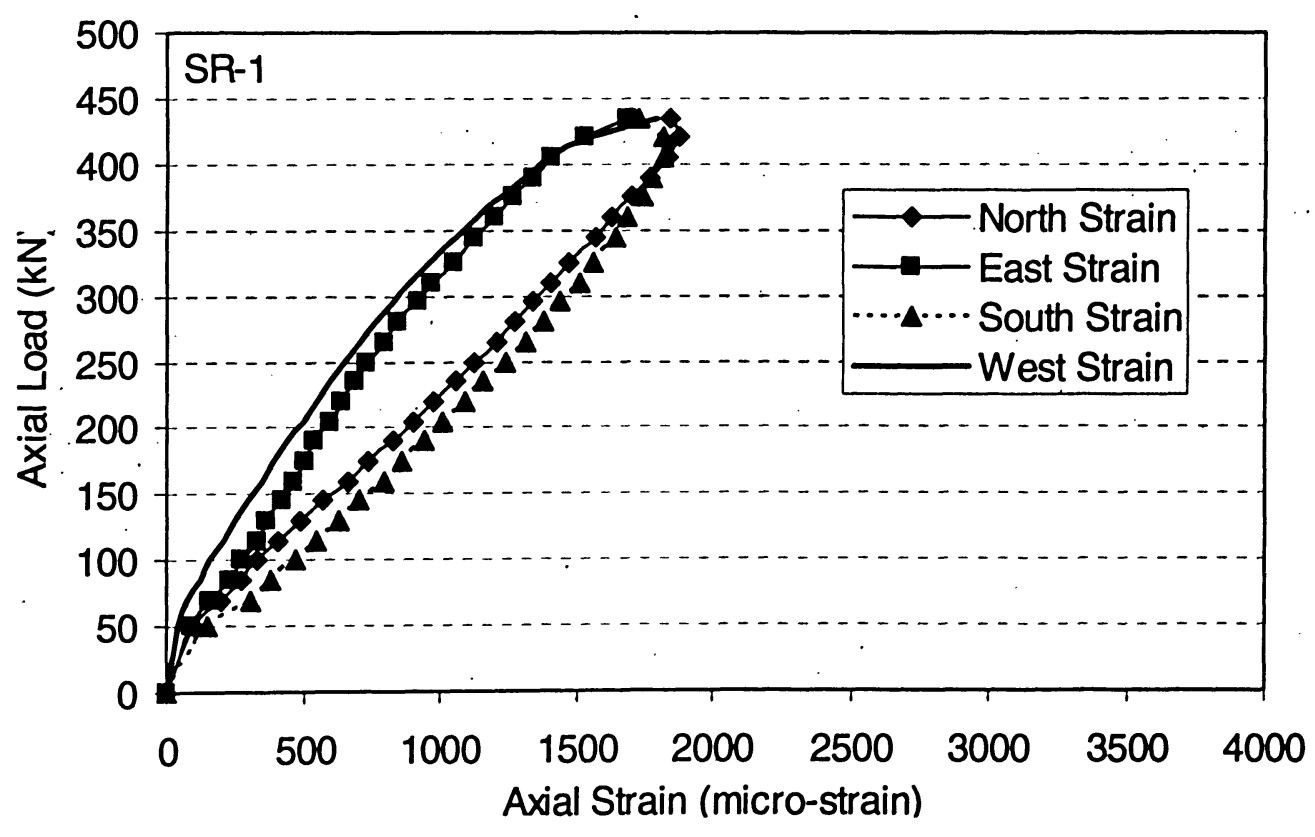

Figure 4.24 Axial load-strain relationships for specimen SR-1 


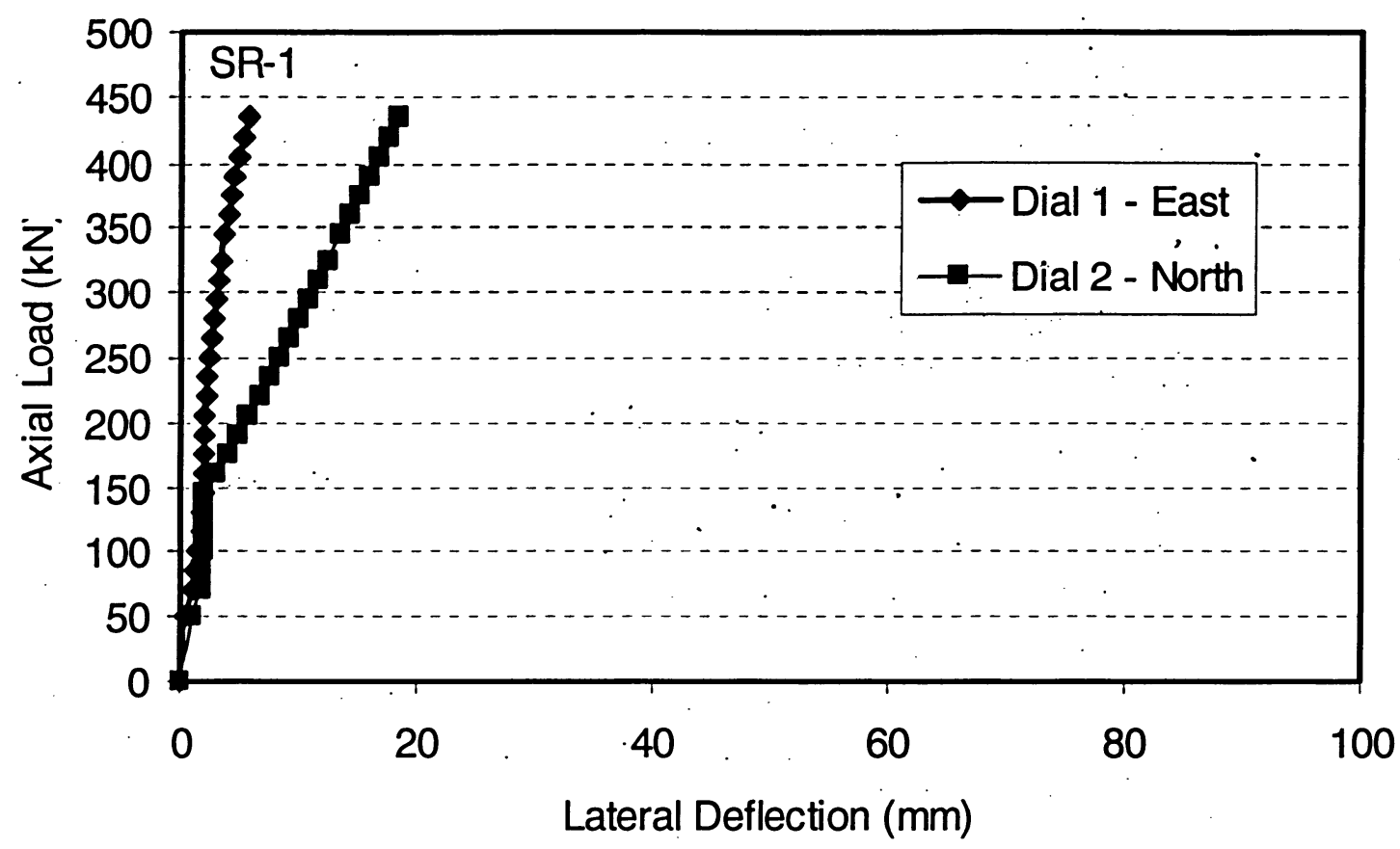

Figure 4.25 Load-lateral deflection curves for specimen SR-1
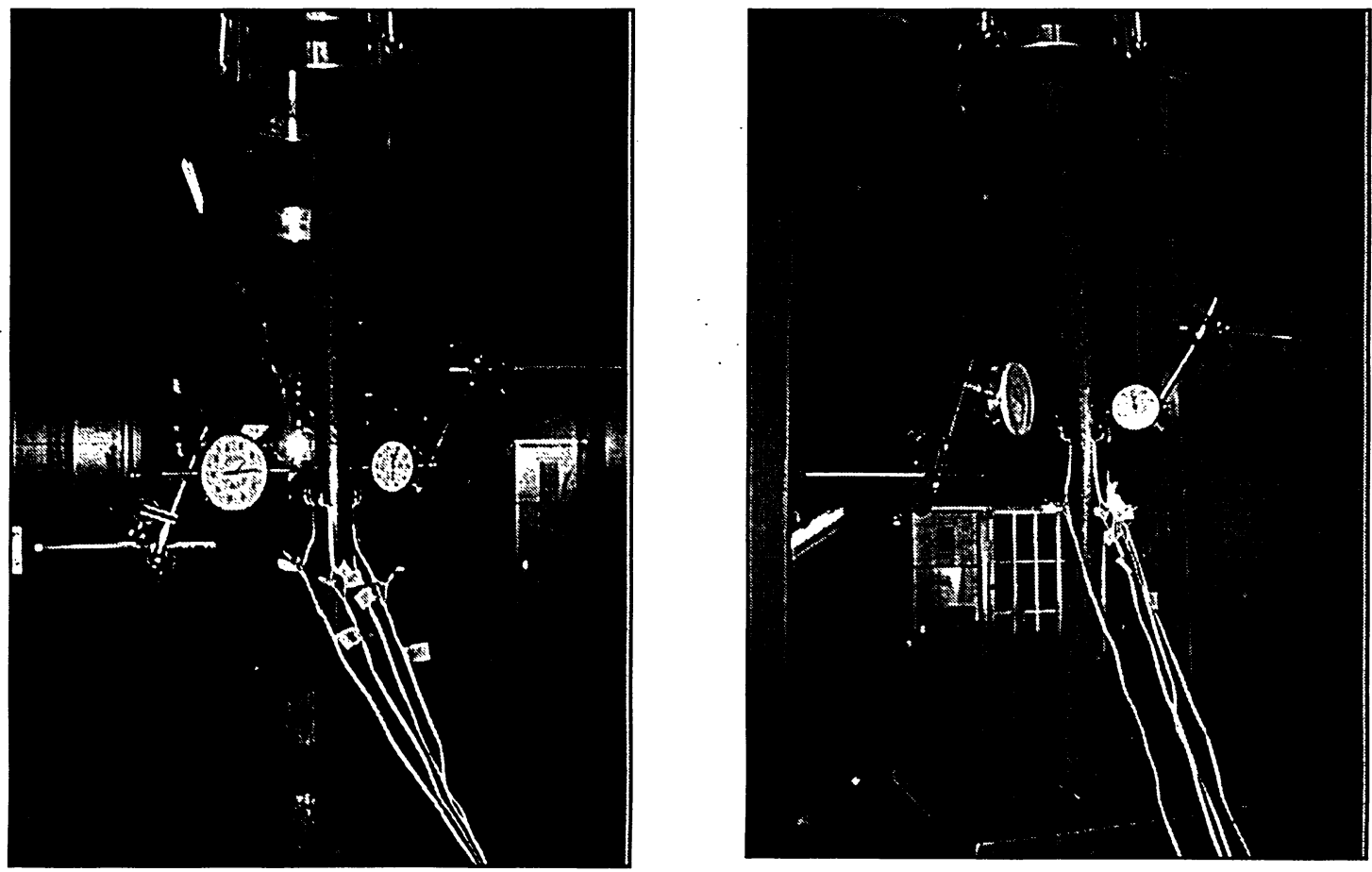

Figure 4.26 Views of specimen SR-2 before and after testing 


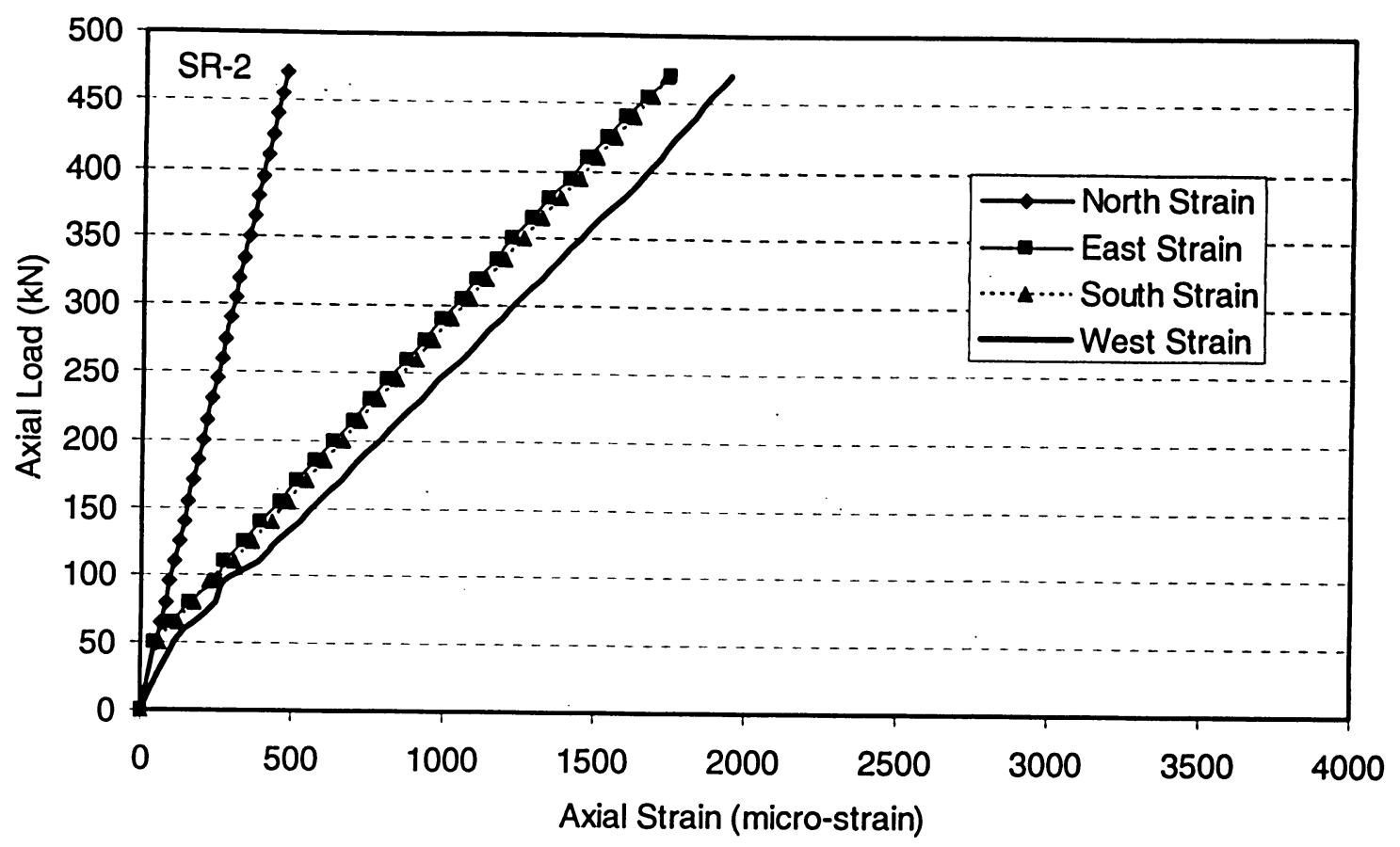

Figure 4.27 Axial load-strain relationships for specimen SR-2

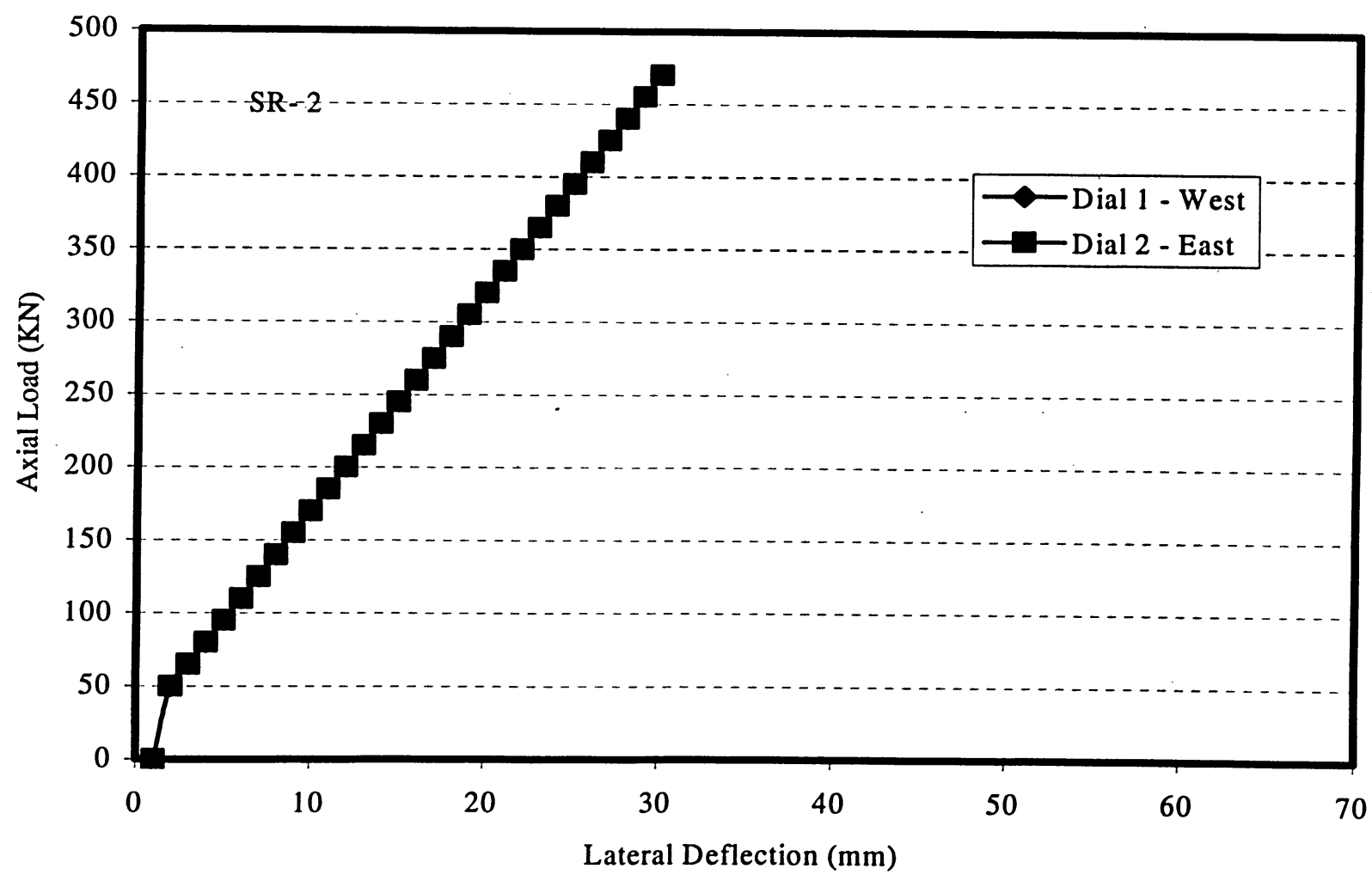

Figure 4.28 Load-lateral deflection curves for specimen SR-2 


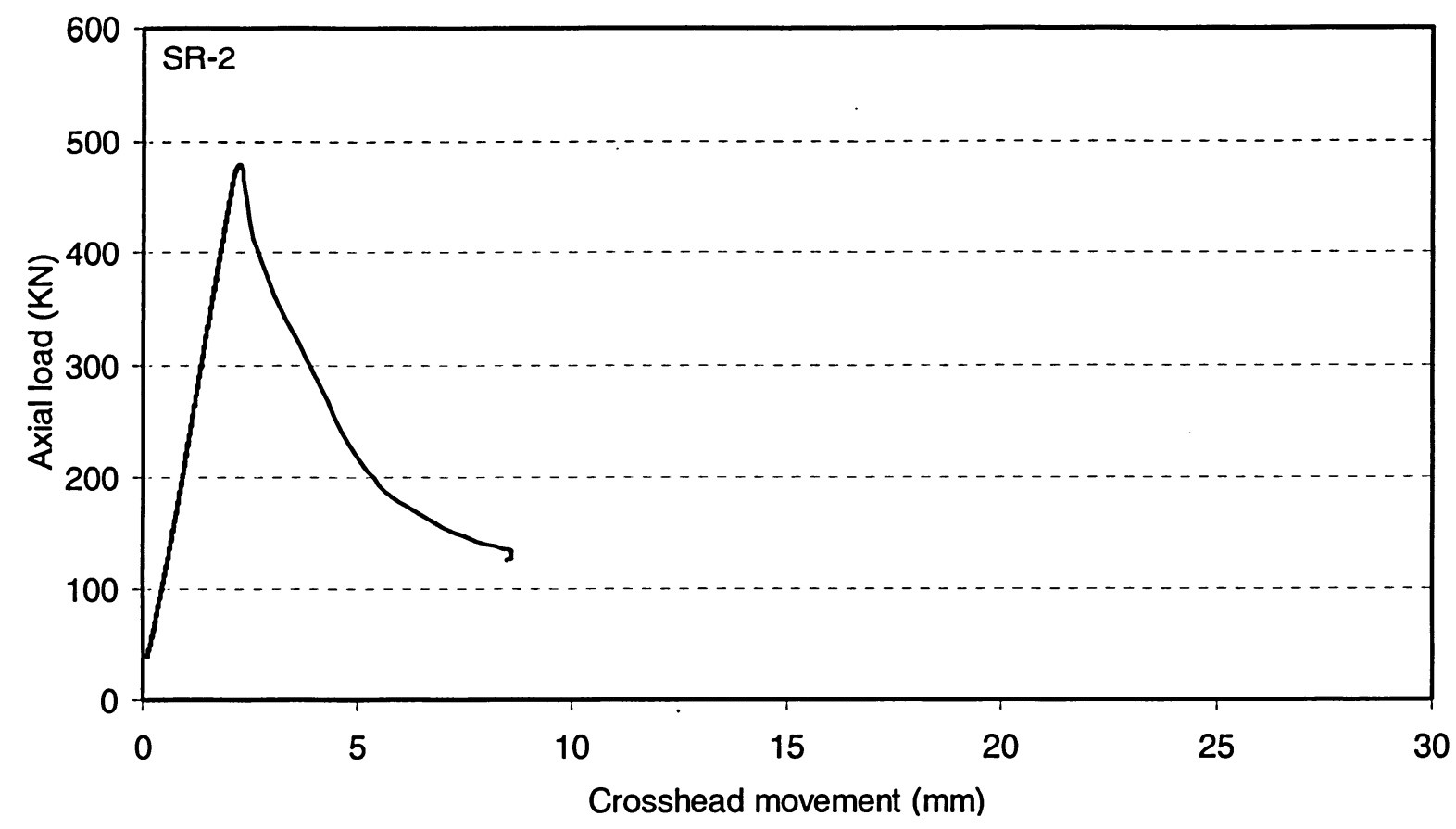

Figure 4.29 Load versus overall shortening curve for specimen SR-2
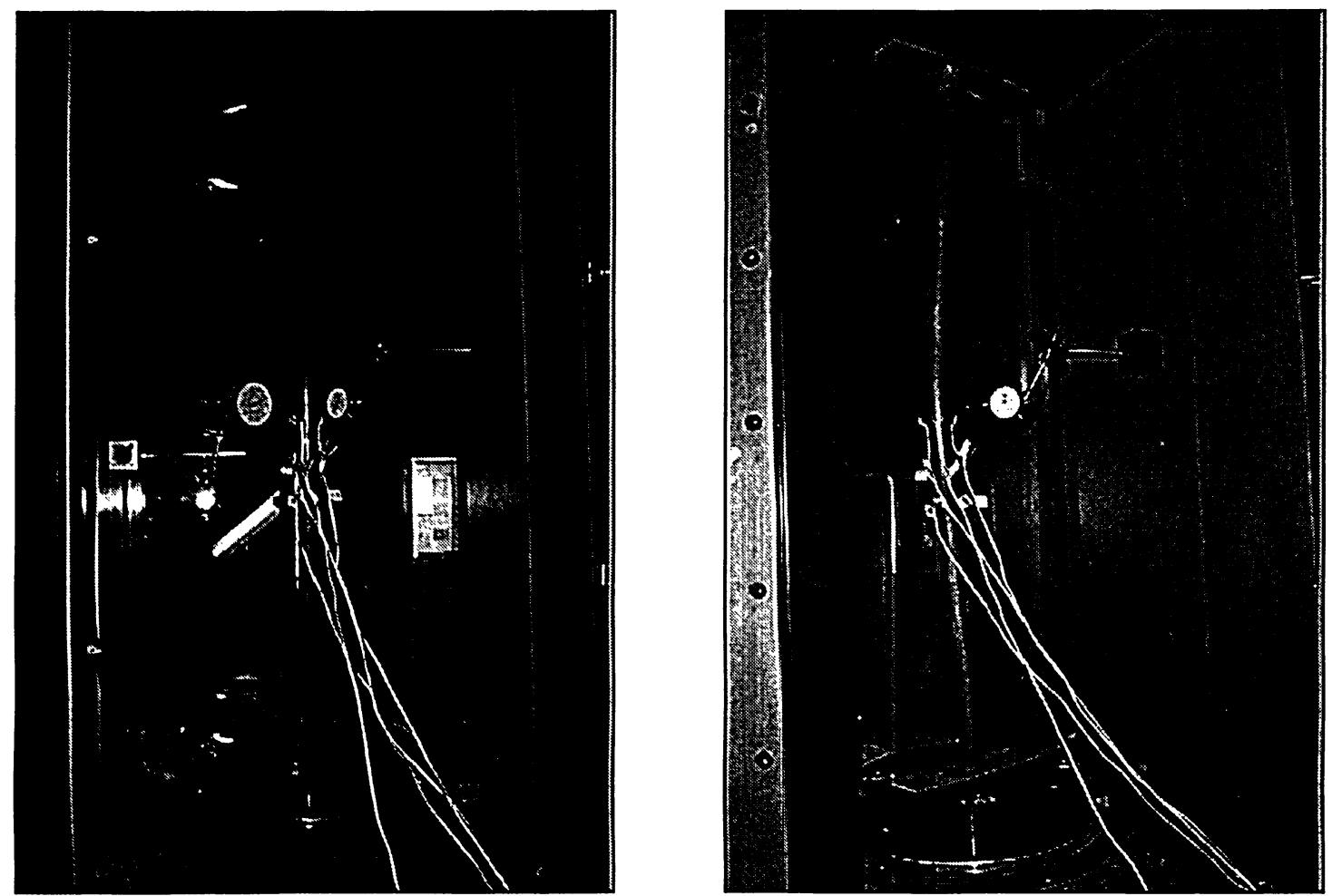

Figure 4.30 Views of specimen SR-3 before and after testing 


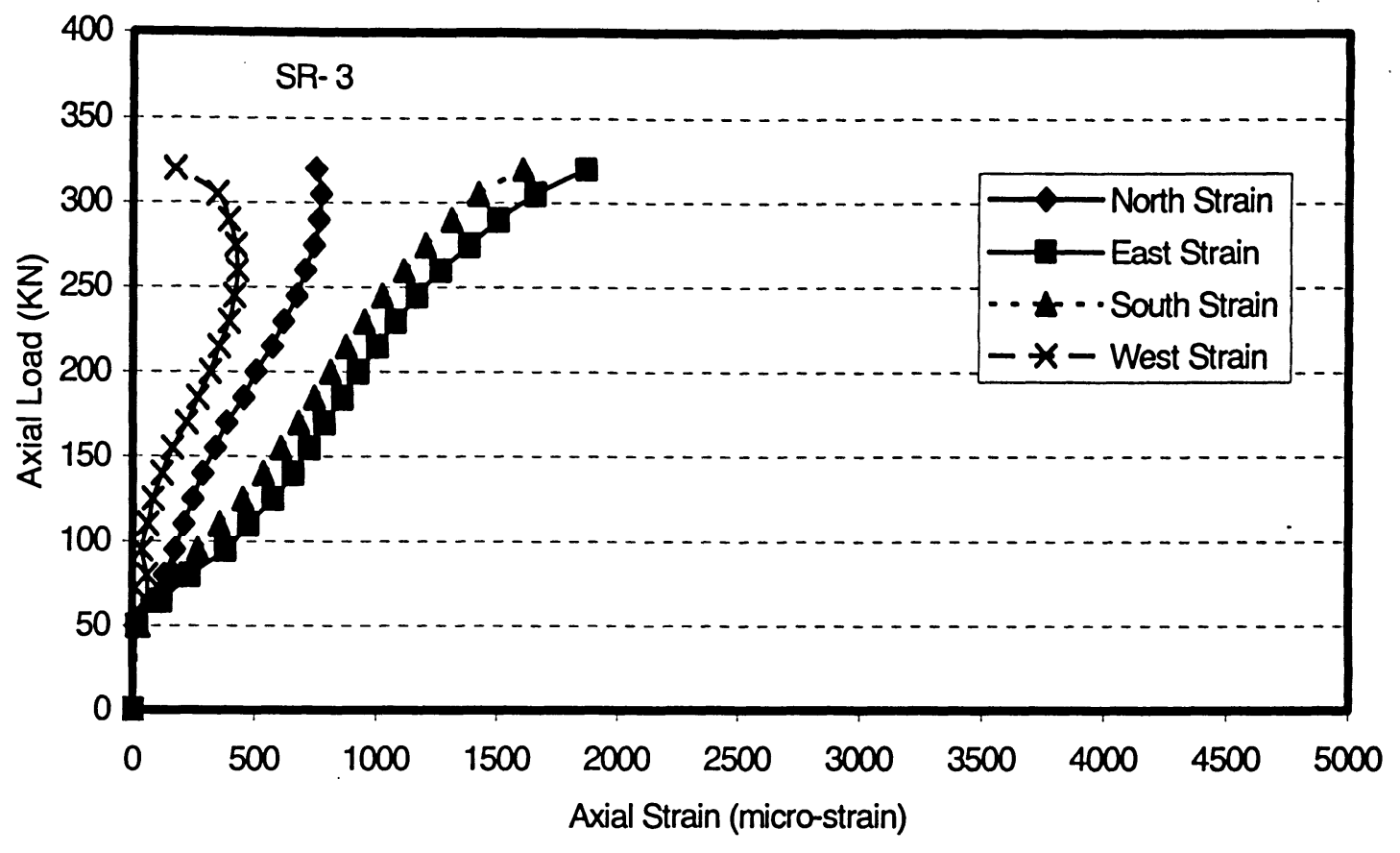

Figure 4.31 Axial load-strain relationships for specimen SR-3

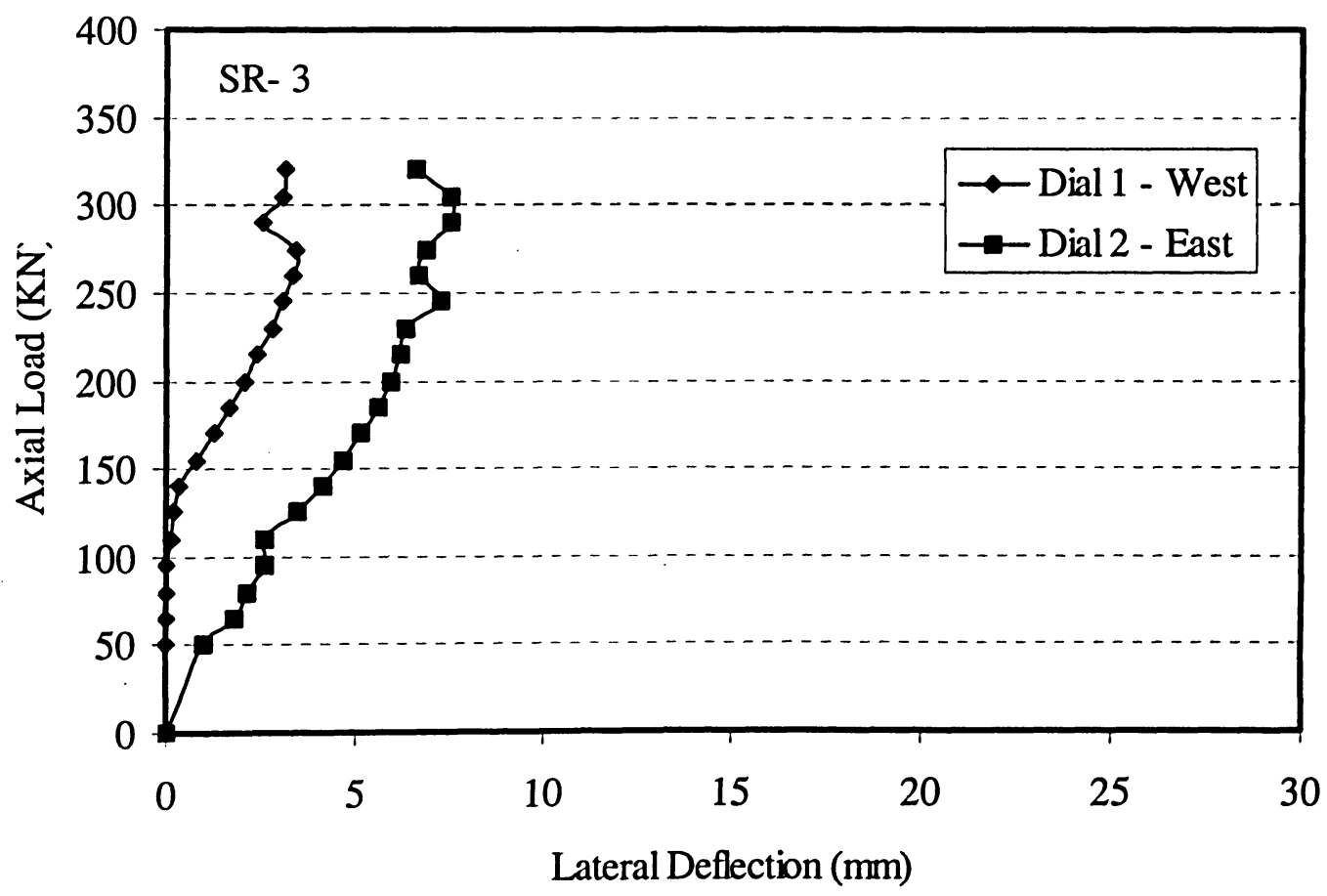

Figure 4.32 Load-lateral deflection curves for specimen SR-3 


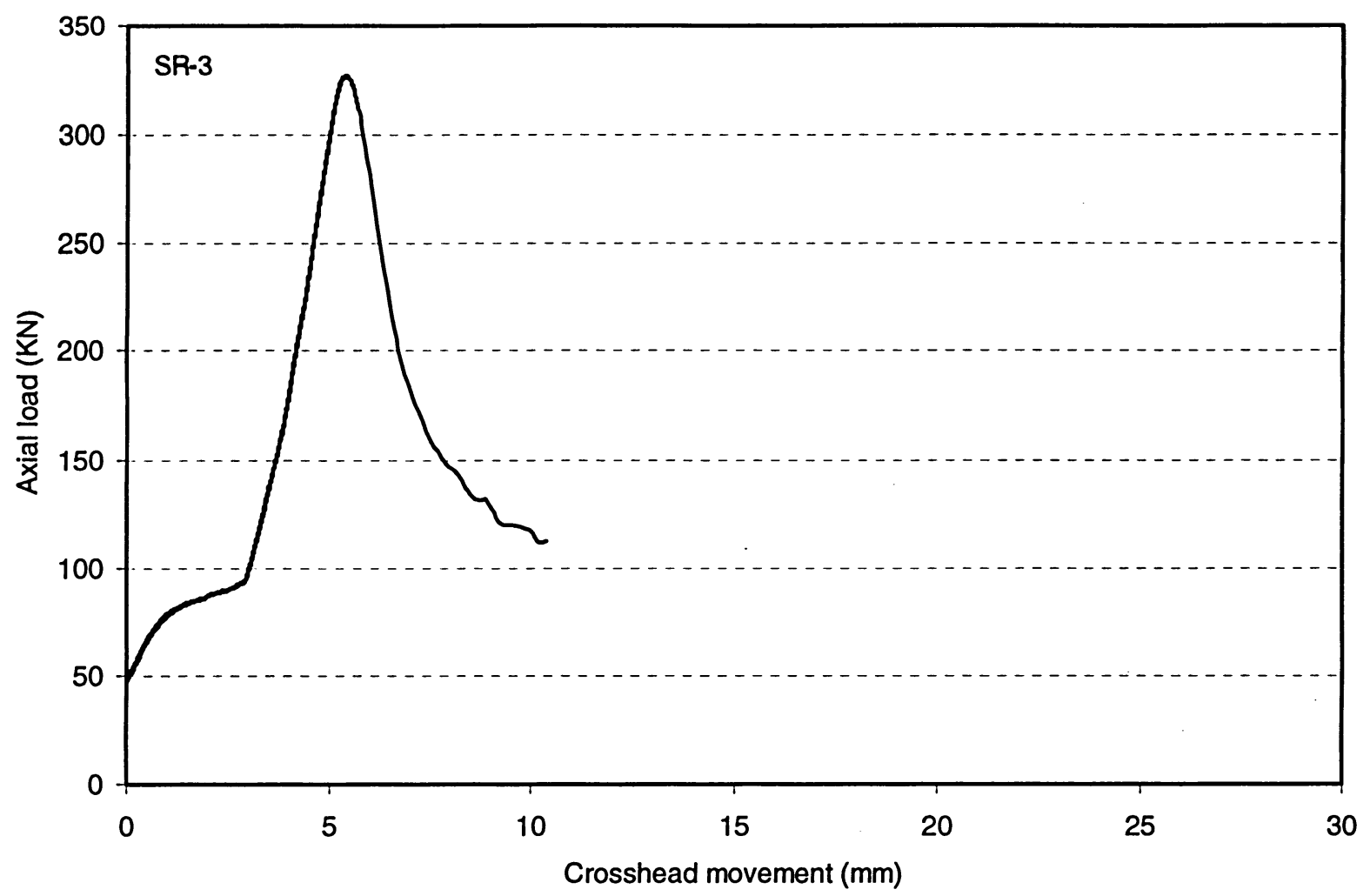

Figure 4.33 Load versus overall shortening curve for specimen SR-3
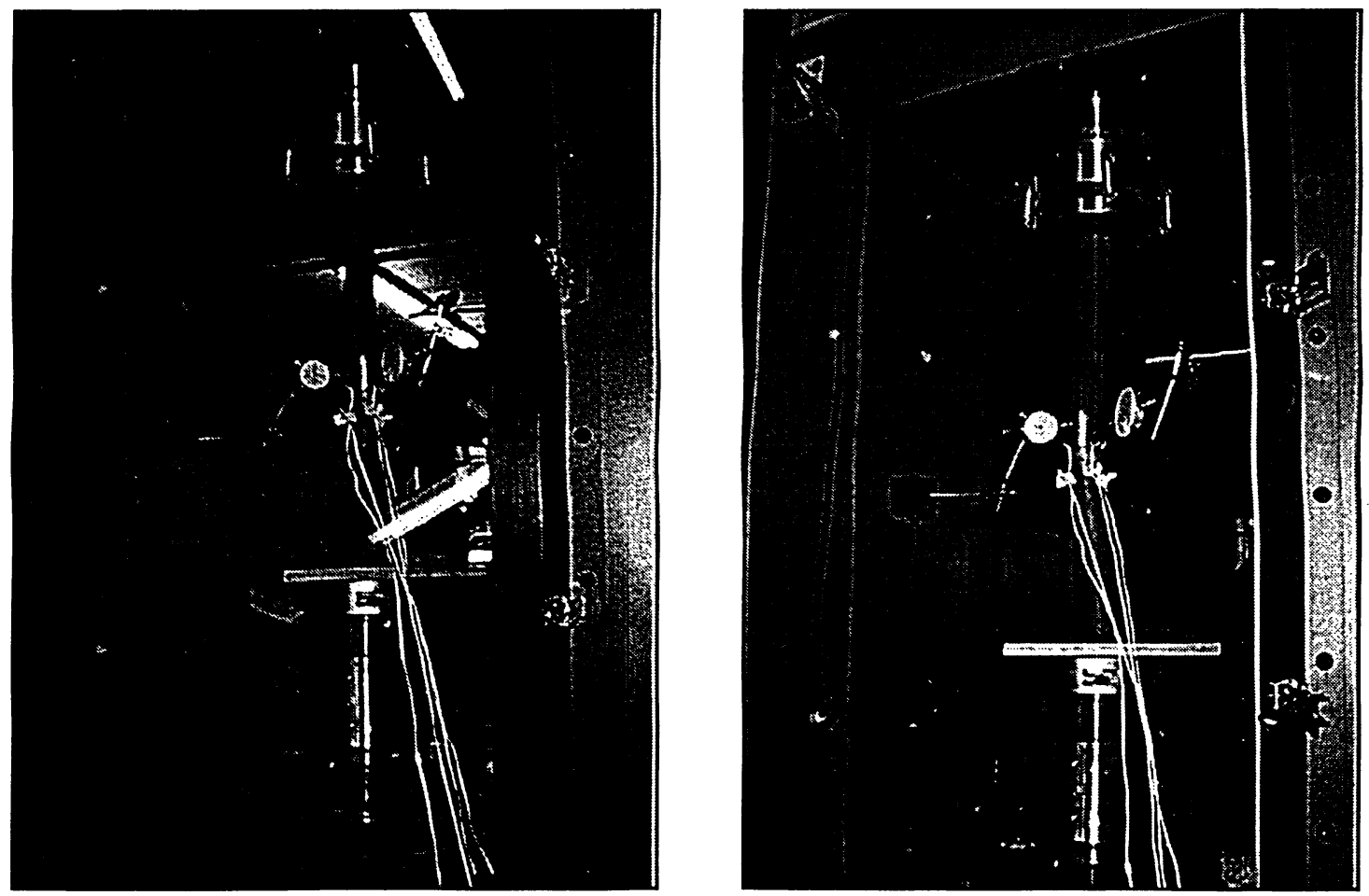

Figure 4.34 Views of specimen SR-4 before and after testing 


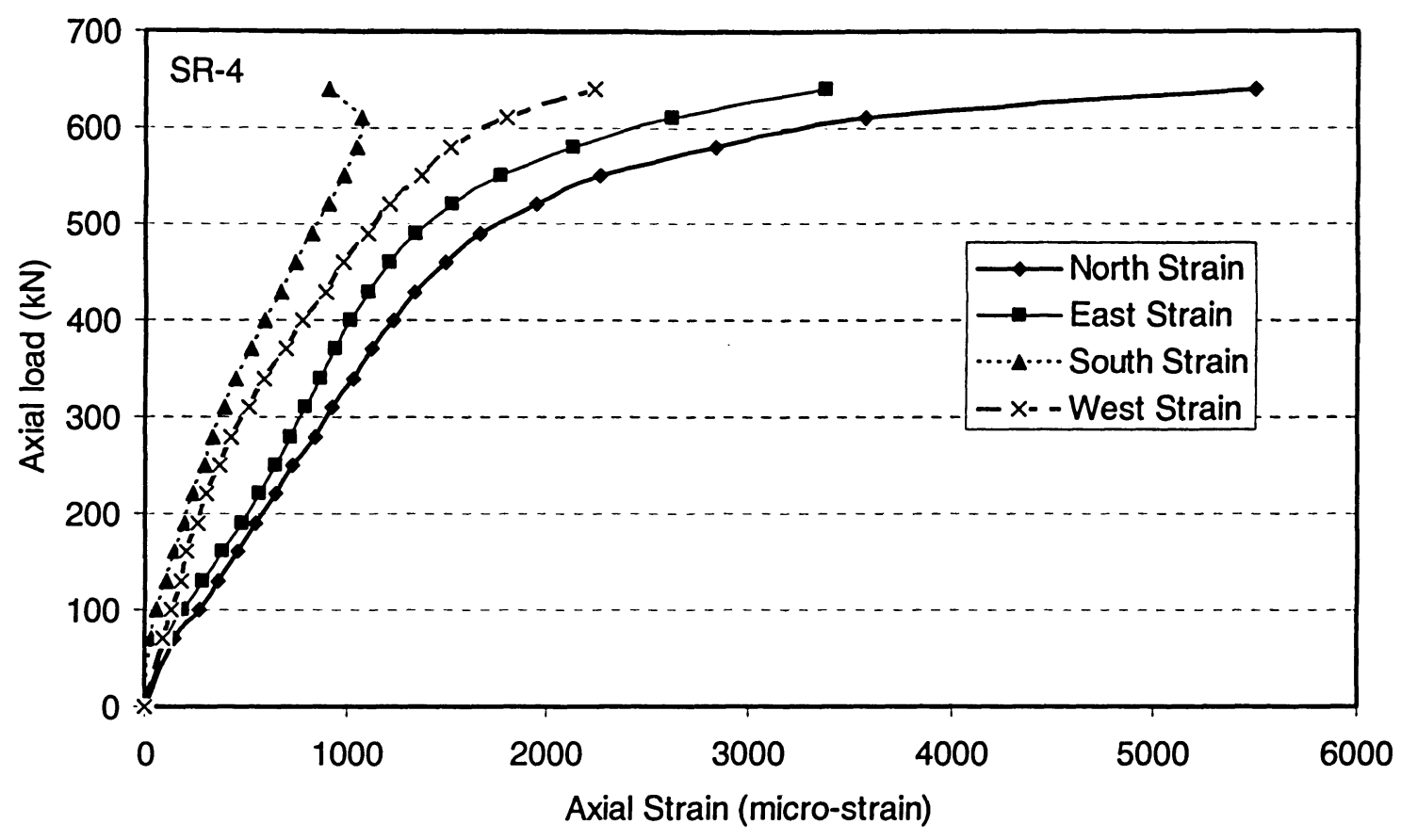

Figure 4.35 Axial load-strain relationships for specimen SR-4

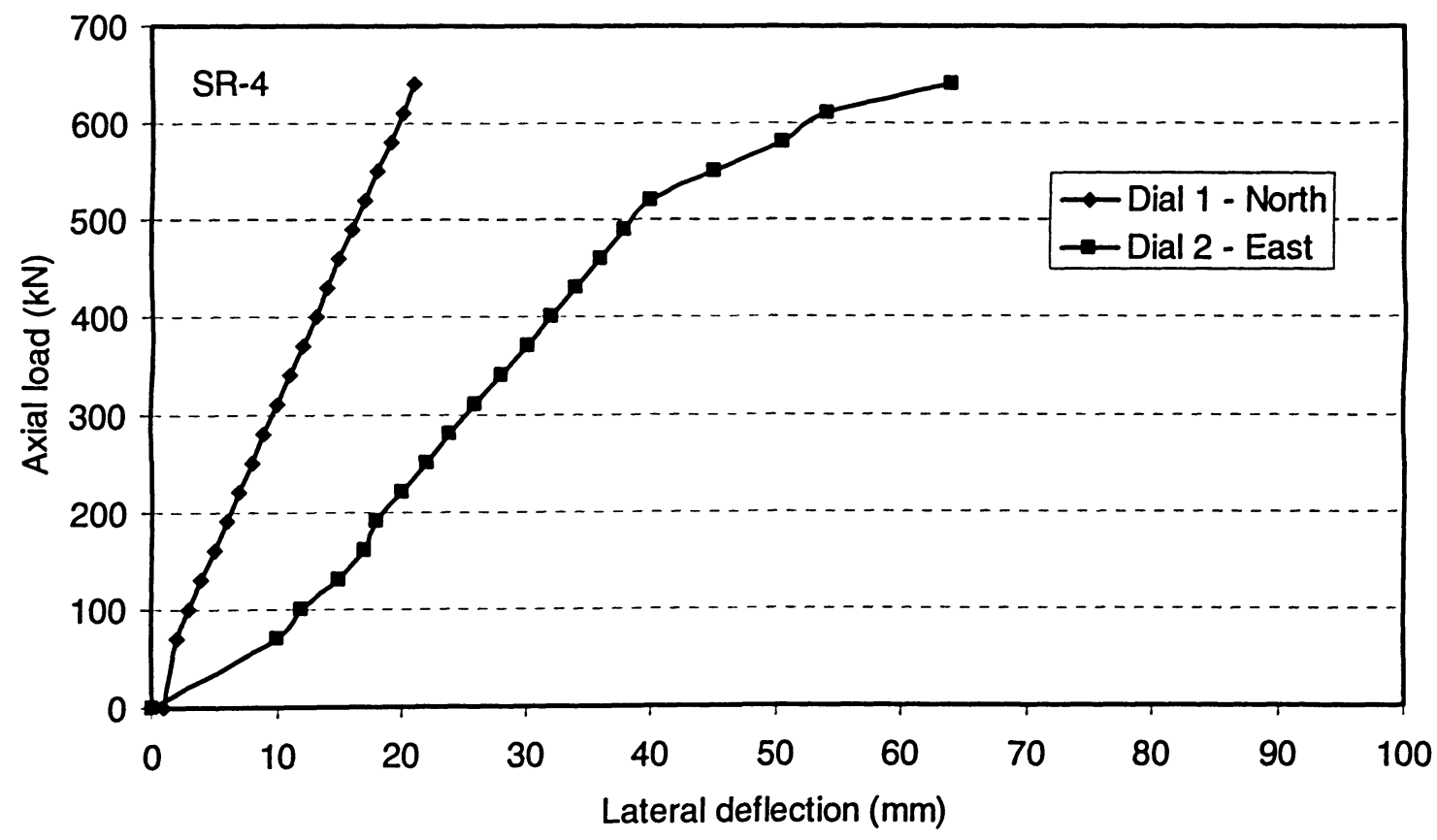

Figure 4.36 Load-lateral deflection curves for specimen SR-4 


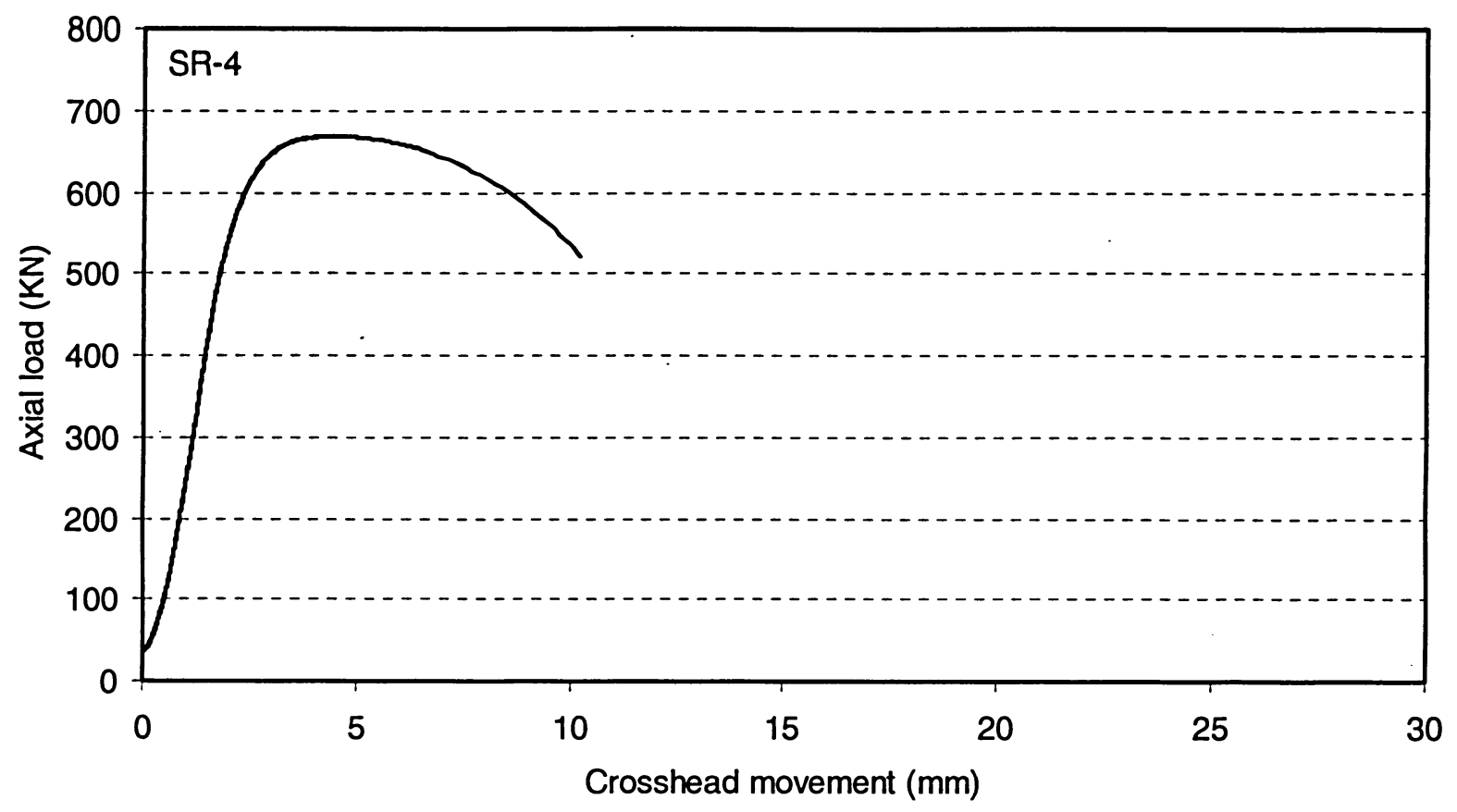

Figure 4.37 Load versus overall shortening curve for specimen SR-4
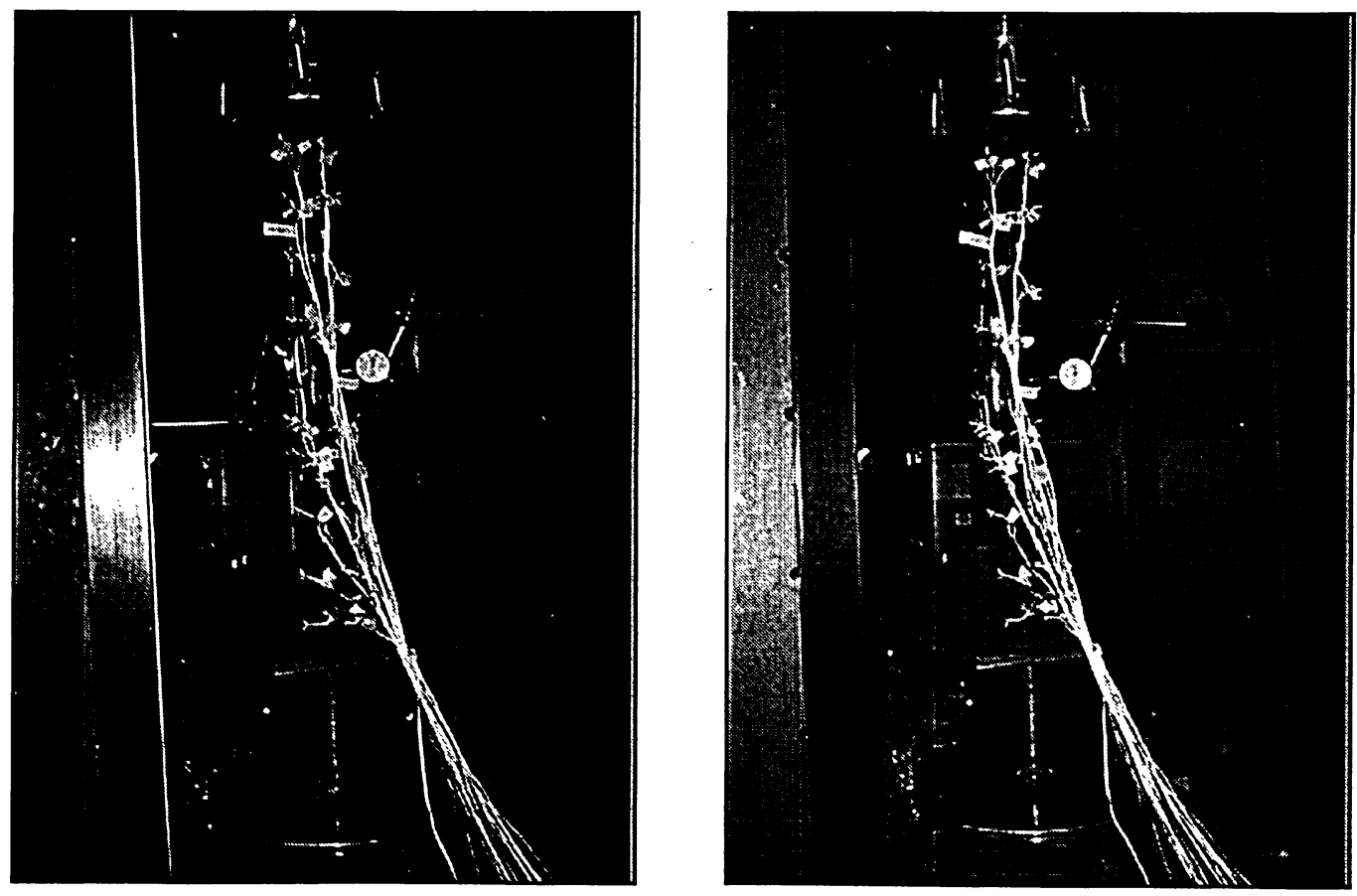

Figure 4.38 Views of specimen SR-5 before and after testing 


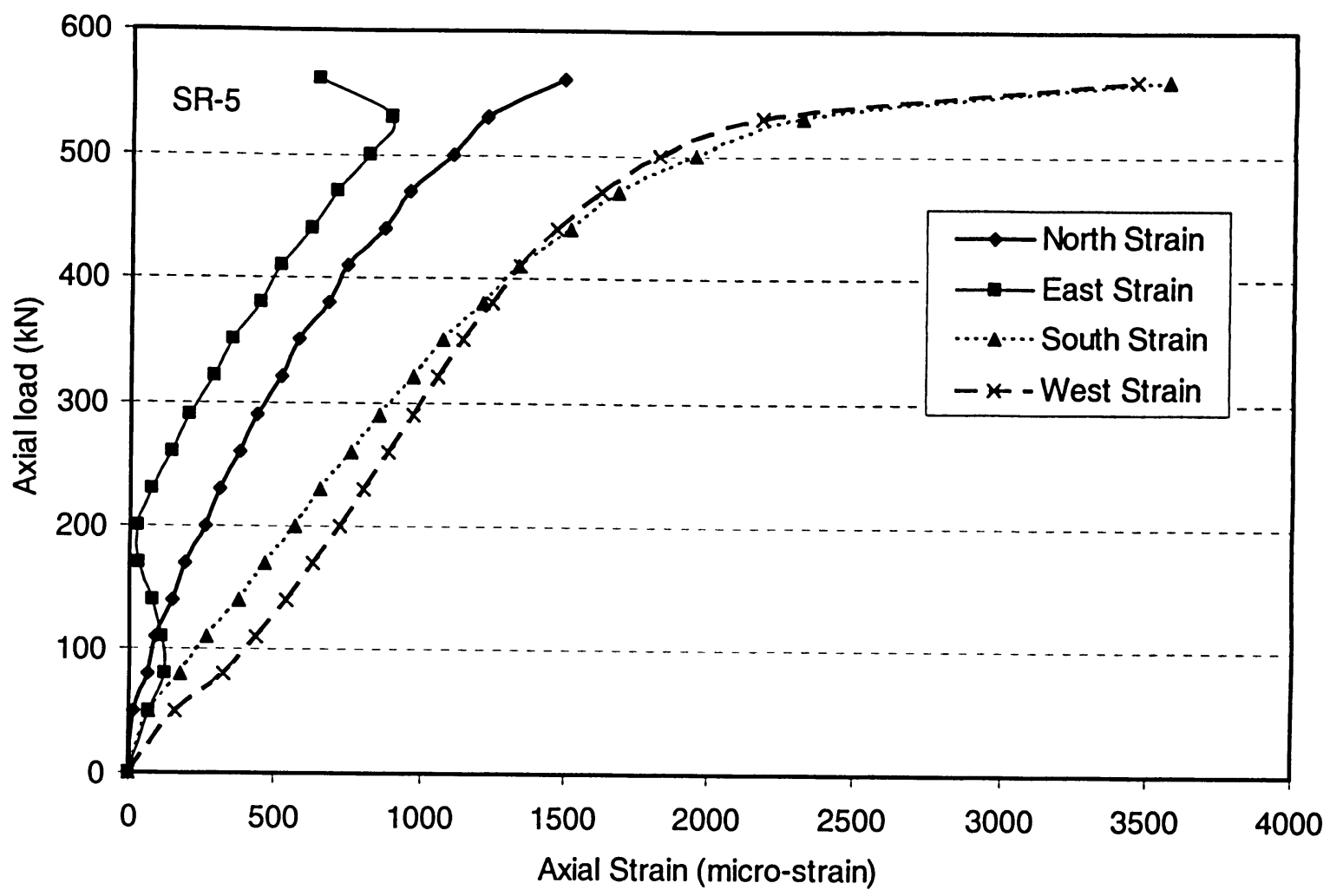

Figure 4.39 Axial load-strain relationships for specimen SR-5

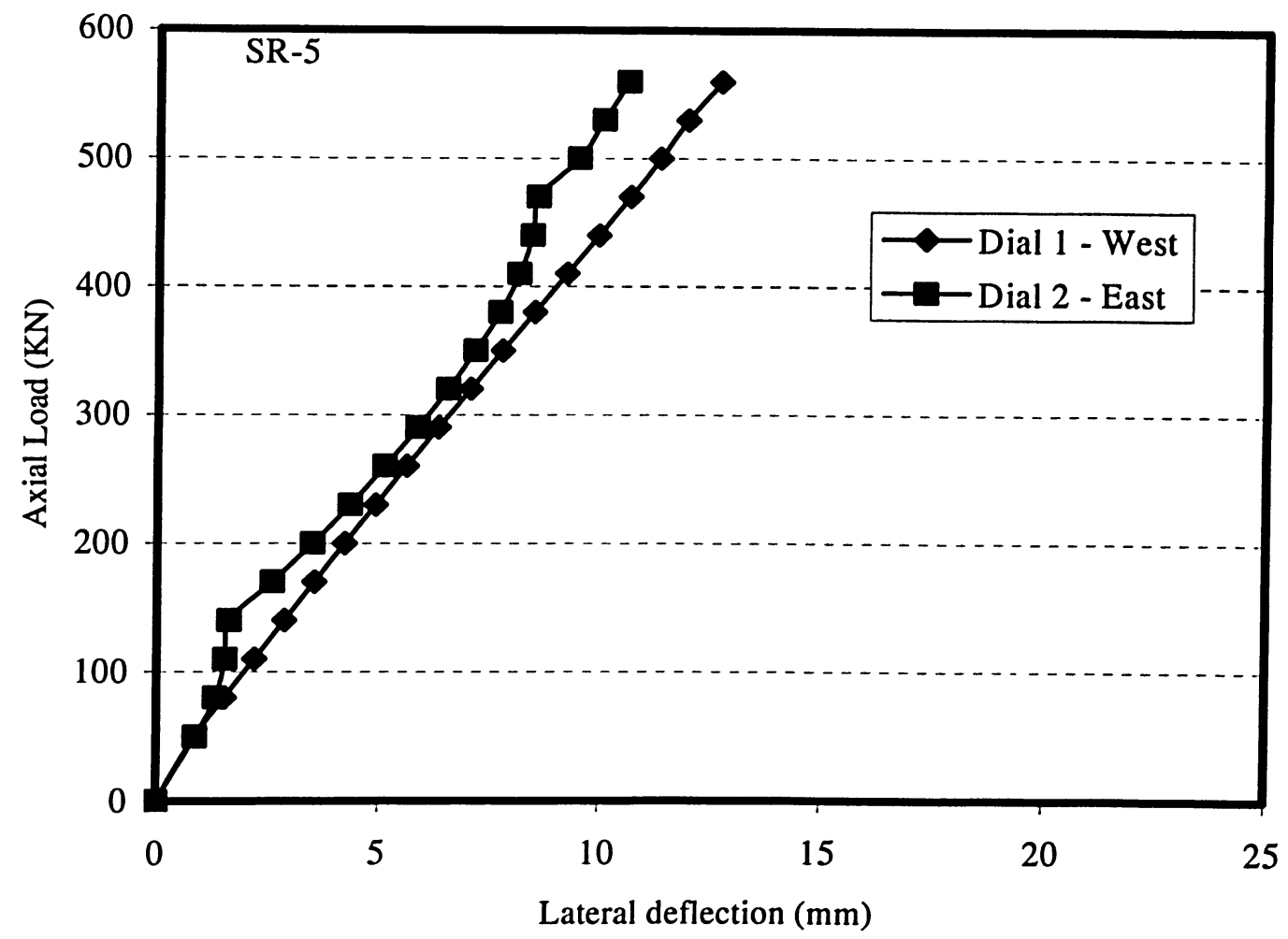

Figure 4.40 Load-lateral deflection curves for specimen SR-5 


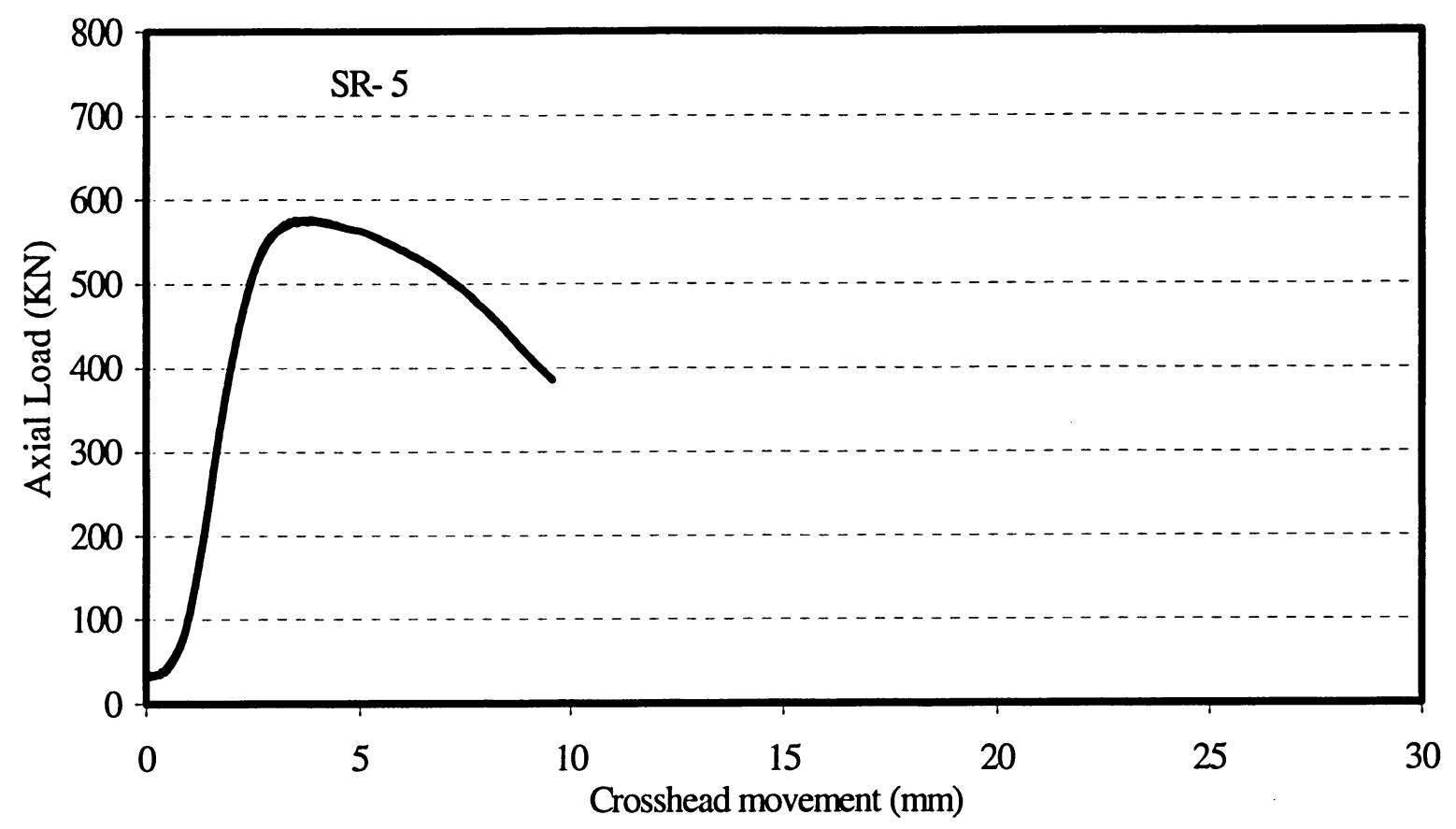

Figure 4.41 Load versus overall shortening curve for specimen SR-5
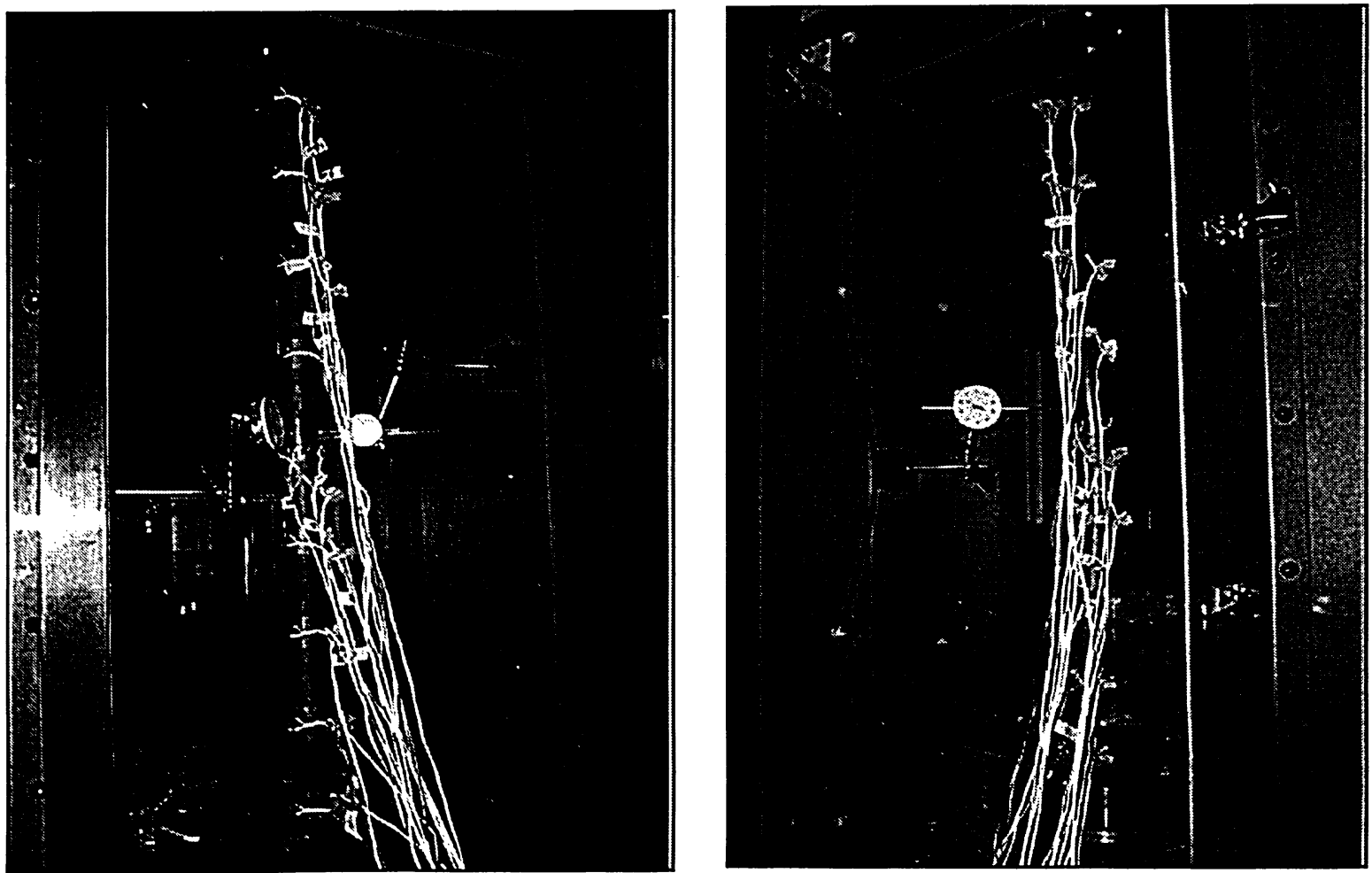

Figure 4.42 Views of specimen SR- 6 before and after testing 


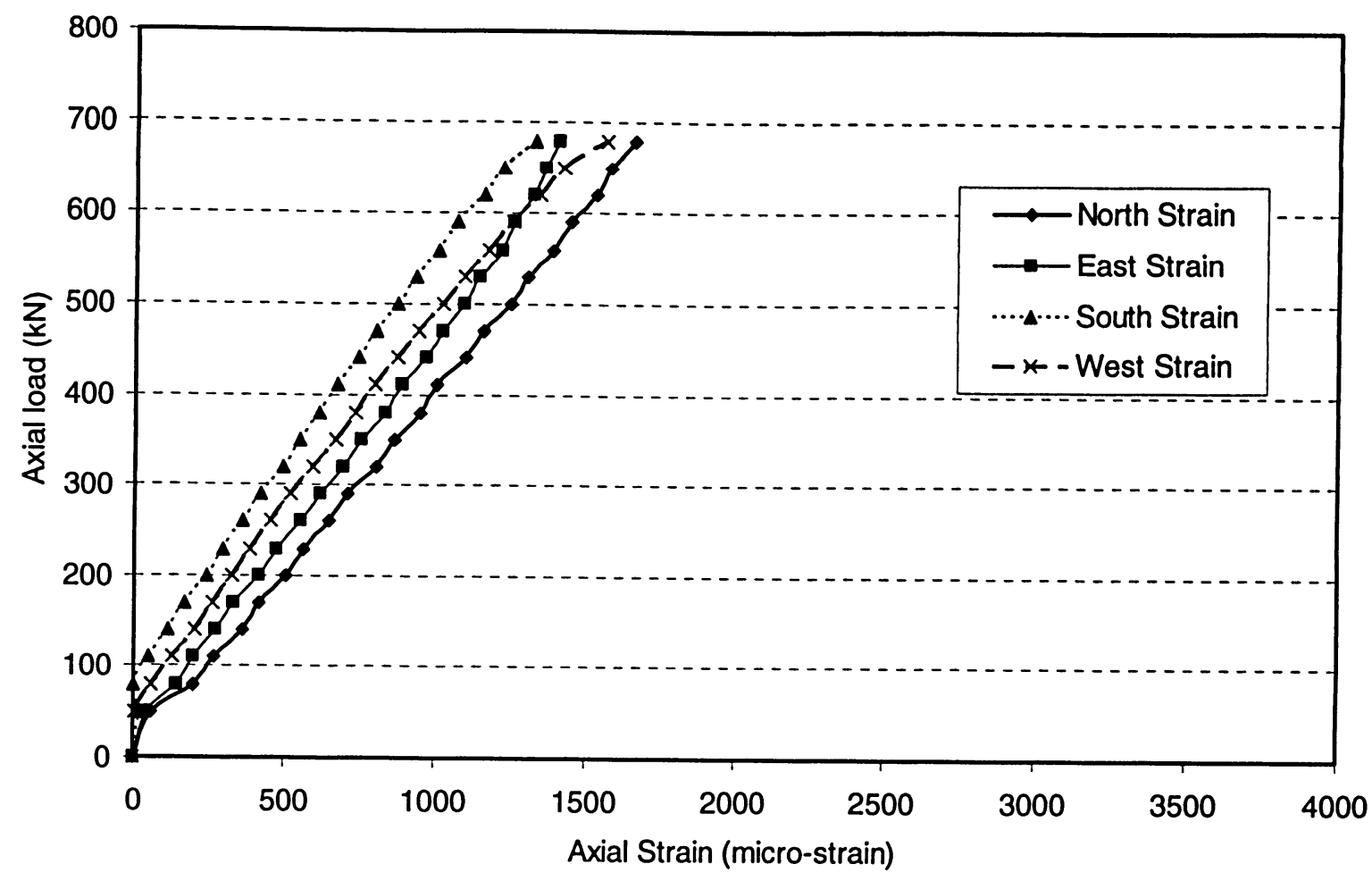

Figure 4.43 Axial load-strain relationships for specimen SR-6

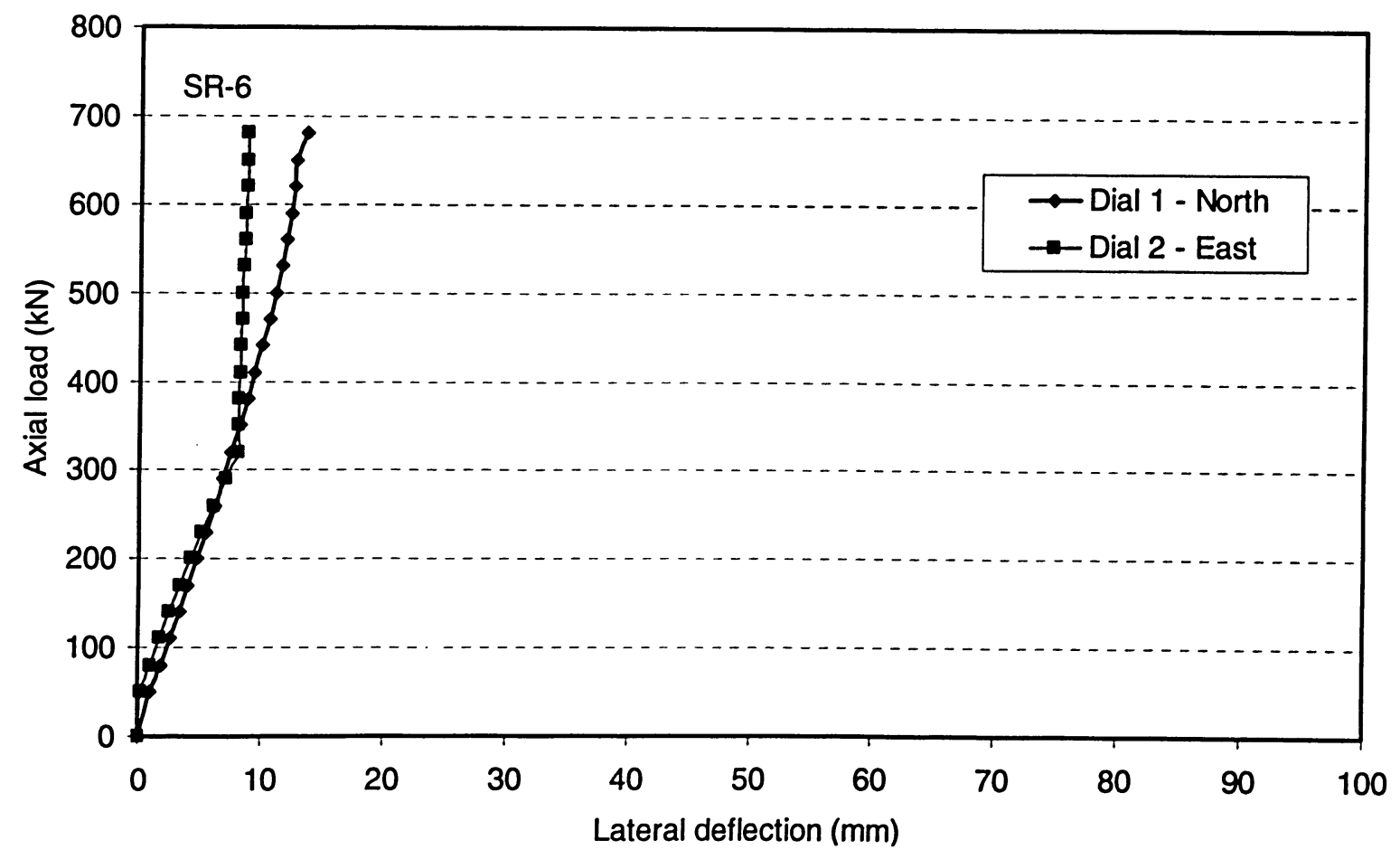

Figure 4.44 Load-lateral deflection curves for specimen SR-6 


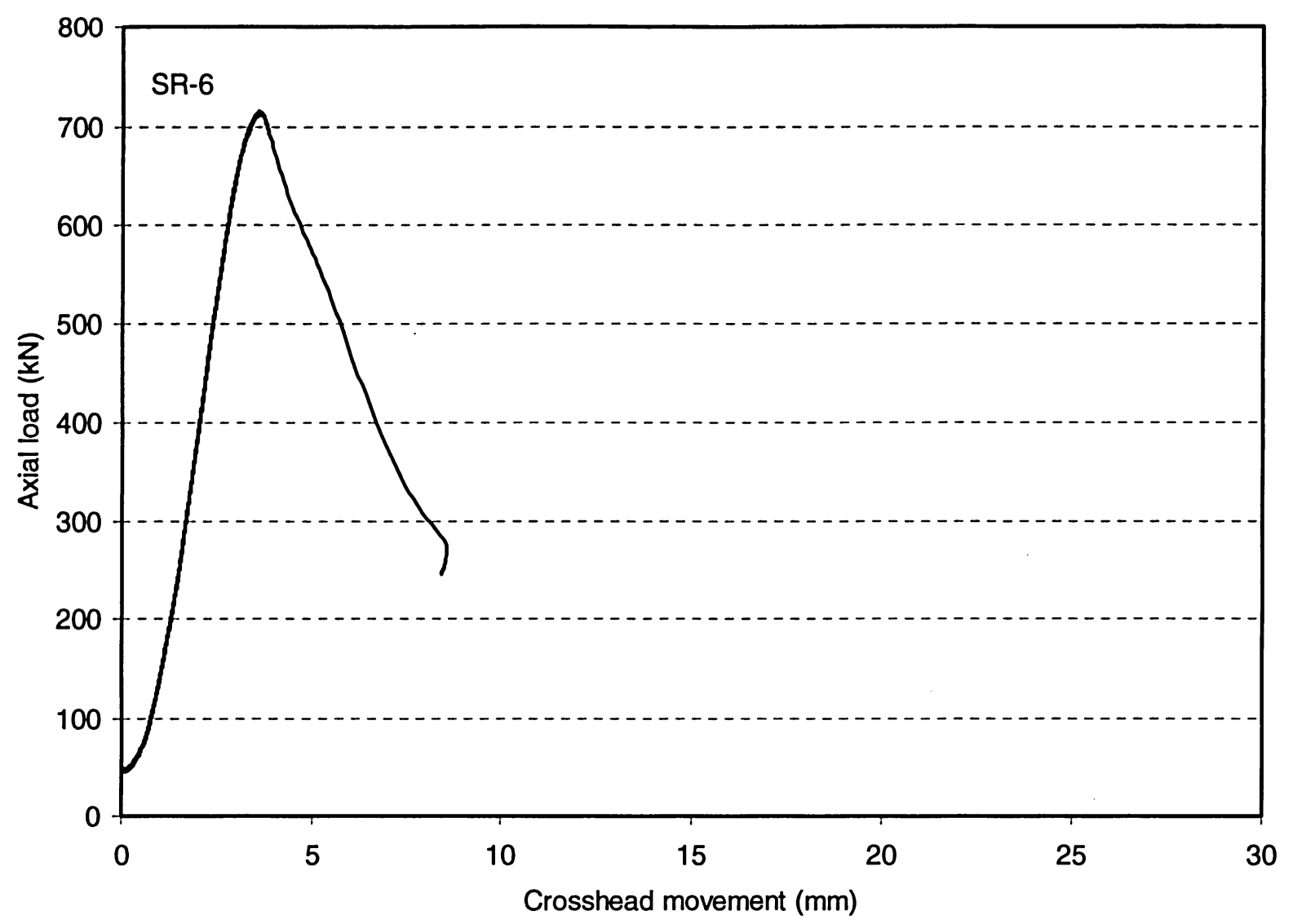

Figure 4.45 Load versus overall shortening curve for specimen SR-6
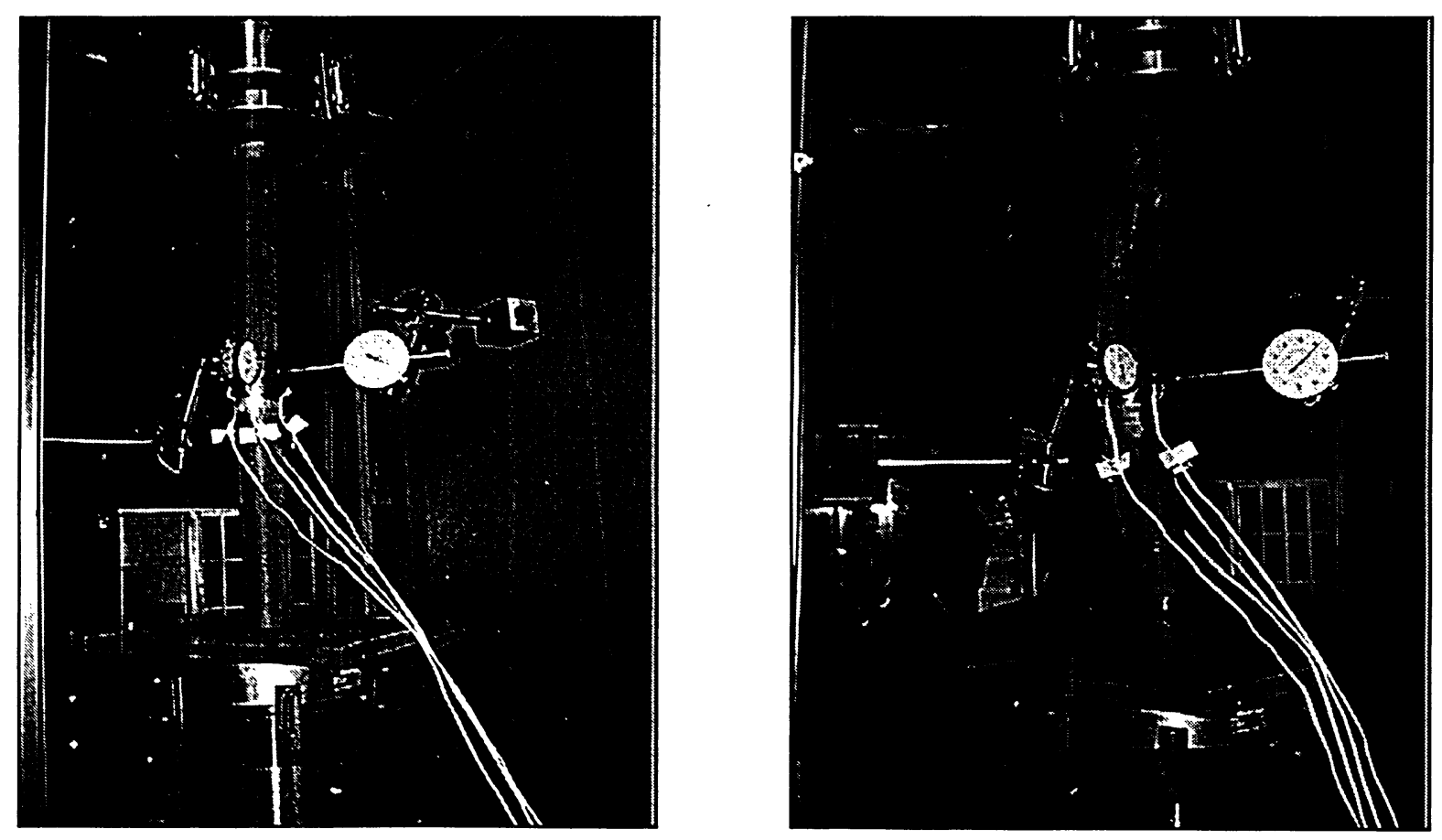

Figure 4.46 Views of specimen SR-7 before and after testing 


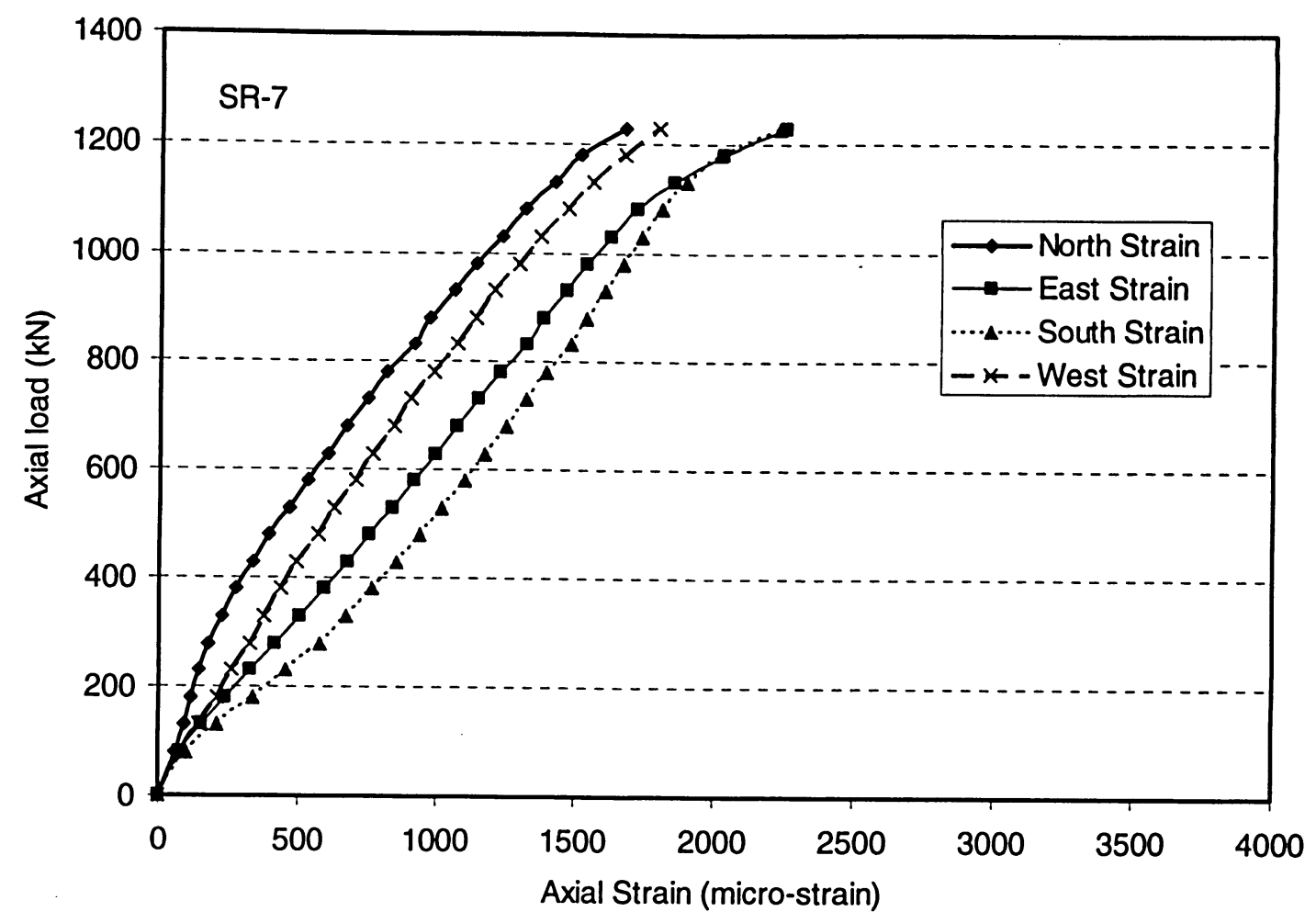

Figure 4.47 Axial load-strain relationships for specimen SR-7

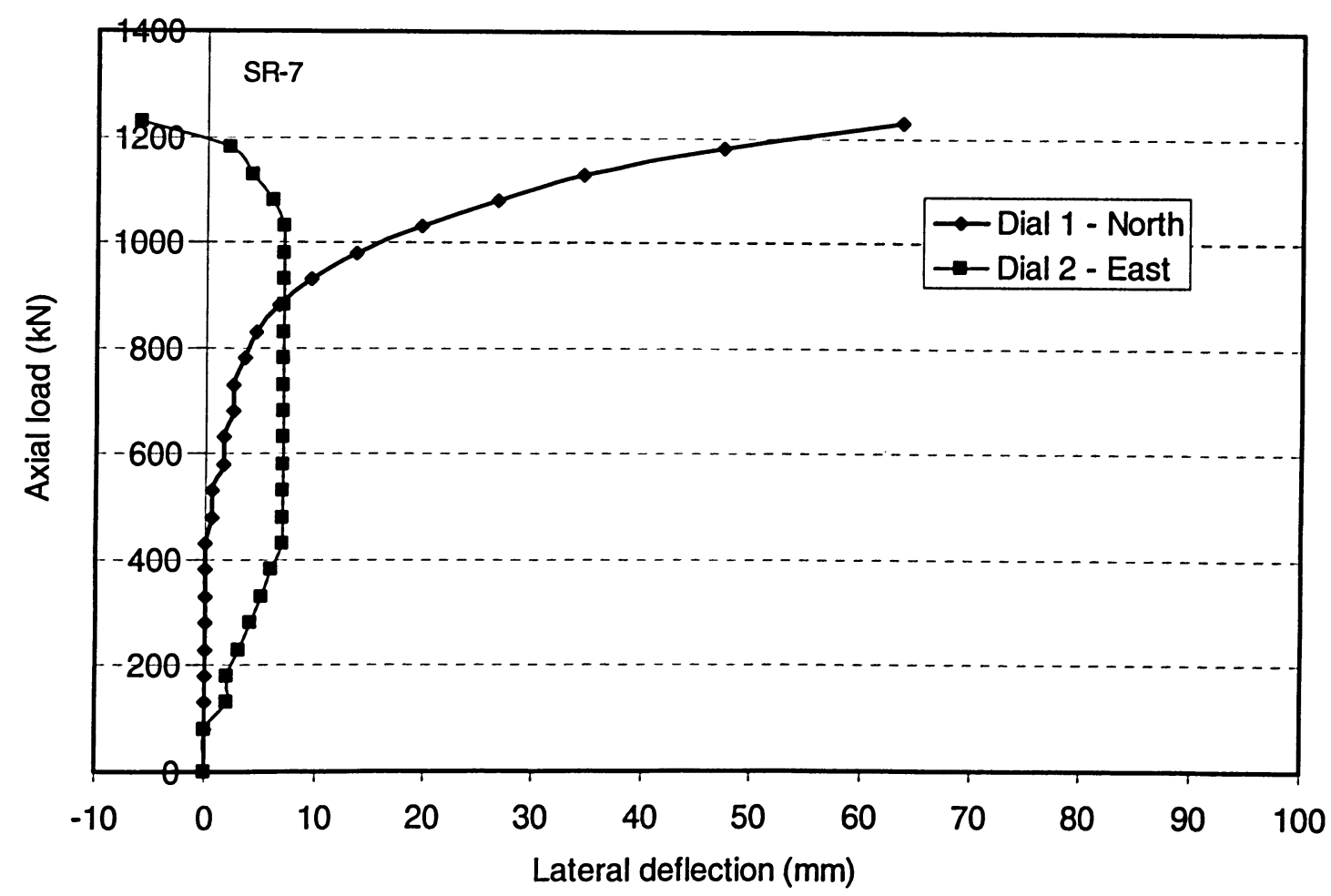

Figure 4.48 Load-lateral deflection curves for specimen SR-7 


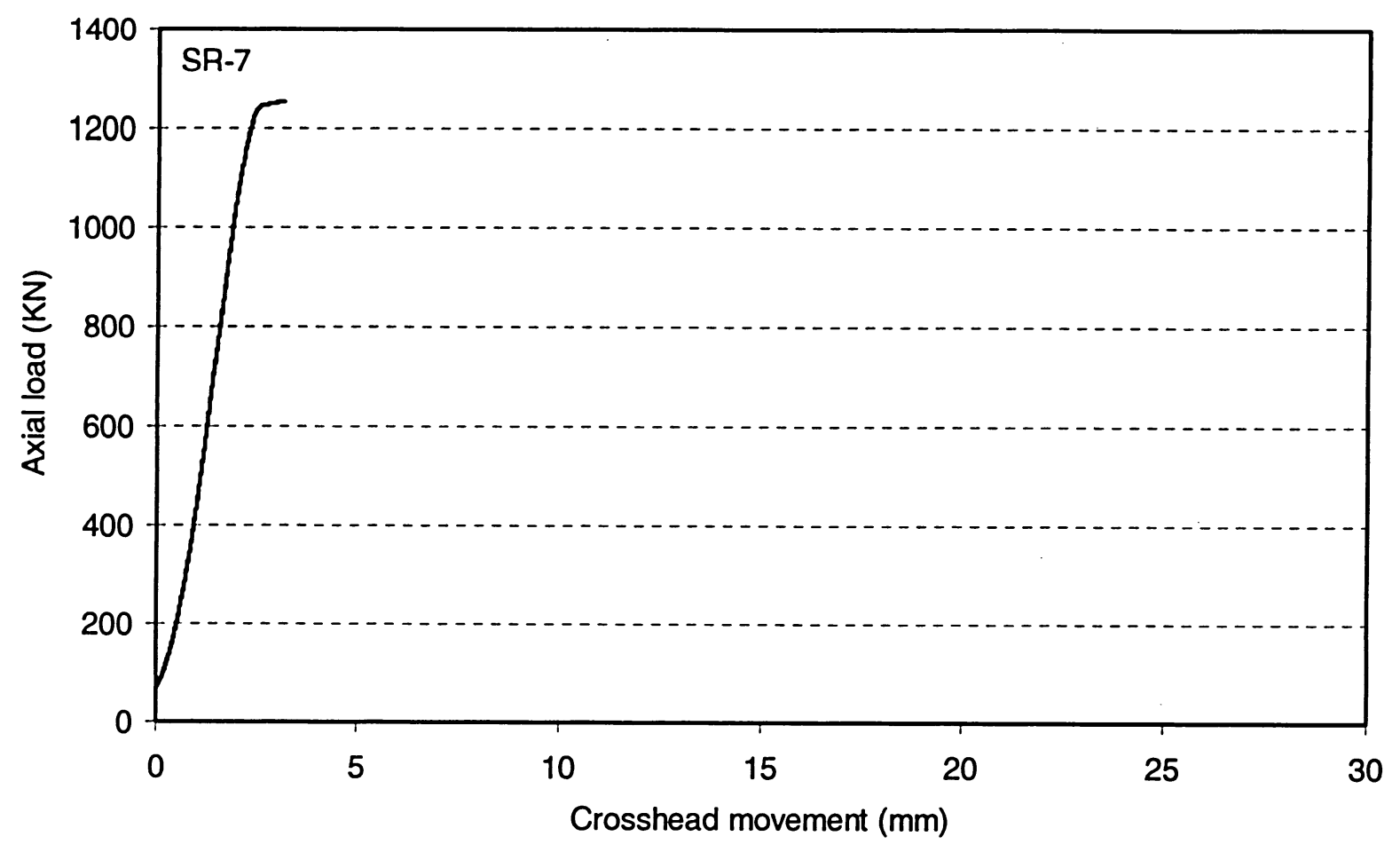

Figure 4.48 Load versus overall shortening curve for specimen SR-7
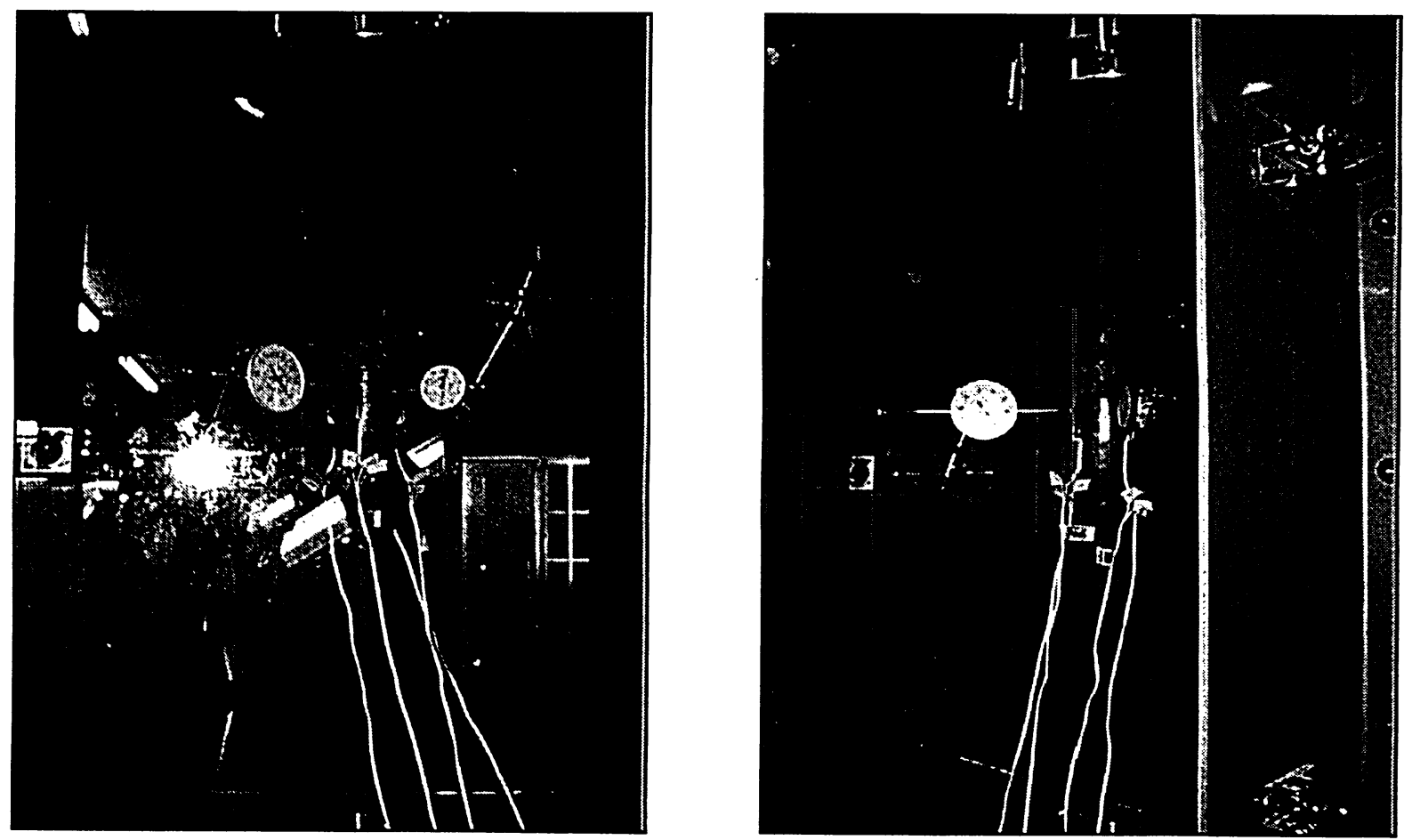

Figure 4.49 Views of specimen SR- 8 before and after testing 


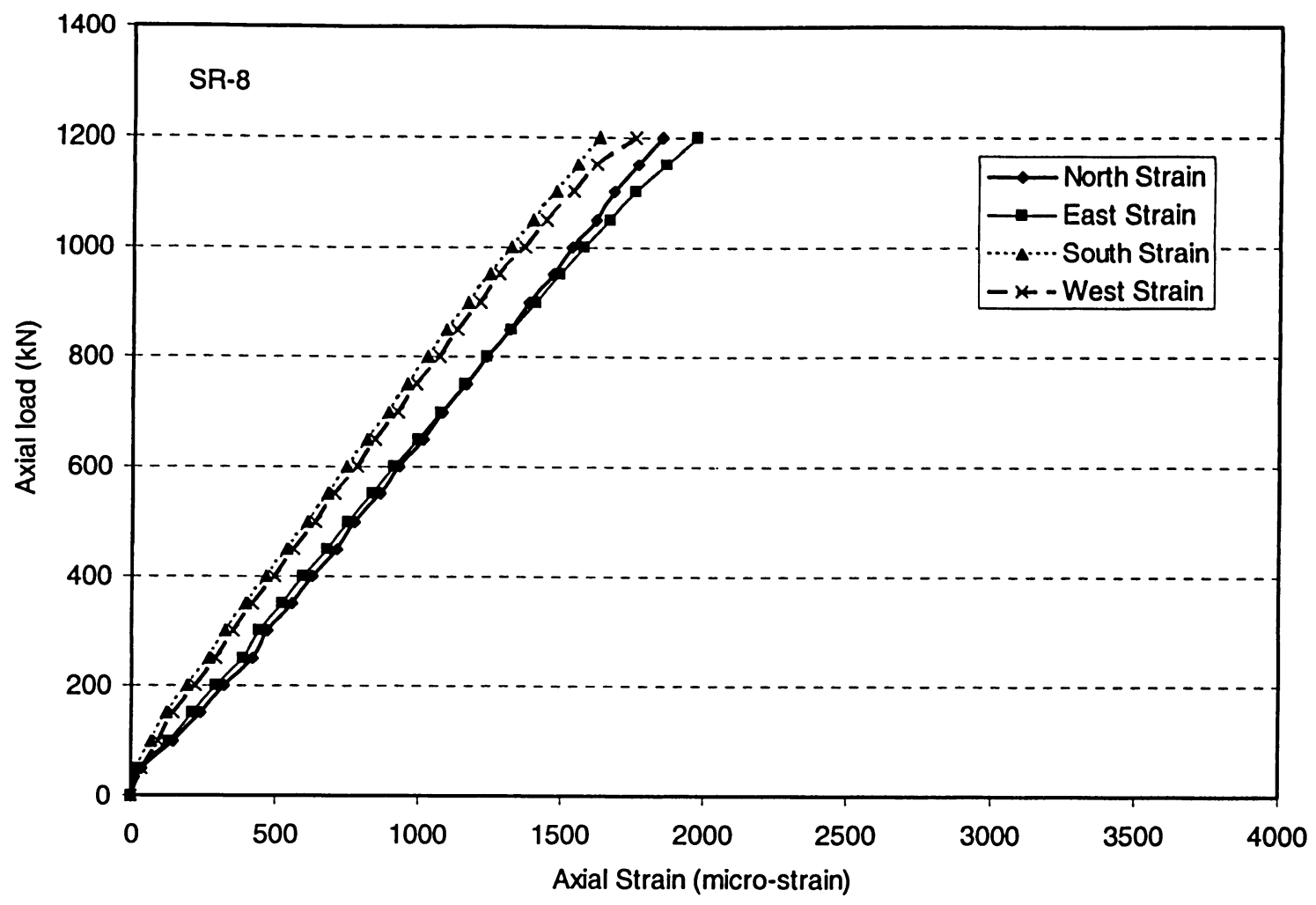

Figure 4.50 Axial load-strain relationships for specimen SR-8

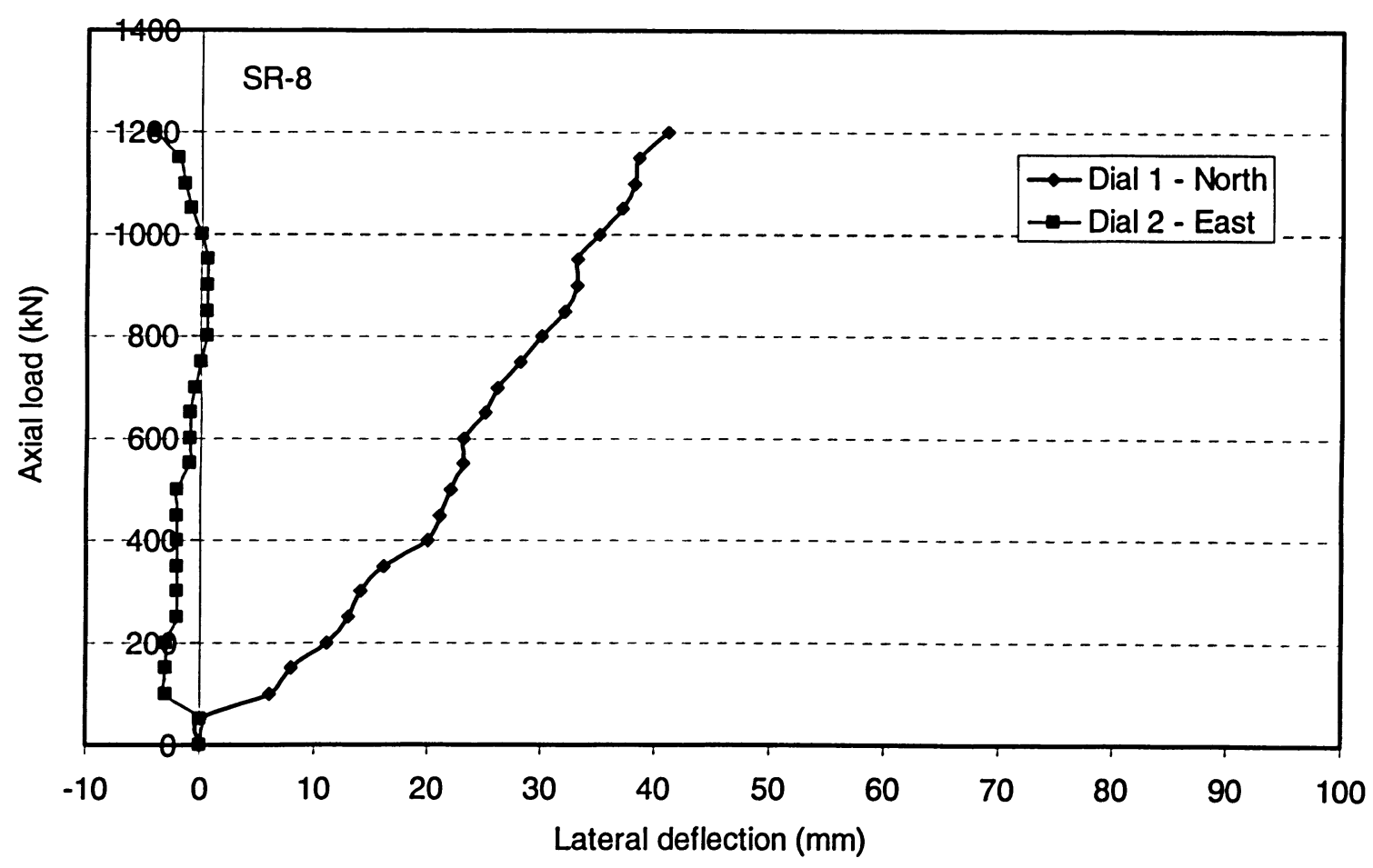

Figure 4.51 Load-lateral deflection curves for specimen SR-8 


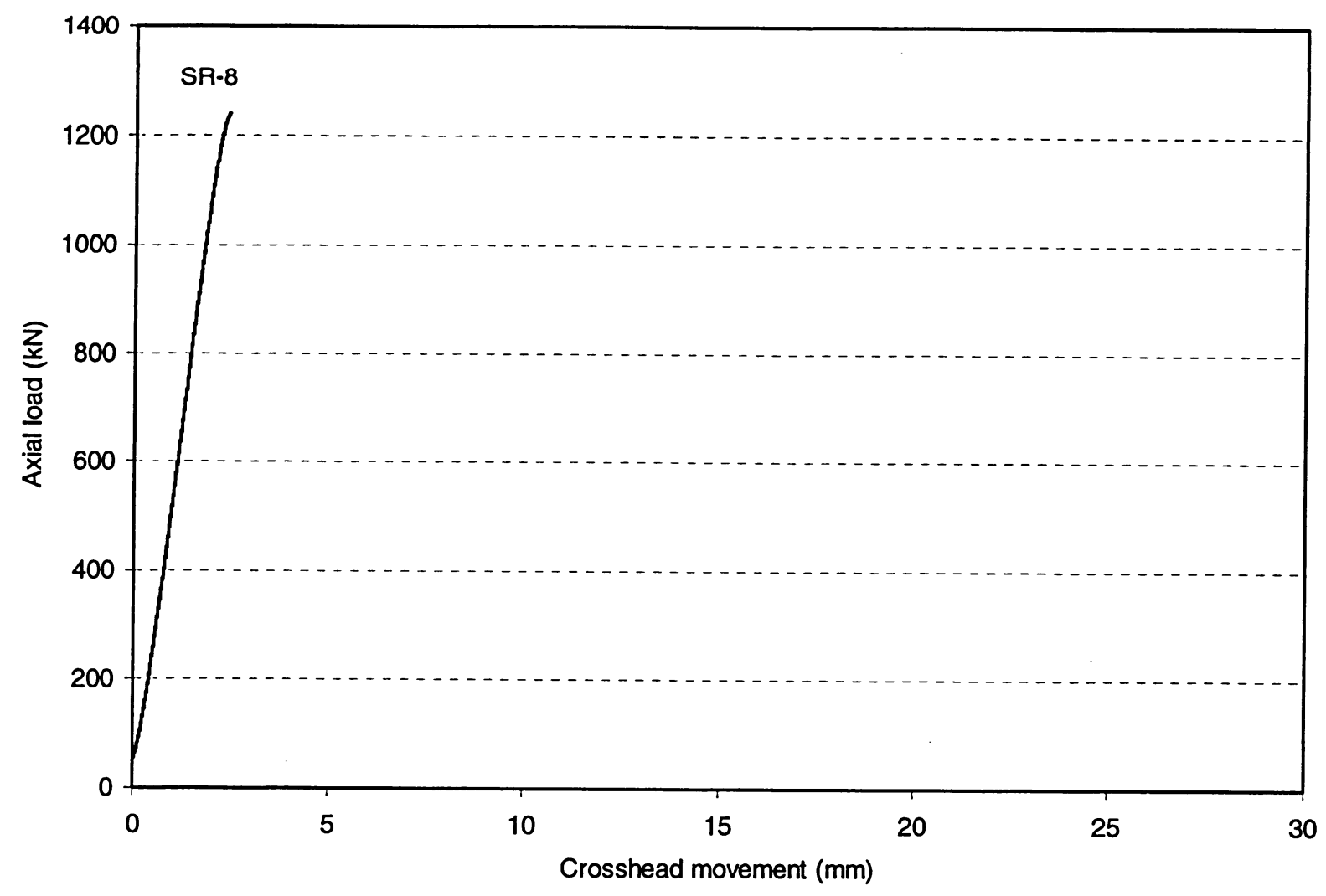

Figure 4.52 Load versus overall shortening curve for specimen SR-8
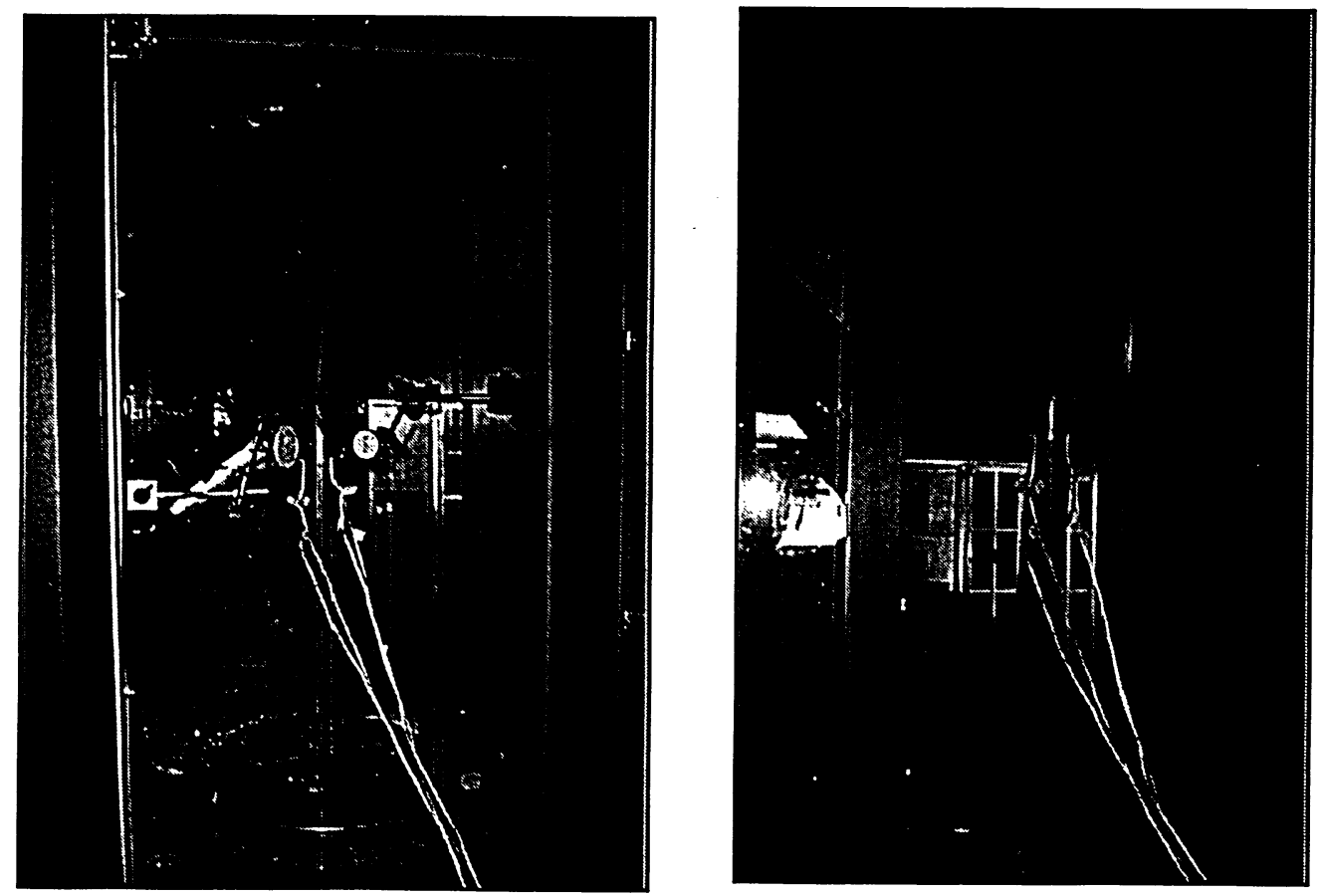

Figure 4.53 Views of specimen SR-9 before and after testing 


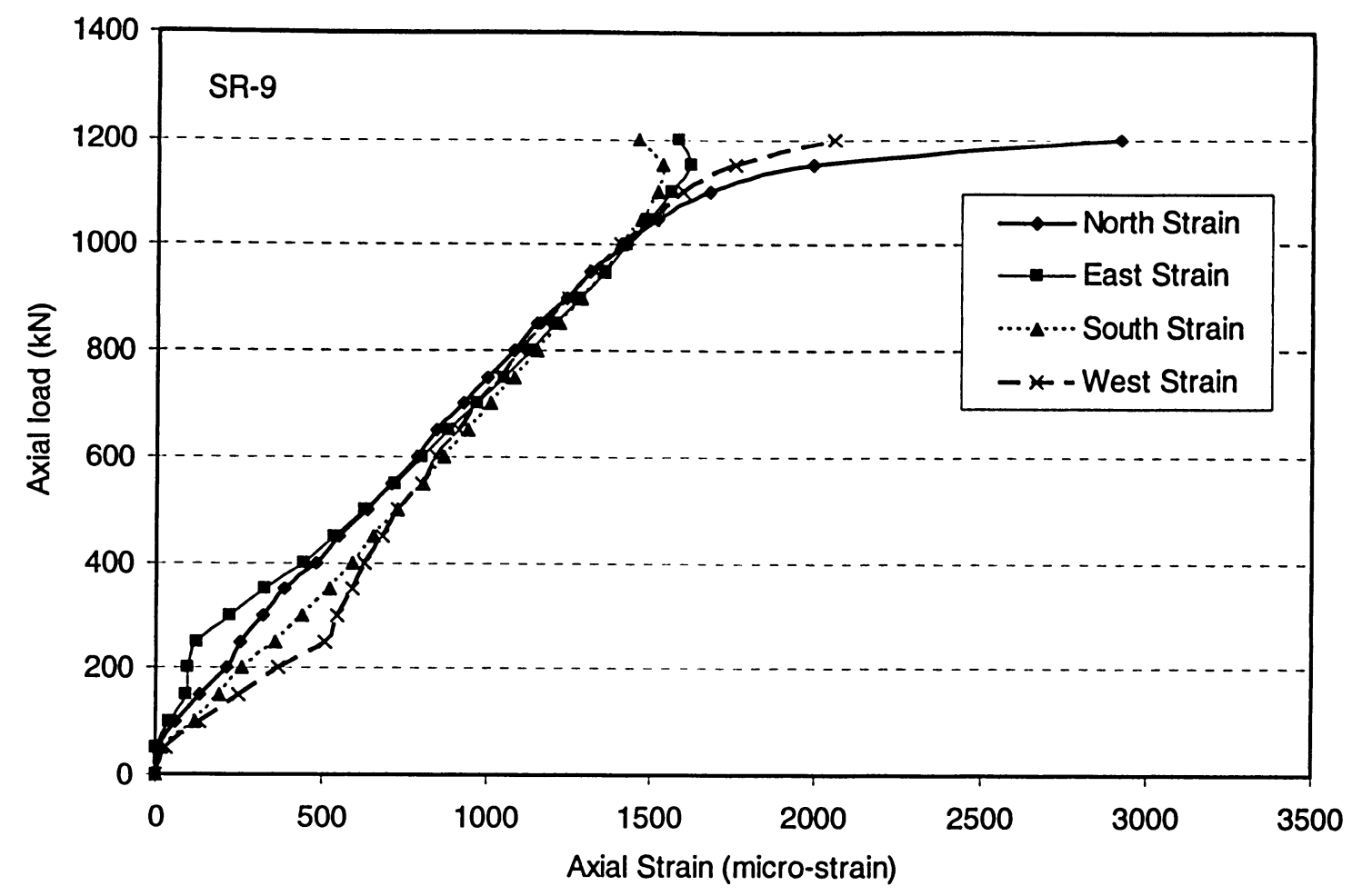

Figure 4.54 Axial load-strain relationships for specimen SR-9

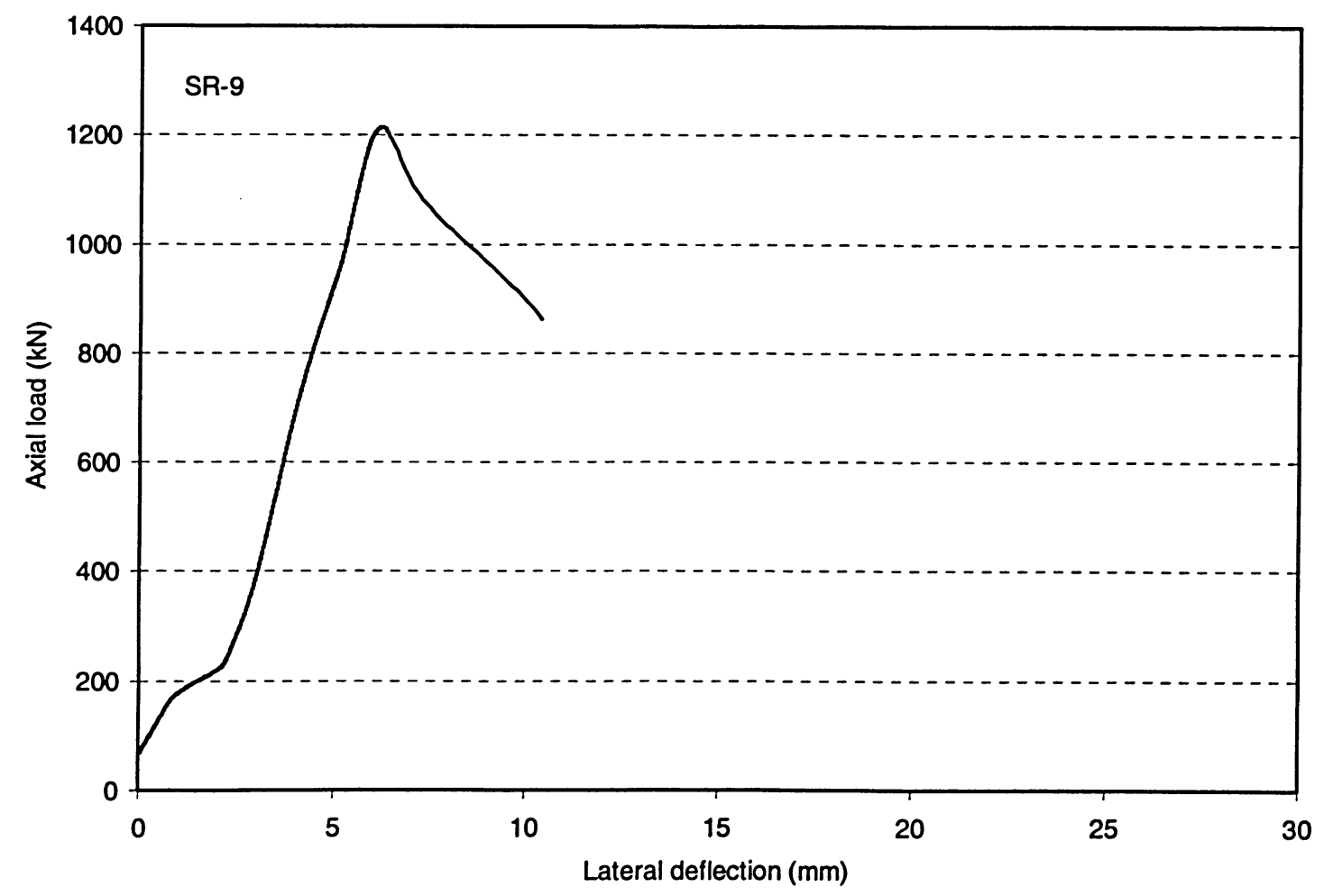

Figure 4.55 Load versus overall shortening curve for specimen SR-9 

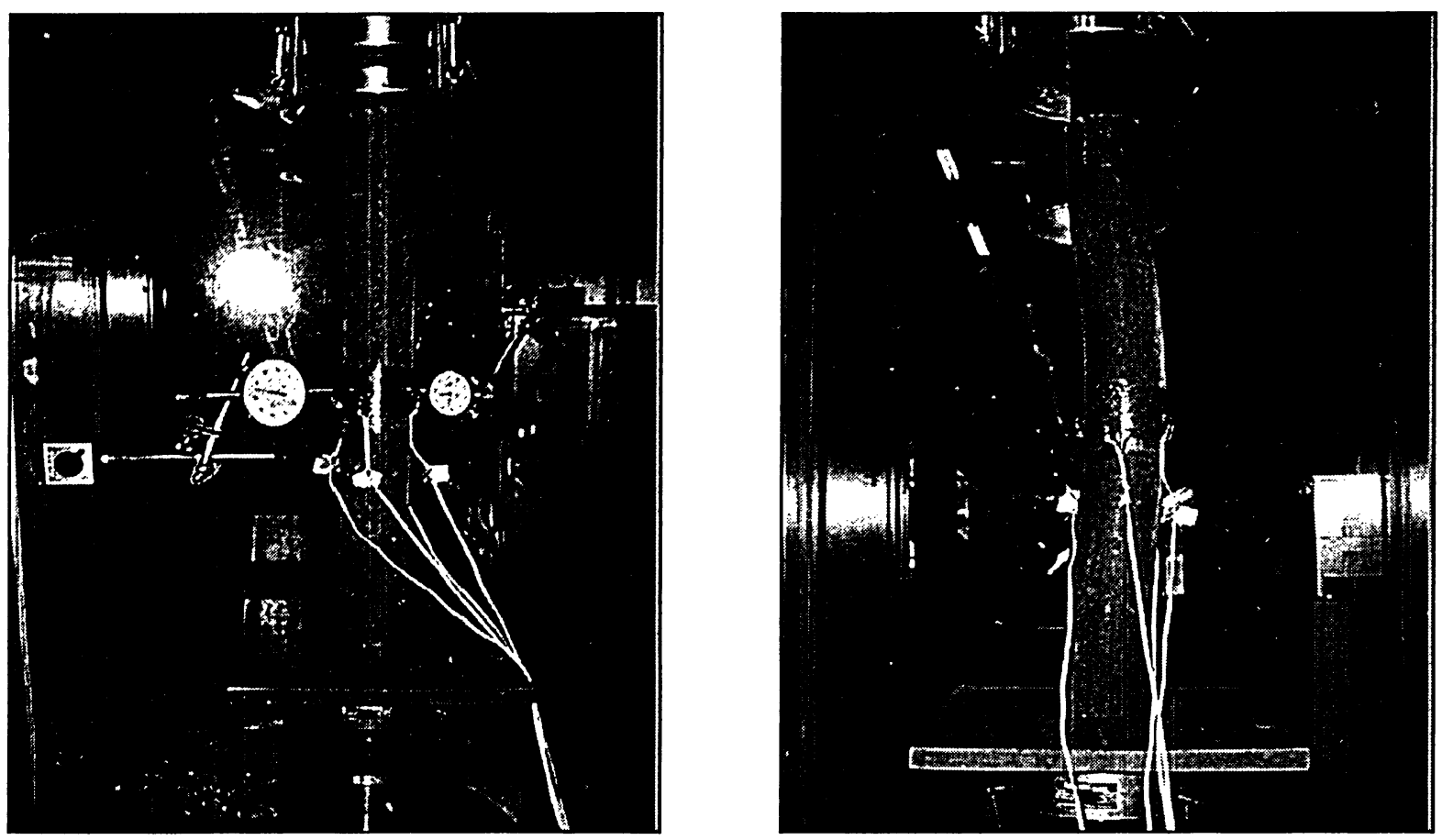

Figure 4.56 Views of specimen SR-10 before and after testing

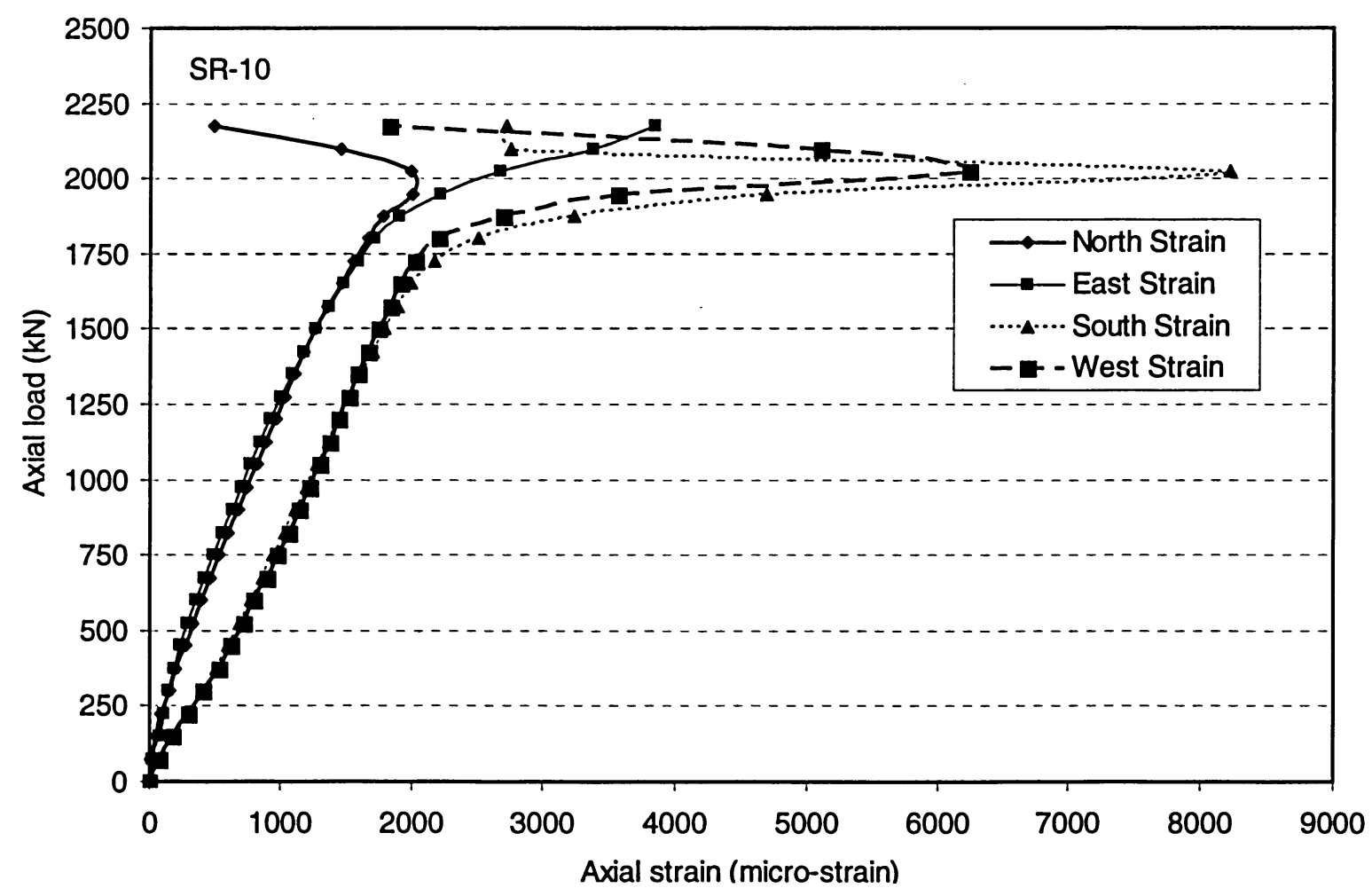

Figure 4.57 Axial load-strain relationships for specimen SR-10 


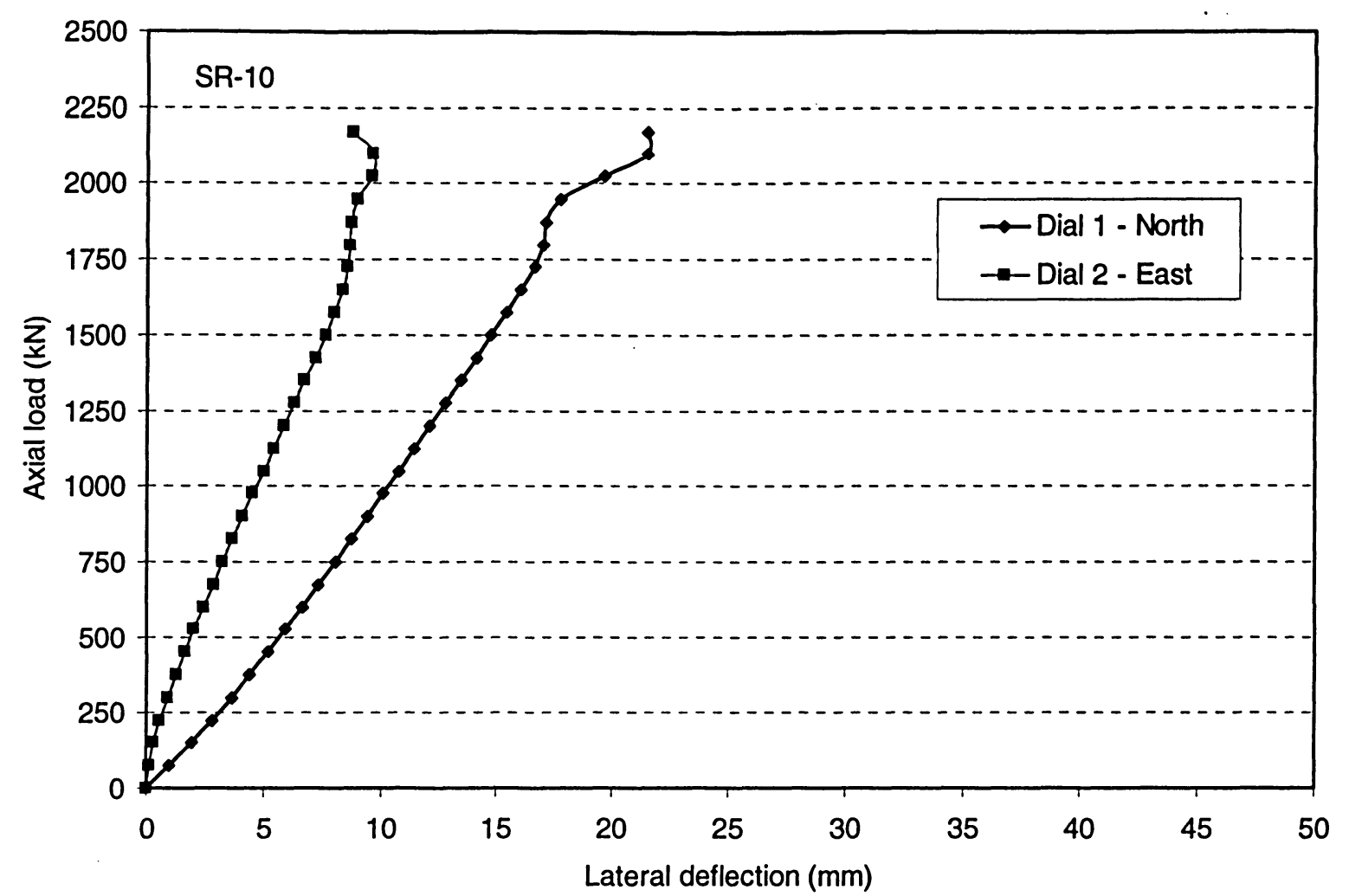

Figure 5.58 Load-lateral deflection curves for specimen SR-10

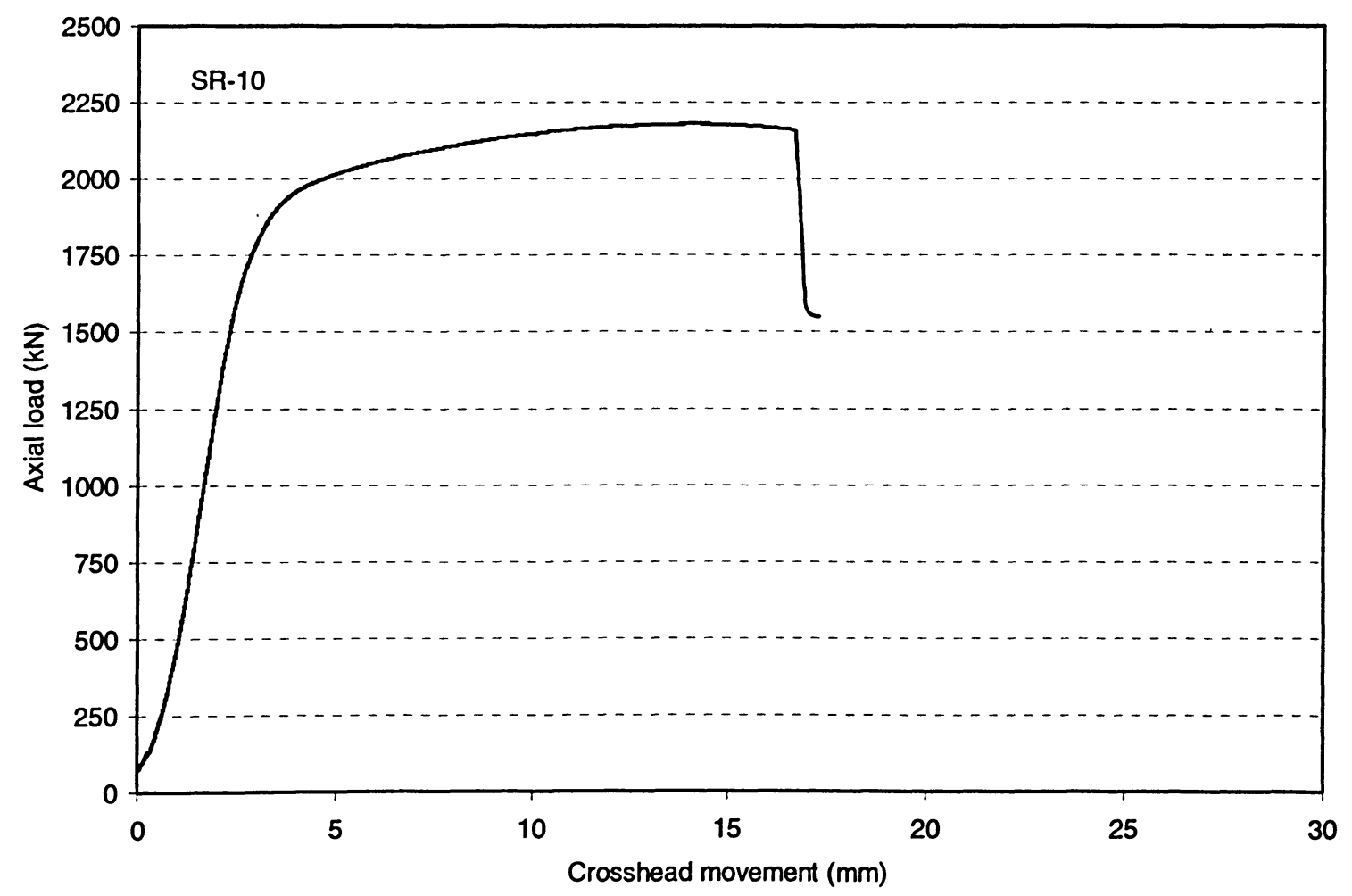

Figure 4.59 Load versus overall shortening curve for specimen SR-10 


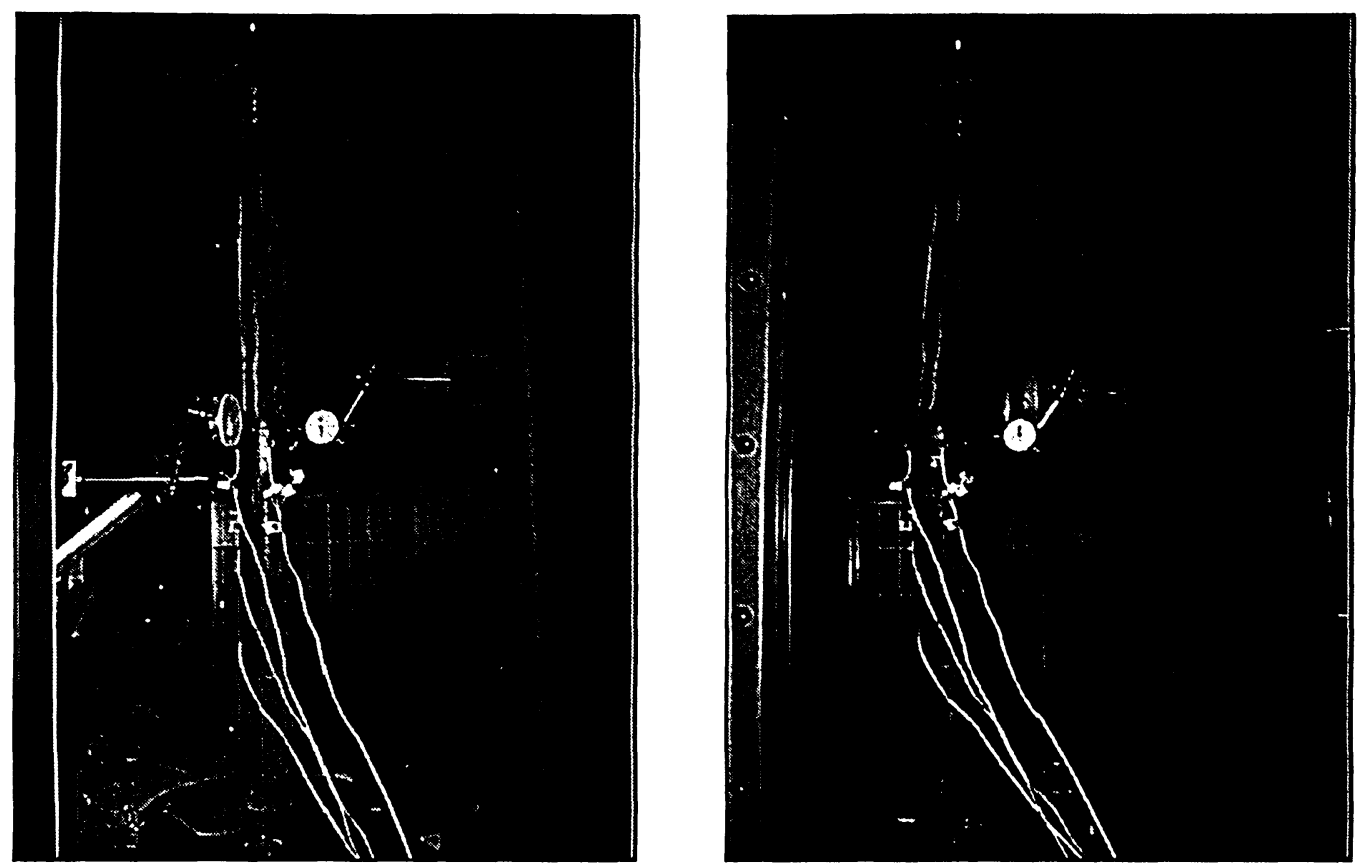

Figure 4.60 Views of specimen SR-11 before and after testing

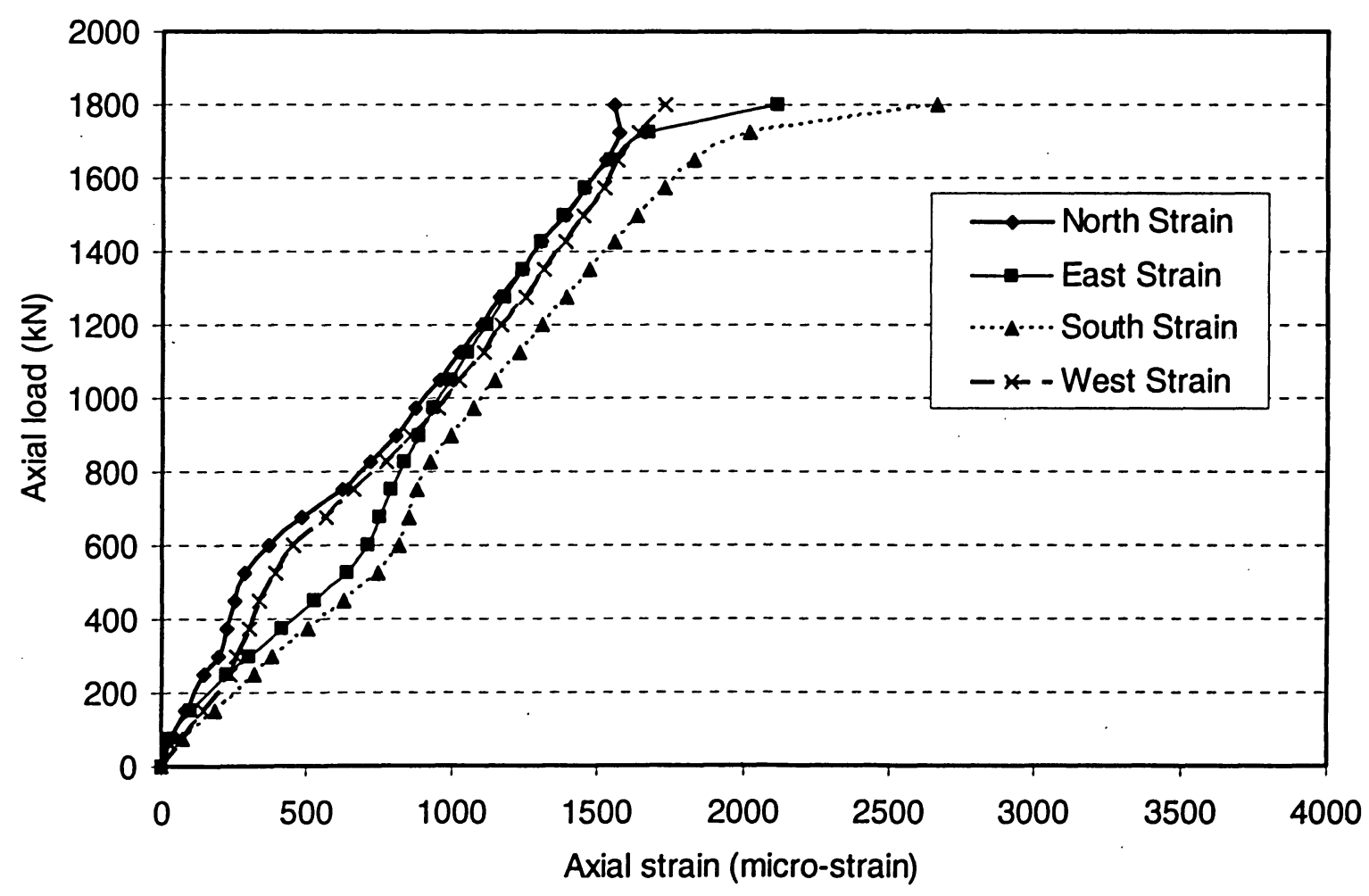

Figure 4.61 Axial load-strain relationships for specimen SR-11 


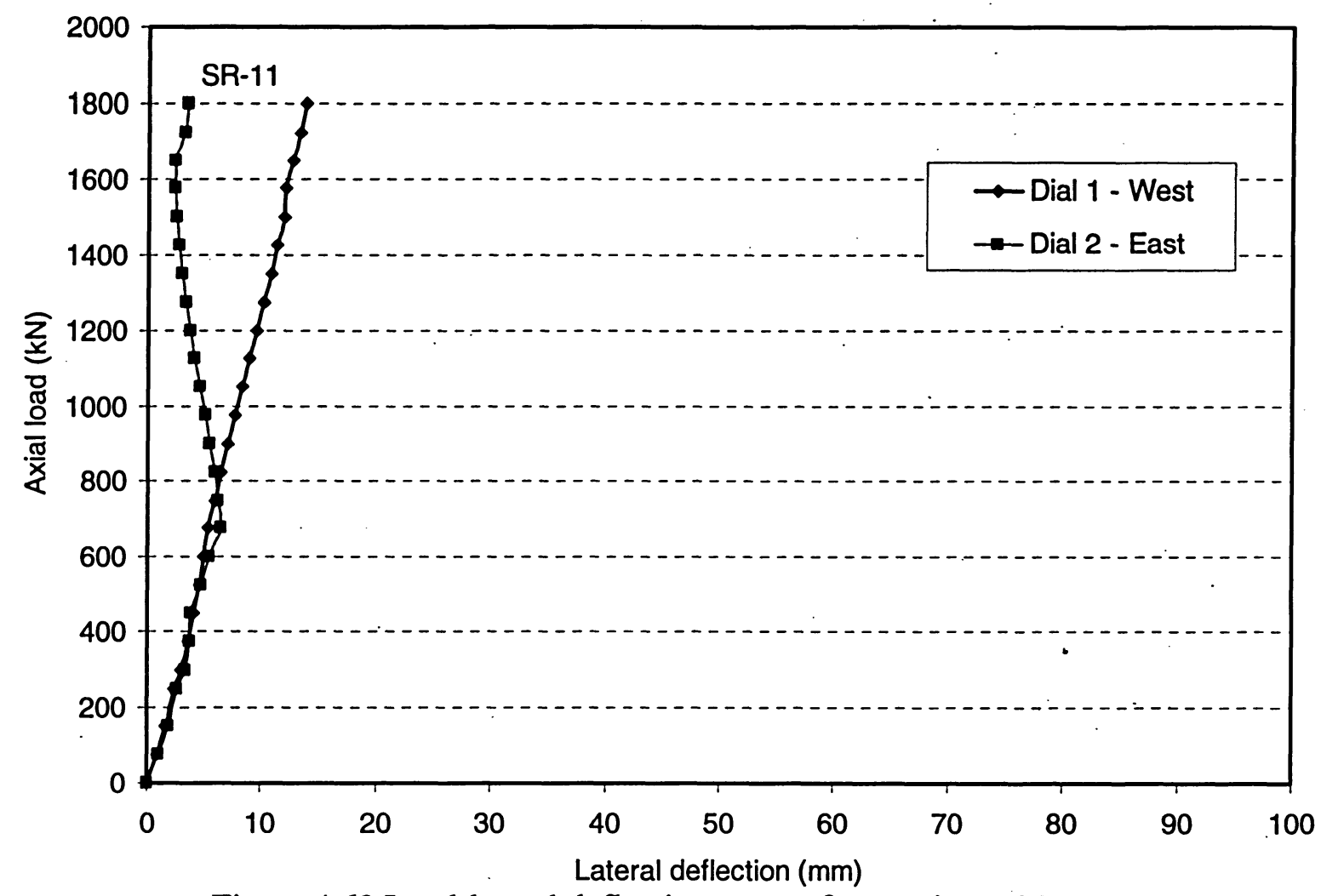

Figure 4.62 Load-lateral deflection curves for specimen SR-11

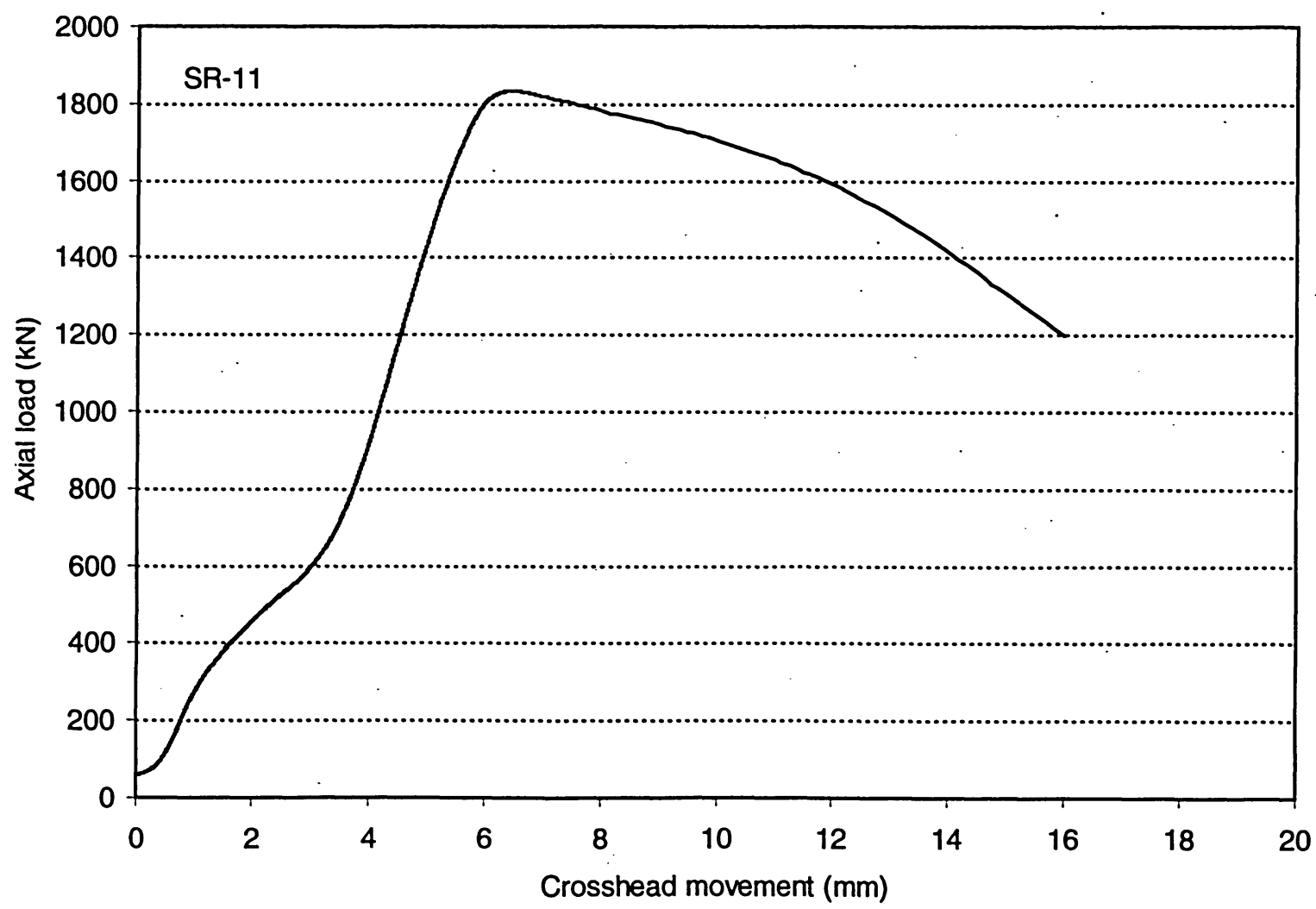

Figure 4.63 Load versus overall shortening curve for specimen SR-11 

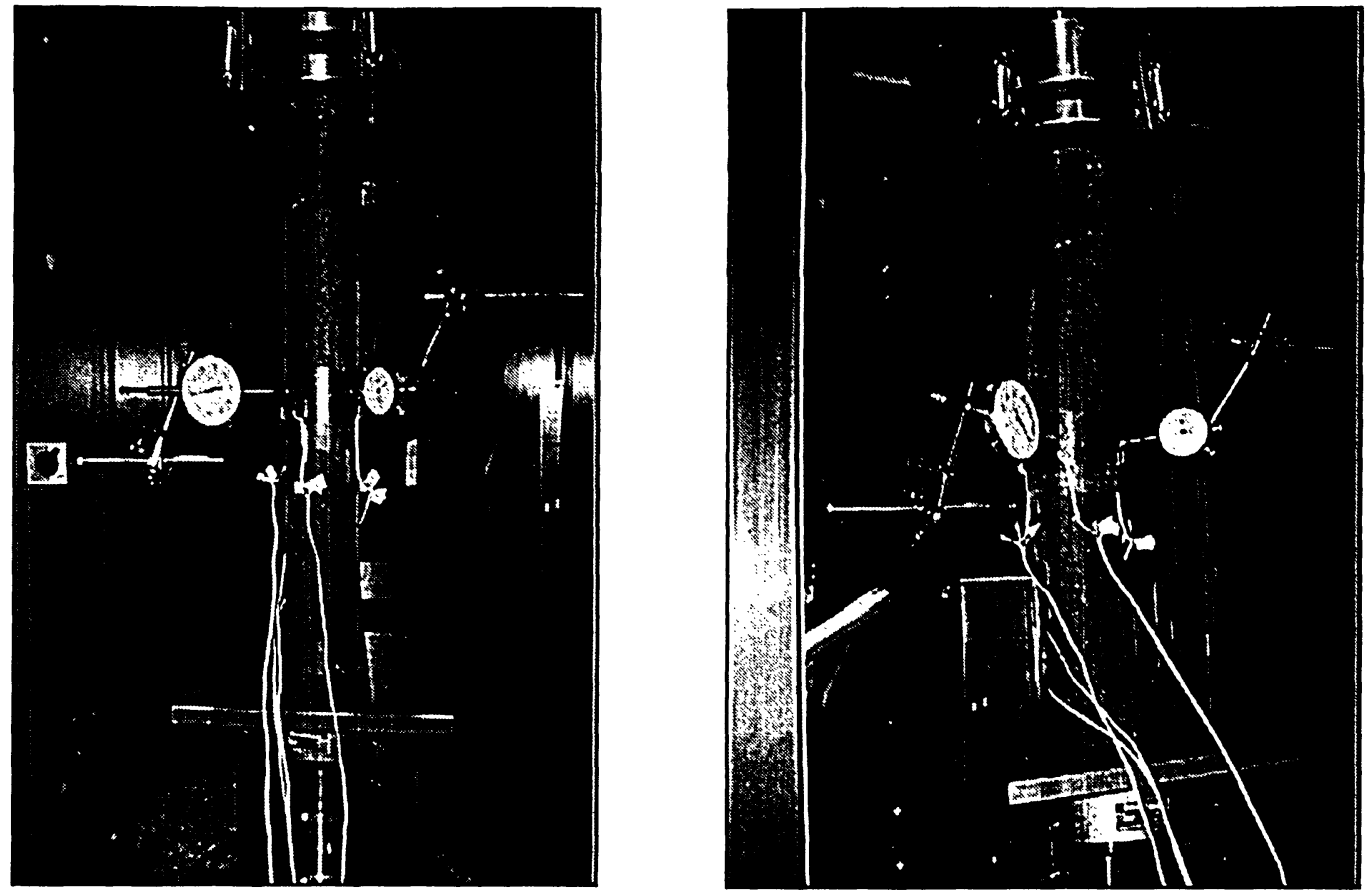

Figure 4.64 Views of specimen SR-12 before and after testing

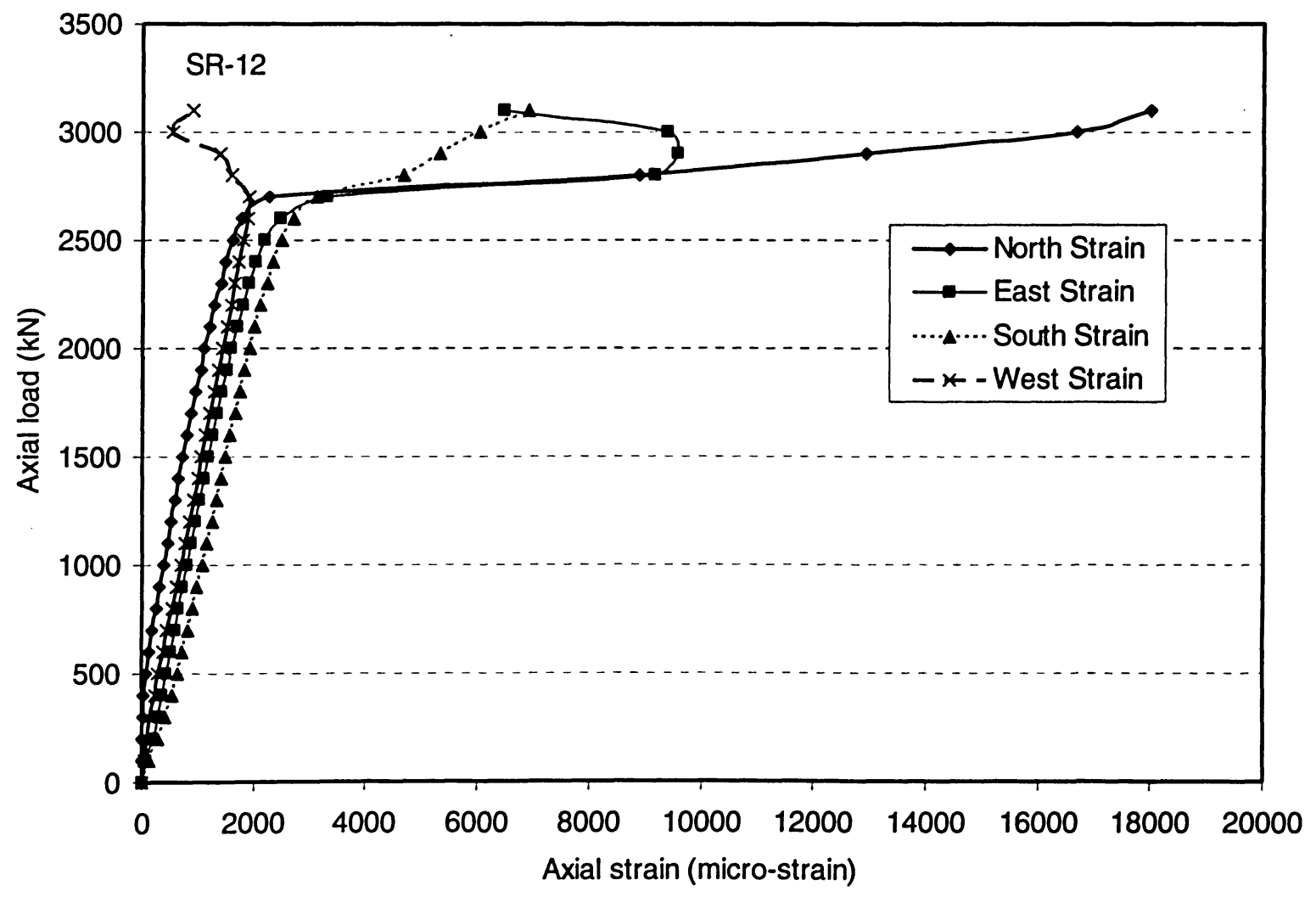

Figure 4.65 Axial load-strain relationships for specimen SR-12 


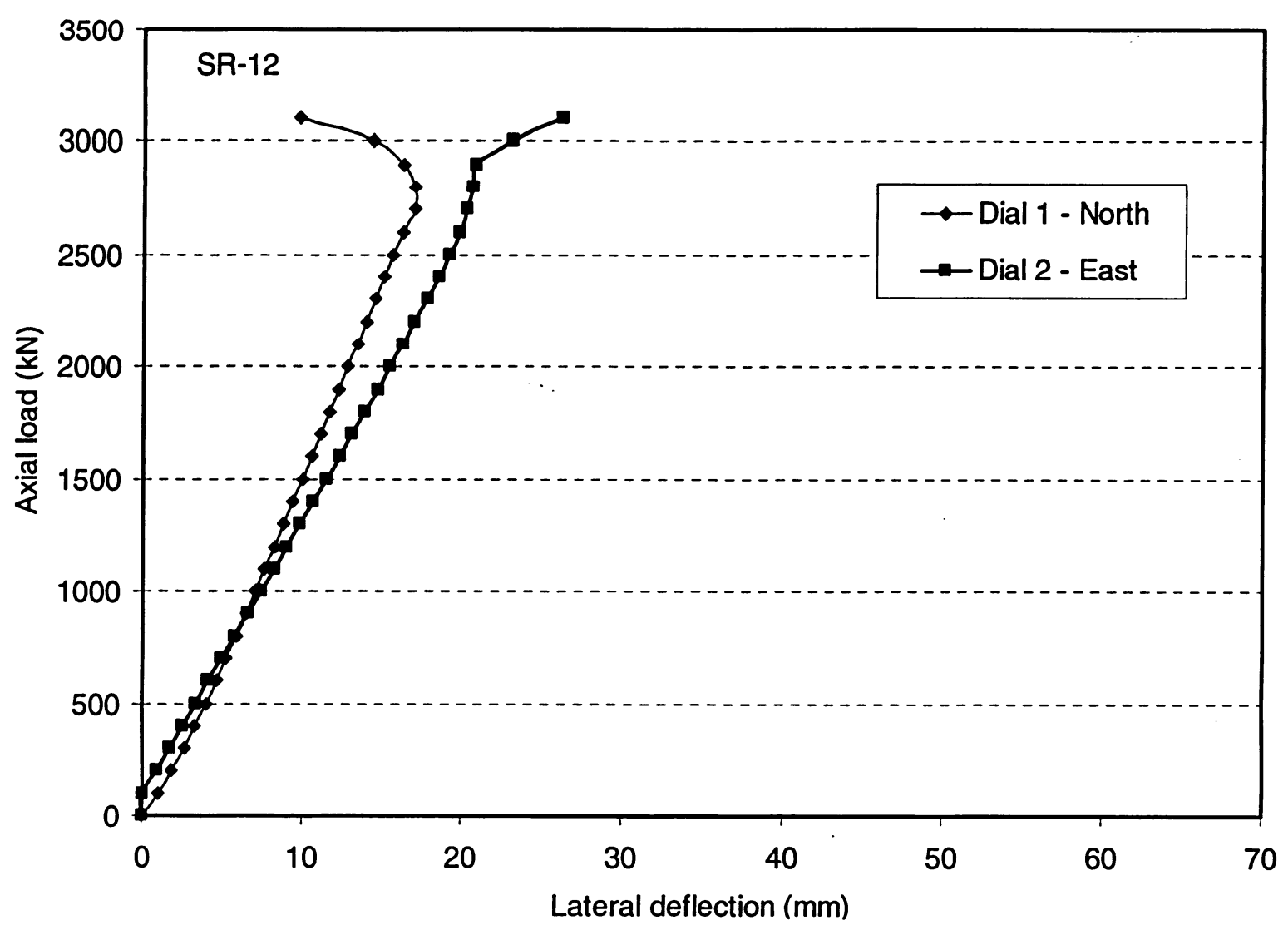

Figure 4.66 Load-lateral deflection curves for specimen SR-12

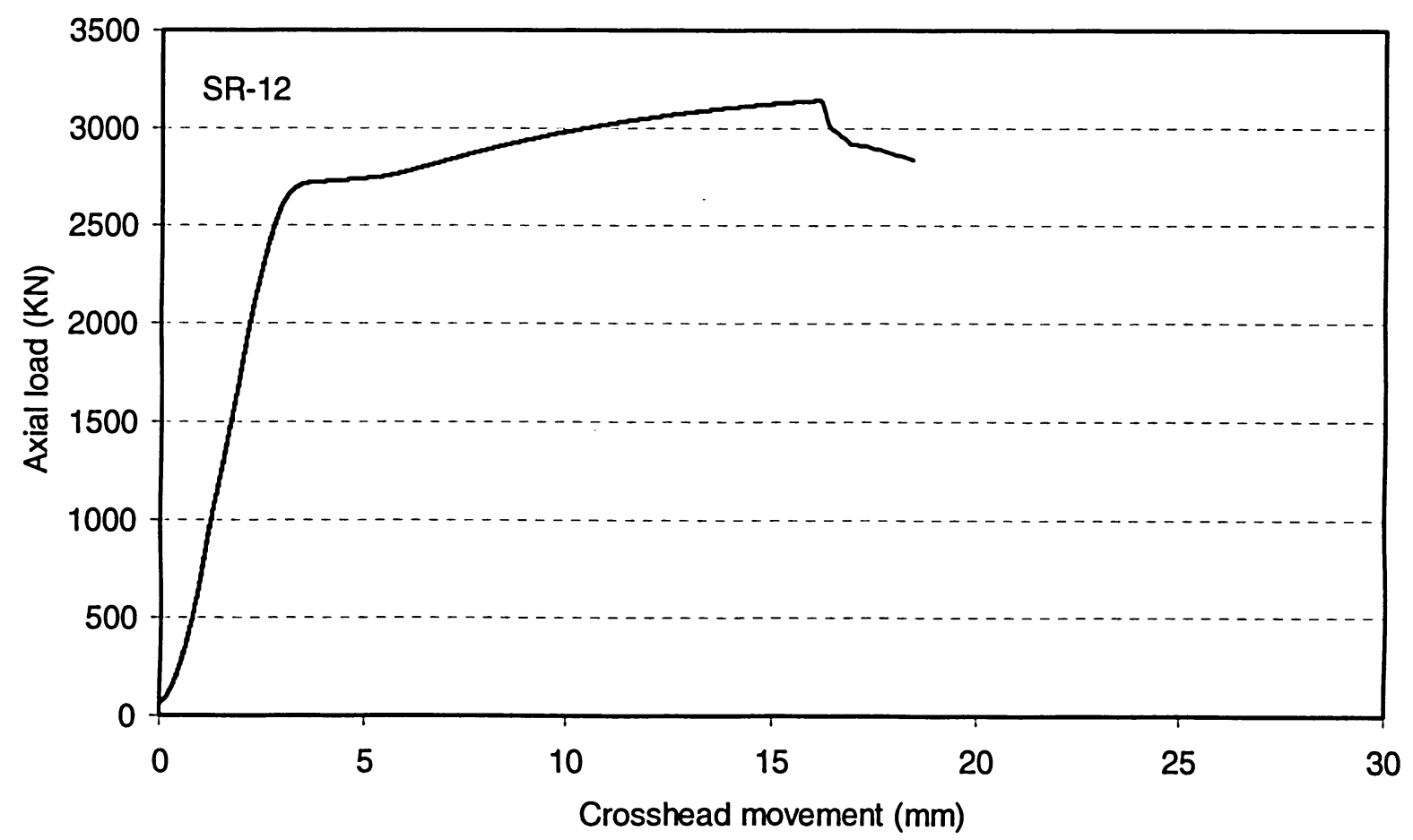

Figure 4.67 Load versus overall shortening curve for specimen SR-12 

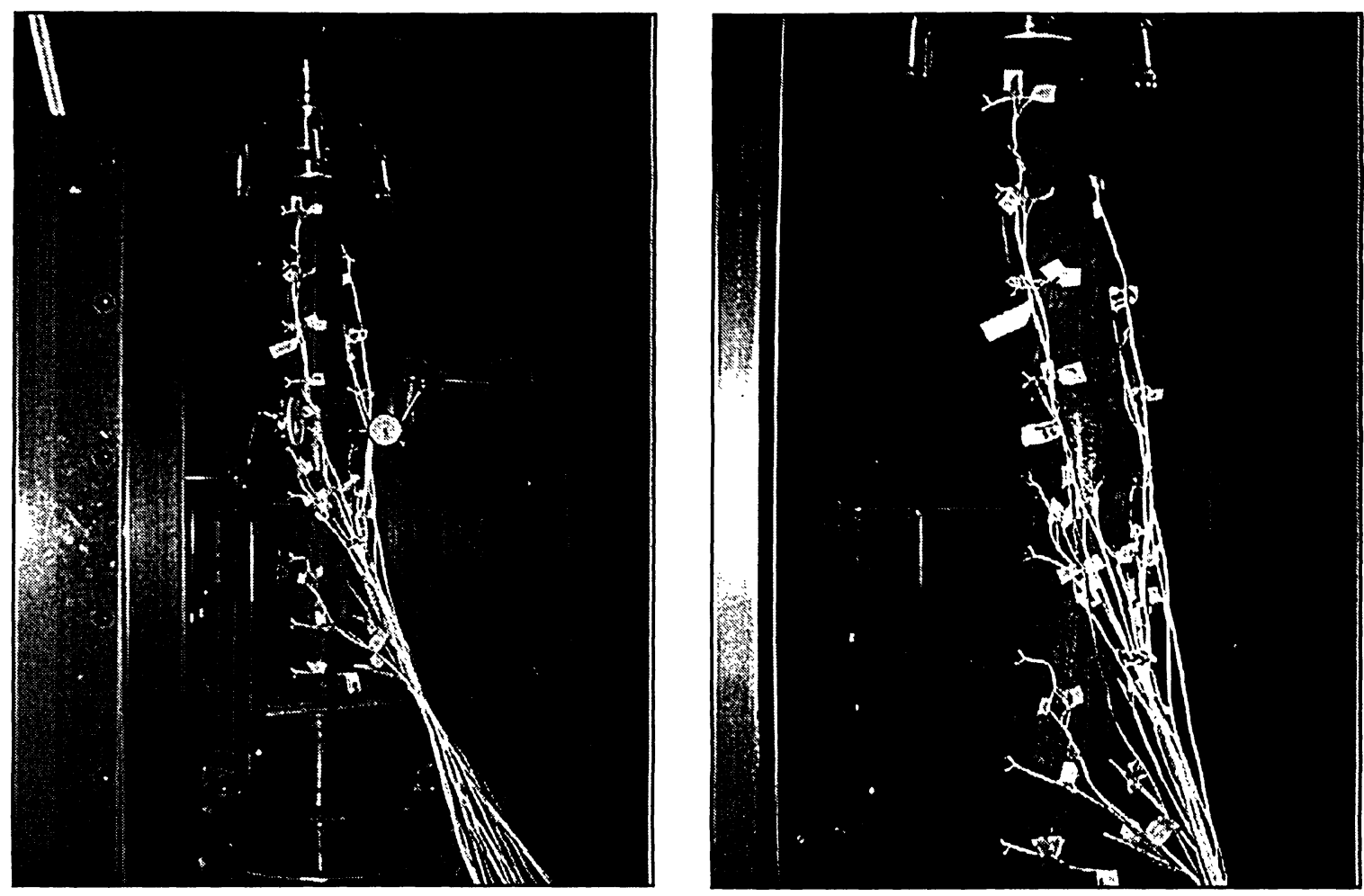

Figure 4.68 Views of specimen SR-13 before and after testing

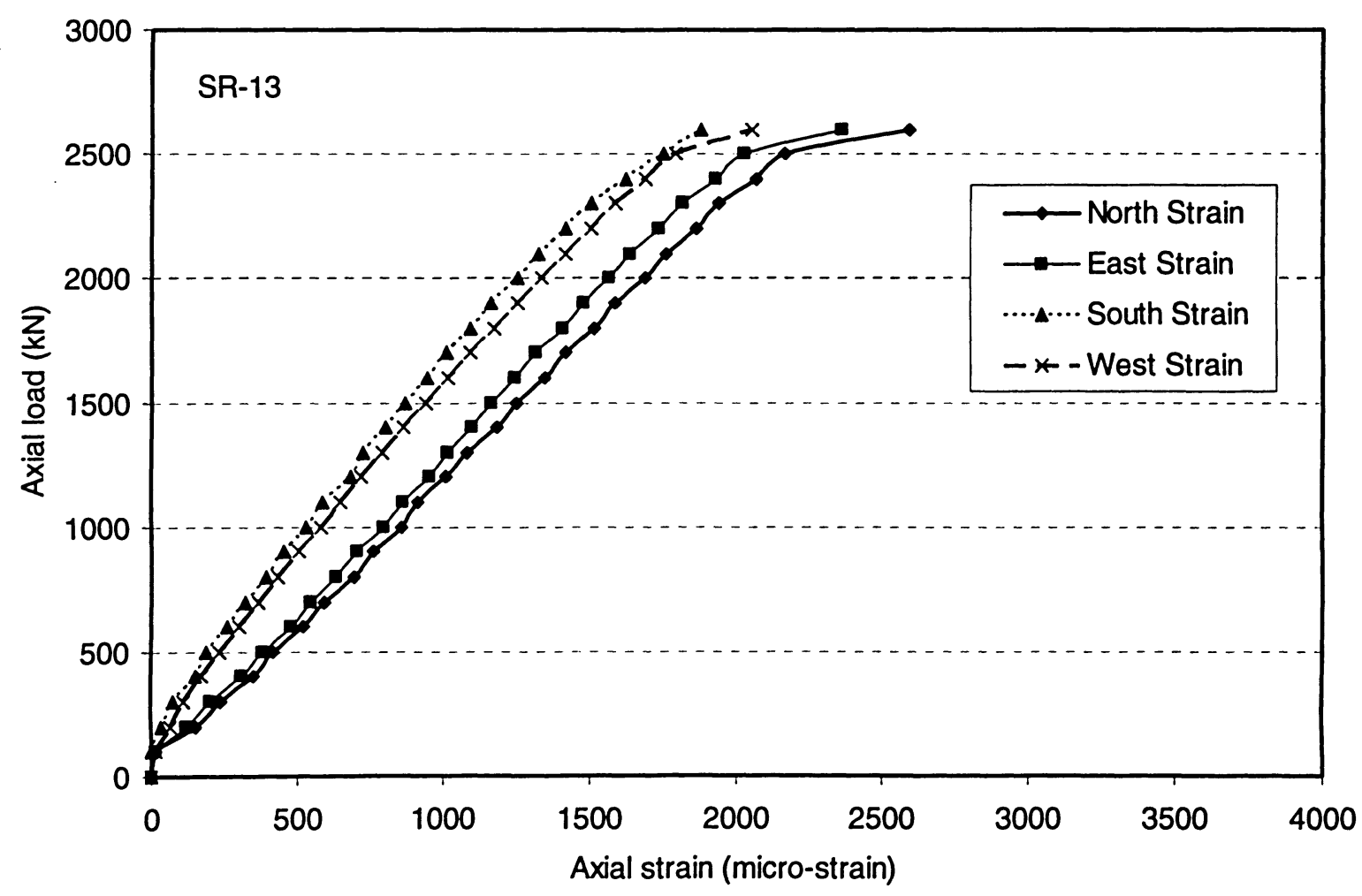

Figure 4.69 Axial load-strain relationships for specimen SR-13 


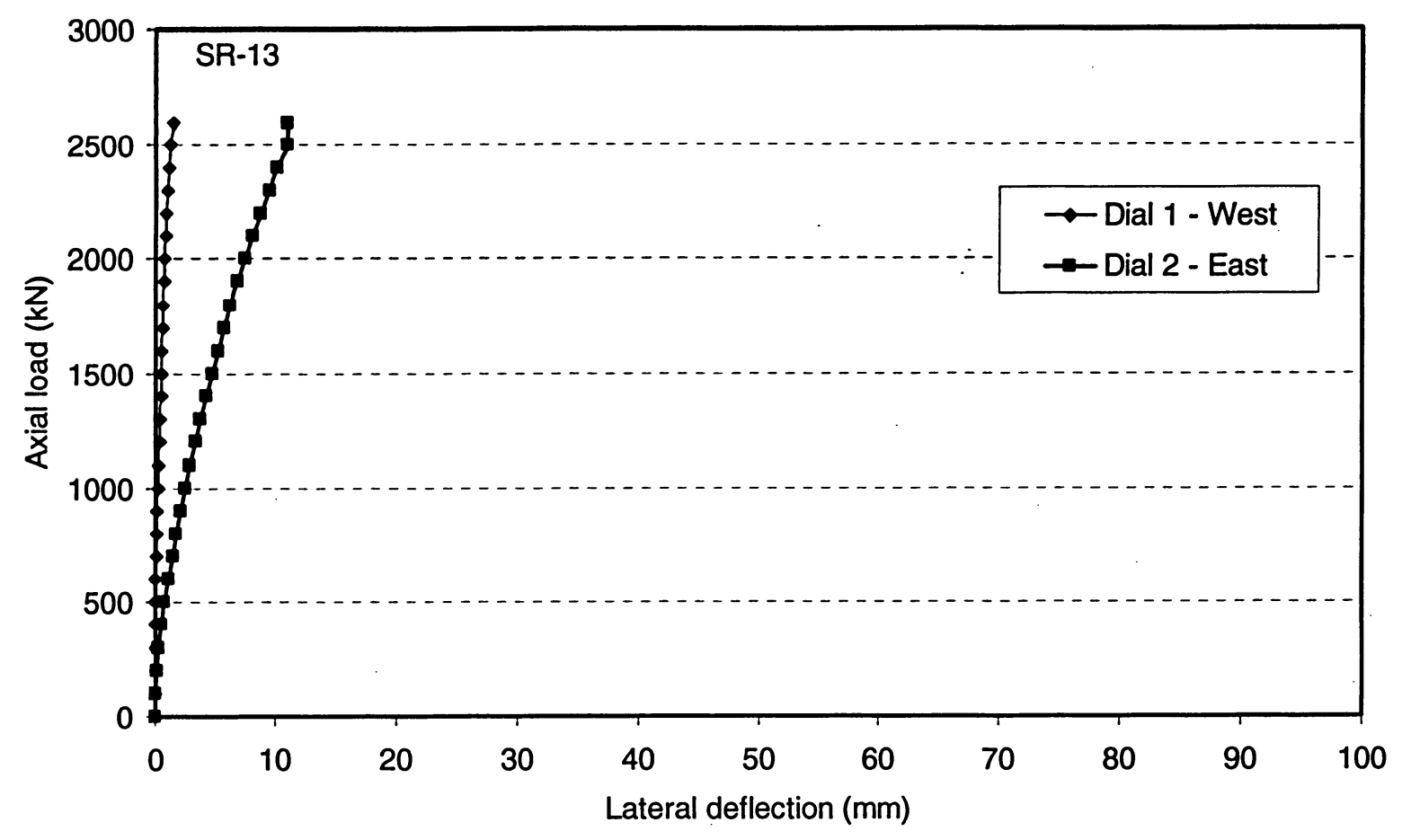

Figure 4.70 Load-lateral deflection curves for specimen SR-13

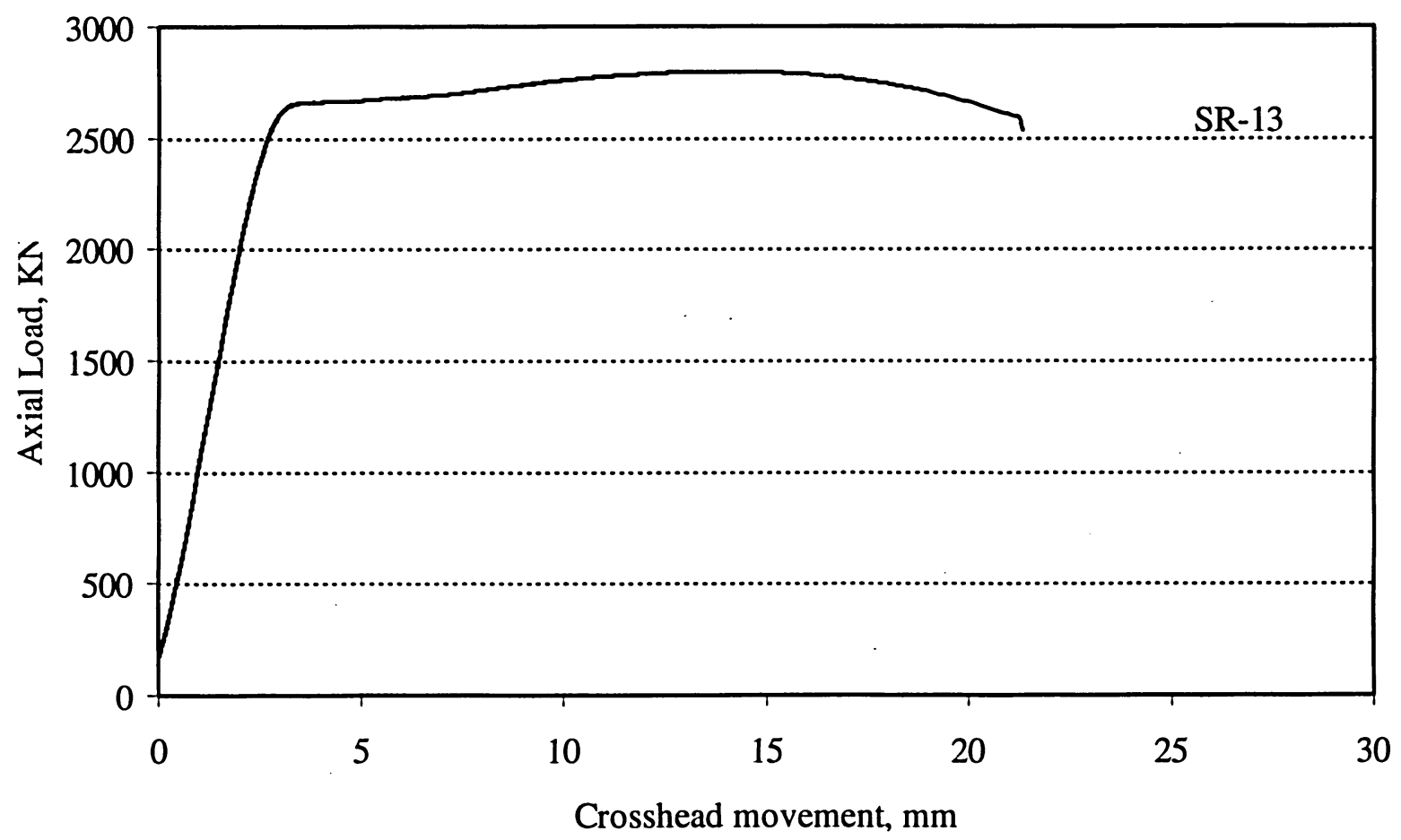

Figure 4.71 Load versus overall shortening curve for specimen SR-13 

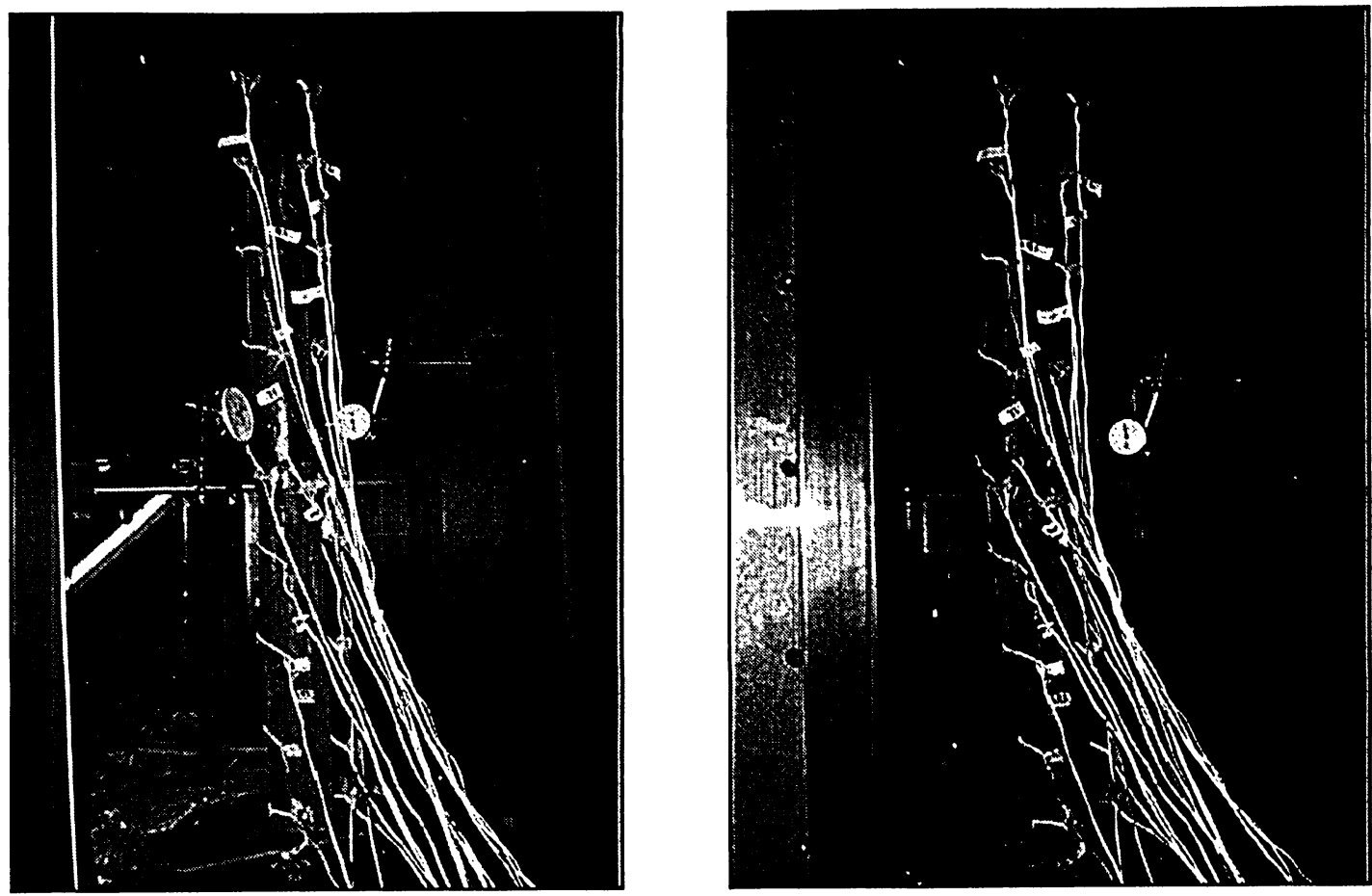

Figure 4.72 Views of specimen SR-14 before and after testing

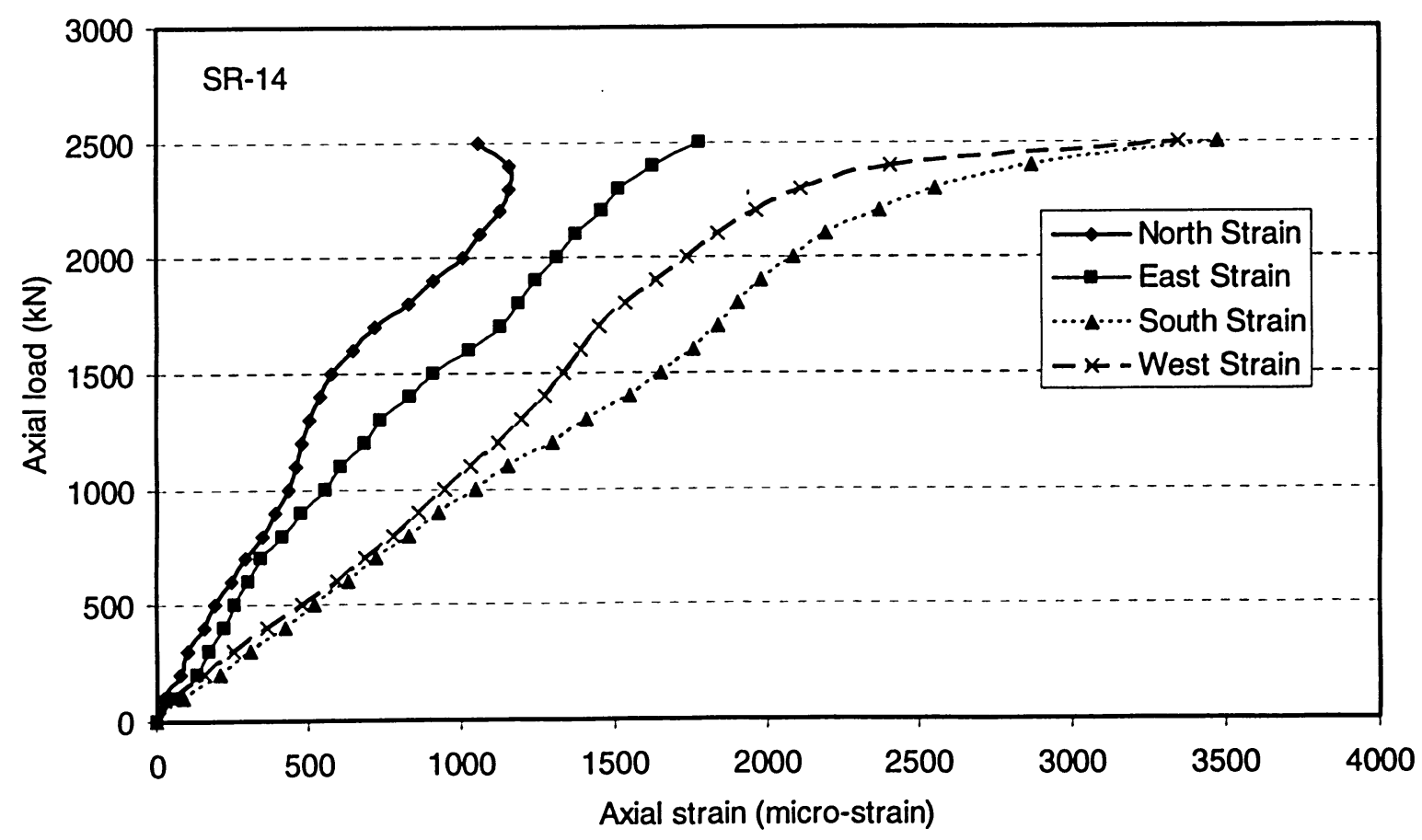

Figure 4.73 Axial load-strain relationships for specimen SR-14 


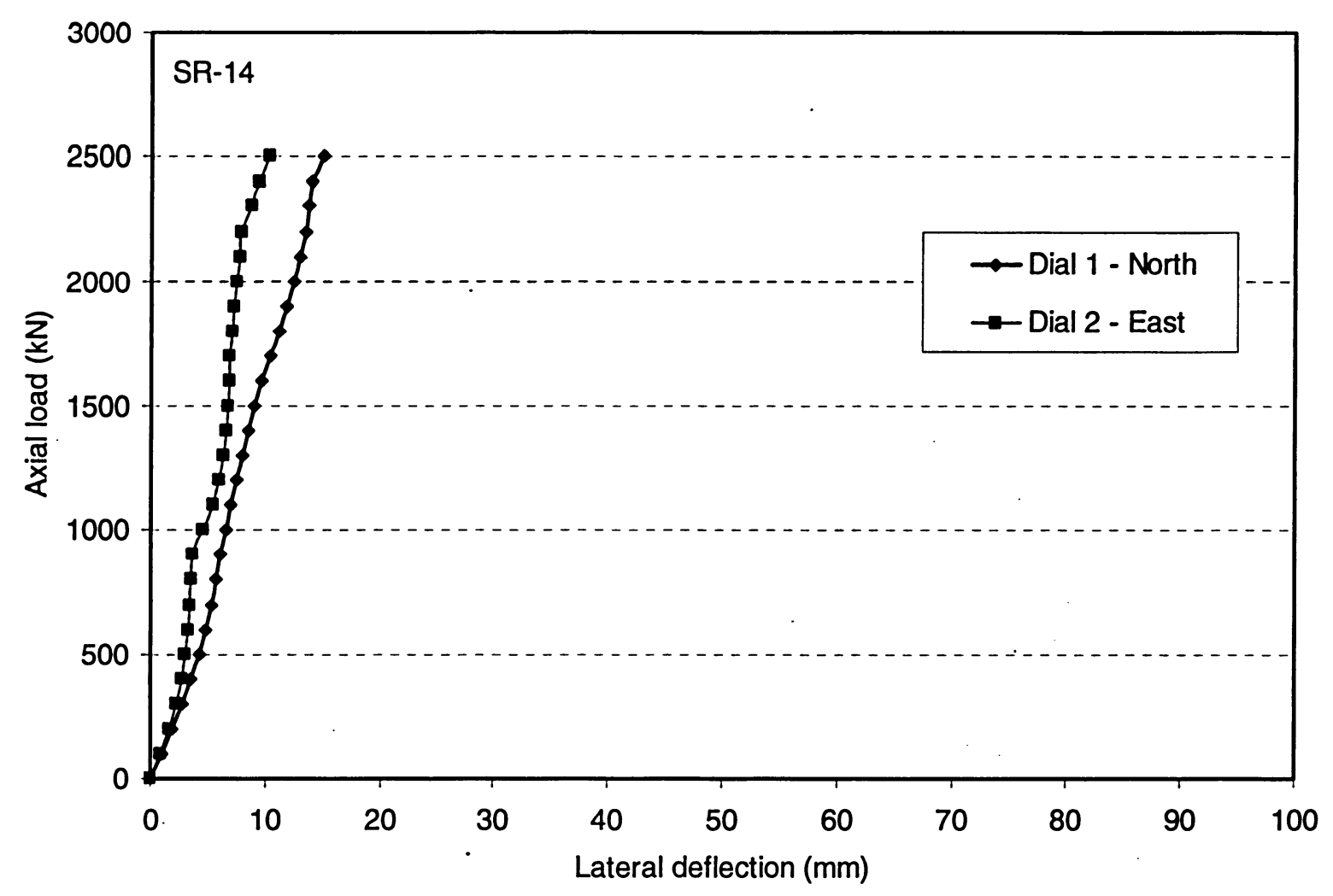

Figure 4.74 Load-lateral deflection curves for specimen SR-14

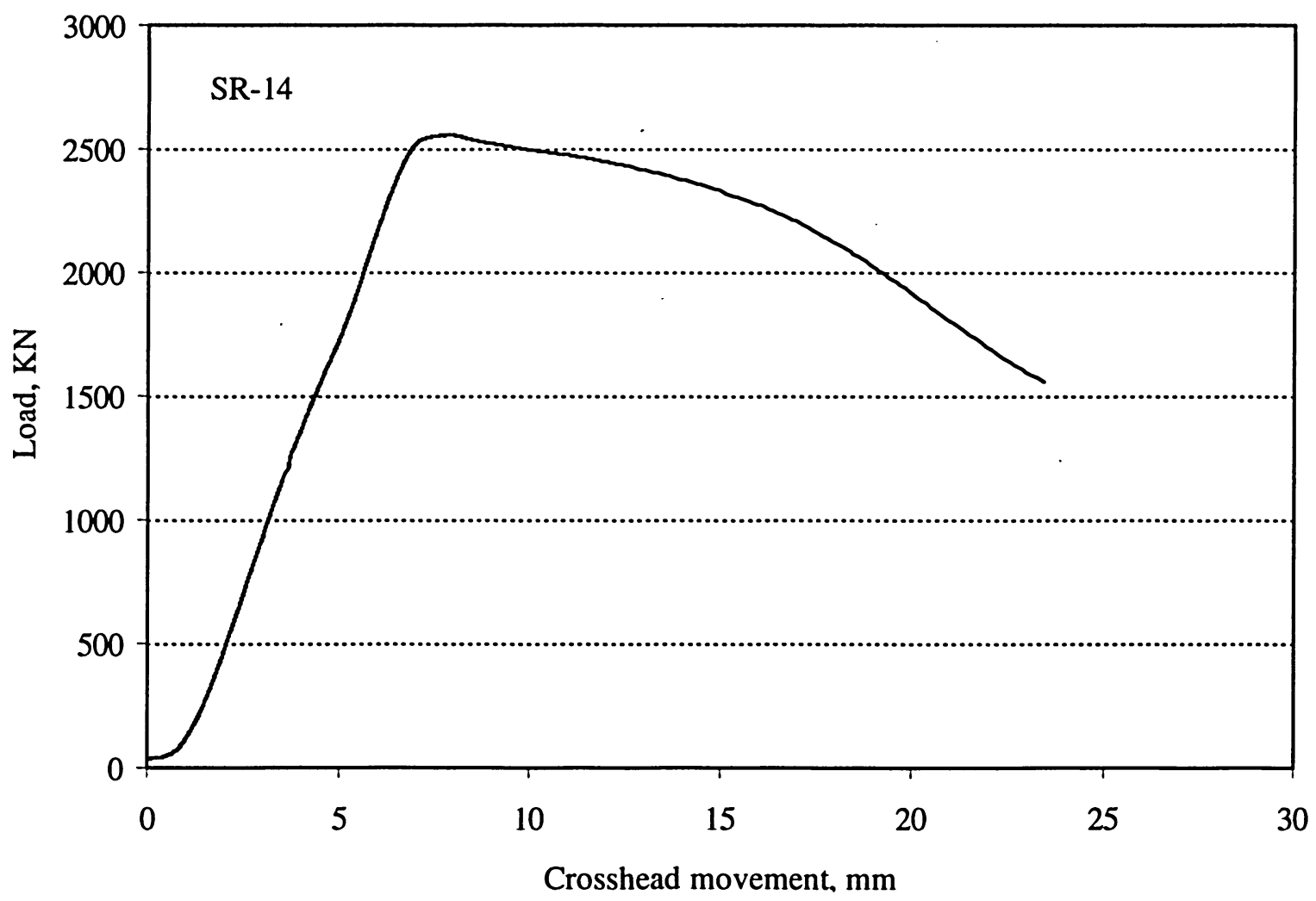

Figure 4.75 Load versus overall shortening curve for specimen SR-14 

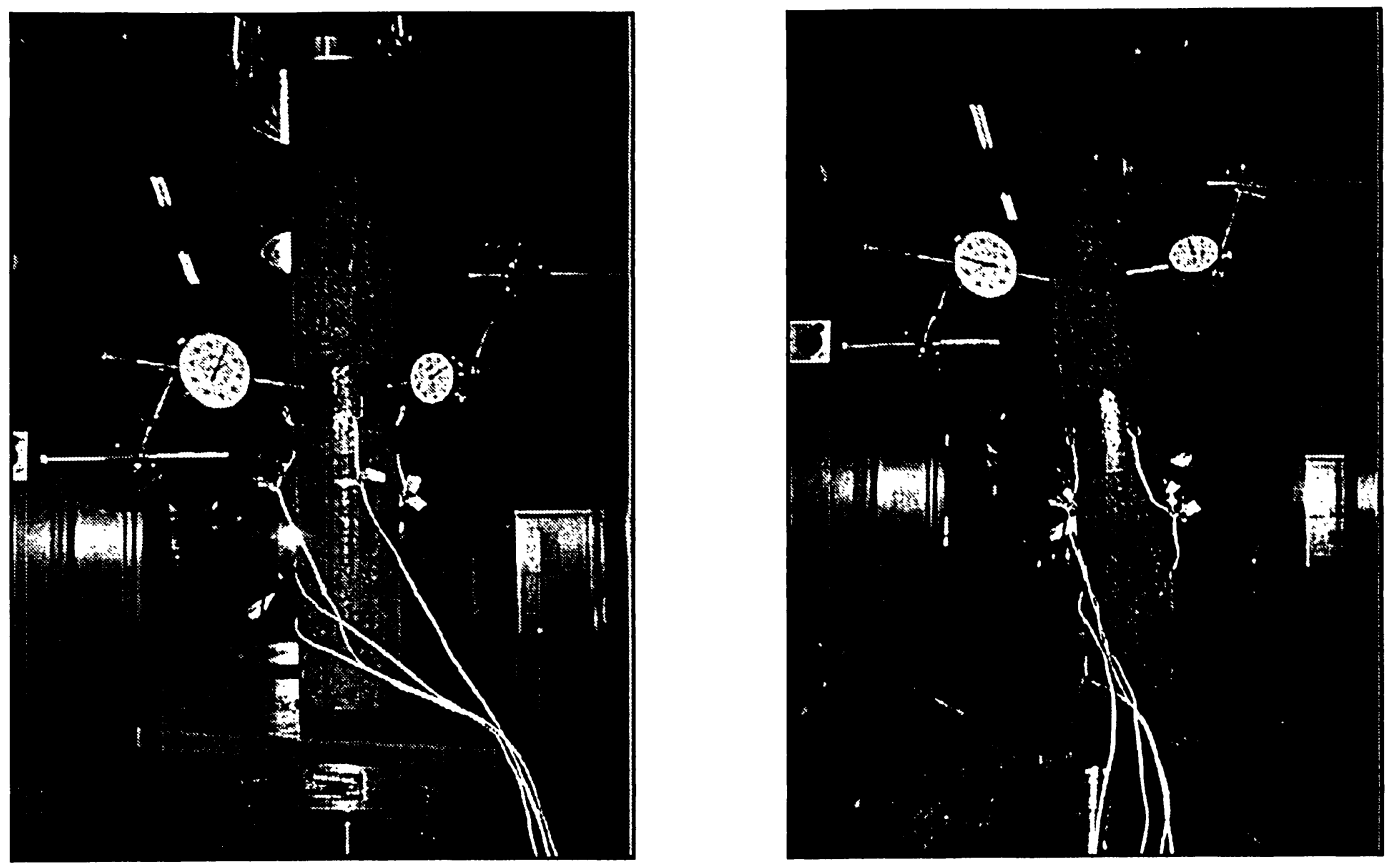

Figure 4.76 Views of specimen SR-15 before and after testing

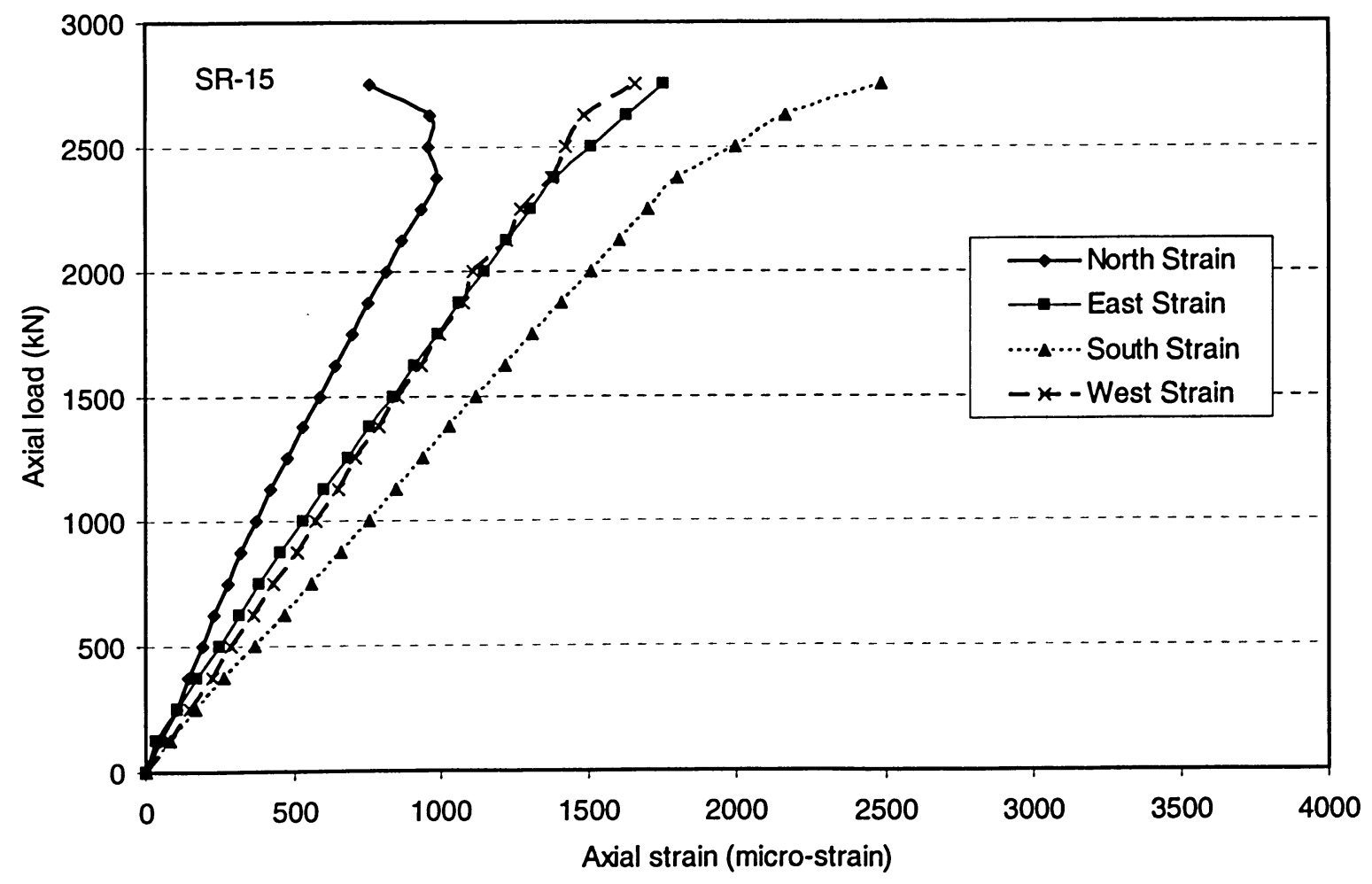

Figure 4.77 Axial load-strain relationships for specimen SR-15 


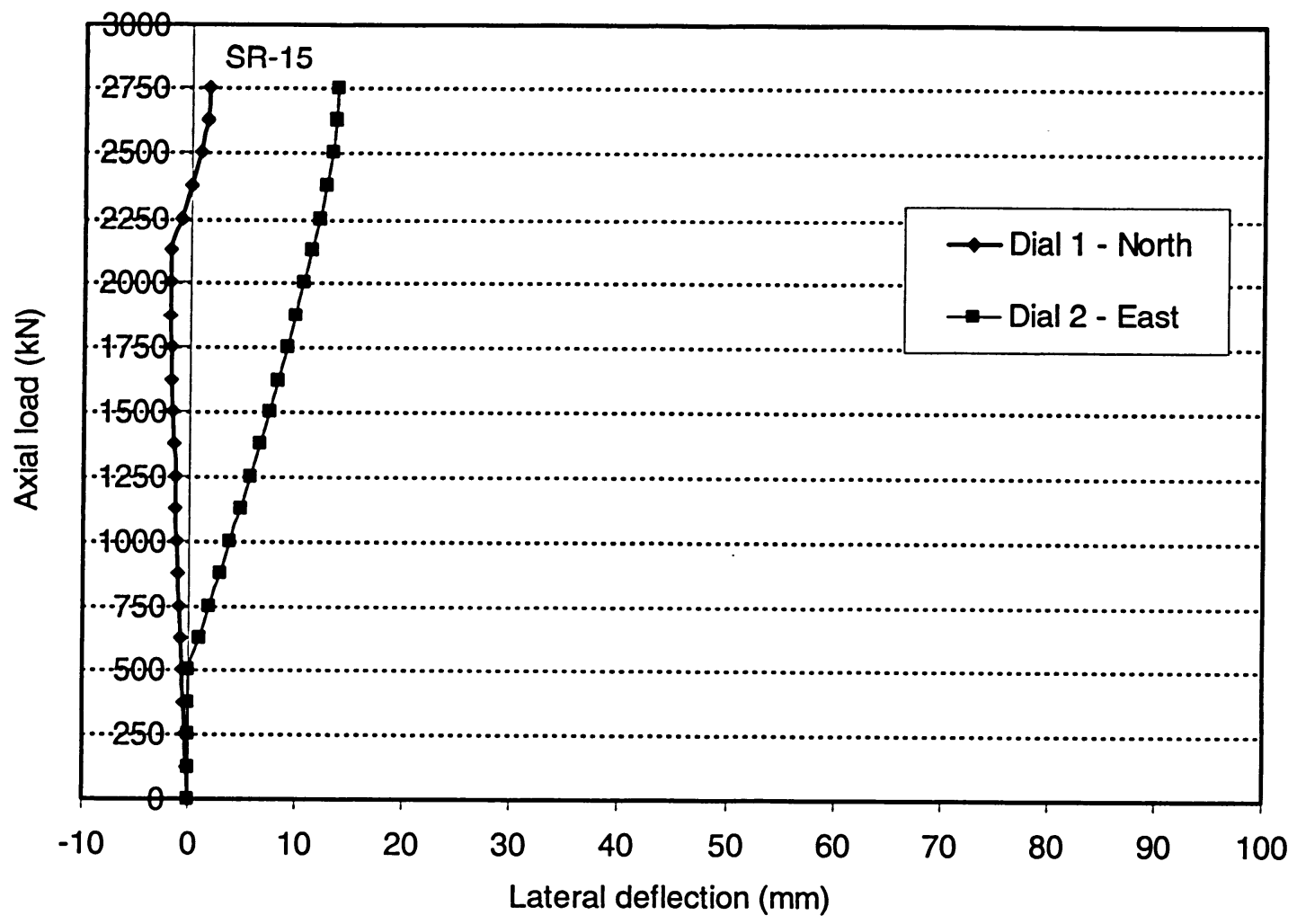

Figure 4.78 Load-lateral deflection curves for specimen SR-15

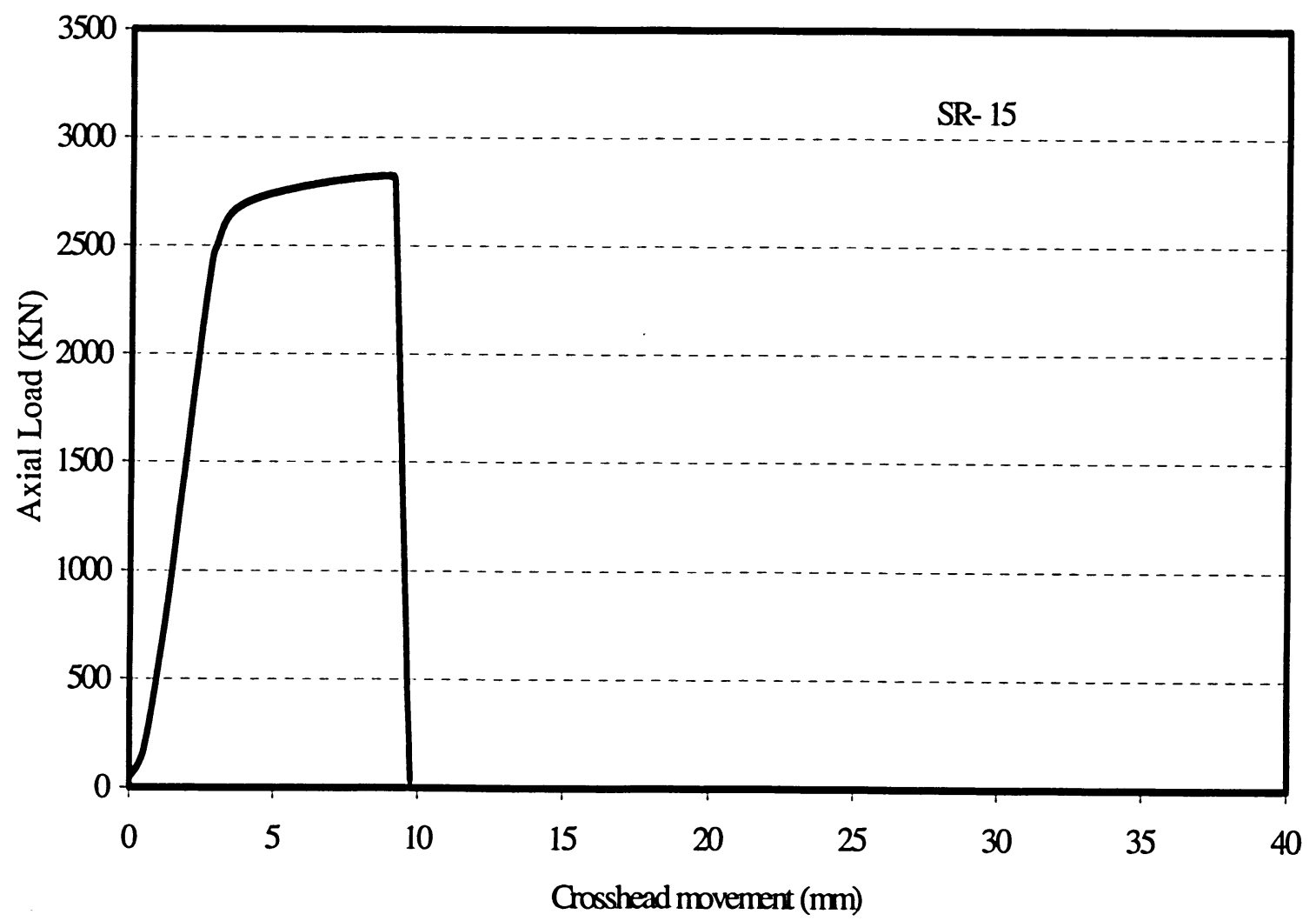

Figure 4.79 Load versus overall shortening curve for specimen NSR-15 

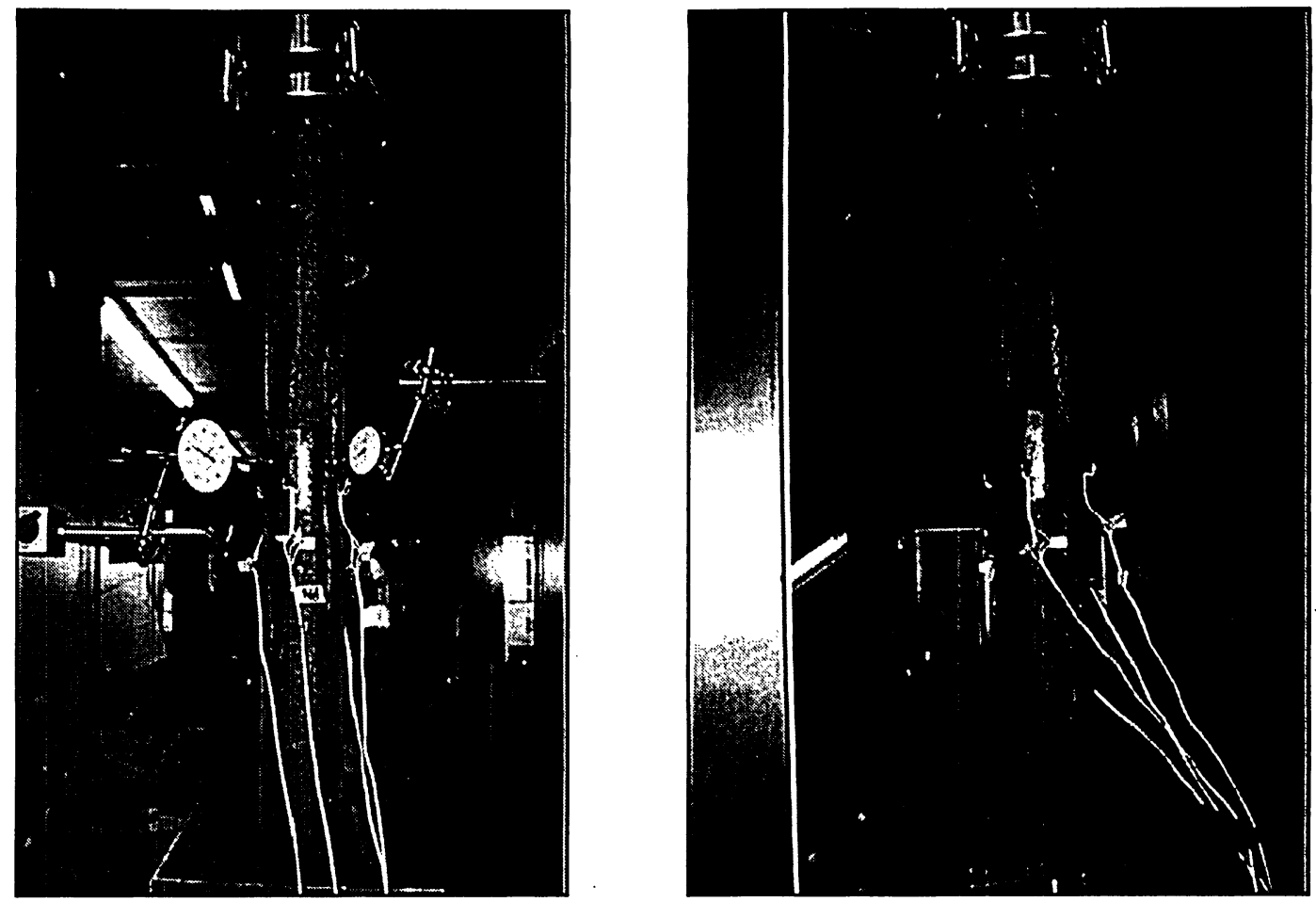

Figure 4.80 Views of specimen SR-16 before and after testing

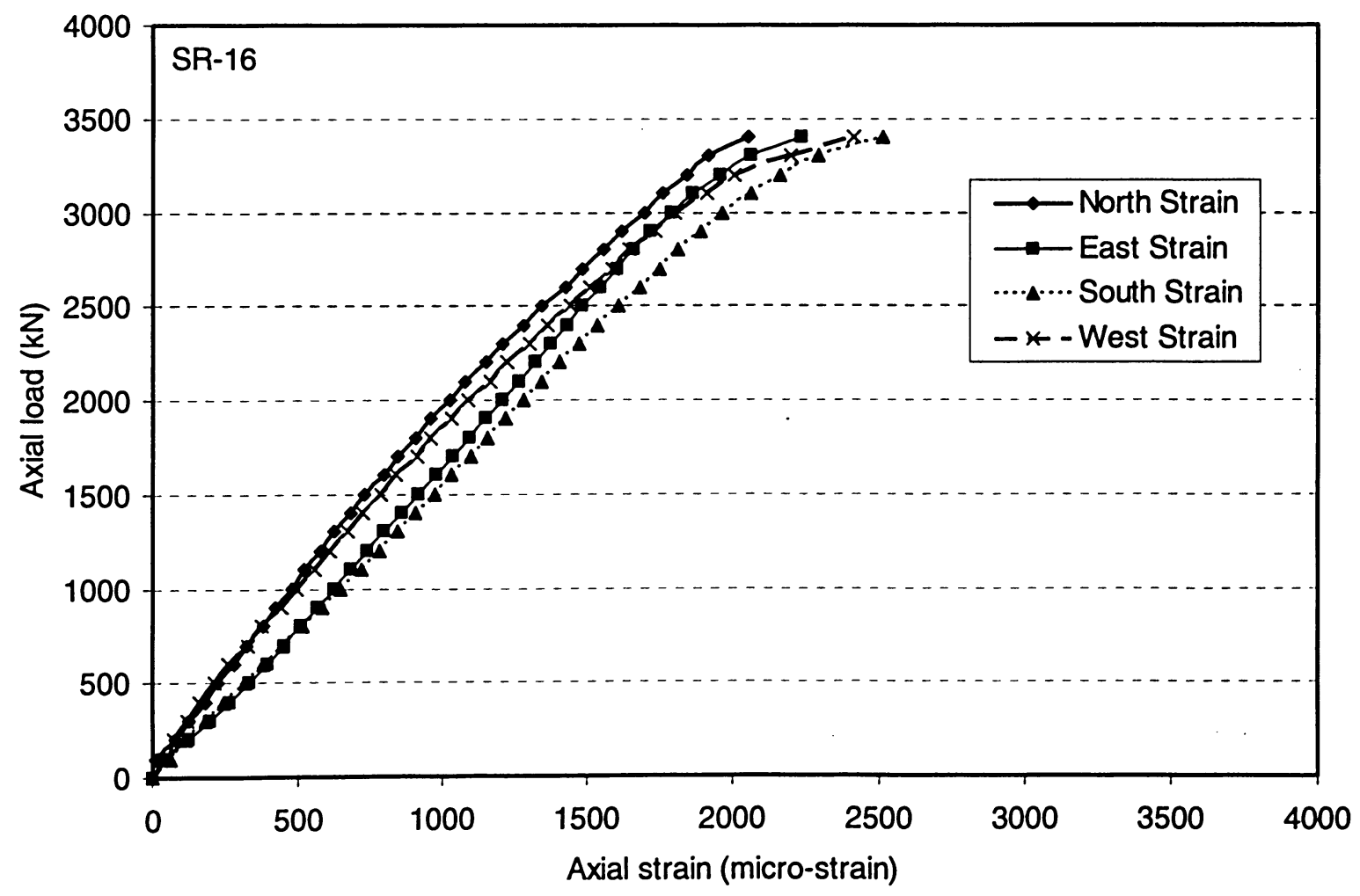

Figure 4.81 Axial load-strain relationships for specimen SR-16 


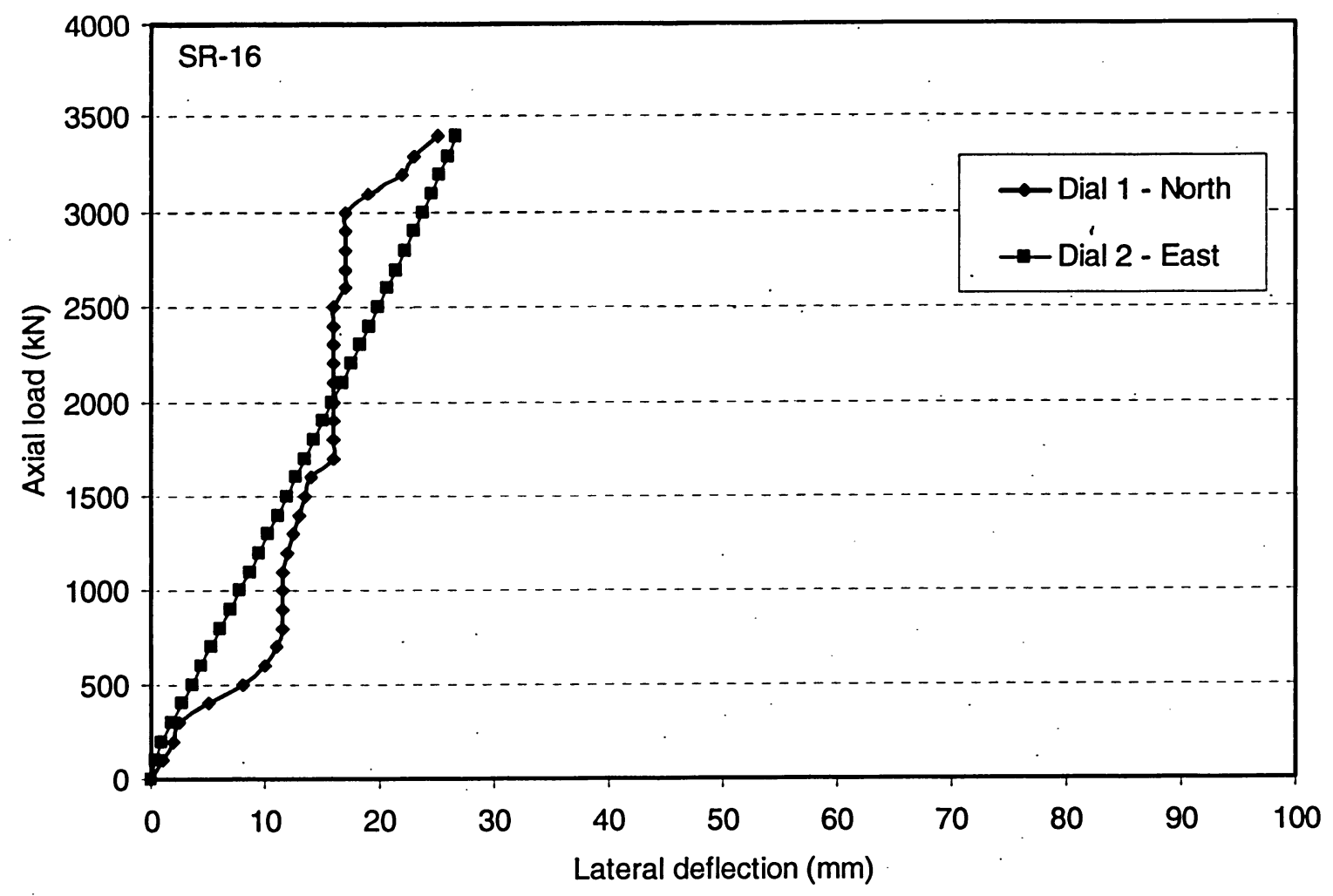

Figure 4.82 Load-lateral deflection curves for specimen SR-16

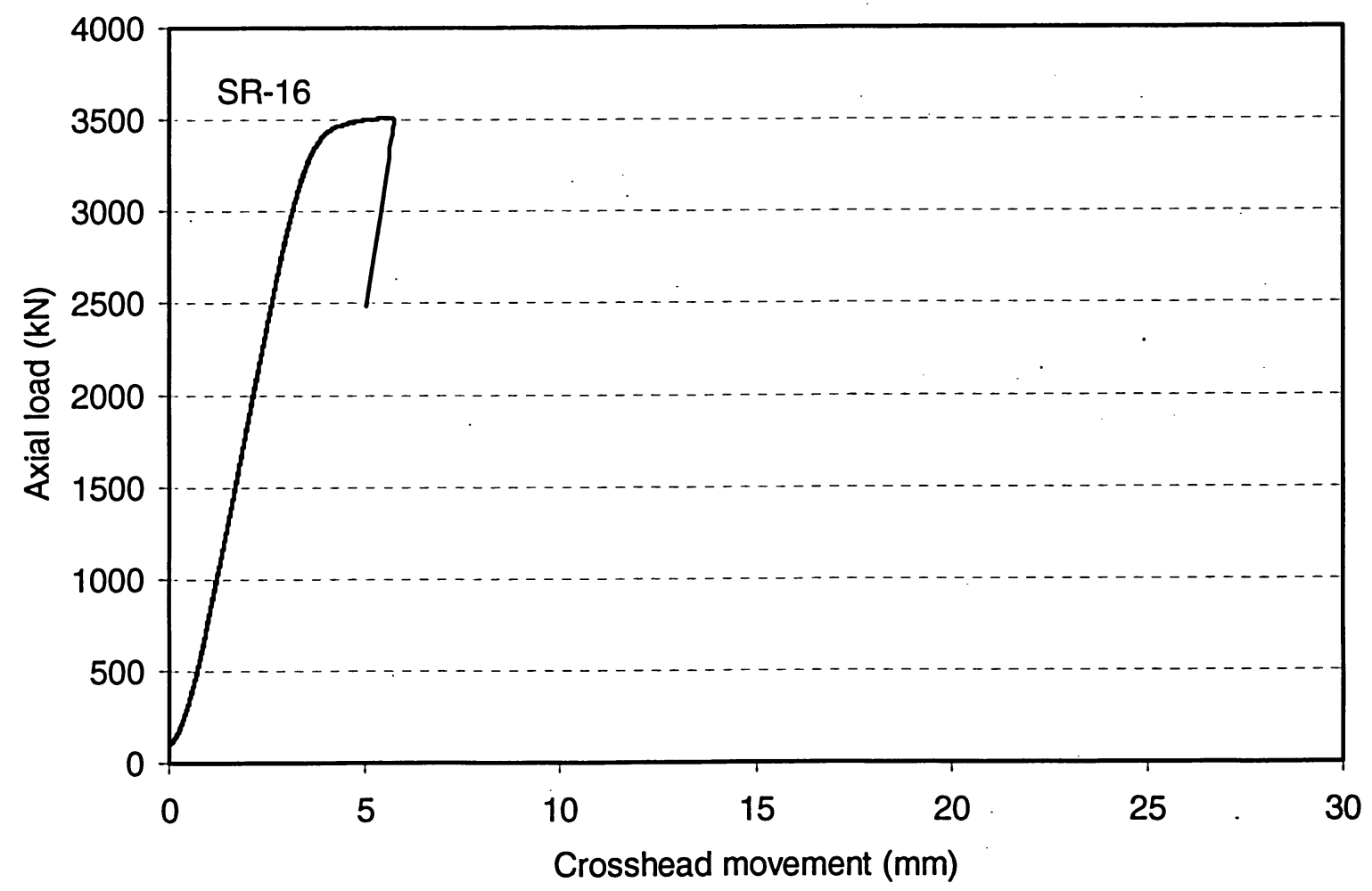

Figure 4.83 Load versus overall shortening curve for specimen SR-16 

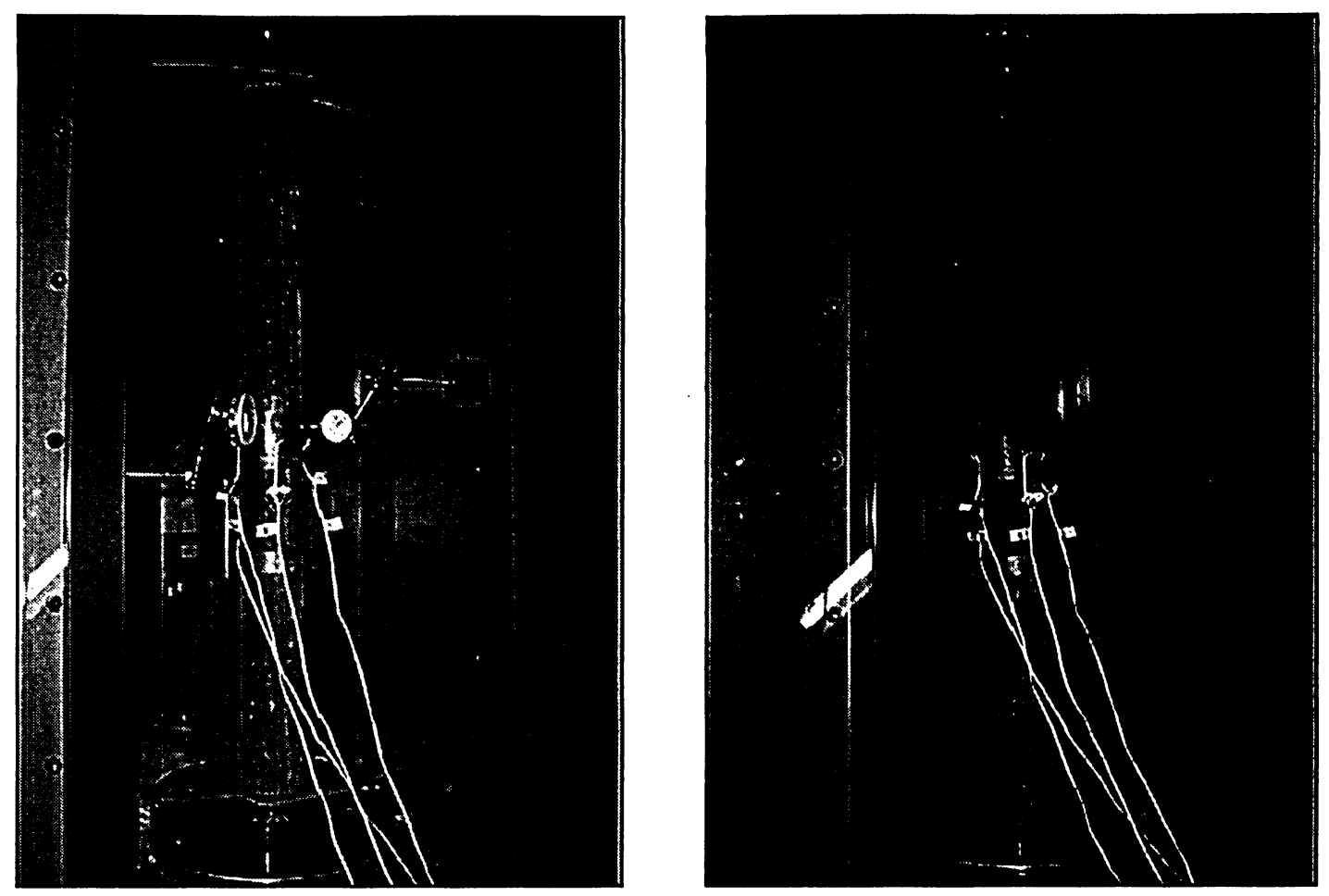

Figure 4.84 Views of specimen SR-17 before and after testing

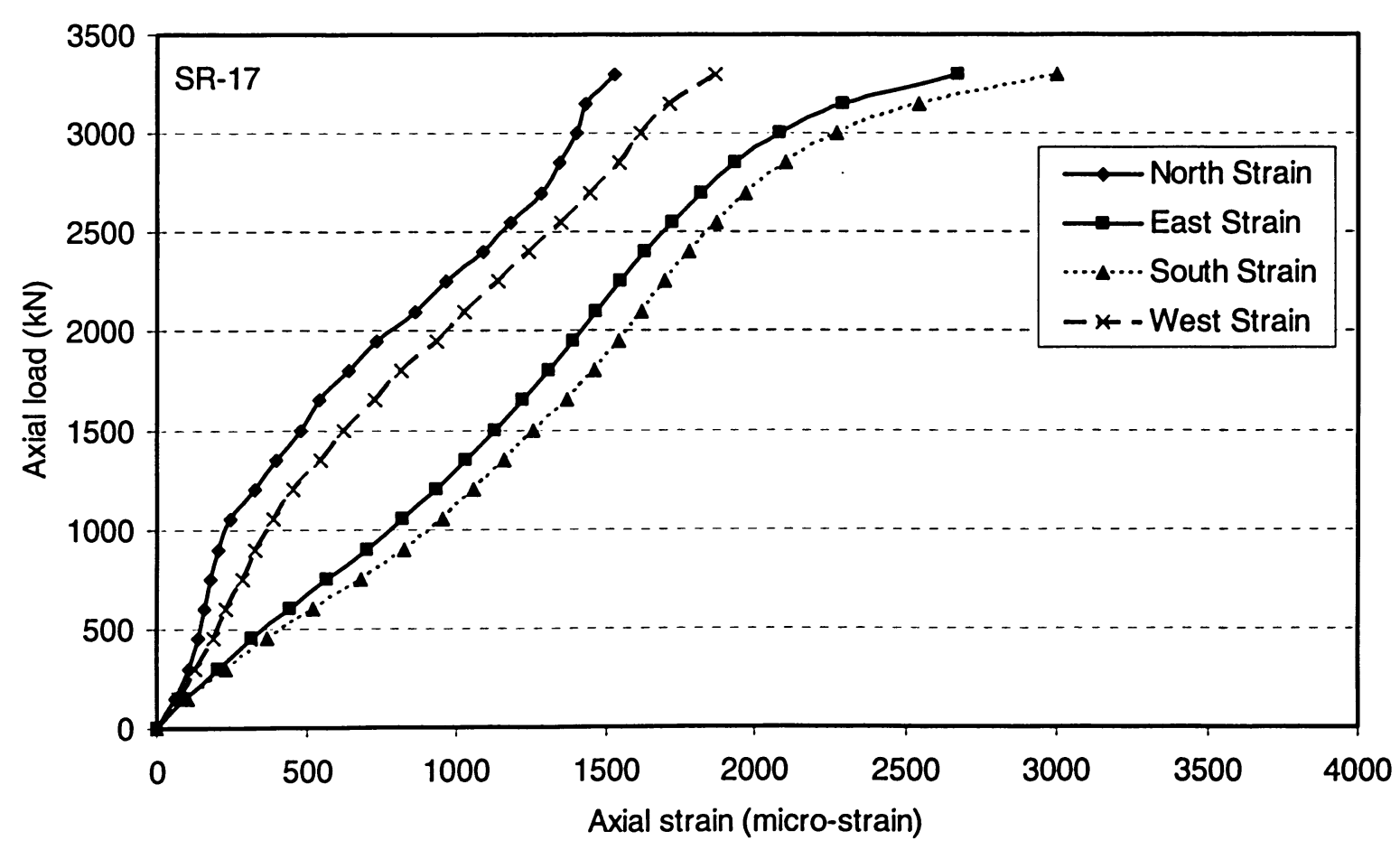

Figure 4.85 Axial load-strain relationships for specimen SR-17 


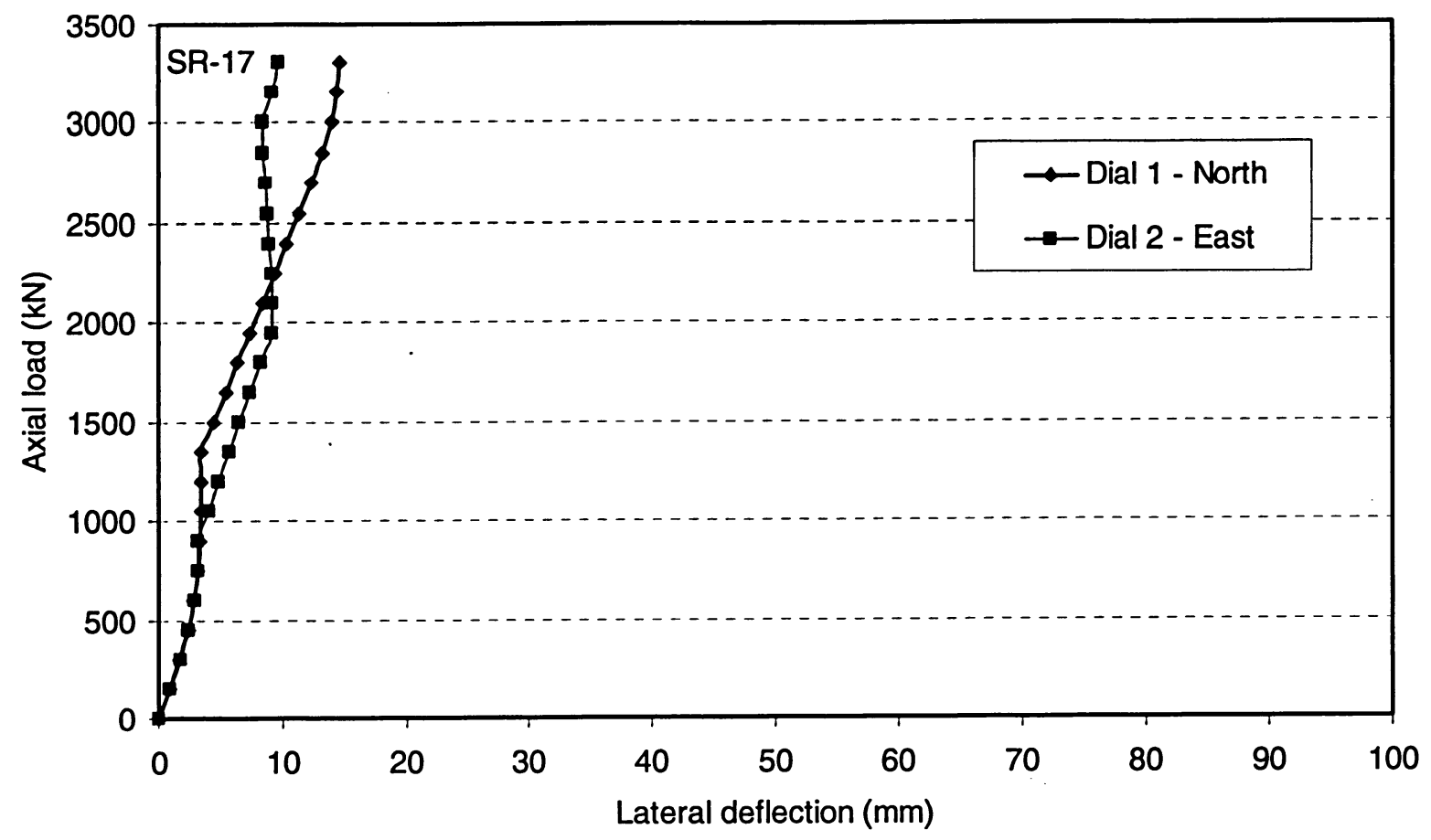

Figure 4.86 Load-lateral deflection curves for specimen SR-17

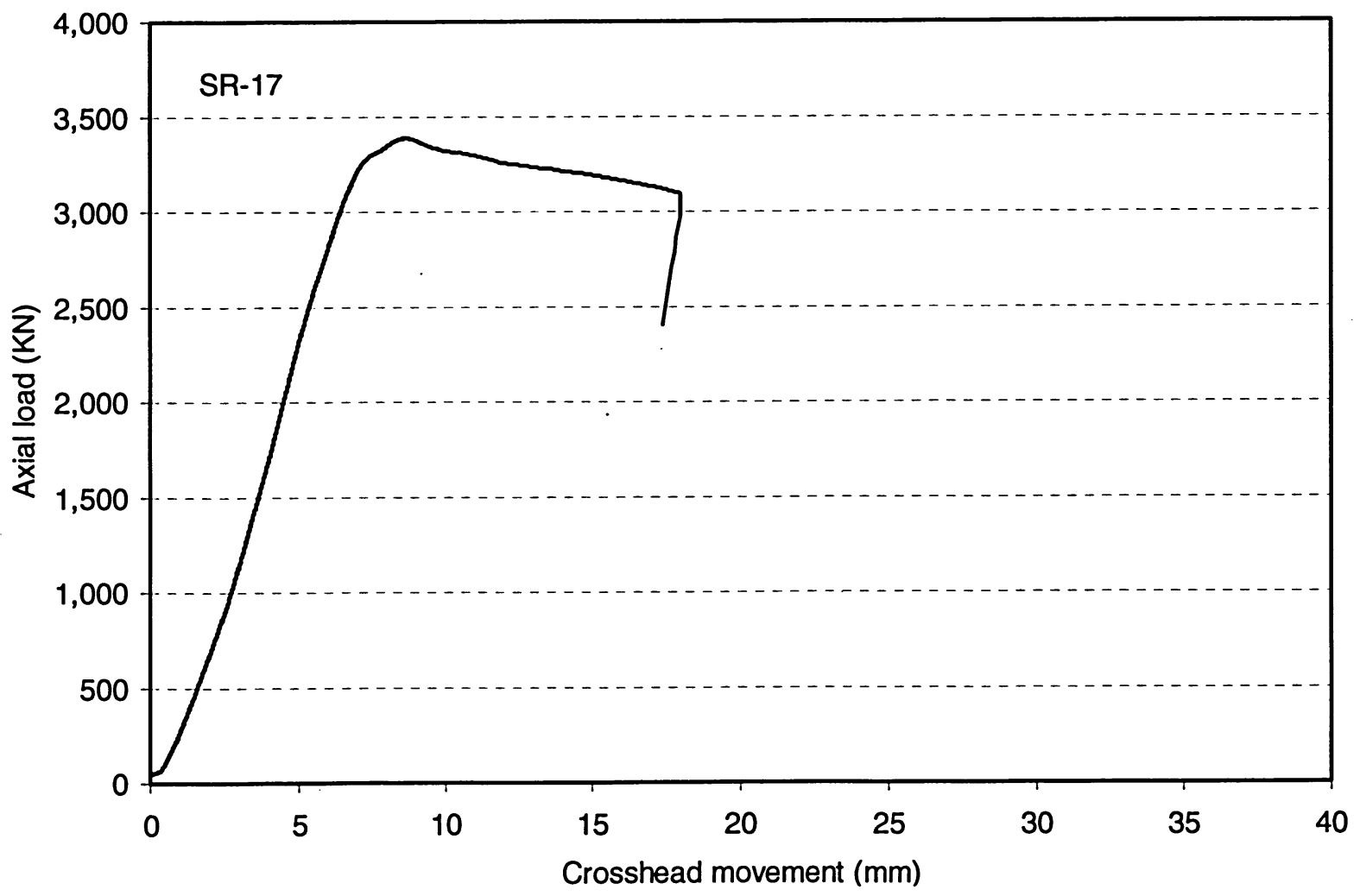

Figure 4.87 Load versus overall shortening curve for specimen SR-17 

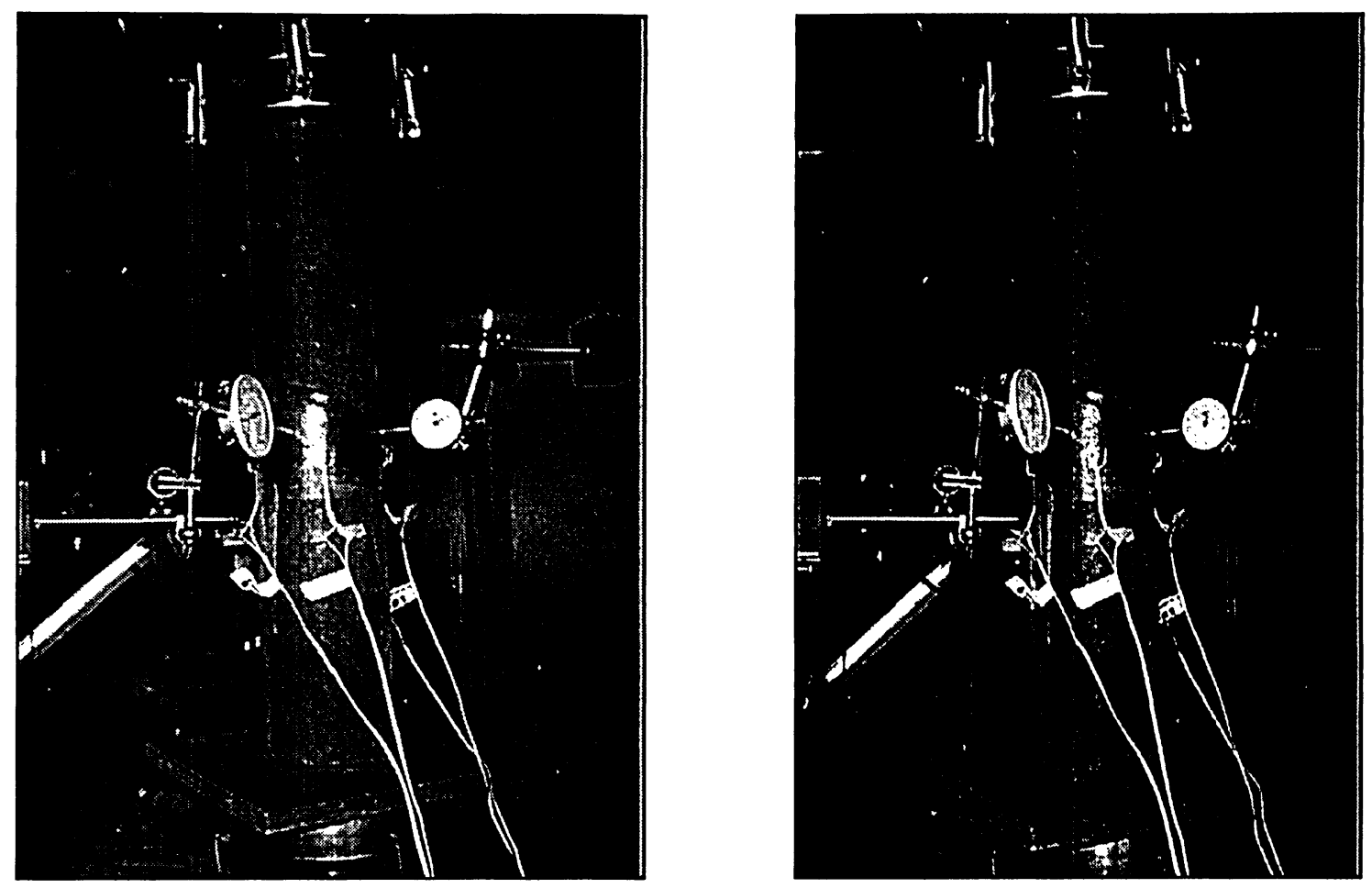

Figure 4.88 Views of specimen SR-18 before and after testing

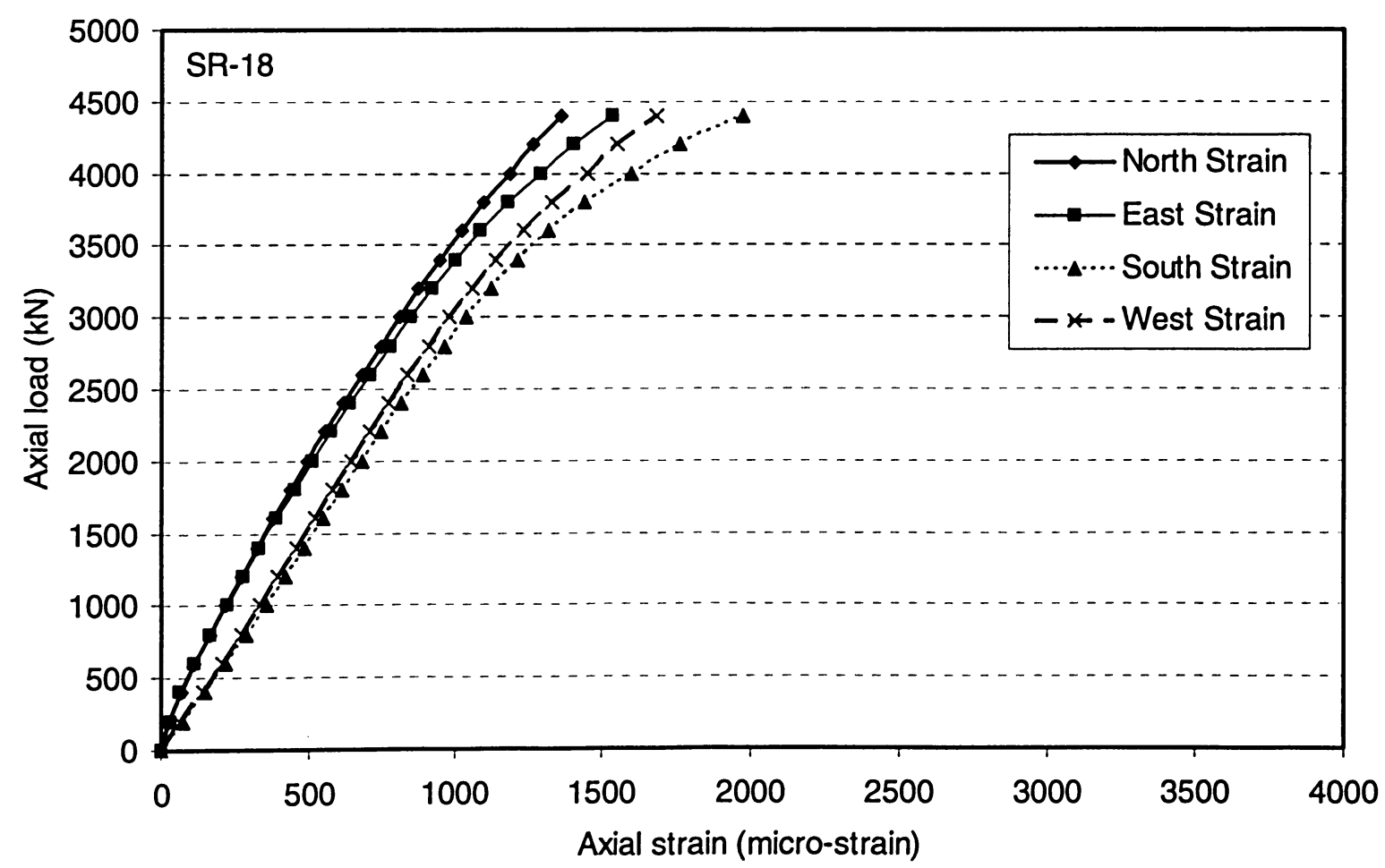

Figure 4.89 Axial load-strain relationships for specimen SR-18 


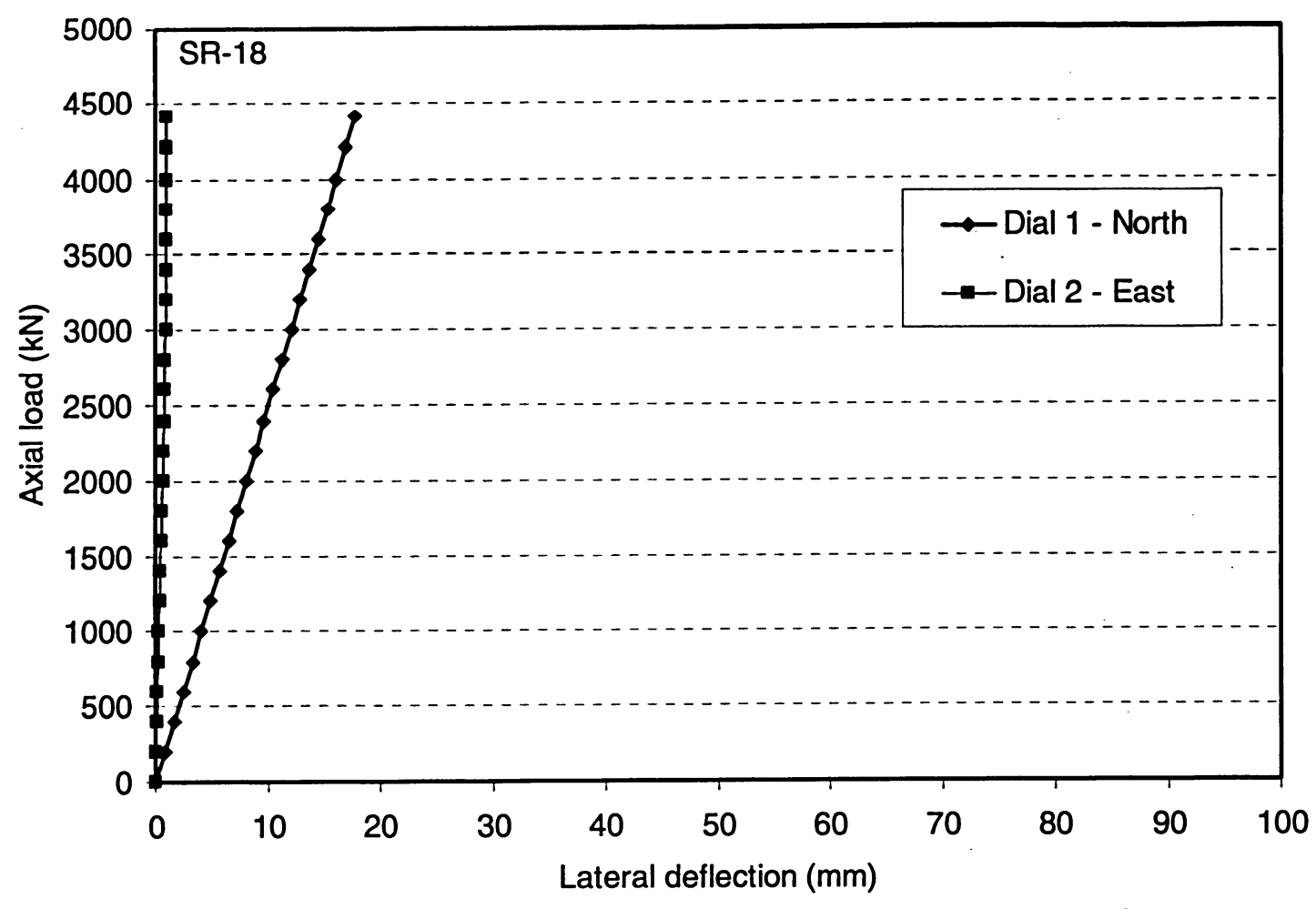

Figure 4.90 Load-lateral deflection curves for specimen SR-18

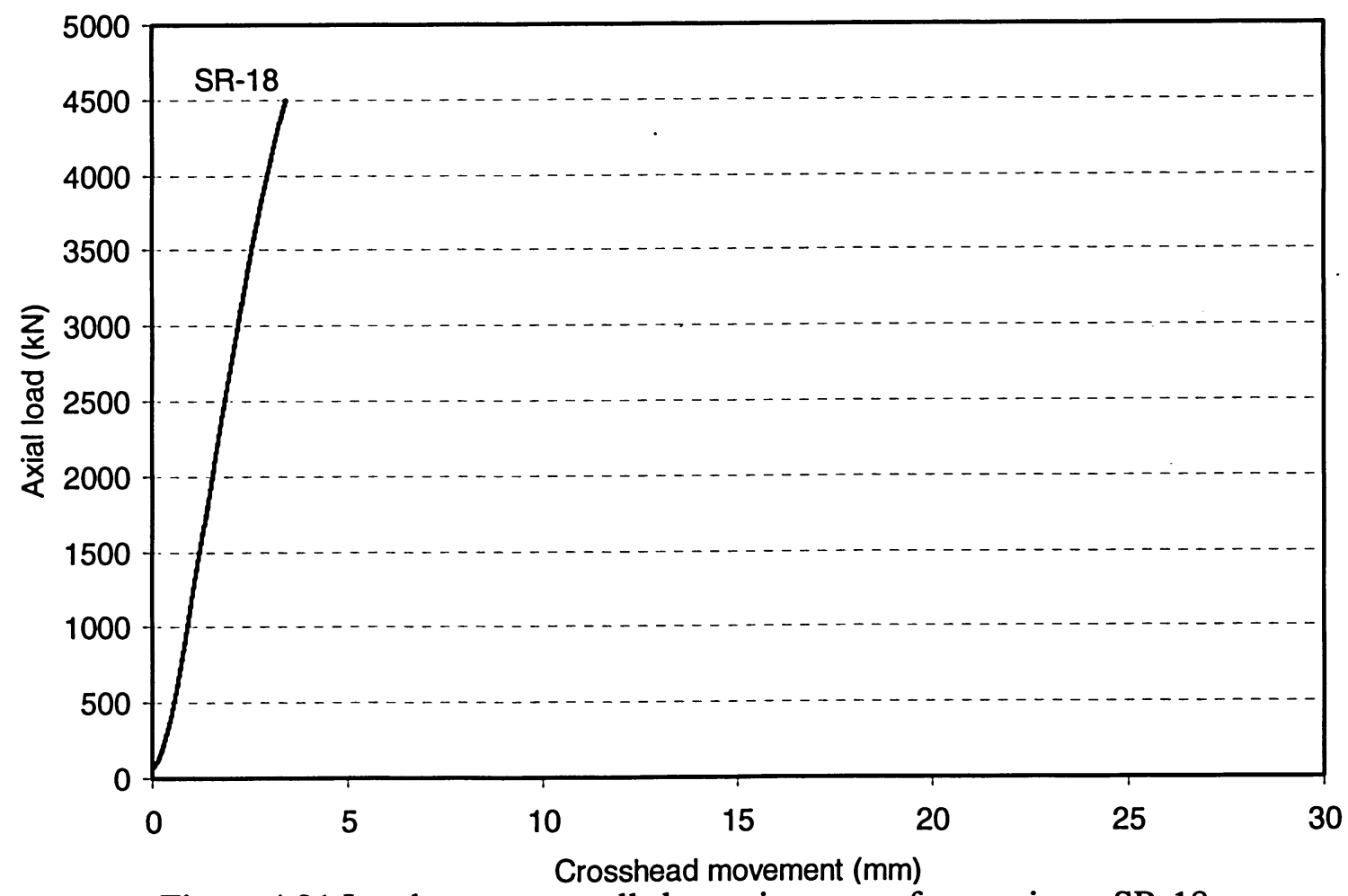

Figure 4.91 Load versus overall shortening curve for specimen SR-18 

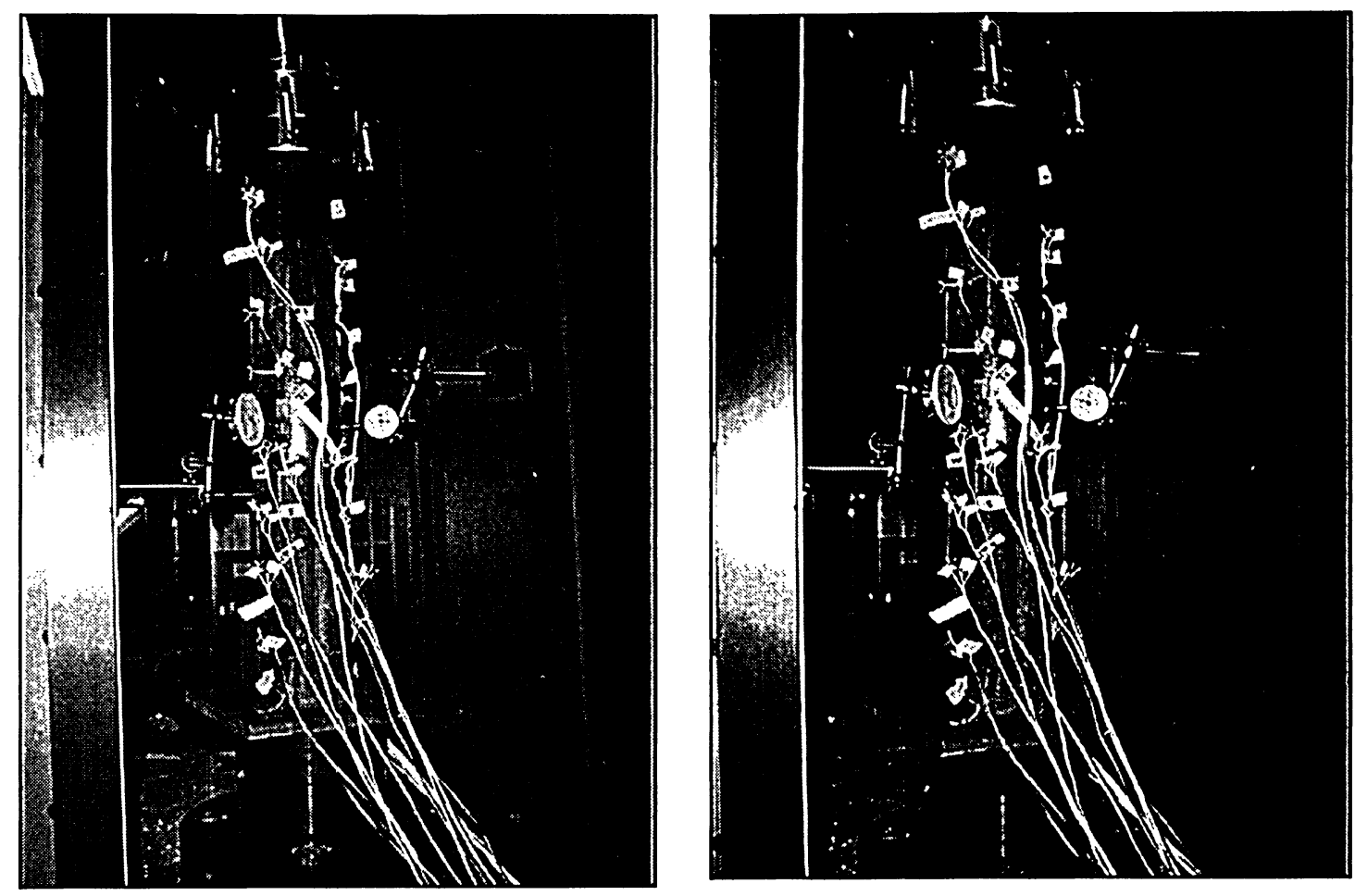

Figure 4.92 Views of specimen SR-19 before and after testing

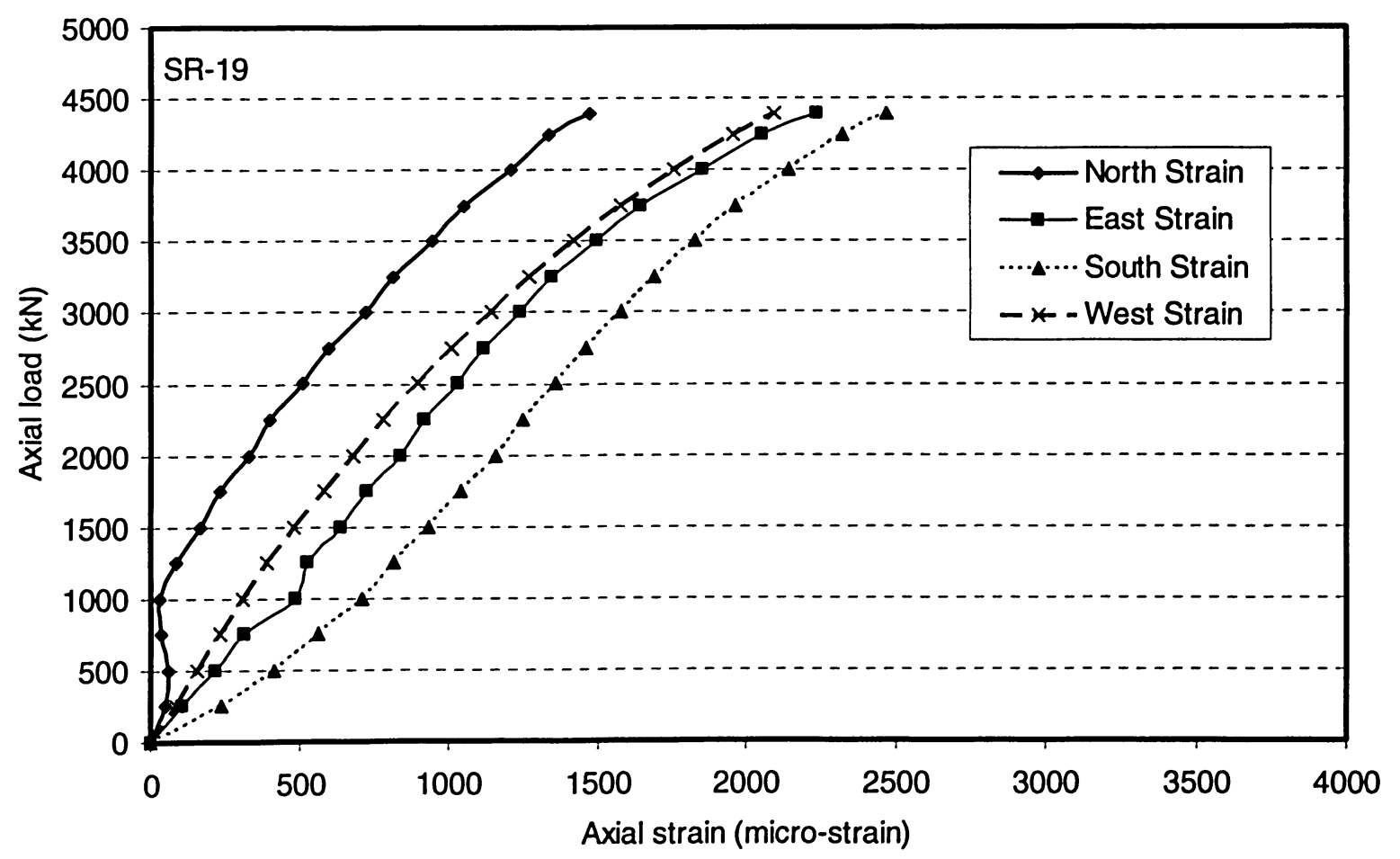

Figure 4.93 Axial load-strain relationships for specimen SR-19 


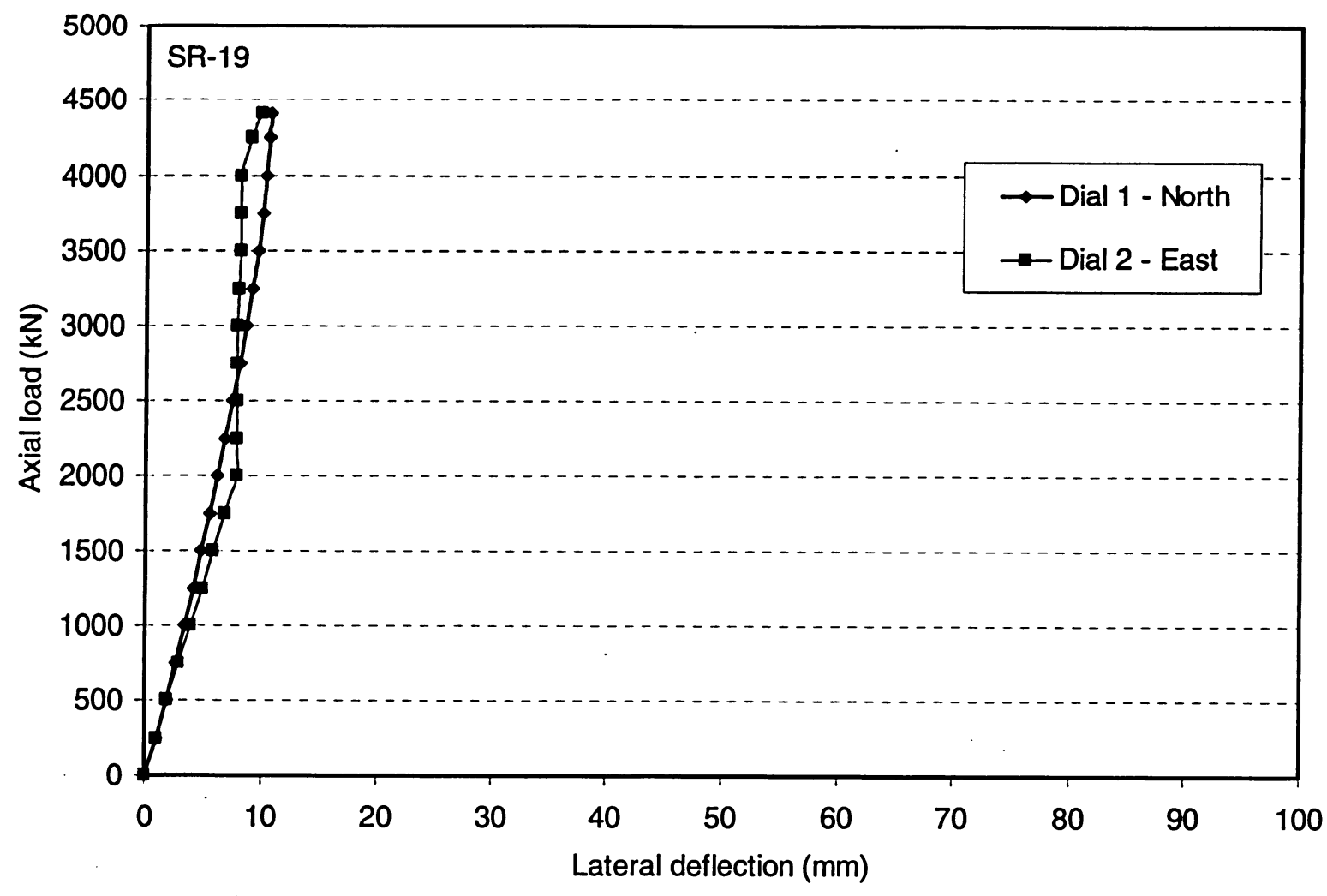

Figure 4.94 Load-lateral deflection curves for specimen SR-19

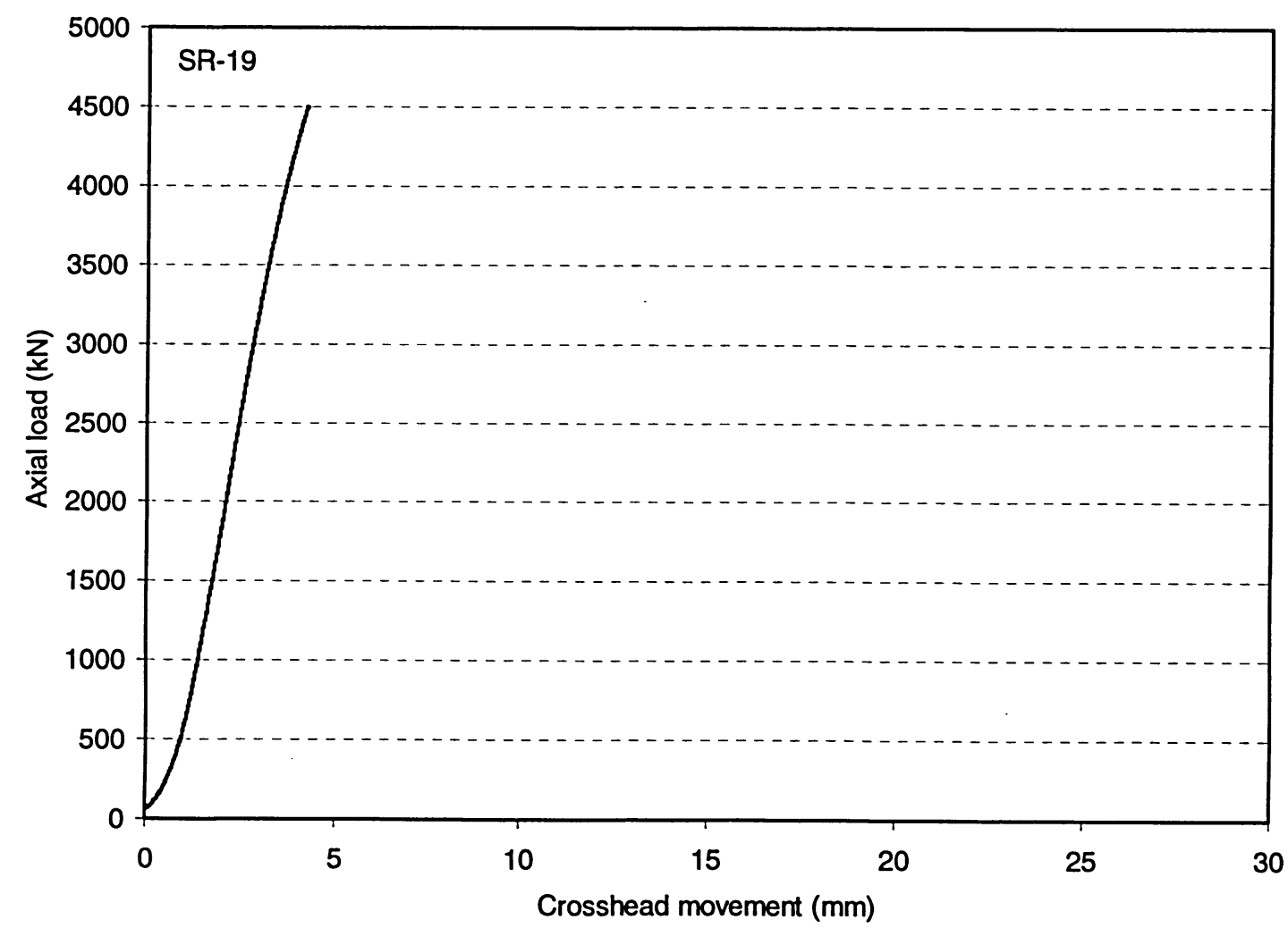

Figure 4.95 Load versus overall shortening curve for specimen SR-19 

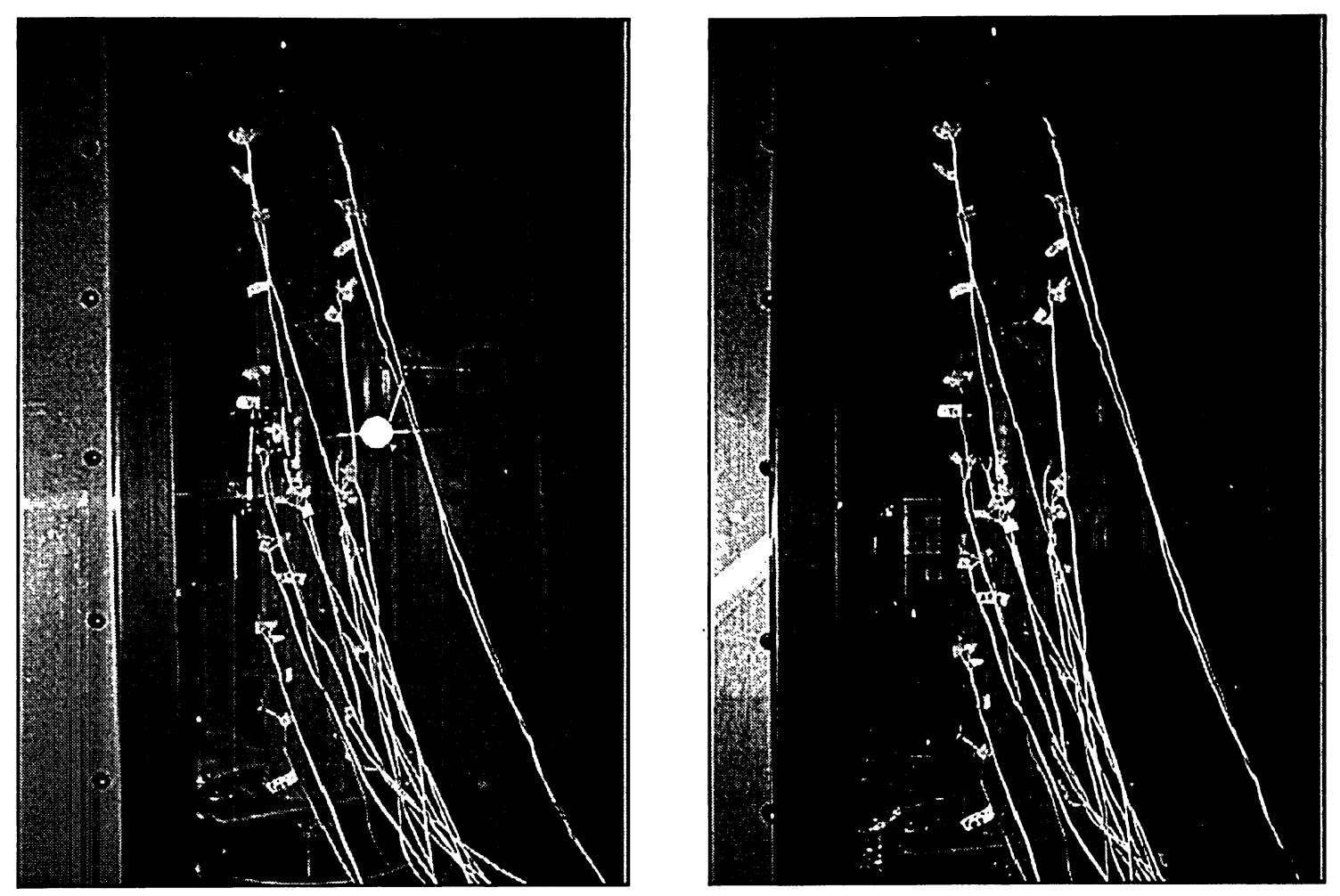

Figure 4.96 Views of specimen SR-20 before and after testing

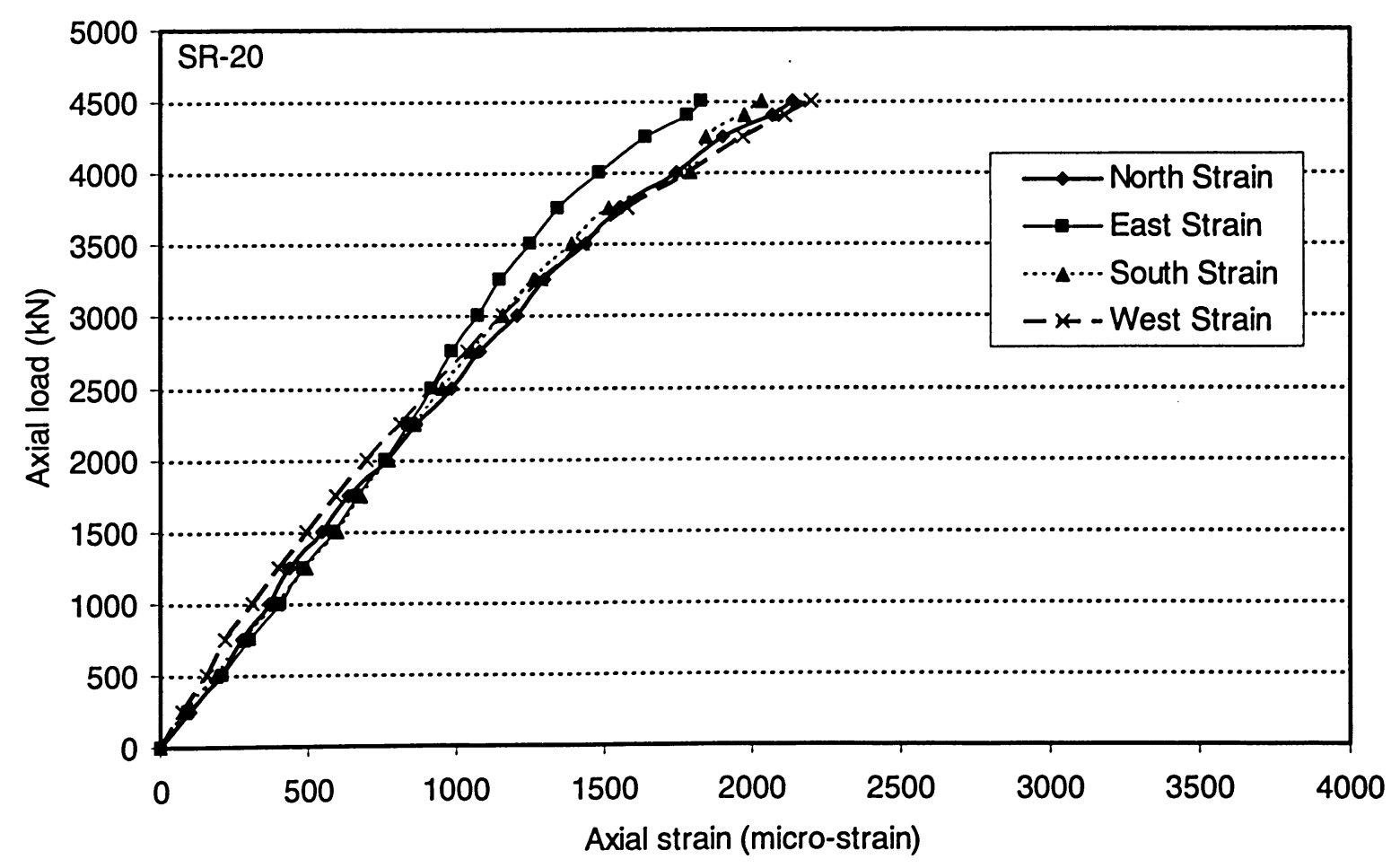

Figure4.97 Axial load-strain relationships for specimen SR-20 


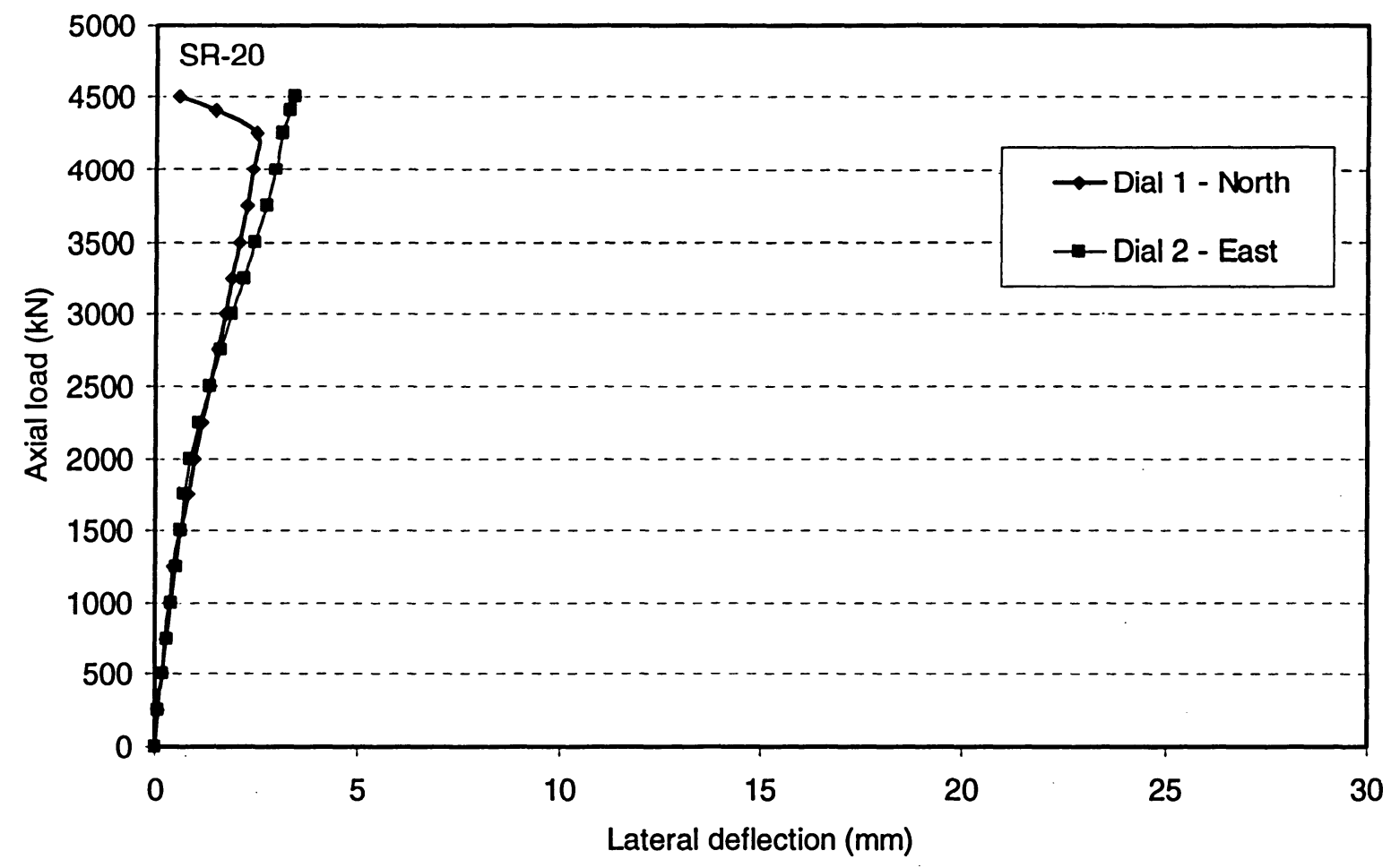

Figure 4.98 Load versus overall shortening curve for specimen SR-20

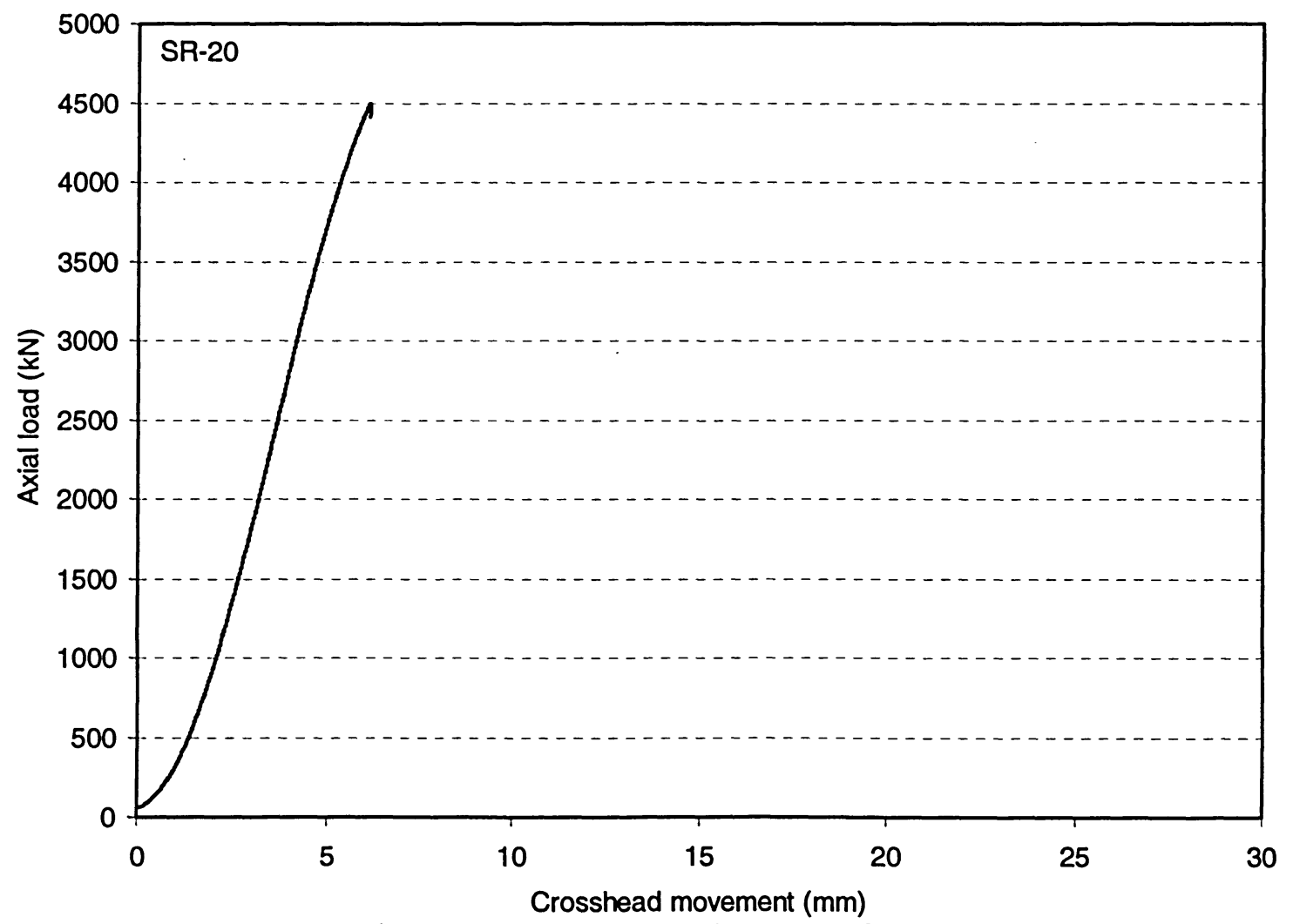

Figure 4.99 Load versus overall shortening curve for specimen SR-20 

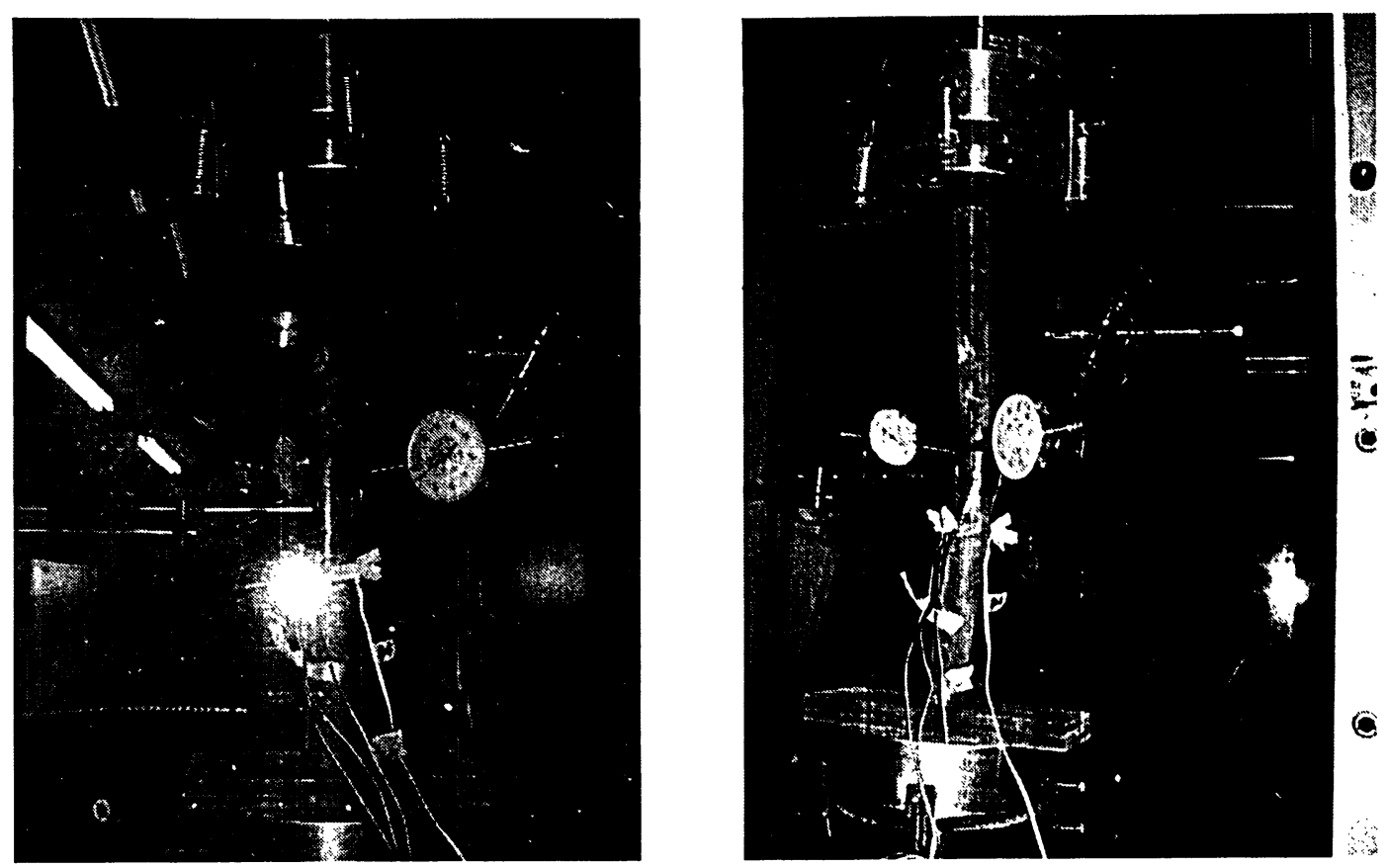

Figure 4.100 Views of specimen NSR-1 before and after testing
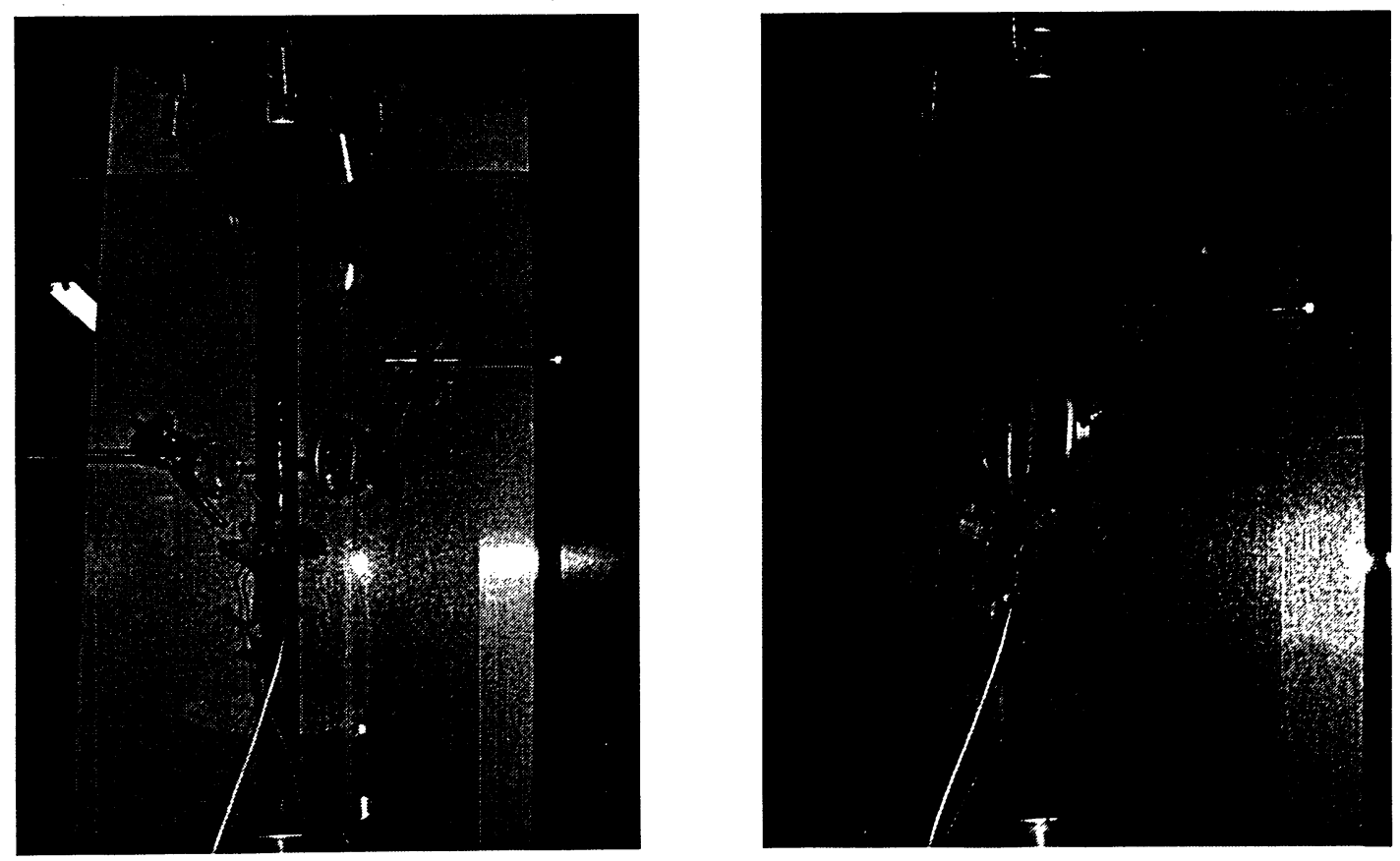

Figure 4.101 Views of specimen NSR-2 before and after testing 


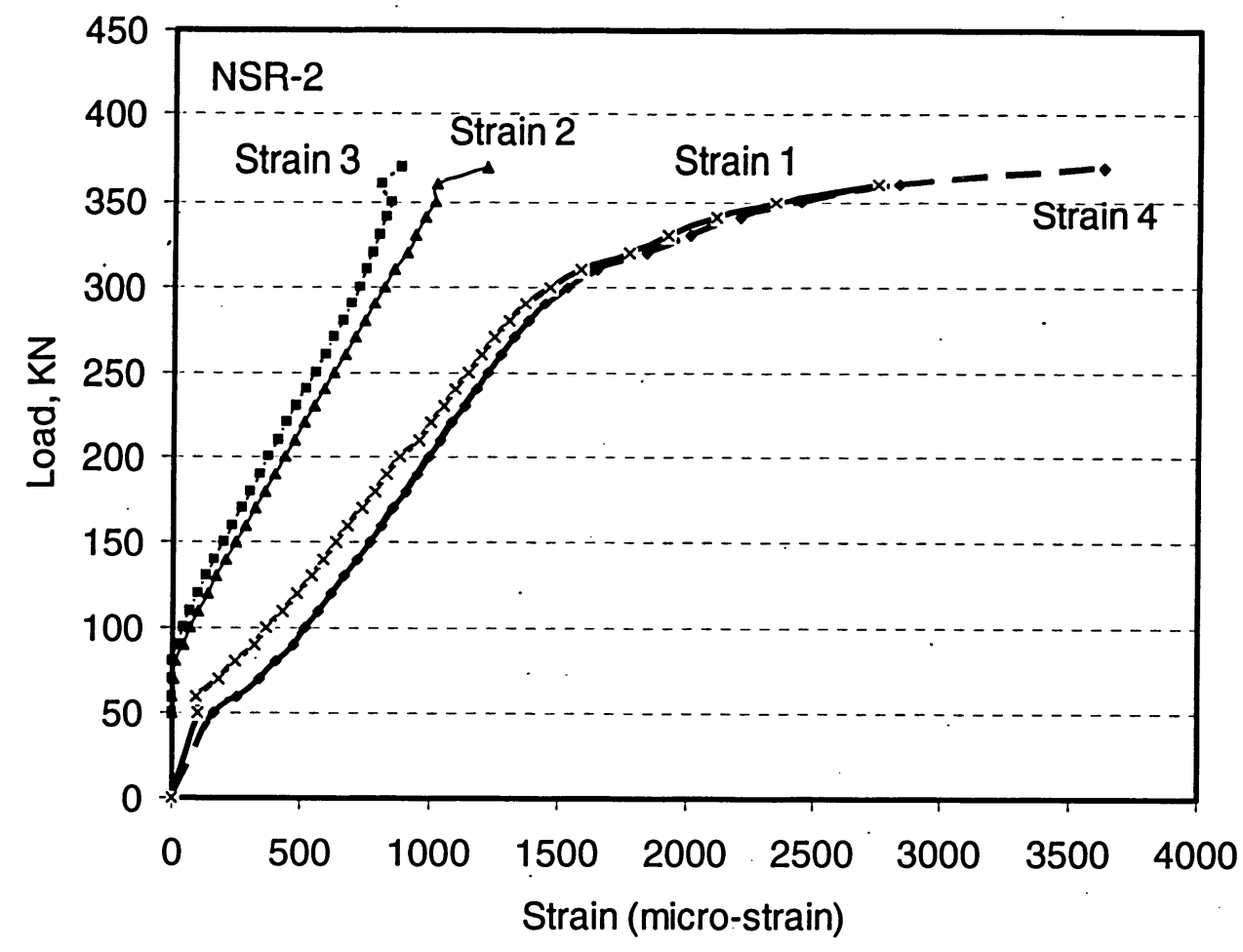

Figure 4.102 Axial load-strain relationships for specimen NSR-2

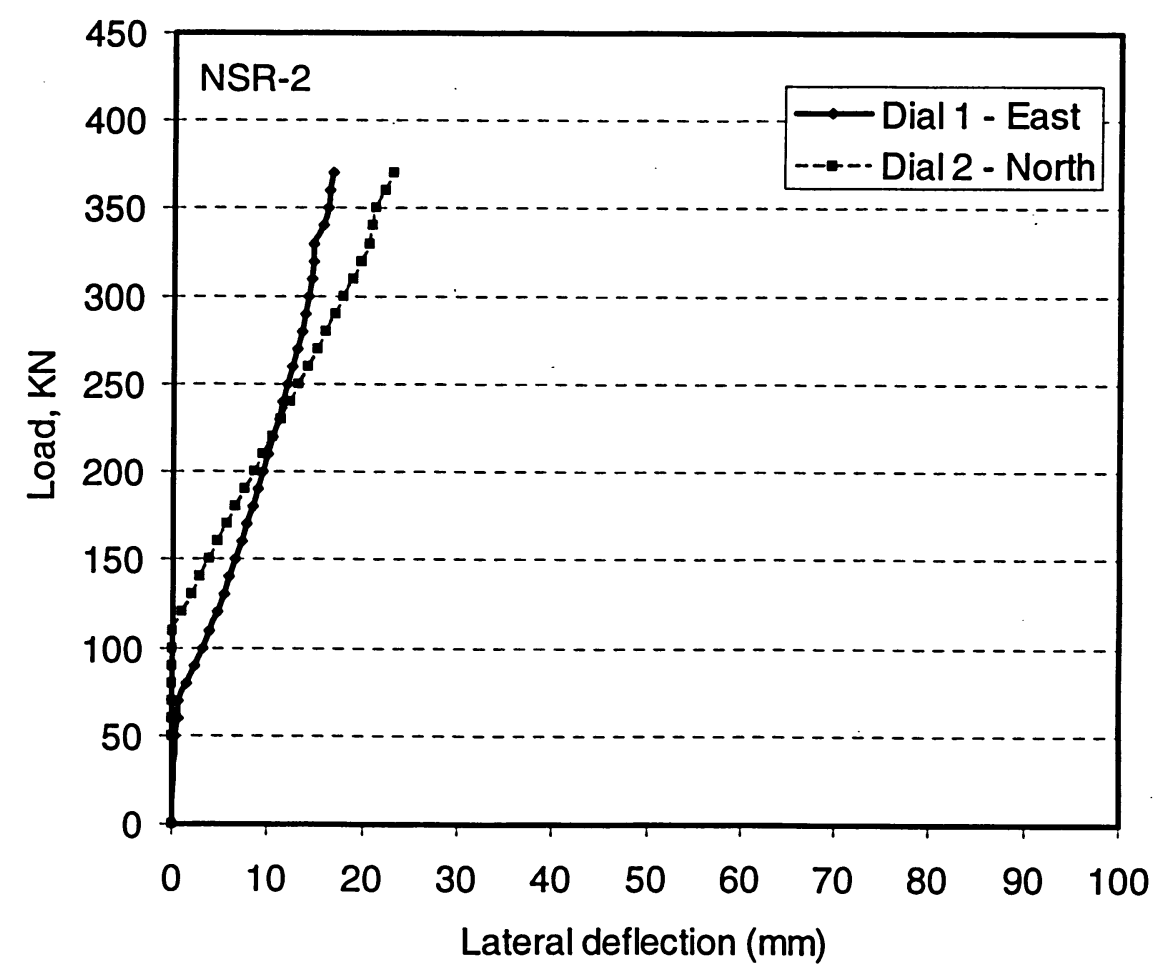

Figure 4.103 Load-lateral deflection curves for specimen NSR-2 


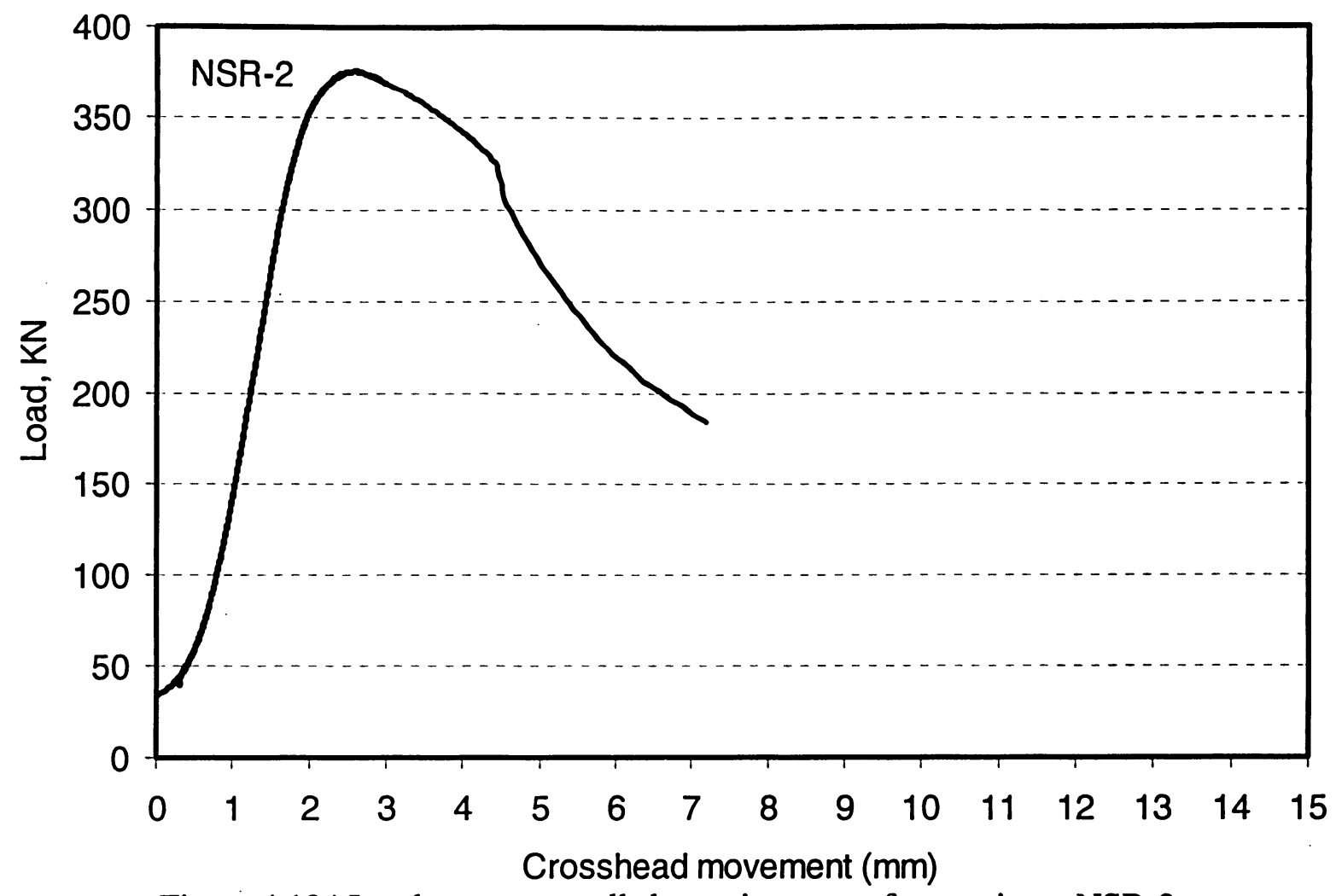

Figure 4.104 Load versus overall shortening curve for specimen NSR-2
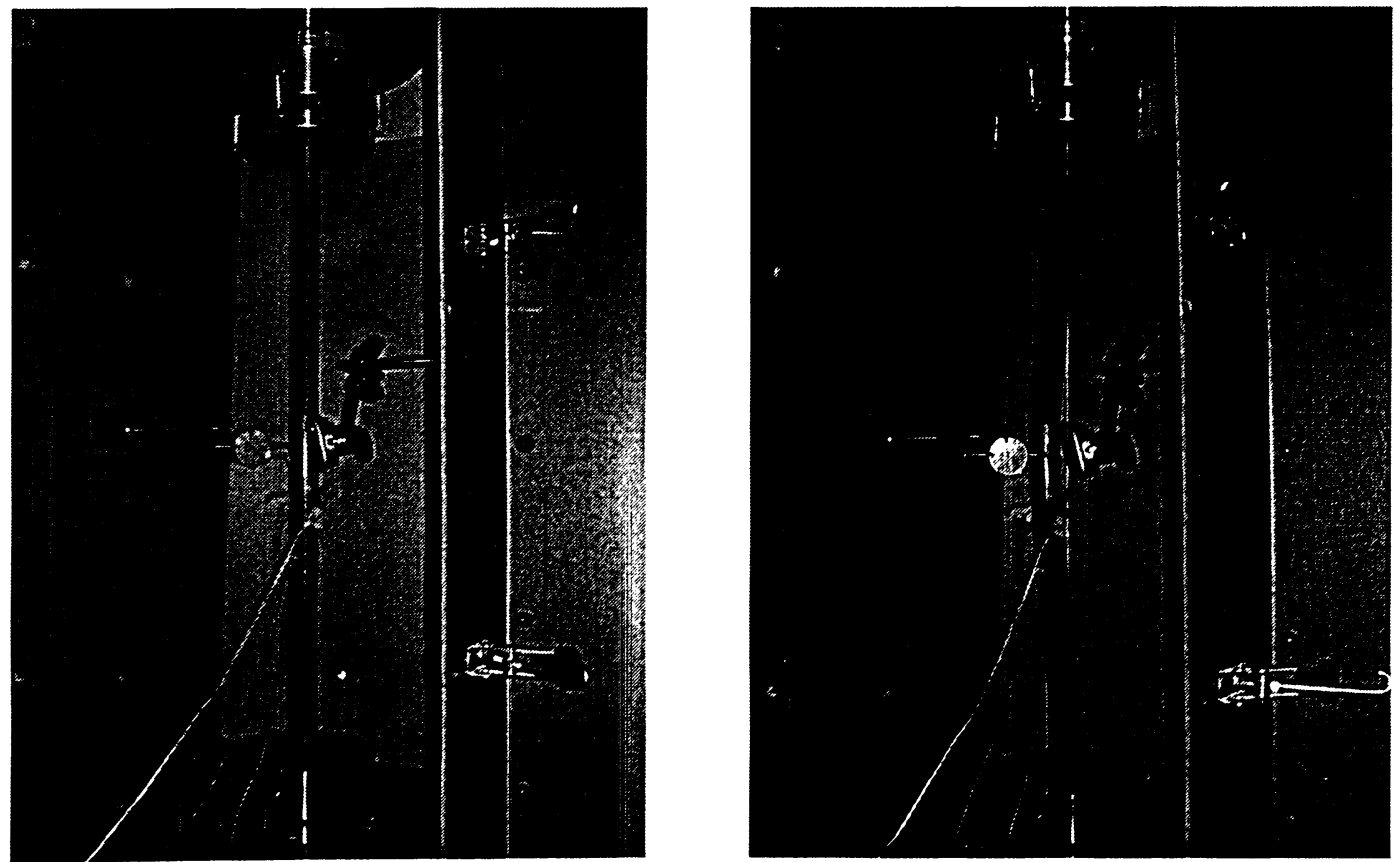

Figure 4.105 Views of specimen NSR-3 before and after testing 


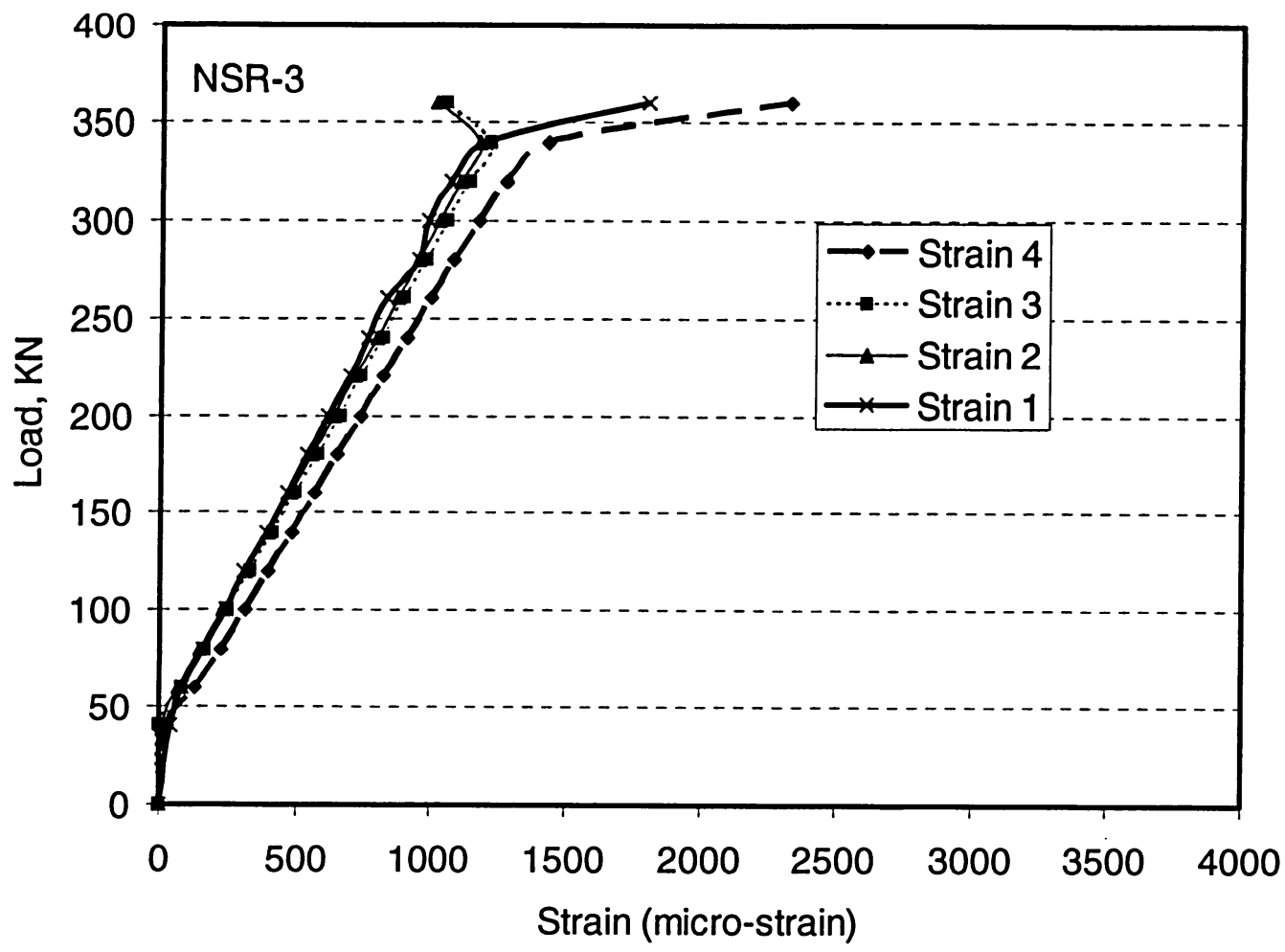

Figure 4.106 Axial load-strain relationships for specimen NSR-3

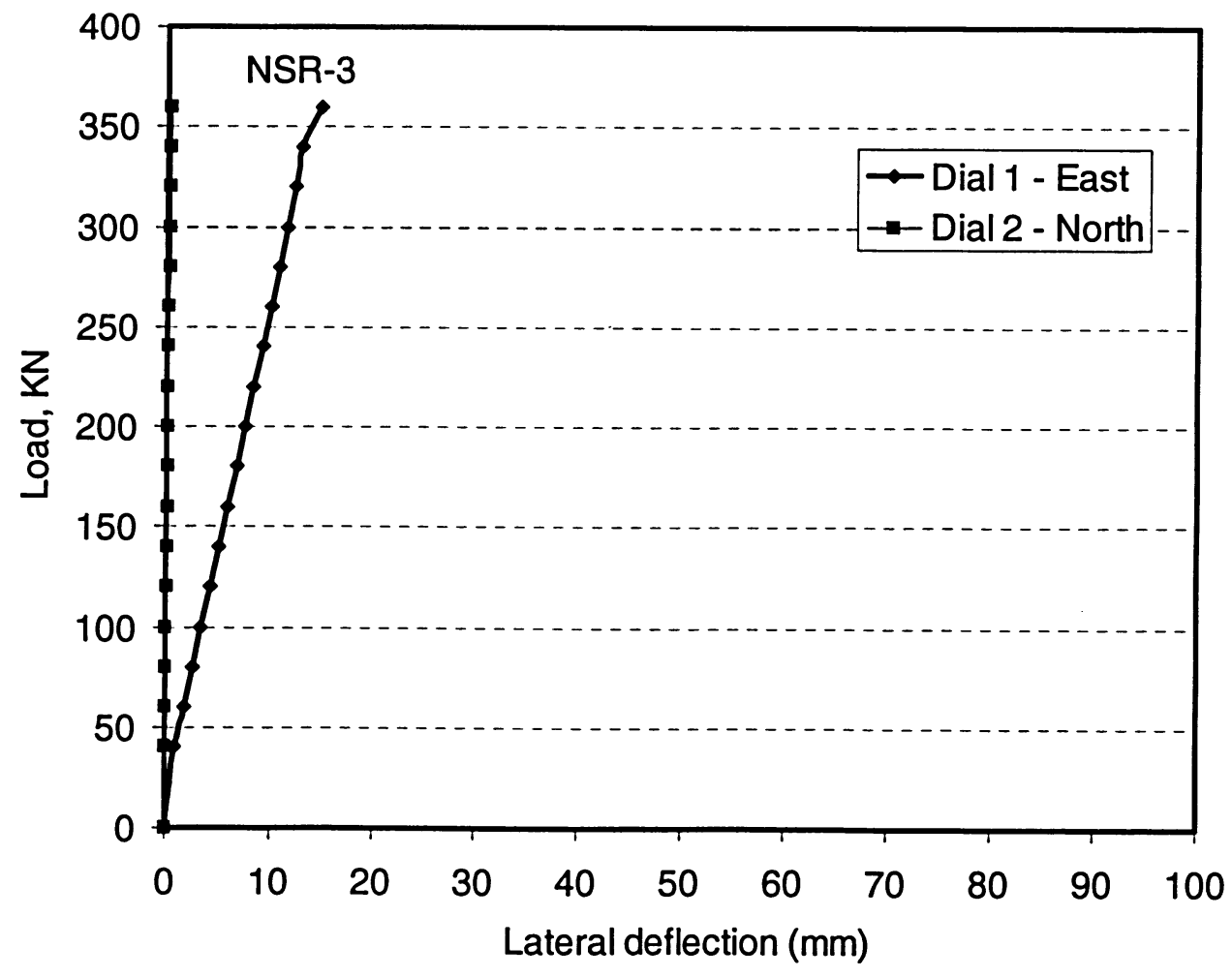

Figure 4.107 Load-lateral deflection curves for specimen NSR-3 


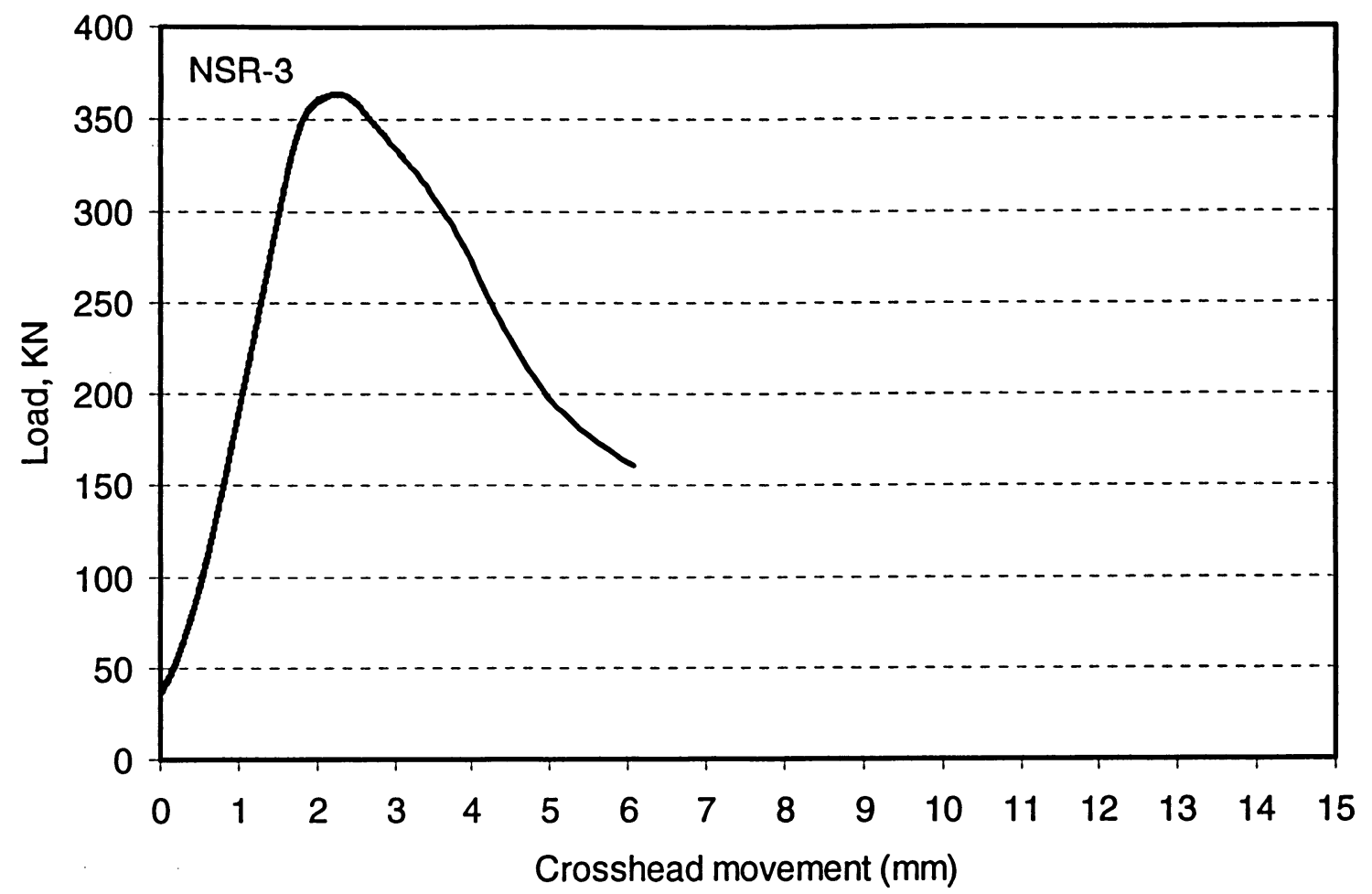

Figure 4.108 Load versus overall shortening curve for specimen NSR-3
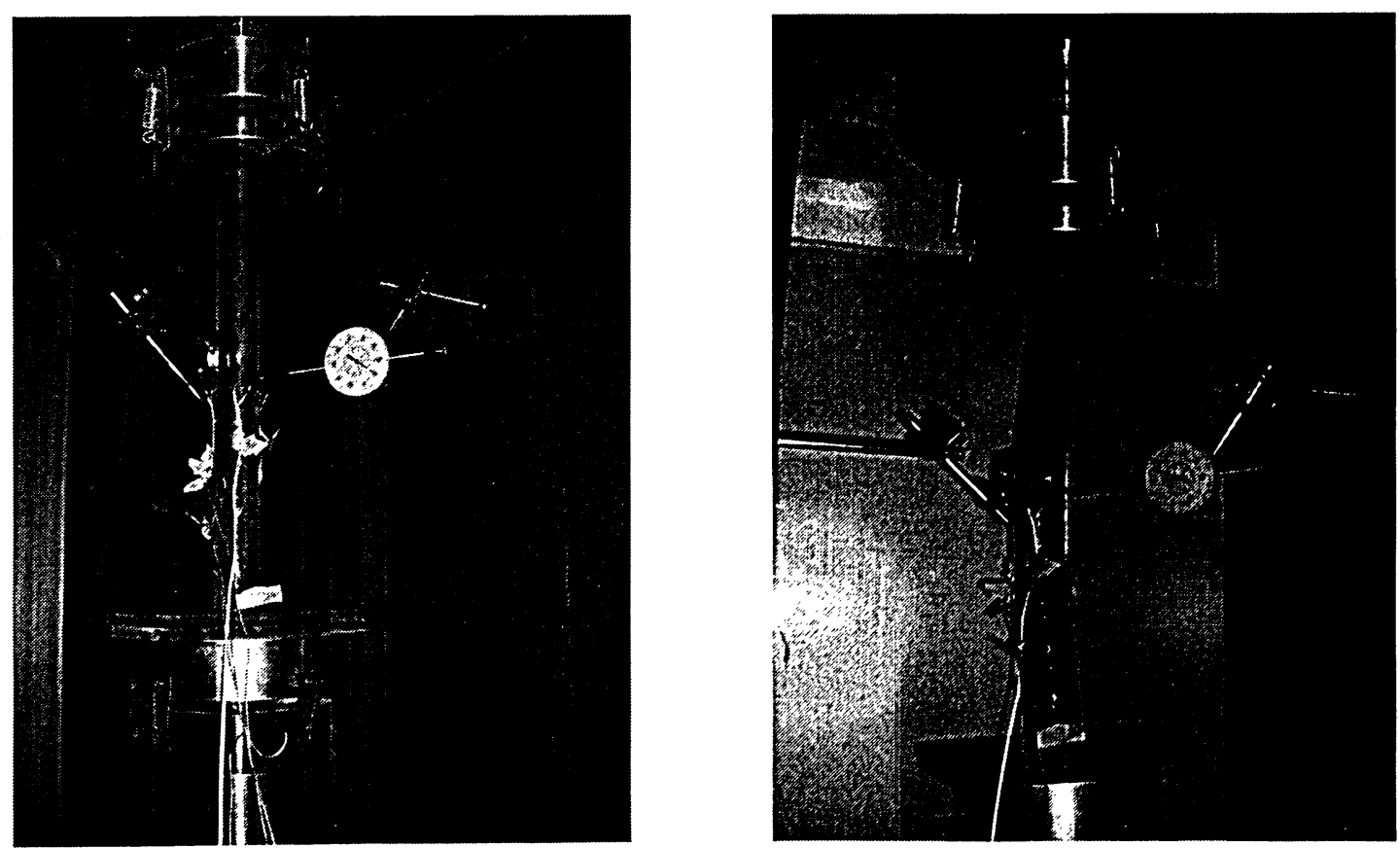

Figure 4.109 Views of specimen NSR-4 before and after testing 


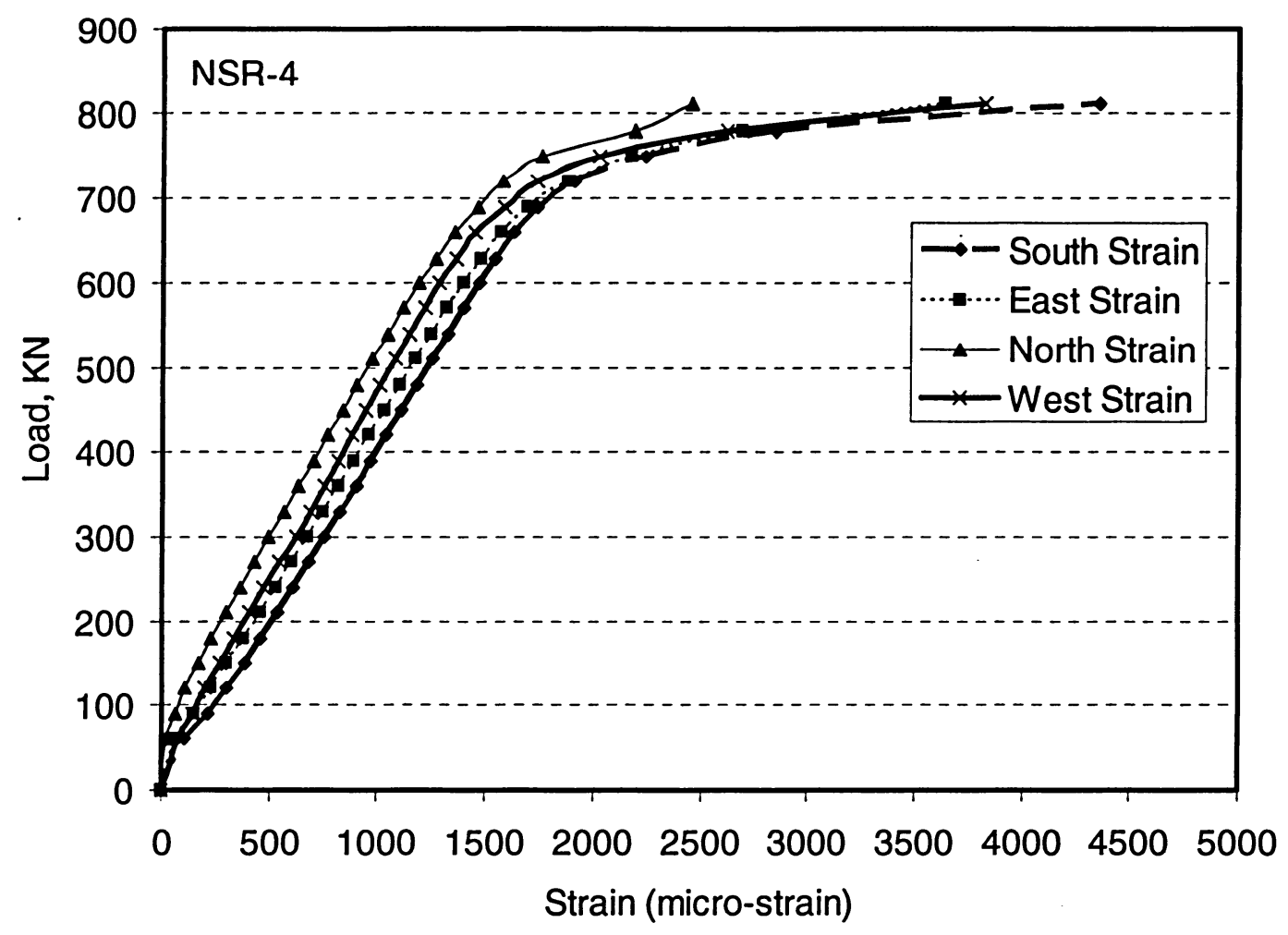

Figure 4.110 Axial load-strain relationships for specimen NSR-4

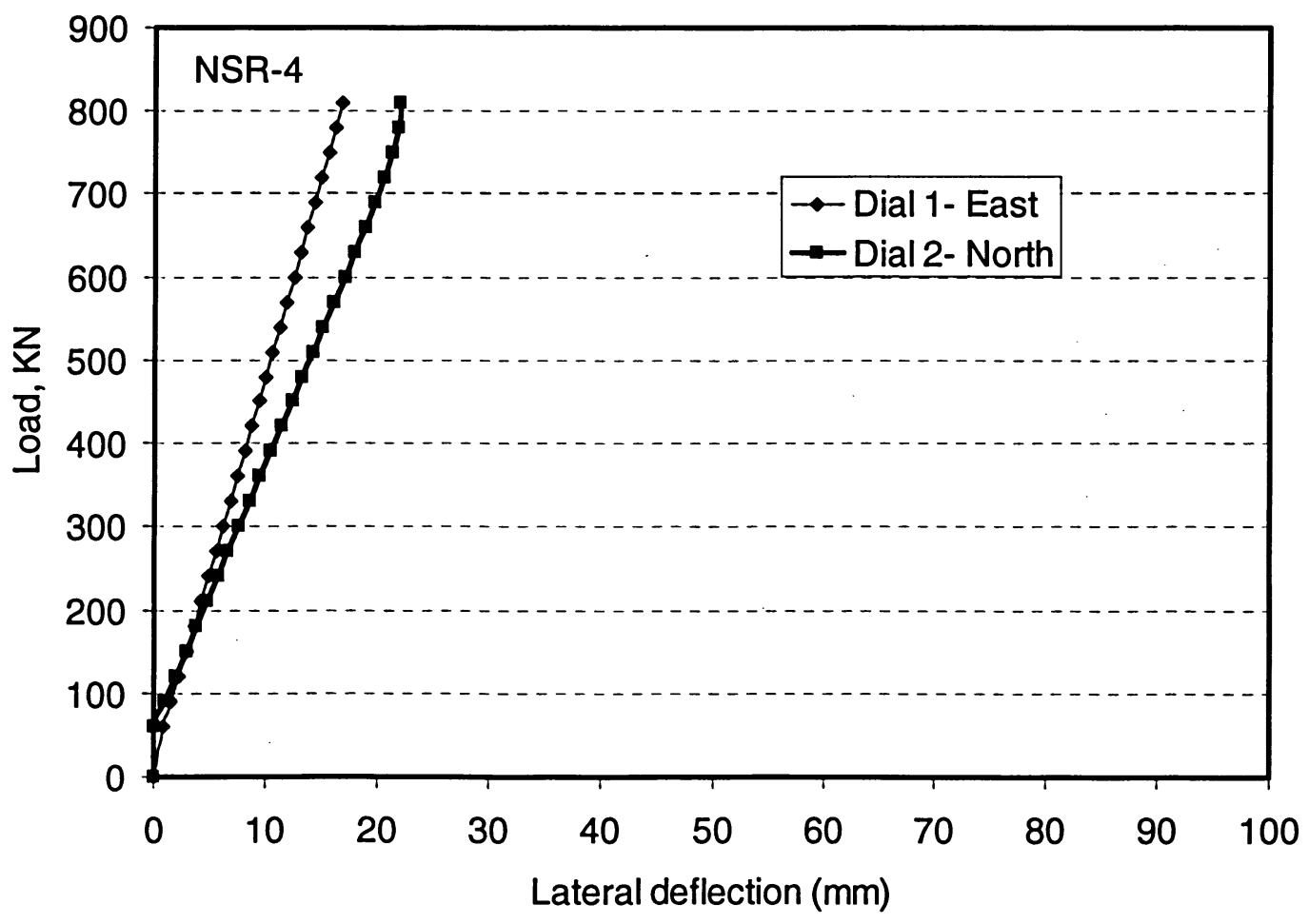

Figure 4.111 Load-lateral deflection curves for specimen NSR-4 


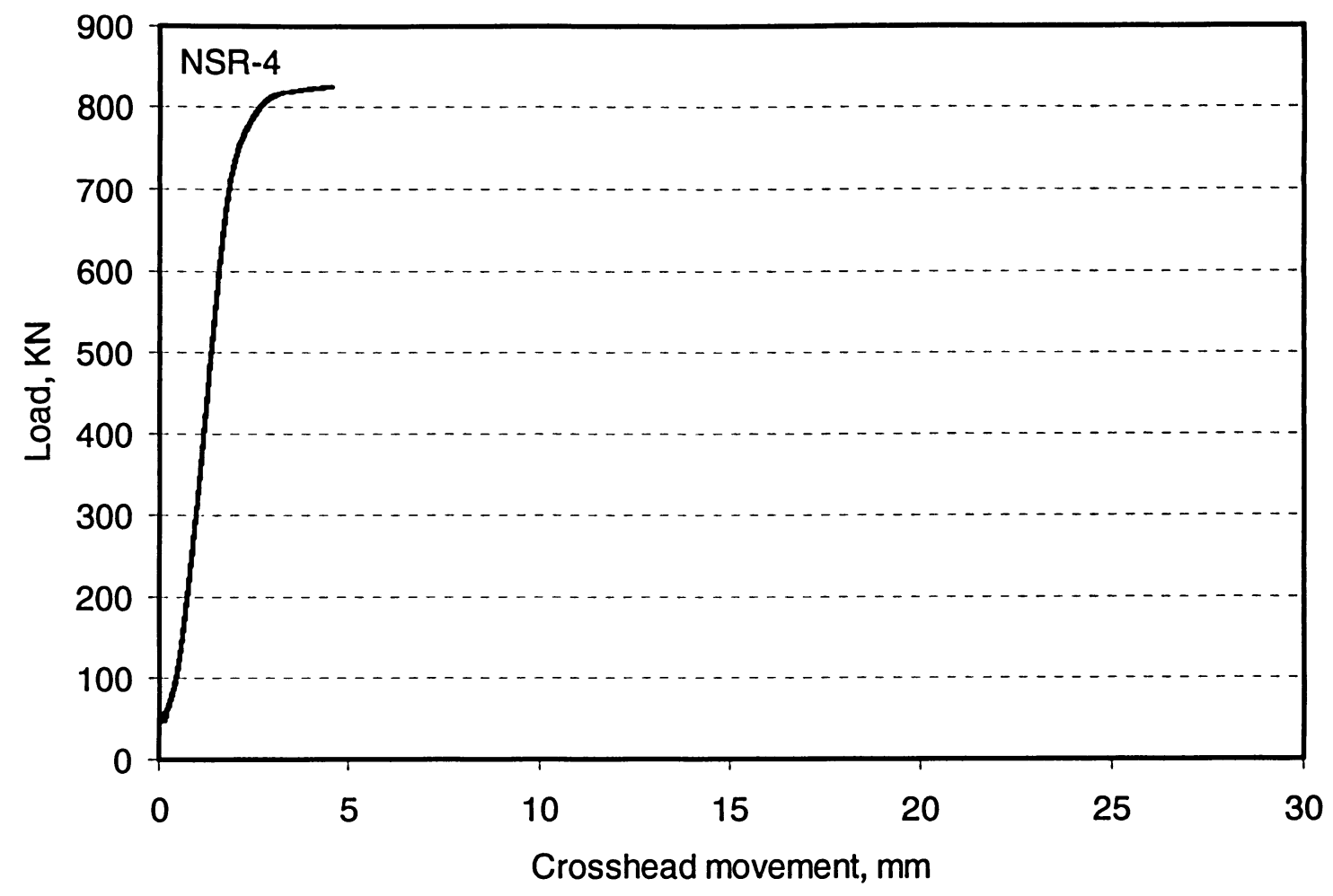

Figure 4.112 Load versus overall shortening curve for specimen NSR-4
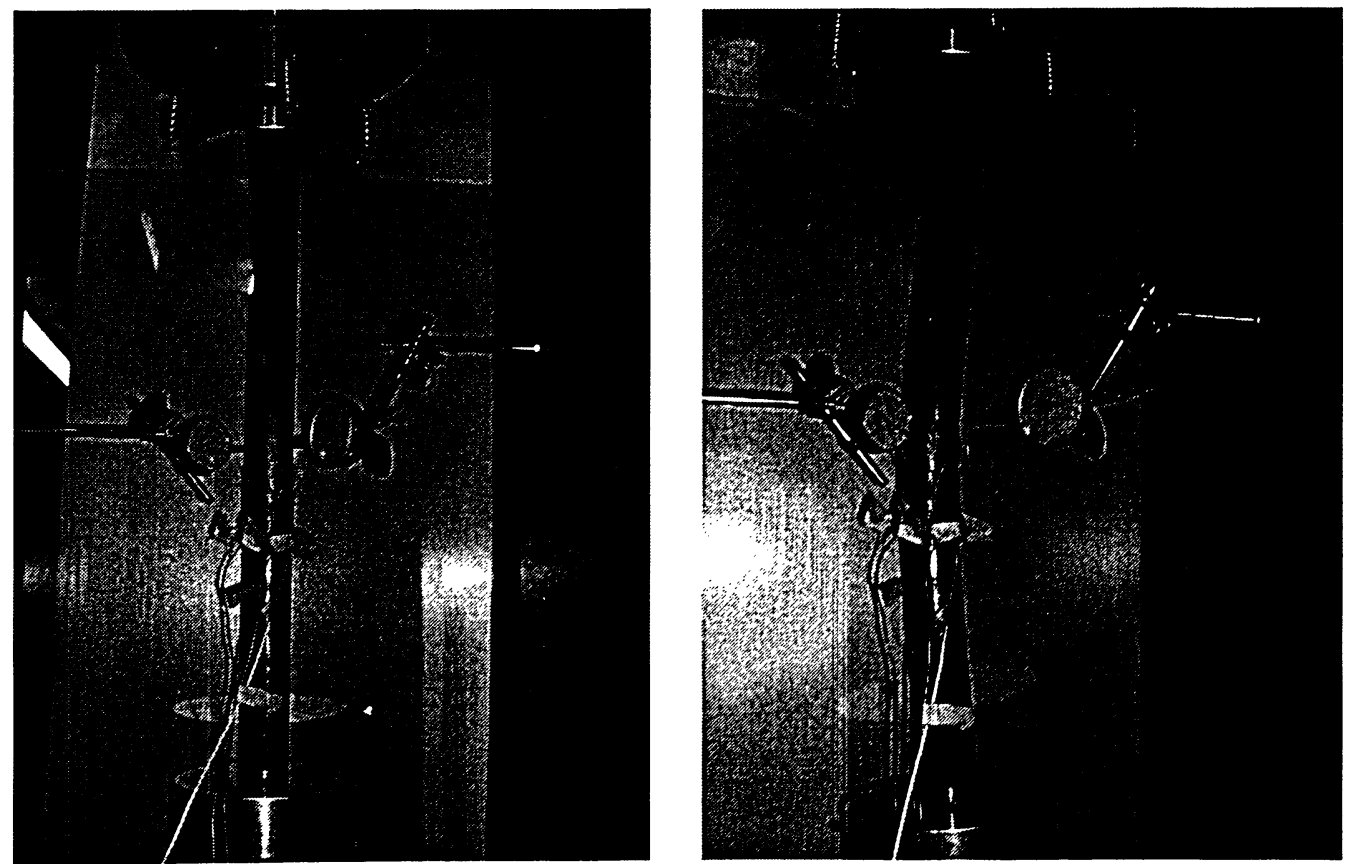

Figure 4.113 Views of specimen NSR-5 before and after testing 


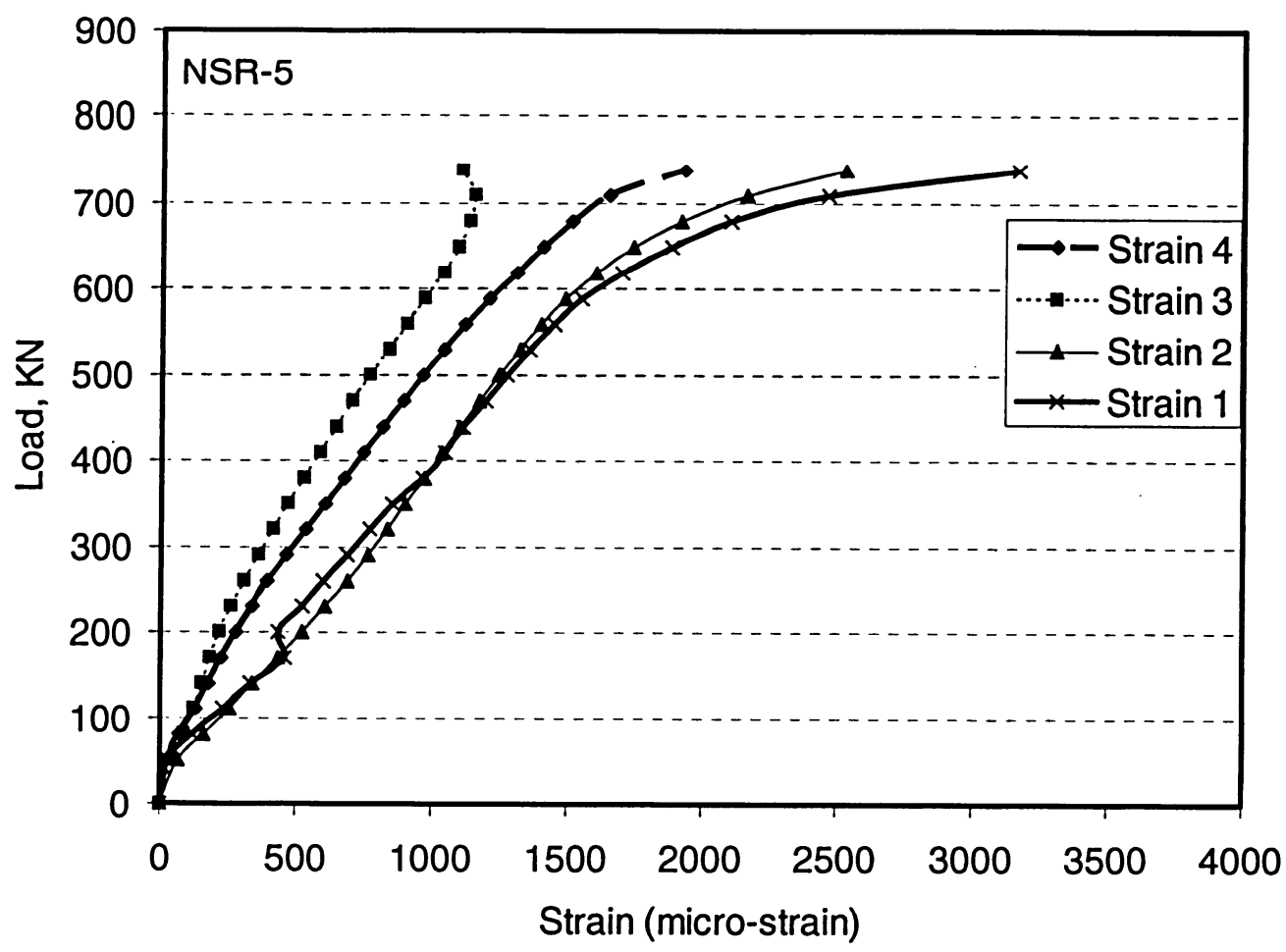

Figure 4.114 Axial load-strain relationships for specimen NSR-5

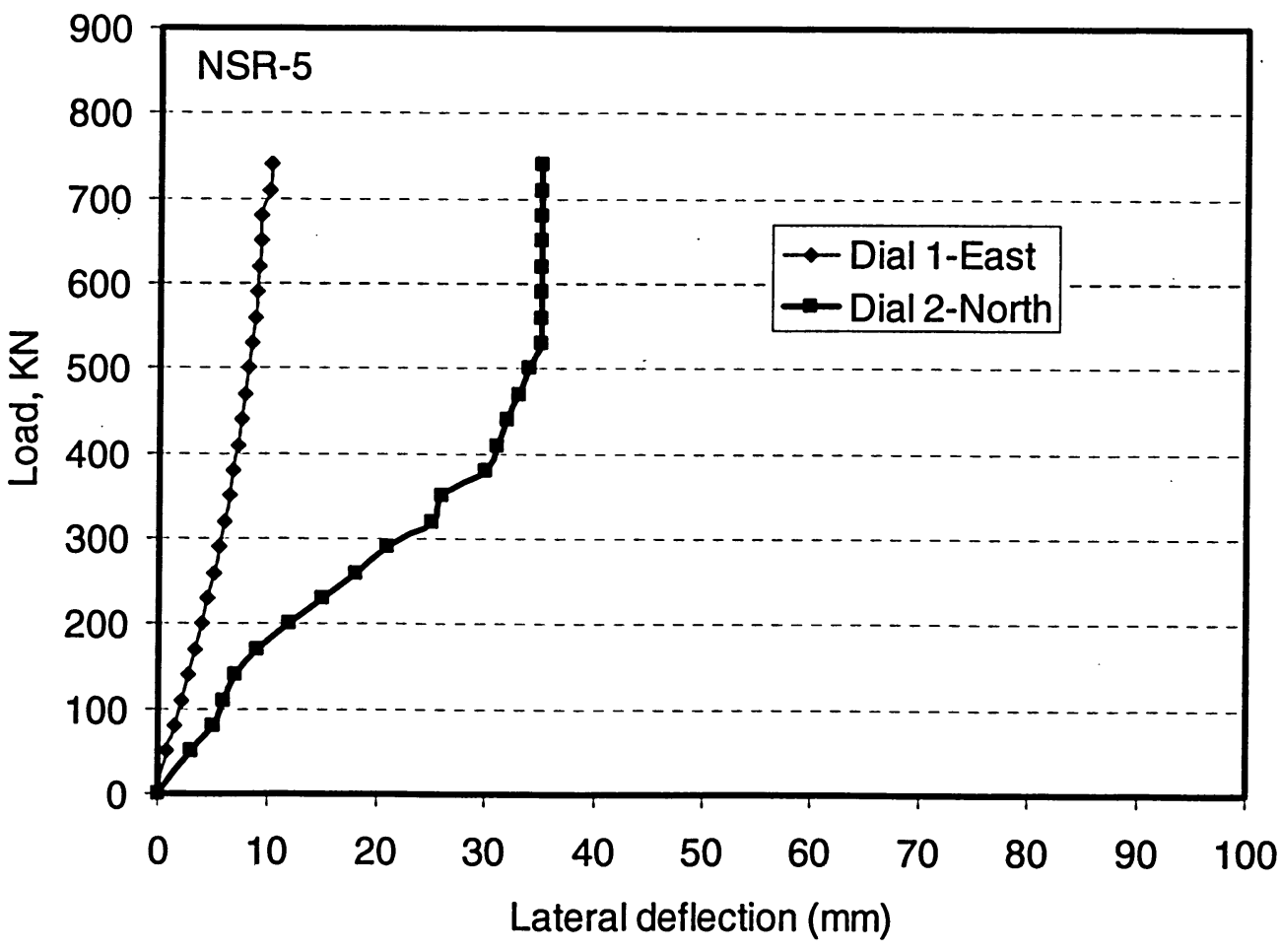

Figure 4.115 Load-lateral deflection curves for specimen NSR-5 


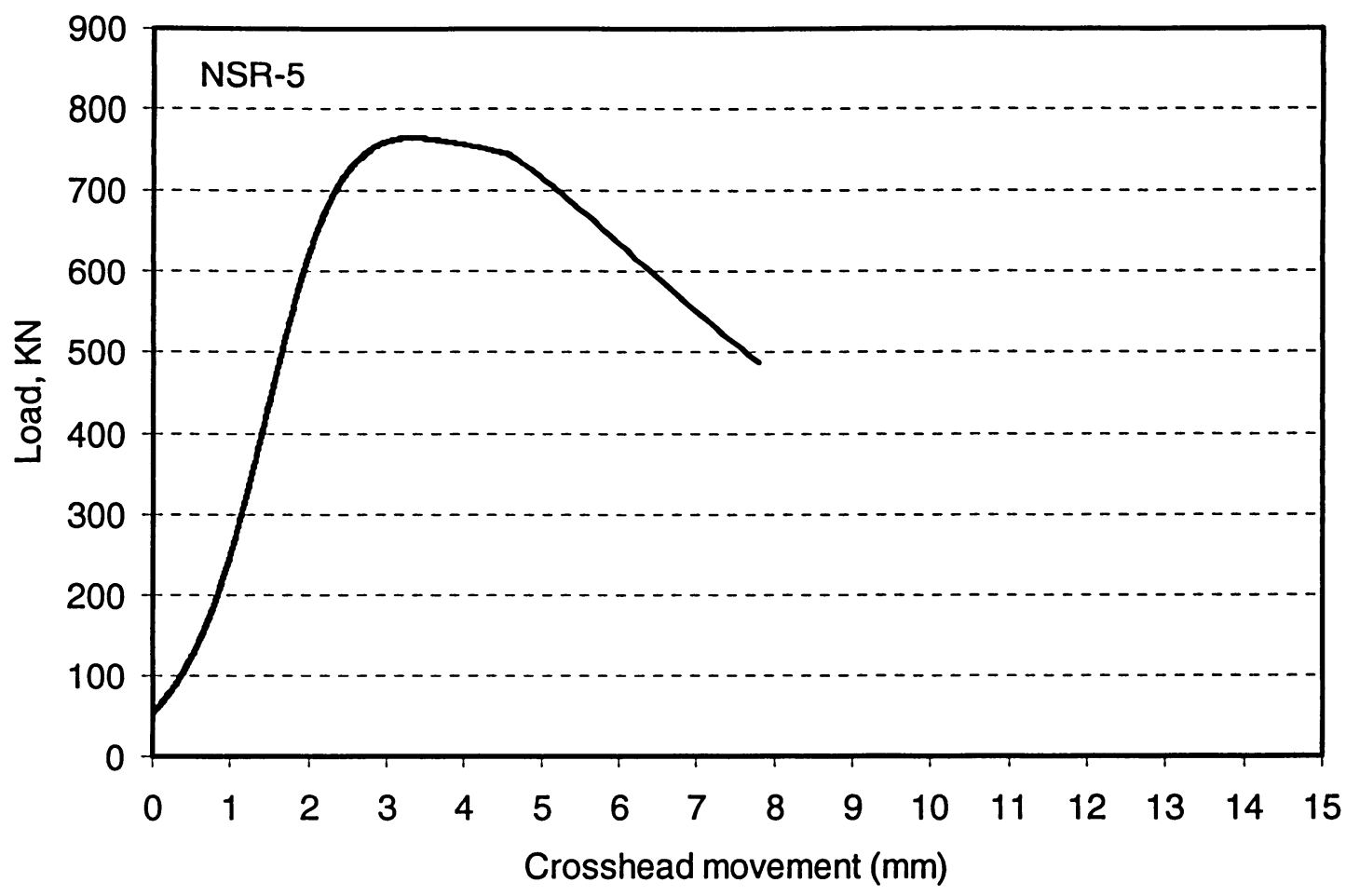

Figure 4.116 Load versus overall shortening curve for specimen NSR-5
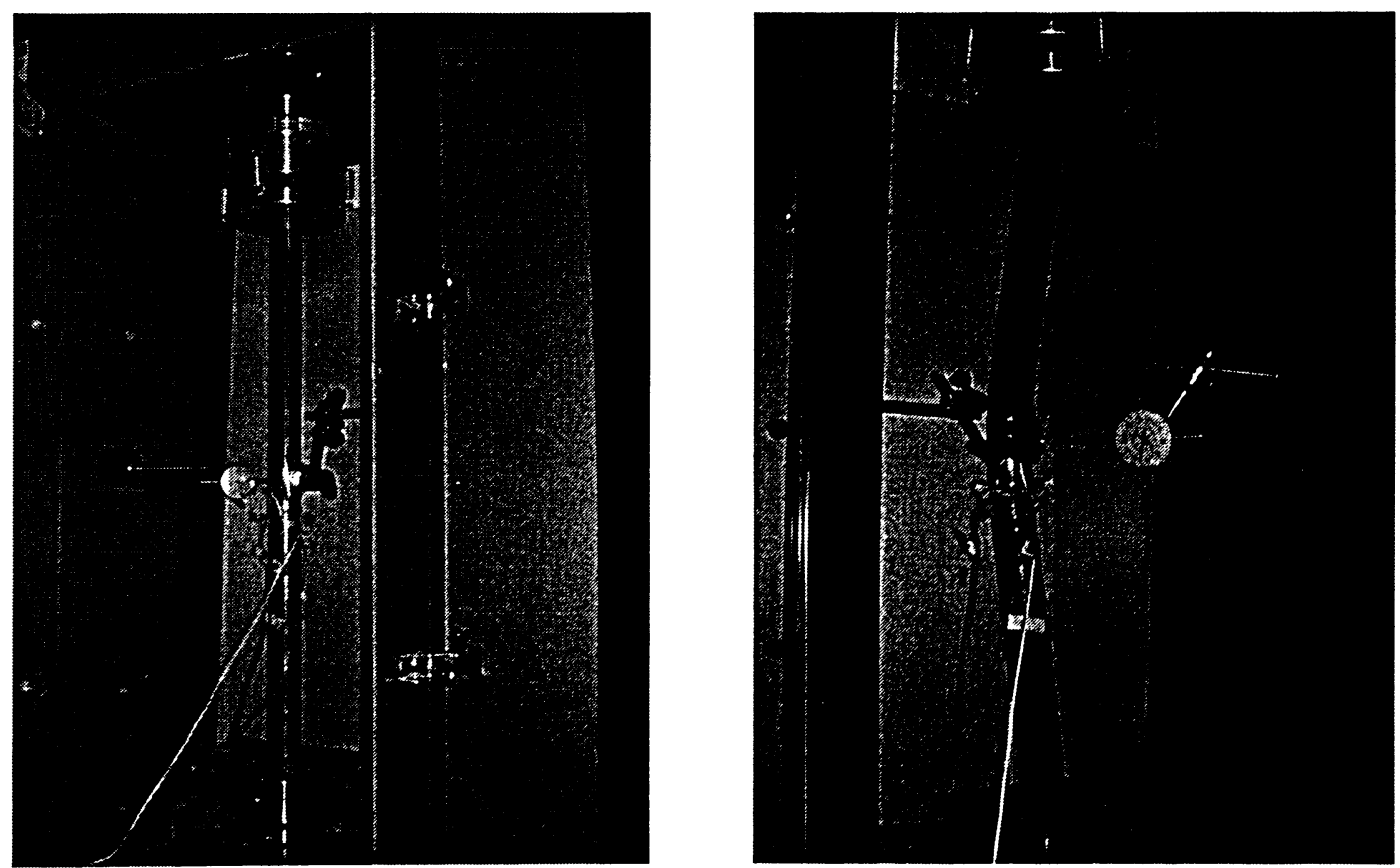

Figure 4.117 Views of specimen NSR- 6 before and after testing 


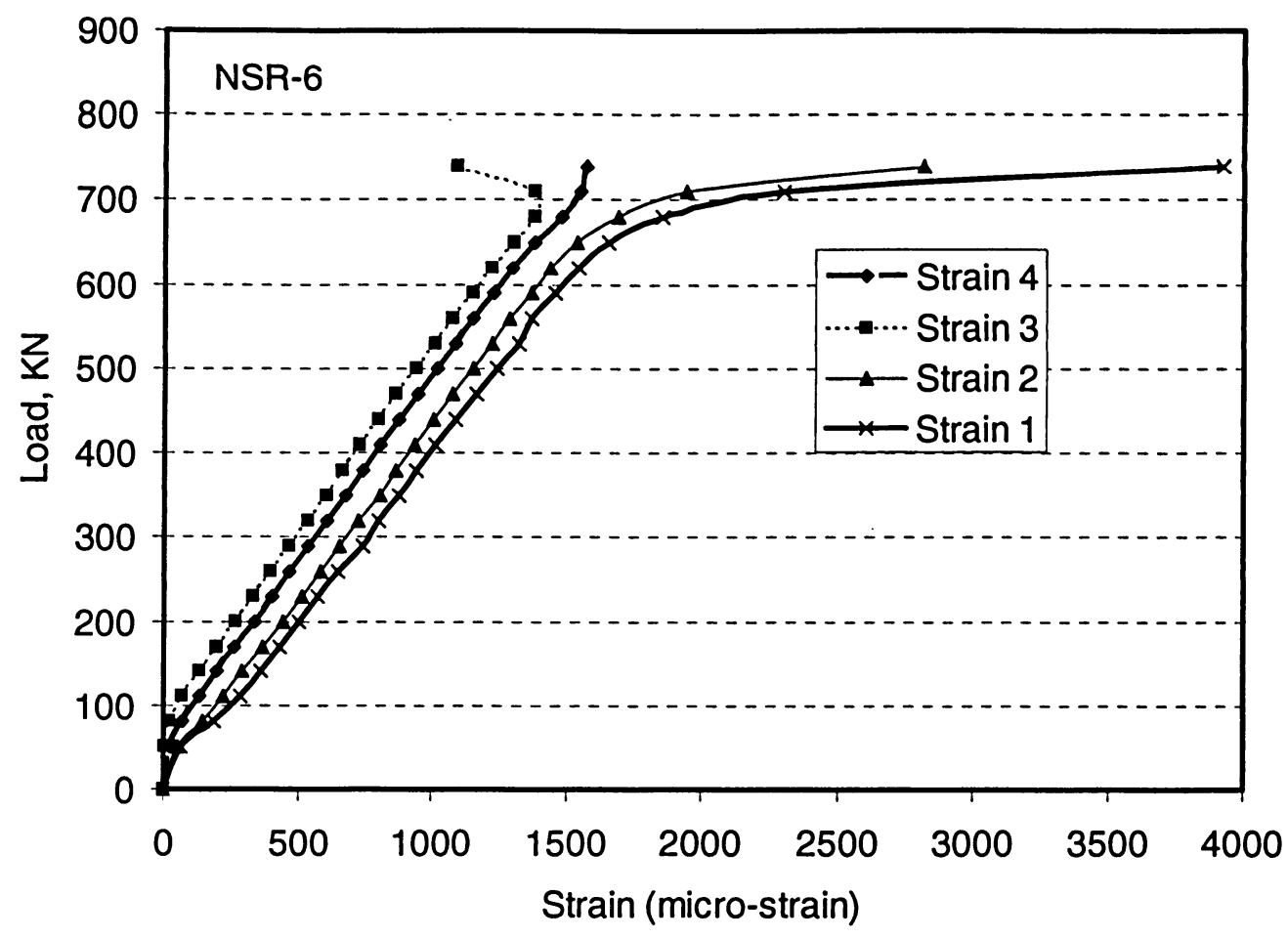

Figure 4.118 Axial load-strain relationships for specimen NSR-6

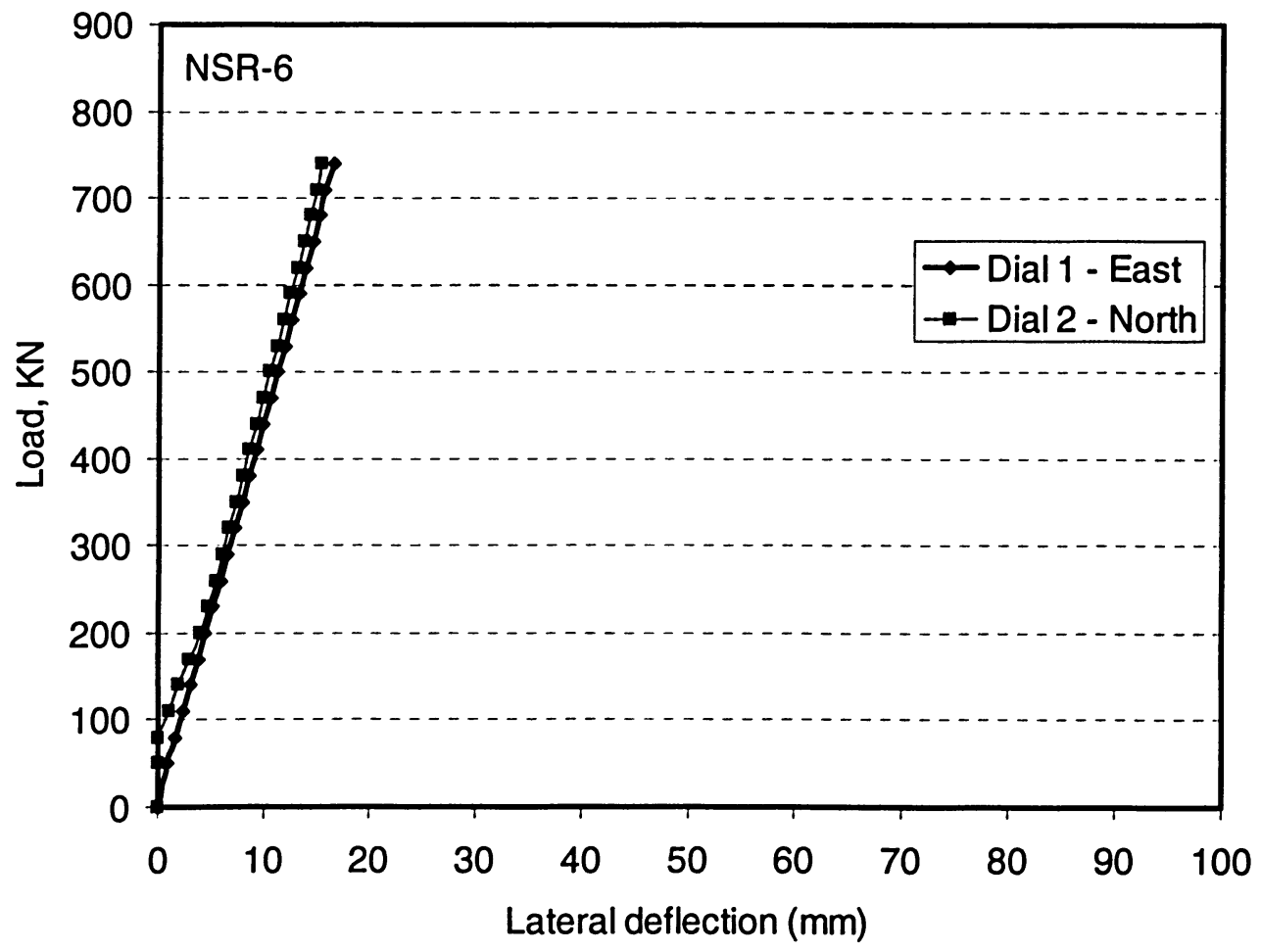

Figure 4.119 Load-lateral deflection curves for specimen NSR-6 


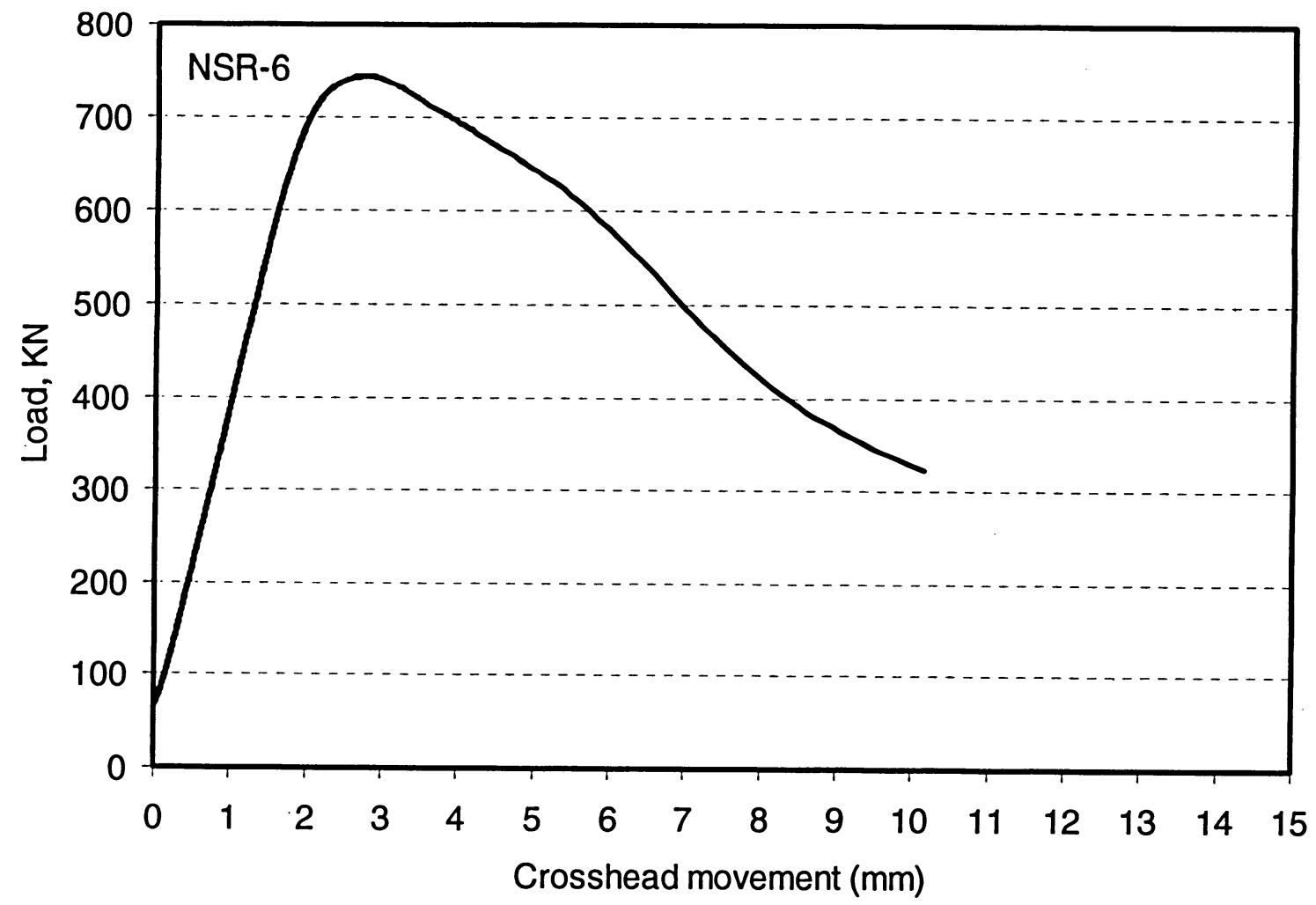

Figure 4.120 Load versus overall shortening curve for specimen NSR-6
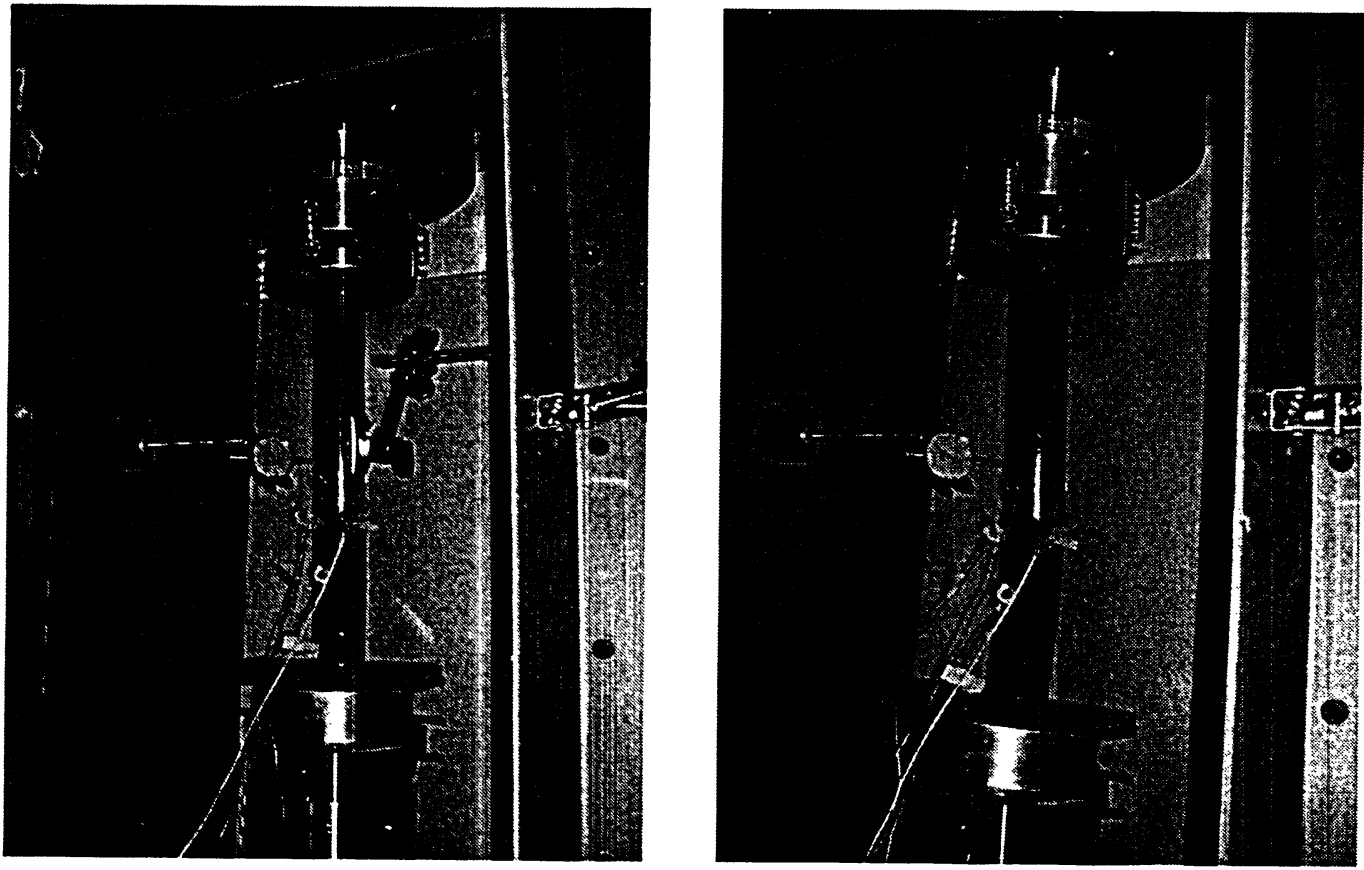

Figure 4.121 Views of specimen NSR-7 before and after testing 


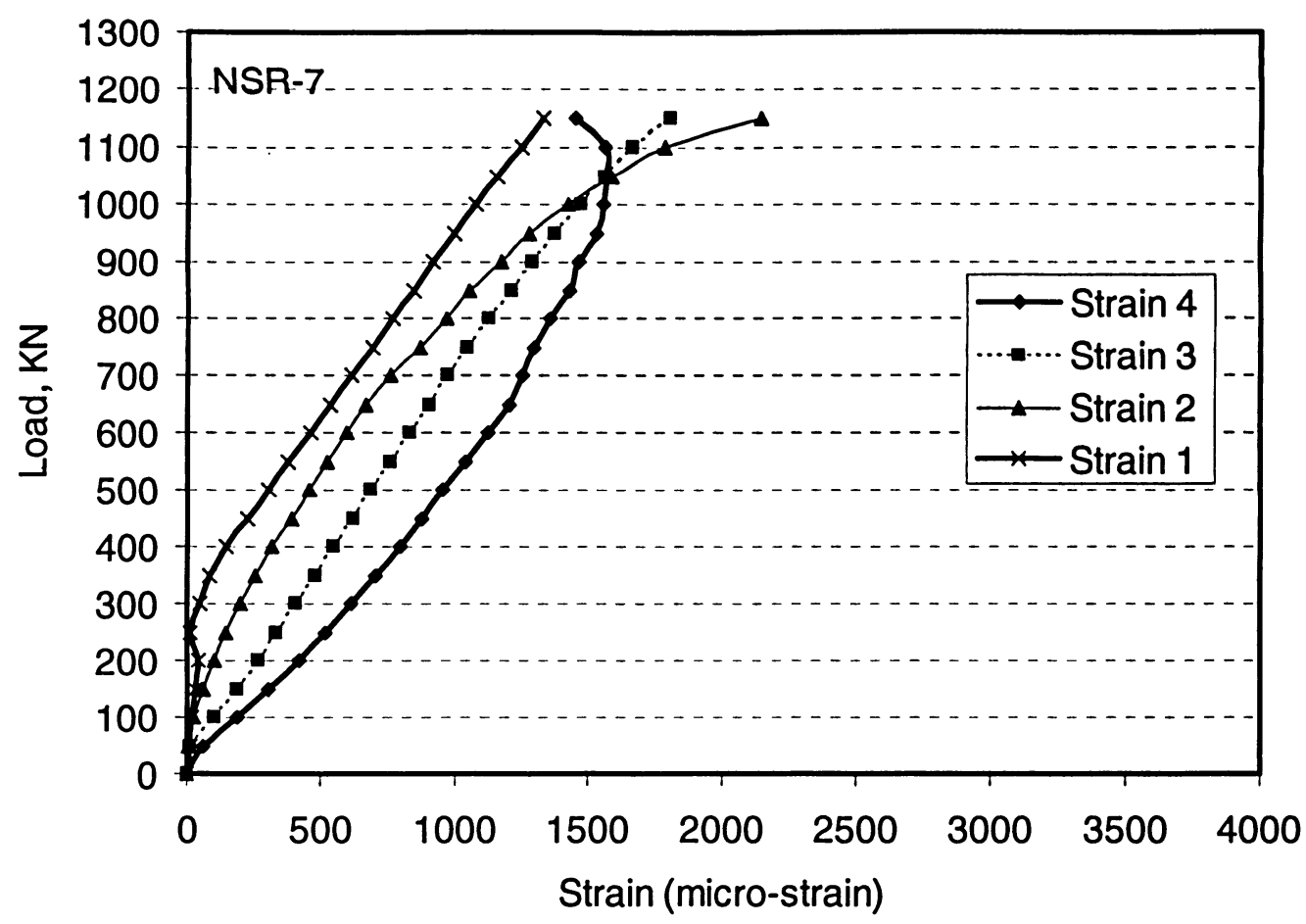

Figure 4.122 Axial load-strain relationships for specimen NSR-7

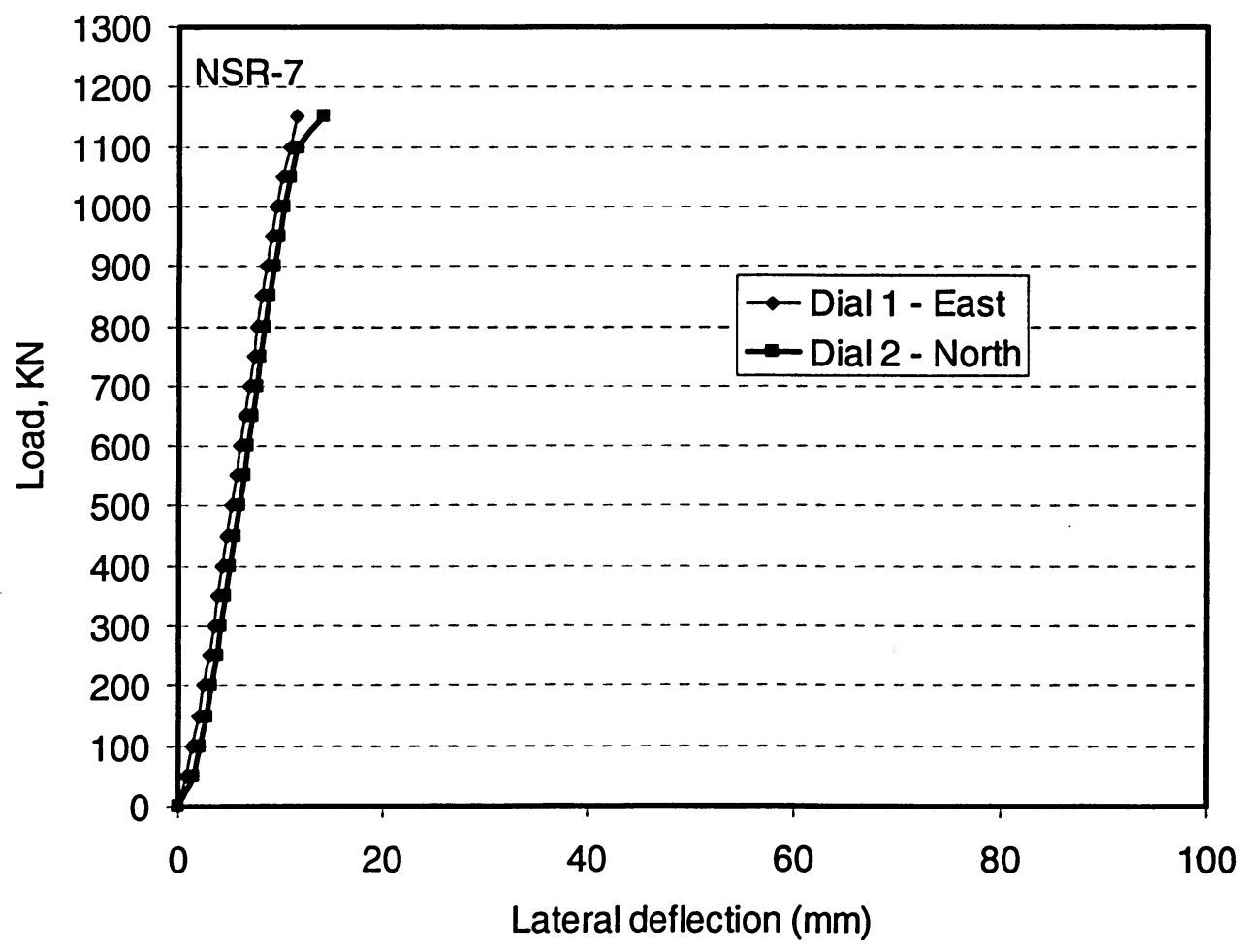

Figure 4.123 Load-lateral deflection curves for specimen NSR-7 


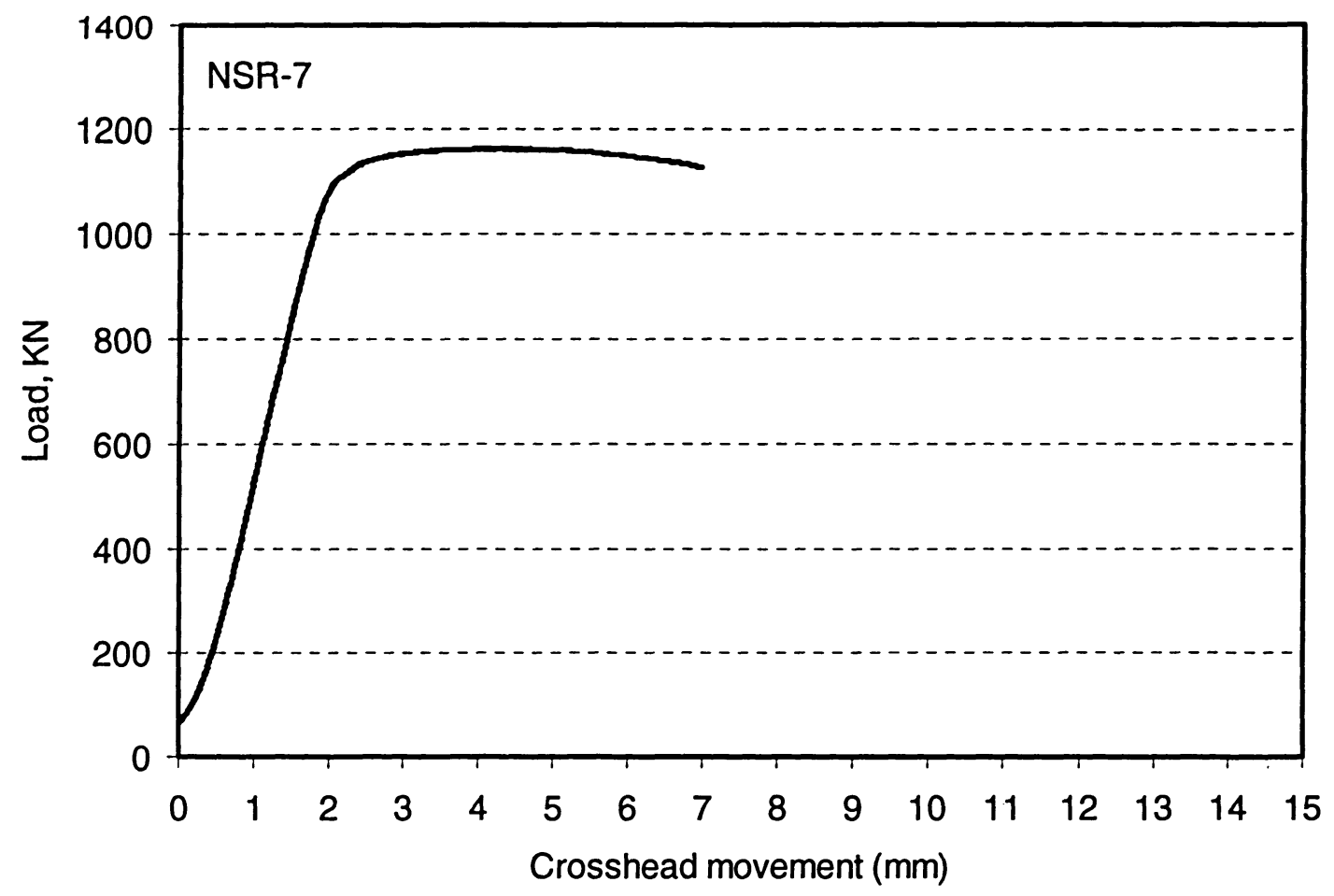

Figure 4.124 Load versus overall shortening curve for specimen NSR-7
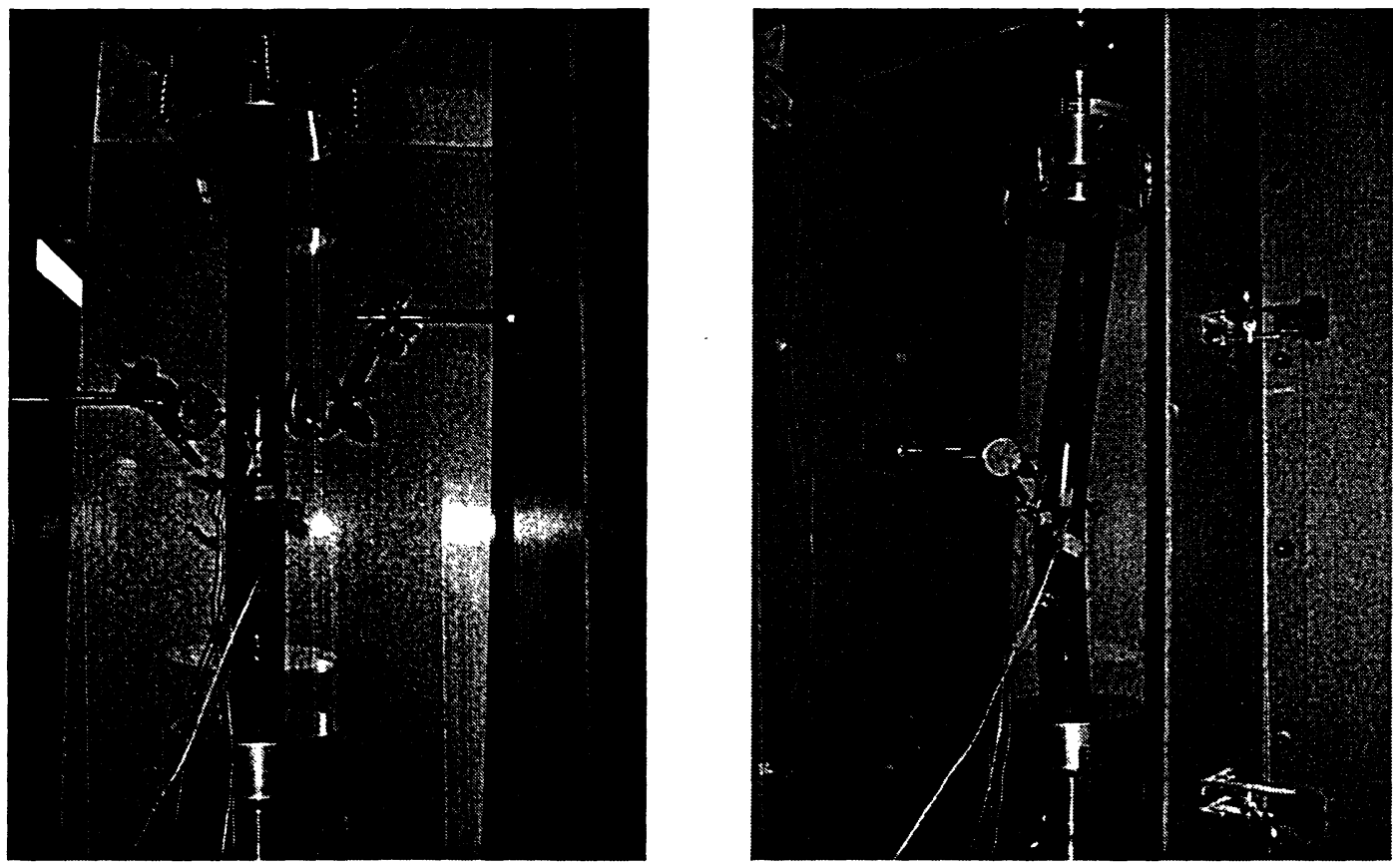

Figure 4.125 Views of specimen NSR-8 before and after testing 


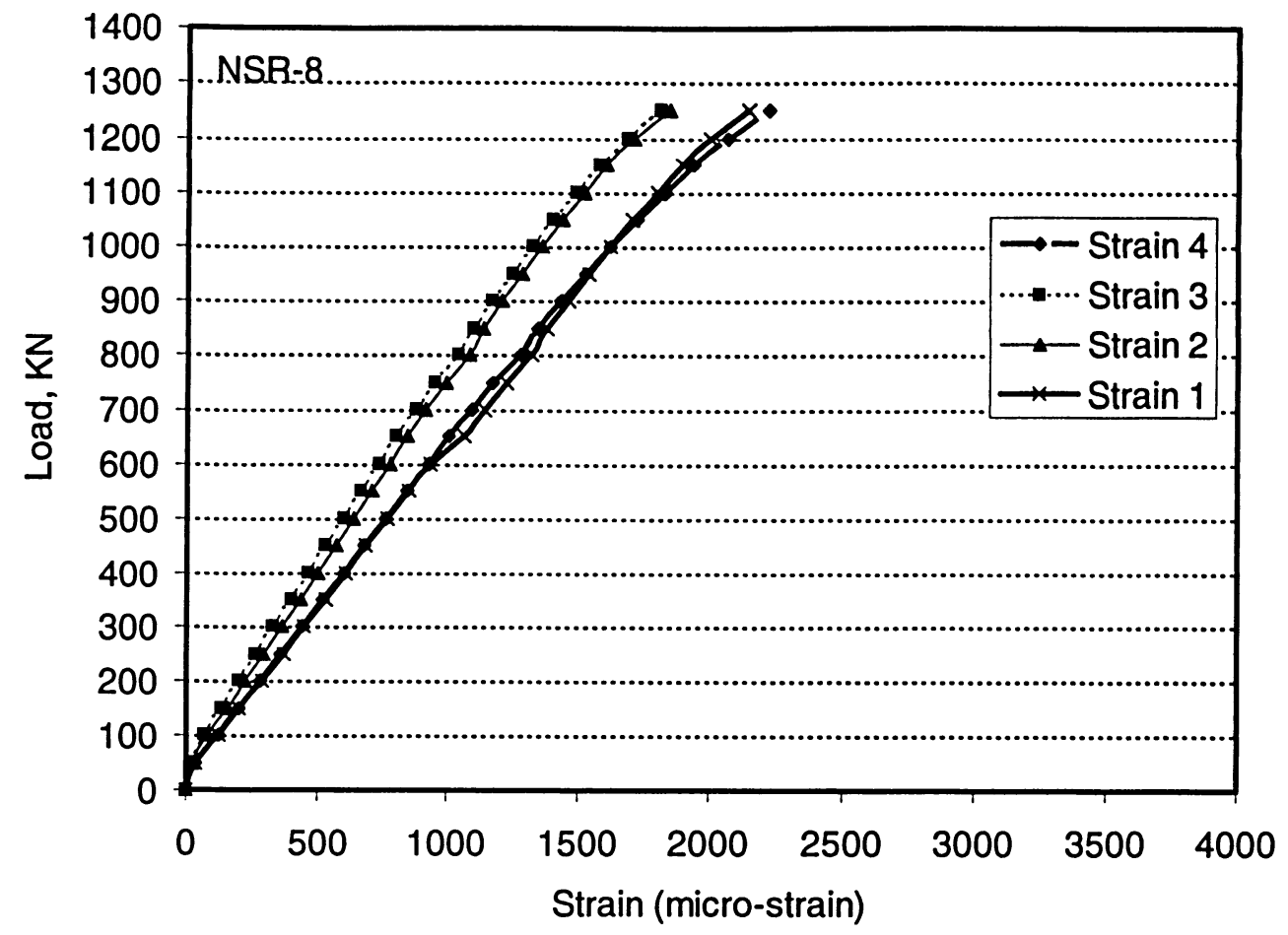

Figure 4.126 Axial load-strain relationships for specimen NSR-8

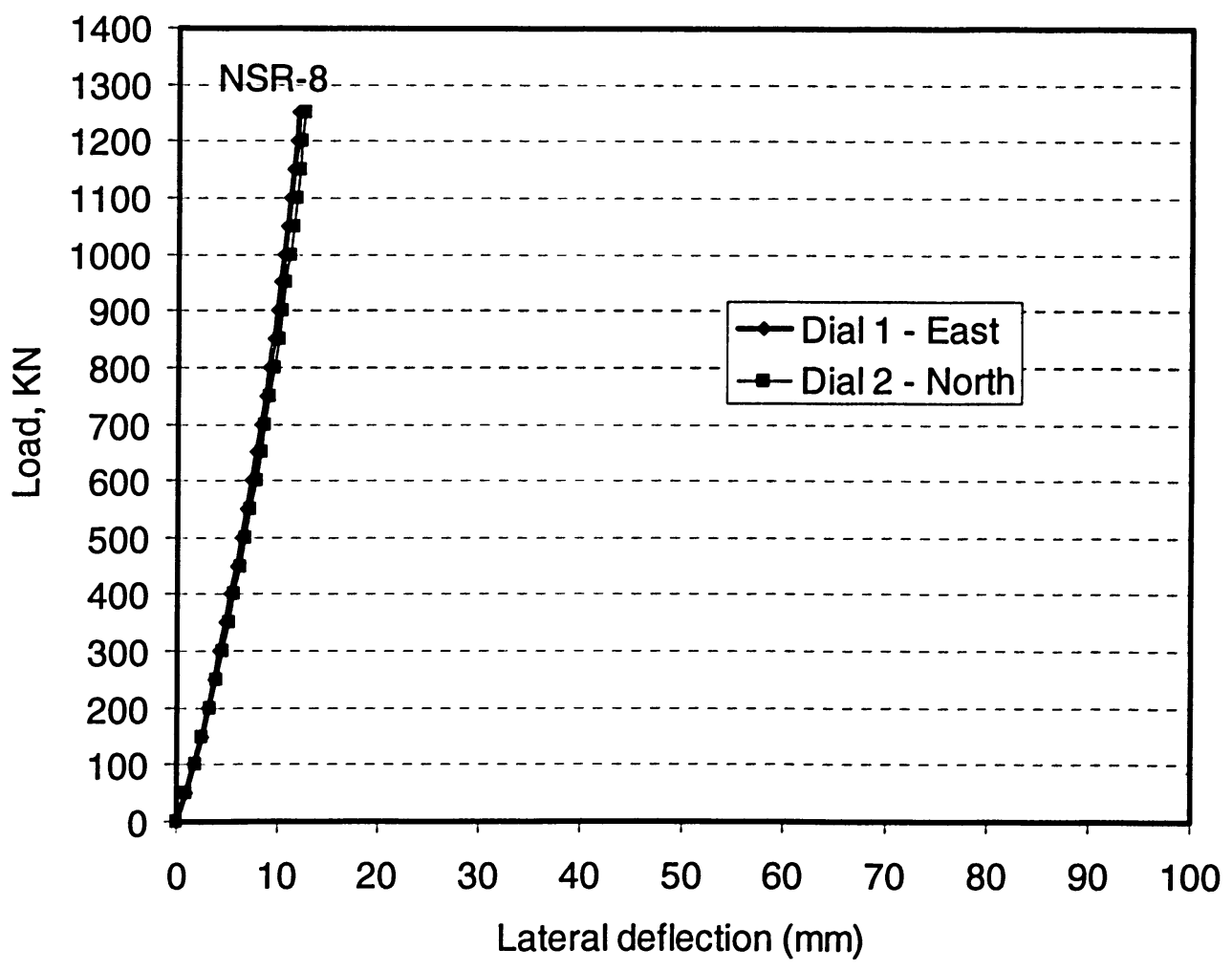

Figure 4.127 Load-lateral deflection curves for specimen NSR-8 


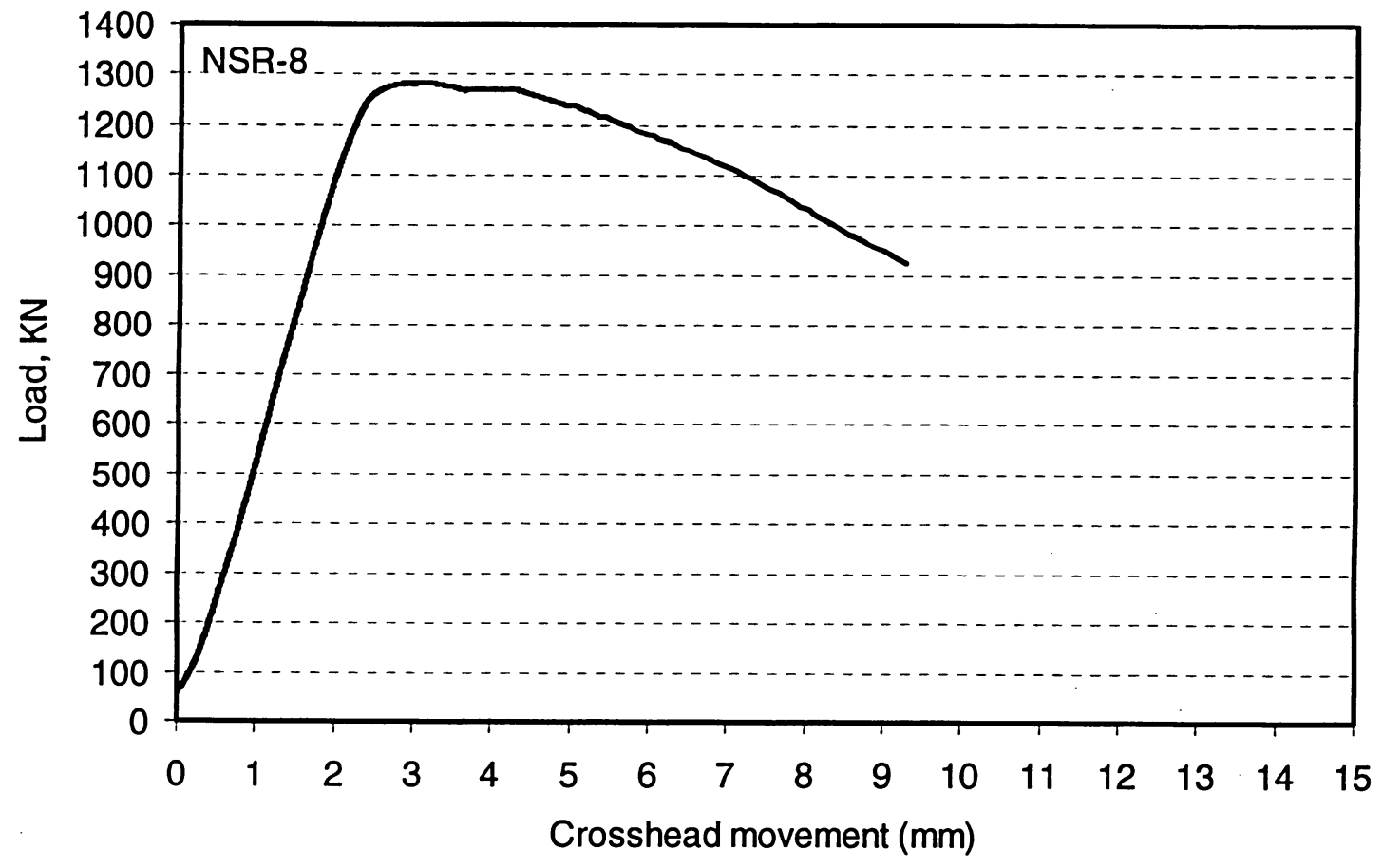

Figure 4.128 Load versus overall shortening curve for specimen NSR-8
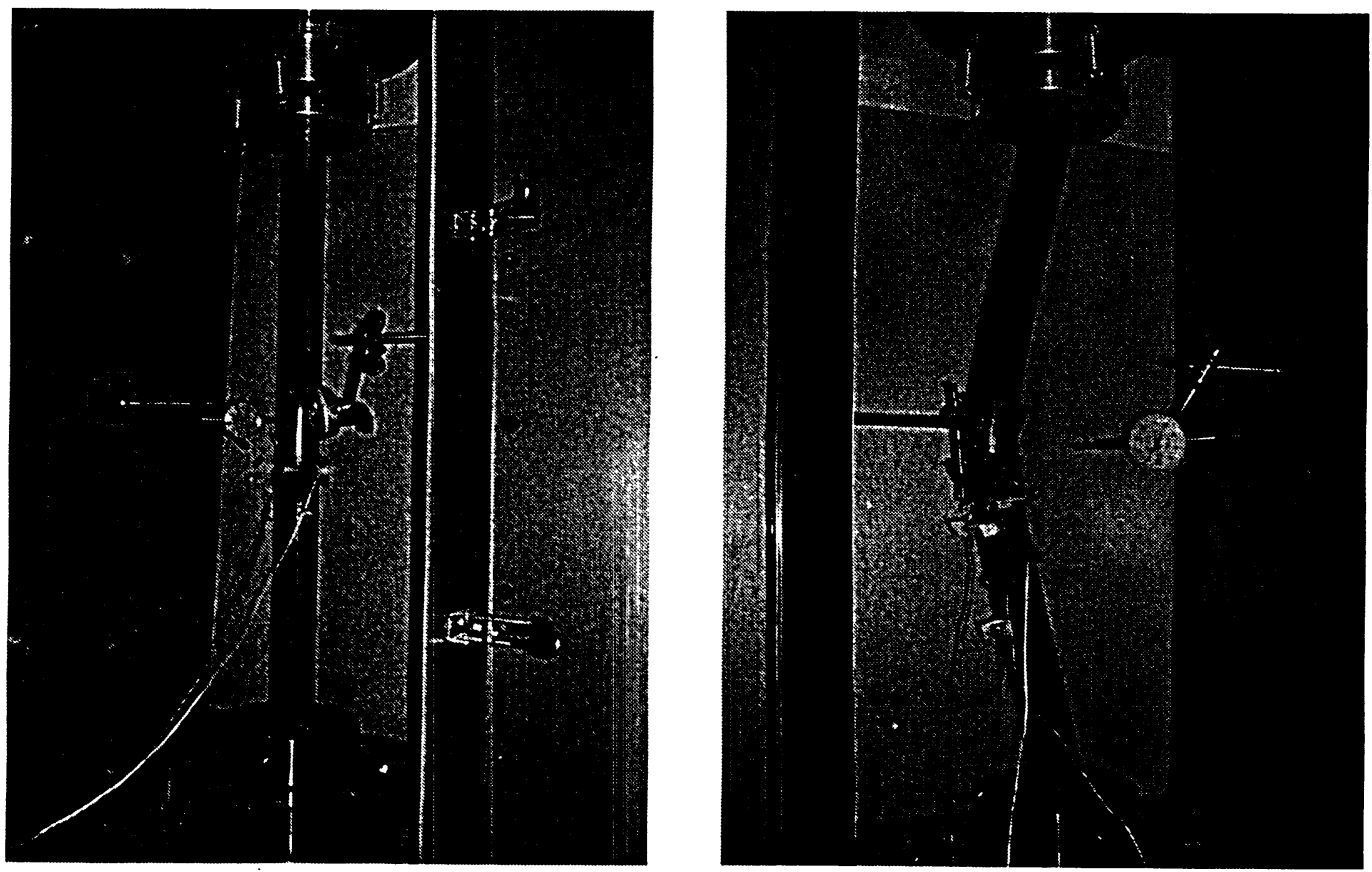

Figure 4.129 Views of specimen NSR-9 before and after testing 


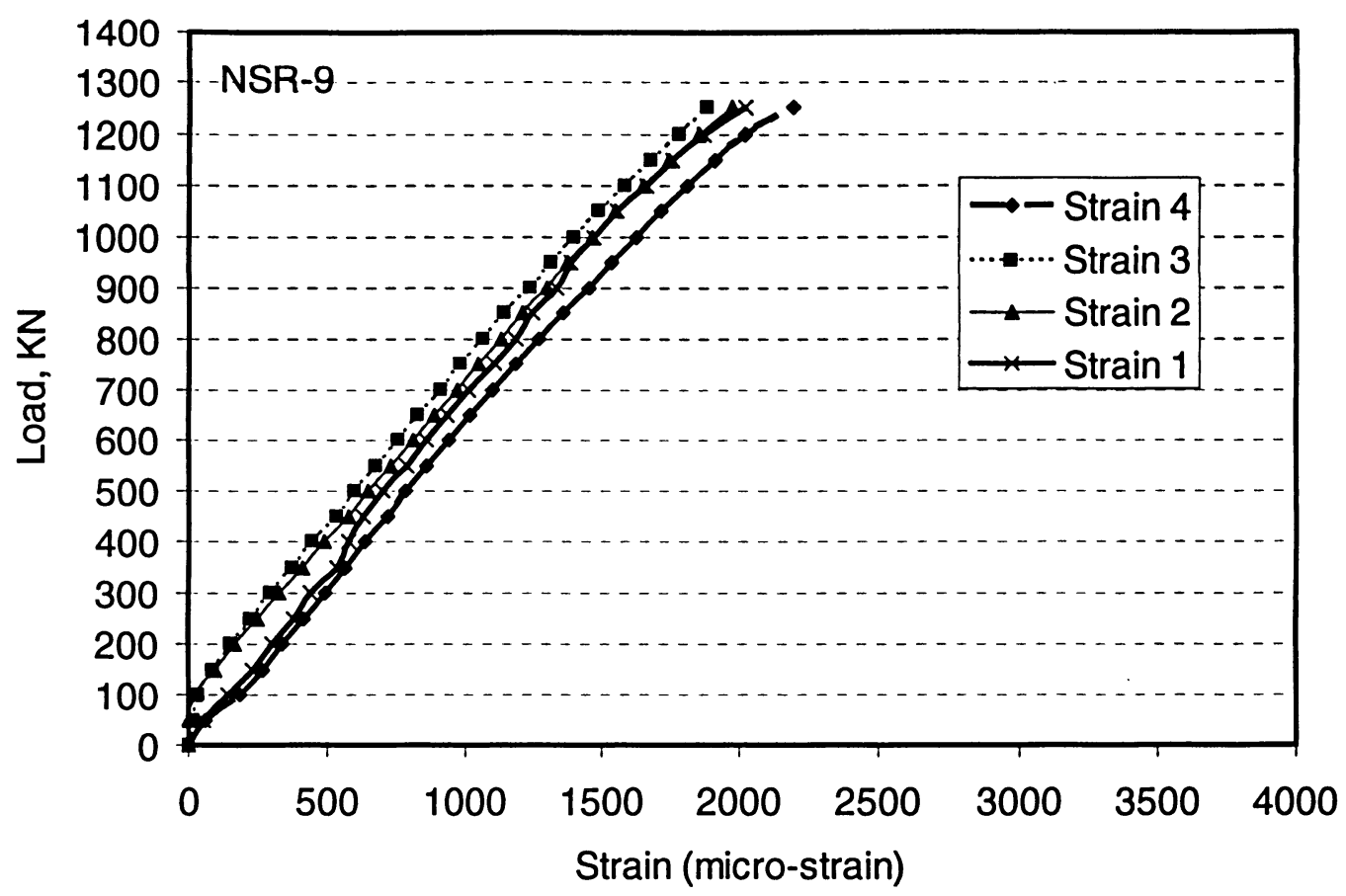

Figure 4.130 Axial load-strain relationships for specimen NSR-9

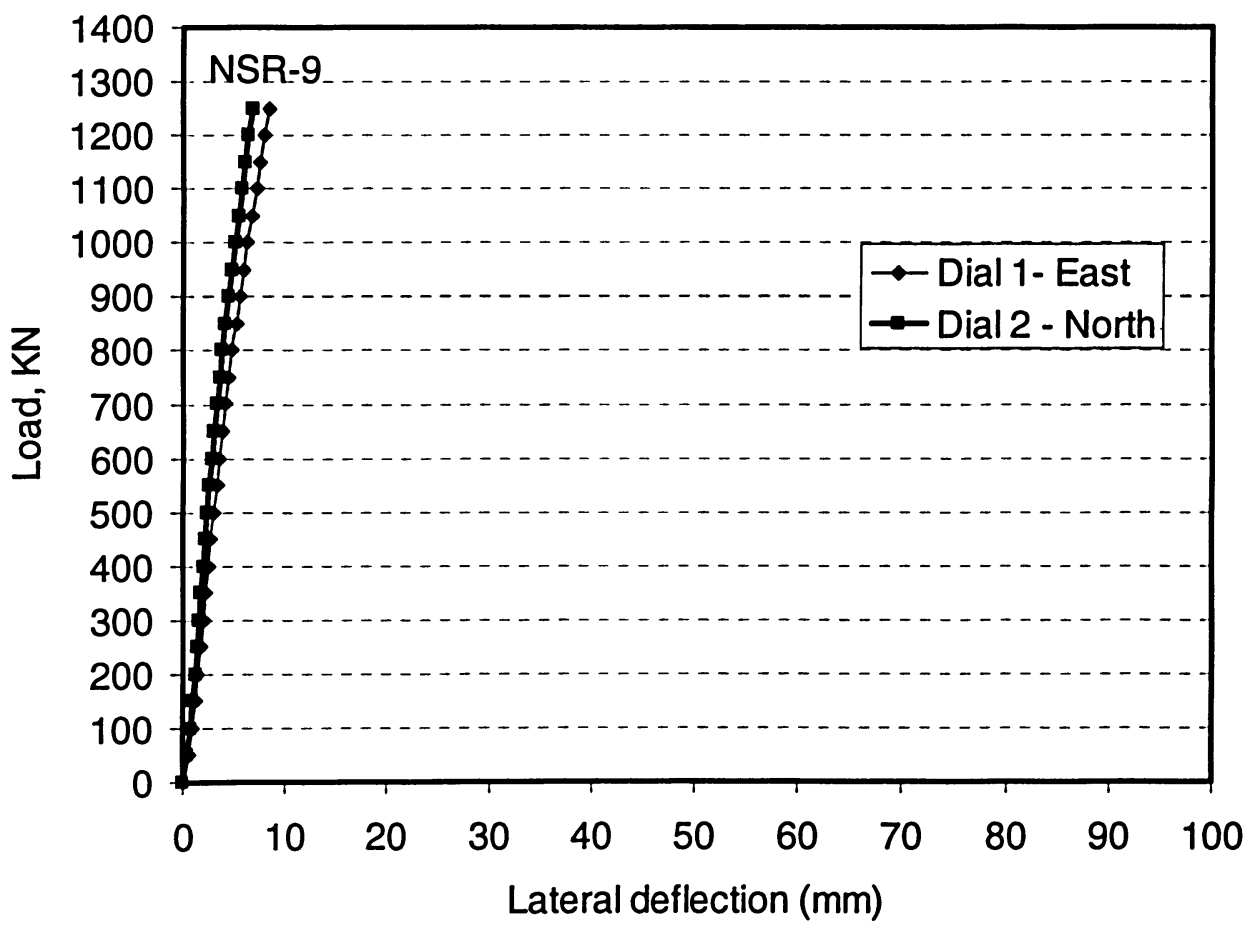

Figure 4.131 Load-lateral deflection curves for specimen NSR-9 


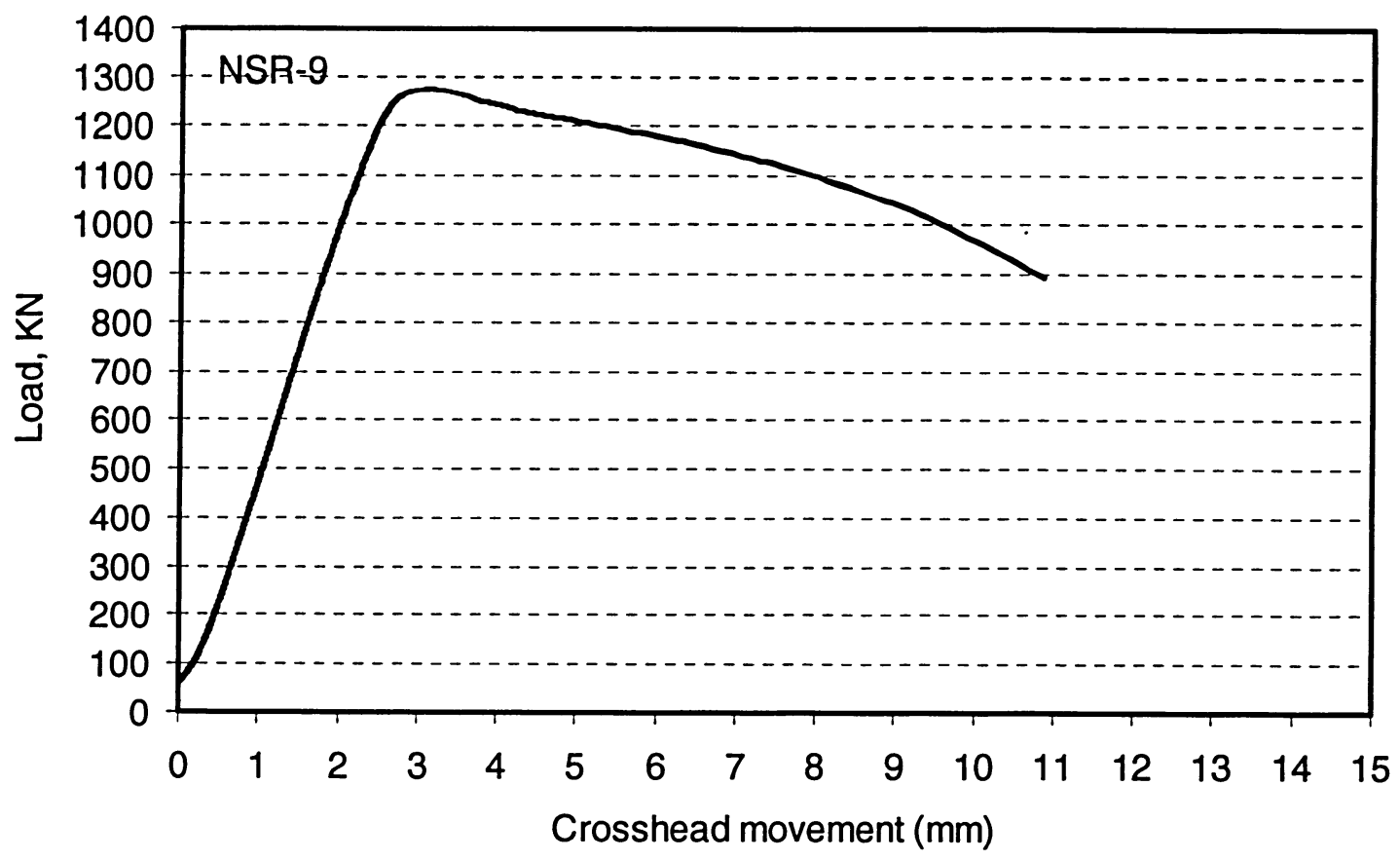

Figure 4.132 Load versus overall shortening curve for specimen NSR-9
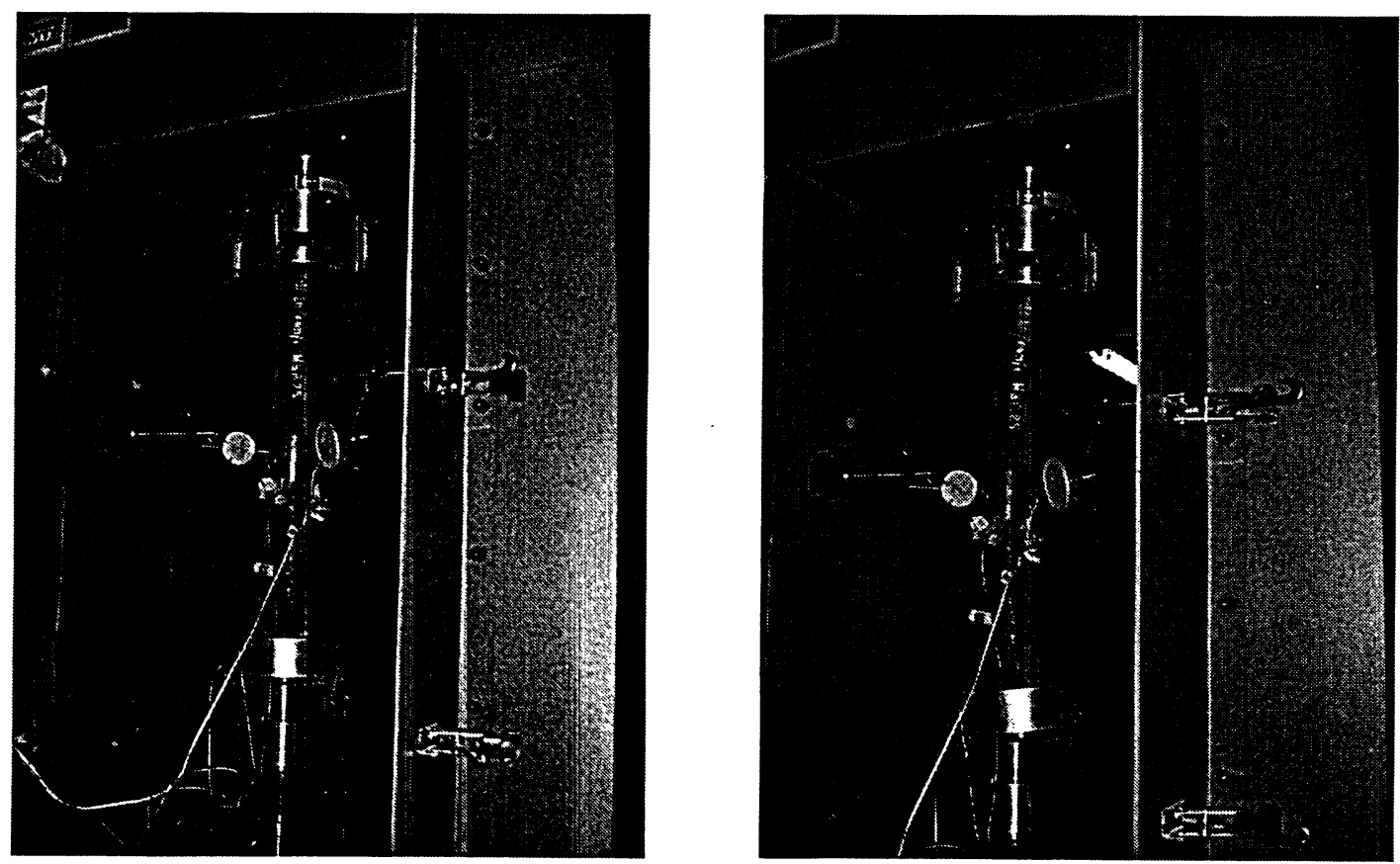

Figure 4.133 Views of specimen NSR-10 before and after testing 


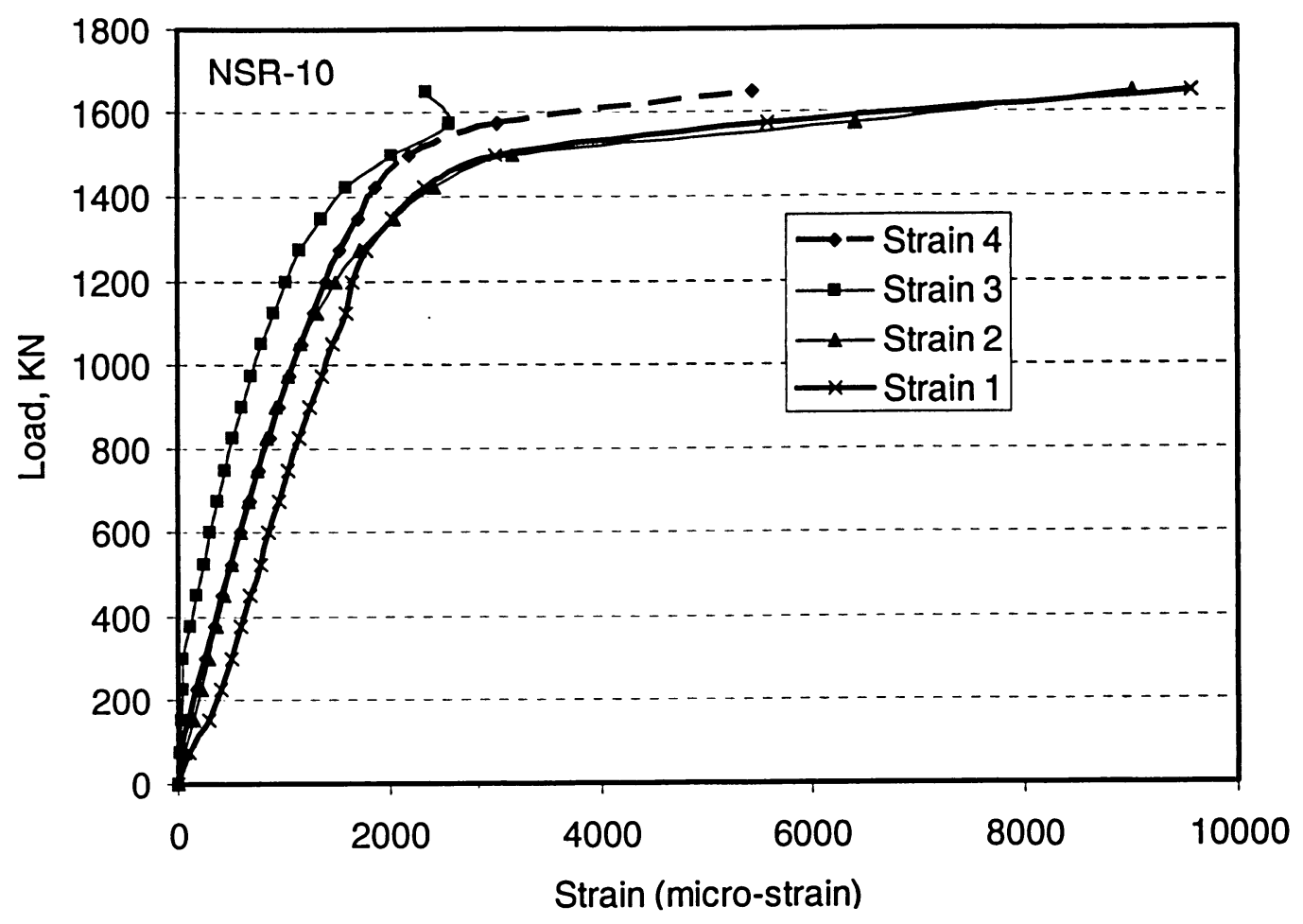

Figure 4.134 Axial load-strain relationships for specimen NSR-10

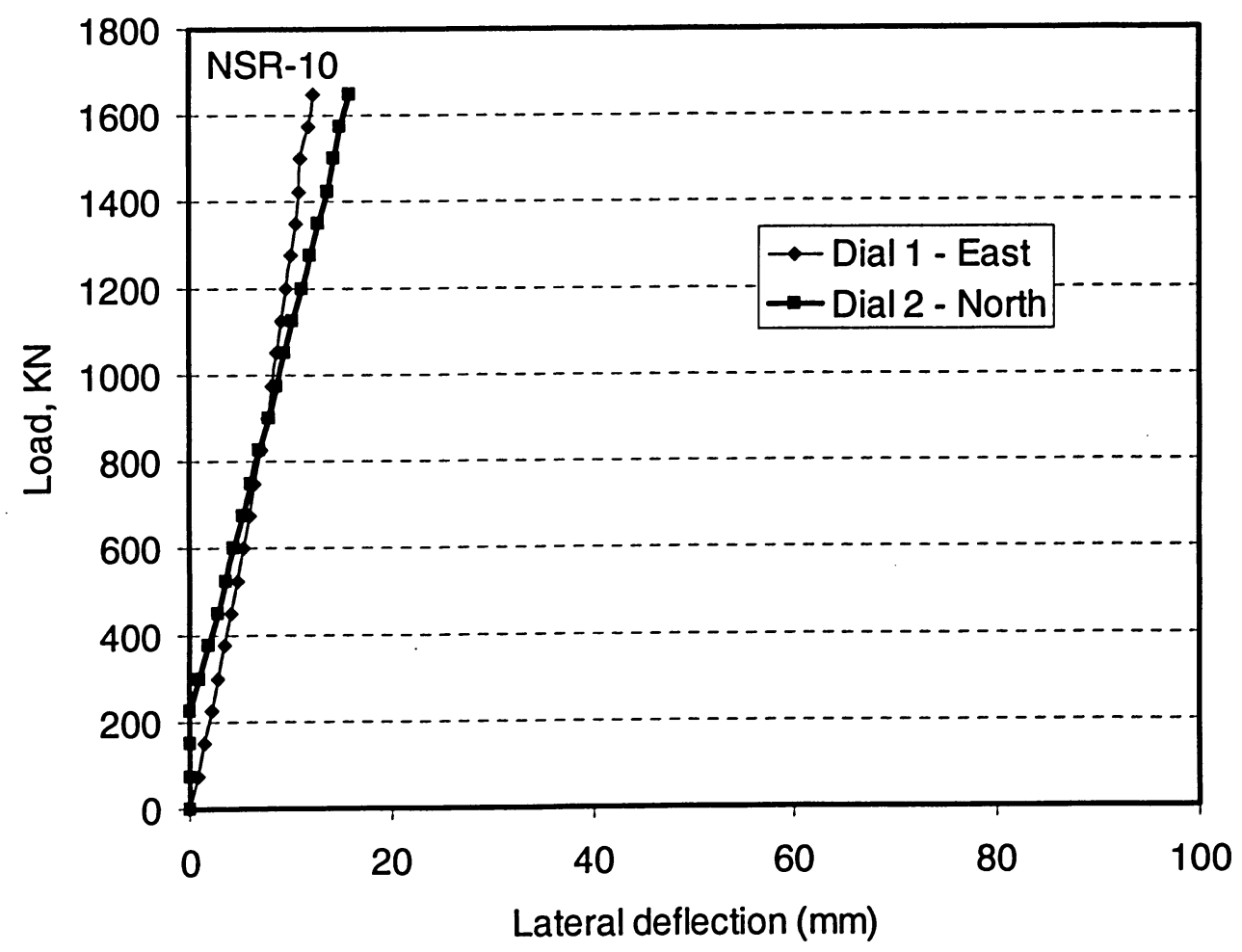

Figure 4.135 Load-lateral deflection curves for specimen NSR-10 


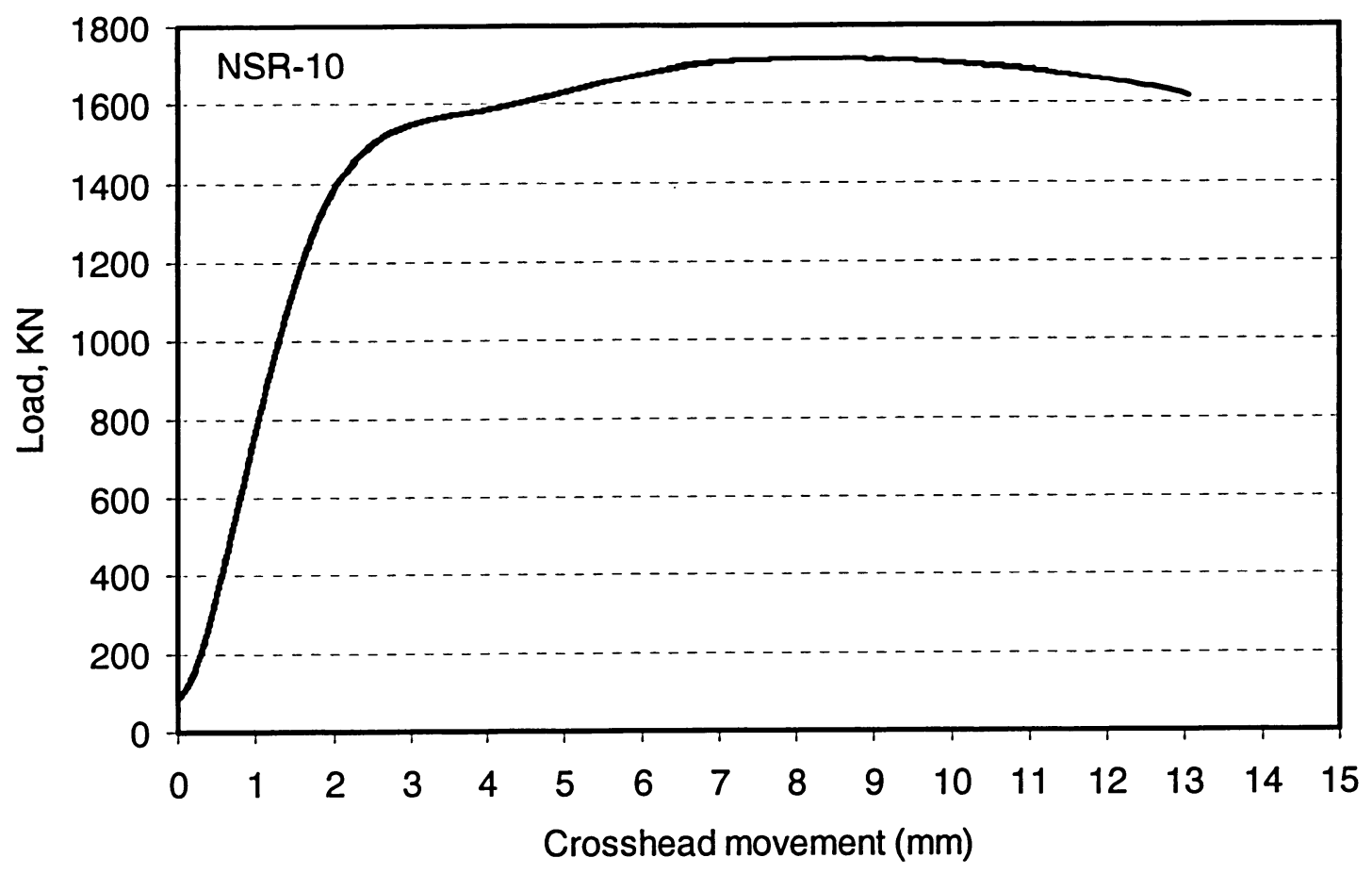

Figure 4.136 Load versus overall shortening curve for specimen NSR-10
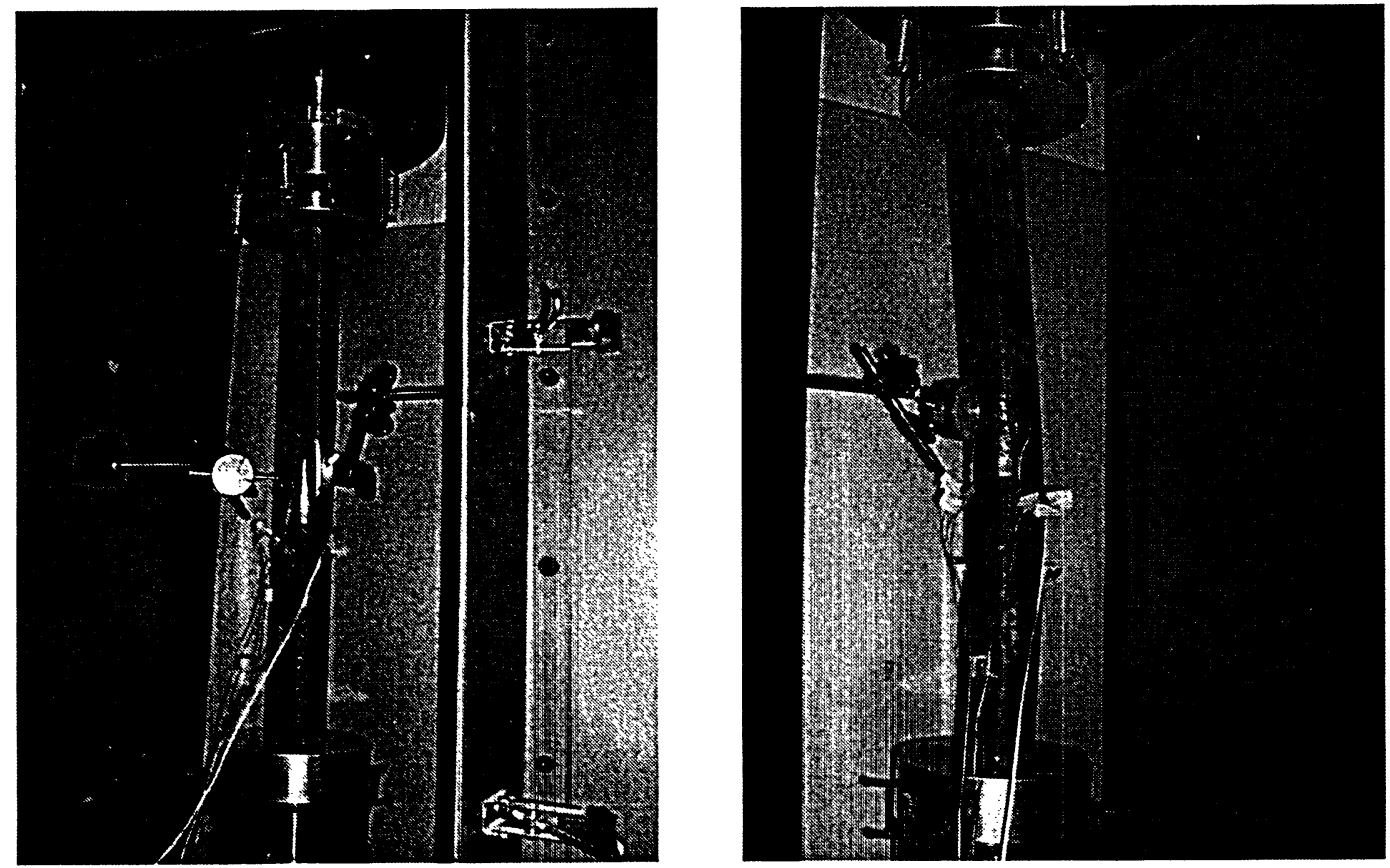

Figure 4.137 Views of specimen NSR-11 before and after testing 


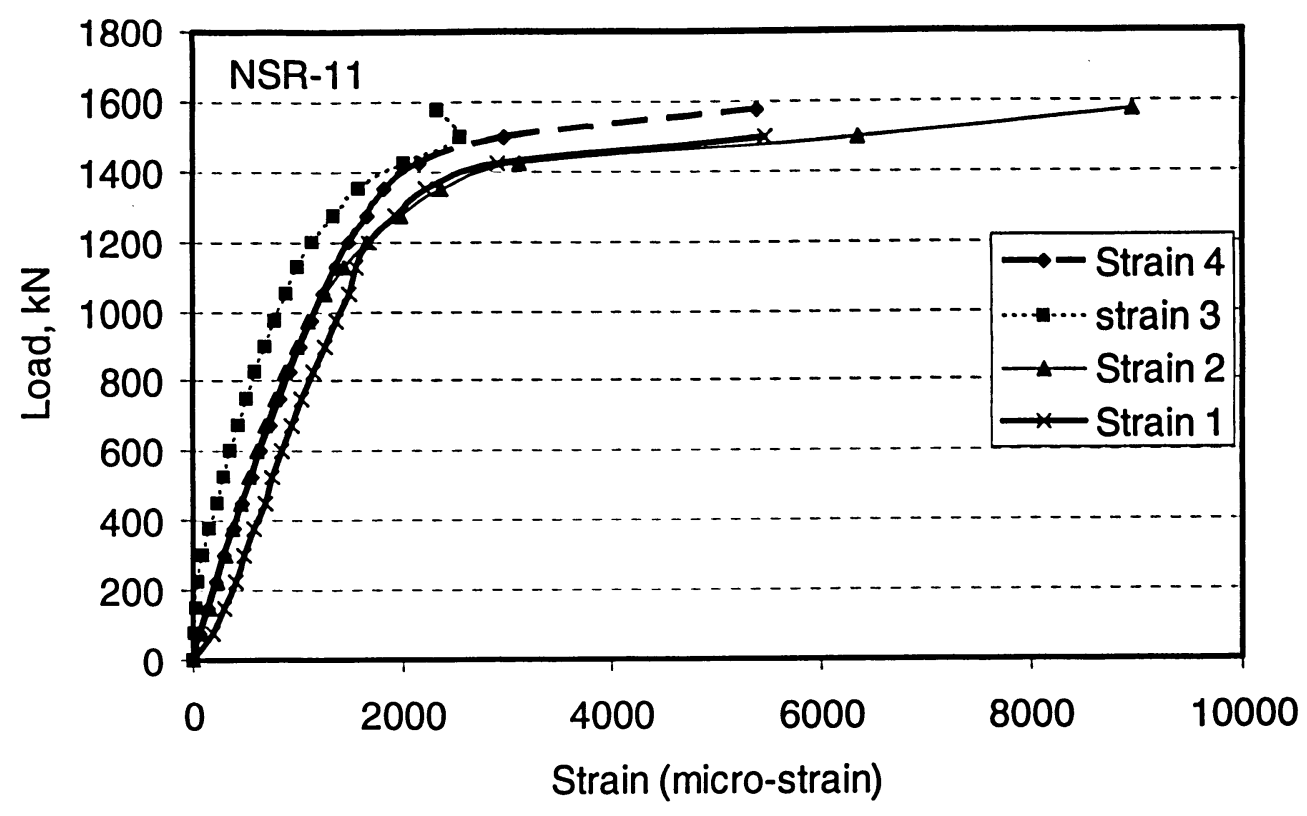

Figure 4.138 Axial load-strain relationships for specimen NSR-11

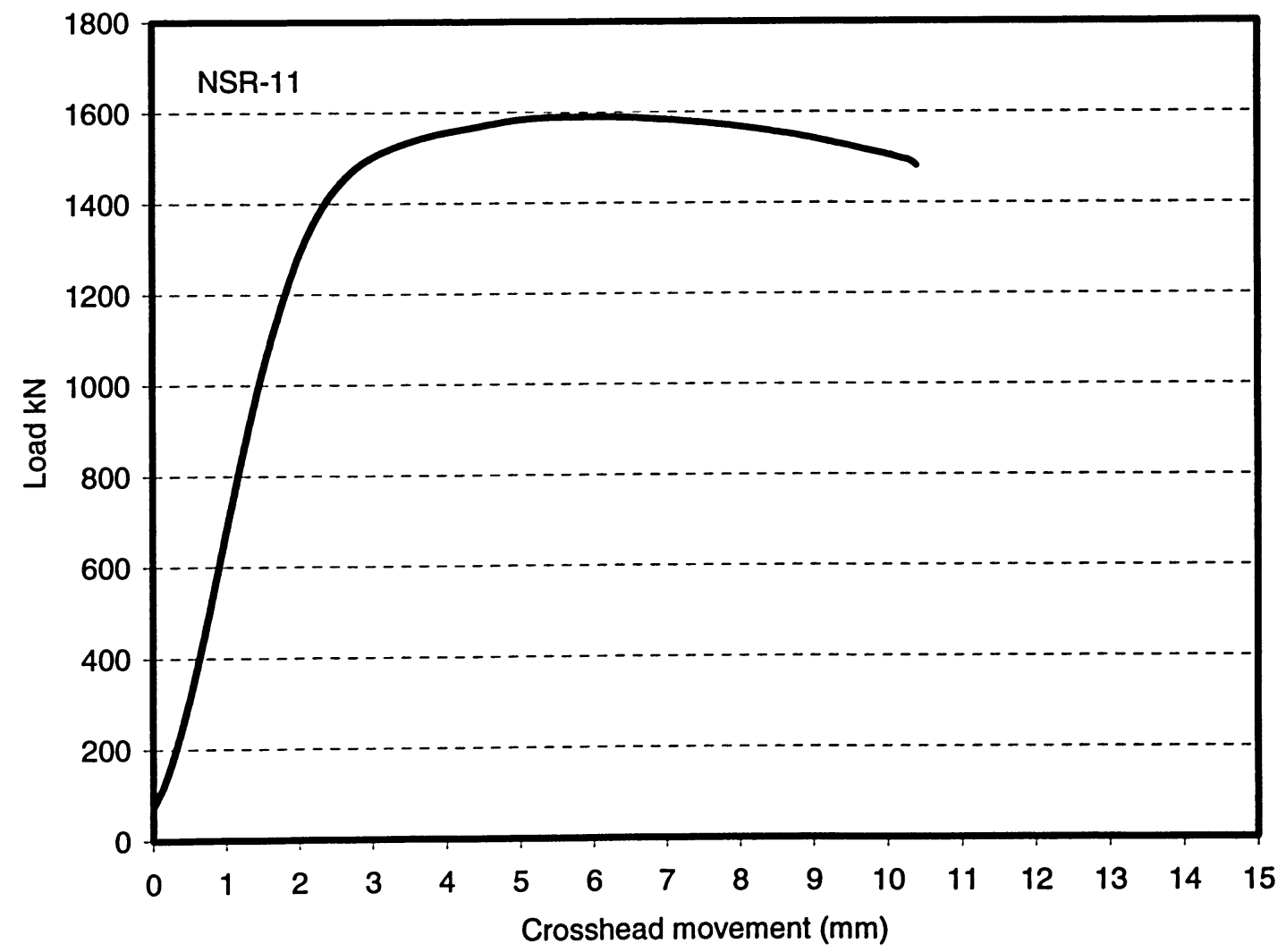

Figure 4.139 Load versus overall shortening curve for specimen NSR-11 

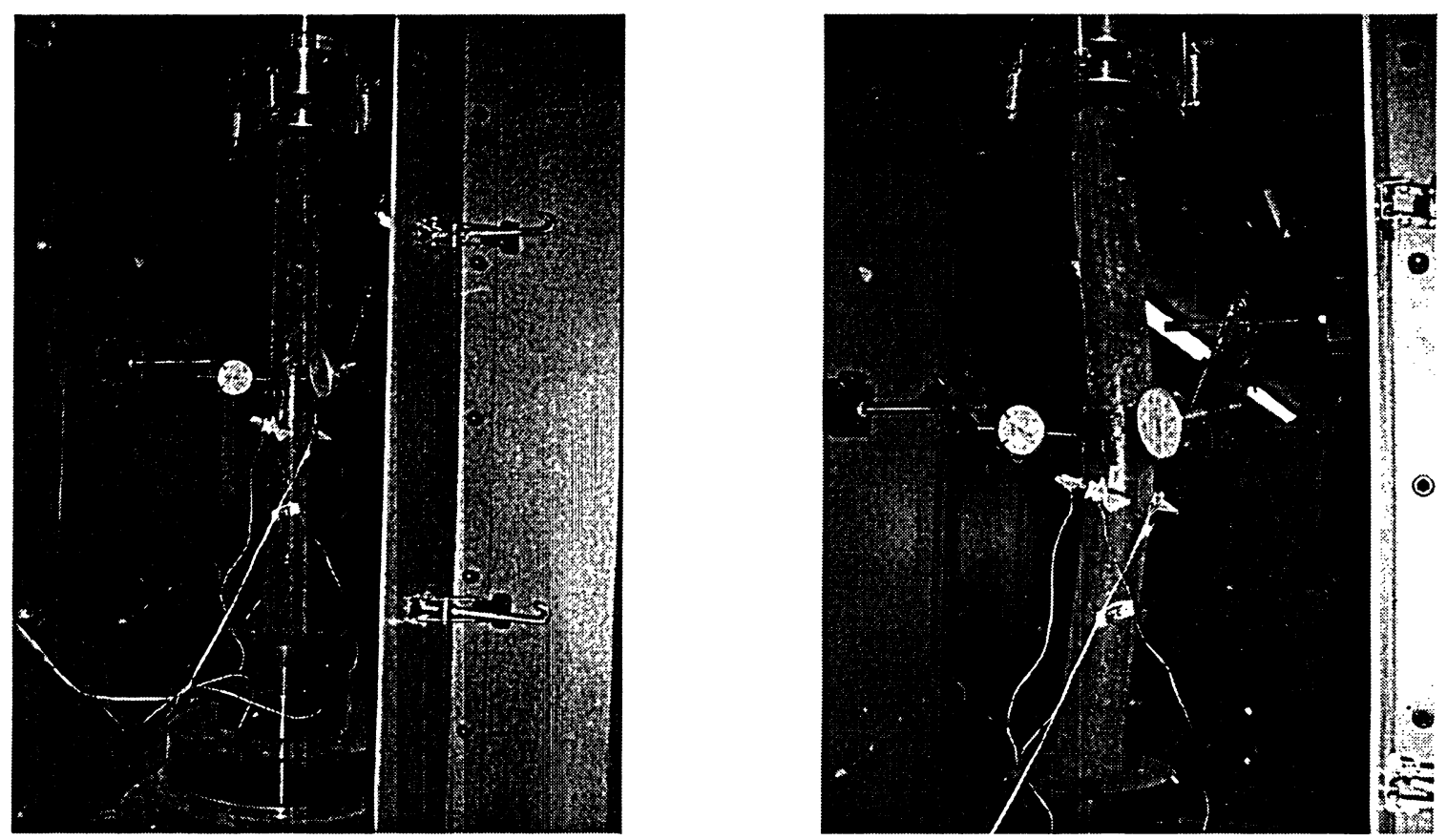

Figure 4.140 Views of specimen NSR-12 before and after testing

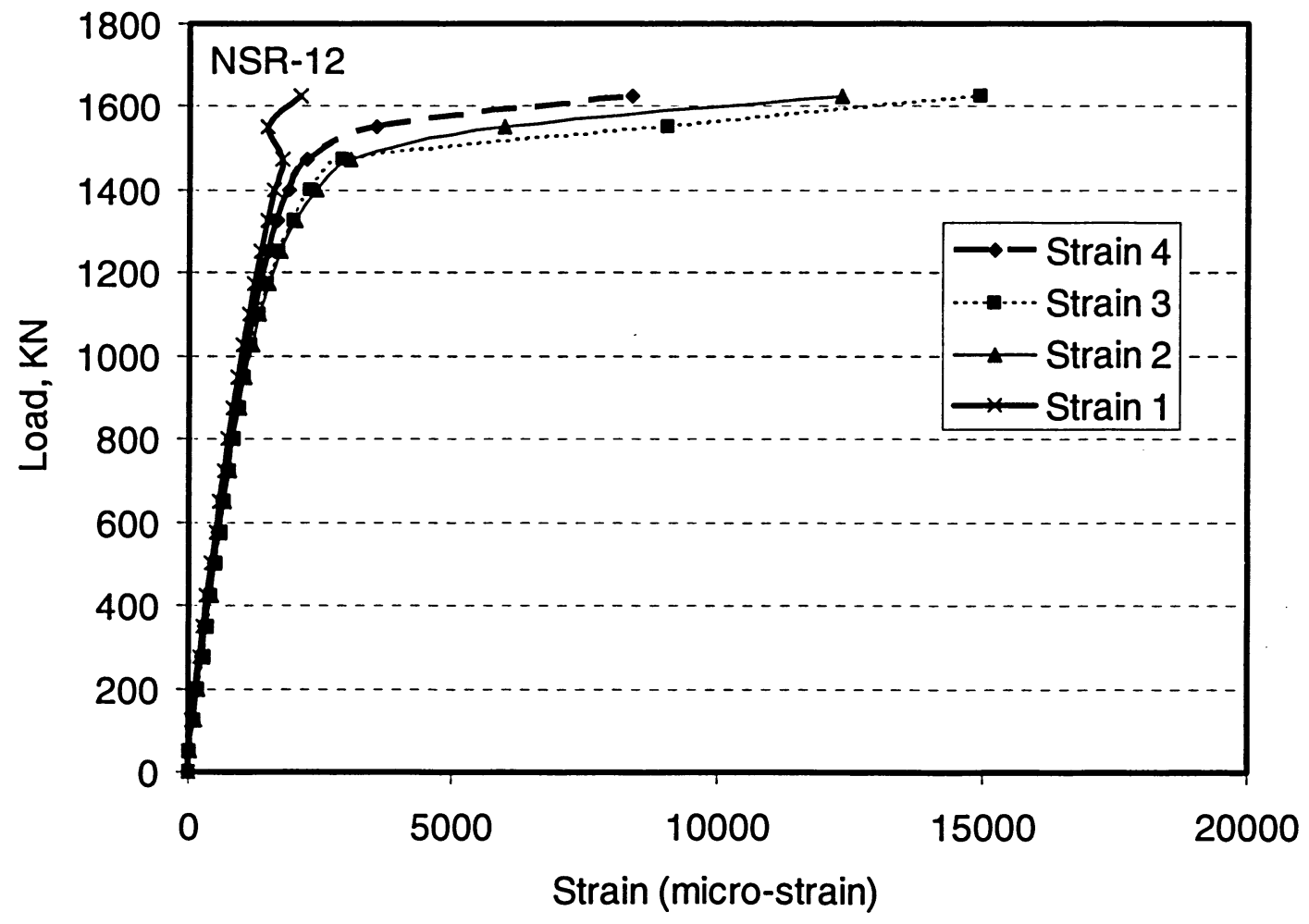

Figure 4.141 Axial load-strain relationships for specimen NSR-12 


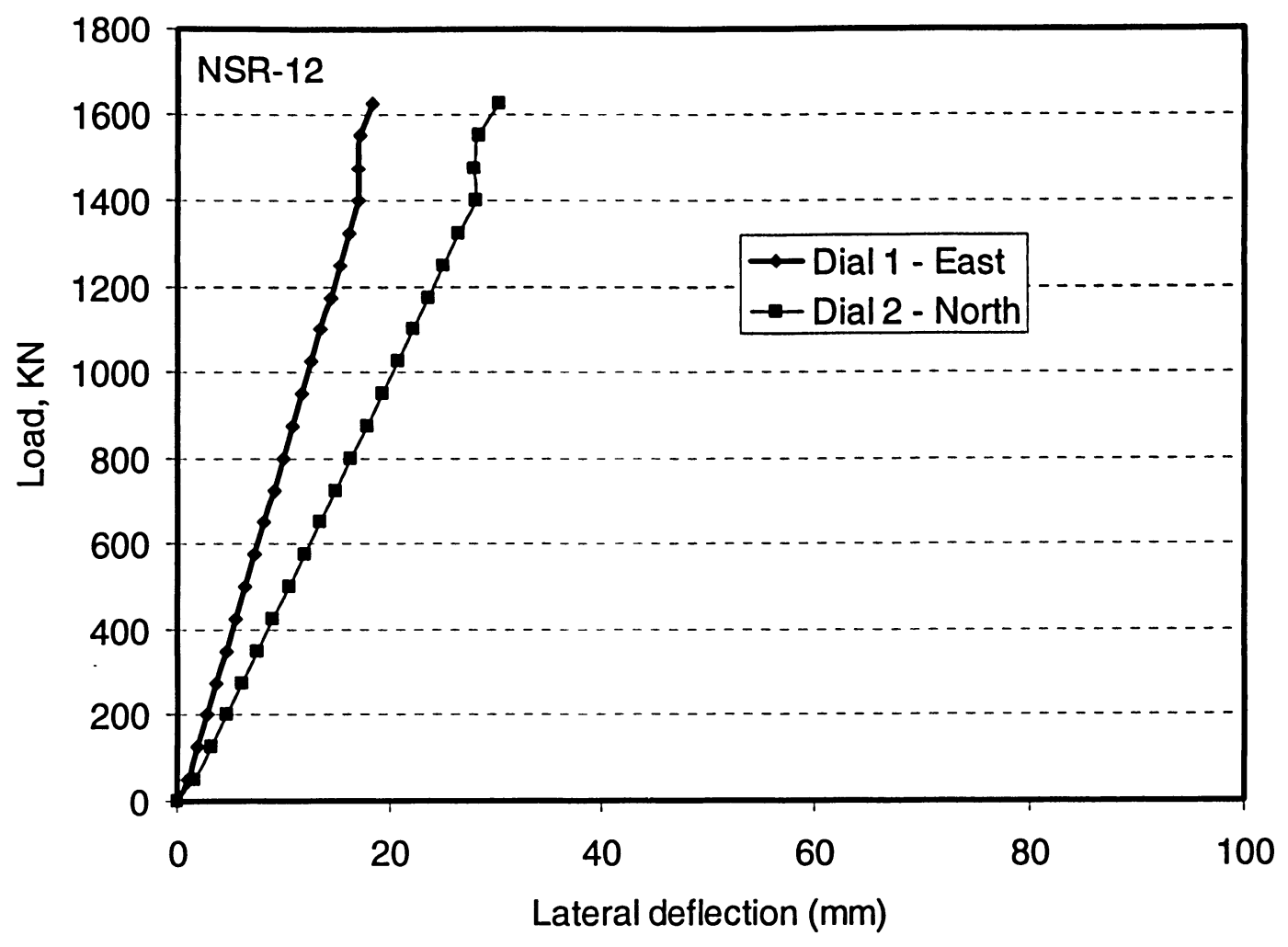

Figure 4.142 Load-lateral deflection curves for specimen NSR-12

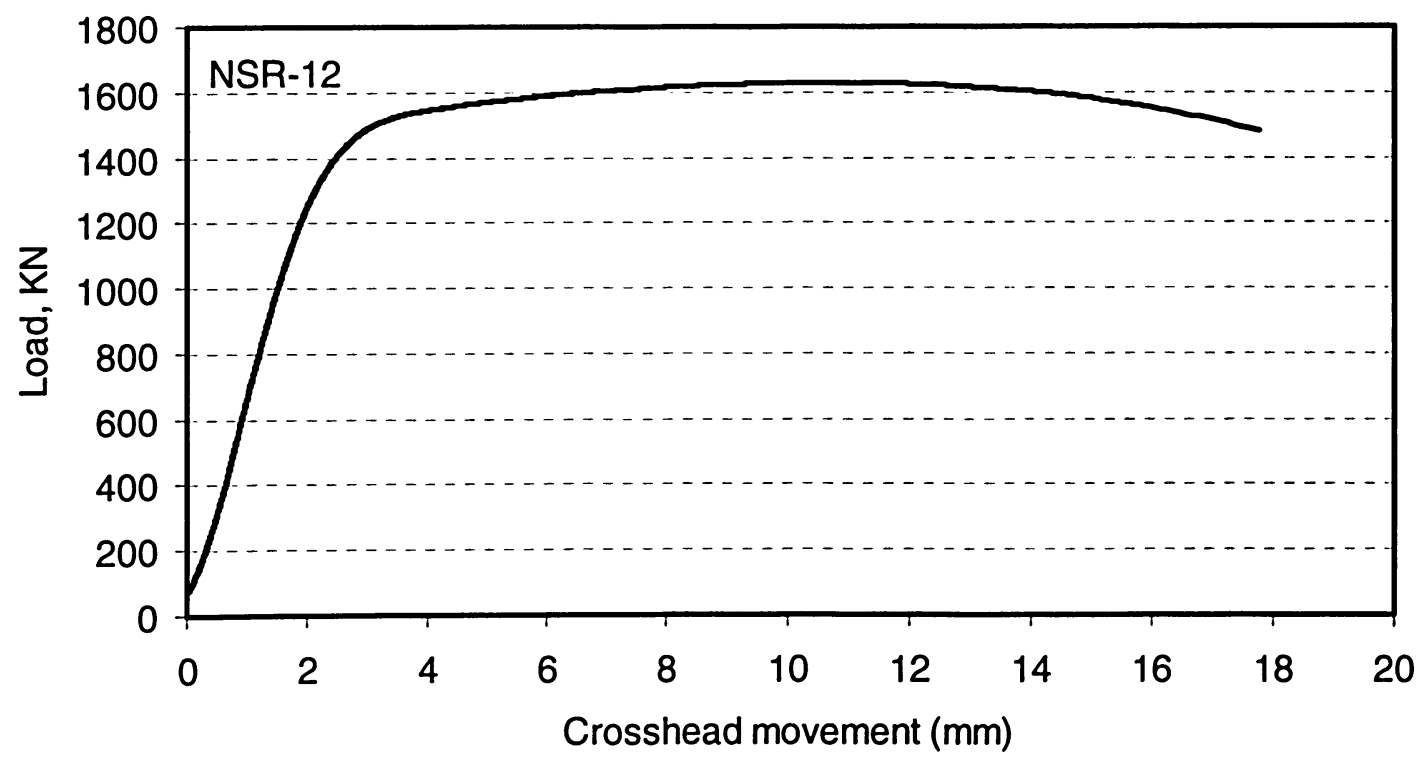

Figure 4.143 Load versus overall shortening curve for specimen NSR-12 

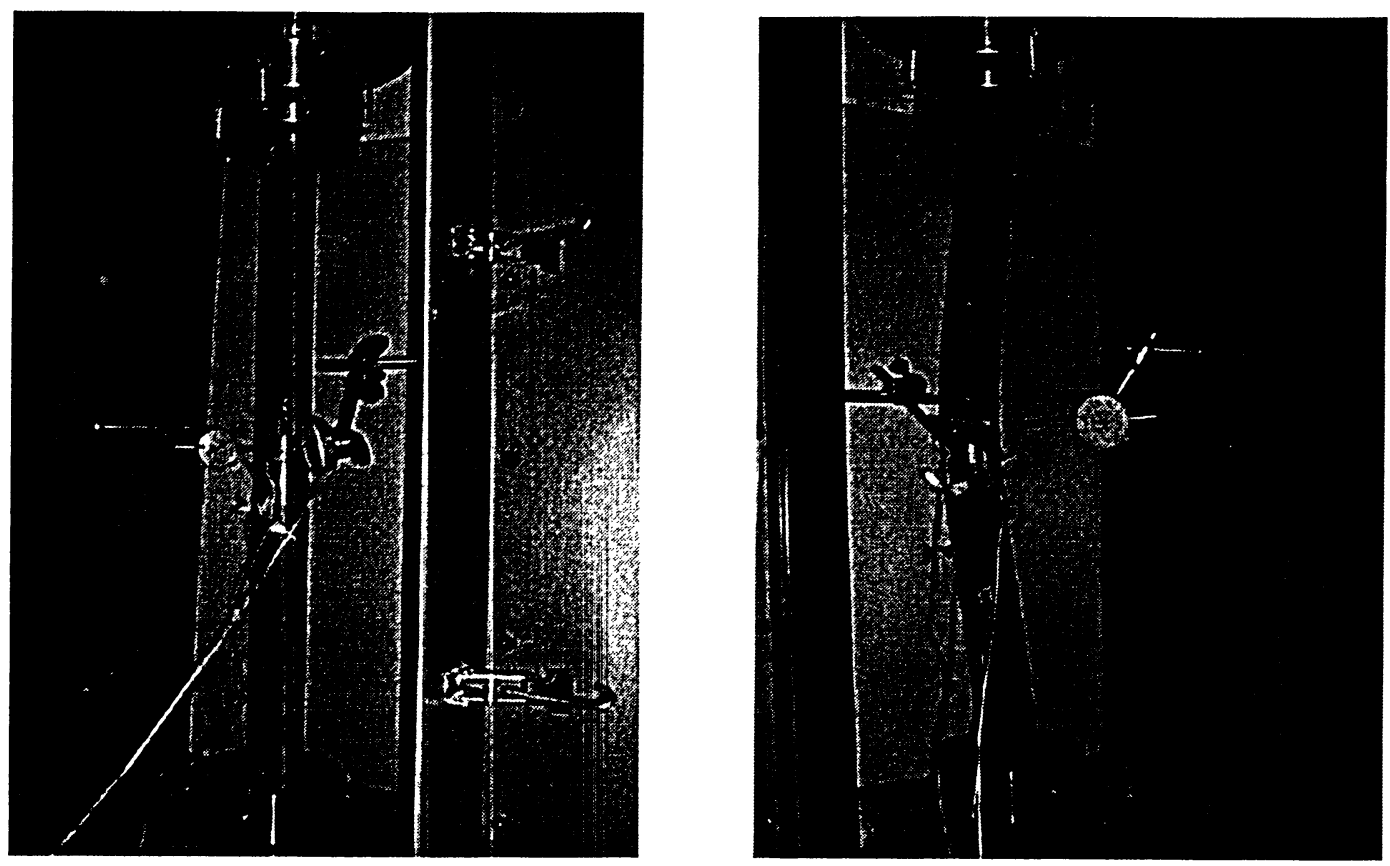

Figure 4.144 Views of specimen NSR-13 before and after testing

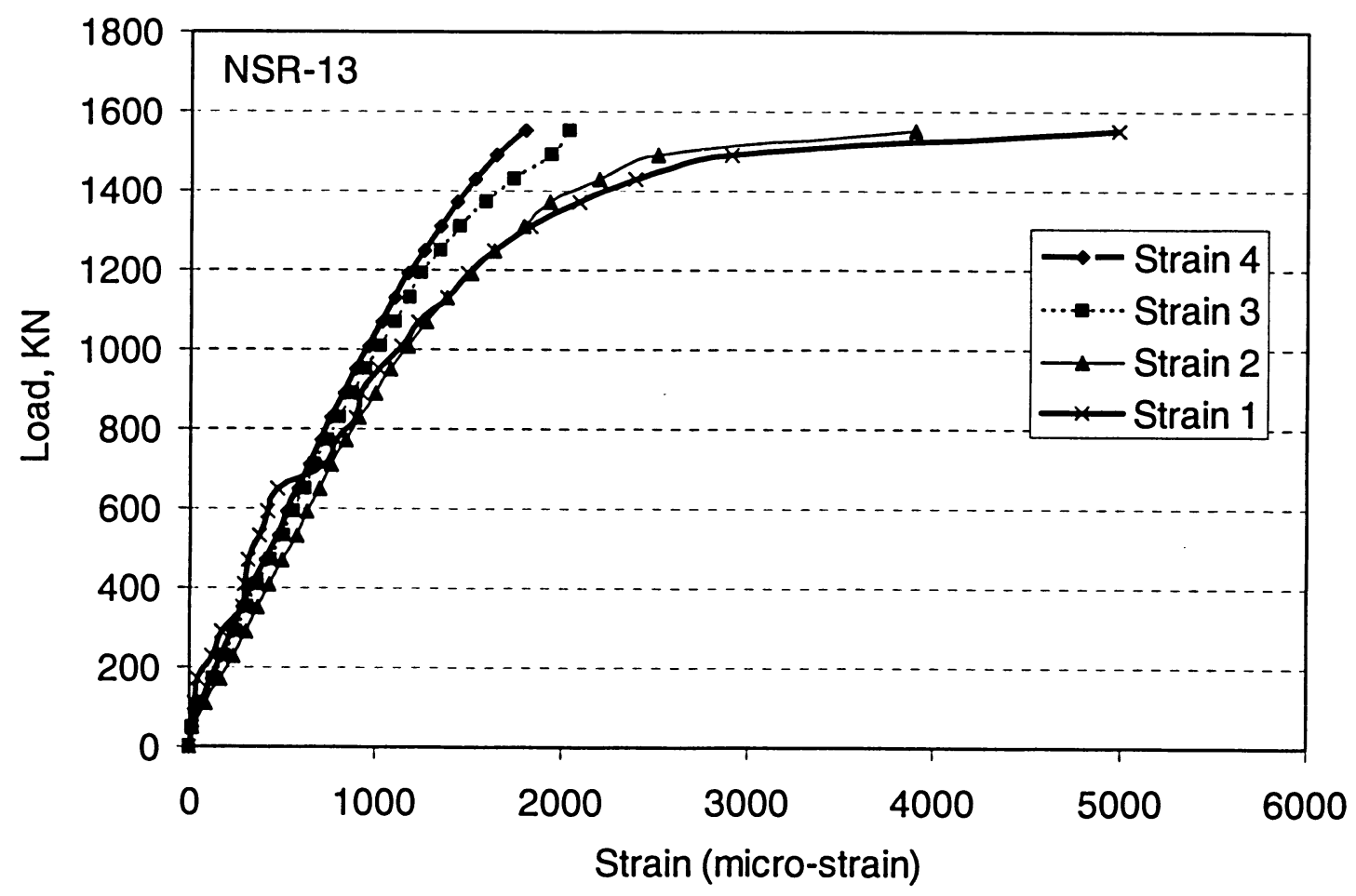

Figure 4.145 Axial load-strain relationships for specimen NSR-13 


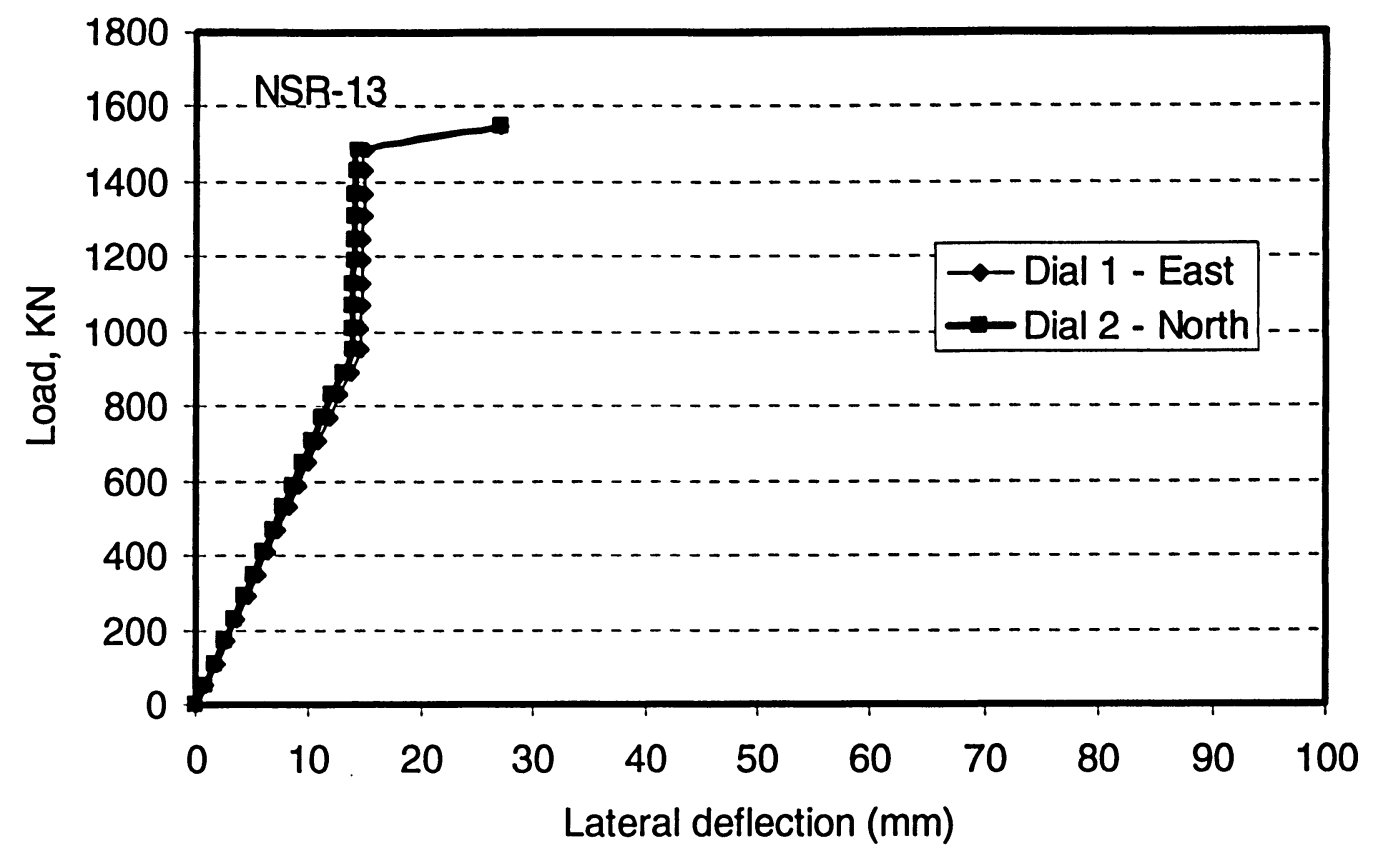

Figure 4.146 Load-lateral deflection curves for specimen NSR-13

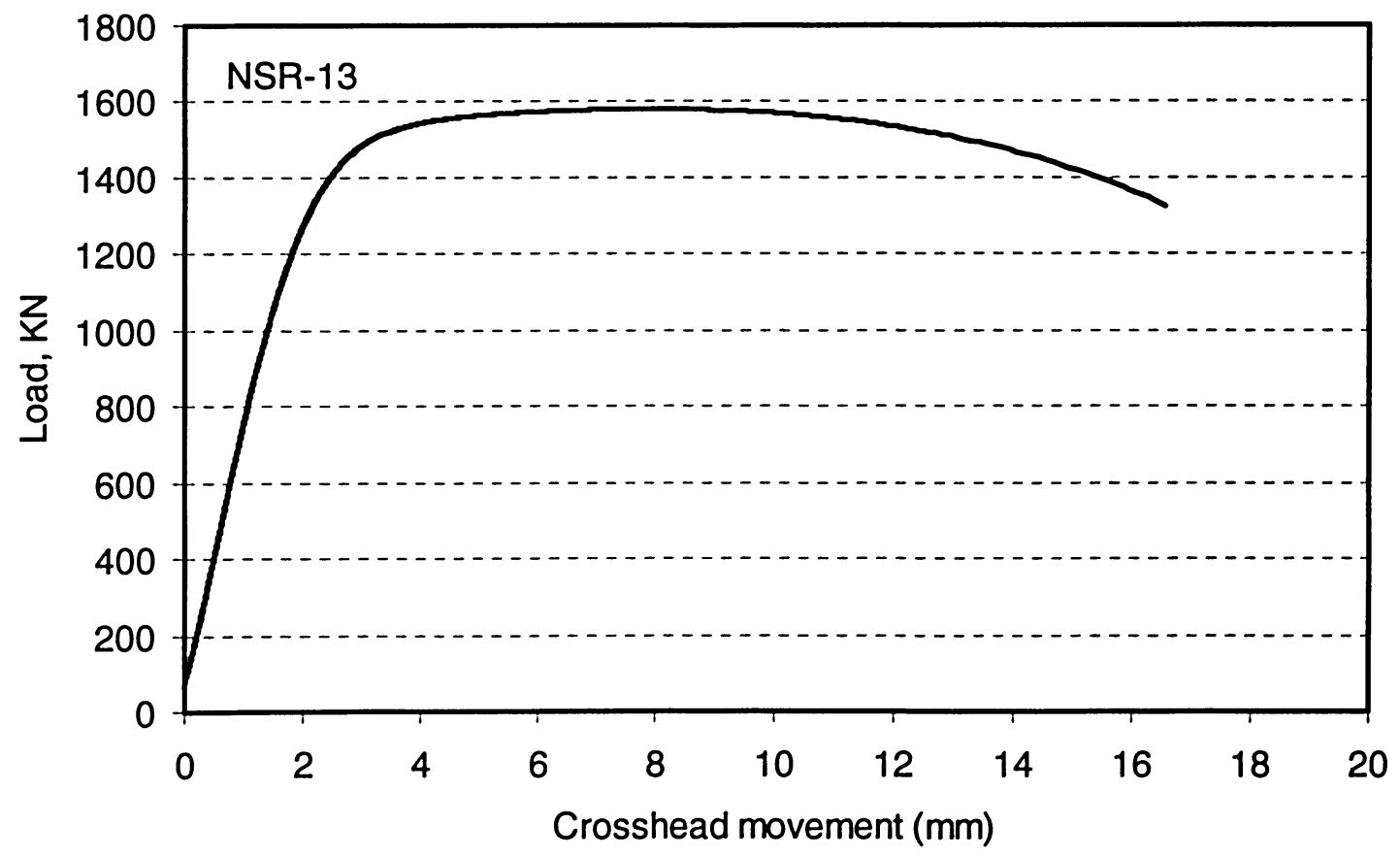

Figure 4.147 Load versus overall shortening curve for specimen NSR-13 

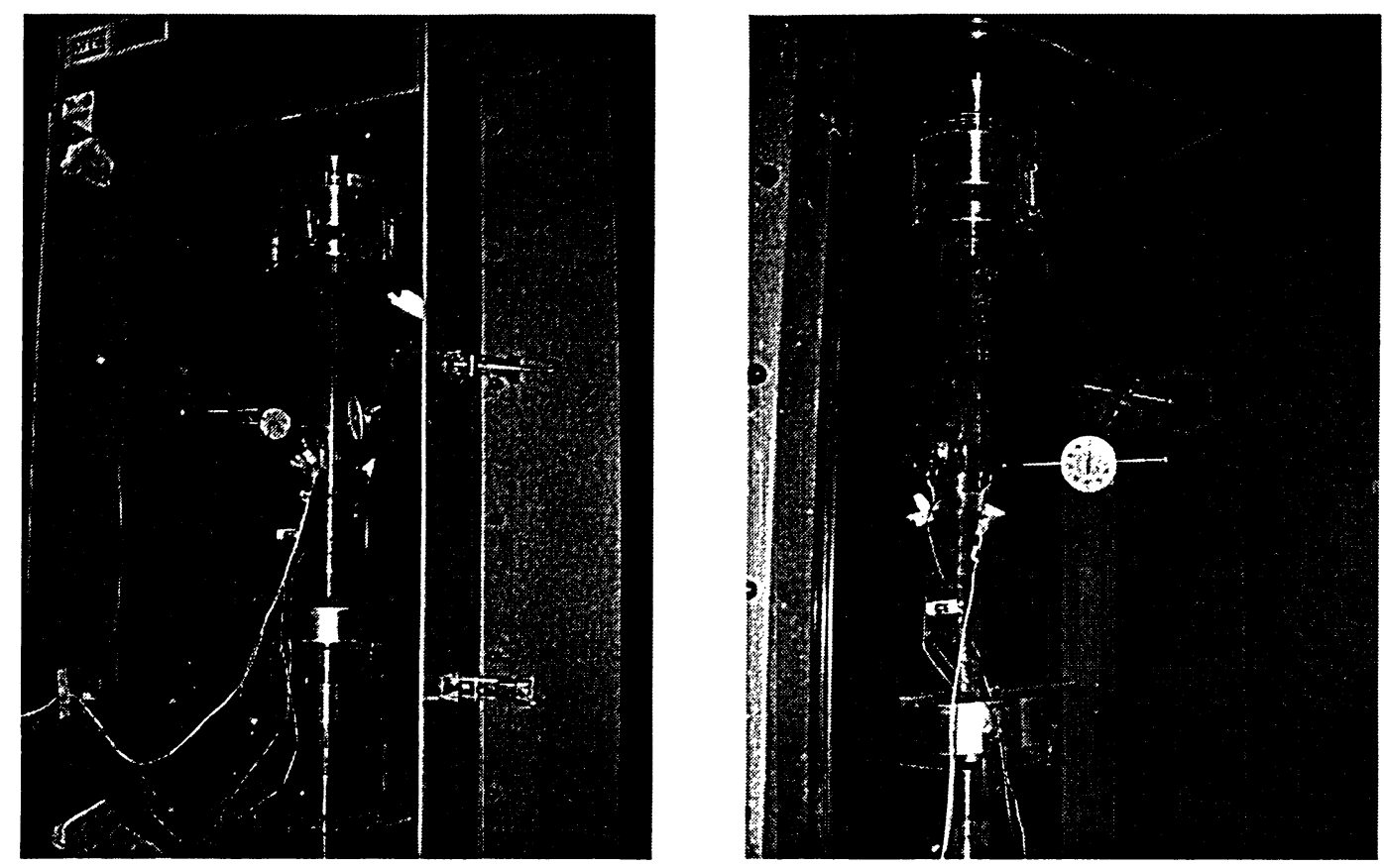

Figure 4.148 Views of specimen NSR-14 before and after testing

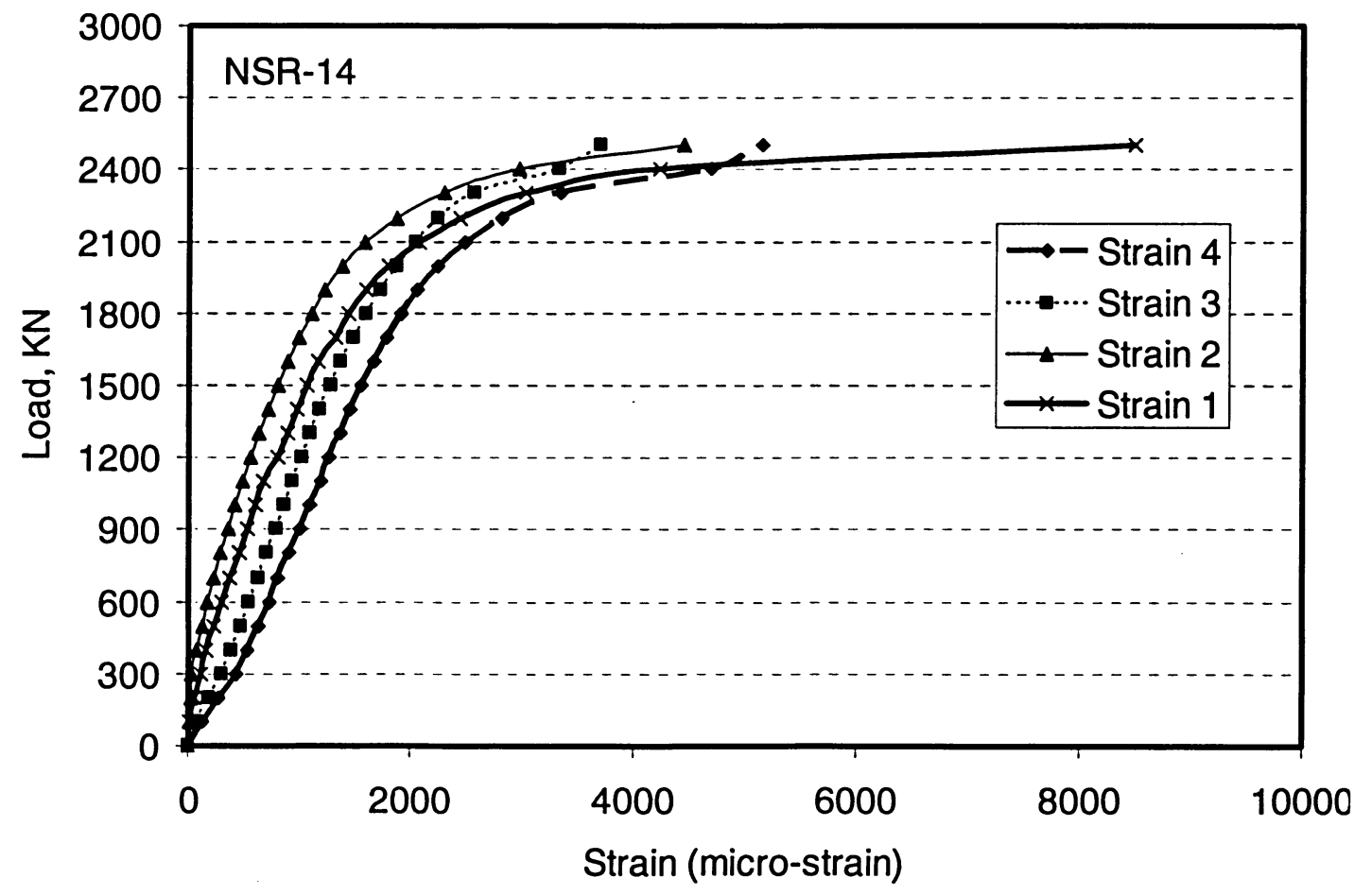

Figure 4.149 Axial load-strain relationships for specimen NSR-14 


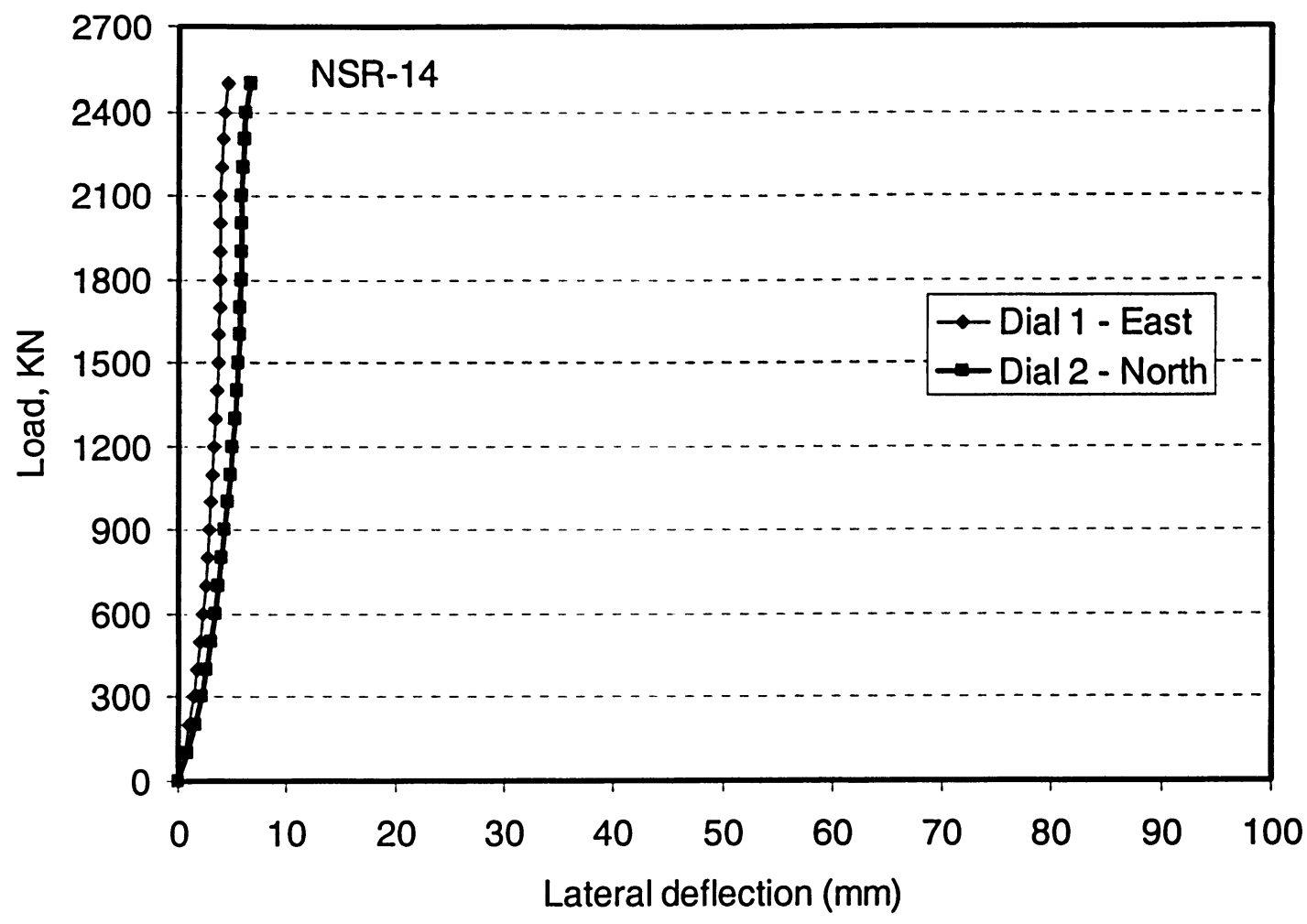

Figure 4.150 Load-lateral deflection curves for specimen NSR-14

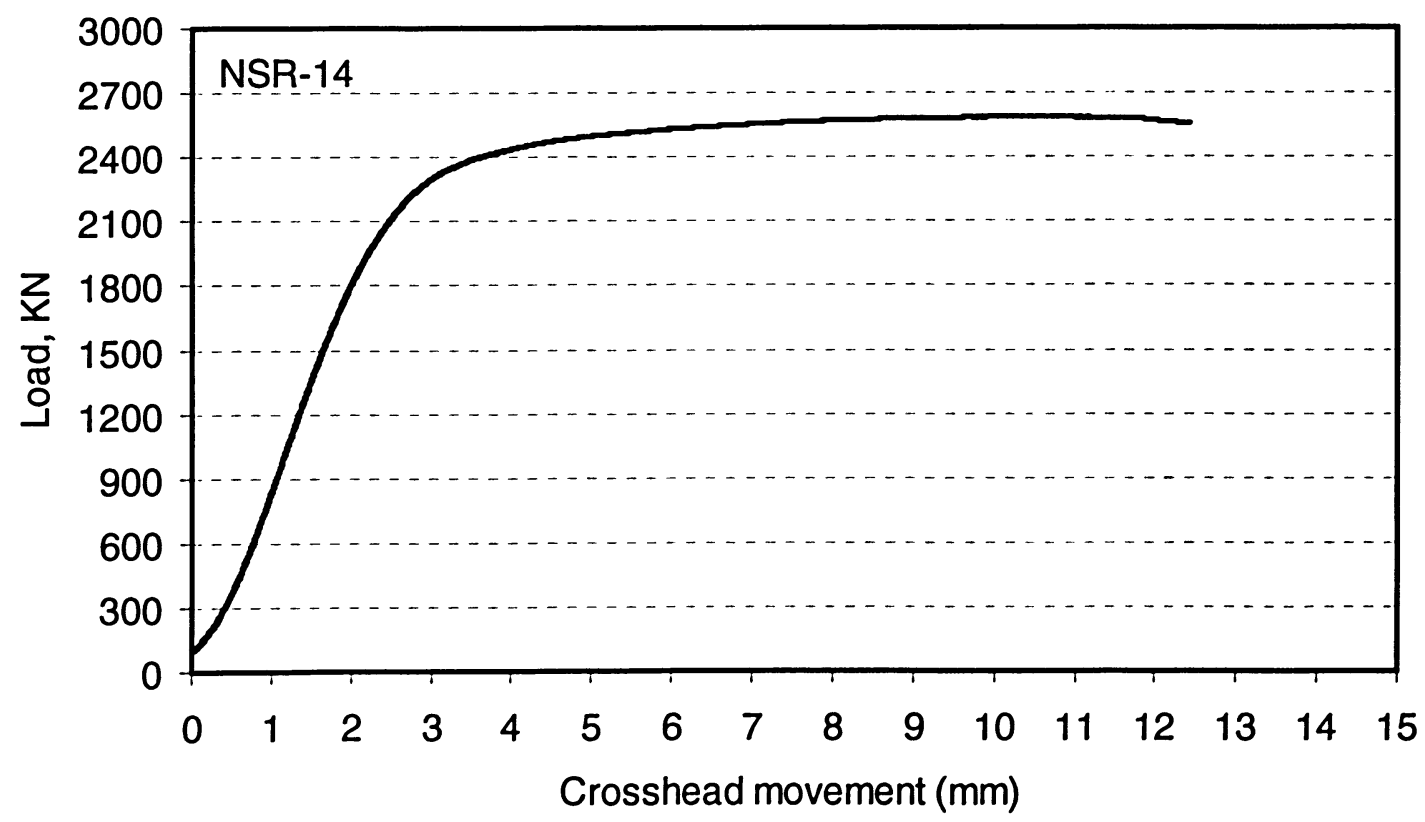

Figure 4.151 Load versus overall shortening curve for specimen NSR-14 

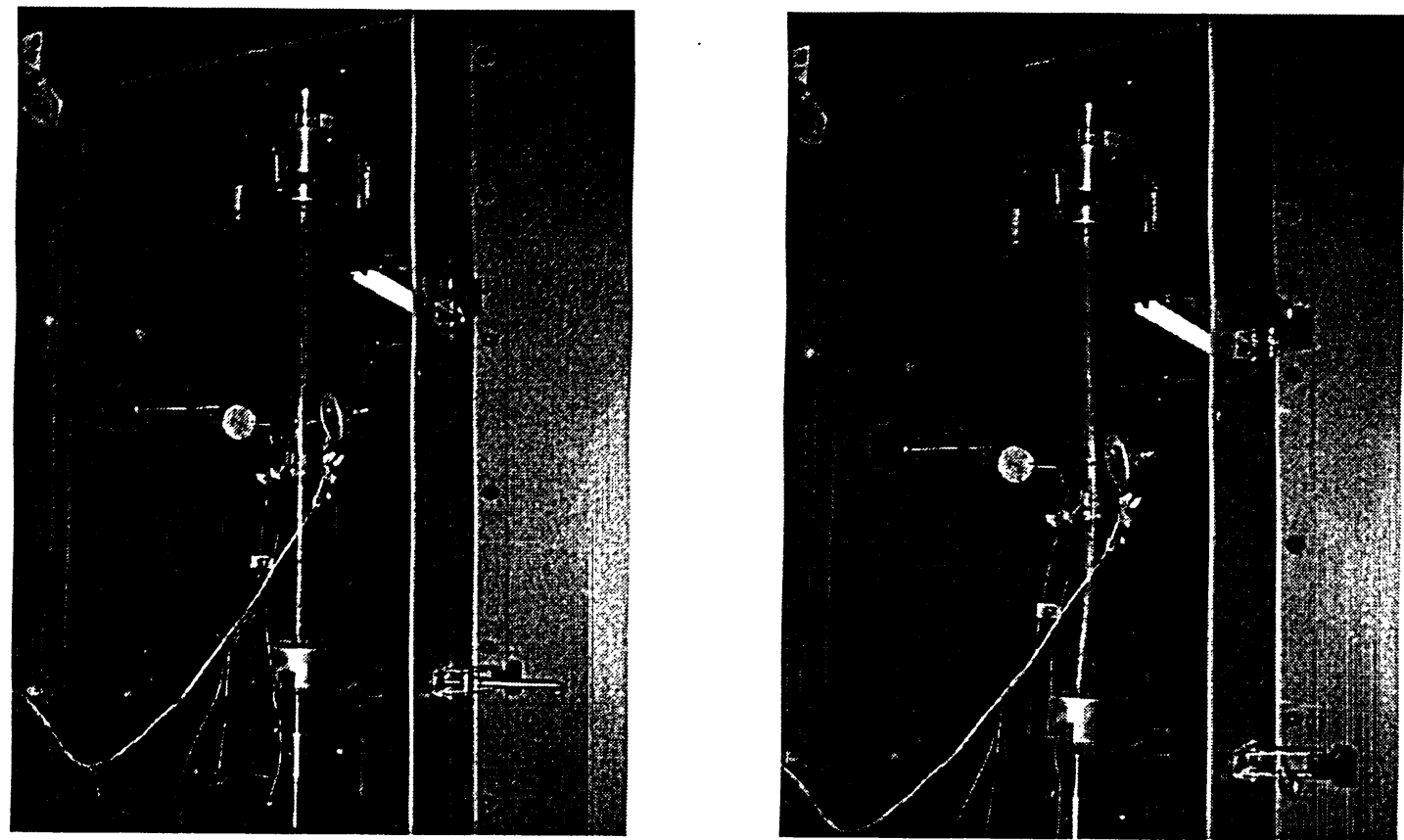

Figure 4.152 Views of specimen NSR-15 before and after testing

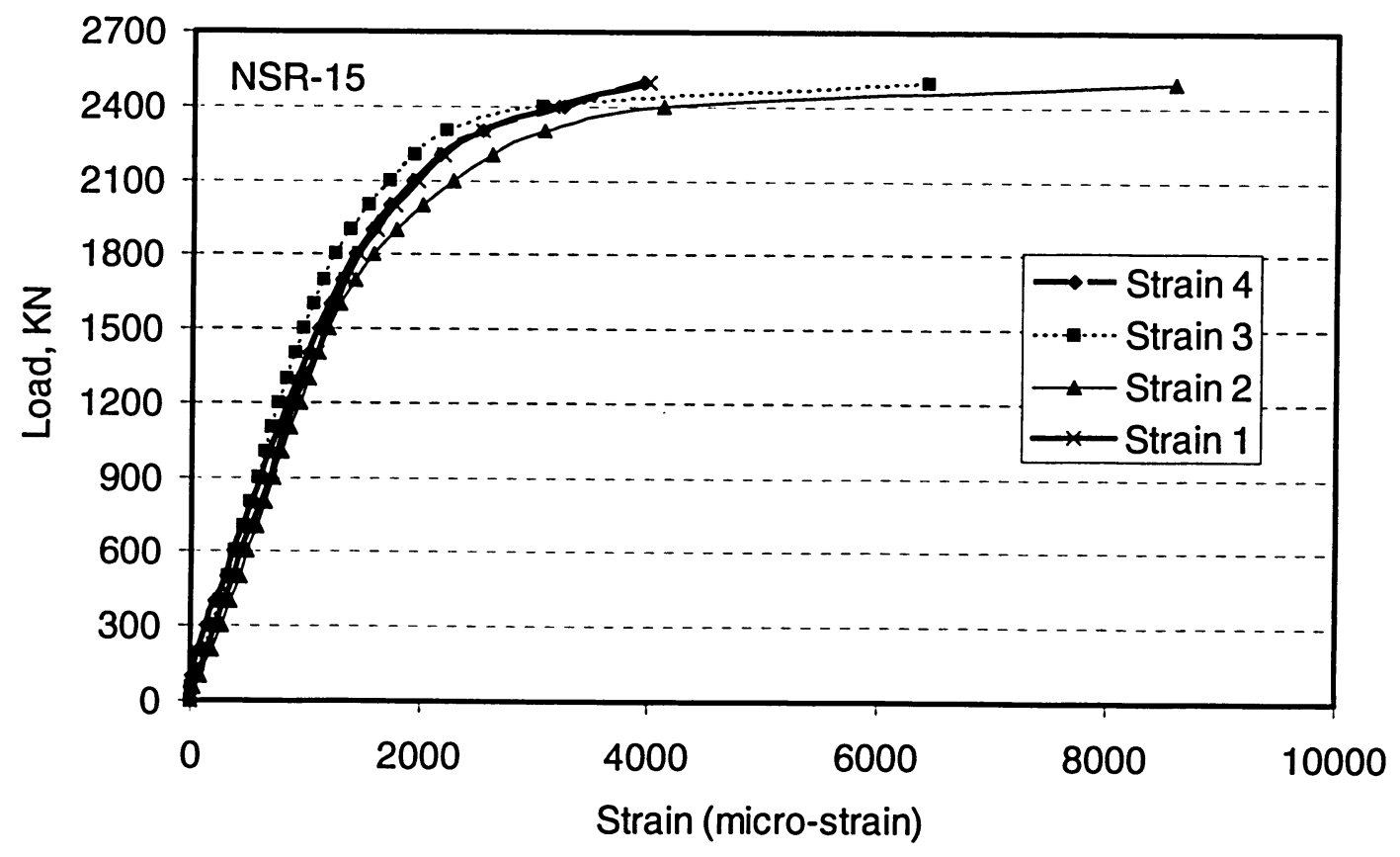

Figure 4.153 Axial load-strain relationships for specimen NSR-15 


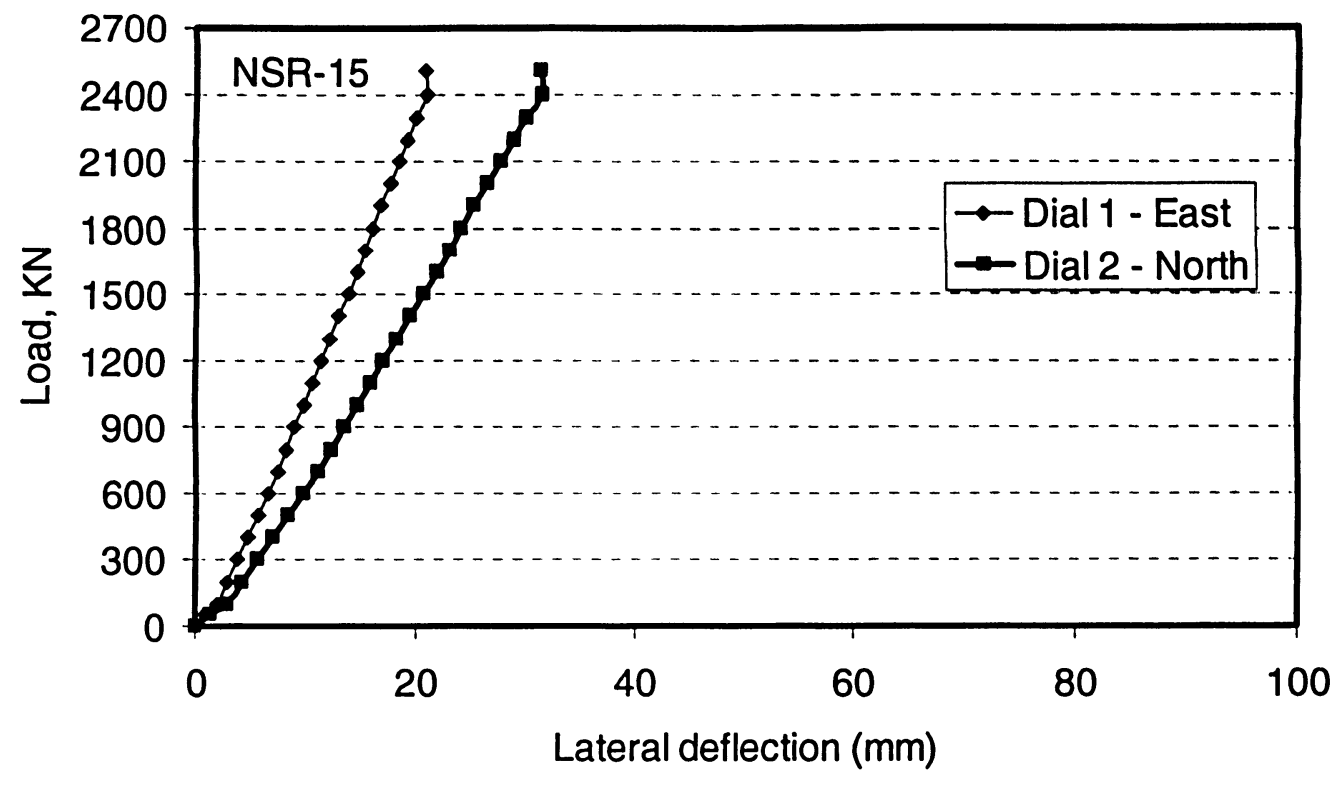

Figure 4.154 Load-lateral deflection curves for specimen NSR-15

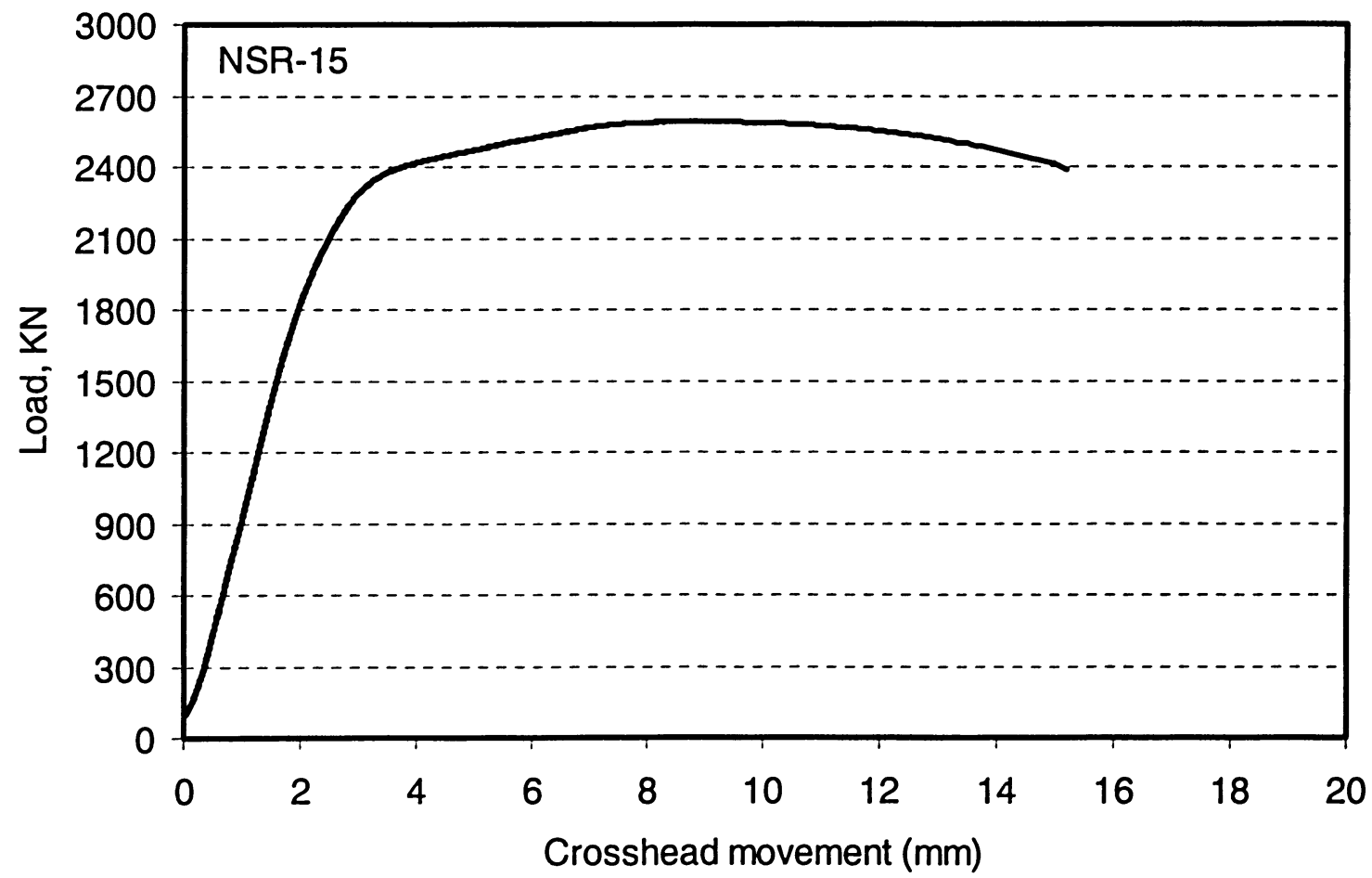

Figure 4.155 Load versus overall shortening curve for specimen NSR-15 

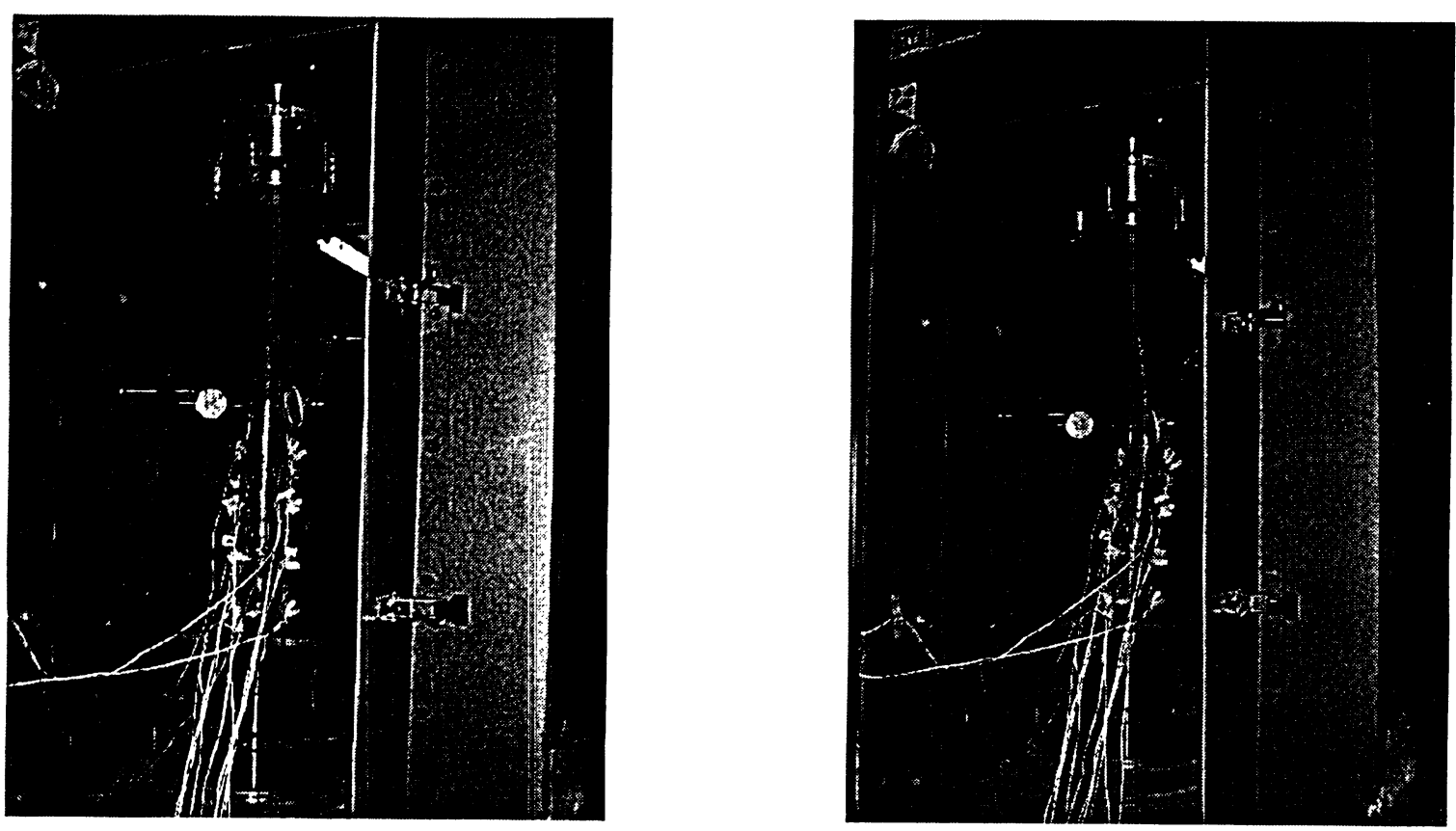

Figure 4.156 Views of specimen NSR-16 before and after testing

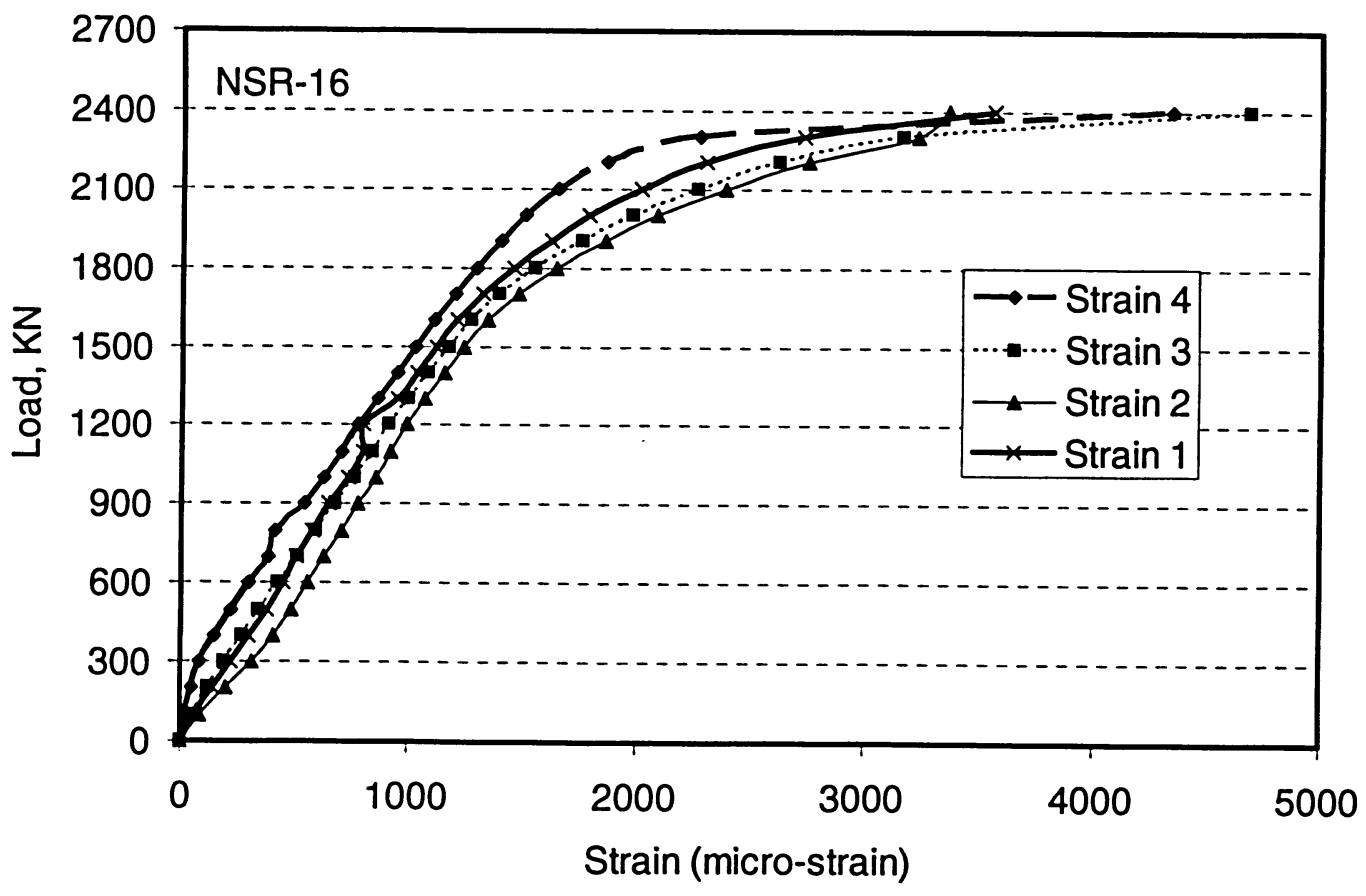

Figure 4.157 Axial load-strain relationships for specimen NSR-16 


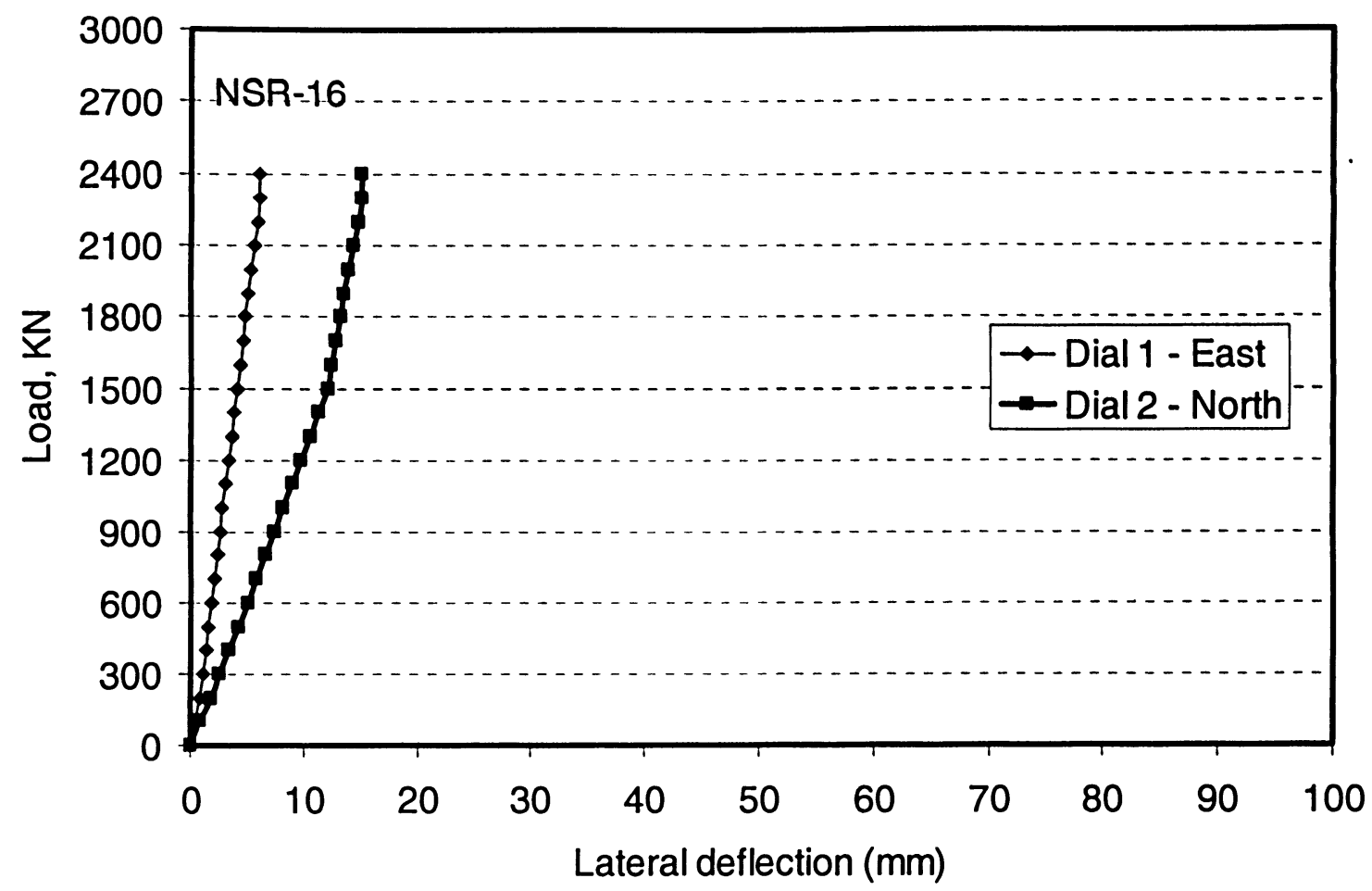

Figure 4.158 Load-lateral deflection curves for specimen NSR-16

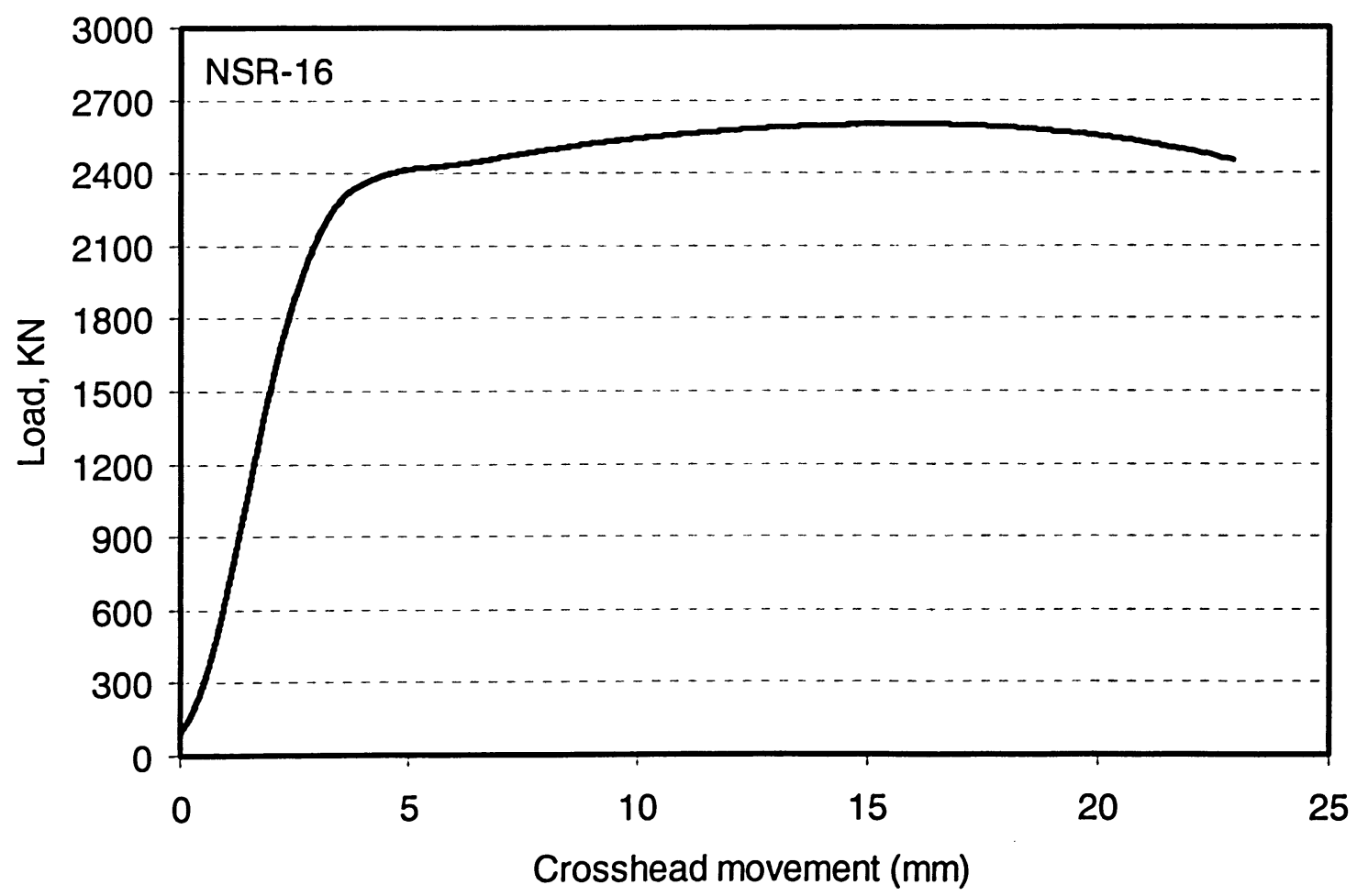

Figure 4.159 Load versus overall shortening curve for specimen NSR-16 

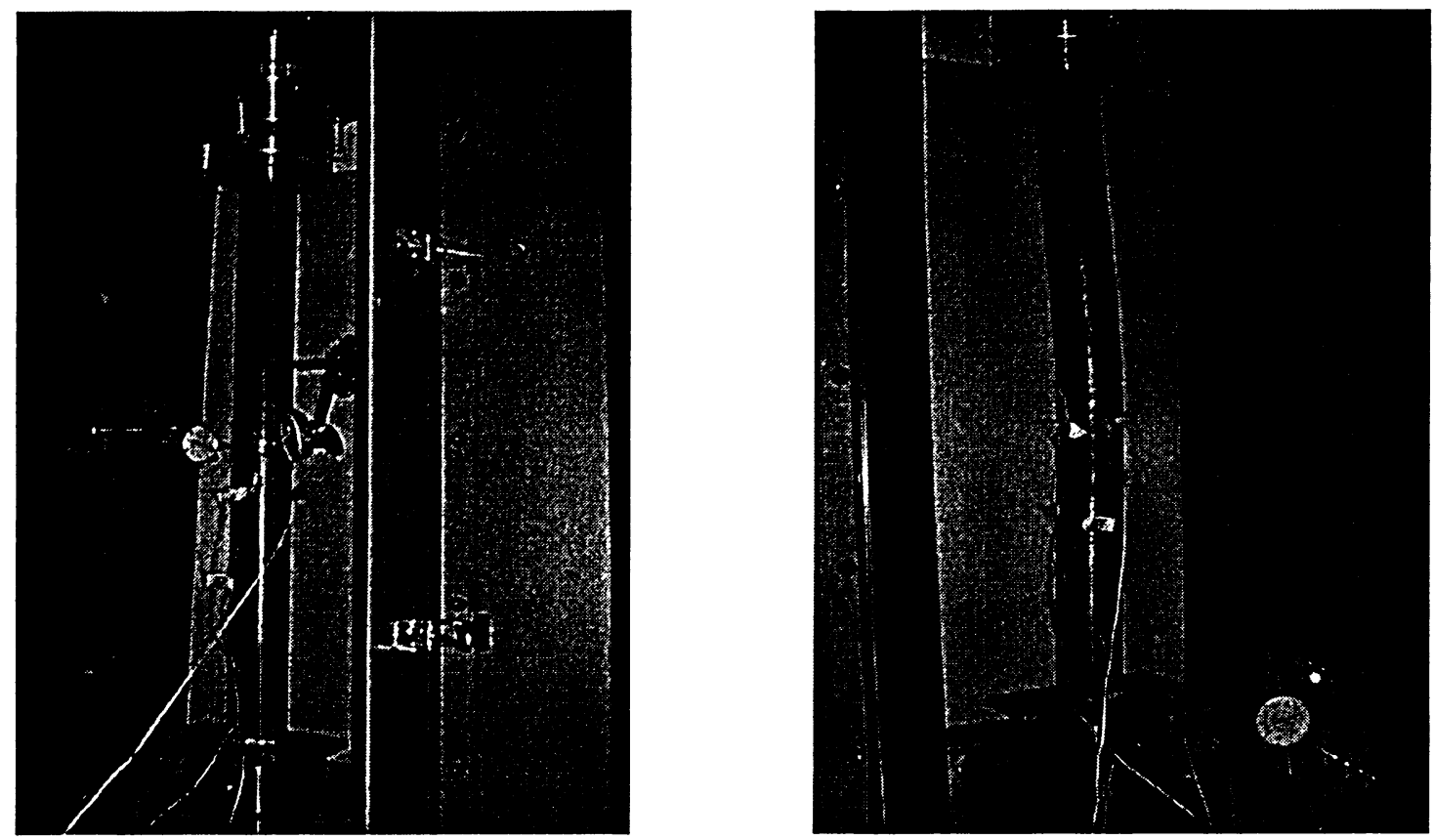

Figure 4.160 Views of specimen NSR-17 before and after testing

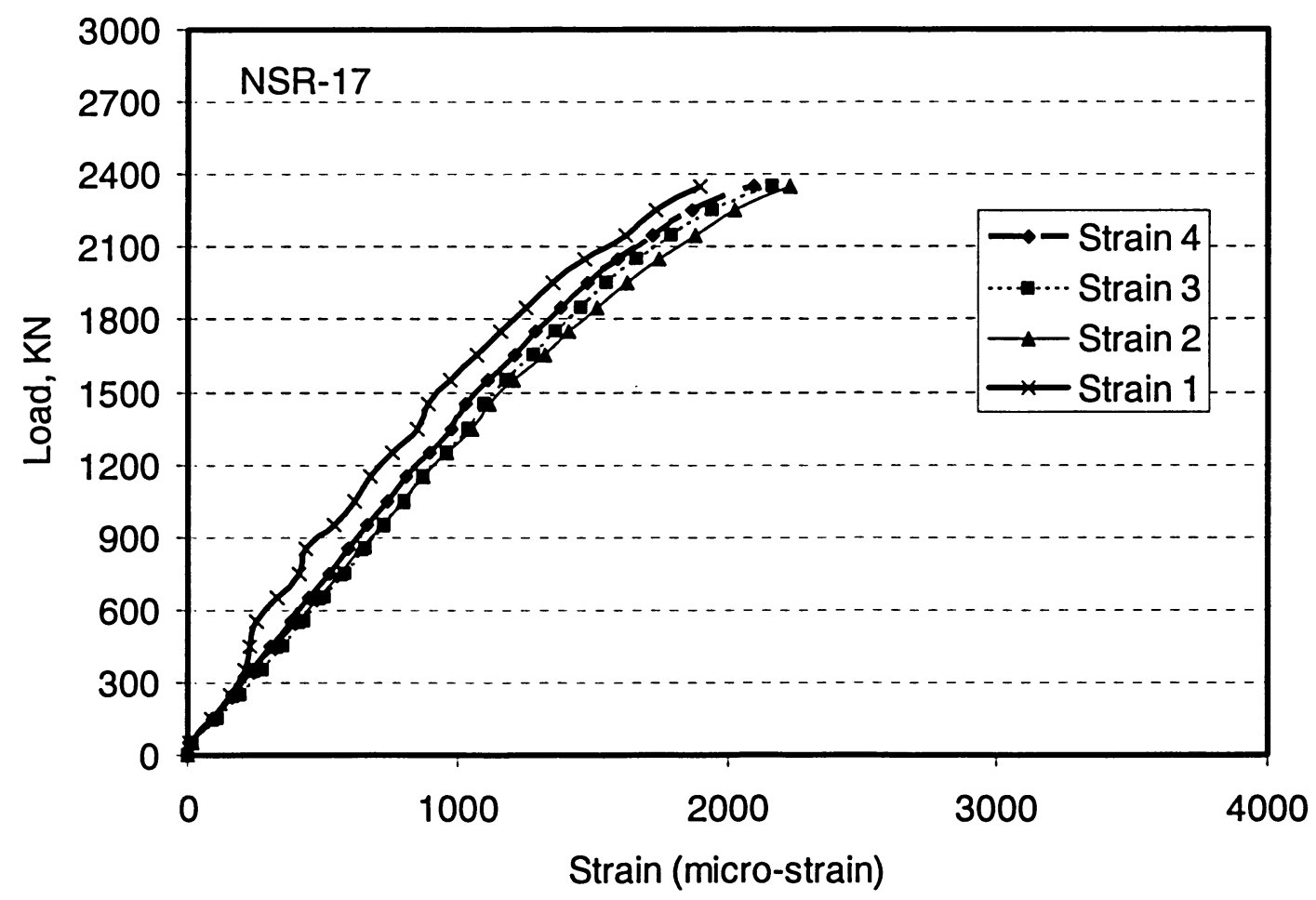

Figure 4.161 Axial load-strain relationships for specimen NSR-17 


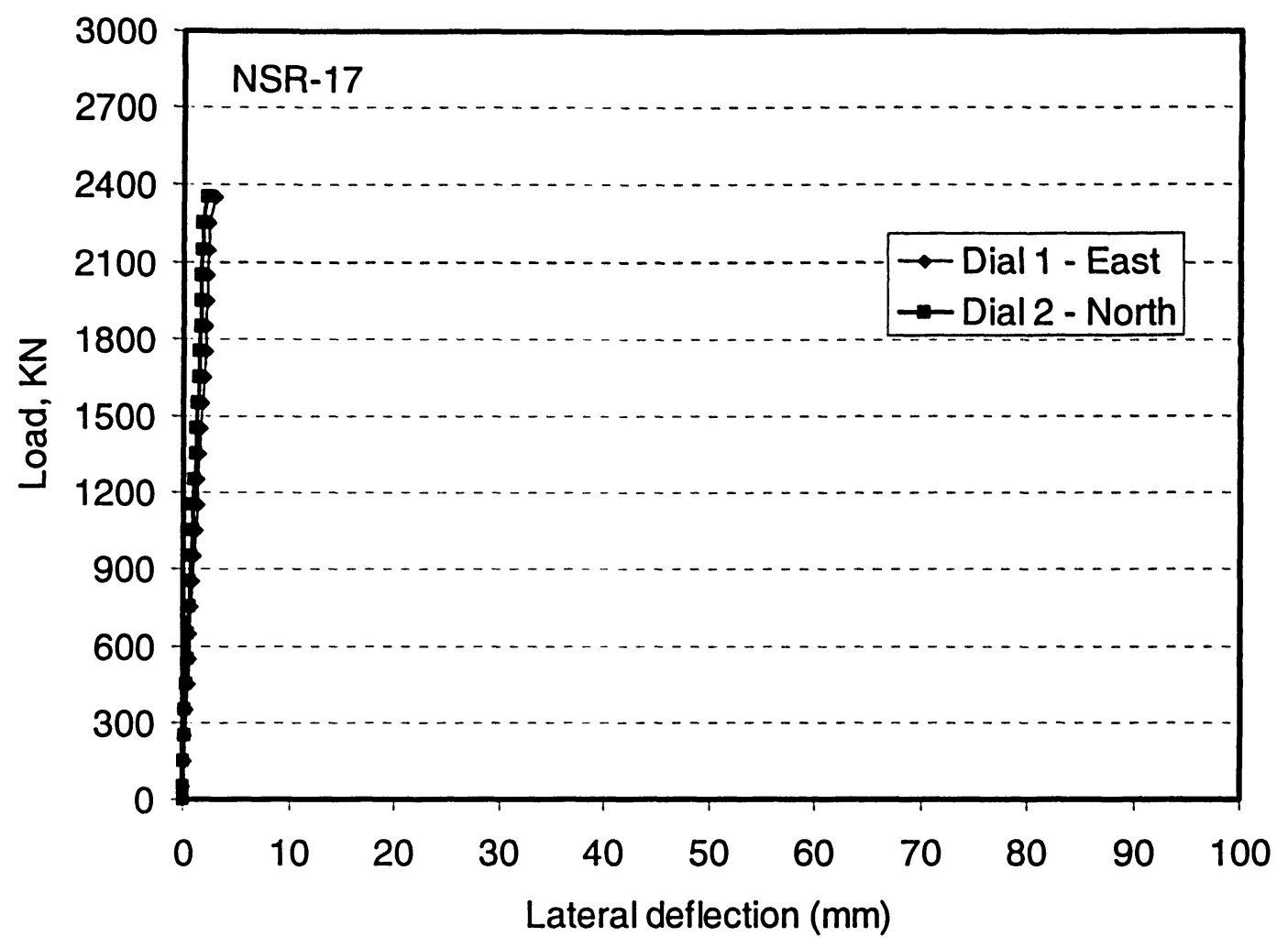

Figure 4.162 Load-lateral deflection curves for specimen NSR-17

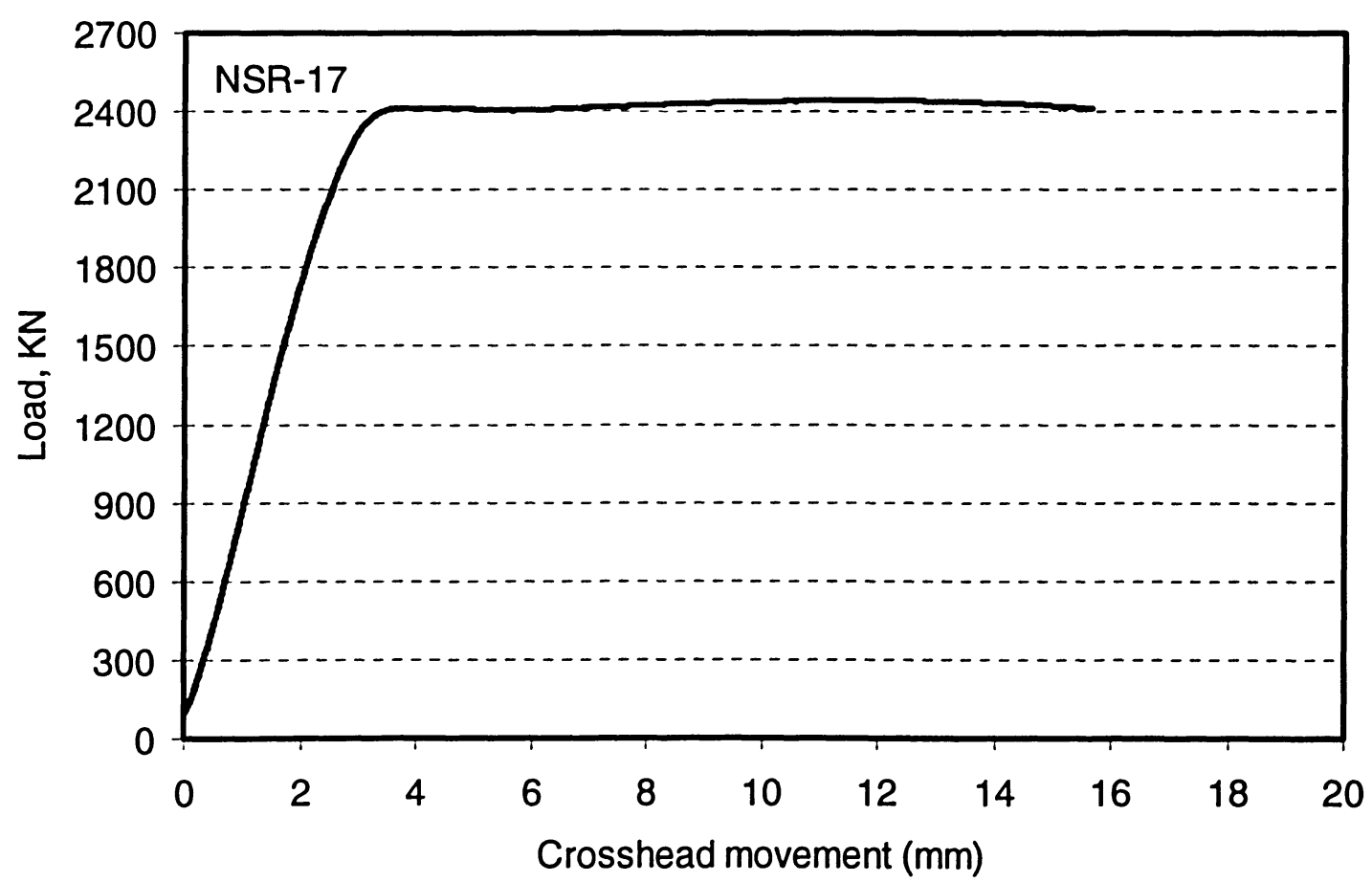

Figure 4.163 Load versus overall shortening curve for specimen NSR-17 

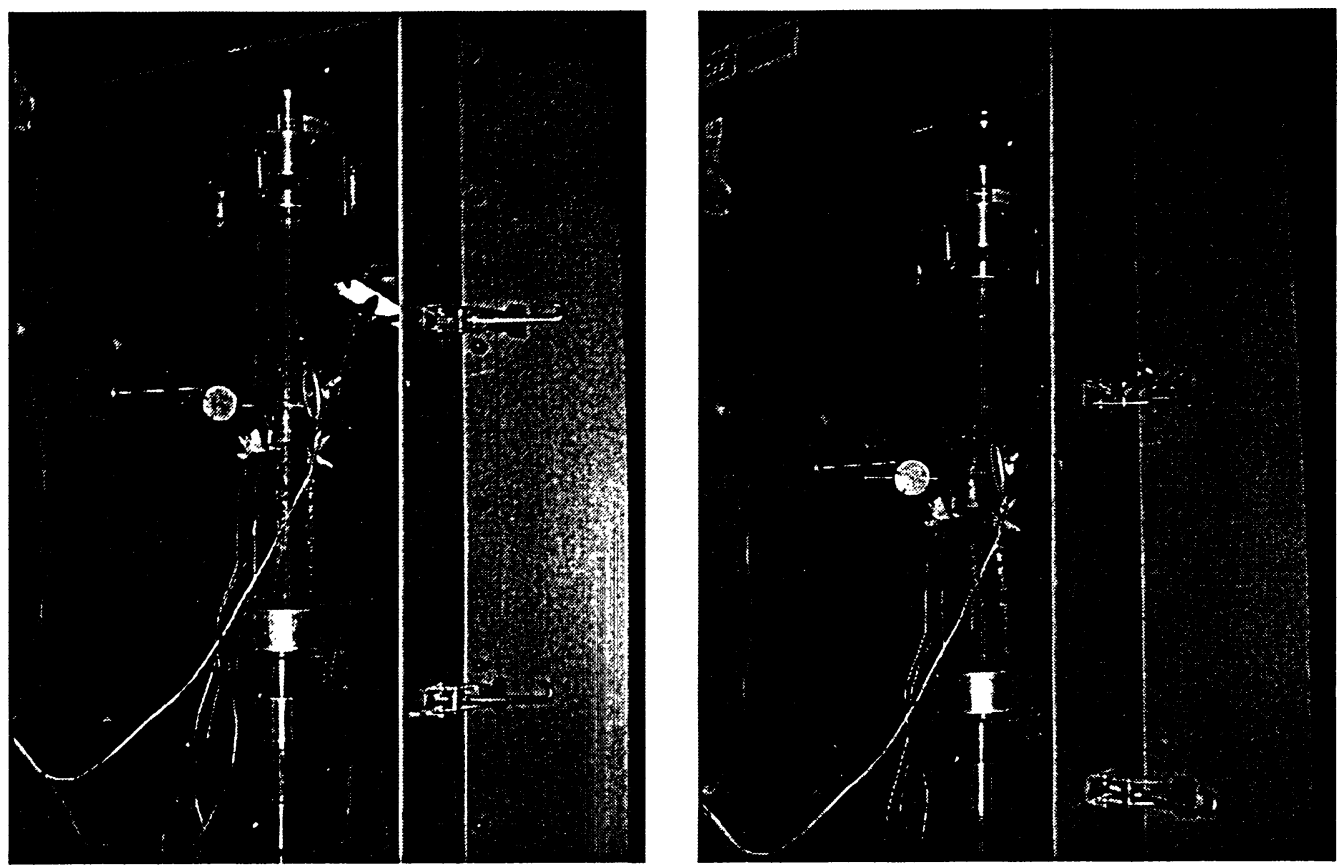

Figure 4.164 Views of specimen NSR-18 before and after testing

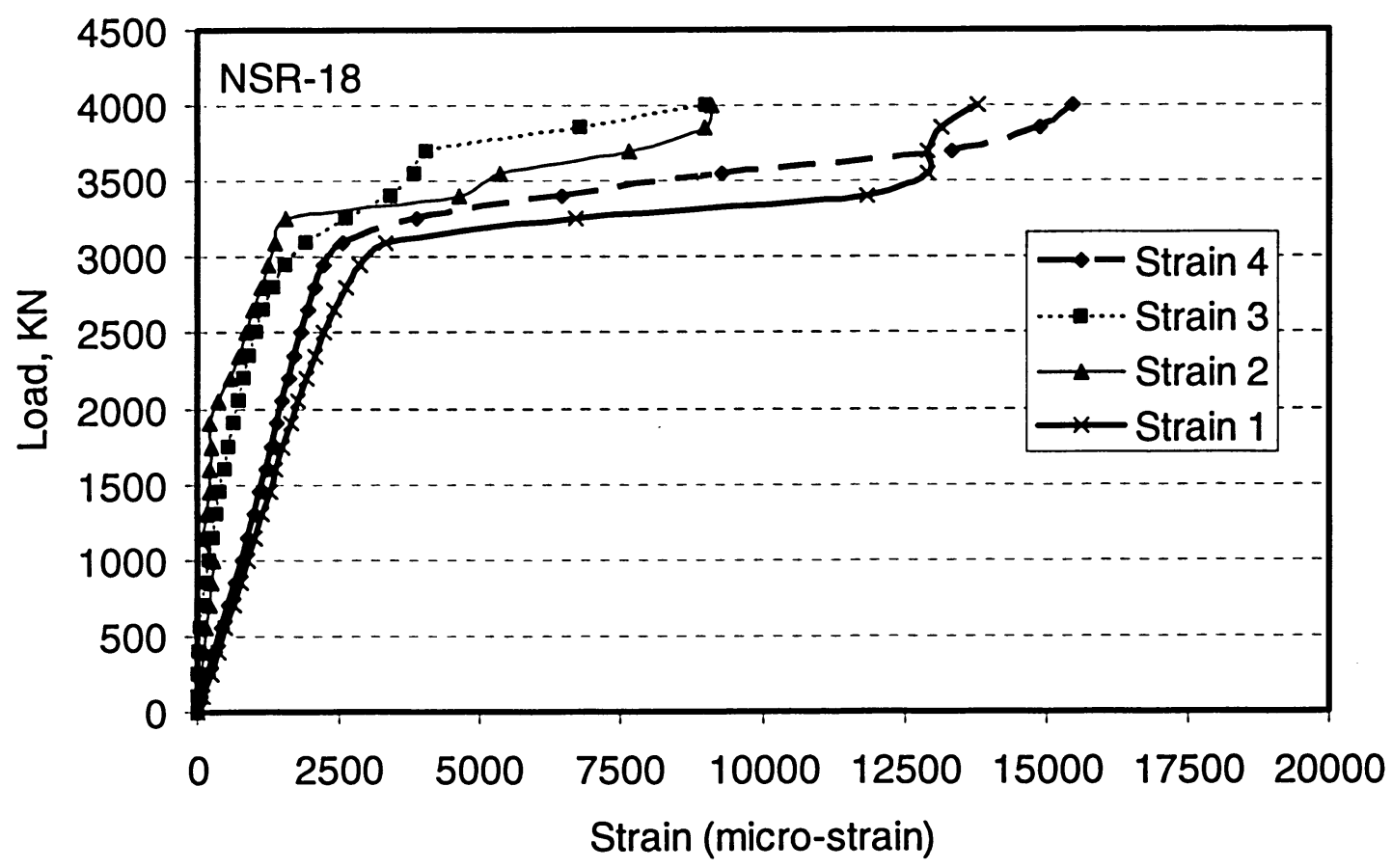

Figure 4.165 Axial load-strain relationships for specimen NSR-18 


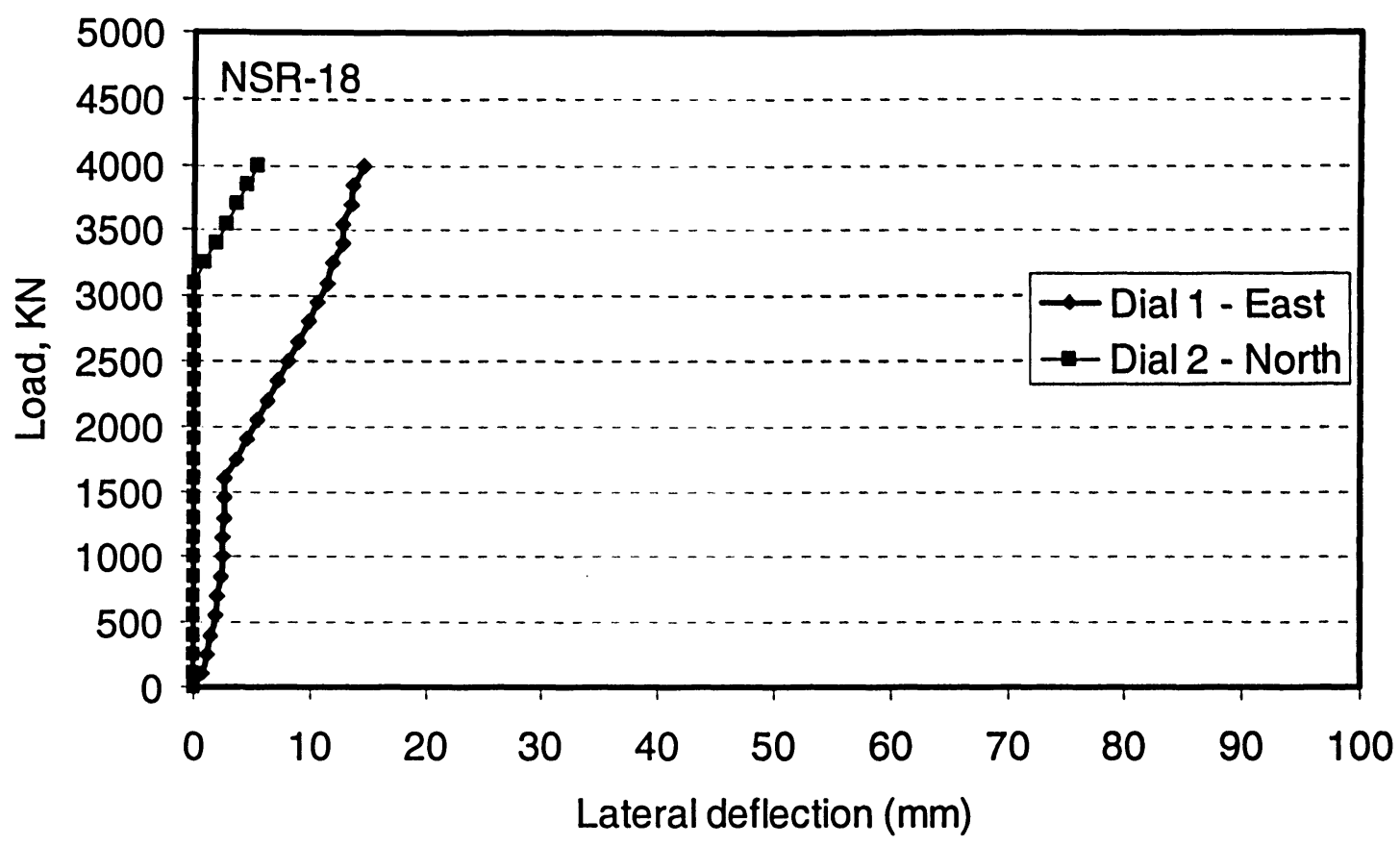

Figure 4.166 Load-lateral deflection curves for specimen NSR-18

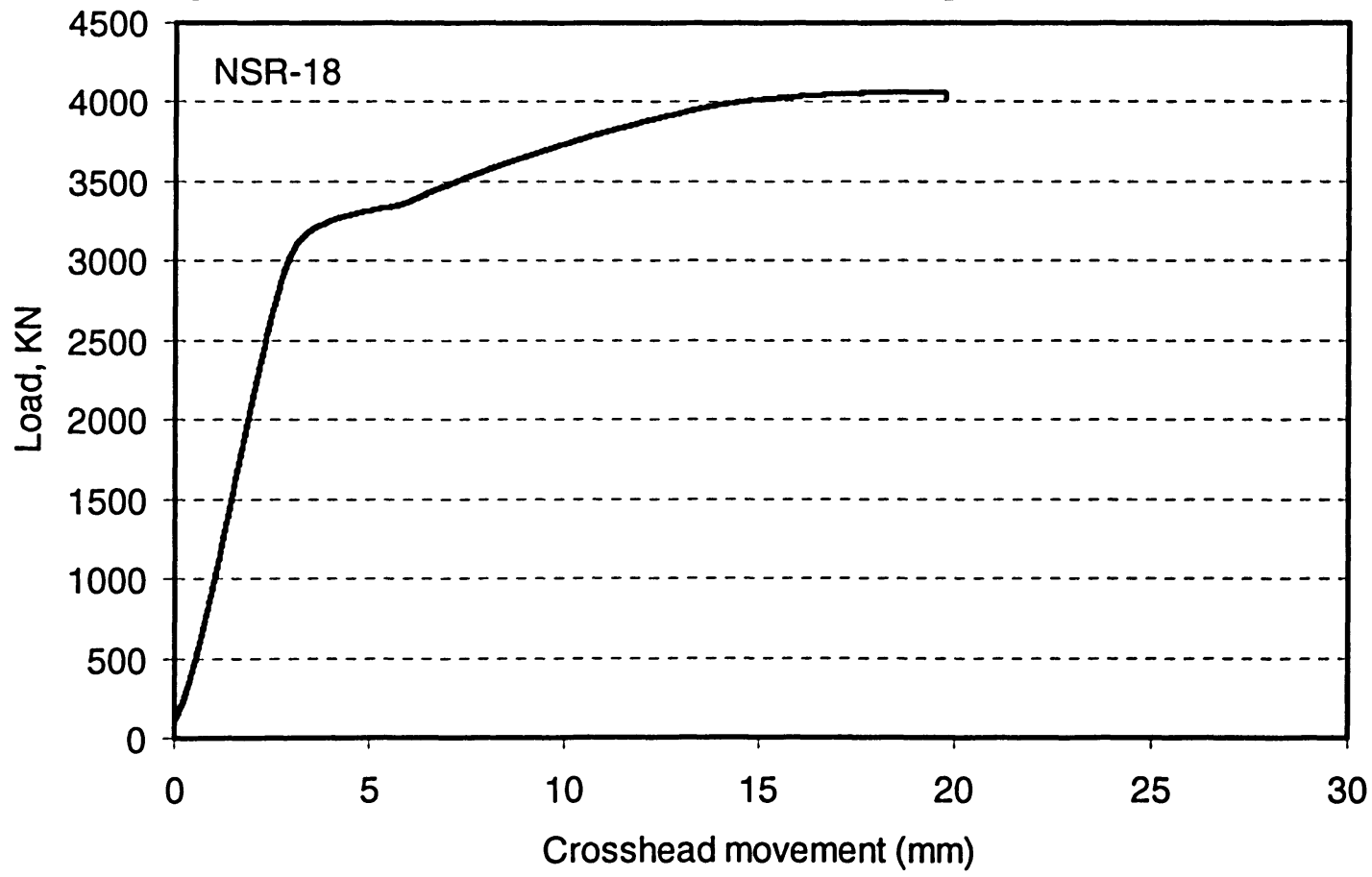

Figure 4.167 Load versus overall shortening curve for specimen NSR-18 

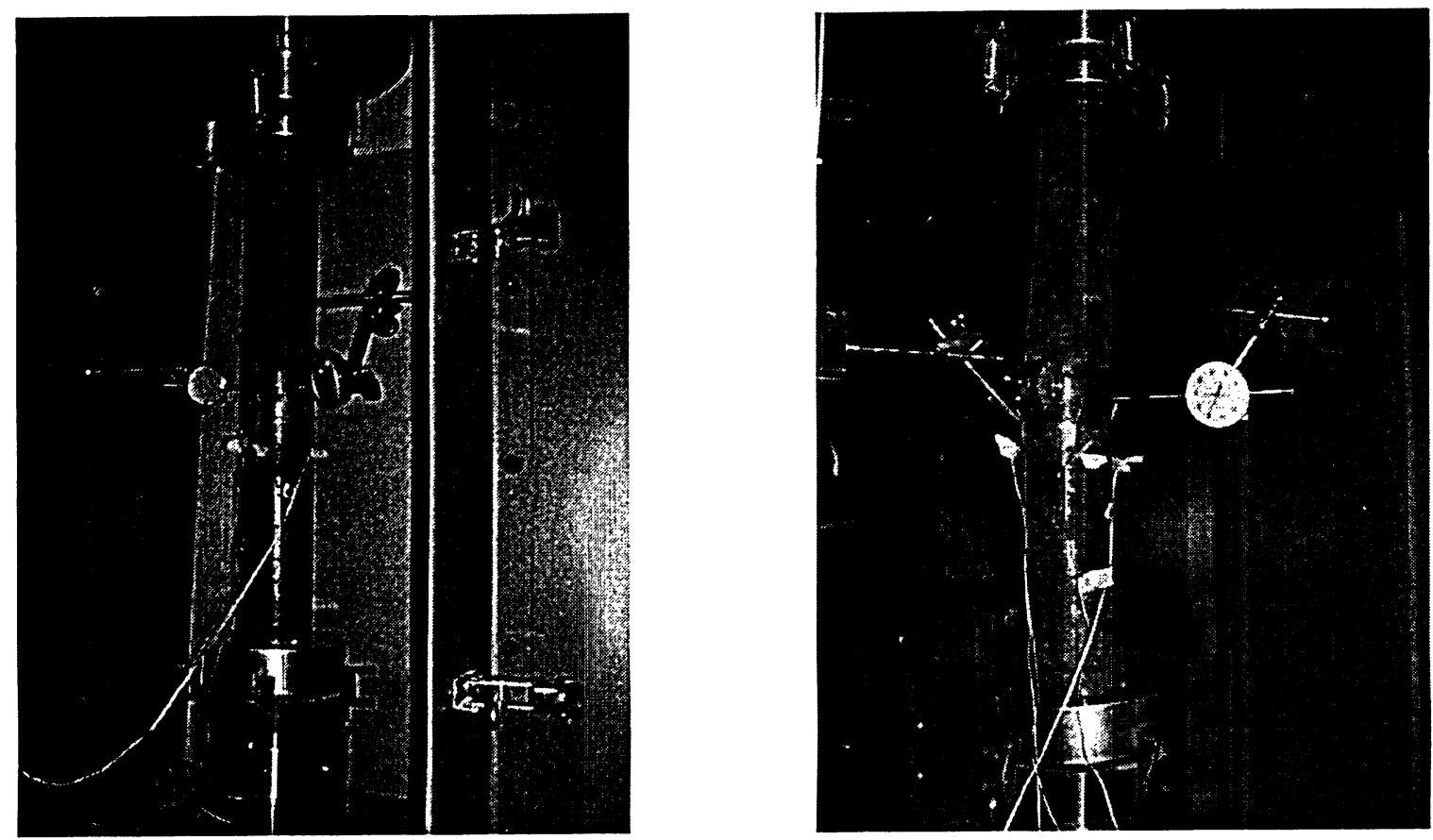

Figure 4.168 Views of specimen NSR-19 before and after testing

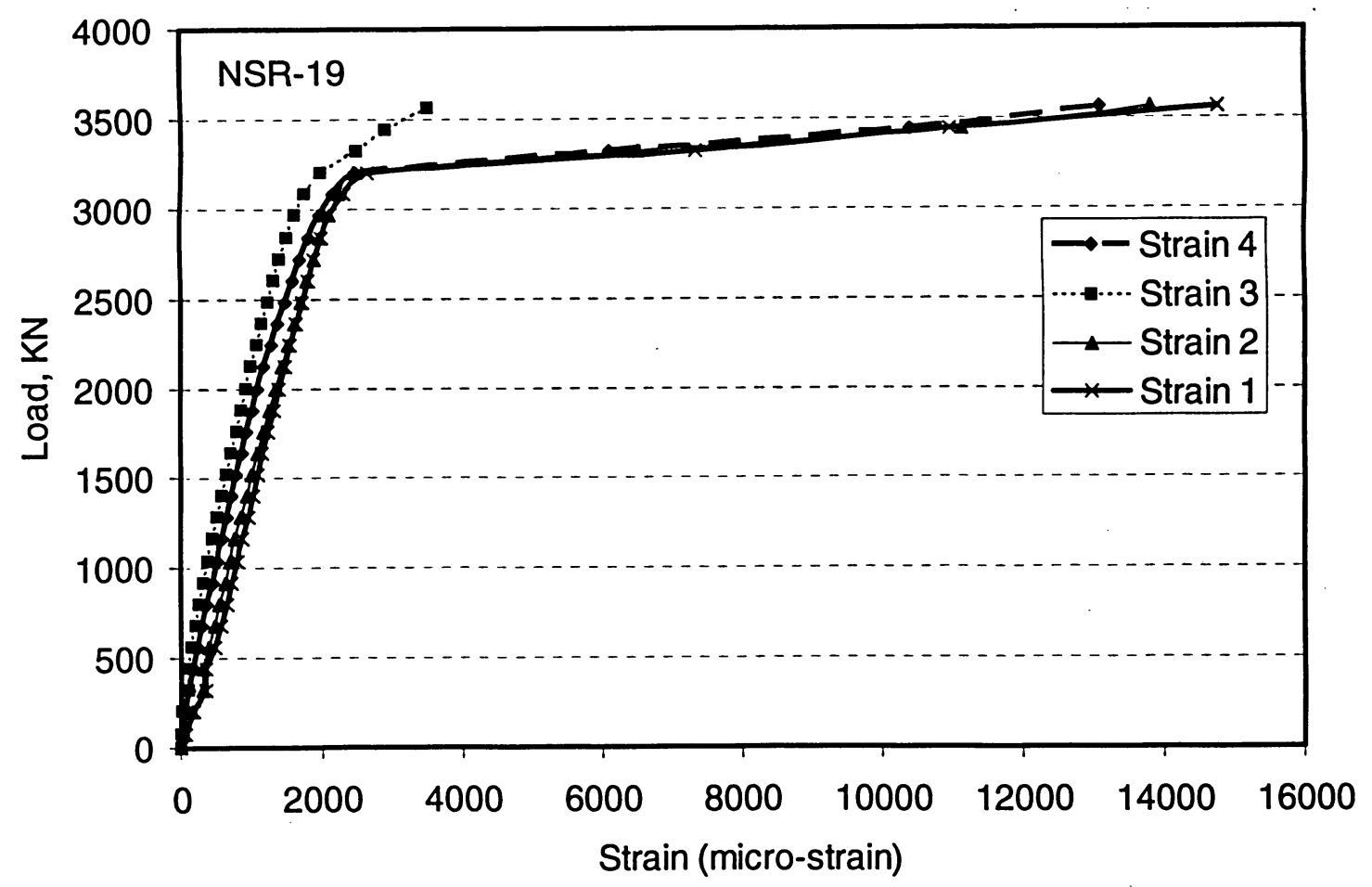

Figure 4.169 Axial load-strain relationships for specimen NSR-19 


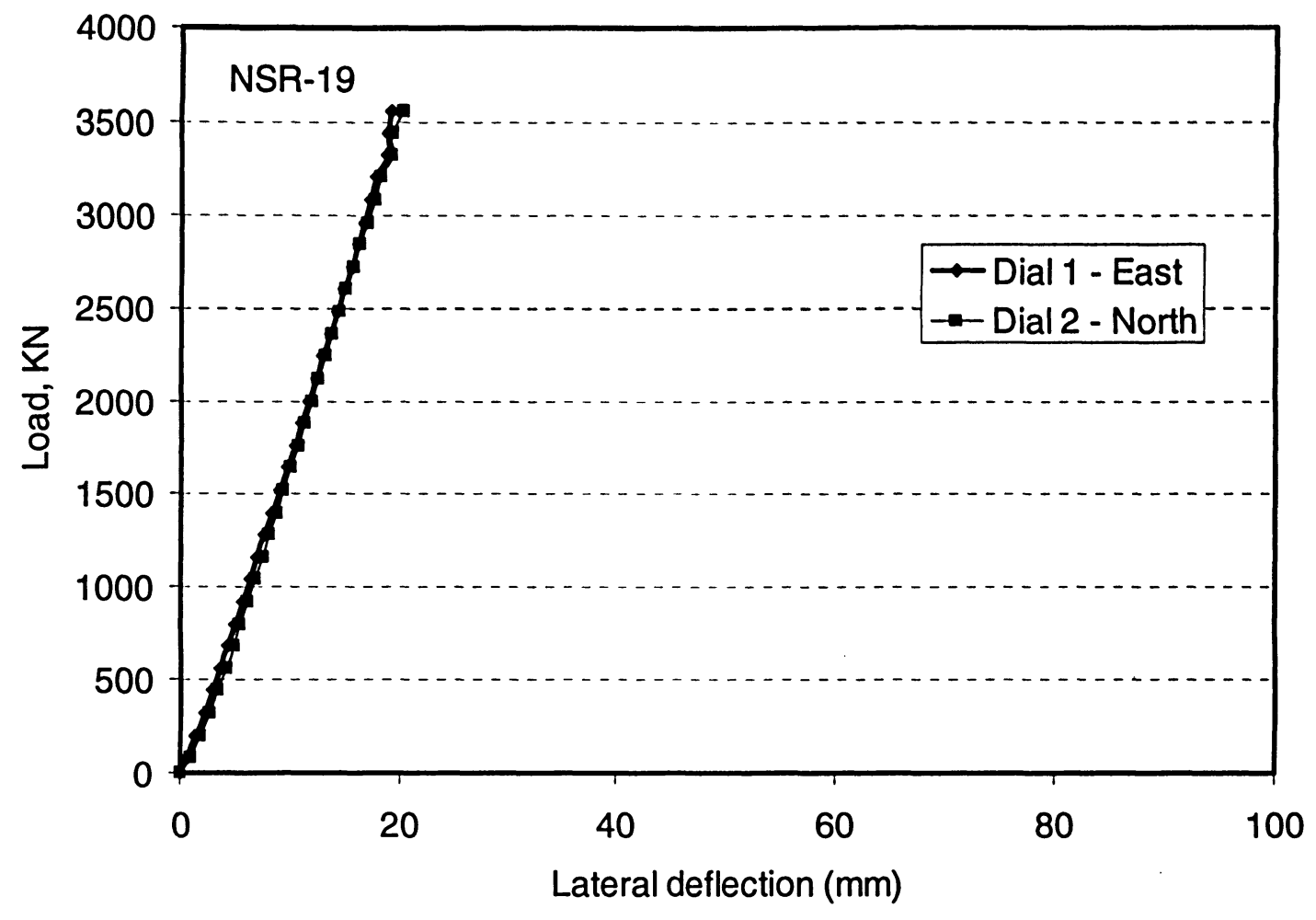

Figure 4.170 Load-lateral deflection curves for specimen NSR-19

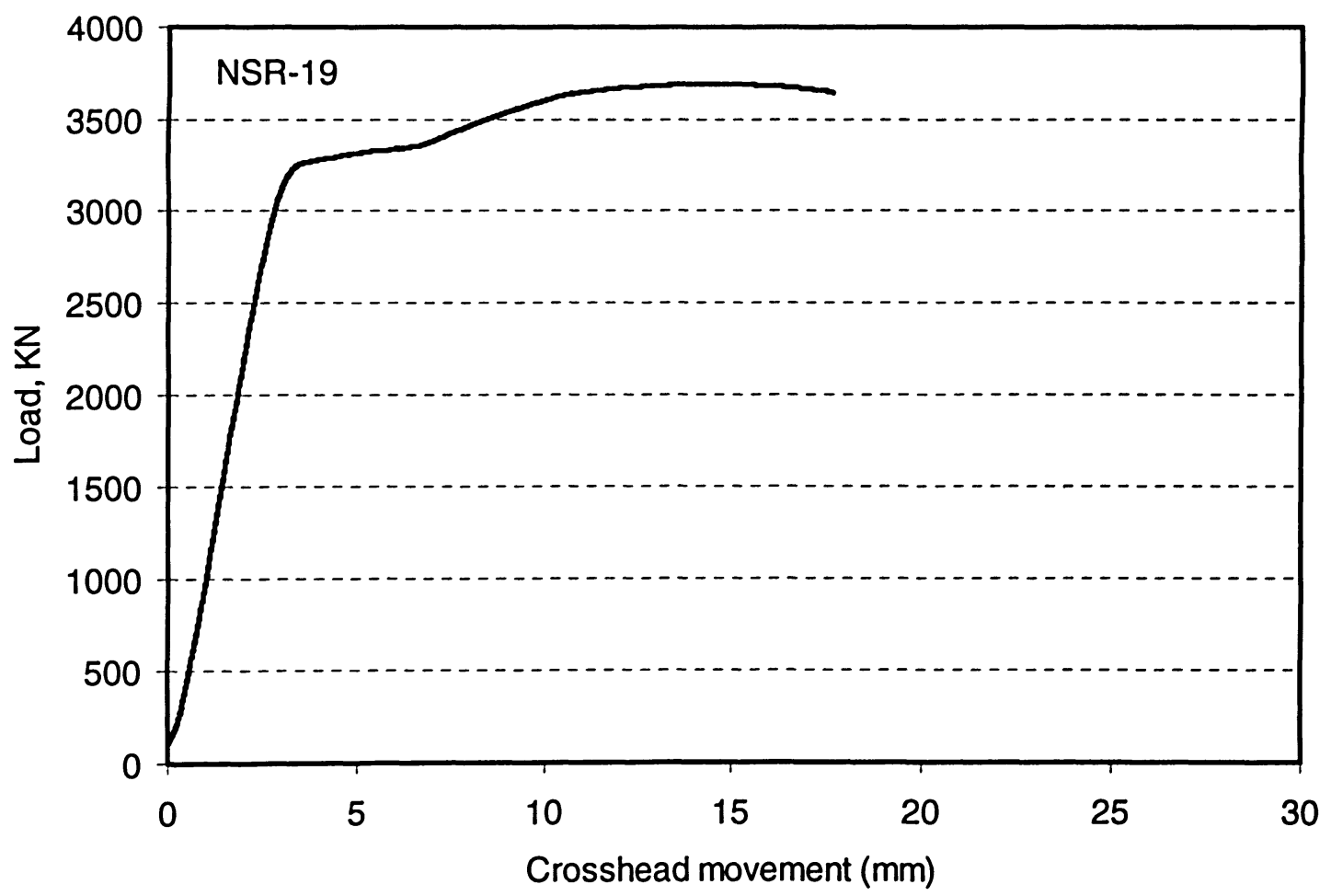

Figure 4.171 Load versus overall shortening curve for specimen NSR-19 

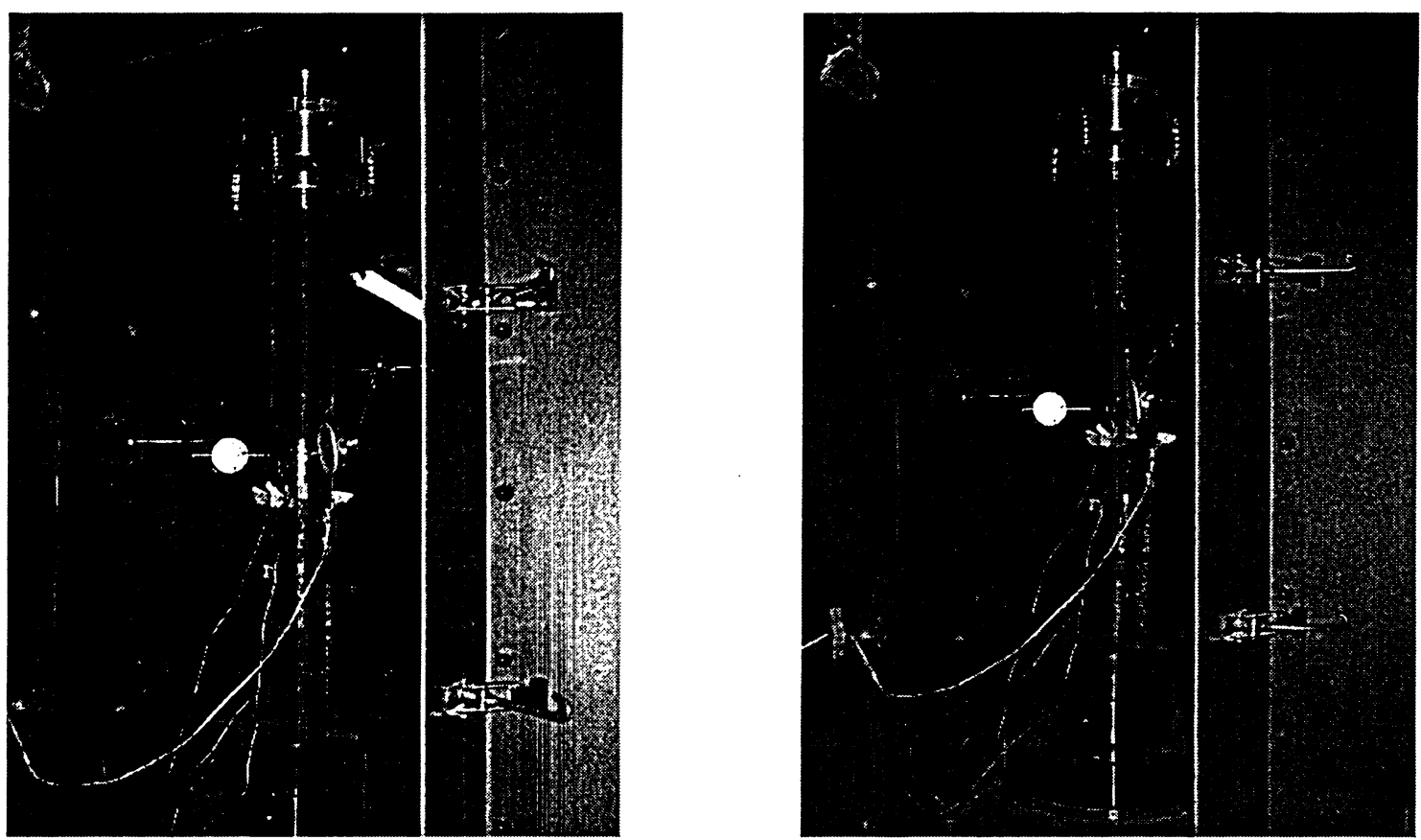

Figure 4.172 Views of specimen NSR-20 before and after testing

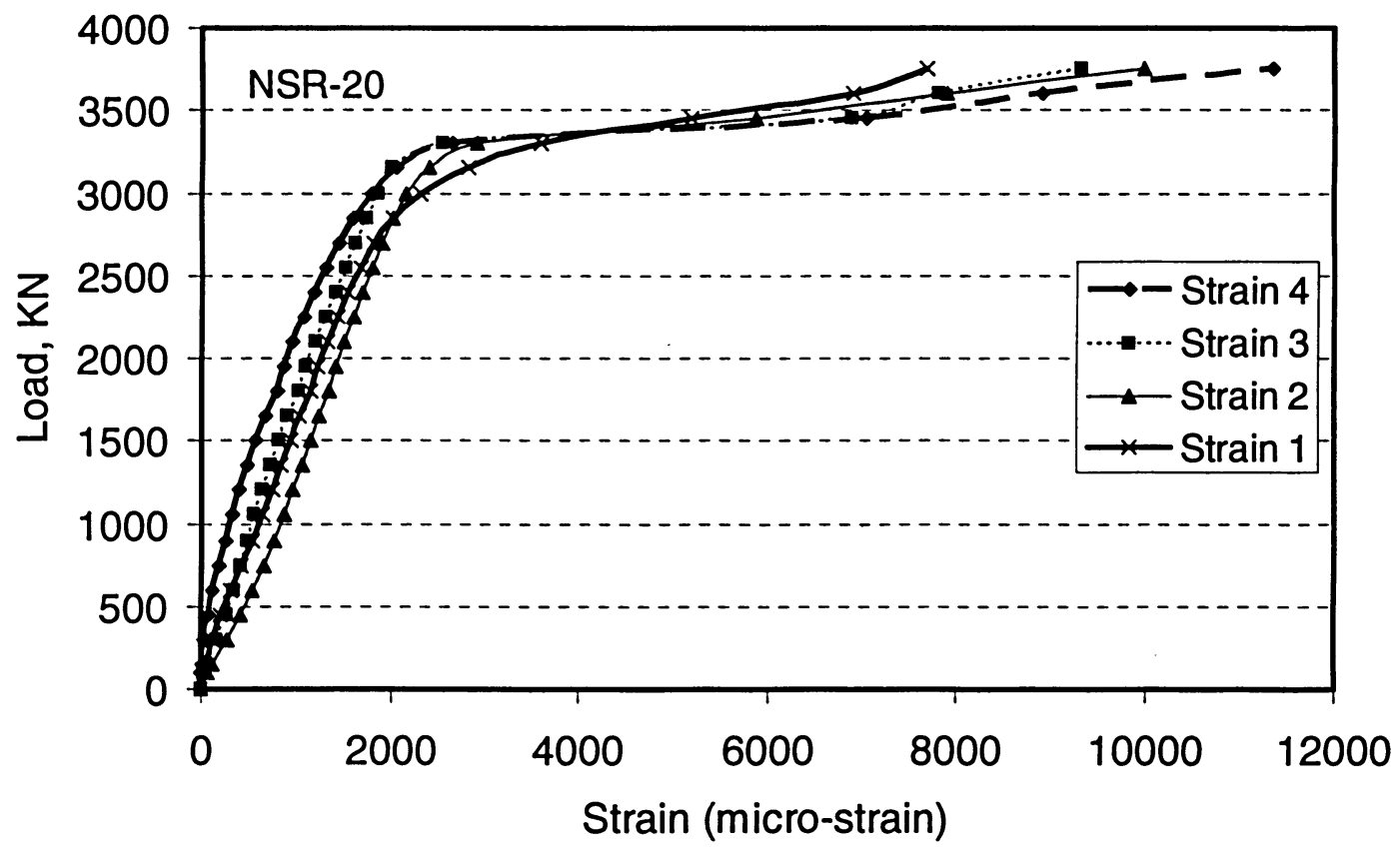

Figure 4.173 Axial load-strain relationships for specimen NSR-20 


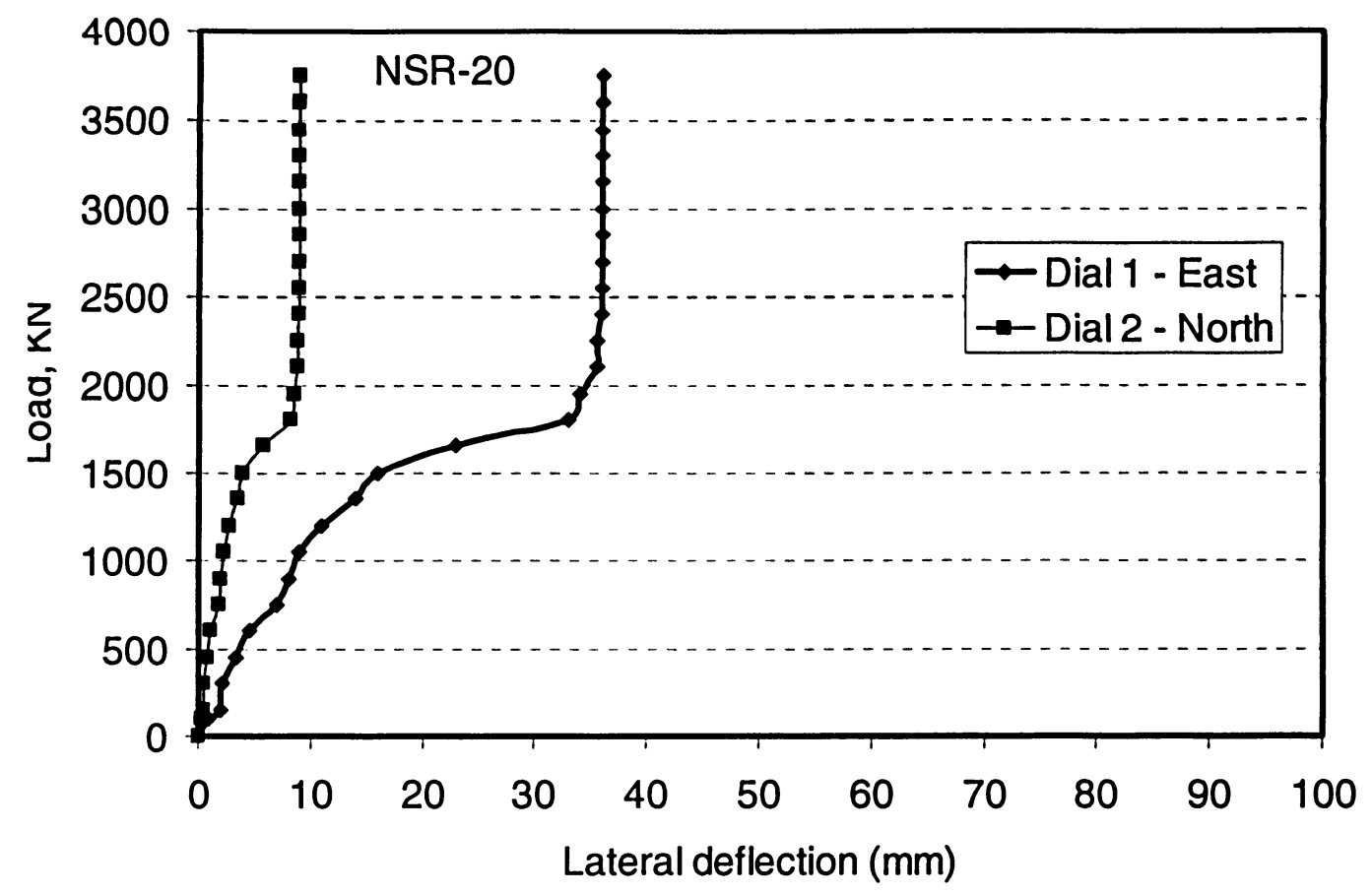

Figure 4.174 Load versus overall shortening curve for specimen NSR-20

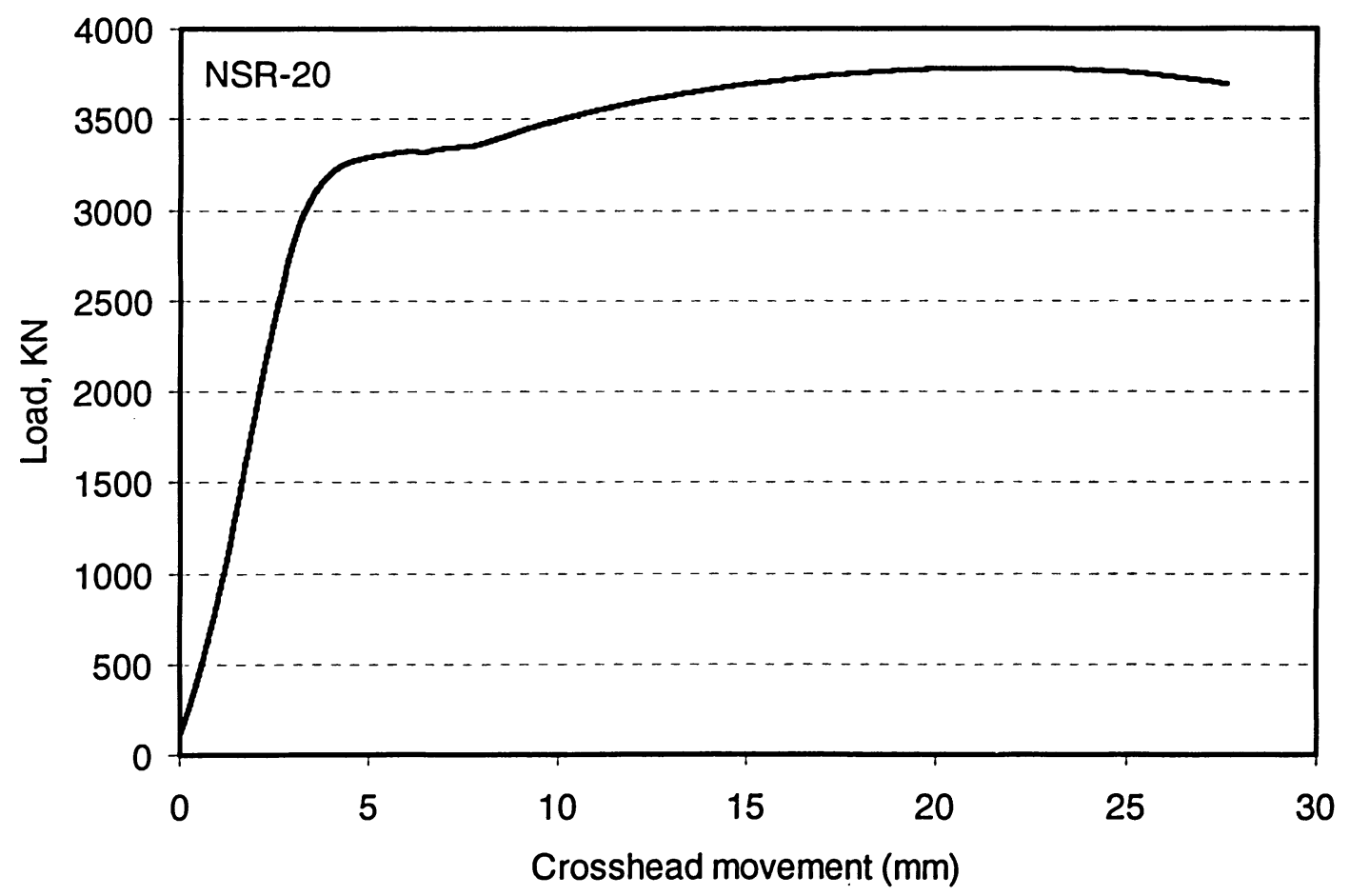

Figure 4.175 Load versus overall shortening curve for specimen NSR-20 

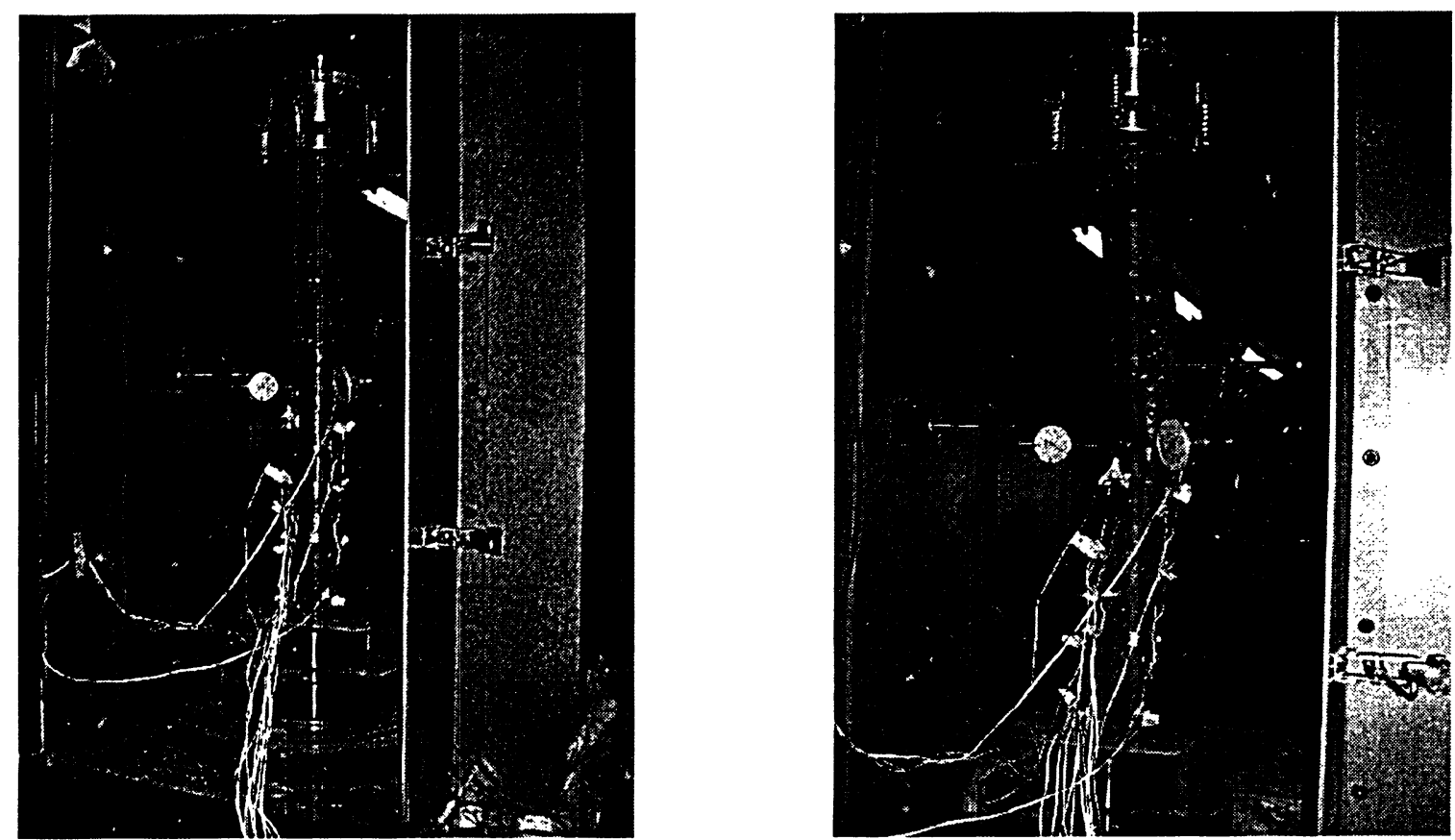

Figure 4.176 Views of specimen NSR-21 before and after testing

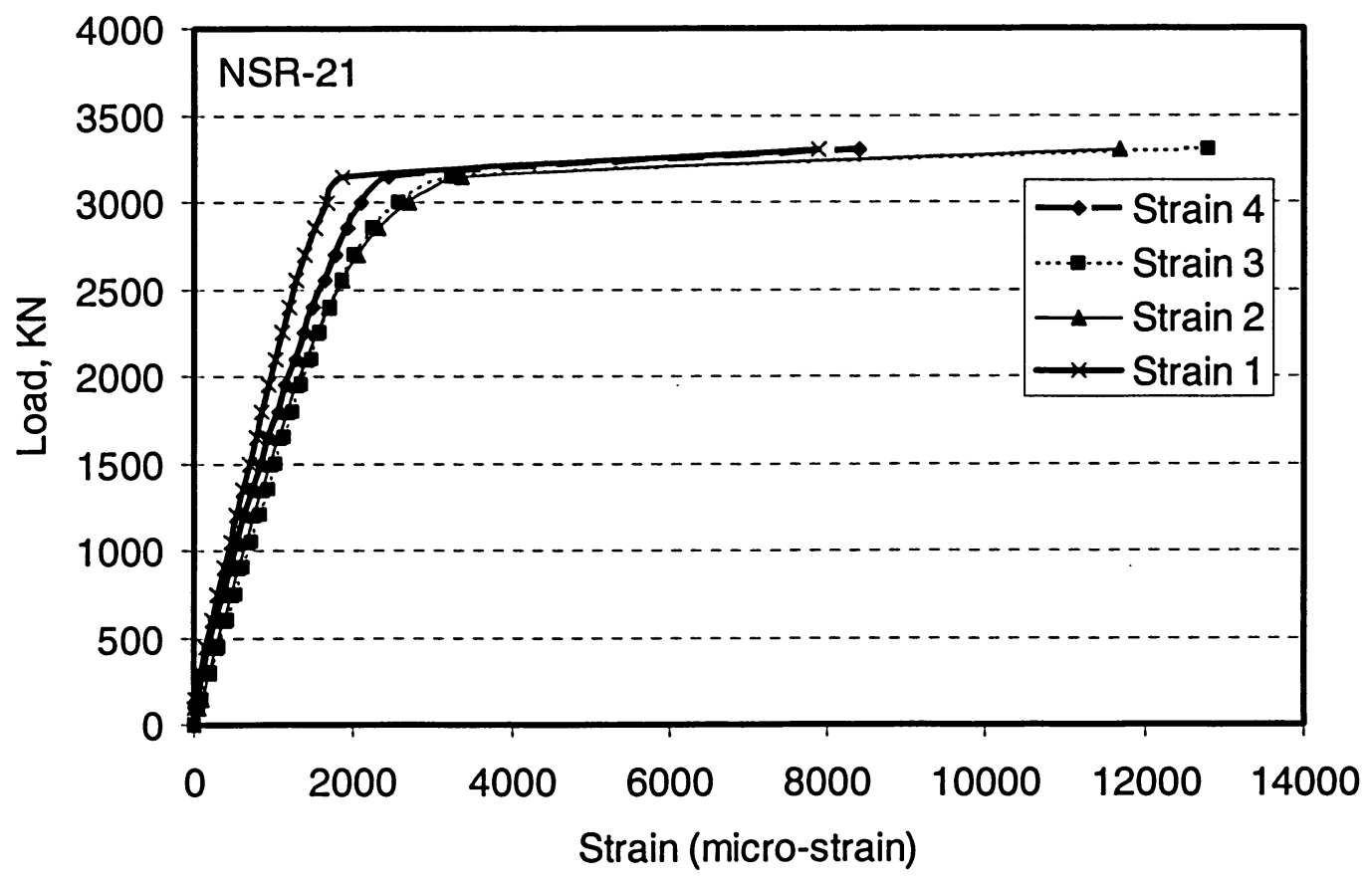

Figure 4.177 Axial load-strain relationships for specimen NSR-21 


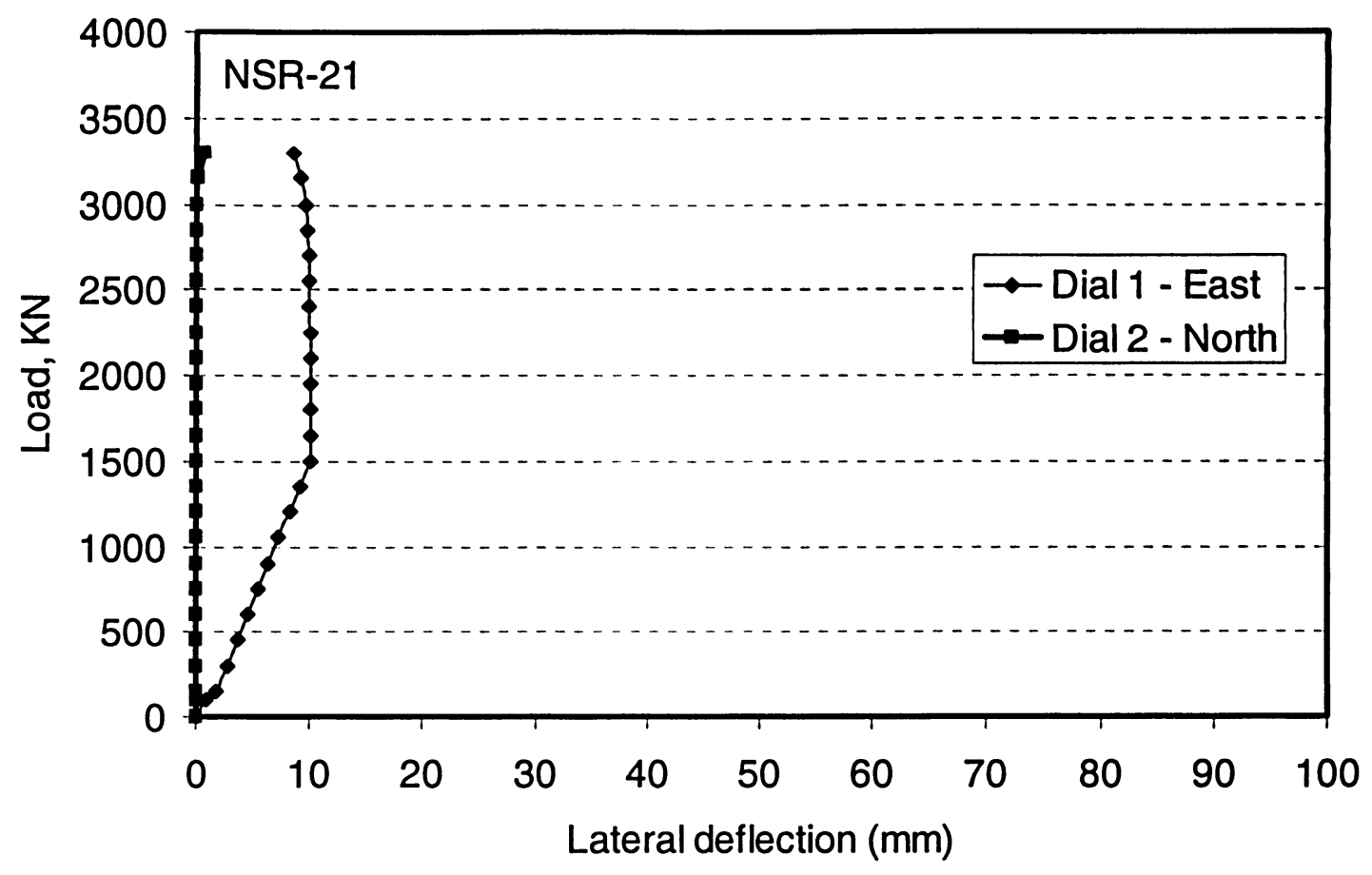

Figure 4.178 Load-lateral deflection curves for specimen NSR-21

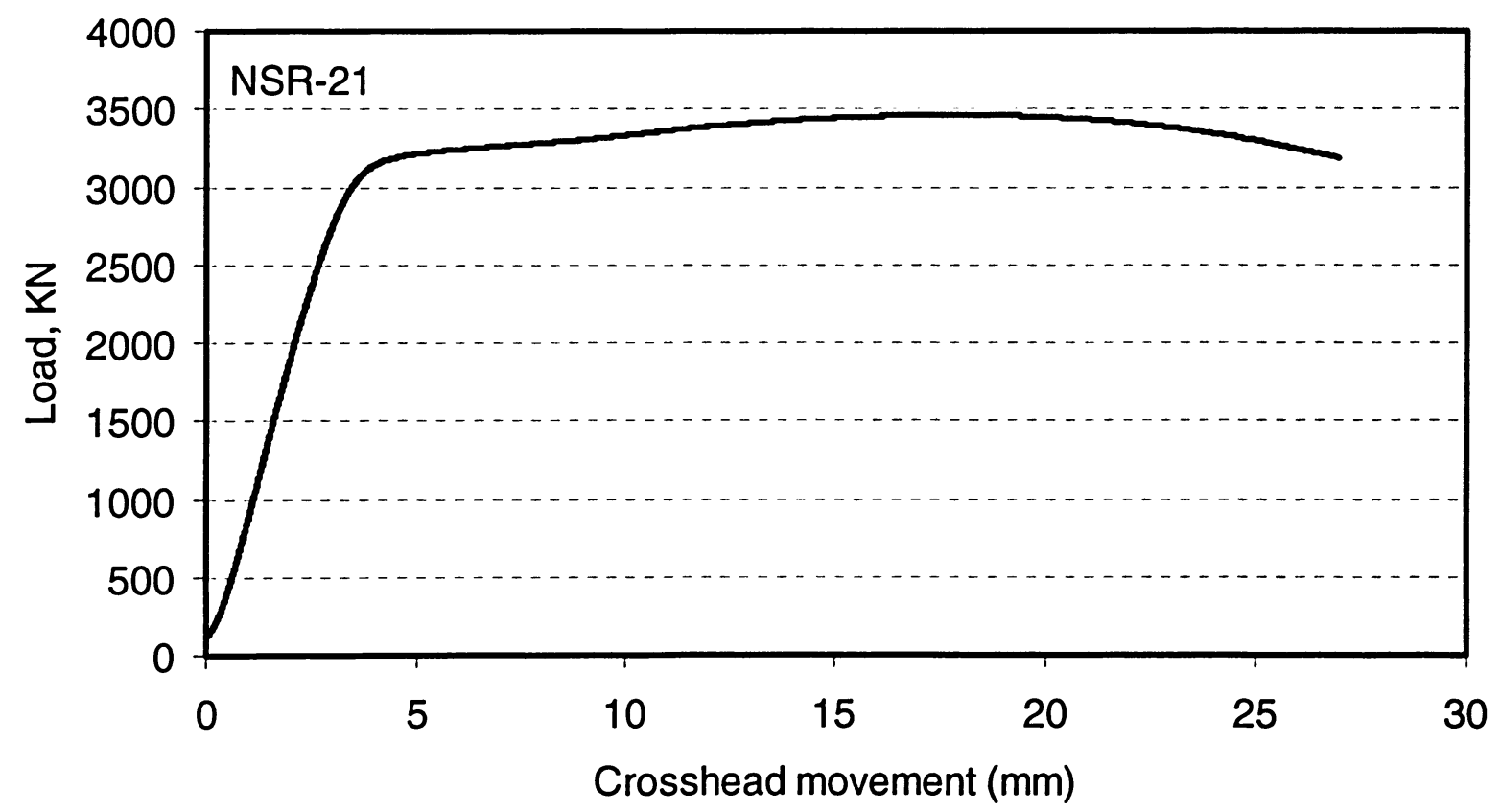

Figure 4.179 Load versus overall shortening curve for specimen NSR-21 

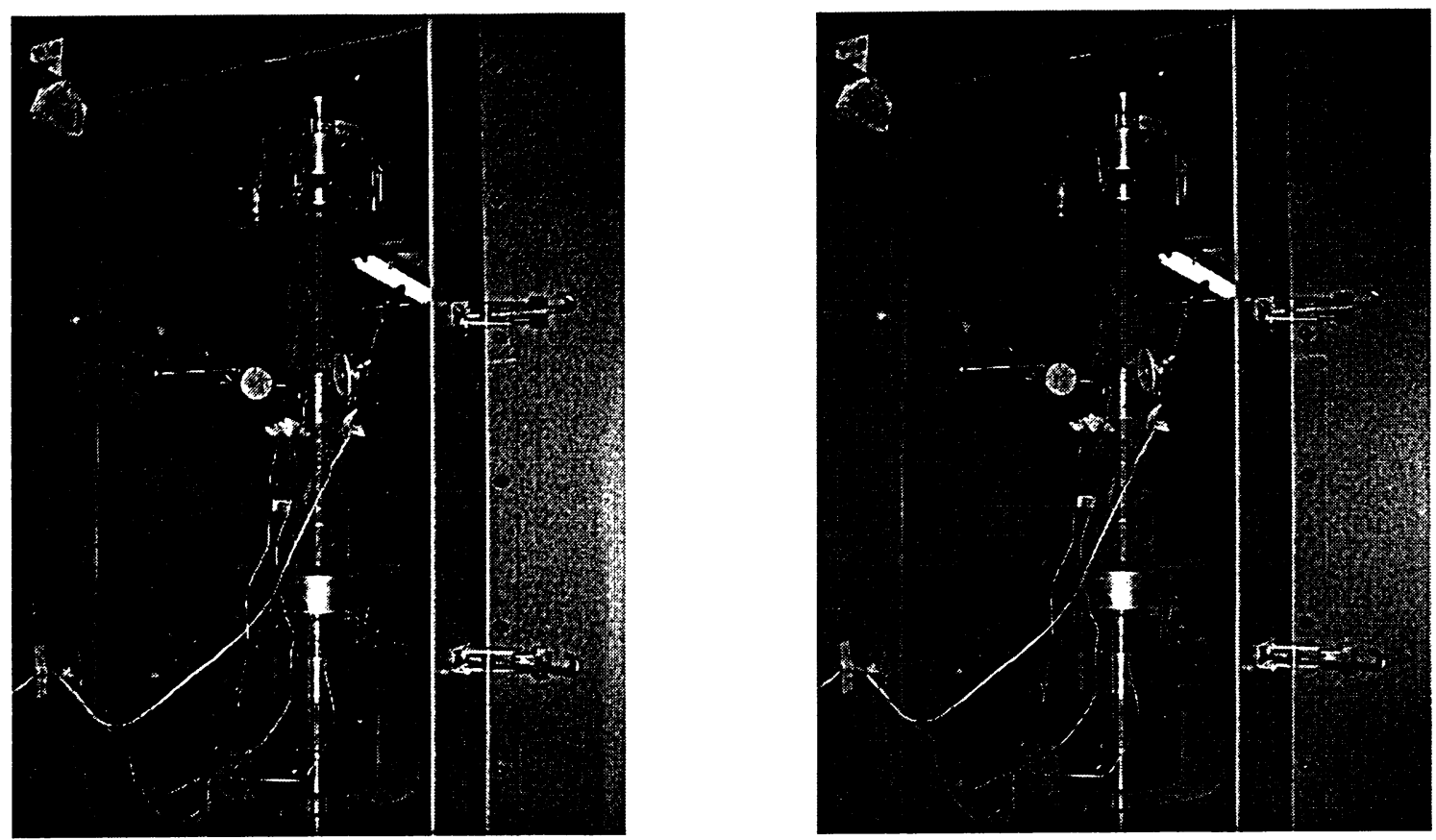

Figure 4.180 Views of specimen NSR-22 before and after testing

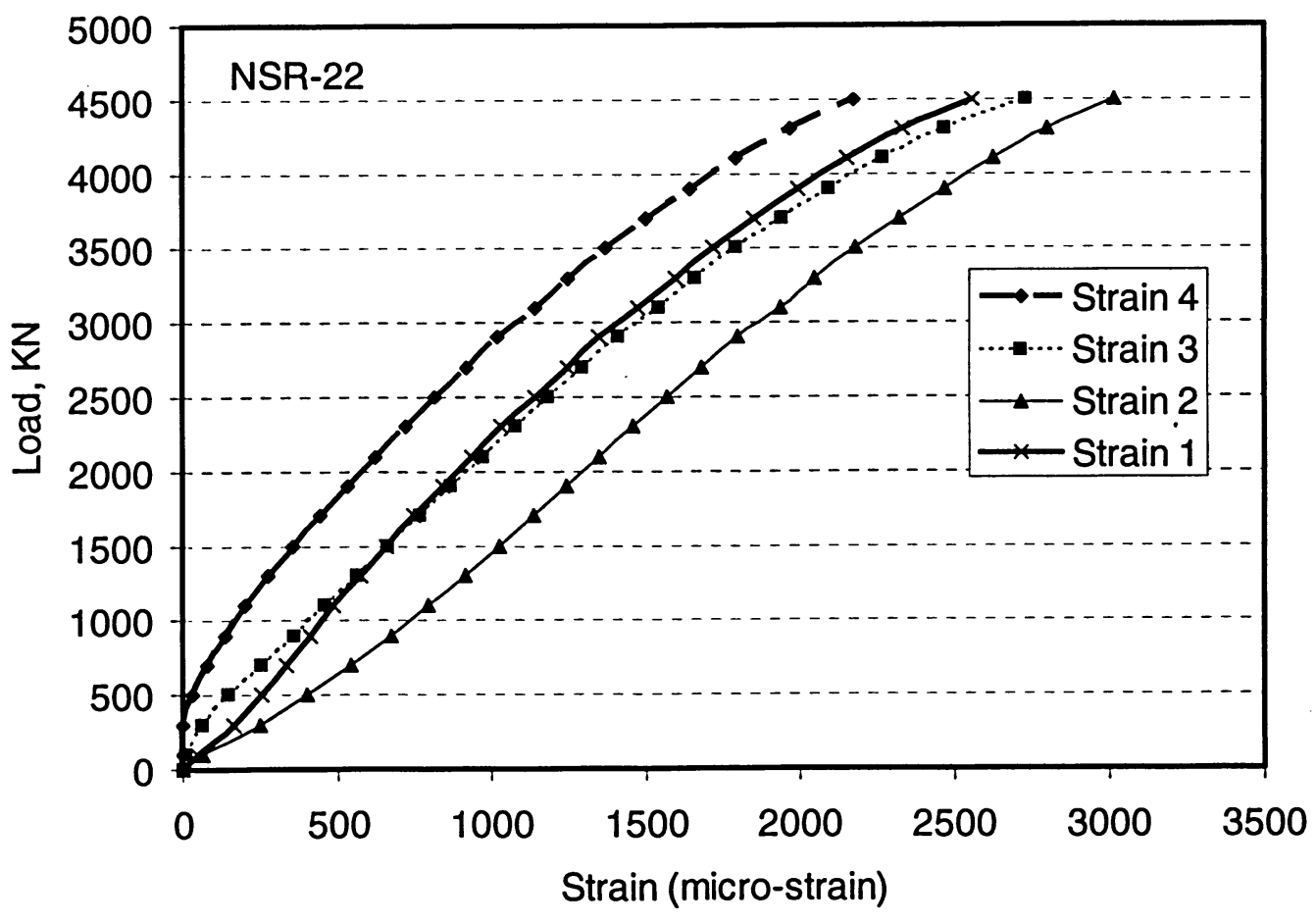

Figure 4.181 Axial load-strain relationships for specimen NSR-22 


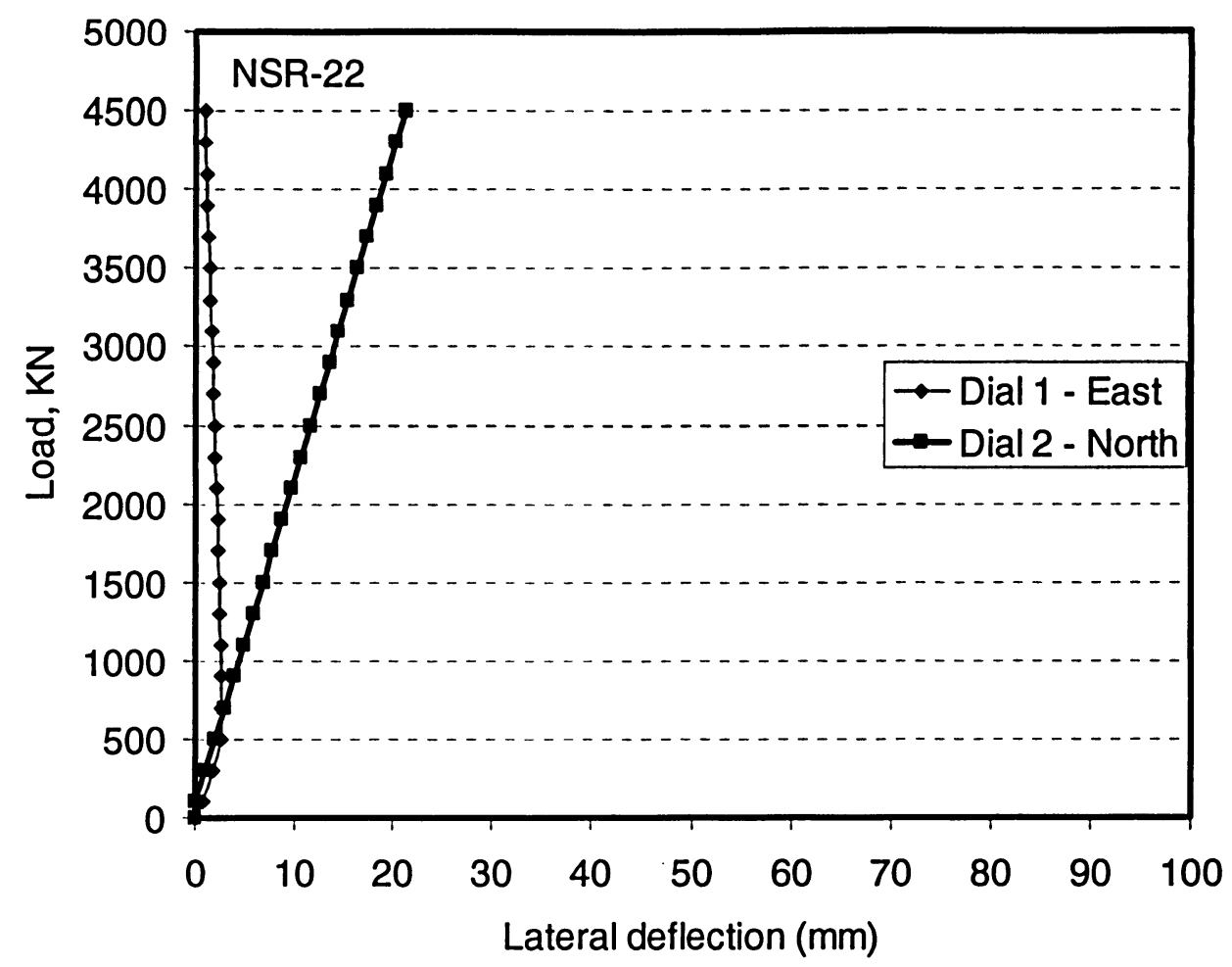

Figure 4.182 Load-lateral deflection curves for specimen NSR-22

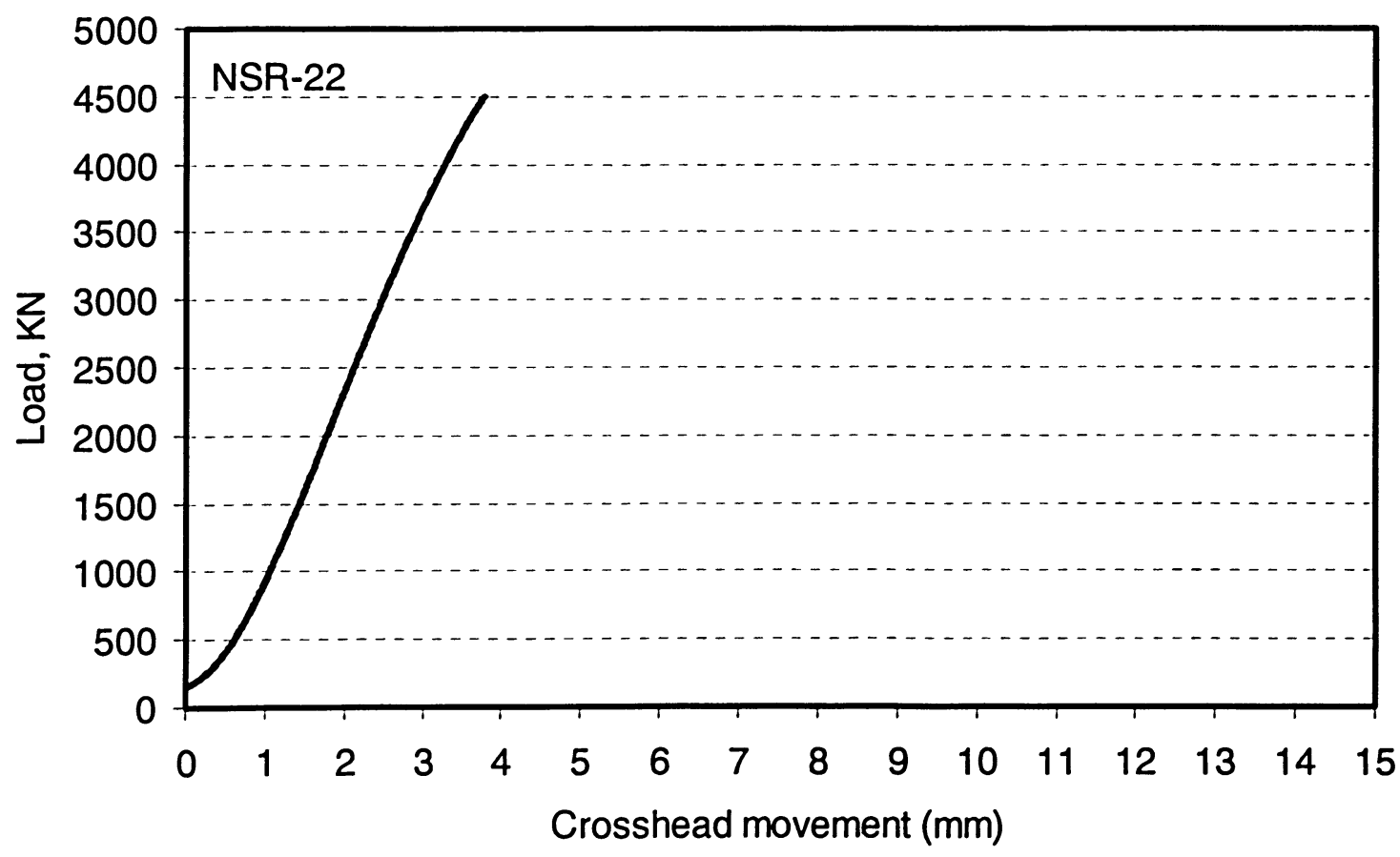

Figure 4.183 Load versus overall shortening curve for specimen NSR-22 

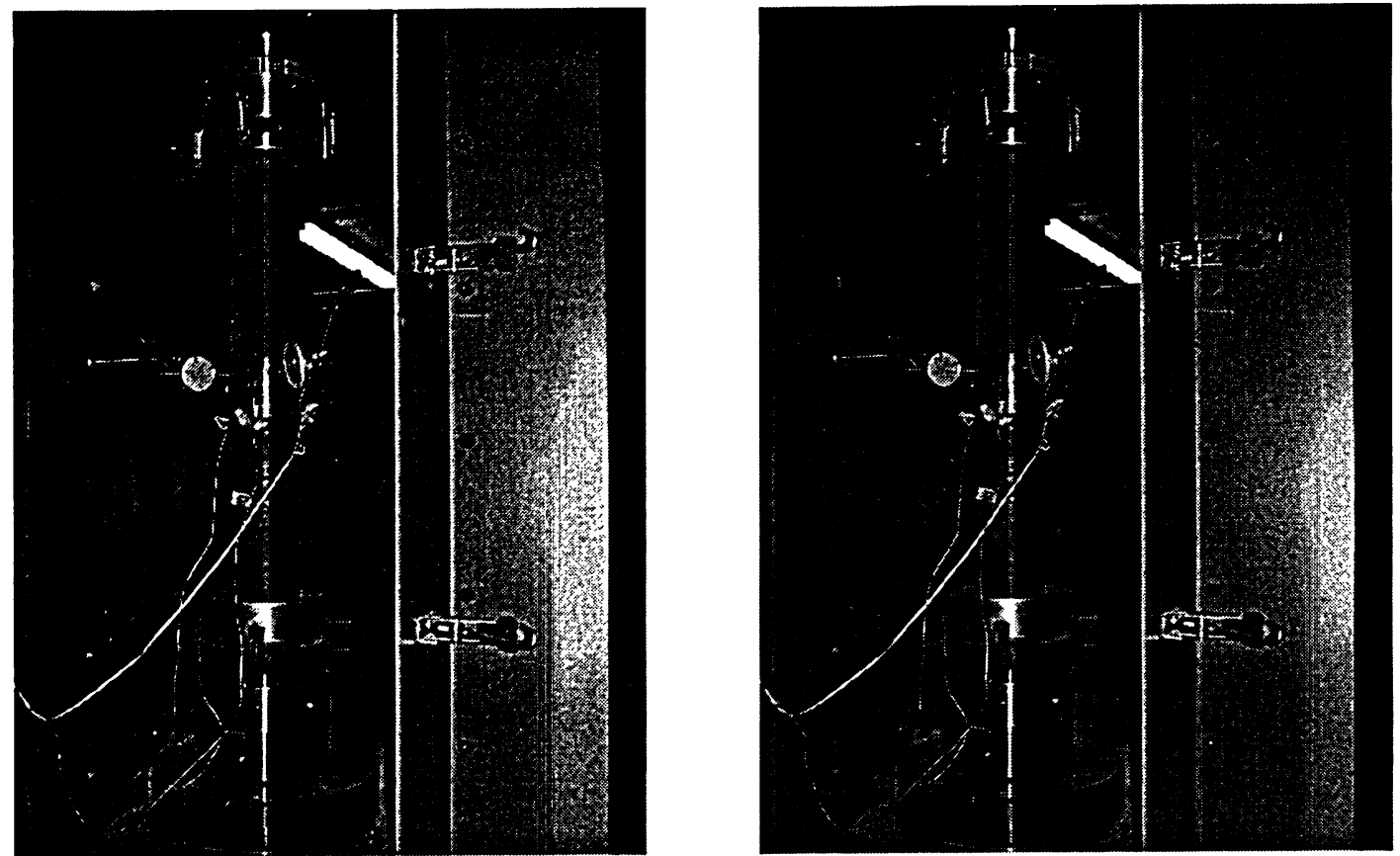

Figure 4.184 Views of specimen NSR-23 before and after testing

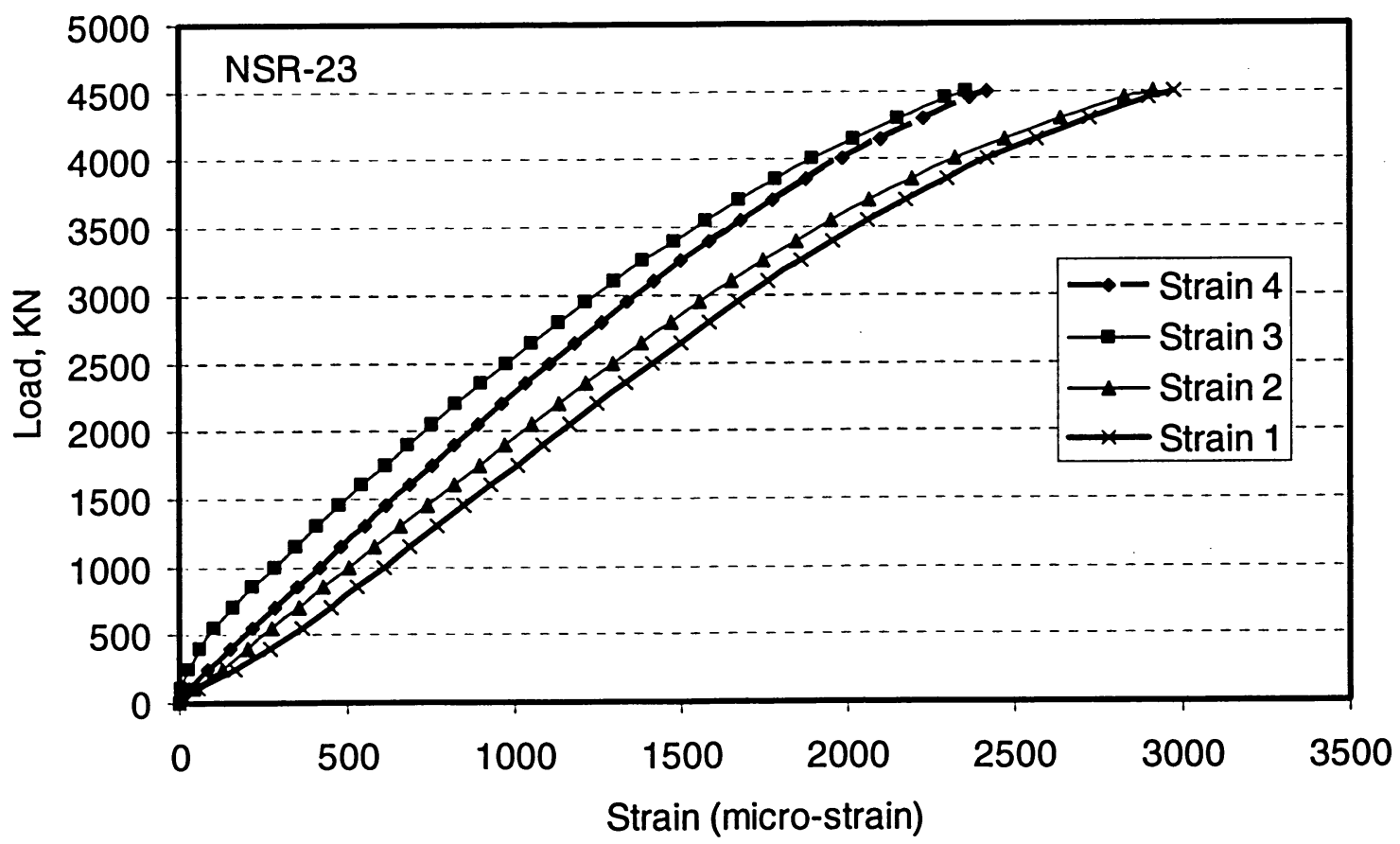

Figure 4.185 Axial load-strain relationships for specimen NSR-23 


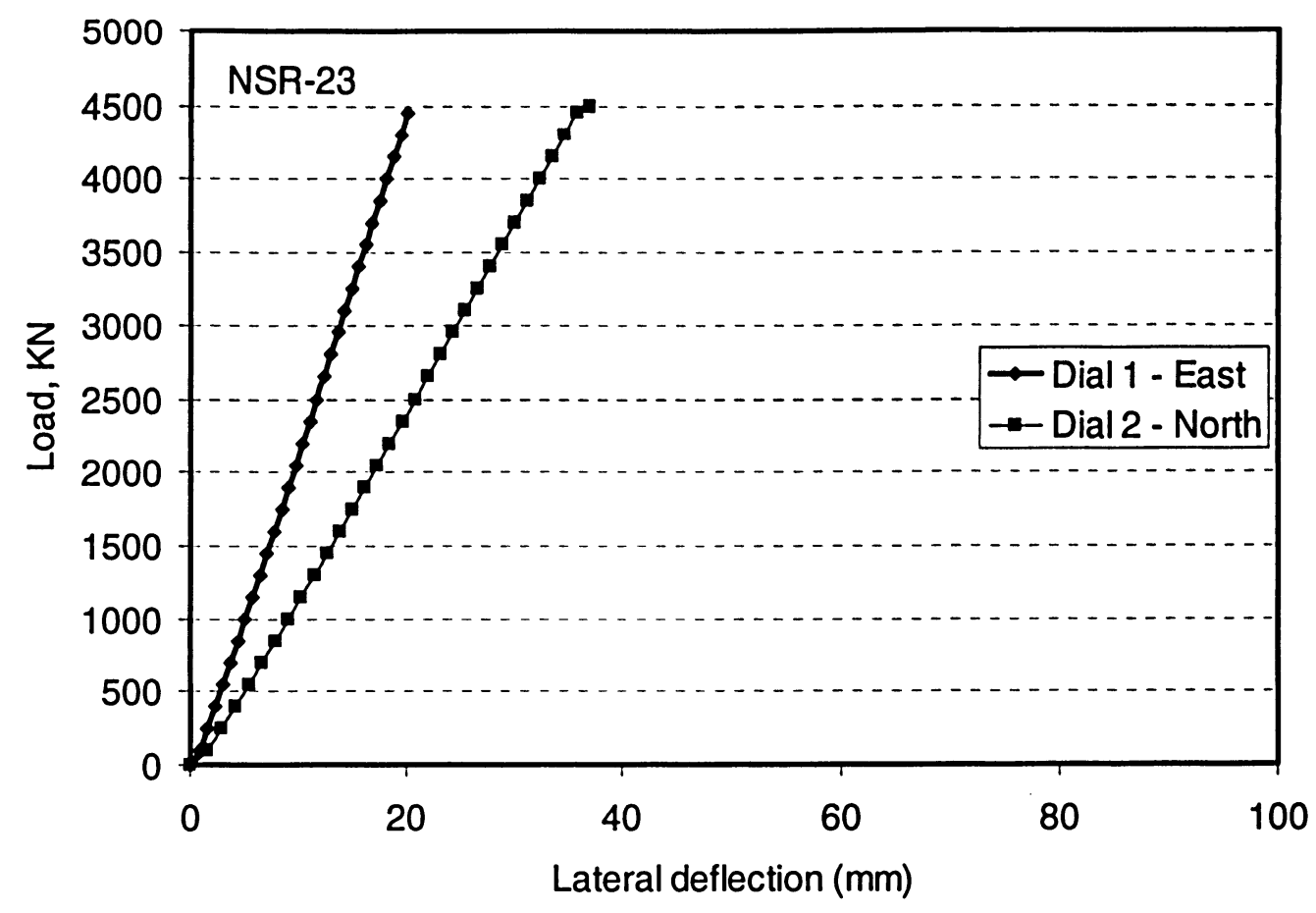

Figure 4.186 Load-lateral deflection curves for specimen NSR-23

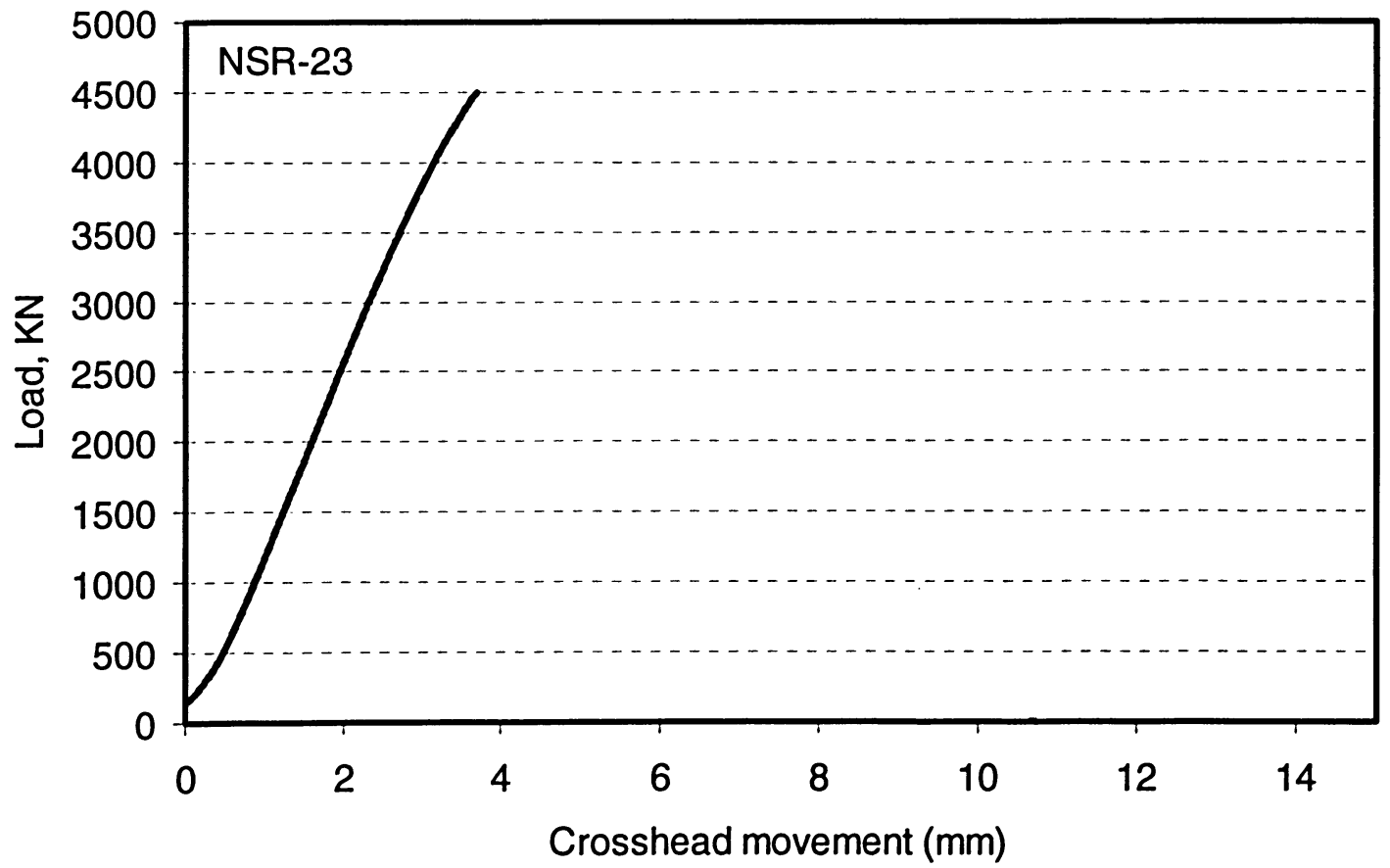

Figure 4.187 Load versus overall shortening curve for specimen NSR-23 

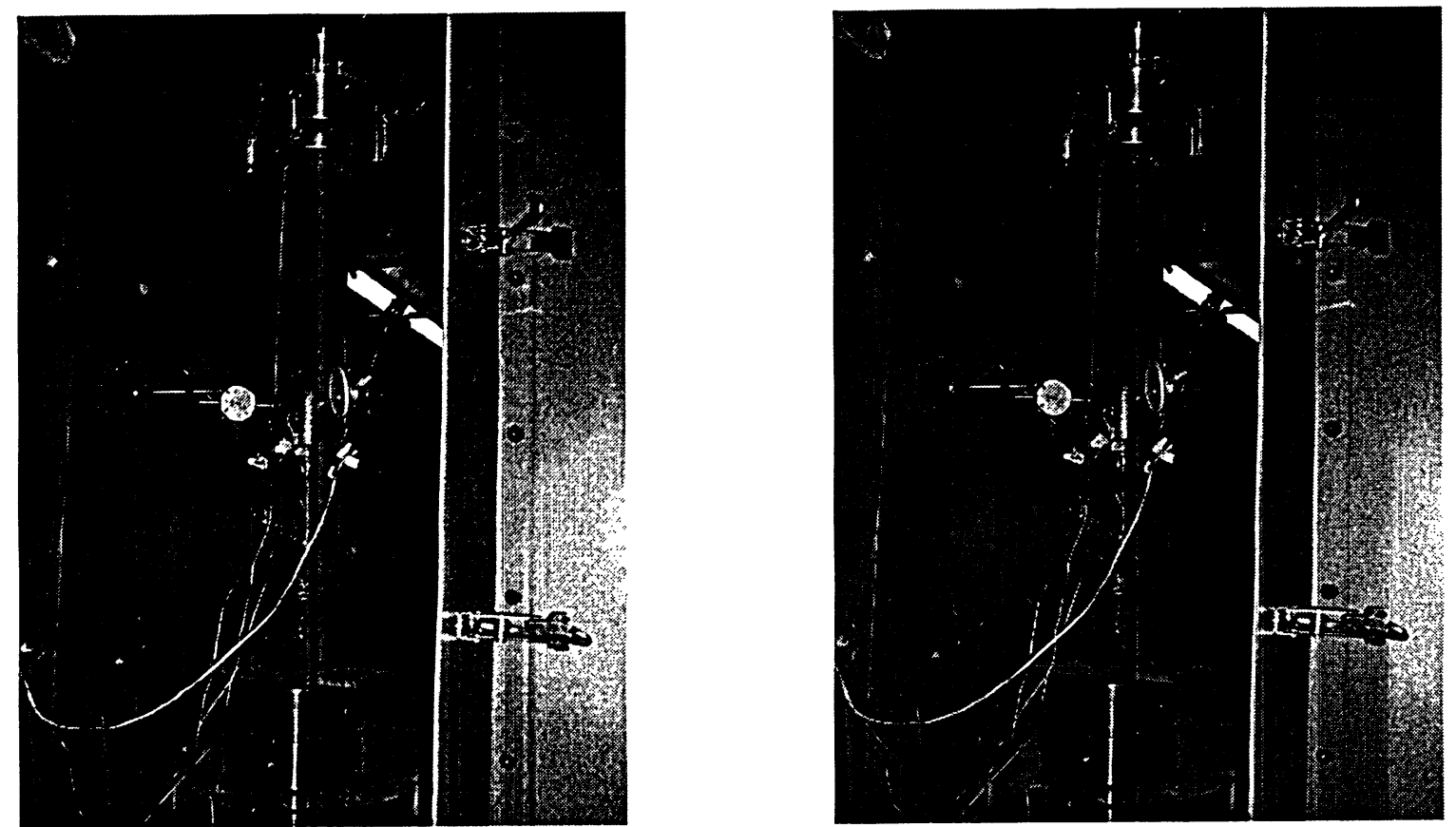

Figure 4.188 Views of specimen NSR-24 before and after testing

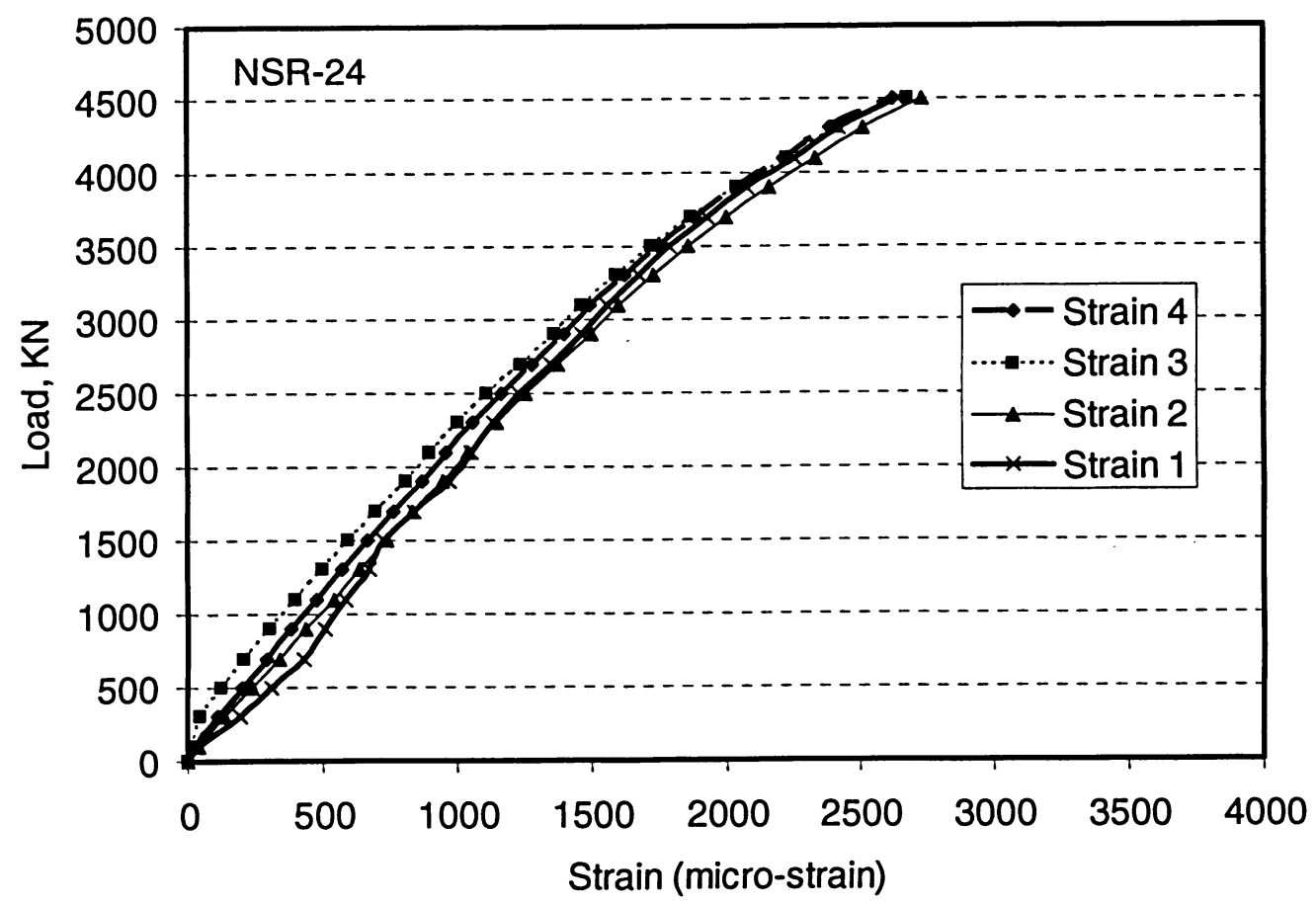

Figure 4.189 Axial load-strain relationships for specimen NSR-24 


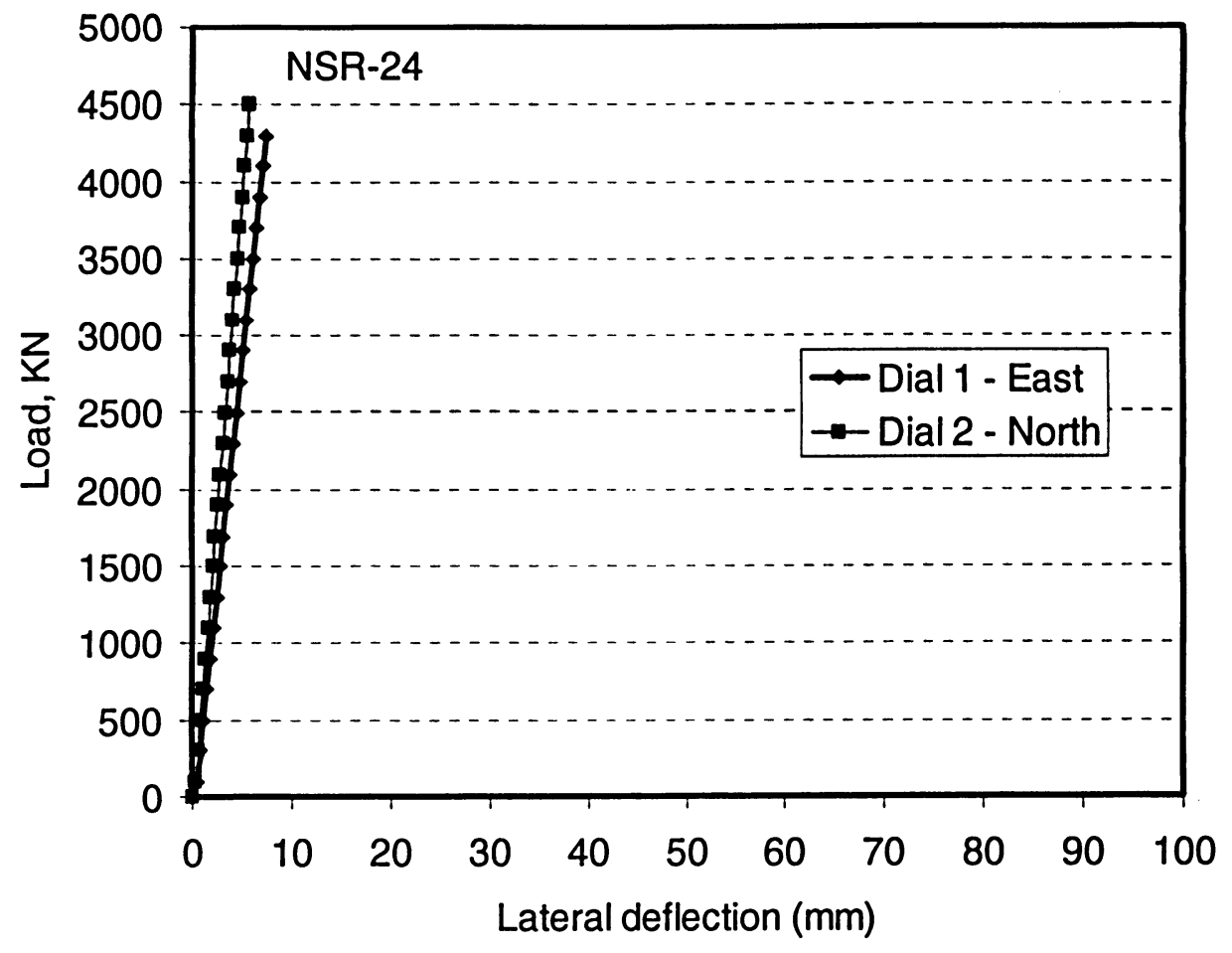

Figure 4.190 Load-lateral deflection curves for specimen NSR-24

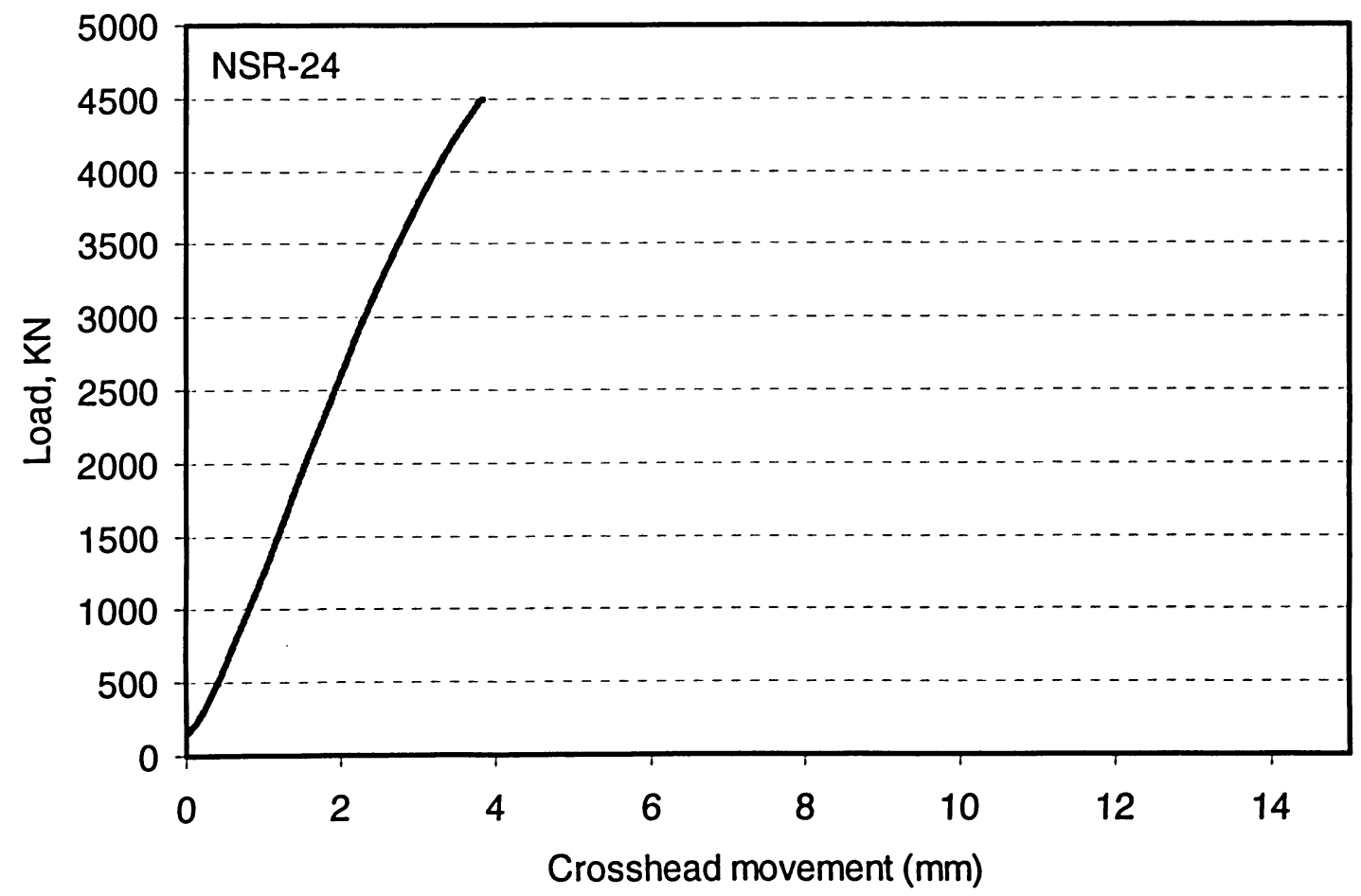

Figure 4.191 Load versus overall shortening curve for specimen NSR-24 

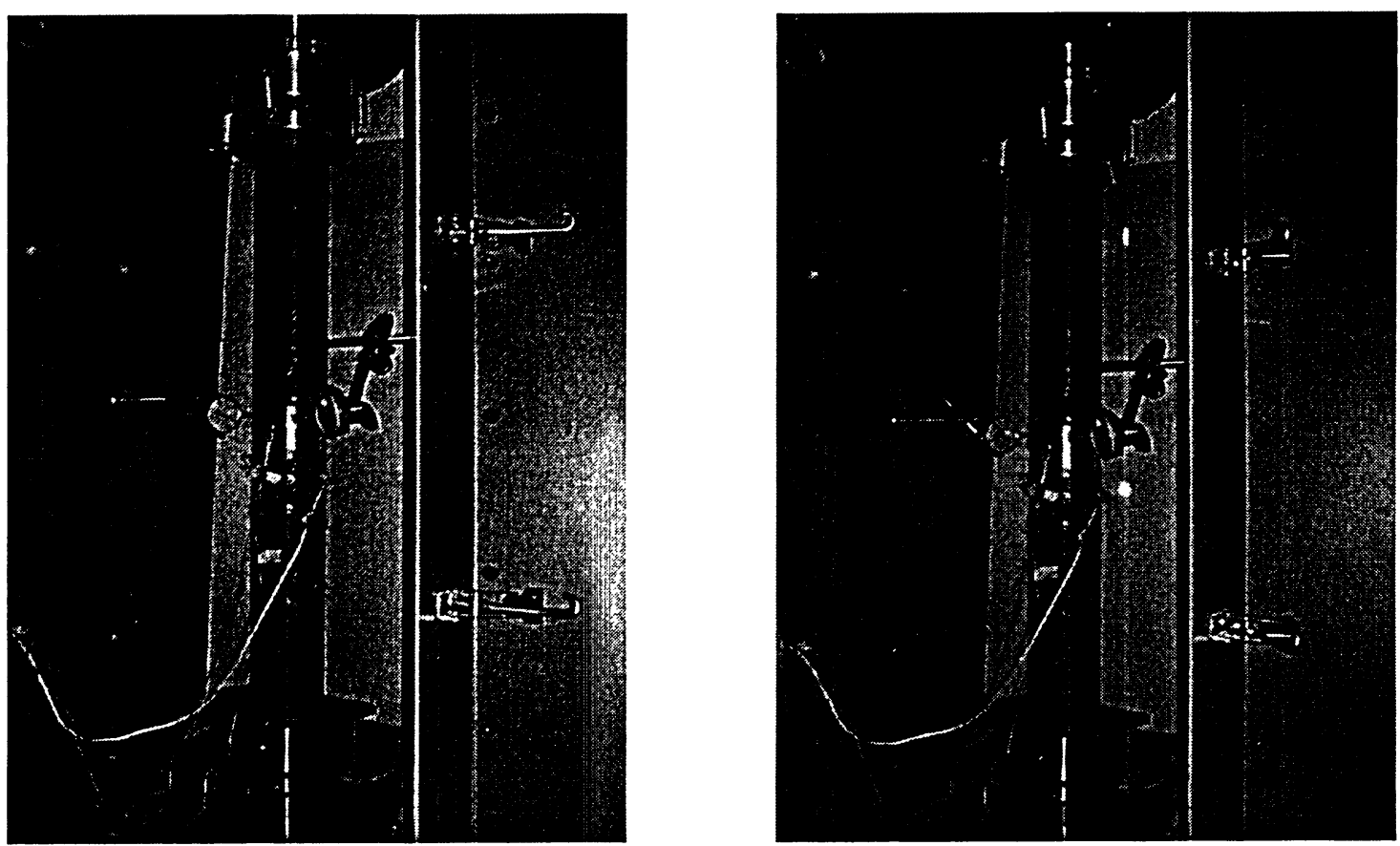

Figure 4.192 Views of specimen NSR-25 before and after testing

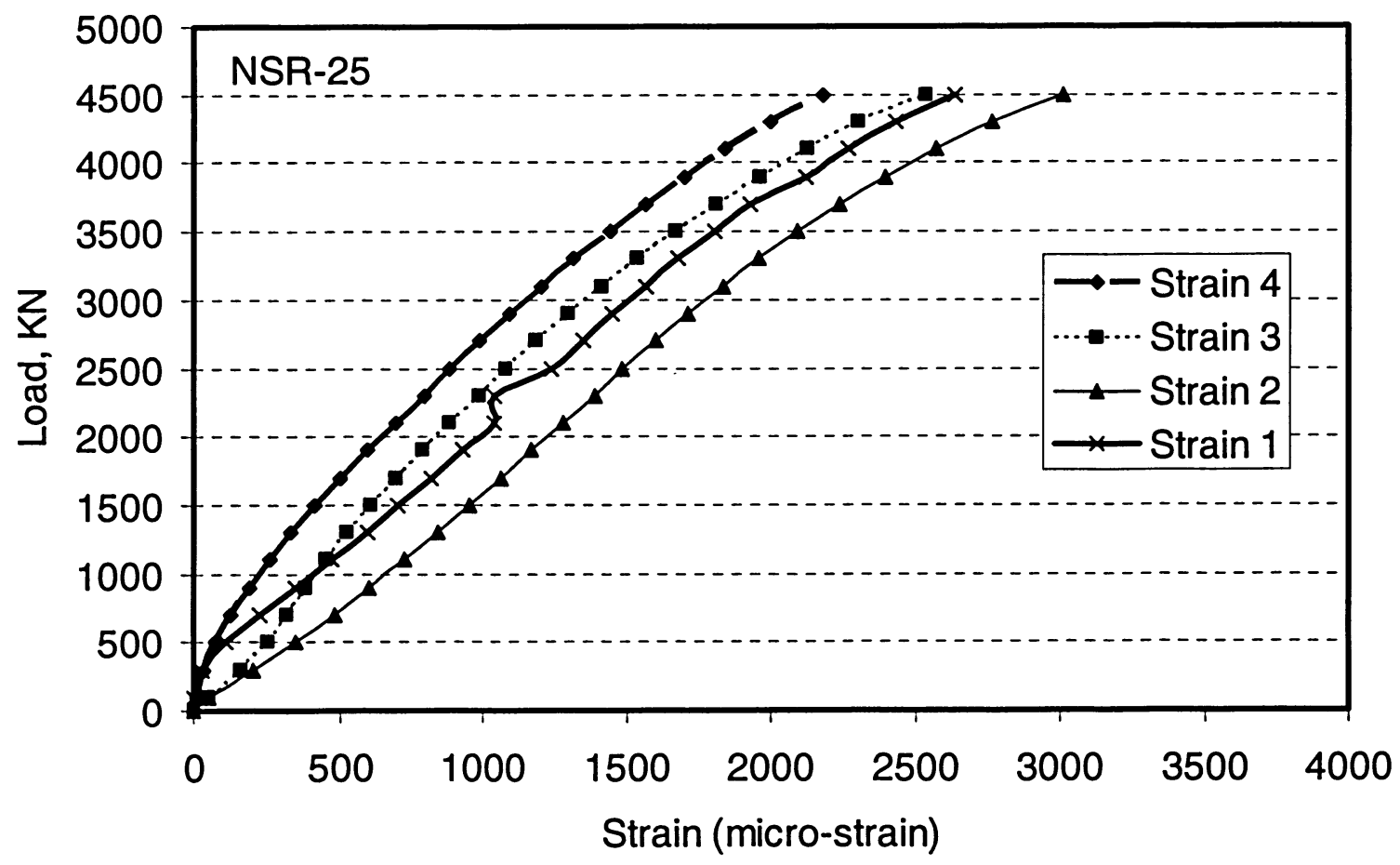

Figure 4.193 Axial load-strain relationships for specimen NSR-25 


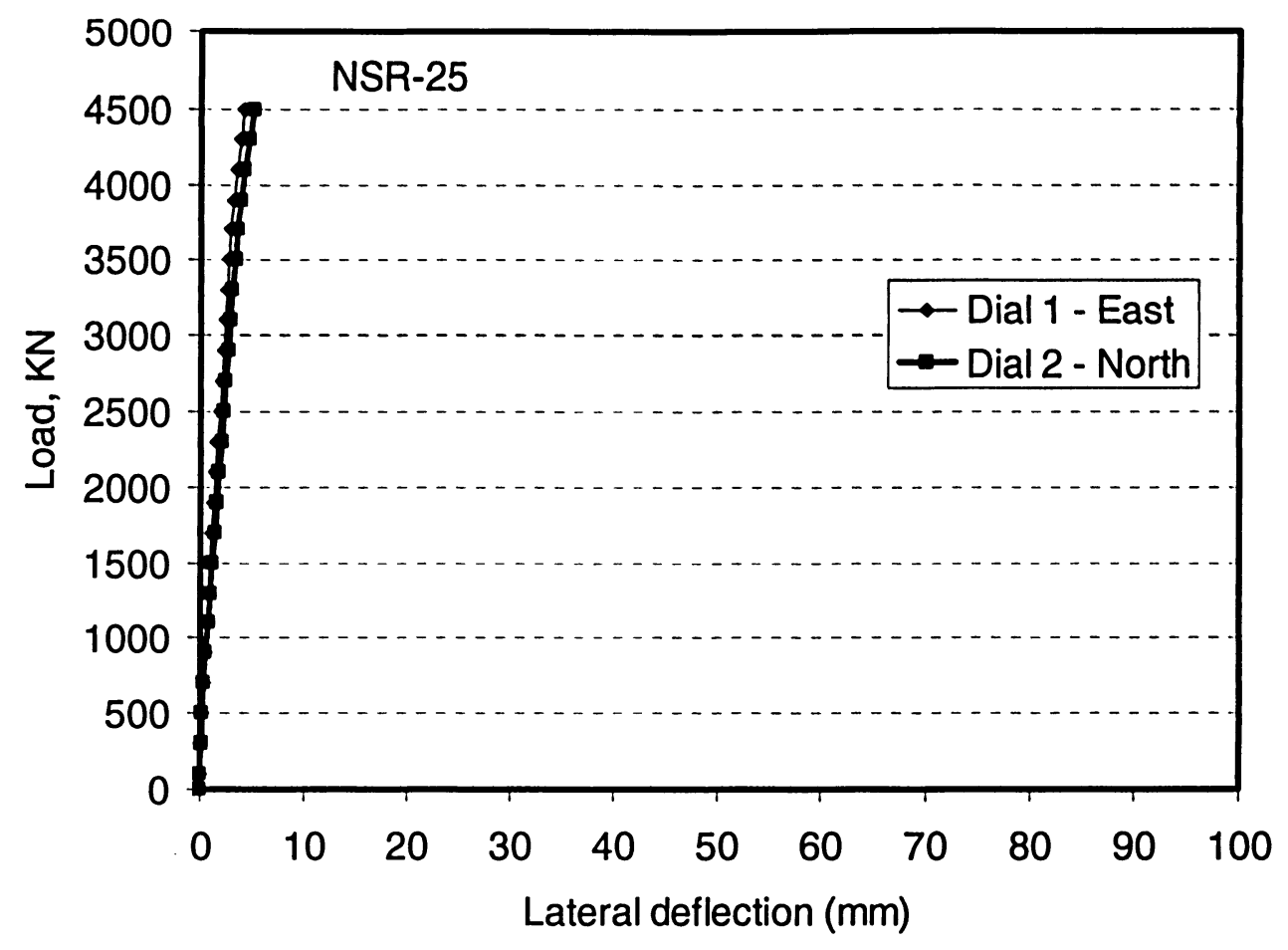

Figure 4.194 Load-lateral deflection curves for specimen NSR-25

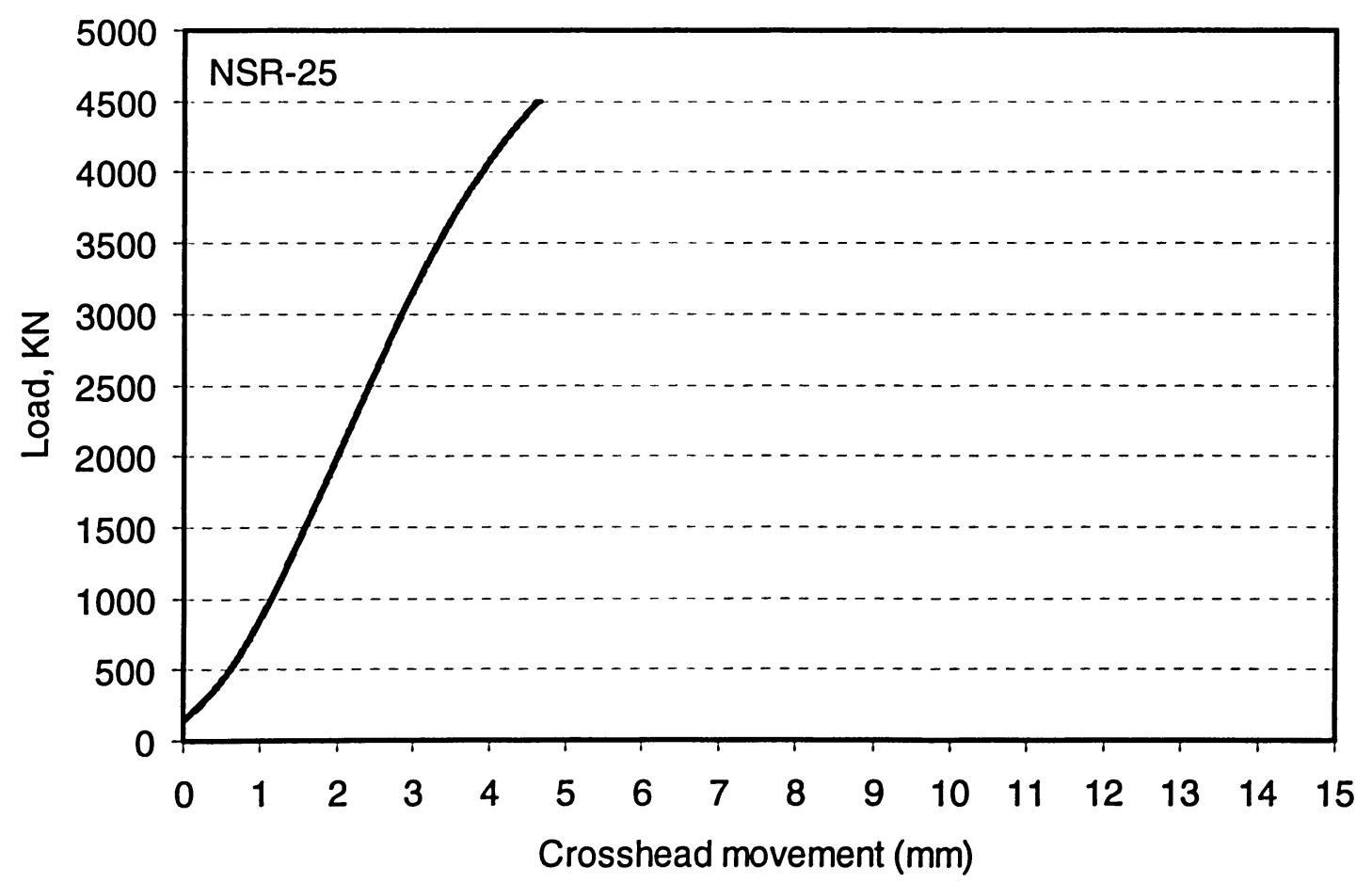

Figure 4.195 Load versus overall shortening curve for specimen NSR-25 

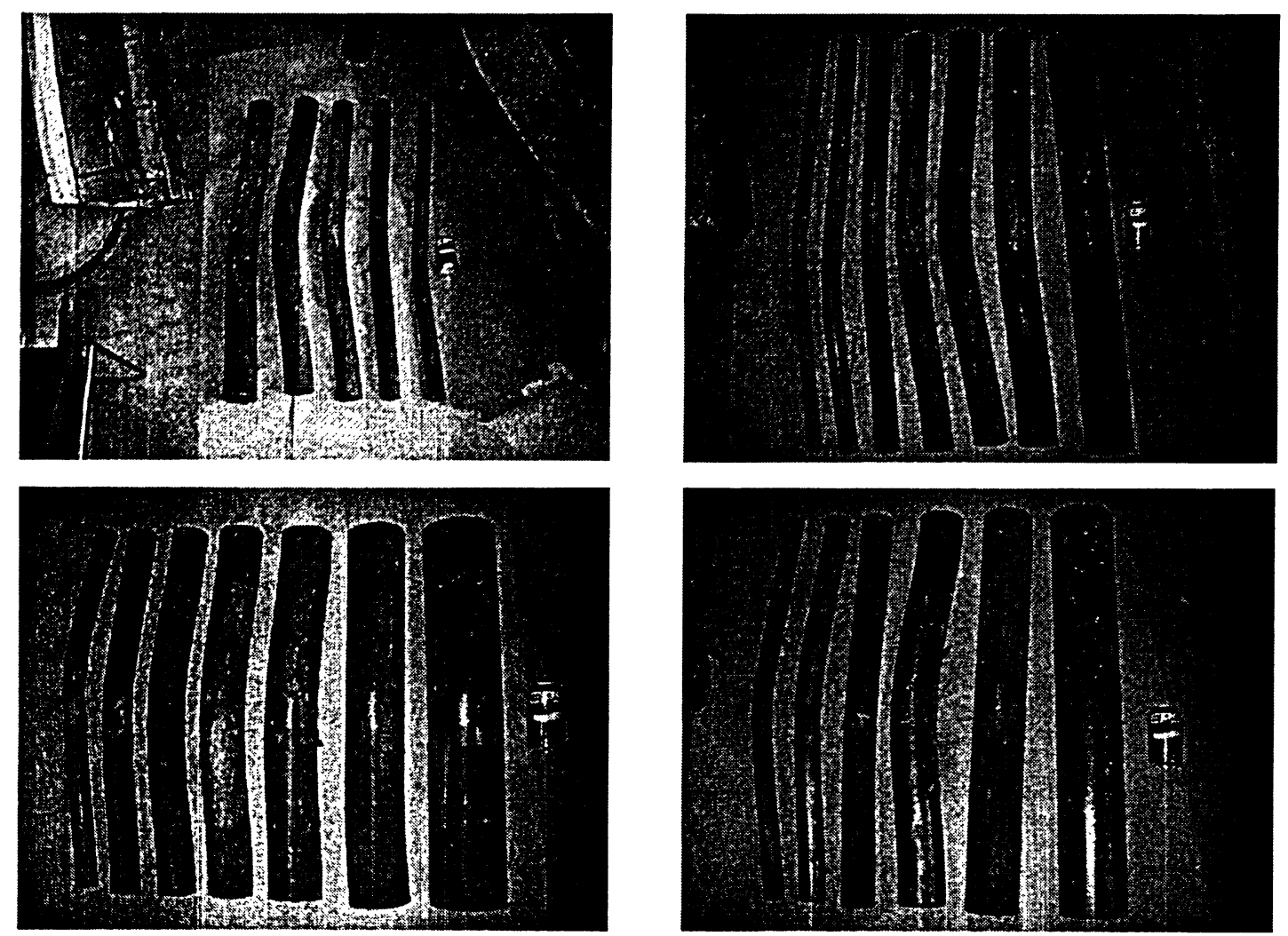

Figure 4.196 Views of the NSR tested specimens
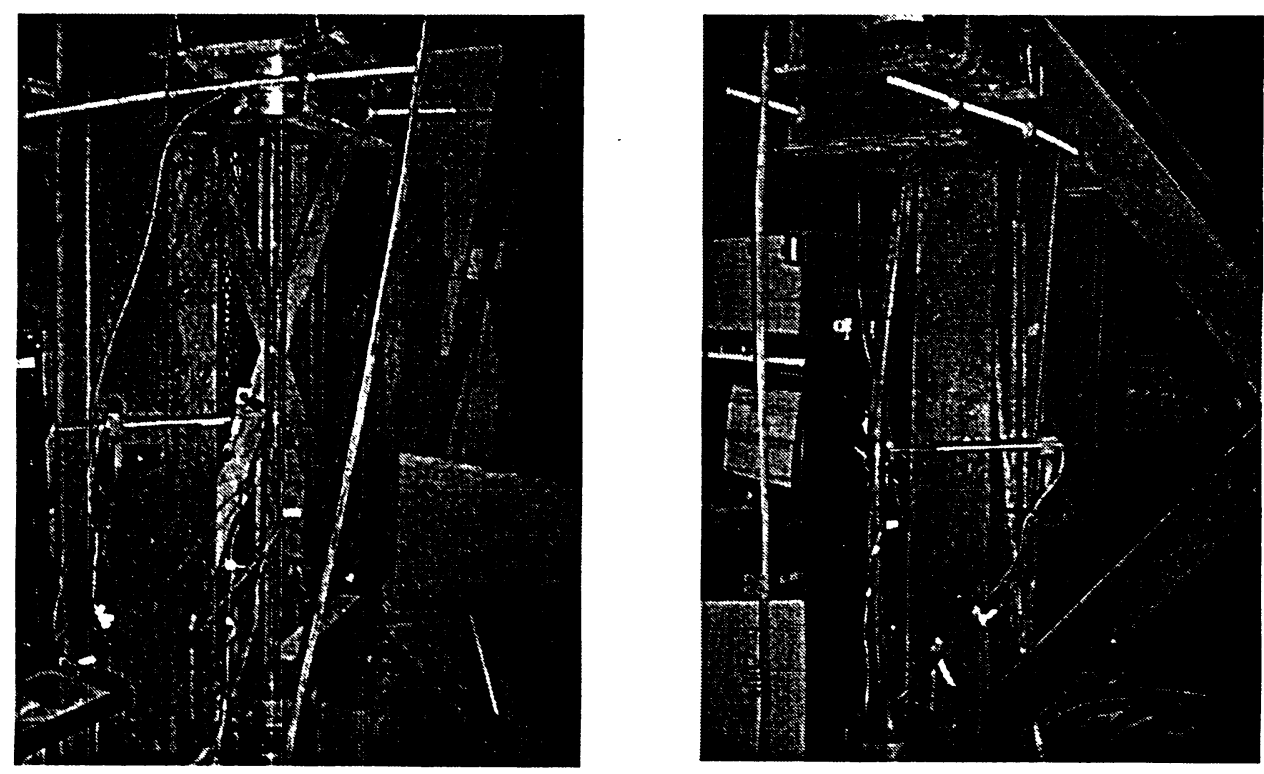

Figure 4.197 Views of specimen NSR-26 before and after testing 


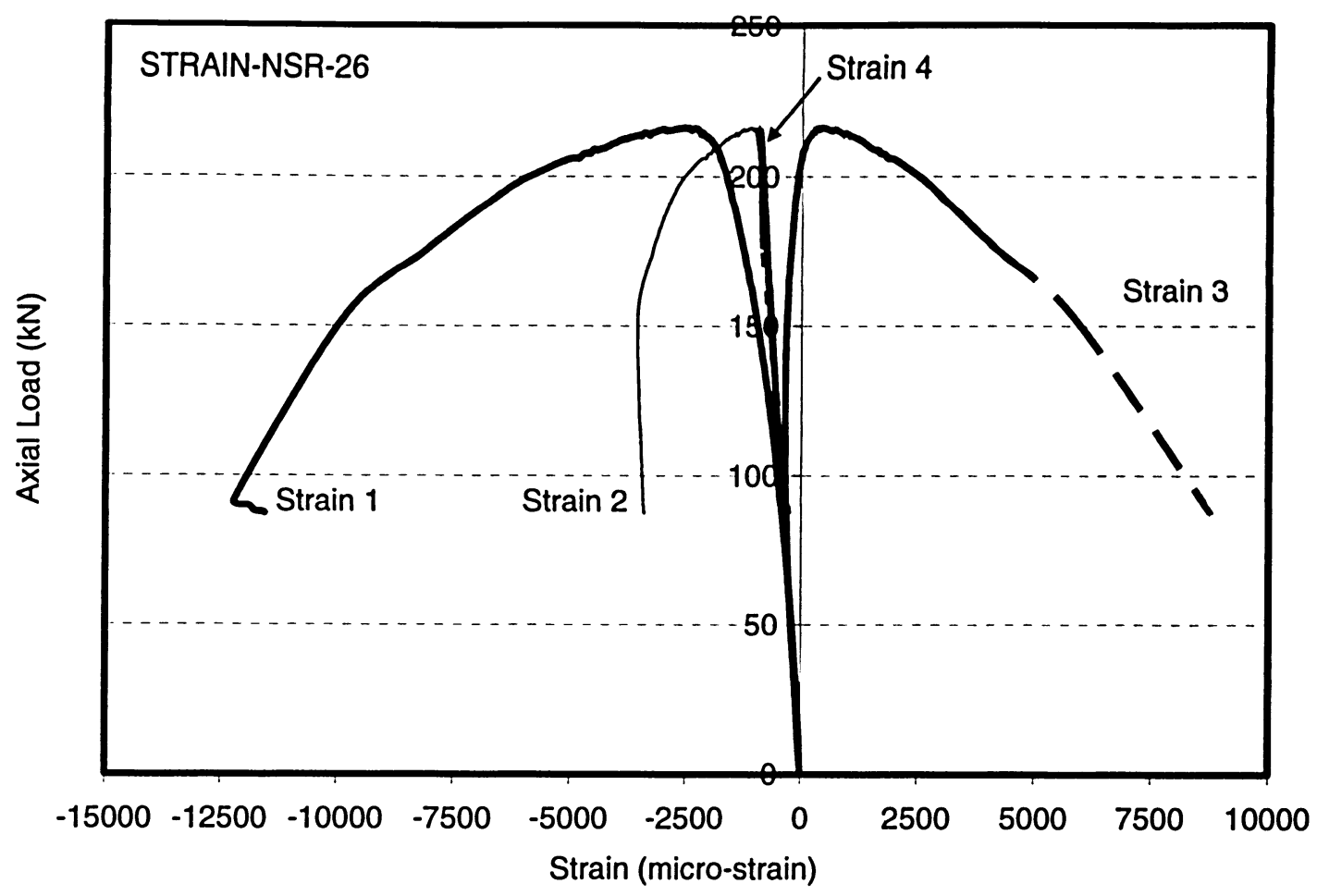

Figure 4.198 Axial load-strain relationships for specimen NSR-26
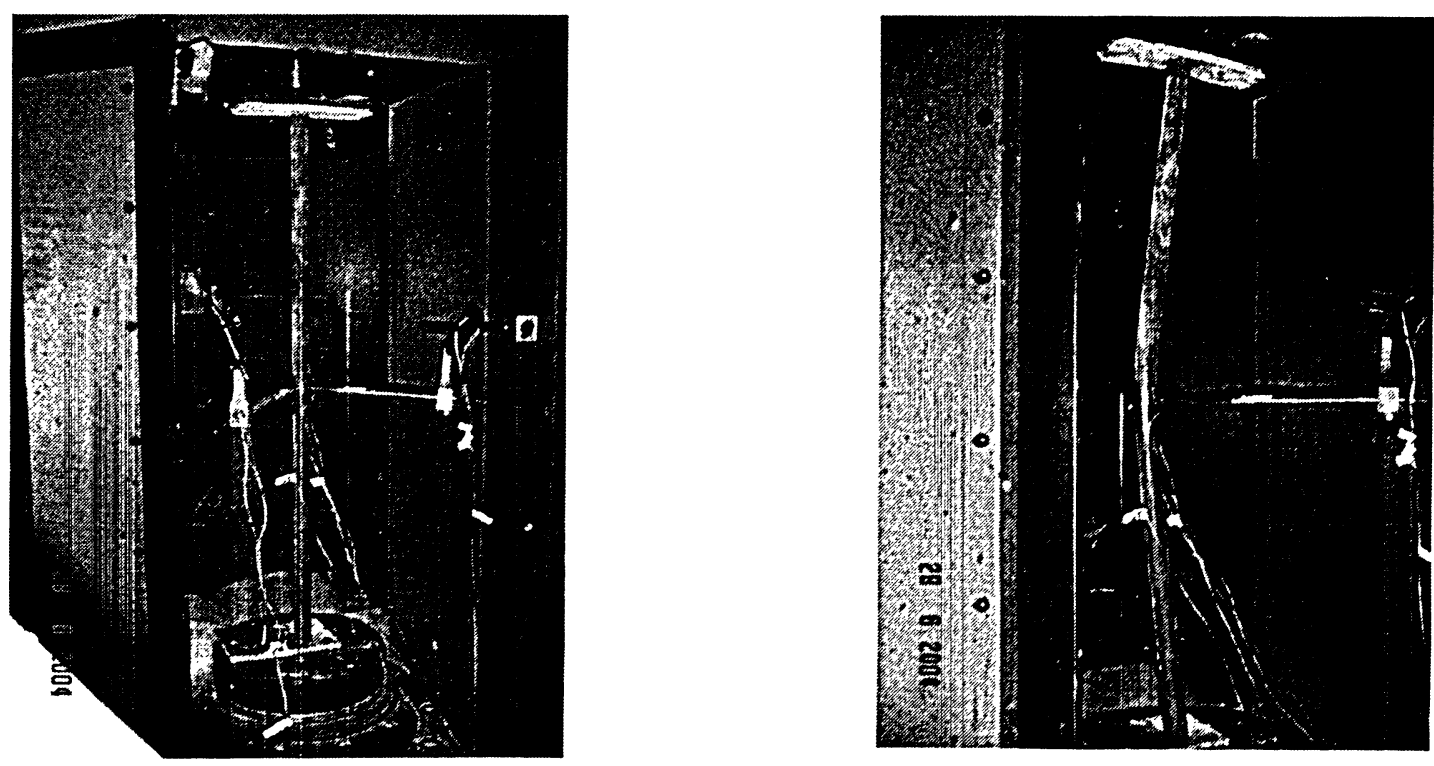

Figure 4.199 Views of specimen NSR-27 before and after testing 



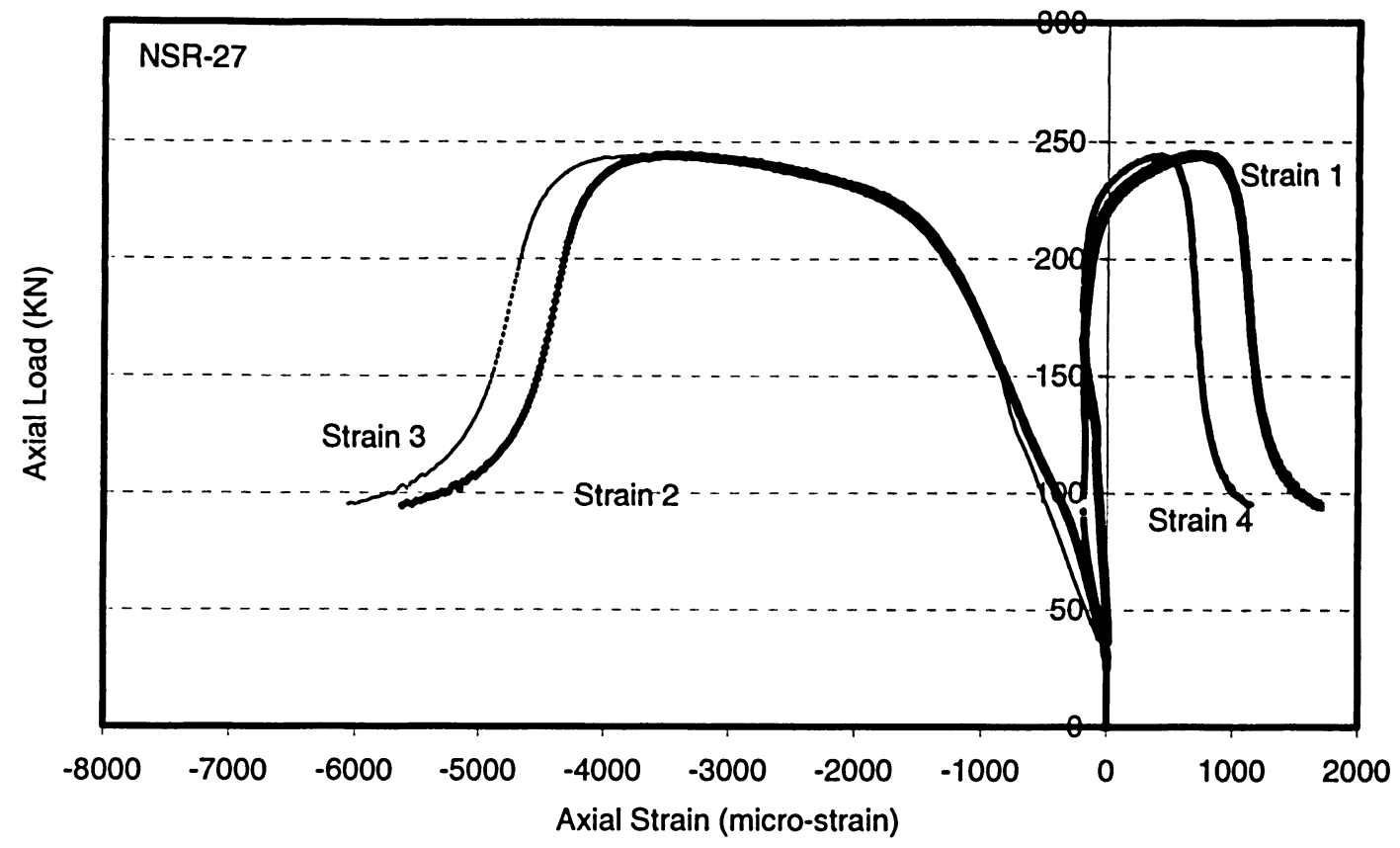

Figure 4.200 Axial load-strain relationships for specimen NSR-27

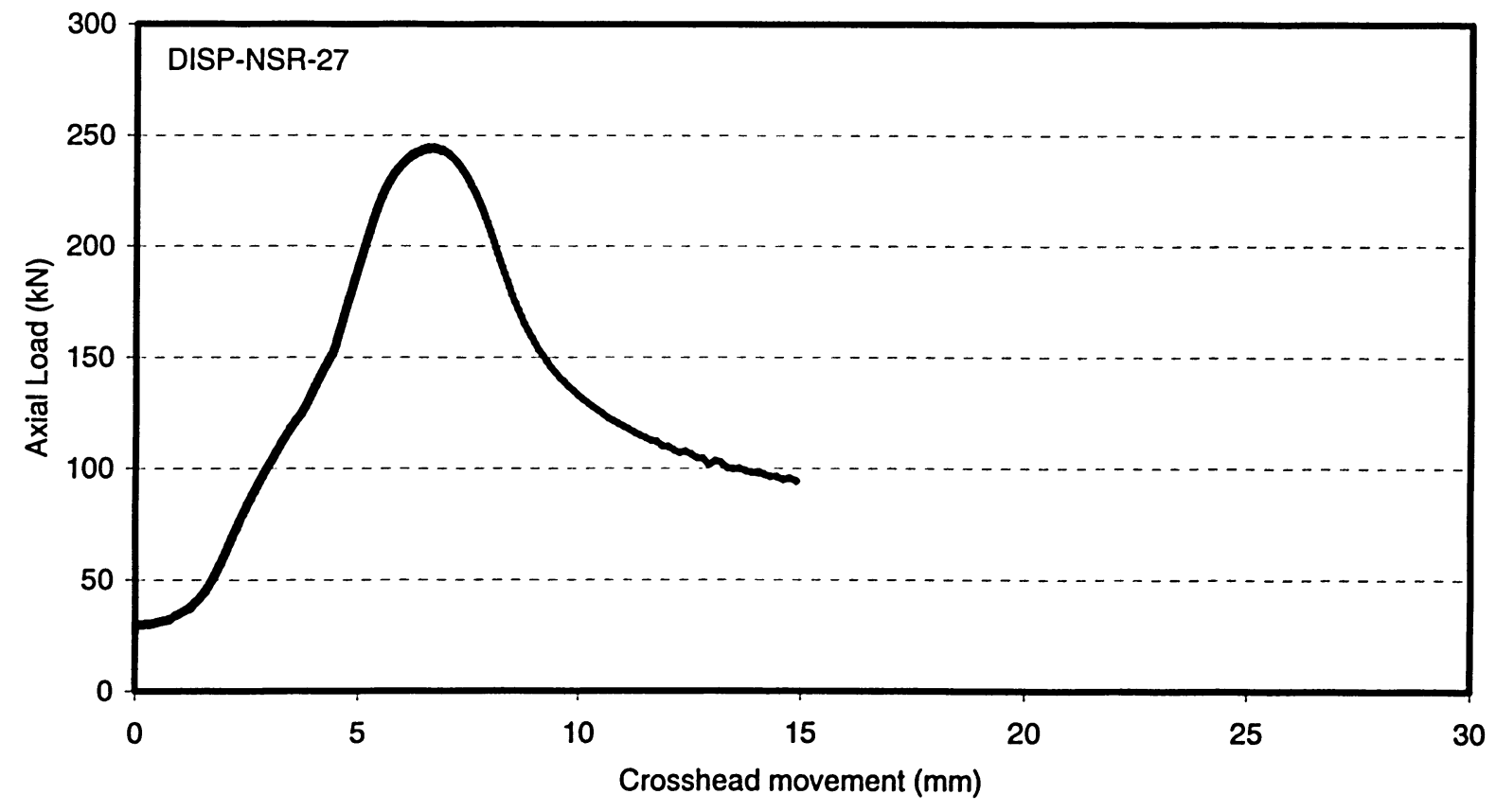

Figure 4.201 Load versus overall shortening curve for specimen NSR-27 

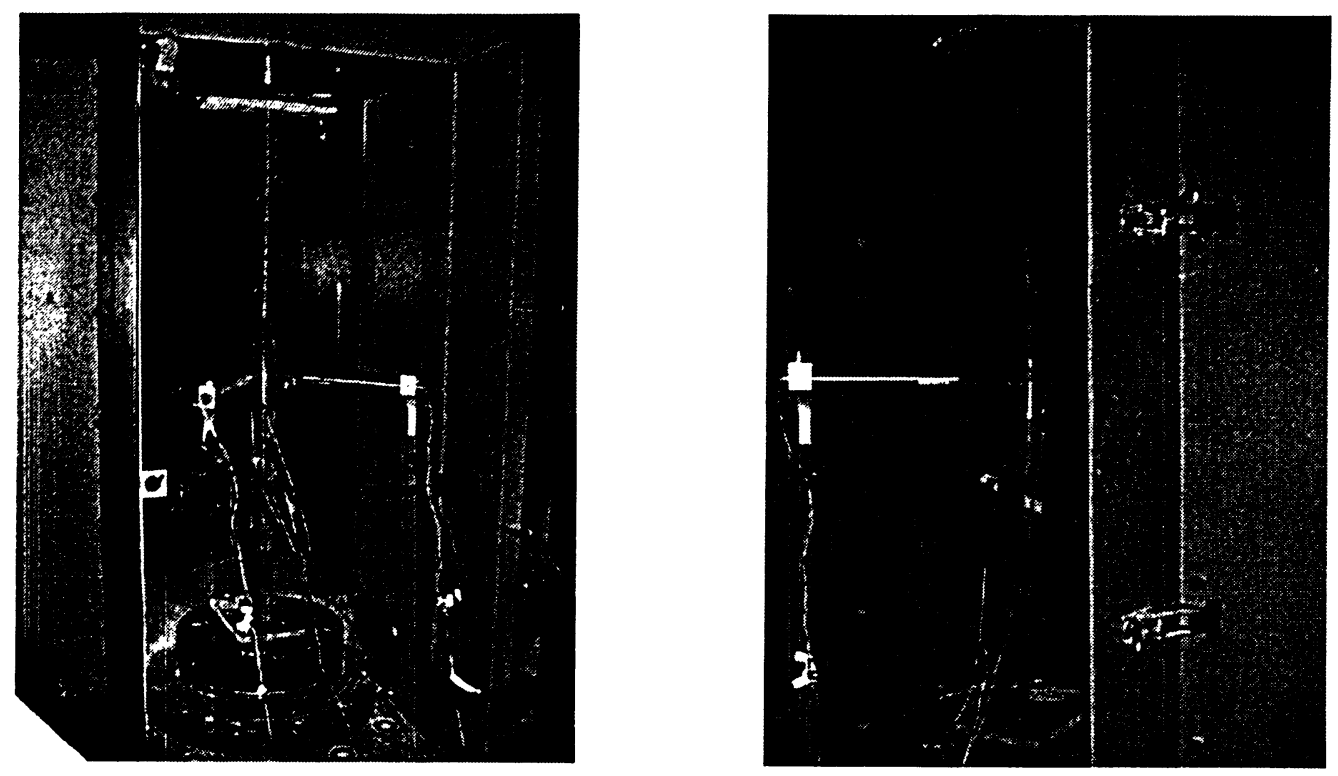

Figure 4.202 Views of specimen NSR-28 before and after testing

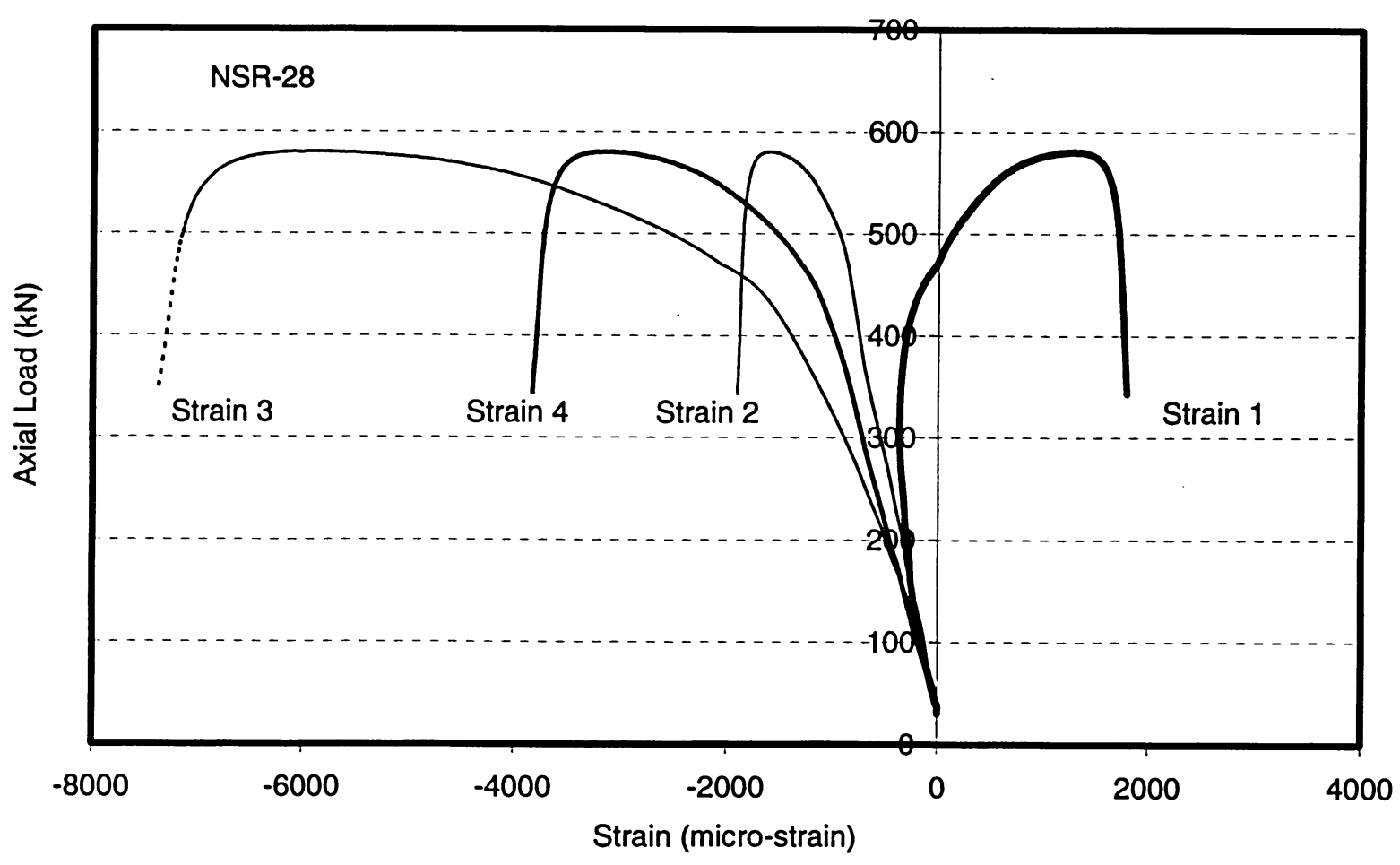

Figure 4.203 Axial load-strain relationships for specimen NSR-28 


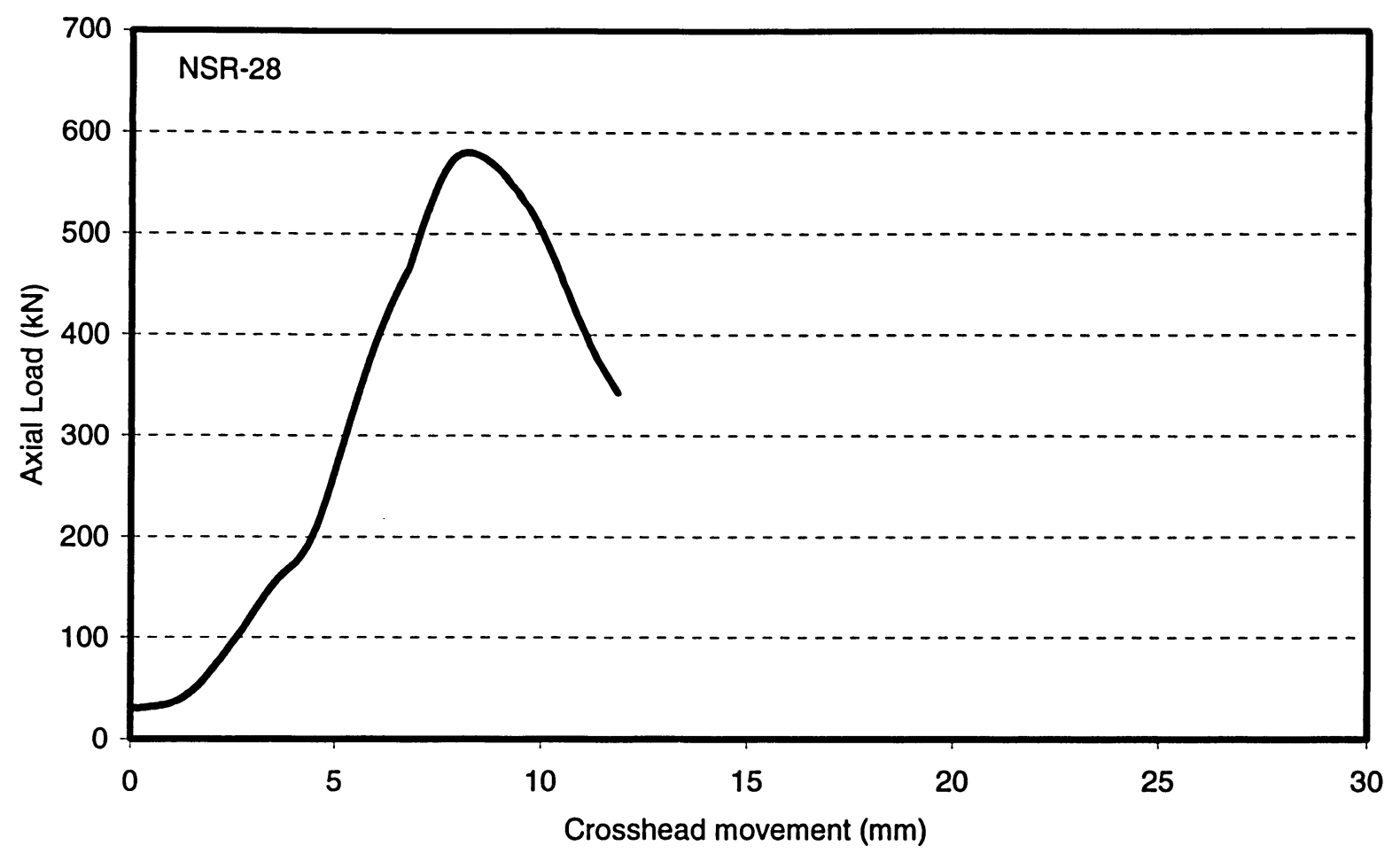

Figure 4.204 Load versus overall shortening curve for specimen NSR-28
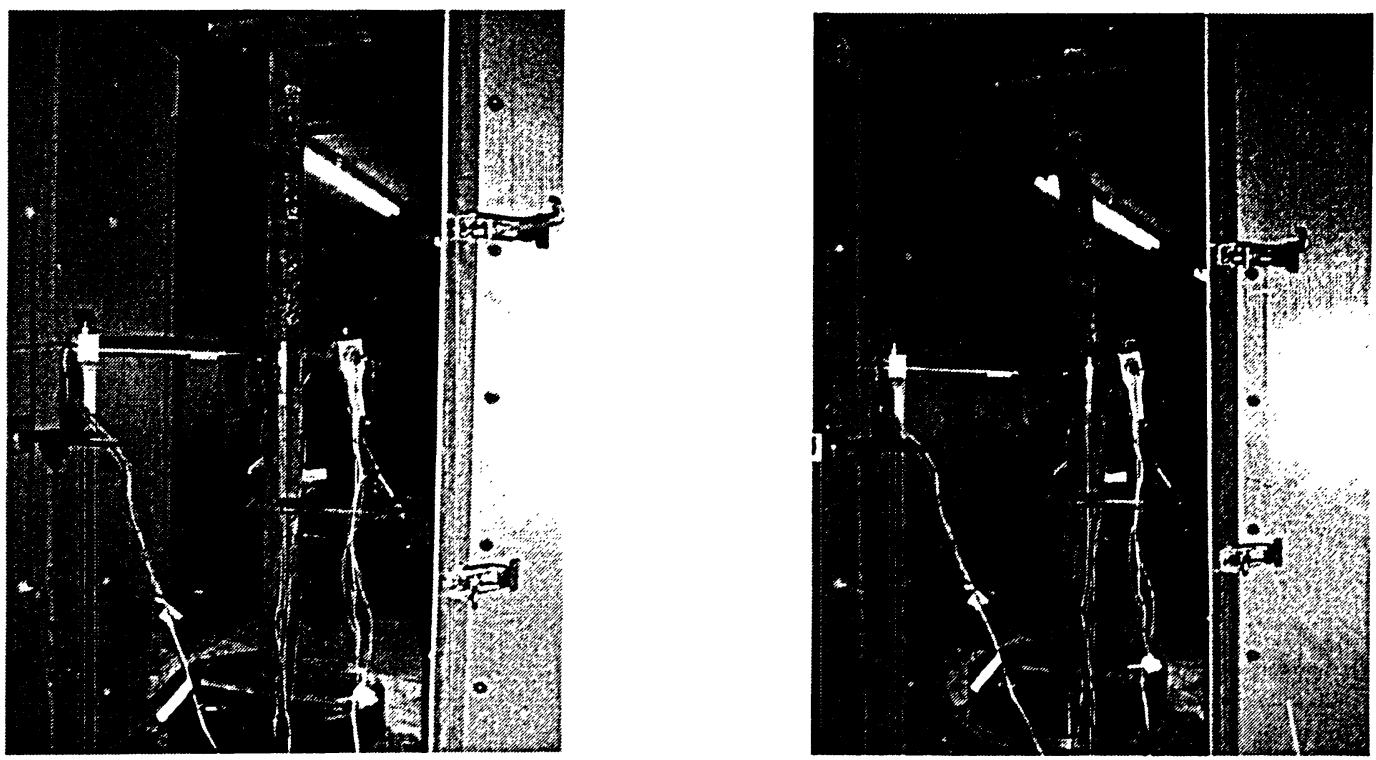

Figure 4.205 Views of specimen NSR-29 before and after testing 


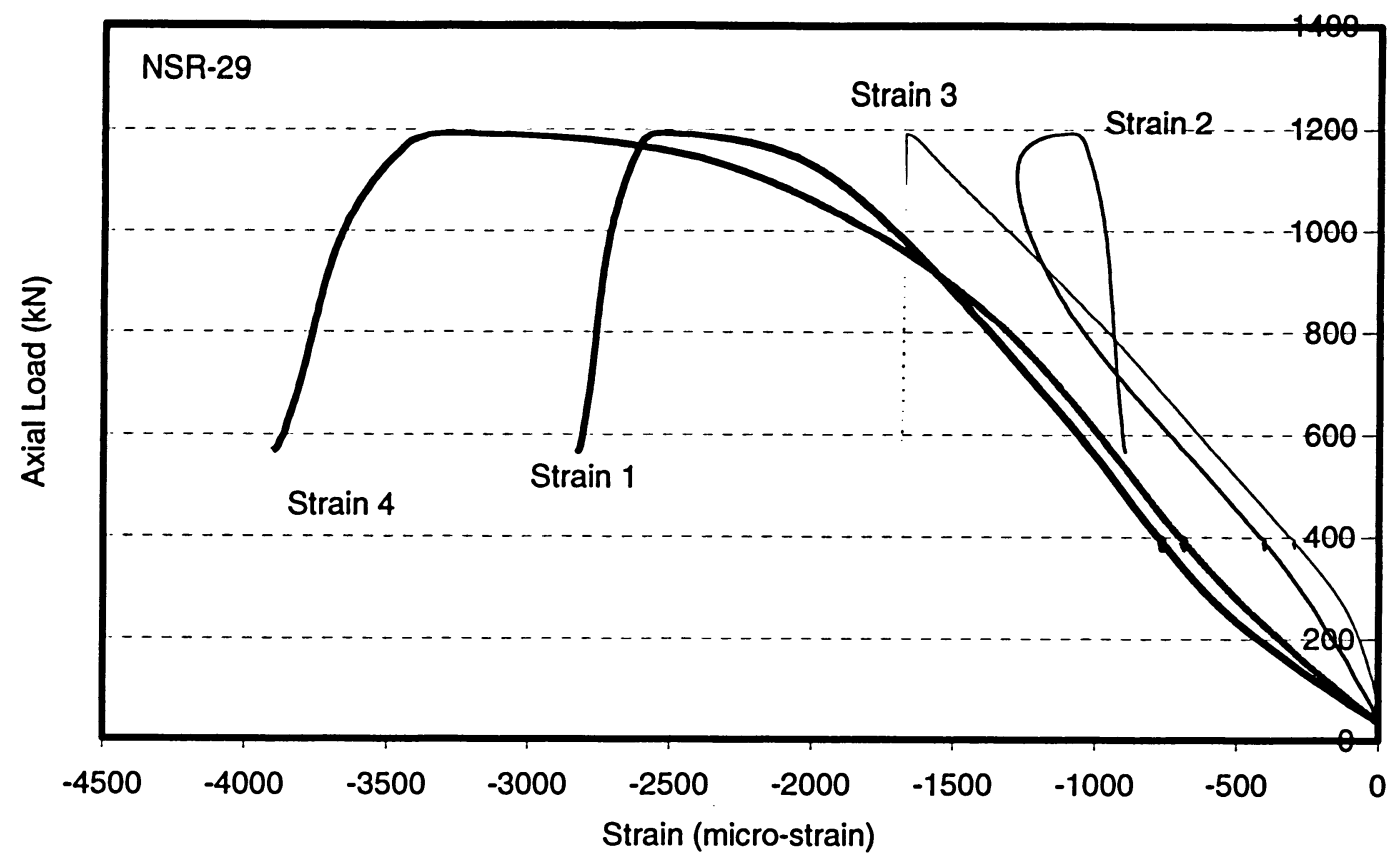

Figure 4.206 Axial load-strain relationships for specimen NSR-29

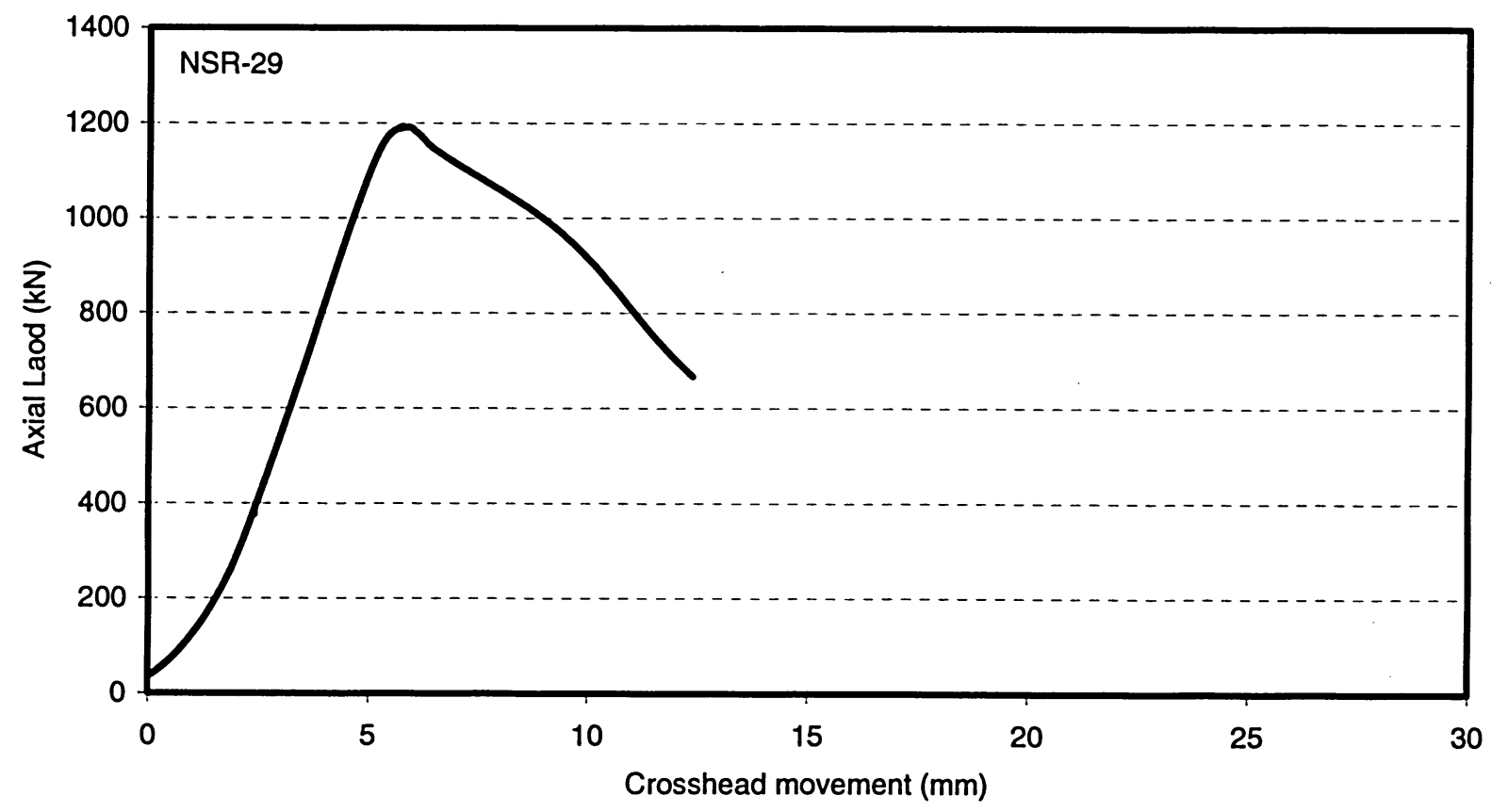

Figure 4.207 Load versus overall shortening curve for specimen NSR-29 


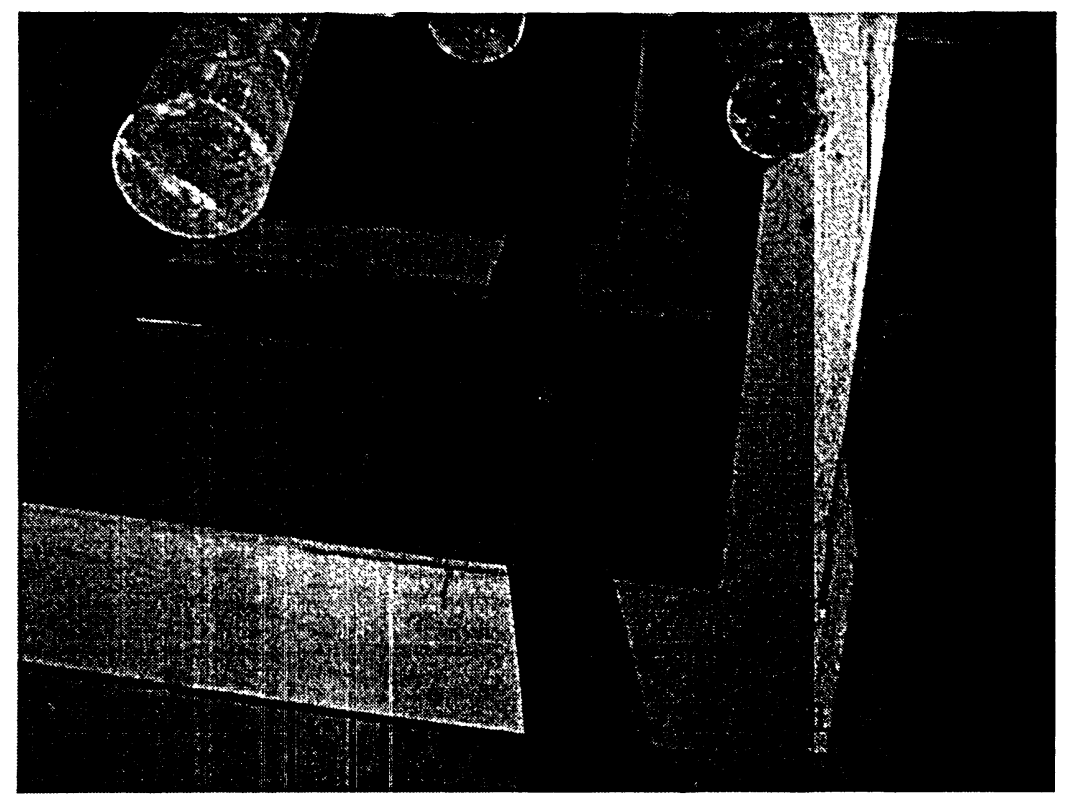

Figure 4.208 Views of specimen NSR-30before and after testing

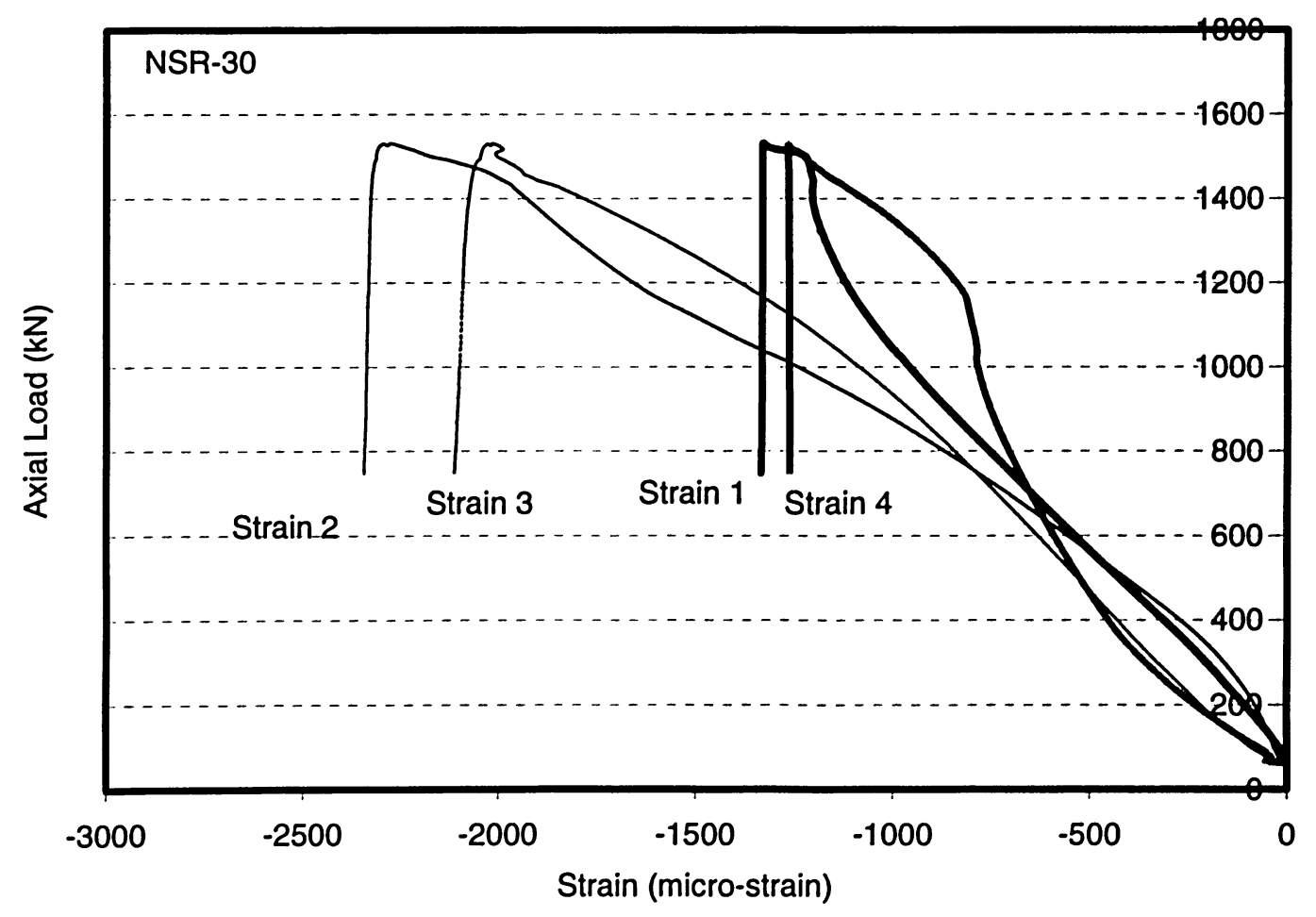

Figure 4.209 Axial load-strain relationships for specimen NSR-30 


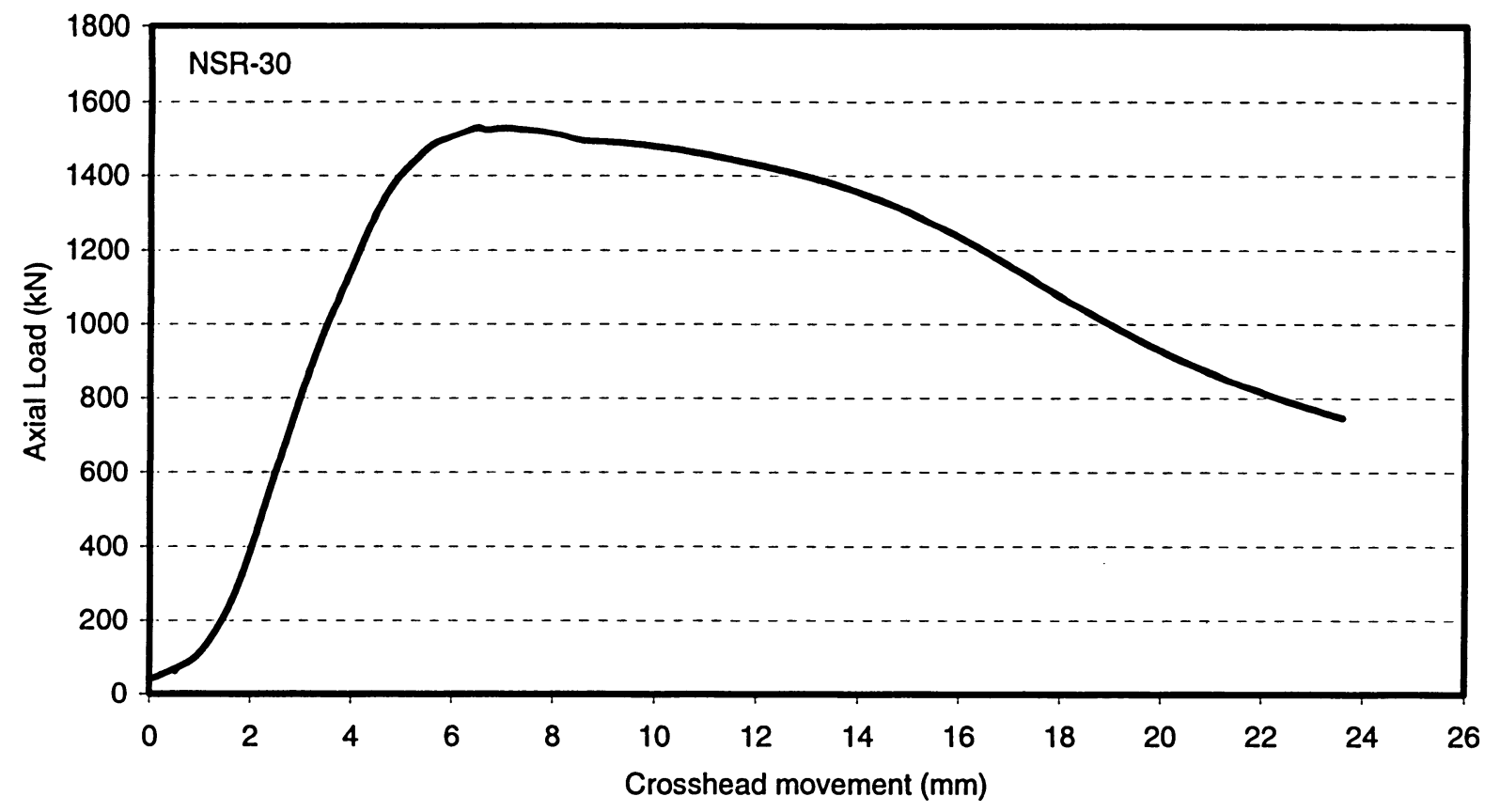

Figure 4.210 Load versus overall shortening curve for specimen NSR-30
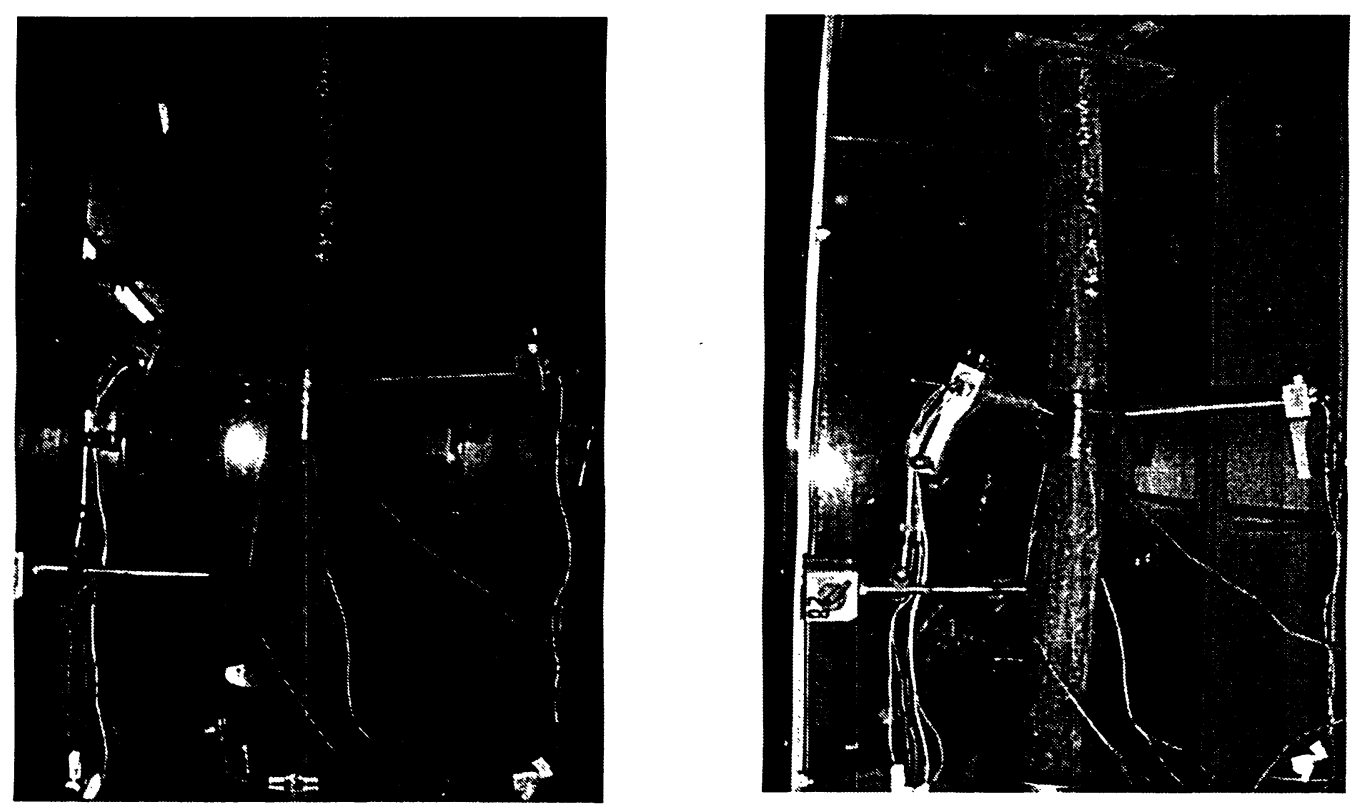

Figure 4.211 Views of specimen NSR-31 before and after testing 


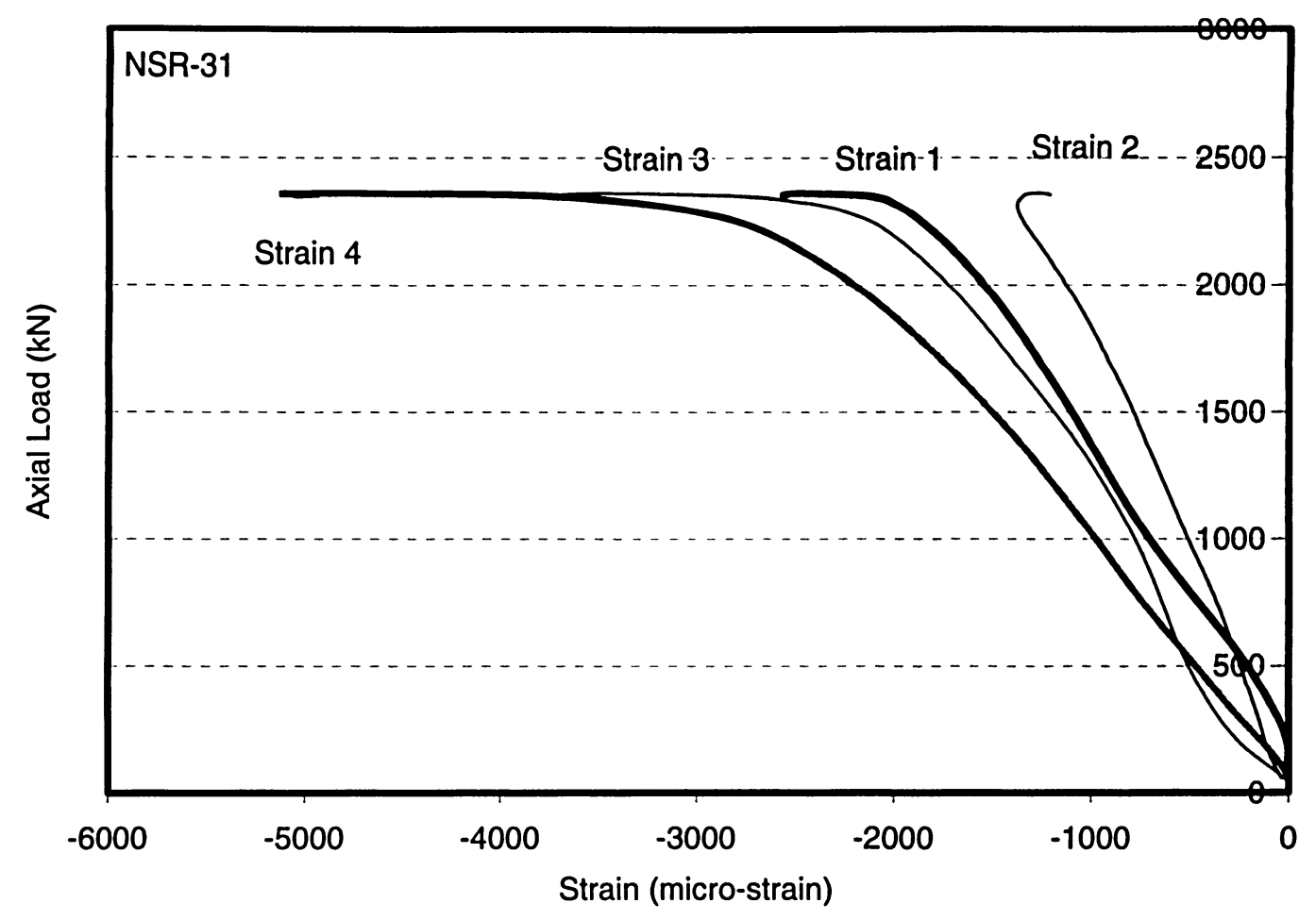

Figure 4.212 Axial load-strain relationships for specimen NSR-31

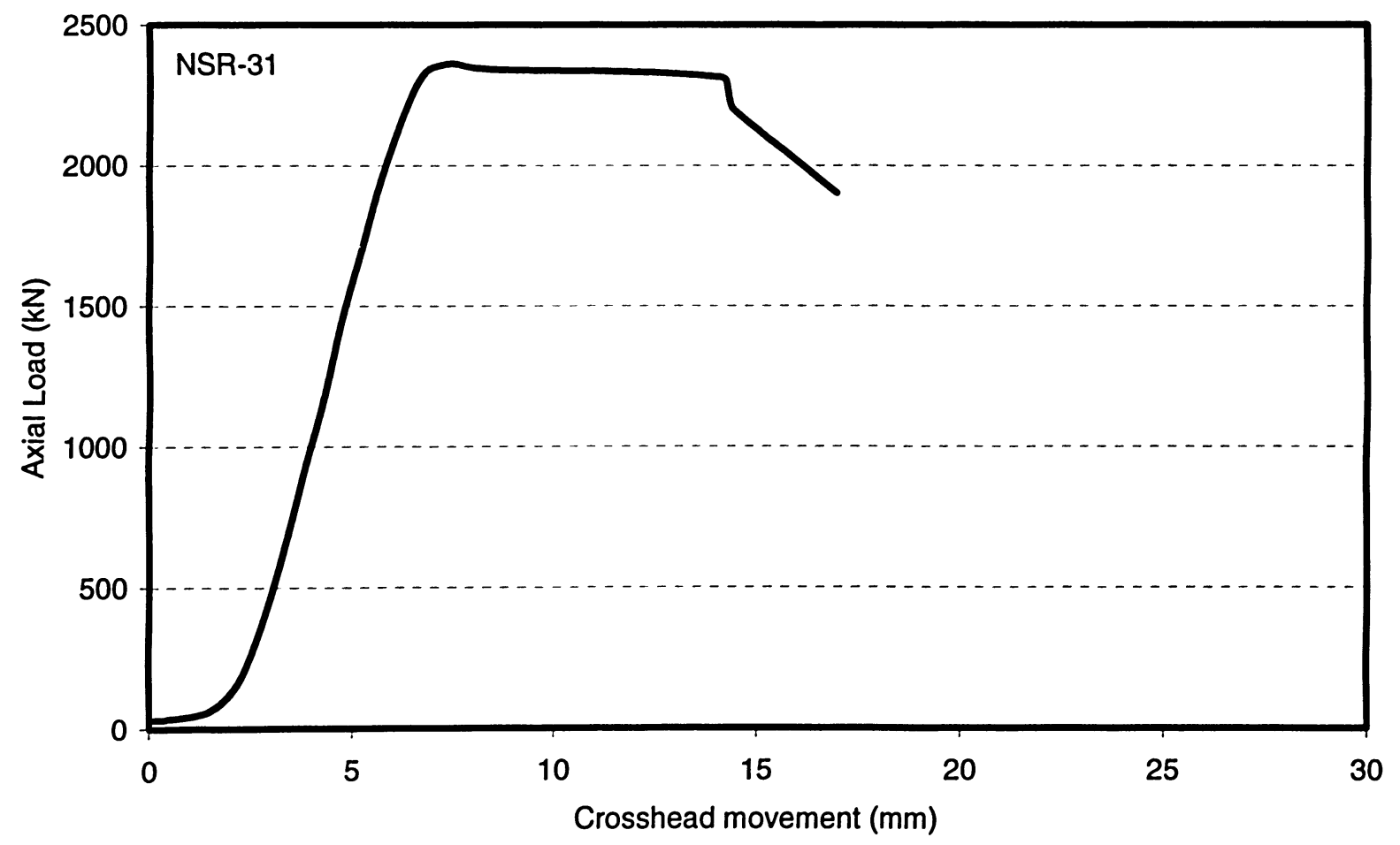

Figure 4.213 Load versus overall shortening curve for specimen NSR-31 

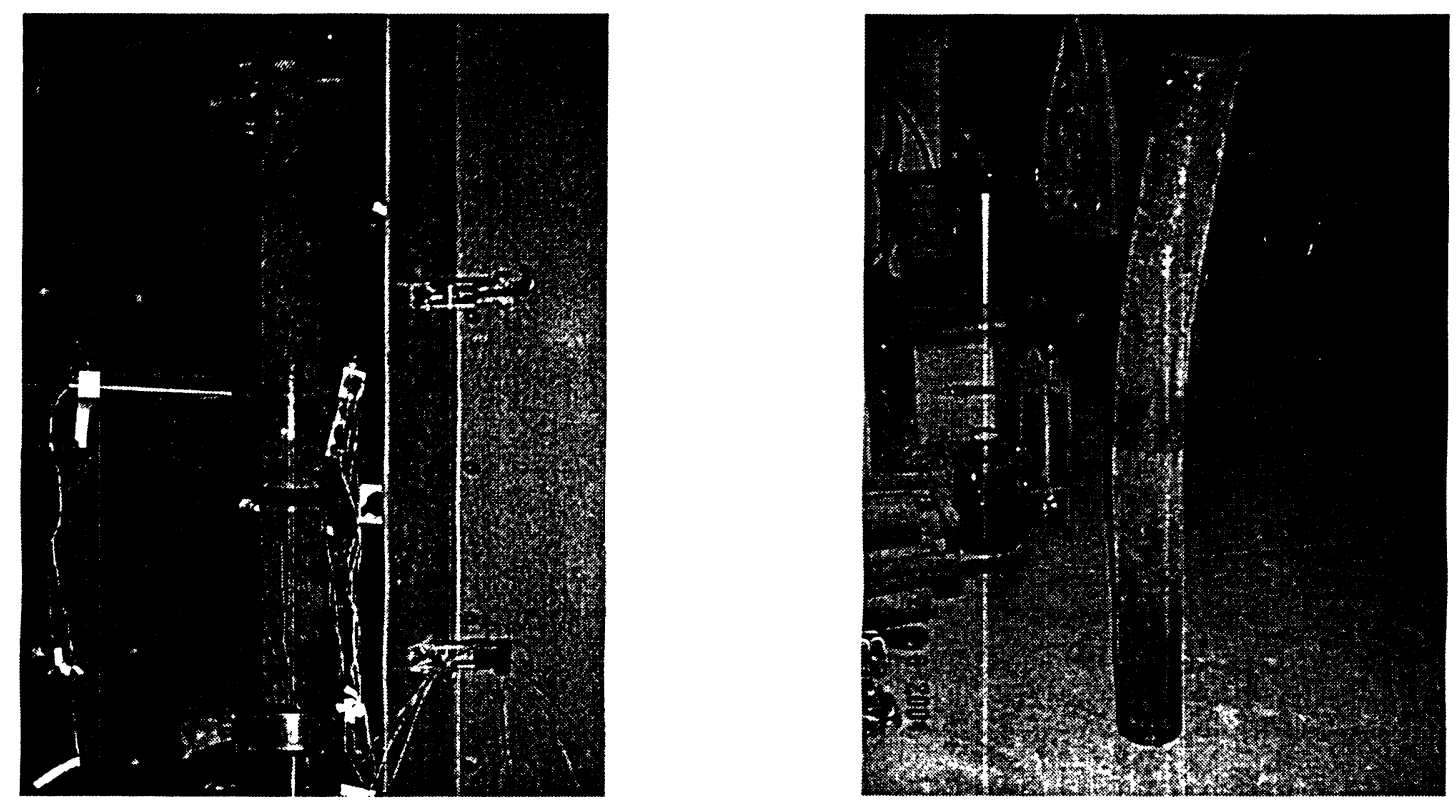

Figure 4.214 Views of specimen NSR-32 before and after testing

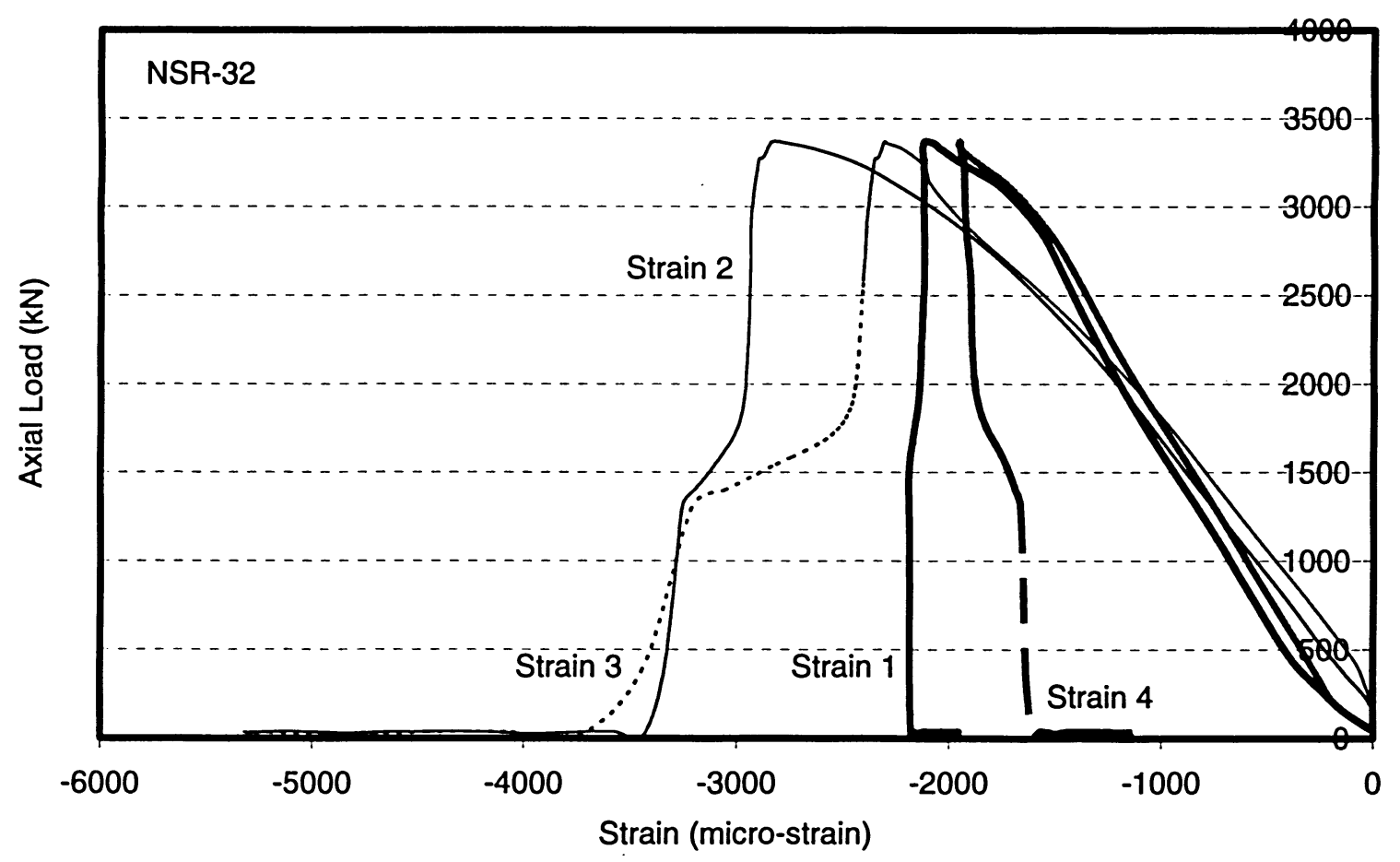

Figure 4.215 Axial load-strain relationships for specimen NSR-32 


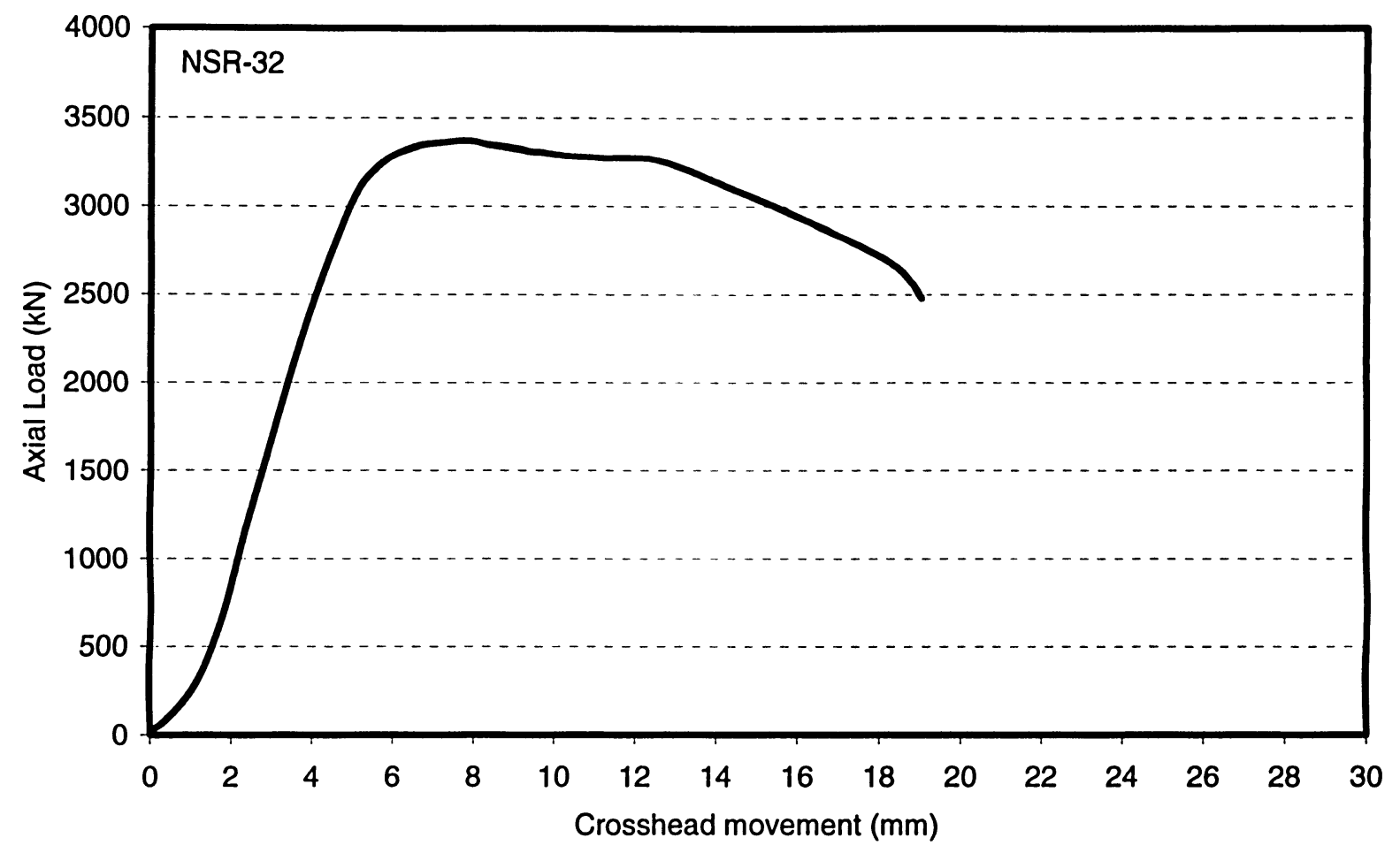

Figure 4.216 Load versus overall shortening curve for NSR-32
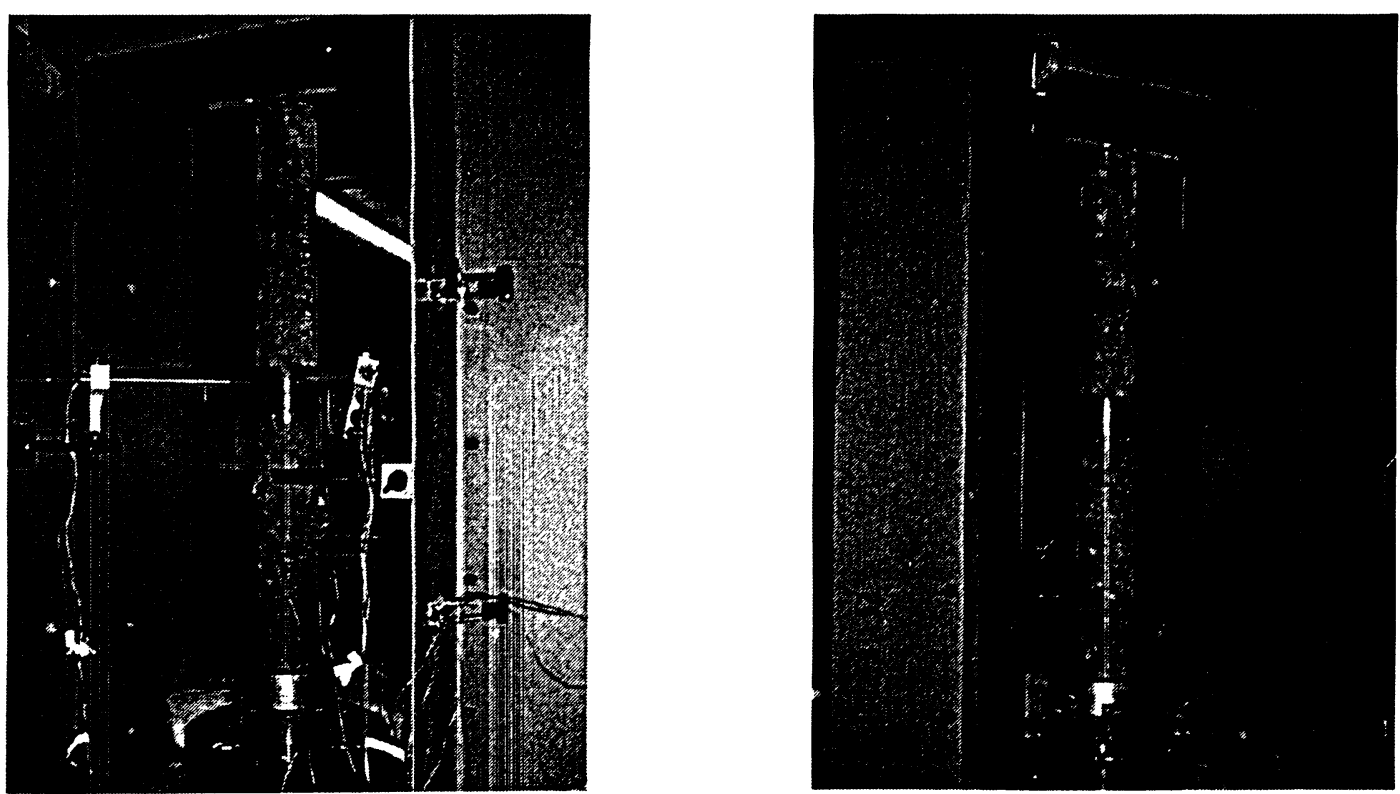

Figure 4.217 Views of specimen NSR-33 before and after testing 


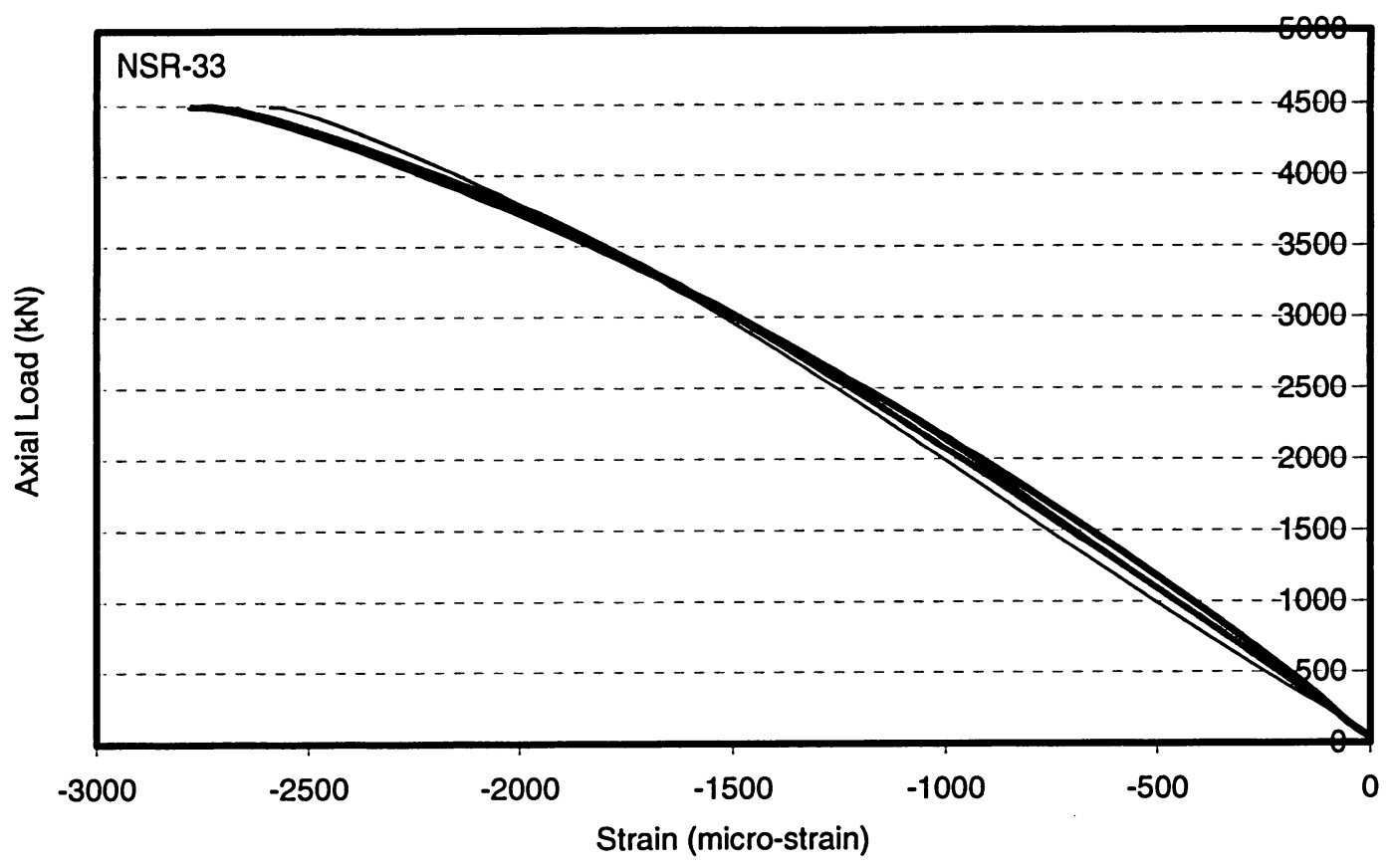

Figure 4.218 Axial load-strain relationships for specimen NSR-33

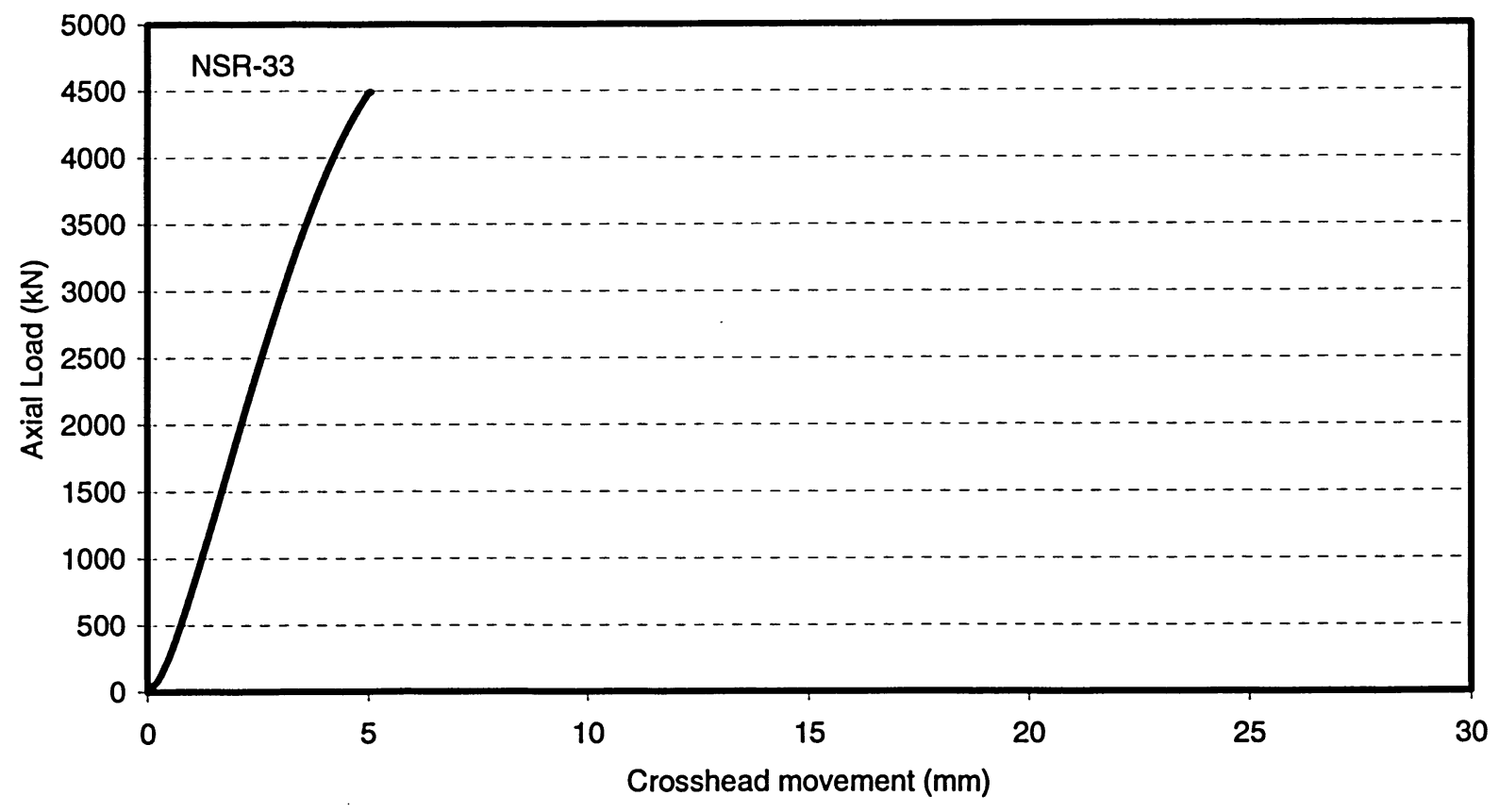

Figure 4.219 Load versus overall shortening for specimen NSR-33 

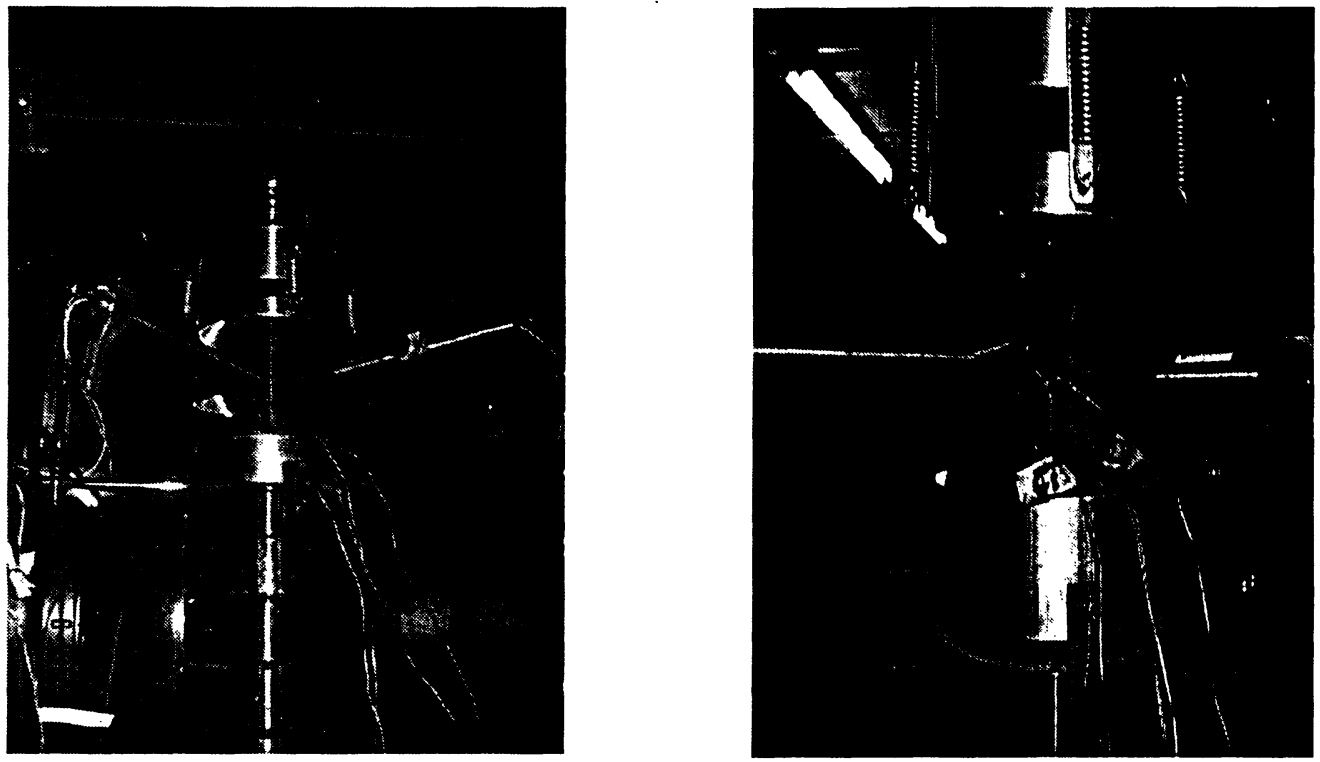

Figure 4.220 Views of specimen SC-1 before and after testing

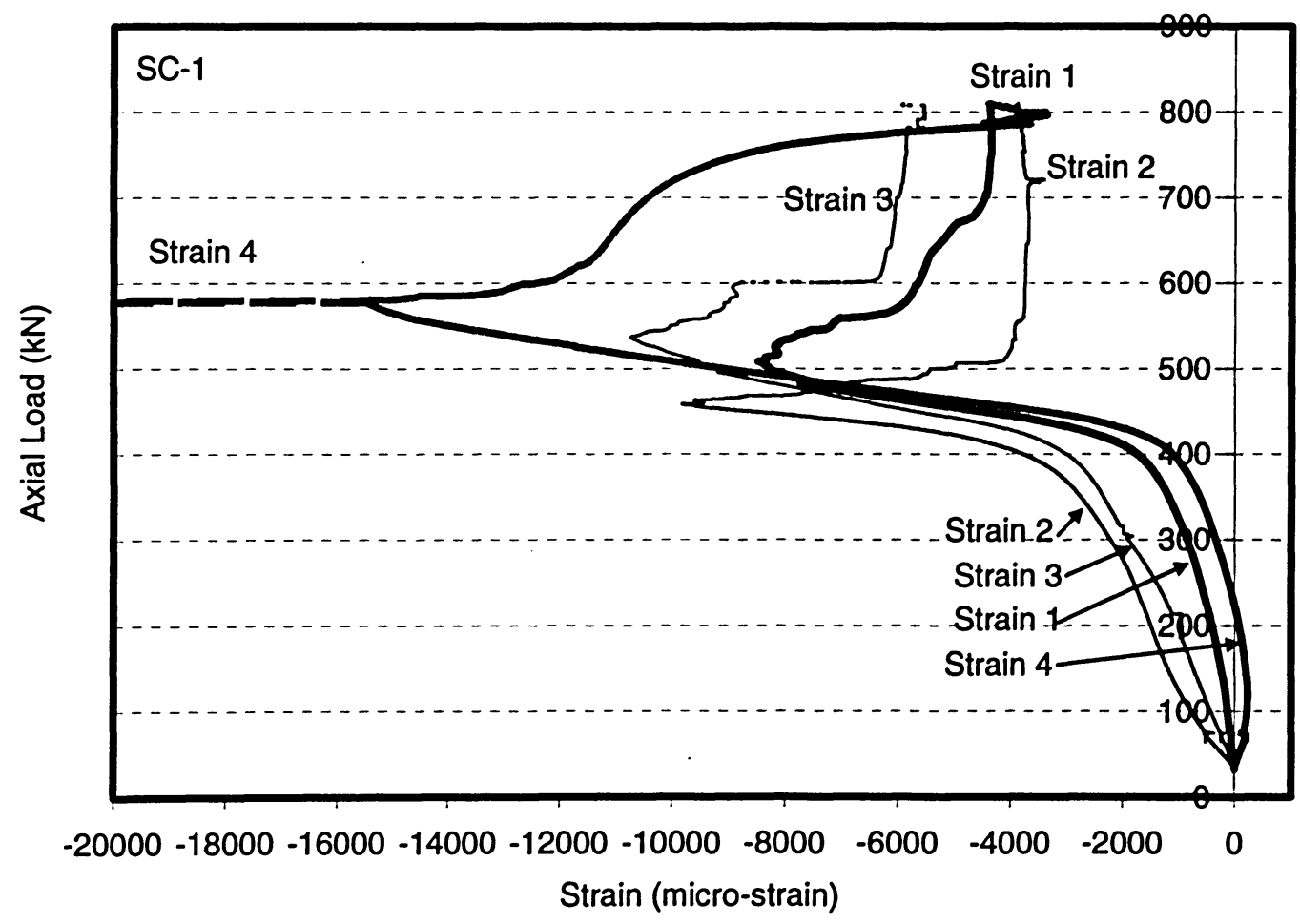

Figure 4.221 Axial load-strain relationships for specimen SC-1 


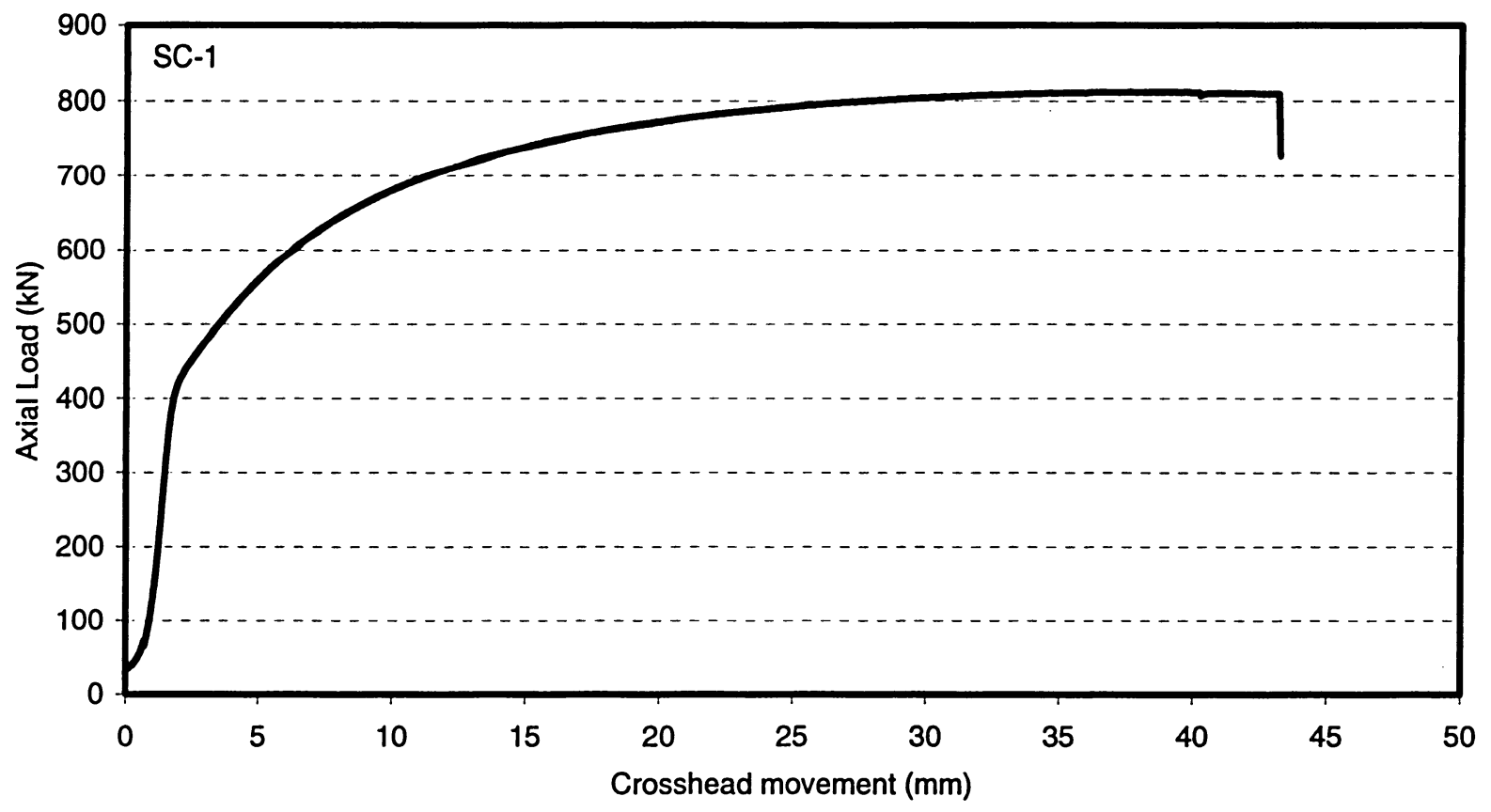

Figure 4.222 Load versus overall shortening curve for specimen SC-1
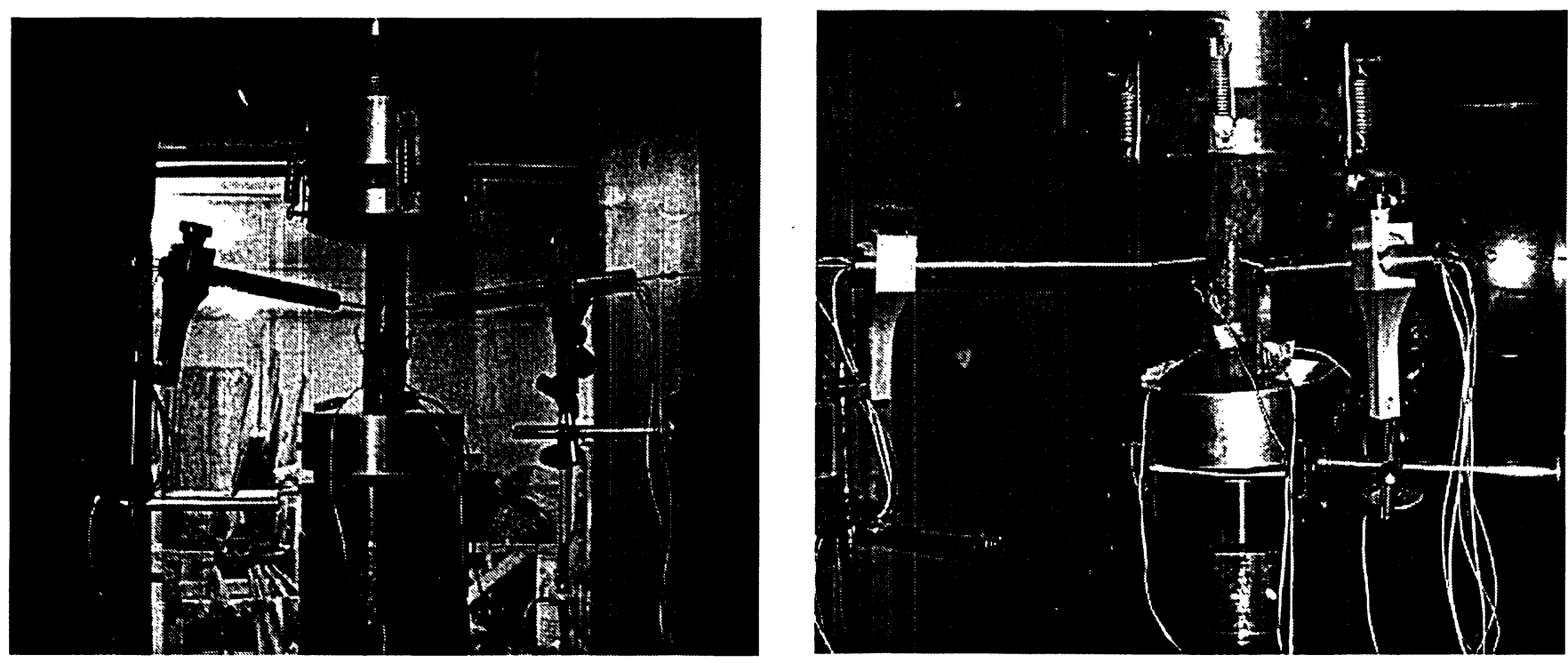

Figure 4.223 Views of specimen SC-2 before and after testing 


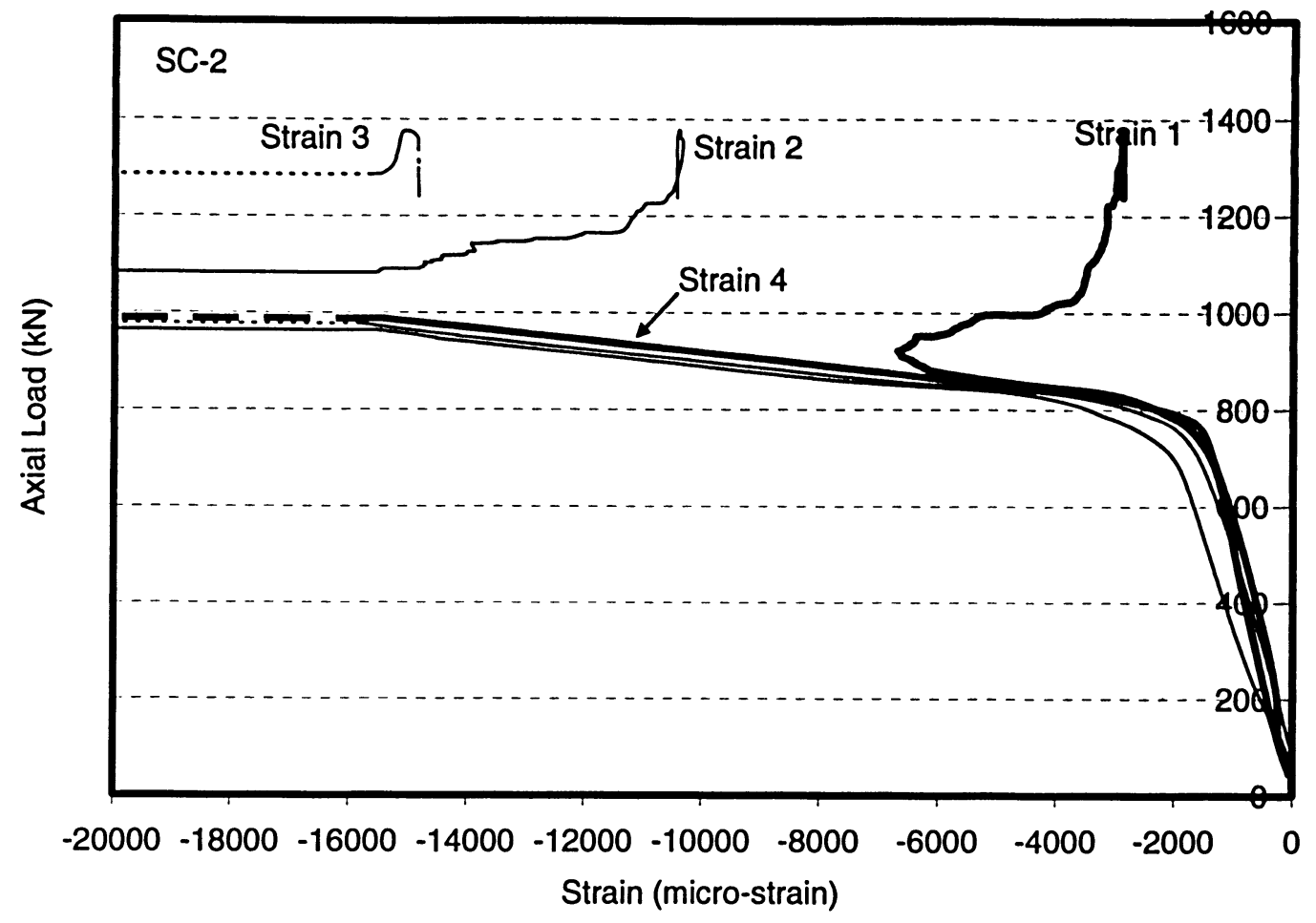

Figure 4.224 Axial load-strain relationships for specimen SC-2

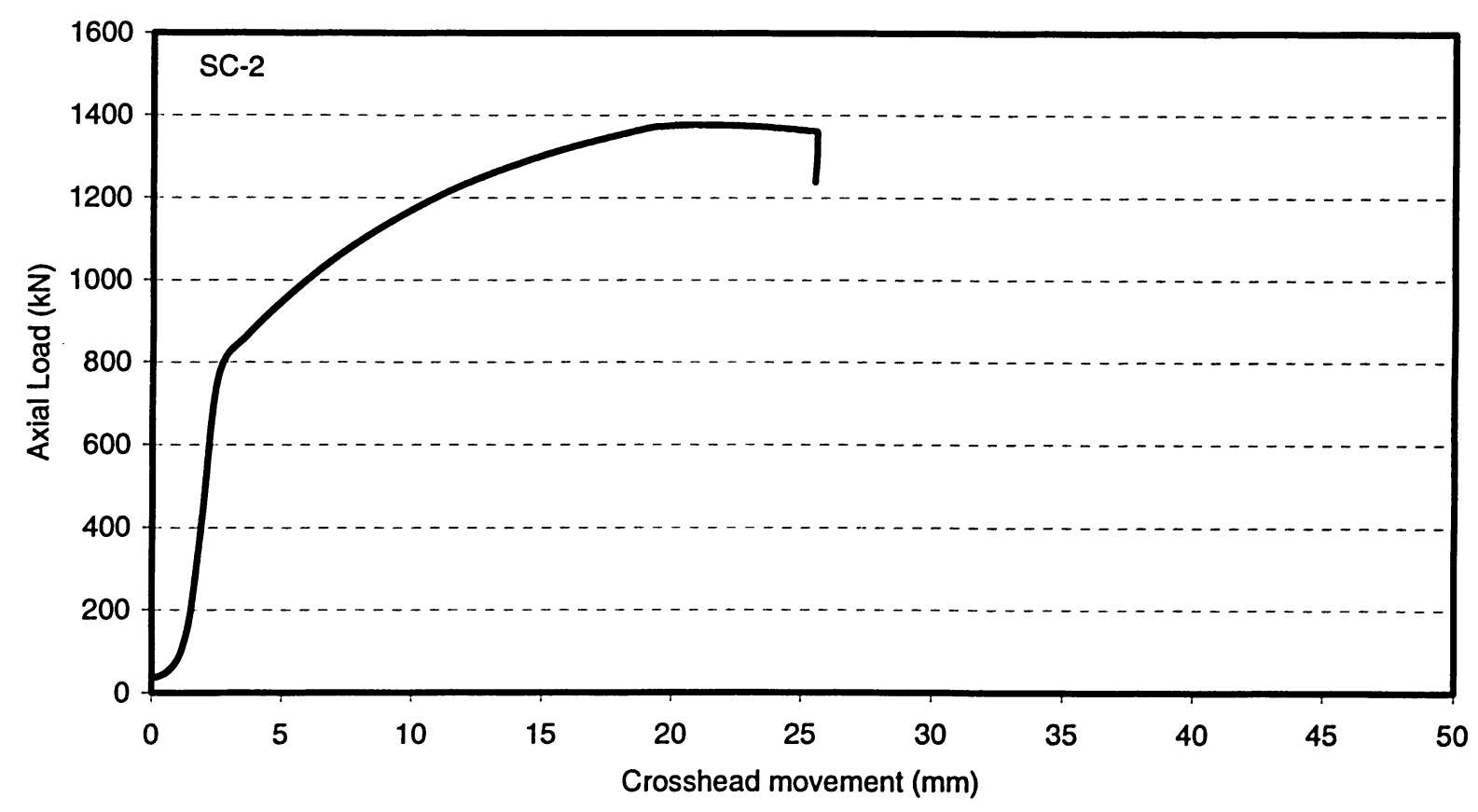

Figure 4.225 Load versus overall shortening curve for specimen SC-2 

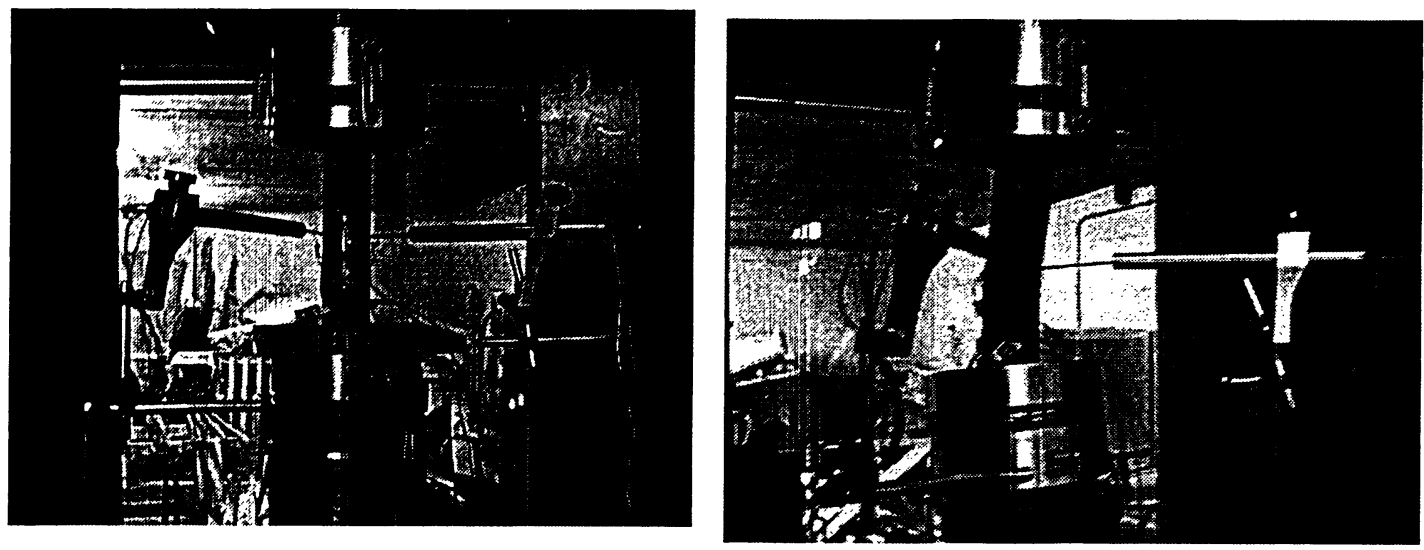

Figure 4.226 Views of specimen SC-3 before and after testing

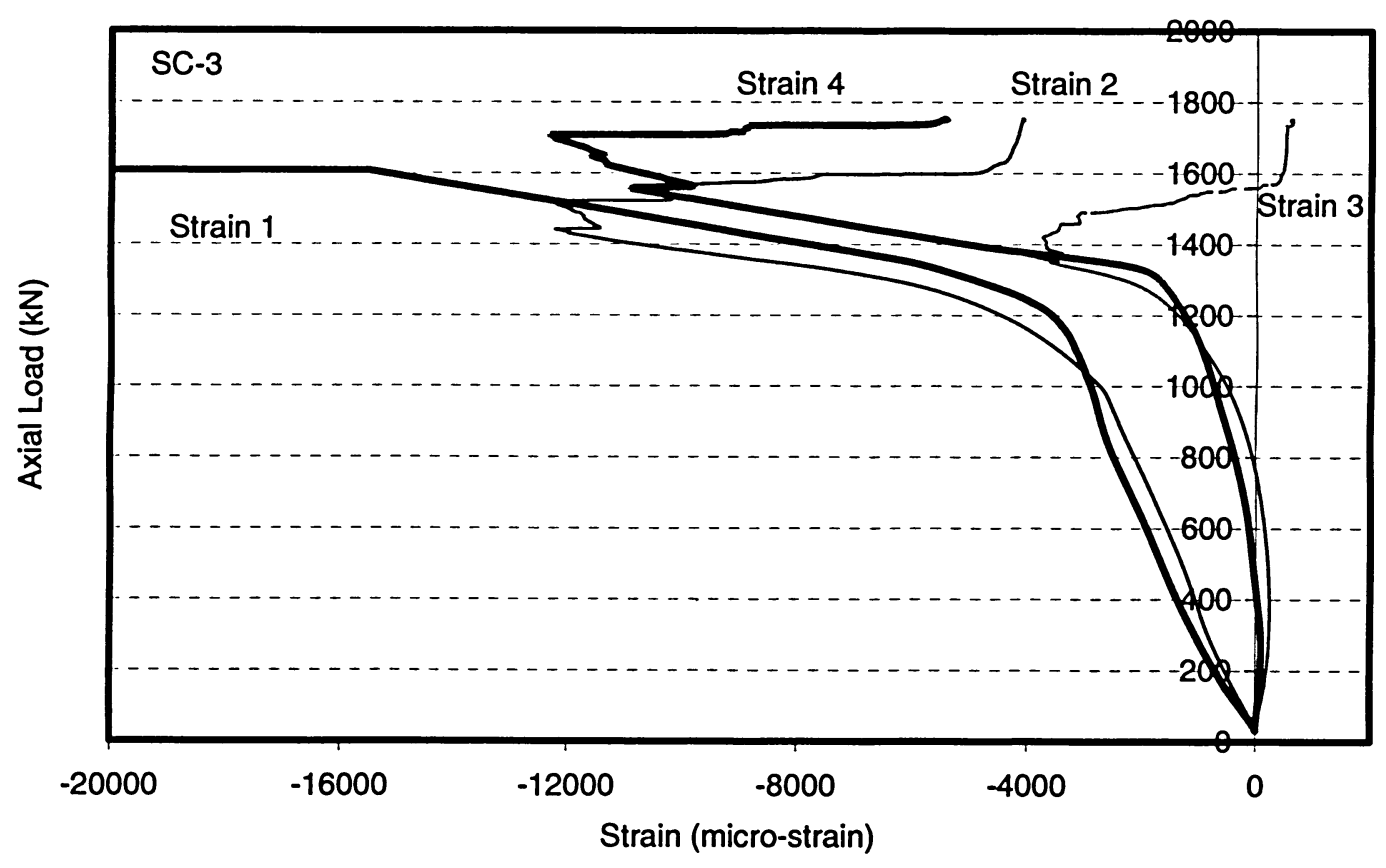

Figure 4.227 Axial load-strain relationships for specimen SC-3 


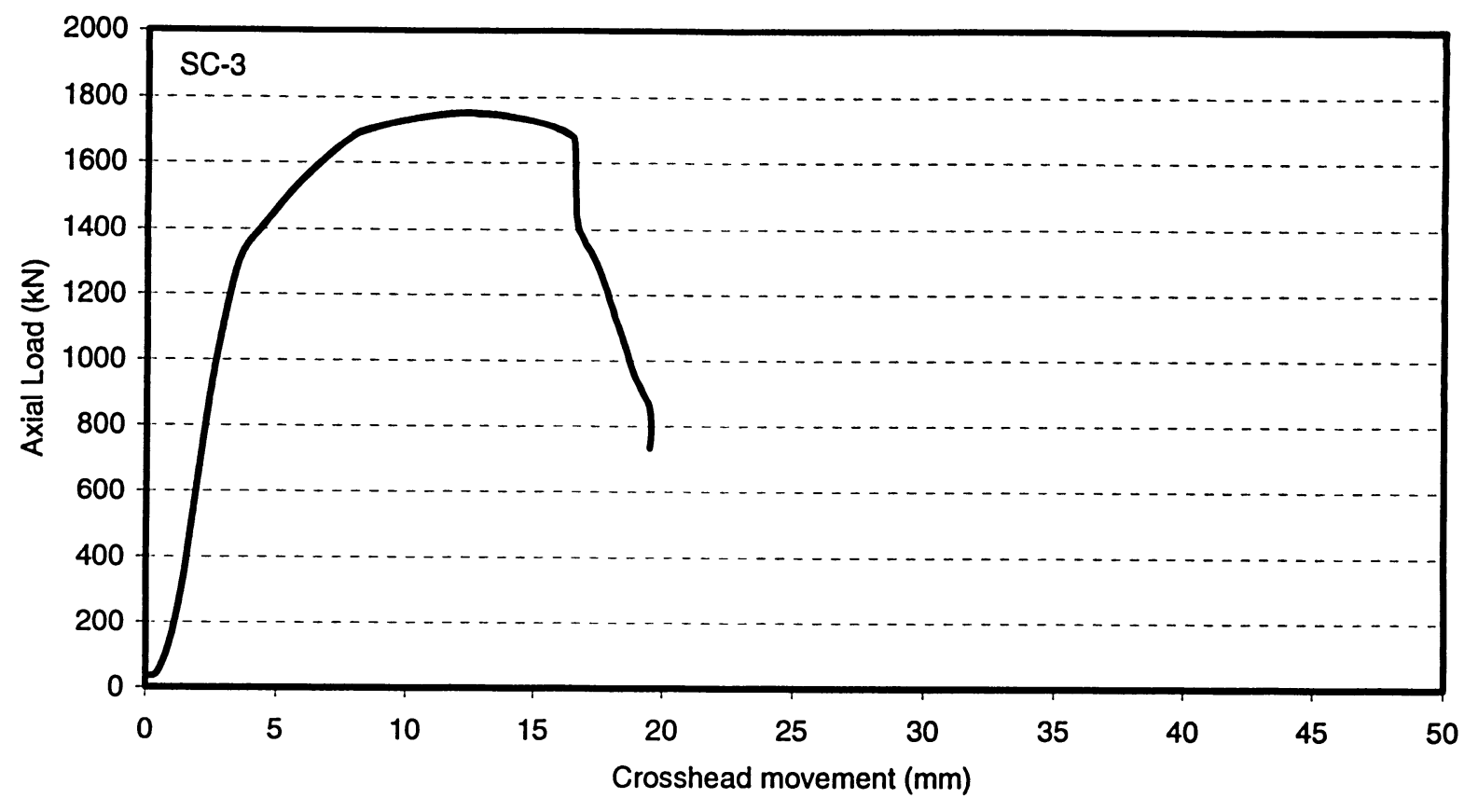

Figure 4.228 Load versus overall shortening curve for specimen SC-3
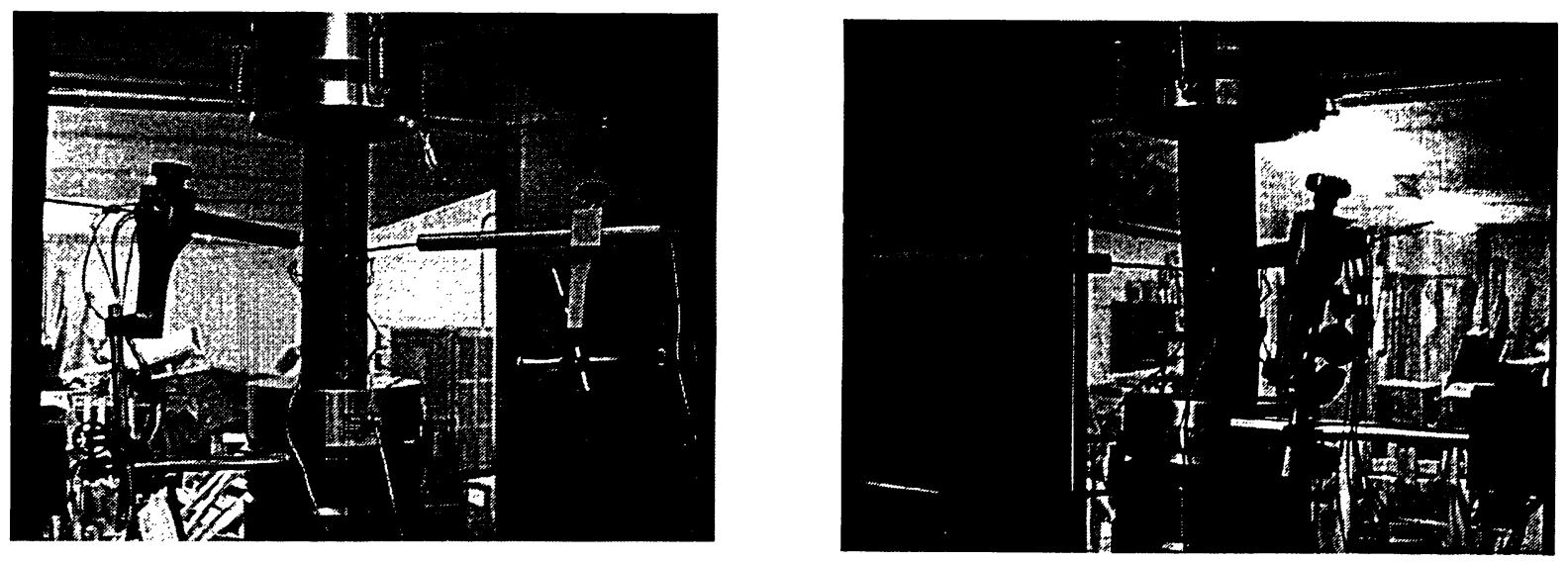

Figure 4.229 Views of specimen SC-4 before and after testing 


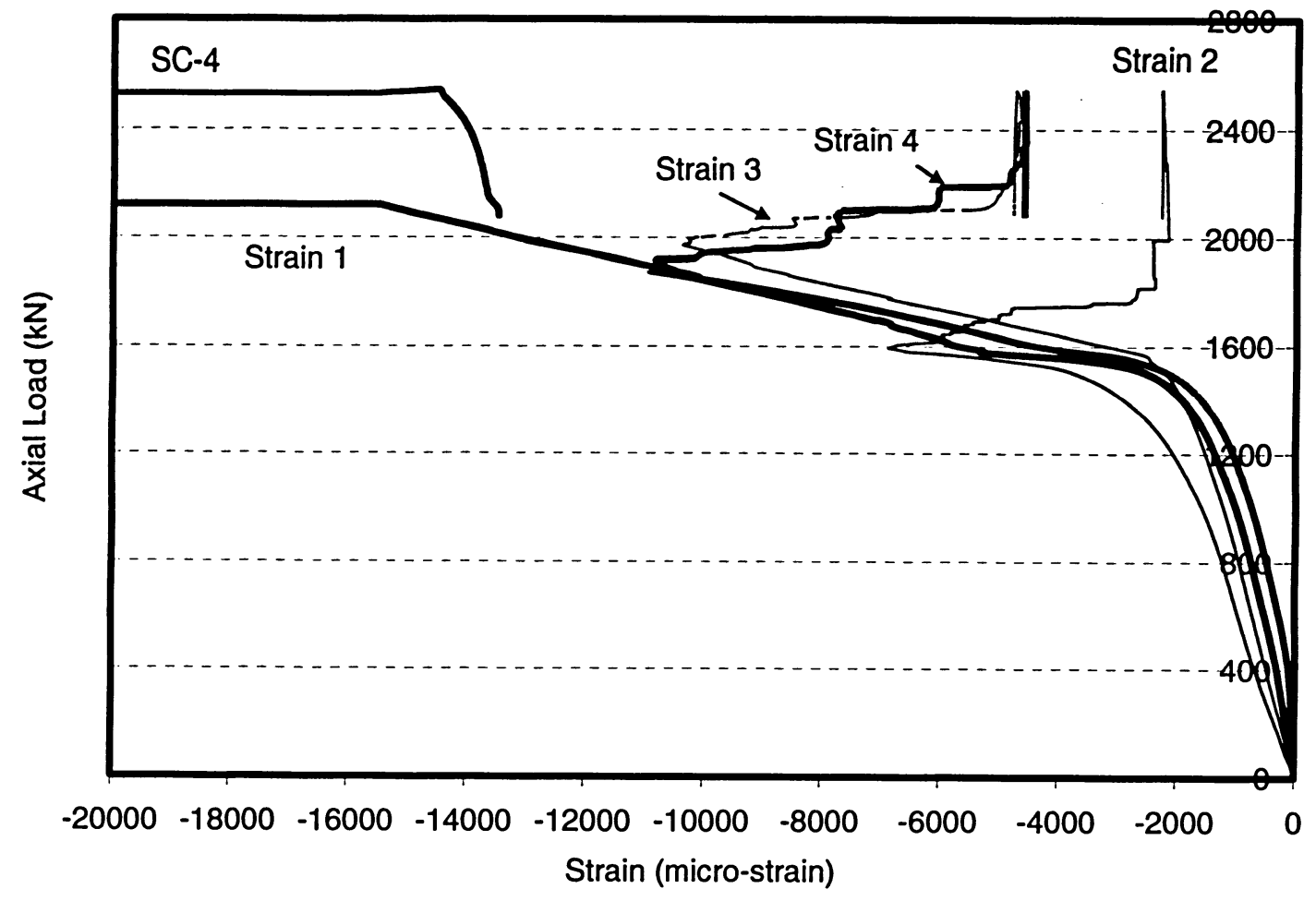

Figure 4.230 Axial load-strain relationships for specimen SC-4

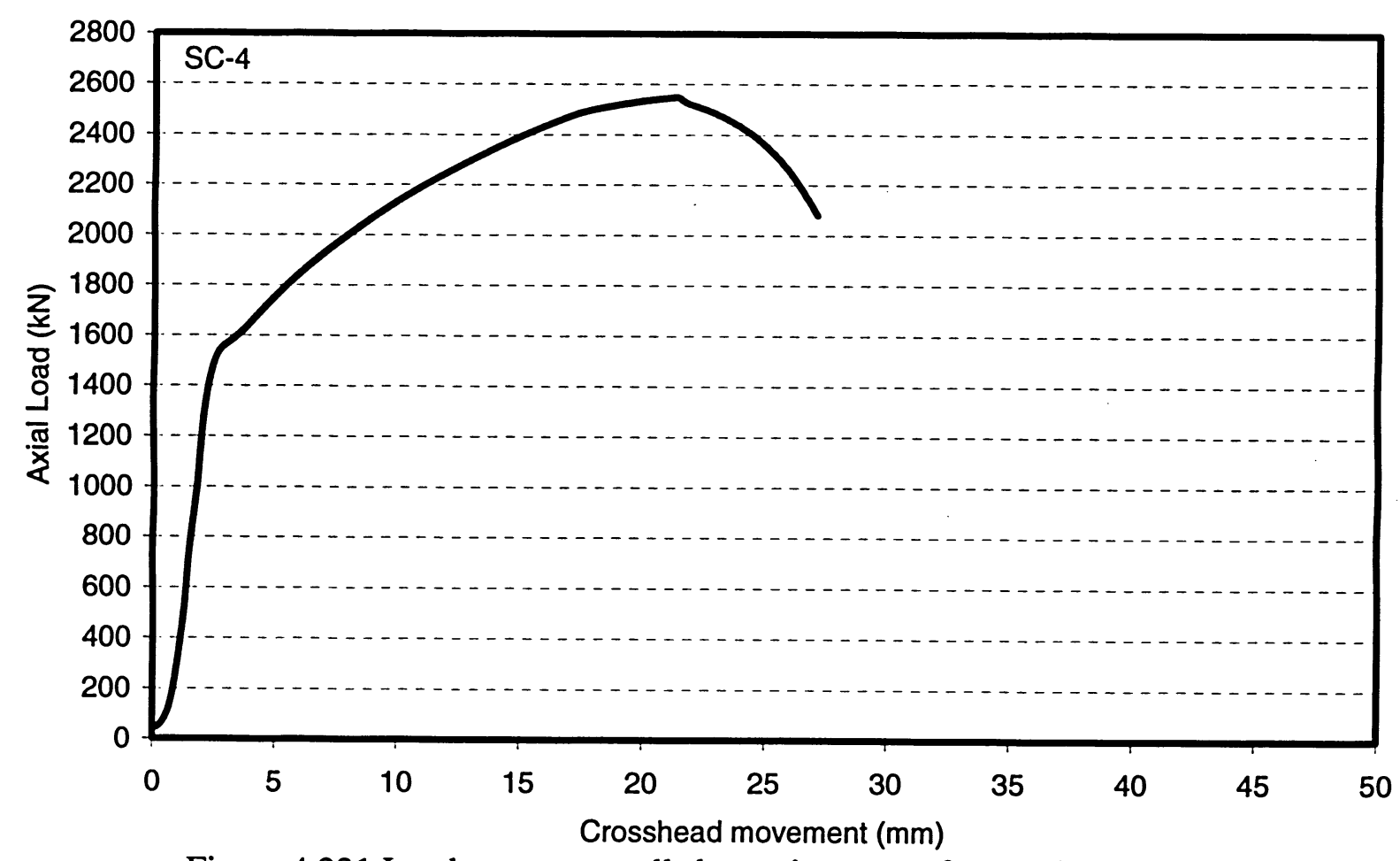

Figure 4.231 Load versus overall shortening curve for specimen SC-4 

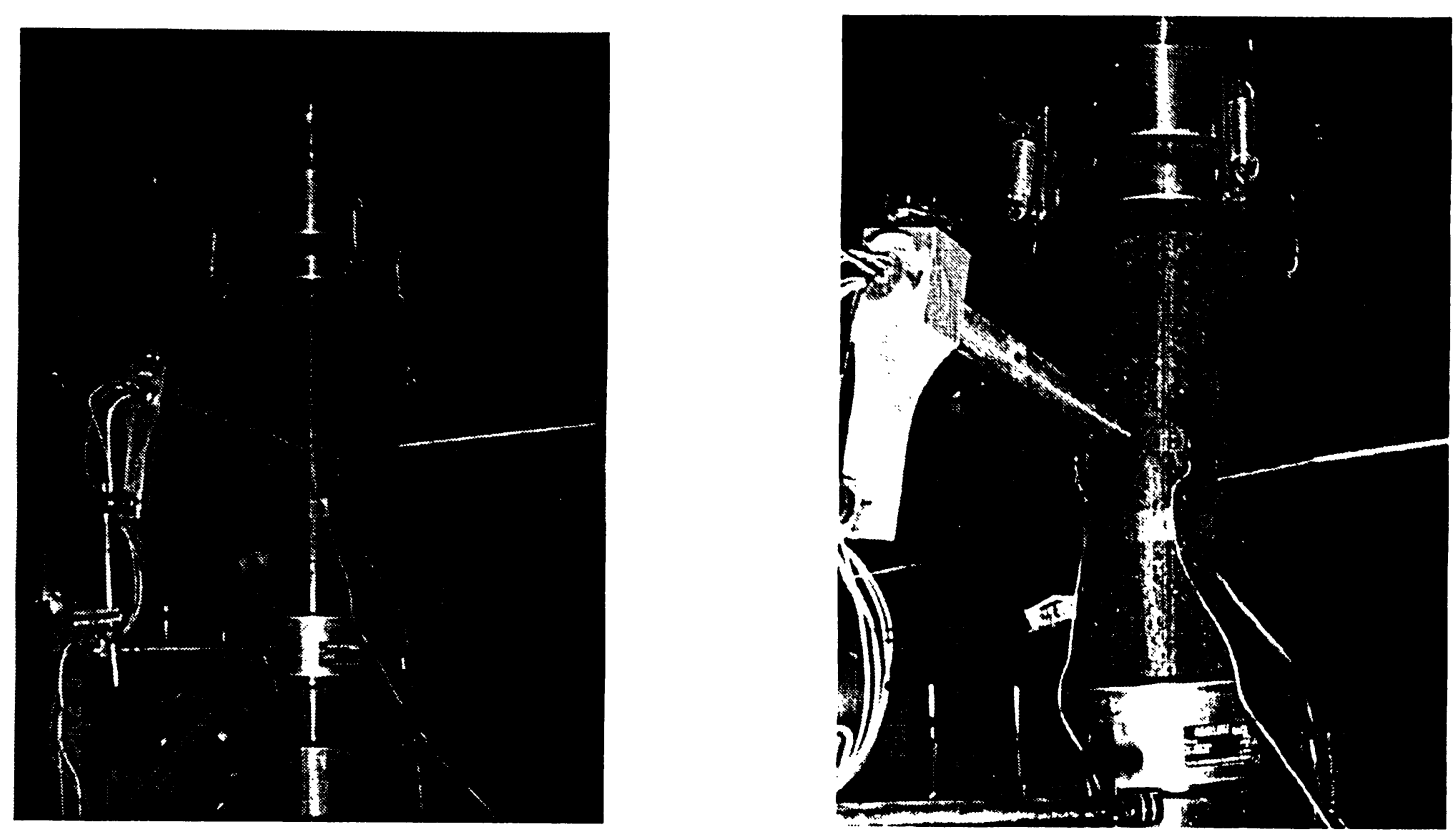

Figure 4.232 Views of specimen SC-5 before and after testing

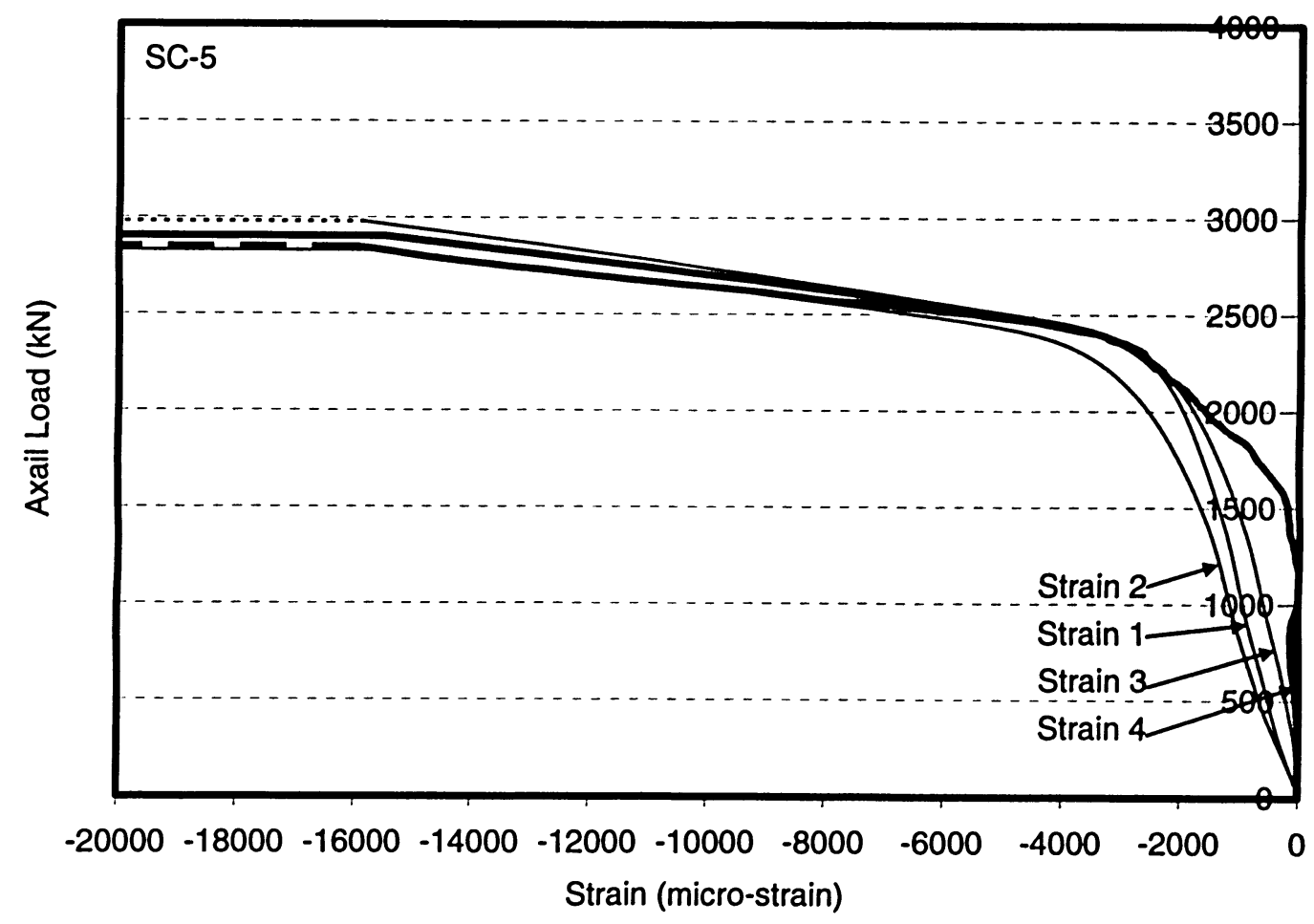

Figure 4.233 Axial load-strain relationships for specimen SC-5 


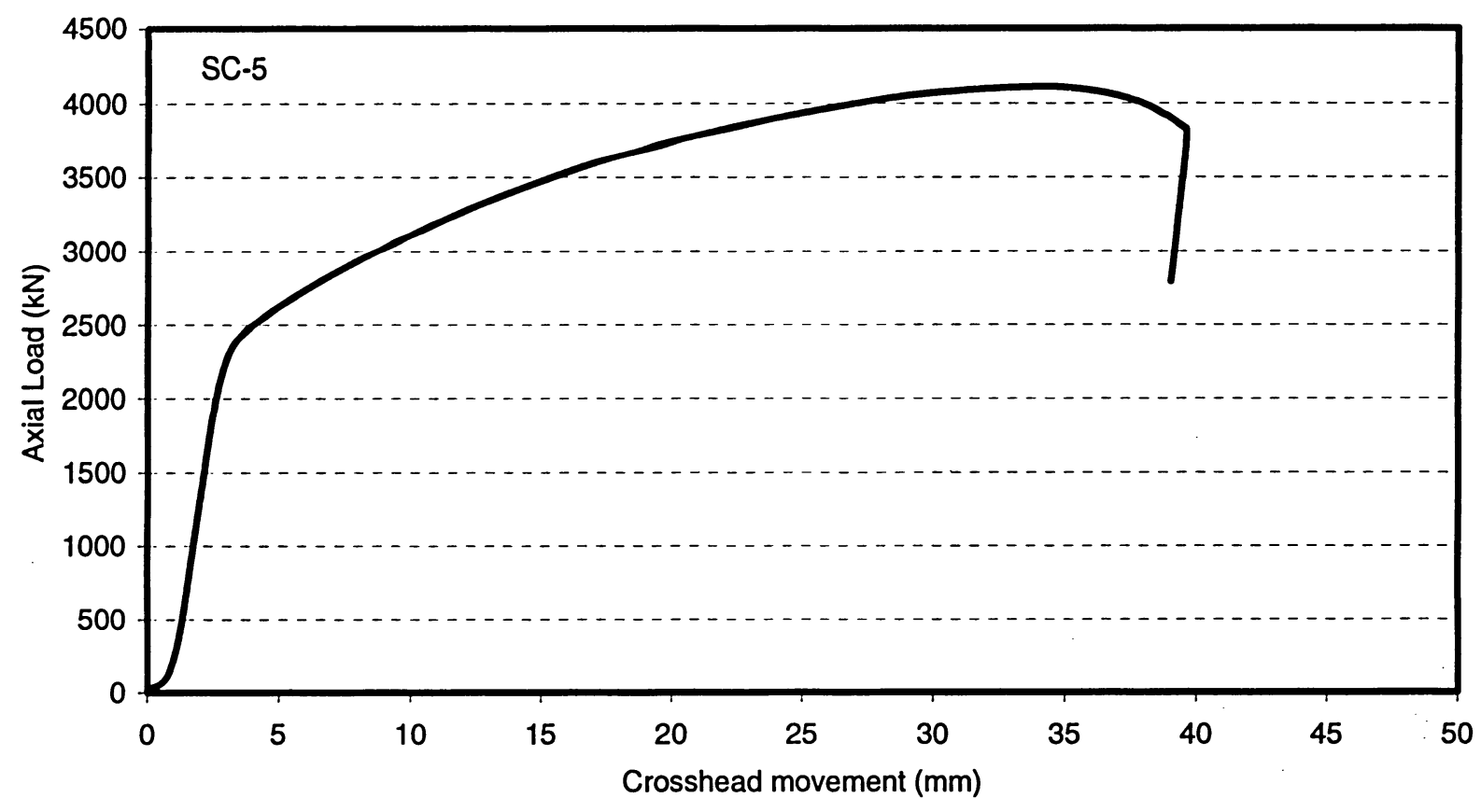

Figure 4.234 Load versus overall shortening curve for specimen SC-5
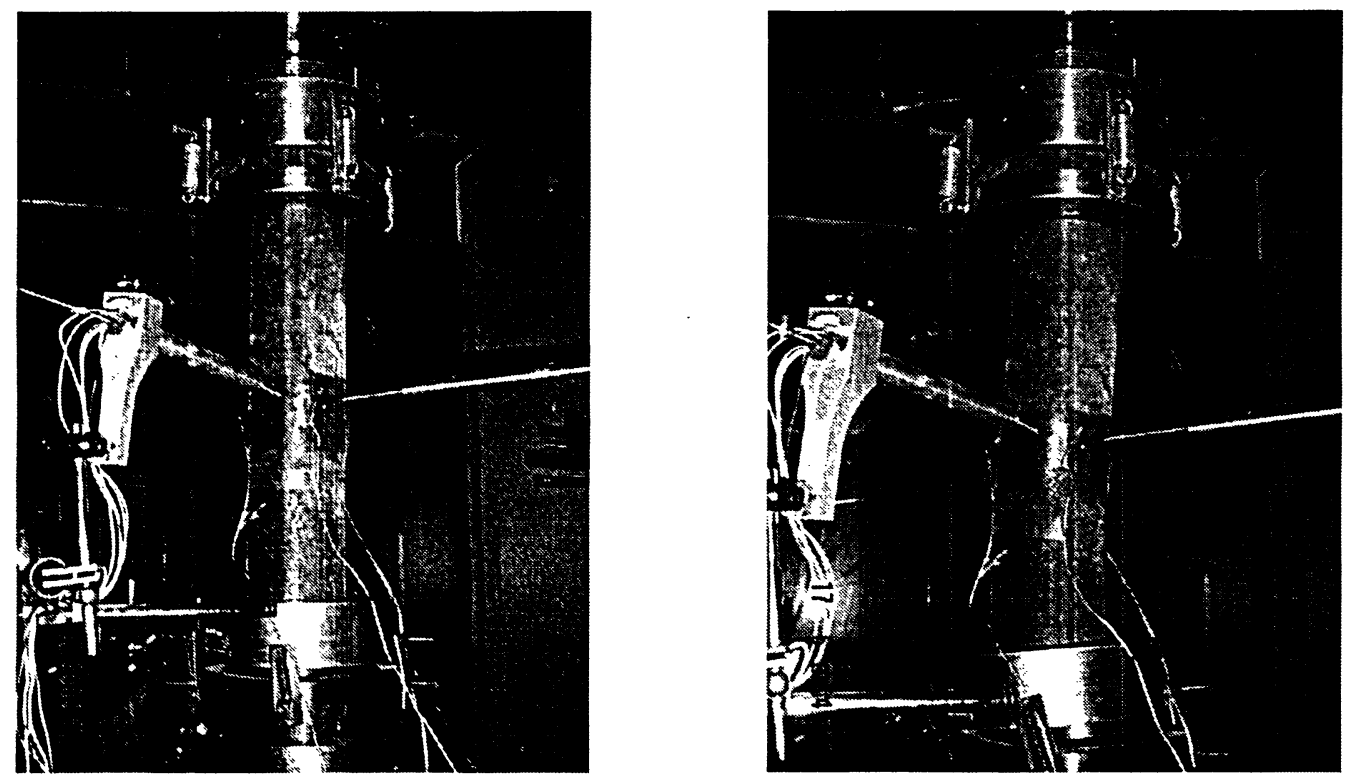

Figure 4.235 Views of specimen SC- 6 before and after testing 


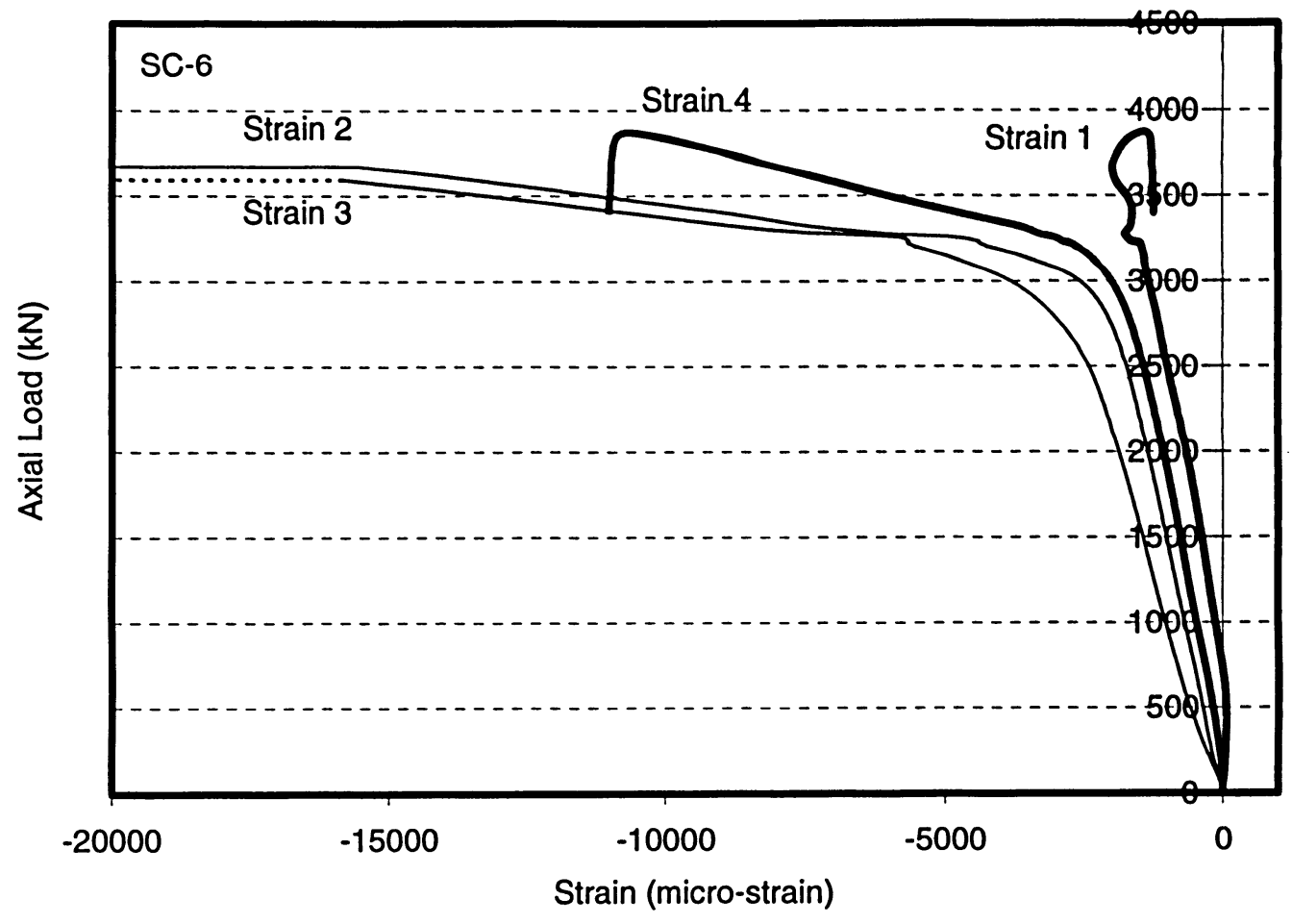

Figure 4.236 Axial load-strain relationships for specimen SC-6

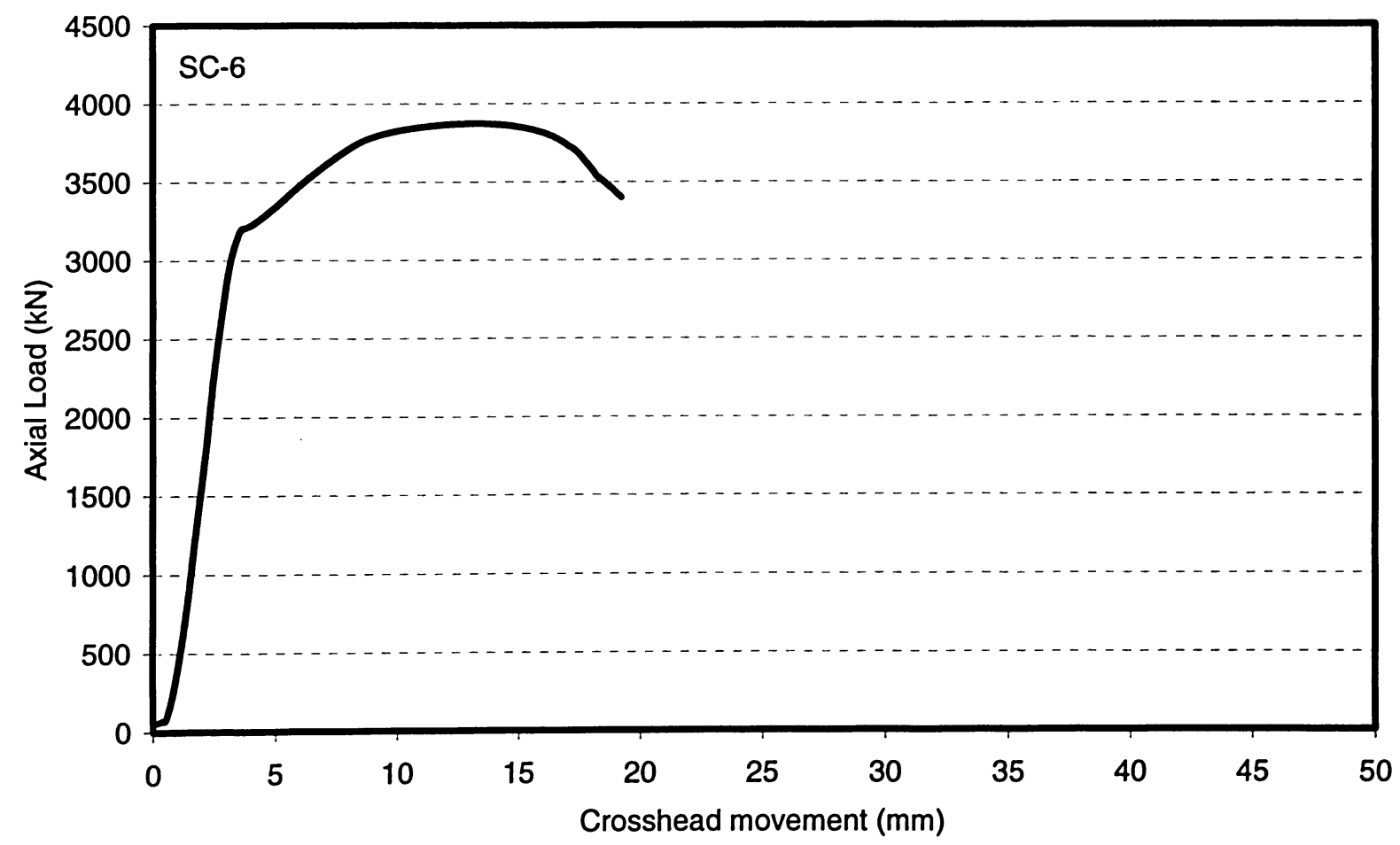

Figure 4.237 Load versus overall shortening curve for specimen SC-6 

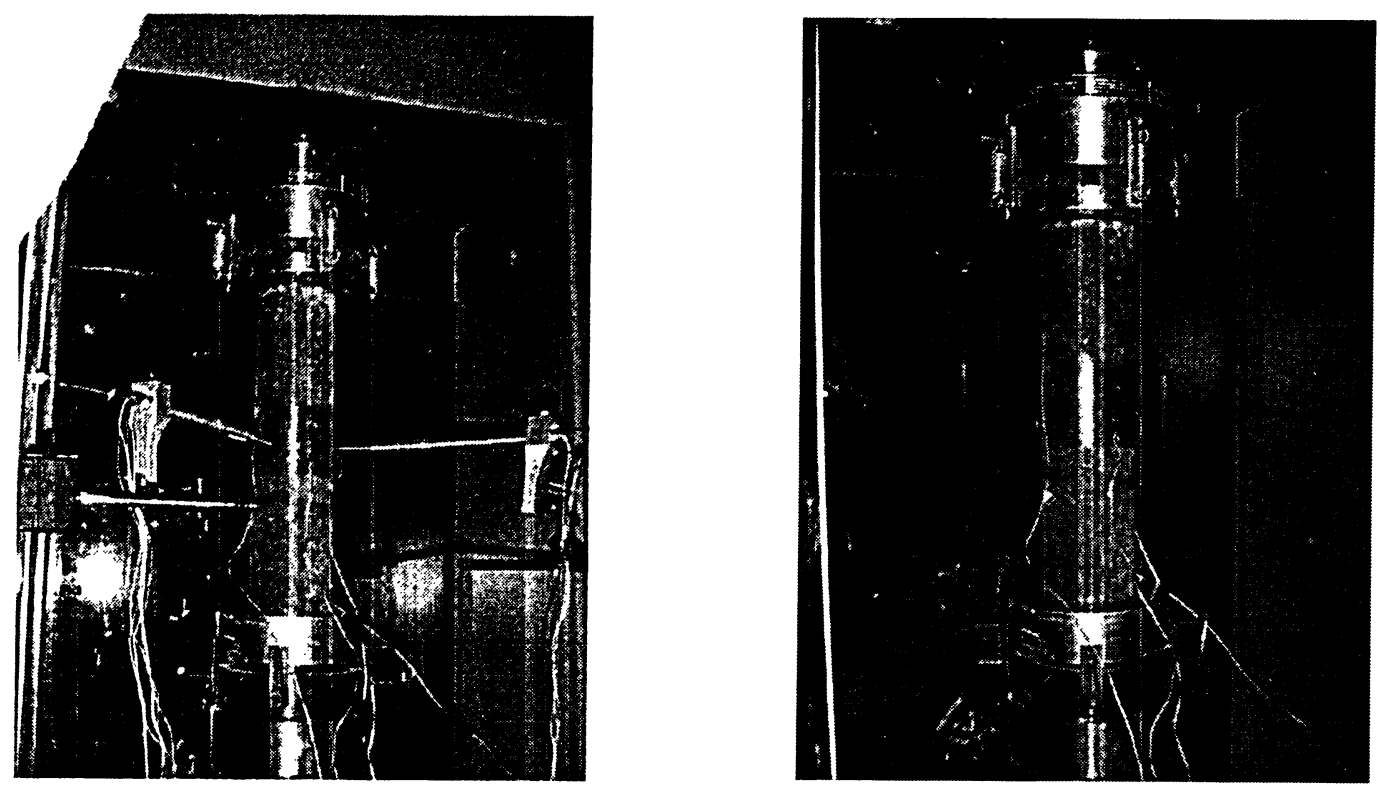

Figure 4.238 Views of specimen SC-7 before and after testing

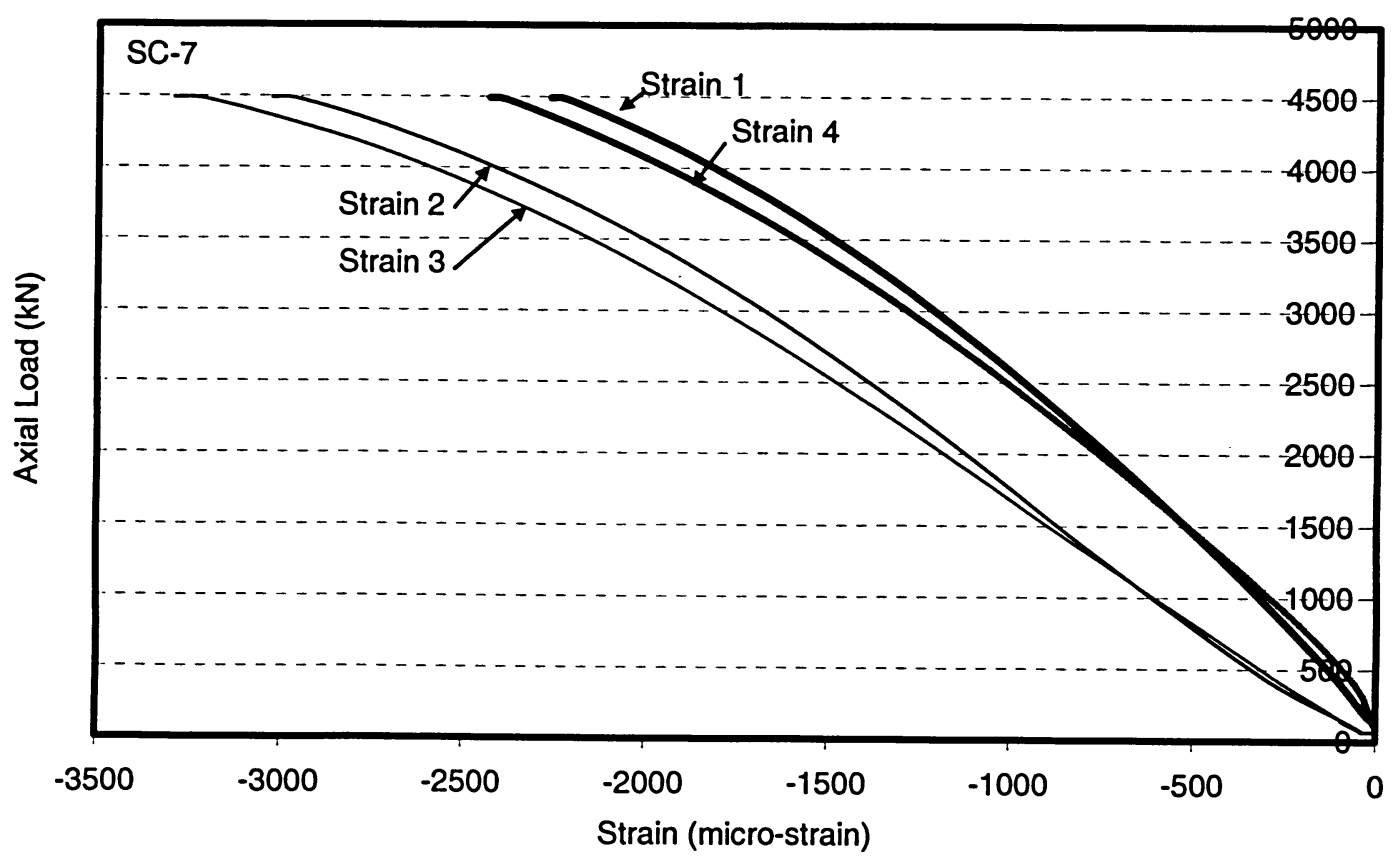

Figure 4.239 Axial load-strain relationships for specimen SC-7 


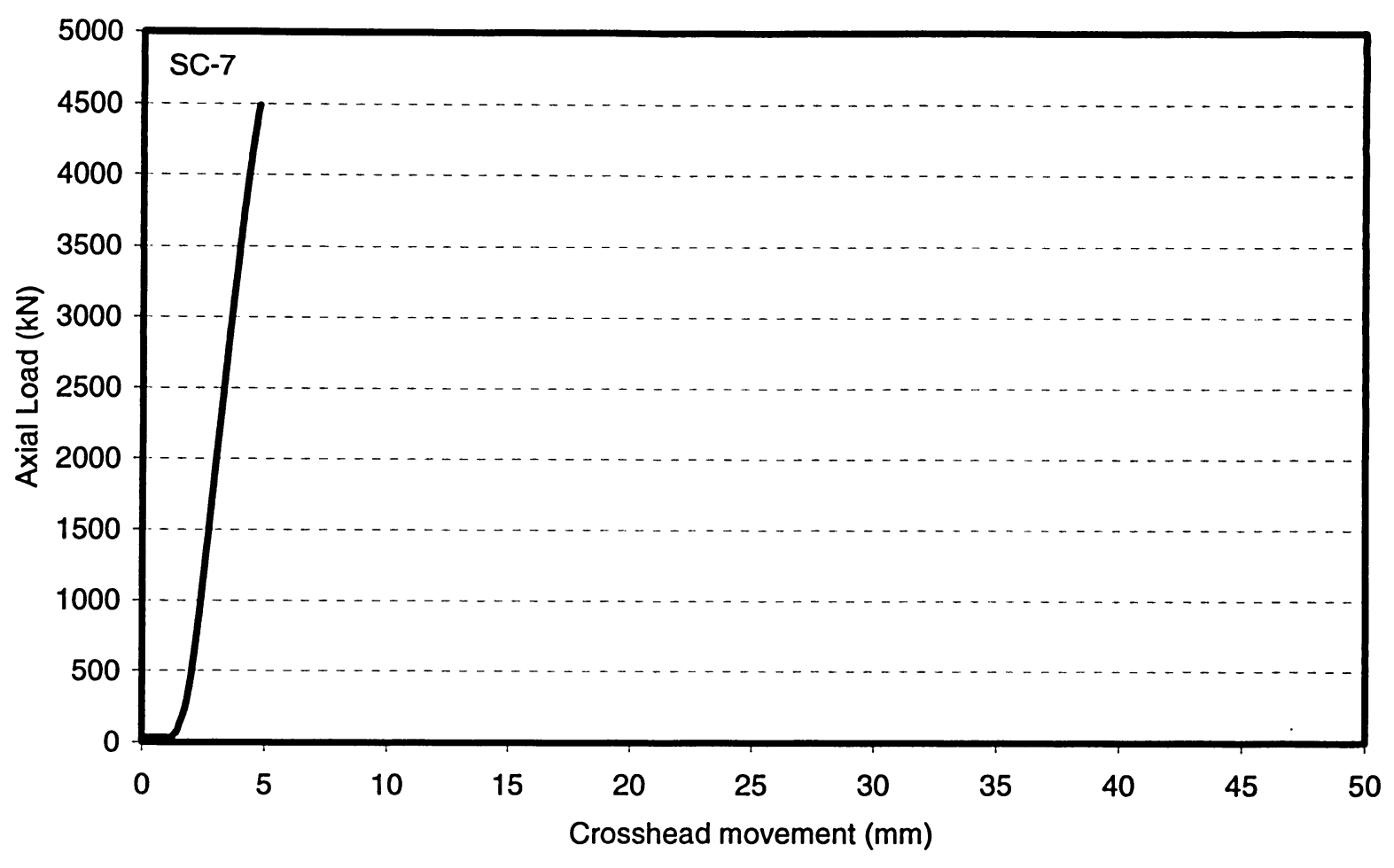

Figure 4.240 Load versus overall shortening curve for specimen SC-7 